AmS-Skrifter 28

Arkeologisk museum, Universitetet i Stavanger

Museum of Archaeology, University of Stavanger

\title{
Bronze Age and Early Iron Age house and settlement development at Forsandmoen, south-western Norway
}

Trond Løken 


\section{AmS-Skrifter 28}

Editorial office:

Arkeologisk museum, Universitetet i Stavanger

Museum of Archaeology, University of Stavanger

Editor of the series: Kristin Armstrong-Oma

Editors of this volume: Kristin Armstrong-Oma, Wenche Brun, Lisbeth Prøsch-Danielsen and Linn Lillian Eikje Ramberg.

Academic editor this volume: Lars Erik Gjerpe

Layout: Ingund Svendsen

Editorial board:

Kristin Armstrong-Oma (chief editor)

Wenche Brun

Lisbeth Prøsch-Danielsen

Linn Lillian Eikje Ramberg

Ingund Svendsen

Publisher:

Museum of Archaeology, University of Stavanger

N-4036 Stavanger, Norway

Tel.: (+47) 51832600

E-mail: post-am@uis.no

arkeologiskmuseum.no

Stavanger 2020

Printed editions: 350

ISSN0332-6306

ISBN 978-82-7760-190-8

Edited by Museum of Archaeology, University of Stavanger

(c) Museum of Archaeology, University of Stavanger. All rights reserved. No part of this book may be reprinted or reproduced or utilised in any form or by any electronic, mechanical, or other means, now known or hereafter invented, including photocopying and recording, or in any information storage or retrieval system, without permission in writing from the publisher.

Front cover photo: View of the central settlement area at Forsandmoen in July 1990 seen towards the north, when most of the excavation areas in 1990 are opened. The Esmark moraine dam the lake Haukalivatnet in the background. Photo: Trond Løken.

Back cover photo: Reconstructed Bronze Age house at Landa, Forsandmoen. Photo: Katharina Lorvik

Cover design: Ingund Svendsen, AM. 


\section{Abstract}

The ambition of this monograph is to analyse a limited number of topics regarding house types and thus social and economic change from the extensive material that came out of the archaeological excavation that took place at Forsandmoen ("Forsand plain"), Forsand municipality, Rogaland, Norway during the decade 1980-1990, as well as the years 1992, 1995 and 2007. The excavation was organised as an interdisciplinary research project within archaeology, botany (palynological analysis from bogs and soils, macrofossil analysis) and phosphate analysis, conducted by staff from the Museum of Archaeology in Stavanger (as it was called until 2009, now part of the University of Stavanger). A large phosphate survey project had demarcaded a 20 ha settlement area, among which 9 ha were excavated using mechanical topsoil stripping to expose the habitation traces at the top of the glaciofluvial outwash plain of Forsandmoen. A total of 248 houses could be identified by archaeological excavations, distributed among 17 house types. In addition, 26 partly excavated houses could not be classified into a type. The extensive house material comprises three types of longhouses, of which there are as many as 30-40 in number, as well as four other longhouse types, of which there are only 2-7 in number. There were nine other house types, comprising partly small dwelling houses and partly storage houses, of which there were 3-10 in number. Lastly, there are 63 of the smallest storage house, consisting of only four postholes in a square shape. A collection of 264 radiocarbon dates demonstrated that the settlement was established in the last part of the $15^{\text {th }}$ century $\mathrm{BC}$ and faded out during the $7^{\text {th }}-8^{\text {th }}$ century $\mathrm{AD}$, encompassing the Nordic Bronze Age and Early Iron Age.

As a number of houses comprising four of the house types were excavated with the same methods in the same area by the same staff, it is a major goal of this monograph to analyse thoroughly the different features of the houses (postholes, wall remains, entrances, ditches, hearths, house-structure, find-distribution) and how they were combined and changed into the different house types through time. House material from different Norwegian areas as well as Sweden, Denmark, Germany and the Netherlands is included in comparative analyses to reveal connections within the Nordic area. Special attention has been given to the interpretation of the location of activity areas in the dwelling and byre sections in the houses, as well as the life expectancy of the two main longhouse types. Based on these analyses, I have presented a synthesis in 13 phases of the development of the settlement from Bronze Age Period II to the Merovingian Period. This analysis shows that, from a restricted settlement consisting of one or two small farms in the Early Bronze Age, it increases slightly throughout the Late Bronze Age to 2-3 solitary farms to a significantly larger settlement consisting of 3-4 larger farms in the Pre-Roman Iron Age. From the beginning of the early Roman Iron Age, the settlement seems to increase to 8-9 even larger farms, and through the late Roman Iron Age, the settlement increases to 12-13 such farms, of which 6-7 farms are located so close together that they would seem to be a nucleated or village settlement. In the beginning of the Migration Period, there were 16-17 farms, each consisting of a dwelling/byre longhouse and a workshop, agglomerated in an area of 300 x $200 \mathrm{~m}$ where the farms are arranged in four E-W oriented rows. In addition, two farms were situated 140 $\mathrm{m}$ NE of the main settlement. At the transition to the Merovingian Period, radiocarbon dates show that all but two of the farms were suddenly abandoned. At the end of that period, the Forsandmoen settlement was completely abandoned. The abandonment could have been caused by a combination of circumstances such as overexploitation in agriculture, colder climate, the Plague of Justinian or the collapse of the redistributive chiefdom system due to the breakdown of the Roman Empire. The abrupt abandonment also coincides with a huge volcanic eruption or cosmic event that clouded the sun around the whole globe in AD 536-537. It is argued that the climatic effect on the agriculture at this latitude could induce such a serious famine that the settlement, in combination with the other possible causes, was virtually laid waste during the ensuing cold decade AD 537-546.

Keywords: Settlement, village, house types, longhouse, workshop, house life expectancy, byre, activity areas, AD 536, palynological analysis, macrofossil analysis, phosphate analysis, Bronze Age, Pre-Roman Iron Age, Roman Iron Age, Migration Period. 


\section{Content}

Preface

I. Objectives of the Forsandmoen project

2. The investigations at Forsandmoen

2.I Previous investigation of prehistoric houses in Rogaland and Scandinavia ......................................................... II

2.2 Landscape

2.3 Ancient monuments in the area

2.4 Artefacts from the Forsand area

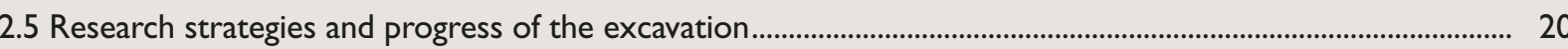

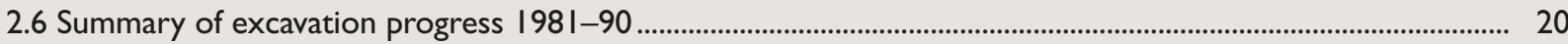

2.7 Further settlement excavations 1992-95, 2007.................................................................................................. 22

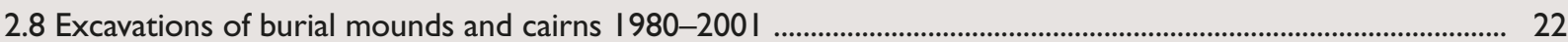

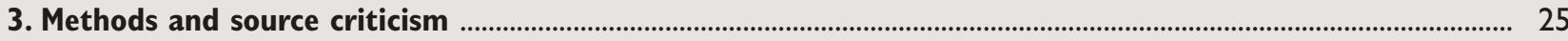

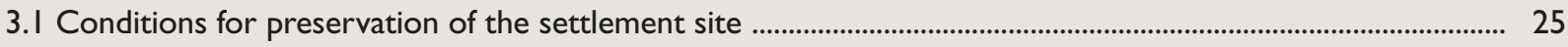

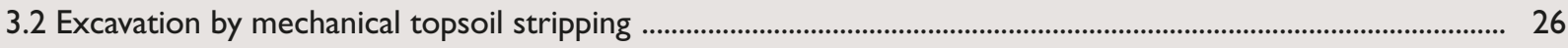

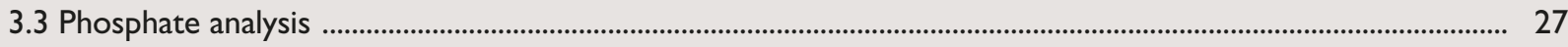

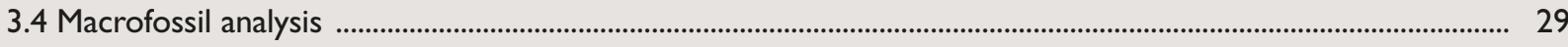

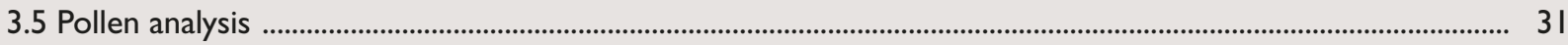

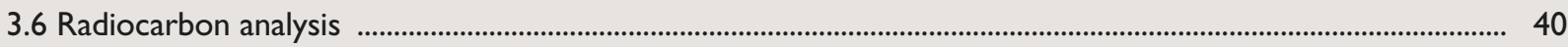

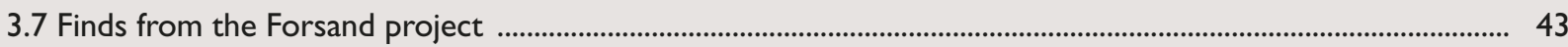

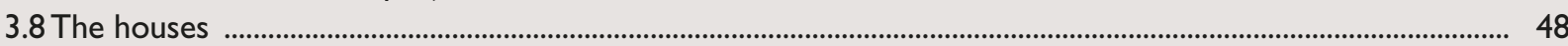

4. Types I and 2: Dwelling houses with wide-spaced trestles................................................................................

4.I The distribution of type I-2 houses and their orientation ................................................................................

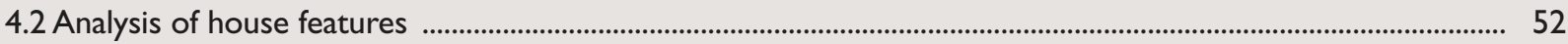

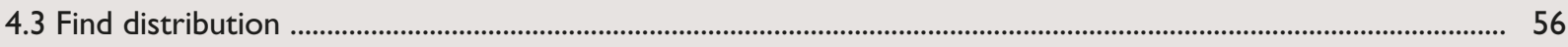

4.4 Comparative houses from Norway and Denmark ............................................................................................ 57

5. Type 3: Dwelling/byre house with opposed, recessed entrances at the middle of the house ................................ 59

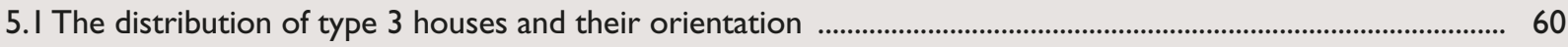

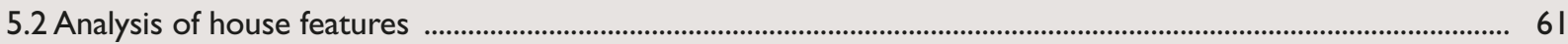

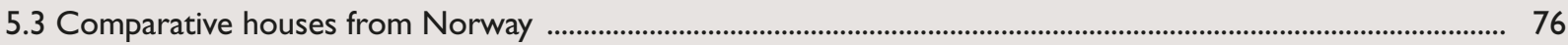

5.4 Comparison between Forsand and the Norwegian type 3 houses ......................................................................... 79

5.5 Comparative houses from southern Scandinavia, Germany and the Netherlands ............................................ 79

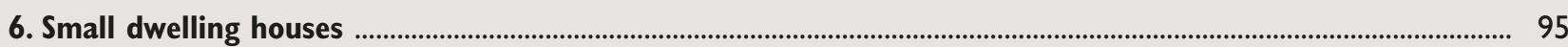

6.I Type 5: Small dwelling house with a central wide-spanned trestle ..................................................................... 95

6.2 Type 6: Small dwelling house with a circular hearth with a clay foundation .......................................................... 98

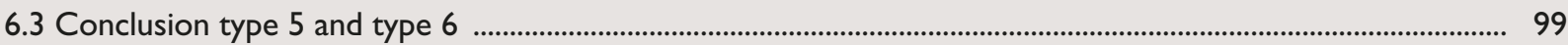

6.4 Type II: Small dwelling house with a hearth and diverging trestles ....................................................................99

6.5 Comparison and interpretation of the house types 5,6 and II ...................................................................... $10 \mathrm{I}$

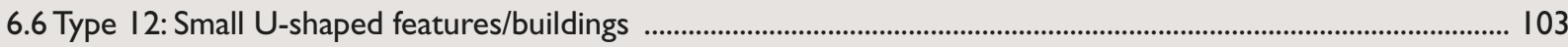

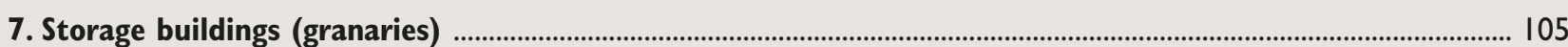

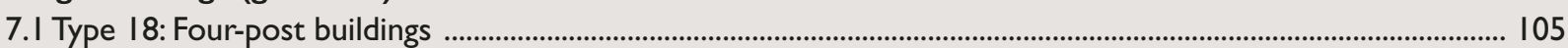

7.2 Type 13: Four-post buildings with a trapezoid layout ............................................................................................. 125

7.3 Type 14: Buildings with four to five diverging trestles ........................................................................................... 126

7.4 Types 15-16: Six- to twelve-post storage buildings .......................................................................................... 127

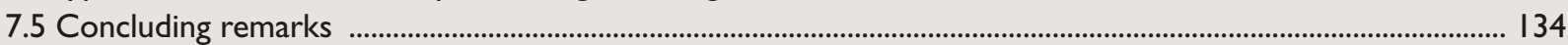


8. Type 7: Large dwelling/byre houses with a central wide-spanned trestle ......................................................... 135

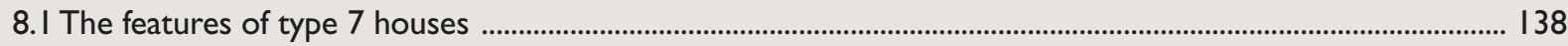

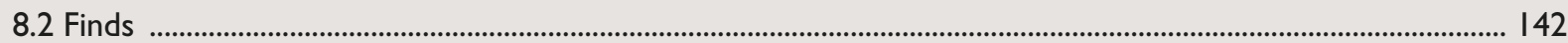

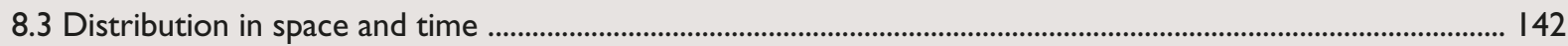

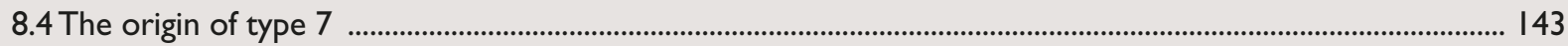

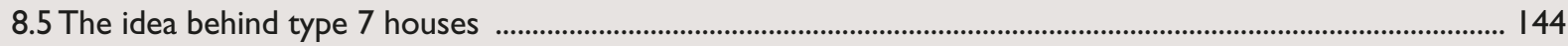

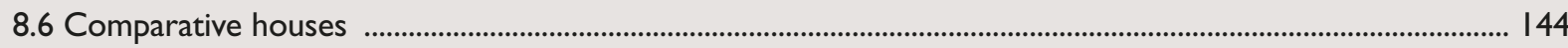

9. Type 8: Large dwelling and byre house with a dwelling area in the centre of the house ................................ 147

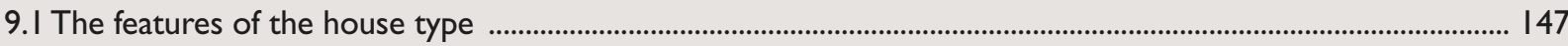

10. Type 9: Large dwelling/byre house with opposed recessed entrances at either end ......................................... I53

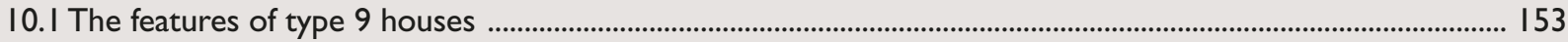

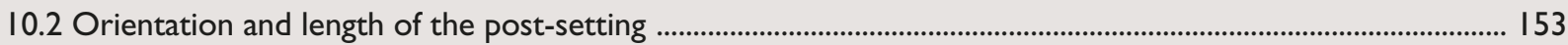

10.3 Shape and size of roof-bearing and entrance postholes ................................................................................... 173

I0.4 Comparison between Roman Iron Age and Migration Period type 9 houses .................................................. 174

I0.5 Comparative houses from Rogaland, Norway and the Nordic region ............................................................. 175

10.6 Comparative houses in the Nordic region ..................................................................................................... 182

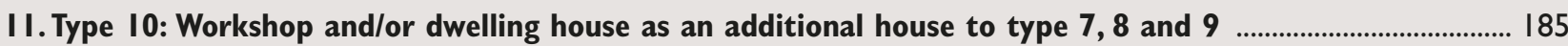

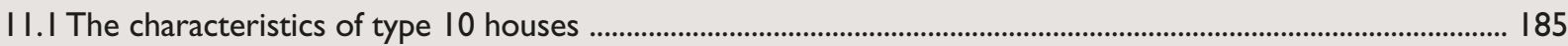

II.2 Structure of the houses and distribution of the finds ...................................................................................... 190

I I.3 Comparison between Forsand and the Nordic region ............................................................................ 191

12. Type 17: Small rectangular workshop …............................................................................................................... I

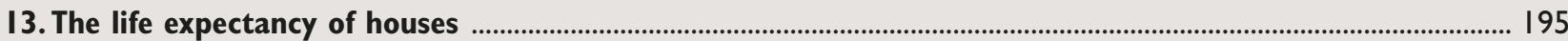

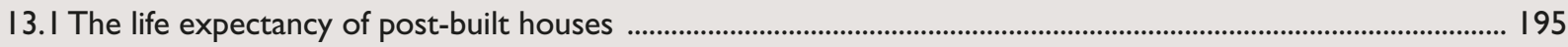

13.2 The life expectancy of type 3 and type 9 houses at Forsand …........................................................................ 196

13.3 Eleven radiocarbon dated house sequences ................................................................................................. 199

14. Interpretation of activity areas in combined dwelling and byre houses ............................................................ 207

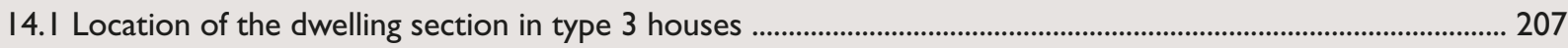

14.2 Location of the dwelling section in type 9 houses ................................................................................................. 2/4

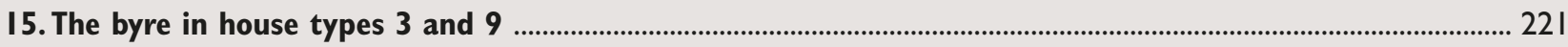

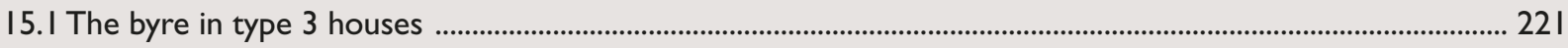

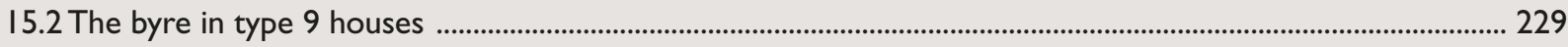

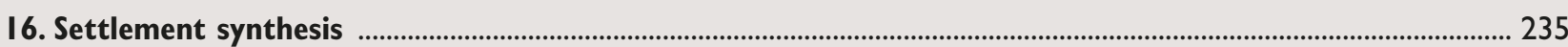

16.I Introduction to the development of the settlement ........................................................................................... 235

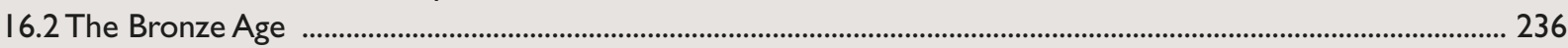

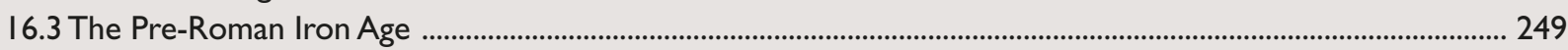

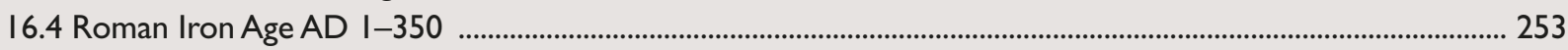

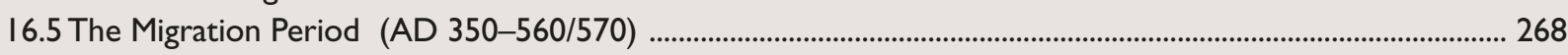

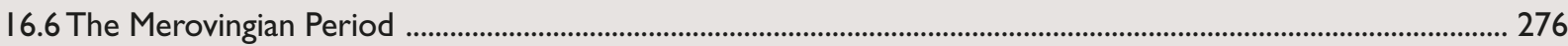

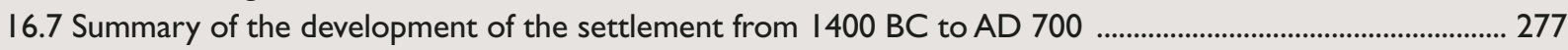

17. The abandonment of the Forsandmoen settlements and the Fimbulwinter in AD 536-37 ............................. 283

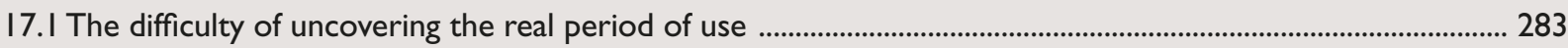

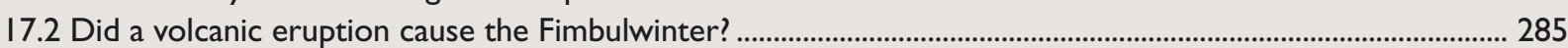

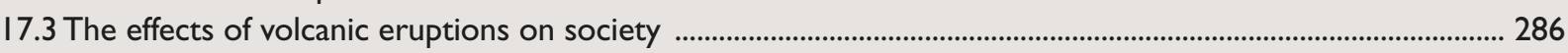

17.4 Can the volume of ${ }^{14} \mathrm{C}$ dates reveal if the decline of Forsandmoen is related to the AD 536 eruption? ....... 288

References 


\section{Periods used in this publication}

\begin{tabular}{|c|c|c|c|c|c|}
\hline Period & $\begin{array}{l}\text { From } \\
\text { calibrated } \\
\text { age BC-AD }\end{array}$ & $\begin{array}{l}\text { To calibrated } \\
\text { age } B C-A D\end{array}$ & Subdivisions & $\begin{array}{l}\text { From } \\
\text { calibrated } \\
\text { age BC-AD }\end{array}$ & $\begin{array}{l}\text { To calibrated } \\
\text { age } B C-A D\end{array}$ \\
\hline Stone Age & $9000 \mathrm{BC}$ & $1700 \mathrm{BC}$ & & & \\
\hline Early Bronze Age (EBA) & $1700 \mathrm{BC}$ & $1100 \mathrm{BC}$ & $\begin{array}{l}\text { BA Period I } \\
\text { BA Period II } \\
\text { BA Period III }\end{array}$ & $\begin{array}{l}1700 \mathrm{BC} \\
1500 \mathrm{BC} \\
1300 \mathrm{BC}\end{array}$ & $\begin{array}{l}1500 \mathrm{BC} \\
1300 \mathrm{BC} \\
1100 \mathrm{BC}\end{array}$ \\
\hline Late Bronze Age (LBA) & $1100 \mathrm{BC}$ & $500 \mathrm{BC}$ & $\begin{array}{l}\text { BA Period IV } \\
\text { BA Period V } \\
\text { BA Period VI }\end{array}$ & $\begin{array}{l}1100 \mathrm{BC} \\
900 \mathrm{BC} \\
700 \mathrm{BC}\end{array}$ & $\begin{array}{l}900 \mathrm{BC} \\
700 \mathrm{BC} \\
500 \mathrm{BC}\end{array}$ \\
\hline Early Iron Age (EIA) & $500 \mathrm{BC}$ & AD 550 & $\begin{array}{l}\text { Pre-Roman Iron Age (P-RIA) } \\
\text { Roman Iron Age (RIA) } \\
\text { Migration Period (Mig. P) }\end{array}$ & $\begin{array}{l}500 \mathrm{BC} \\
A D \text { I } \\
\text { AD } 400\end{array}$ & $\begin{array}{l}\text { AD I } \\
\text { AD } 400 \\
\text { AD } 550\end{array}$ \\
\hline Late Iron Age (LIA) & AD 550 & AD 1050 & $\begin{array}{l}\text { Merovingian Period (Mer. P) } \\
\text { Viking Period (VP) }\end{array}$ & $\begin{array}{l}\text { AD } 550 \\
\text { AD } 800\end{array}$ & $\begin{array}{l}A D 800 \\
A D 1050\end{array}$ \\
\hline
\end{tabular}

\section{Tables and Figures}

Fig. 4 and Tables 5, 23, 35, 36, 37, 38, 4I, 42 and 45 are found in the separate folder Tables and Figures. 


\section{Preface}

Rogaland is known for having a large number of farms with visible house ruins, many of which have been archaeologically investigated. Despite the existence of well-known Danish Bronze Age and Iron Age settlements with no visible traces, corresponding finds were still yet to be made in Rogaland in 1980. When we happened to find traces of post-built houses in 1980 in connection with the excavation of a burial mound at Forsandmoen ("Forsand plain"), it represented the dawn of a new era in settlement archaeology research, first in Rogaland and then from approximately 1990 in the rest of Norway. An interdisciplinary research project was eventually organised, funded mainly by the Museum of Archaeology in Stavanger. The aim was to examine such large parts of the area that one could formulate well-grounded theories about its development and establish an understanding of the changes in the settlement throughout the entire habitation period. The funding situation required that the field investigations be distributed over ten years (1981-1990). All the members of the project team were involved in concurrent reporting and publishing activities and contributed to many articles throughout the 1990s and beyond. Due to the different tasks of the project participants, a planned monograph on the project has unfortunately not been realised. It is now 29 years since the Forsandproject excavations were completed, and other activities associated with the Museum of Archaeology have occupied much of the project participants' time.

However, this book is an attempt to publish some of the important topics from the Forsand excavations. The main emphasis is on a thorough analysis of all the features of the 274 houses and how these have been combined into 17 different types of houses, as well as how they developed and changed in time and space as living spaces. I have given special attention to the interpretation of the location of activity areas in the dwelling and the byre sections of the houses, as well as the life expectancy of the two main longhouse types. On the basis of these analyses I present a synthesis of the development of the settlement in 13 phases based on radiocarbon dating, from Bronze Age Period II to the Merovingian Period, in addition to a hypothesis of the main causes for the abrupt abandonment of the settlement shortly before AD 550 .

Many have been engaged in the excavation work and in processing the material. I would like to thank the 36 archaeologists (students from Norway, Denmark, Sweden and Iceland) and 54 local co-workers who helped to excavate the settlement at Forsandmoen.

Magnar Dalland was the head of the excavation for the first couple of years, while Olle Hemdorff and Lars Pilø were heads throughout most of the excavation and also responsible for parts of the reporting work. Without their enthusiasm, friendship and daily discussions, the project would hardly have managed to investigate so much of the settlement site and to obtain good, uniformly collected archaeological material.

I would especially like to thank Odmund Møllerop, previous Director of the Museum of Archaeology in Stavanger, for facilitating the opportunity to investigate this prehistoric settlement not visible above the ground by provide funding for an excavation in 1981. In addition, he wanted it to be organised as a long-term interdisciplinary project. I would also like to thank previous museum directors Bjørn Myhre, Roy Høibo and Harald Jacobsen for their support after the project period and the current Director of the Museum of Archaeology, Ole Madsen, for their interest when, six years after I retired, I came to the museum with a manuscript for this monograph in 2016.

Associate Professor Sverre Bakkevig and Professor Lisbeth Prøsch-Danielsen were my collaborators during the entire project period and I am thankful for all the good academic discussions we had during the project and for their enduring friendship. Both have published a number of articles relating to material from the studies (vegetation history, macrofossil analysis, phosphate analysis), which have provided important knowledge that has been incorporated into this monograph. I am also grateful for all the other interdisciplinary discussions we had at the Museum of Archaeology. To me, these discussions were important elements in the research process. In addition, I had numerous fruitful 
discussions with my Norwegian and Scandinavian colleagues at many seminars, conferences and on other occasions.

Visits by Director Steen Hvass of the VejleMuseerne, and Professor Dr Haio Zimmermann of the Lower Saxony Institute for Historical Coastal Research (NIhK) during the start-up phase of the project meant a lot in terms of the development of methodologies and strategies for mechanical topsoil stripping adapted to Norwegian conditions. At the same time, I was invited by Steen Hvass and Jens Nielsen to participate in their excavations in Denmark, at Vorbasse by Vejle, and at Sejlflod by Ålborg in Jutland, which inspired me in the further work.

For research on a settlement area from most of the Bronze and Iron Age, with few good, dated artefacts, sufficient access to radiocarbon dates is very important. Throughout the 1980s, the Research Council of Norway and the National Laboratory for Age Determination at the Norwegian University of Science and Technology granted Norway's largest dating series for one site, and Head of Laboratory Steinar Gulliksen's assessments of the dates meant a lot for the interpretation of the settlement. Aud Simonsen of the Museum of Archaeology conducted pivotal wood-type analyses for all the dates.

Professor Anne Karin Hufthammer of the University of Bergen analysed the highly fragmented bone material.

Professor Lotte Selsing, Museum of Archaeology, University of Stavanger initiated a pollen-analytical project to investigate the two bogs Åsheim and Åsen, situated in the hills adjacent to Forsandmoen, and Helge Høeg, government scholar, collected, analysed and published the material.

I would like to thank Forsand municipality and previous Mayors Årstein Løland and Fridtjof Nordland for supporting the excavation during the 1980s by hiring local workers, who made an important contribution to the excavation project through the cleaning of the gravel surfaces and by sifting soil to extract macrofossils. In the 1990s, Forsand municipality was, in cooperation with the Rogaland County Council and the Museum of Archaeology, responsible for the establishment of the prehistoric village, Landa, where reconstructions of five houses from the Late Bronze Age and the late Roman Age / Migration Period were built alongside an exhibition showing results and artefacts from the site.
However, this book would not have been completed without my good friend and colleague Lars Pilø, Oppland County Council, who responded positively to my request in 2014 if he could read critically and comment on an unfinished manuscript that I had been working on for a long time. Director/Professor Bjørn Myhre and Research Director Mads Ravn, VejleMuseerne, had commented on parts of the manuscript some years earlier, but now I needed inspiration to finish my work. Therefore, I am grateful to Lars Pilø for his work, so that some of the topics that were originally formulated in the project could be presented in this book.

I would also like to thank Professor Lisbeth PrøschDanielsen and Associate Professor Eli-Christine Soltvedt for their useful comments on parts of the text. I also want to thank Theo Bell Gil for making the maps in the book, and John Smedstad Moore who translated, improved and corrected the text. Thank you to photographer Terje Tveit and Senior Executive Officer Bente Brønnick from the museum's Collections Department for new photographs of finds from the project and other photographic material. Associate Professor Lars Erik Gjerpe was the academic guest editor and made good contributions to the text. The members of the editorial board at the Archaeological Museum, University of Stavanger, who are responsible for the publication, also deserve a big thank you for their invaluable support in the process towards the publication of this book, as well as for their editorial work. Professor Kristin Armstrong Oma is the chair of the Editorial Board, and the board's members are: Associate Professor Linn Eikje Ramberg, Professor Lisbeth Prøsch-Danielsen, researcher Wenche Brun and graphic designer Ingund Svendsen.

I would also like to thank my two reviewers for their good comments and suggestions for changes to the text, which in my opinion have resulted in a better book. Any errors and shortcomings in the text are my responsibility.

Finally, I would also like to thank my wife Arnhild, who has meant so much to me in what eventually became a lifelong project and especially for inspiring me to complete this monograph.

Trond Løken Nesodden, November 2020 


\section{Objectives of the Forsandmoen project}

Large-scale settlement excavations using mechanical topsoil stripping have, during the last five decades, brought to light a vast settlement data throughout the Scandinavian countries. These investigations have mainly been development-led excavations, where the perimeter of the excavation area is determined by the development project. The excavations often explore only parts of the ancient settlement site. Most of the excavations are thus rather limited in size, counting only a few house remains. Often, the house remains were not unearthed in their entirety, because they extended beyond the excavation borders. The results from such small development-led excavations are normally stored in museum archives and only rarely included in the ongoing settlement discourse.

Other excavations comprise larger areas, where many complete houses are found. Still, most of them include only parts of a settlement site and normally only a few houses from the same period or of the same type/function. This kind of partial excavation limits the possibilities of detecting patterns in the house data or in the organisation of the settlement. Even large development-led excavations meet such difficulties, where the excavated area is limited by the extent of a planned road, railway or gas pipe, cutting a small corridor through what is believed to be a much large site. However, the larger the excavation, the more houses and other structures from the site will be available for detailed research, which may cover the houses and their layout, construction, function and symbolic interpretations, as well as changes in size and organisation of the site throughout the period of habitation.

If a large number of houses and other structures are found, the collected data from excavated postholes, hearths, pits etc., even from a medium-sized excavation, will be so vast that it would be impossible to include all the information when publishing the project. Mainly, the publications comprise the layout of one or more houses in 1:200-1:4/500 scales as a basis for comments and discussion. Even in large excavations, the patterns in the house data, except for the most obvious traits (such as the location of the entrance(s) and hearths, division into dwelling areas and byres), are only to some degree identified. Very little emphasis has been put on the actual construction of houses.

The most obvious reason for this is that the amount of data is so large and the time for writing reports or research so limited. Archaeologists are neither engineers nor architects. Consequently, they rarely look at a house as a construction that creates physical shelter in the daily life of the people at the settlement sites.

Archaeologists meticulously draw layouts and sections of all postholes, showing in detail the horizontal shape, documented by a large number of digital measurements, as well as documenting the dark cores of the posts and the cross-section of a post's angle of inclination, and so on.

In most Danish publications of excavations with mechanical topsoil stripping, cross-sections of the structures are hardly presented, while most Swedish publications present cross-sections of the postholes from the roof-bearing posts of each house. Still, the material has not been used for any detailed analysis of the houses and their construction. Then one may ask, is such detailed documentation a waste of time and resources? If this kind of information is not used better in future research work, one could agree. But I would argue that this is vital information concerning important aspects of prehistoric life. This type of settlement research is still relatively new, and one must try to collect as much important data as possible to form the basis for future research by later generations of archaeologists - hopefully also in collaboration with engineers and architects. This volume highlights some of the potential of detailed information on postholes, hearths and the distribution of artefacts and macrofossils.

In prehistoric societies, we can observe that different objects were manufactured in a certain way at certain times, with a time-specific form and ornamentation. The form is a product of the functional and ideological aspects attached to the object. As we also know, no two prehistoric objects in the Scandinavian area before the Viking Period are identical, since they are manufactured individually by hand. In some periods, one type of object may have a general shape with few 
variations among all the objects of the same type. In other periods, the form of a type of object changes rapidly. This change is related to consensus in the society on how specific objects should be formed, due to changing needs and opinions on how the object should be manufactured. This way of giving form to objects is an important way to mark one's membership in a certain society and to dissociate oneself from others. Such messages can be given by small objects, i.e. how different colours are organised in a glass bead necklace, or by the type of weapons a person carries.

Aside from burial mounds, hill forts and other defensive constructions, houses are the largest manmade prehistoric constructions in the Scandinavian countries. Houses are the first structure that people would see when approaching a settlement. Houses can be very visible markers of group affinity and social status. People would have made use of this opportunity to give such signals to the surrounding world, considering how important it was to be part of a local society as well as a larger tribal area or chiefdom. In large settlements, family groups could also express their position in relation to other members of the settlement.

The data from many small investigations is scattered at large distances from each other, situated in different landscapes and soil conditions, and excavated by different scholars with different methods of documentation. If one intends to develop a house typology, the data must be comprehensive and geographically limited, since regional variations are likely (Tesch 1993:13); such a dataset is not the best point of departure for detailed research on the construction of houses and their features. What is needed is a completely excavated settlement site, where the settlement traces are well preserved. Not only must the geographical location of the individual houses be preserved, but also details concerning their construction, such as outer walls, gables, entrances, hearths, interior walls and doorways, stall boxes, refuse pits, wells, outdoor activity areas, fences and so on. So far, not many such sites have been excavated in Scandinavia. Hodde (Hvass 1985), Vorbasse (Hvass 1979, 1980, 1983), Nørre Snede (Hansen 1987), Grøntoft (Becker 1965, 1968, 1972, Rindel 1997), Sejlflod (Nielsen 1983) and Præstestien (Siemen 2000) are Danish examples. Fosie IV (Björhem \& Säfvestad 1993), Brogård (Carlie 1992) and Görla (Eriksson 1995) from Sweden and Feddersen Wierde (Haarnagel 1979) and Flögeln (Zimmermann 1992) from Northern Germany are other examples. However, among those that have been extensively published, only few have used the data to explore in detail the various features of the houses in an effort to establish an understanding of the different houses.

The only excavation in Norway corresponding to those mentioned above is the Forsand project, which also satisfies most of the requirements mentioned above. It has, however, one major disadvantage to the other sites in that no fences were preserved at the site. The site is well suited for detailed research concerning the construction of a series of house types as well as the development of the settlement. A few burial mounds and other prehistoric remains have also been excavated at Forsandmoen, but my discussion will focus on the buildings. While more detailed stratigraphical comparisons between farms and buildings are harder to come by, the available information will be used to compare different types of farms. The house types are the point of departure for new insight into social and economic organisation of agriculture, animal husbandry and dwellings. Four of the house types are represented in significant quantities, between 30 and 63 in number, giving an excellent possibility to examine the main structures and special features of the individual houses. Although the potential of such analyses cannot be fully explored in this work, I will outline some of the potential regarding resource management and the agricultural organisation. Finally, I will discuss what caused the flourishing settlement at Forsandmoen to end in the $6^{\text {th }}$ century AD. 


\section{The investigations at Forsandmoen}

When local farmer Brynjulf Fossan wanted to cultivate land for pasture, the process leading to the investigation at Forsandmoen started. In 1979, he applied to the Museum of Archaeology in Stavanger for permission to remove four larger and two smaller burial cairns. The larger cairns measured $14-16 \mathrm{~m}$ in diameter and $1.5 \mathrm{~m}$ in height and were among the largest on the plain. Since local farmers had already removed several other such cairns in the period between the two world wars (see below), this application to the cultural heritage authorities was turned down, except for two small cairns.

An excavation of the two small cairns was conducted during June and July 1980 . One contained a small stone cist, which was empty. Both cairns had been plundered; however, a cruciform brooch was found outside one of them, dating the cairns to the Migration Period (Bårdsgård 1980a, 1980b).

More interesting was what was found underneath one of the cairns: a 0.1-metre thick layer of clay, a few postholes, a large cooking pit and some sherds of coarsetempered pottery, indicating that the cairn covered part of a habitation site with the remains of a post-built house with a clay floor.

\subsection{Previous investigation of prehistoric houses in Rogaland and Scandinavia}

Longhouses without stonewalls were hardly known in Rogaland in the early 1980s. At the time, Iron Age settlements with stone-walled houses had been excavated in Rogaland for 70 years, beginning with the excavation of three longhouses at Småhaugane in 1908 (Shetelig 1909). The main period of excavation of Iron Age farms was the 1920-40s, when Petersen (1933, 1936, 1938 , 1944) excavated at least 110 houses (Løken 1998a:169, Myhre 1980). This campaign was initiated by the first meeting for Norwegian archaeologists, held in Oslo in 1927 (Brøgger 1927:104f). At the meeting, there was agreement to prioritise several main research subjects; among these was the investigation of the Iron Age farm. The last large excavation inspired by the goals set up in 1927 was Hagen's investigations at Sostelid in VestAgder in the years 1947-49 (Hagen 1953). This excava- tion introduced new approaches in the investigations of Iron Age farms in Norway, including pollen analysis, which was undertaken as a part of an exploration of the entire settlement area. In the 1950s, there were hardly any investigations of Iron Age farms in Rogaland. Then, due to development planning in the 1960s, several minor excavations of Iron Age farms were carried out (Espedal 1966, 1967, Møllerop 1962, 1964, Skjølsvold 1970a, 1970b). The next major step forward was the research project undertaken at Ullandhaug near Stavanger in 1967-68, where the excavations were planned with the use of modern excavation techniques and with an interdisciplinary cooperation that included vegetation history and macrofossil analysis, as well as phosphate analysis (Myhre 1980).

At the end of the 1960s, 146 houses had been excavated in Rogaland. However, the chronological distribution was biased. Few settlements were older than AD 1, the bulk being from the late Roman Iron Age and Migration Period, and a smaller number from the Late Iron Age. Since Professor A. W. Brøgger (1925) had suggested that there were no permanent farm settlements or any use of metal for tools before AD 1, there was no apparent reason to search for houses that were believed not to exist.

All the investigated Iron Age settlements so far consisted of visible house ruins, where the outer walls normally had been made of large stones in the outer and inner wall course, while the middle part consisted of a fill of smaller stones and earth/turf. Larger and smaller parts of more than 350 such farms in Rogaland, comprising approximately 800 house ruins, were known (Løken 1999:52), and it was believed that this was the only type of farm in the Iron Age. With the benefit of hindsight, the fact that these farms were mainly distributed in Jæren and the adjoining parts of Dalane (Løken 1983:81) should have led to caution before reaching such a conclusion. Abundant grave finds from the Roman Iron Age and the Migration period in the remaining areas of Rogaland suggested a pattern of dense habitation - also in areas where only a few farmhouses with stone-built outer walls had come to light. To give one example: 50 burial mounds were registered 
on the Forsandmoen heathland, but no house ruins. In such areas, it seems reasonable to suggest a different building tradition.

Large scale excavations with mechanical topsoil stripping had been undertaken in Denmark since the early 1960s and had revealed hundreds of post-built houses from settlement sites beneath cultivated fields (Becker 1965, 1968, 1971, Hvass 1979, 1980, Kaul 1985, Nielsen 1983, Siemen 1985). To a certain degree, Norwegian archaeologists were aware of this new development in Danish archaeology, but even so believed that such finds were not possible in the stony and hilly Norwegian landscape. During the 1970s, five excavations showed that three-aisled house remains without visible surface markers also could occur in other parts of Norway than Rogaland.

The first excavation took place near Oddernes church, Kristiansand in 1971-72 (Rolfsen 1976). When a shovel dozer had removed the topsoil, 4-5 small houses appeared, situated in a row together with nine pit-houses and hundreds of refuse pits from the early Roman Period. In 1972, Myhre (1973) excavated two small houses underneath a field at Gjerland, Sogn og Fjordane, and Rolfsen (1980) excavated a settlement with four rectangular houses and a pottery workshop at Augland near Kristiansand. In 1978, a late Roman Age / Migration Period settlement was revealed by mechanical topsoil excavation at Bertnem in Namdalen, NordTrøndelag (Farbregd 1980, Løken 1992a). For the first time in Norway, large post-built houses $(40 \times 8.5 \mathrm{~m})$ were found after removing the topsoil, thus bearing the promise of a new era of research in Norwegian archaeology. The fifth find that created the basis for the future field work at Forsandmoen was an excavation that I conducted at Opstad, Tune in Østfold (Løken 1978, 1998b) in 1976. A 20 m long Late Bronze Age post-built house was revealed underneath and partly outside two large burial mounds. This demonstrated for the first time that three aisled Bronze Age houses of a similar shape as in Denmark had been built in Norway as well.

I was the supervisor of the excavations atForsandmoen in 1980. When I saw the remains of a house, my experience from Opstad together with the recently published results from Trøndelag came to mind, and I recognised the possibility of comprehensive settlement traces. If this was the case, the large agricultural machines that the farmer intended to use would destroy them. The Museum of Archaeology had made an agreement with the farmer that the area planned to be cultivated should be investigated during the summer of 1980, except for the four large cairns. If an excavation could confirm additional settlement traces in the area, further investigations had to be done in a hurry.

The previous director of the Museum of Archaeology, Odmund Møllerop, grasped the opportunity to bring the investigation of Iron Age settlements into a new era and initiated a trial excavation in the area around the cairn where the settlement traces were found. The trial excavation was undertaken in August the same year. Settlement traces were found in all the trial trenches in the planned cultivation area. The farmer was informed that the regulations set out in the Cultural Heritage Act prevented him from cultivating the area until the museum had finished the necessary excavations. He patiently waited 10 years before all parts of the area could be cultivated.

\subsection{Landscape}

The Forsand area is situated in the inner fjord district bordered by two fjords, the Lysefjord and the Høgsfjord, to the NW and SW respectively (Fig. 1). To the N, E and $S$, Forsandmoen is encircled by mountains reaching 5-600 m.a.s.l. (Fig. 2). The Fenno-Scandinavian Ice Sheet withdrew from the area at the end of the Younger Dryas, approximately $11.4 \pm 0.4$ ka (Briner et al. 2014). During the Younger Dryas, the Lysefjord was filled by a glacier, depositing a marginal moraine at the mouth of the Lysefjord. Thus, the threshold into the fjord is only $13 \mathrm{~m}$ below the present sea level, while other parts reach depths up to $456 \mathrm{~m}$. Huge lateral moraines were also built up on both sides at the outlet of the Lysefjord. To the south (at the Forsand side of the fjord), this lateral moraine is called Rygjen ("the Backbone"). Rygjen reaches an altitude of $64 \mathrm{~m}, 30 \mathrm{~m}$ higher than the plain on the distal side of the ridge. Between Rygjen and the fjord is a fertile area covering 65 ha, which has been the core area for the three historic farms Forsand, Gjøyse and Berge.

The Lysefjord glacier was braided, and another marginal moraine, called the Esmark moraine, dams up the southern end of the lake Haukalivatn (Andersen 1992:99f, Esmark 1823, Simonsen 1977). The Esmark moraine is an impressive moraine, with steep sides facing Forsandmoen, and with the ridge (87 m.a.s.l) raised $30 \mathrm{~m}$ above the nearby part of the plain (Fig. 3).

Forsandmoen is a gravelly glaciofluvial outwash plain with clear signs of braided stream patterns (PrøschDanielsen \& Simonsen 1988:86) and was built up in the fjord between these terminal moraines. Due to the heavy weight of the Inland Ice Sheet, the land was depressed. As soon as the deglaciation started, the land and outwash plain emerged. The plain between the two 


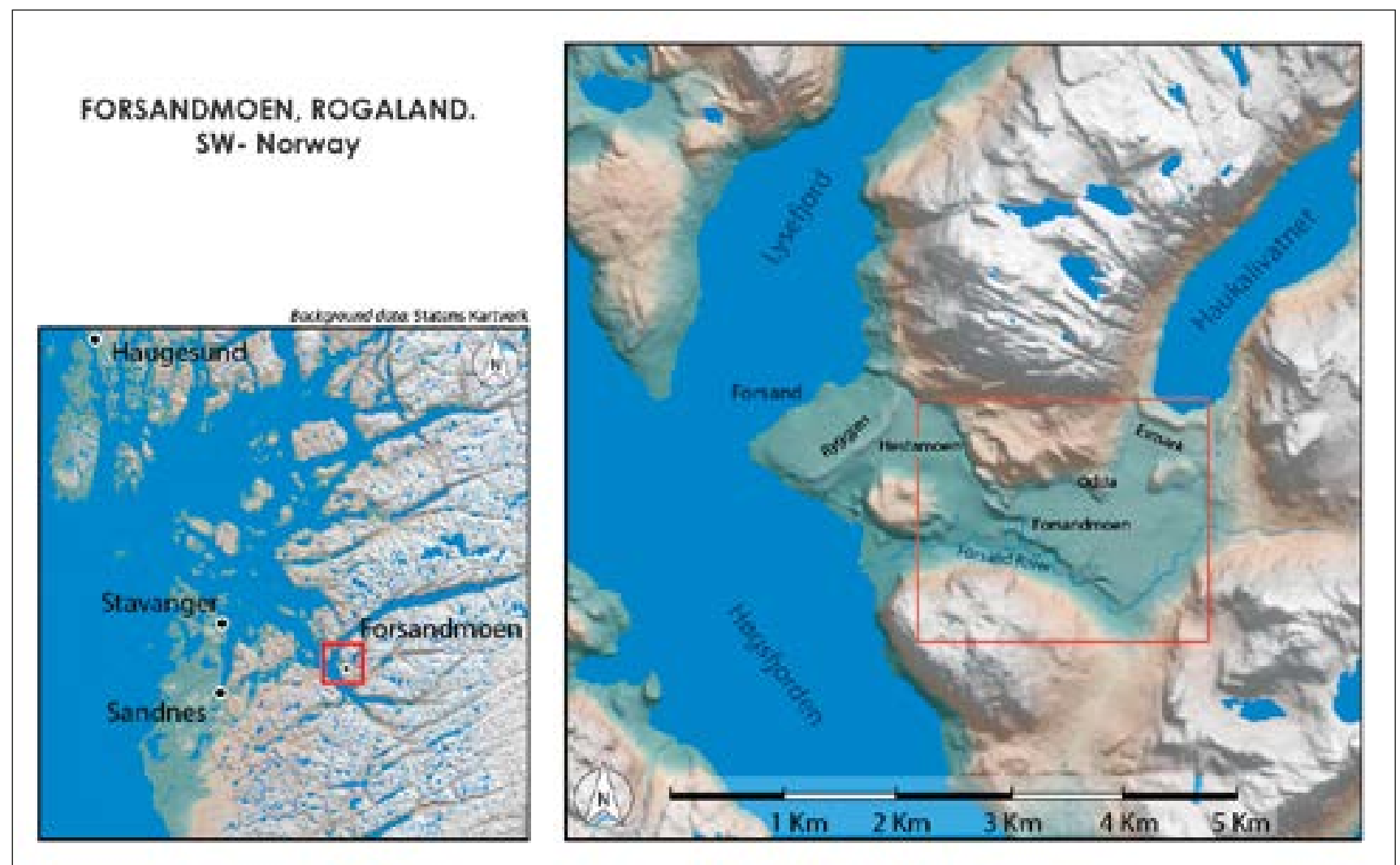

Fig. I. The location of Forsandmoen at the east side of the outlet of the Lysefjord in Forsand, Rogaland. The excavation areas, as well as the late Weichselian moraines Rygjen and Esmark, are marked (map: T. G. Bell, AM, UiS).

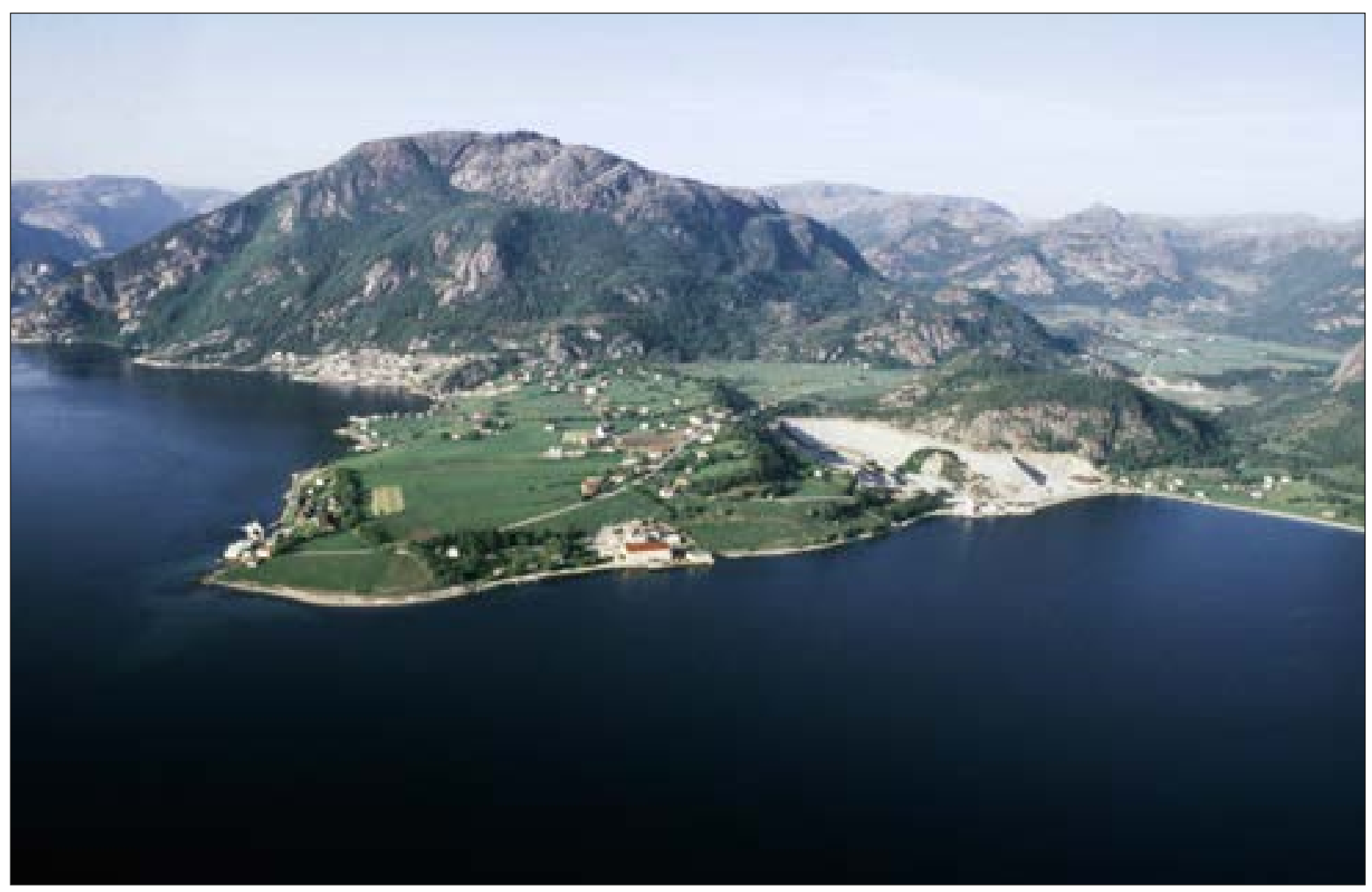

Fig. 2. Aerial view of Forsand proper at the outlet of the Lysefjord (left) in June 1980, seen towards NE. The marginal moraine Rygjen is situated in the centre and Forsandmoen to the right (photo: R. Jonsrud, AM, UiS). 


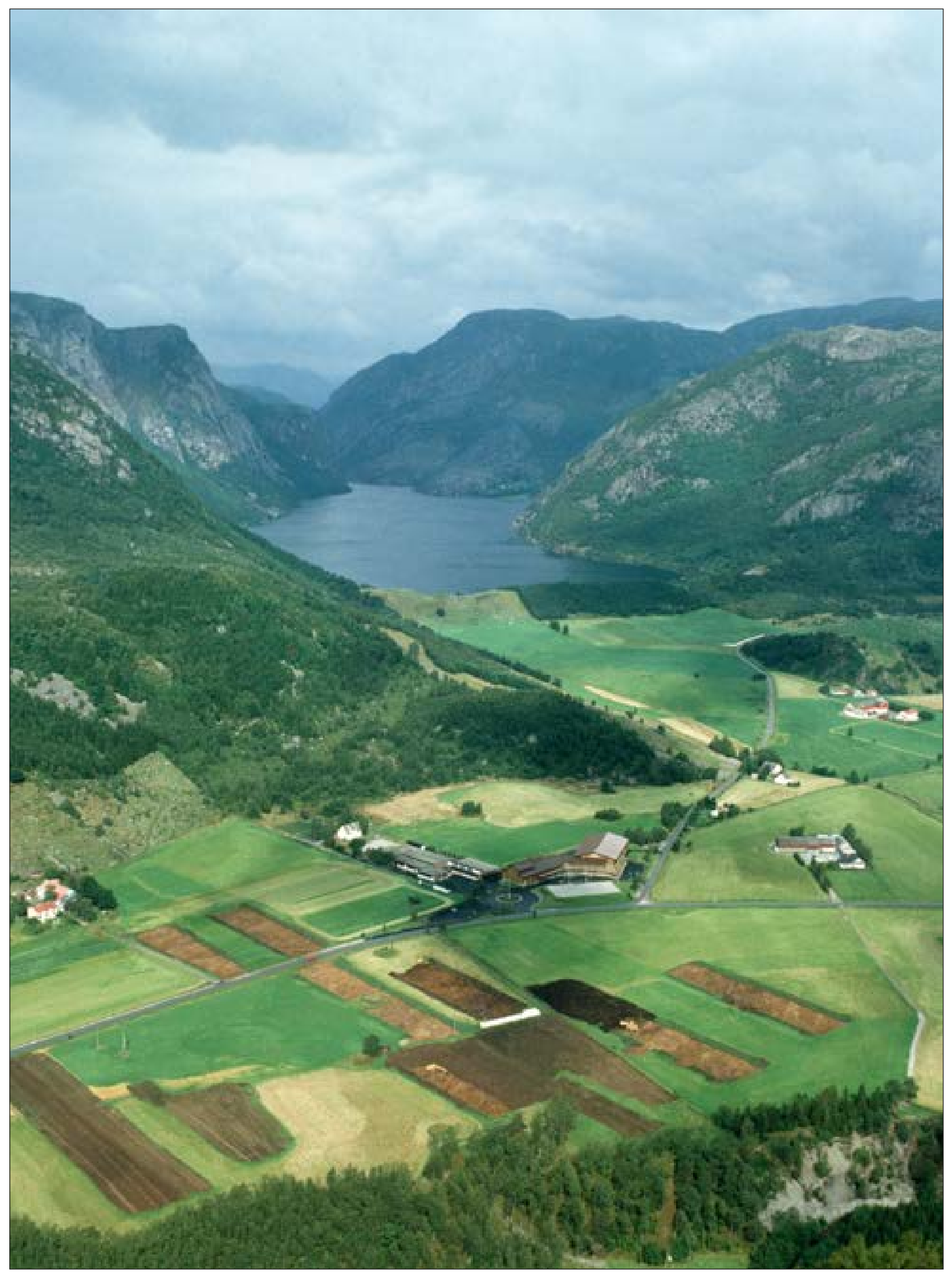

Fig. 3. View of the central settlement area at Forsandmoen in July 1990 seen towards N, when most of the excavation areas in 1990 are opened. The Esmark moraine dams the lake Haukalivatnet in the background. 
end moraines is enclosed by hillsides to the N, E and S. To the W is the small hill called Åsen. Between this hill and the northern slopes of the mountain Uburen, the plain has access to the Høgsfjord to the SW.

The river Forsandåna runs along the eastern and southern border of the outwash plain, receiving most of its water from the hillsides to the $\mathrm{E}$ and $\mathrm{S}$. At the southern border, the river Forsandåna has cut a gully into this part of the plain, lowering the surface by $20 \mathrm{~m}$. Only one brook runs through the plain proper, having its source in the area west of the Esmark moraine from water coming from the hillsides.

The outwash plain is divided into two parts by a small, but rather steep hill (Steinberg) and by deep braided stream patterns south-west of this hill. The eastern part, measuring 190 ha, is called Forsandmoen, while the western part, measuring 50 ha is called Hestamoen ("Horse plain"). Hestamoen consists of coarse gravel embedded with large stones and is thus less suitable for settlement and agriculture than the large inner areas of Forsandmoen. Only the parts of Hestamoen situated furthest away from Rygjen seem suitable for settlement. Unfortunately, here sand and gravel resources were already used for industrial purposes before the archaeological excavations at Forsandmoen started. It has therefore been impossible to find out whether this part was settled in prehistoric time or not. However, one burial cairn, located at the western edge of the sand quarry, was documented in 1980 (Floor 1980) but was later destroyed without being archaeologically investigated. It is uncertain whether this cairn represented a burial from a settlement site nearby or if it was a border marker actually belonging to the prehistoric farms at the outlet of the Lysefjord, as opposed to the settlements at Forsandmoen on the eastern side of the braided stream landscape.

At Forsandmoen, the Quaternary deposits vary from coarse gravel and large stones near the Esmark moraine, grading into finer textures southwards and westwards. Just in front of the Esmark moraine, 1-2 $m$ deep undulating braided stream patterns can be recorded. Further south, these patterns are wider and smoothed out to depths of only $10-30 \mathrm{~cm}$. These factors have been decisive for land-use, agriculture and for the settlement pattern throughout prehistoric time; the eastern part of the plain is best suited for agricultural purposes, the western and smallest part is the best area to locate settlements.

A headland (Odda) protrudes southwards into the outwash plain, just west of the previously mentioned brook. Along the bottom of this headland and the border to the base of the mountain further west, the surface is always moist due to the steady water supply running down the hillsides. Shallow pits would provide sufficient water supply for a settlement. Due to the headland, the area is sheltered from easterly, cold winter winds. This area also has another advantage, as it is exposed to sunlight both in the summer and in the winter months. Other areas at Forsandmoen are sometimes in the shadow of the $440 \mathrm{~m}$ mountain Uburen during the winter months. During the period from the vernal to autumnal equinox, Uburen does not cast a shadow anywhere on the central plain. However, where the large late Roman Iron Age and Migration Period village is situated, the sun will be hidden most of the day by the mountain in the remaining part of the year.

Forsandmoen belongs to the middle fjord districts. Today, it has a mean annual rainfall of $1700 \mathrm{~mm}$, with a maximum in the late autumn and minimum in April and May. July is the warmest month, with a mean temperature around $15.5^{\circ} \mathrm{C}$. As the winter temperature is generally around $0{ }^{\circ} \mathrm{C}$, the fields are seldom snowcovered for a long period (Nitter 2009).

\subsection{Ancient monuments in the area}

When travelling across Forsandmoen in 1822, the geologist Jens Esmark noticed that a lot of burial mounds situated there had traces of plundering (Esmark 1823, Simonsen 1977). Eight years later, as Kraft (1830:250) travelled all over Norway gathering statistical information, he remarked that there were a lot of mounds on a plain in the valley ascending from Forsand and approximately $1 / 4$ Norwegian mile $(2.8 \mathrm{~km})$ from the seashore, and that this was the largest collection of mounds in the district. Like Esmark, he noticed signs of excavations in most of them. One of the mounds had an upright stone (menhir, bauta) that had nearly fallen down, while another was situated along the road to the plain. Kraft also reported a rare circular stone packing, which he compared with a foundation wall of a circular house. He concluded that Forsand must have been an important place in ancient times.

In 1862, Nicolay Nicolaysen (1860-66:321) observed many burial mounds on the plain. In 1866, Nicolaysen (1860-66:798) visited the plain and reported that there were 30-40 circular burial mounds scattered throughout the plain. Contradictory to Esmark and Kraft, he claimed that hardly any had been plundered. He also mentioned a long barrow at the far end of the plain, which had been "excavated" in the central part. This barrow is very likely the one mentioned below, 
which was excavated in 1992. Nicolaysen also noticed a 2.5 -alen-high $(1.5 \mathrm{~m})$ menhir as the only one at the plain. Nicolaysen argued against Kraft's interpretation of a circular house foundation wall. He interpreted this as the outer remains of a $14.5 \mathrm{~m}$ wide, circular barrow where the interior had been removed. The very different opinions as to whether the plundering / "excavations" of the mounds had taken place before 1820 or after 1866 , leaves this question concerning the history of the cemetery unsolved.

A soil fertility map of the until then (in the last centuries) unsettled area of Hestamoen, Forsandmoen and the surrounding hillsides, was drawn up in connection with the redistribution of the previously common pastures on the heathland in 1908 (the Berge farm) and in 1910 (the Forsand farm). The purpose was to distribute the most fertile areas in an equal way. These maps mark 24 burial cairns, labelled as unarable areas and therefore of little value; of these 24, eleven still exist today.

The former director of the Stavanger Museum, Jan Petersen, visited the plain several times in the late 1920s in connection with his excavations of the last remains of the burial cairns that had been removed by farmers during their cultivation of the former heathland.

Nine of the cairns reported as impediments in the first decade of the $20^{\text {th }}$ century are not reported later in connection with the large scale topographic (land-use) map survey conducted in 1980 for the municipality of Forsand. The survey in 1980 was a systematic survey, where the surveyors searched through the landscape in order to describe and map the ancient monuments that still existed.

One must bear in mind that, until the beginning of the $20^{\text {th }}$ century, the plain was only used for collecting heath as fodder and as grazing area for cattle. The information from the $19^{\text {th }}$ and early $20^{\text {th }}$ century therefore gives a reasonable account of how many and what types of monuments were present at Forsandmoen at that time. The available evidence shows that there have been at least 49 round cairns. Fig. 4 shows only 31 burial cairns located within the borders of the excavation areas.

Most of the cairns (36) were situated in the central, western part of Forsandmoen, within an area measuring approximately $550 \mathrm{~m} \mathrm{E}-\mathrm{W}$ and $350 \mathrm{~m} \mathrm{~N}-\mathrm{S}$. Another concentration was situated in the south-eastern corner of the plain, where at least eleven cairns, including a long barrow, are known. Elsewhere, there are only individual cairns, like the one most easterly on the plain, and the one to the north, near the Esmark moraine.

Petersen (1945) reported that, east of the burial cairns around the main settlement area, a N-S oriented ancient stone fence constituted a border between uncleared areas with many visible stones to the east and cleared areas to the west. However, it is uncertain whether this fence had been constructed by the pioneer farmers in the 1920s or whether it originates from the prehistoric settlement.

Petersen reported in 1926 that there were fields of clearance cairns over large parts of the plain. The extent of such fields was not documented properly before the thorough survey of 1980. By that time, most of the plain was cultivated so only limited parts of these once very extensive fields of clearance cairns were preserved. Only two such fields were registered, both in the south-eastern corner of the plain - the one containing approximately 58 cairns in a 1.8 ha field and the other one having 74 cairns in a 2.8 ha field (Fig. 6) (Løken \& Hemdorff 1996). These areas with clearance cairns in the south-eastern corner of the plain document that crop husbandry have taken place in this area. Even though there are no such preserved cairns in the central area of the western part of the plain, the large number of stone heaps along the southern edge of the plain indicates the previous occurrence of such cairns in these areas. The continued excavations in 2007 (Dahl 2008), which revealed a surviving clearance cairn situated at the border between two farms, support this understanding.

So far, we have only dealt with the ancient monuments at Forsandmoen, and the solitary cairn at Hestamoen. However, burial mounds or cairns are also known from Forsand proper. The total number does not exceed six, surprisingly few compared to the number at Forsandmoen. This small number is probably due to the continuous settlement with intensive crop production throughout the Medieval Period and later.

Finally, I would like to shed some light on the occurrence of ancient monuments in the areas around Forsandmoen. Directly across the Lysefjord from Forsand proper, at Oanes, there is a typical Roman Iron Age / Migration Period farm. The deserted farm consists of four large longhouses with outer stonewalls, five burial cairns, infields with stone fences, an enclosure, lynchets and 100 clearance cairns (Floor 1980).

In the valley Heia heading SE from the SE corner of Forsandmoen towards Rossavik, a similar farm is situated on the northern slope. The main house measures $50 \mathrm{~m}$ in length, with an ancillary house of $8 \mathrm{~m}$ in length. A cattle path points up the hillside and encircles a 4 ha infield with 30 clearance cairns, several fields with lynchets and approximately $6-7$ burial mounds/cairns. The length of the main house is as long as the longest house 
uncovered at Forsandmoen. The large burial mound is also of the same size as the largest ones at Forsandmoen, indicating a household head of similar social status. A central hearth from the dwelling area was dated to 1550 \pm 80 BP, AD 400-600 (T-8251, Table 2), simultaneous to the Migration Period settlement at Forsandmoen. Further to the SE, there are three similar farms on the slopes of Rossavik ("Horse Bay"), each consisting of one or two longhouses together with burial cairns, clearance cairns and stone fences. Excavations in the 1930s and the 1940s (Petersen 1933, 1936, 1944, 1952) showed that two of these are dated to the Roman Iron Age / Migration Period, while the last one seems to be from the Viking Period / early Medieval Period. These farms are deserted farms situated at the most elevated area belonging to the historic farm Rossavik. In addition, the Rossavik farm has several burial mounds below the farmstead towards the seashore, pointing at another Early Iron Age farm here. Two grave finds dated to the Early Iron Age were found in the same area. Therefore, at least three farms existed simultaneously here in the last centuries of the Early Iron Age.

This survey shows that the area surrounding Forsandmoen was densely settled at the same time as the village consisting of approximately 15 farms occupied Forsandmoen.

\subsection{Artefacts from the Forsand area Stone Age 9000-1700 BC}

The earliest traces of people in the area derive from the top of the marginal moraine at Oanes, at the mouth of the Lysefjord, just opposite Forsand proper, where there are the remains of a large Early Mesolithic settlement, strategically located at the mouth of the fjord, overlooking both the Lysefjord and the Høgsfjord.

At Forsand proper, the earliest artefacts consist of different types of axes and adzes belonging to the Late Mesolithic, 6000-4000 BC (Løken 2001a:6). In addition, some waste material has been collected from settlements in the area. Similar material has also been found at the farms Mæle and Helle at the mouth of Espedal, at Rossavik, as well as Oanes, Erevik and Lerang to the north of the Lysefjord. From the Early and Middle Neolithic, there are finds of axes belonging to a hunter-gather way of life from the same farms. From the Late Neolithic, the few finds of polished axes, flint daggers and sickles indicate the introduction of a more sedentary way of life based on agriculture at Forsand proper, as well as some other farms mentioned above.

The only Stone Age find from Forsandmoen before the settlement investigation began in 1980, was a flaked arrowhead from the Late Neolithic or the Early Bronze Age, indicating activity in the area.

\section{Bronze Age, 1700-500 BC}

Some of the Late Stone Age artefacts, like the flint daggers, sickles and strike-a-light flints are also dated to the Early Bronze Age, which shows that a sedentary agricultural society continued into the Bronze Age in the area around Forsandmoen (Løken 2001a:8). A gold bracelet was found in 1959 on a little ledge underneath a small hill near the seashore at Berge farm, at the northernmost part of Forsand proper. On top of the hill, there were remains of a burial cairn, obviously looted in earlier times. The bracelet may have been part of the grave inventory in the cairn. The preserved part of the bracelet weighs $30 \mathrm{~g}$ and is dated to the Late Bronze Age Periods V-VI (Marstrander 1977). As one of only six or seven Norwegian Late Bronze Age finds of golden objects, this find may point to a settlement capable of producing an economic surplus.

\section{Early Iron Age, 500 BC-AD 550}

Burial finds from the Pre-Roman Iron Age are generally few in Rogaland as well as in Norway as a whole (Pilø 1989). This is also the case for the early Roman Iron Age. The situation changes at the turn to the late Roman Iron Age and especially in the $4^{\text {th }}$ century AD. From that time on and throughout the Migration Period, there are hundreds of recorded burials in Rogaland (Slomann 1972), and the Forsand area mirrors Rogaland in general. At Forsand proper, there is one grave find with two ceramic vessels dated to the latter half of the Pre-Roman Iron Age (Løken 2001a:10), and two grave finds from the $4^{\text {th }}$ and $5^{\text {th }}$ century AD, respectively, the last from a small stone cist. Two surviving barrows in the area also comprise a stone cist, indicating a date to the late Roman Iron Age or Migration Period.

Farmers cultivated large areas of the plain throughout the $20^{\text {th }}$ century and up to 1980 , removing several burial cairns during this process. The farmers often collected artefacts found in the stone cists in the cairns and sent them to the museum in Stavanger. On occasion, the director of the museum was contacted to give him the opportunity to conduct an investigation before the grave was completely removed. Thus, seven grave finds from the central, western part of Forsandmoen are known, and all but two dated to the $4^{\text {th }}-6^{\text {th }}$ century AD (Løken 2001a:11). The last ones can most likely be dated to the Early Iron Age in general. The graves represent both male and female graves. 


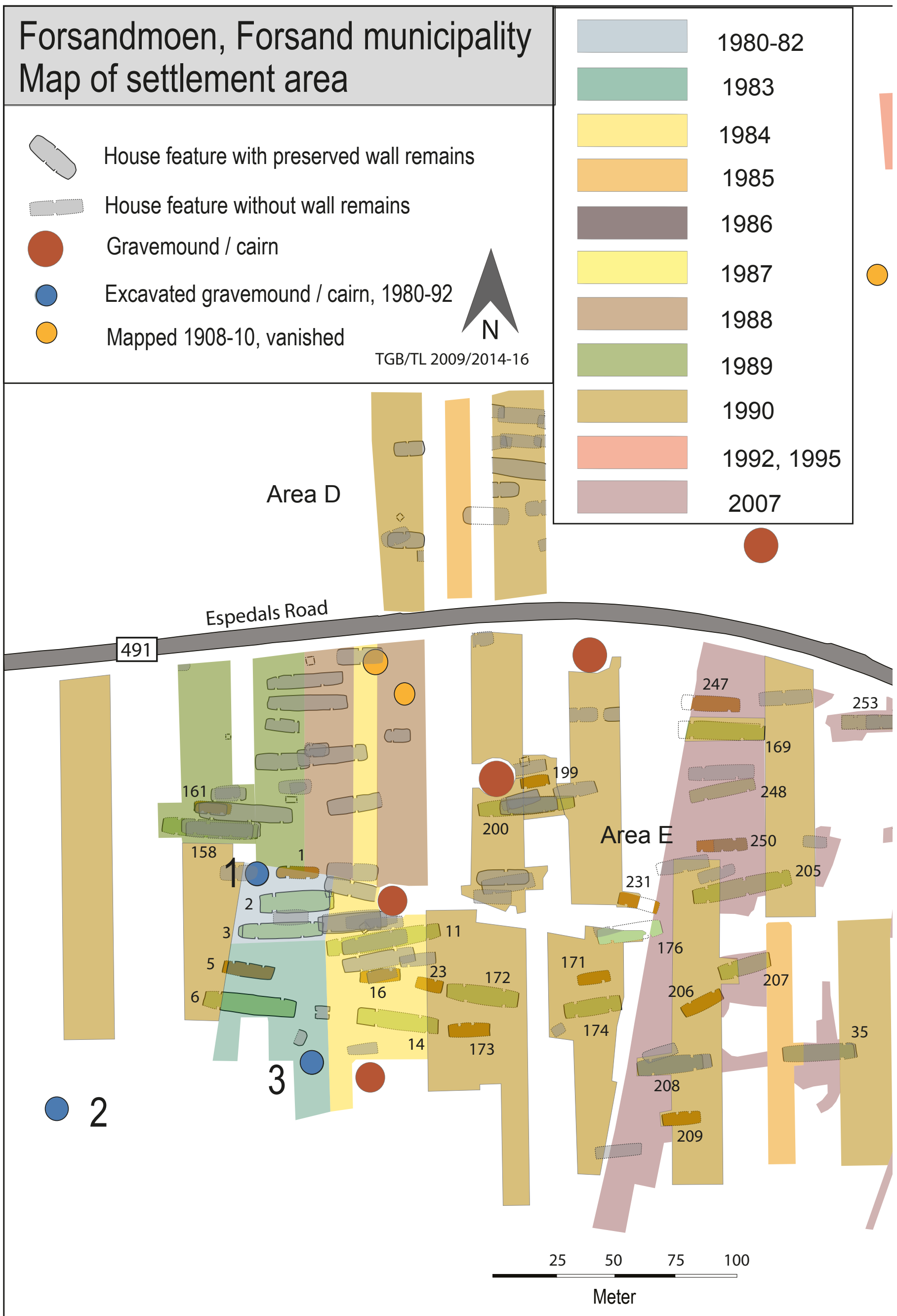


Two graves were male graves, equipped with spears and lances, and two graves were female graves, containing small personal objects and one to three ceramic vessels.

The straightforward interpretation of these grave finds in 1980, prior to the settlement investigations, would have been that the area had been home to a settlement during the late Roman Iron Age and Migration Period - an isolated farm. However, the large numbers of burial cairns (49 in this area) indicated that the settlement might have comprised more than one farm or might have lasted for a much longer period than indicated by the dated grave finds.

\section{Late Iron Age, AD 550-1050}

The Late Iron Age is normally a period with an abundance of grave finds in Norway, also in Rogaland. In Forsand, however, finds are quite scarce. Two or three grave finds originate from Forsand proper. No such finds are known from Forsandmoen, but a male weapon grave has been found in the small valley Rettedal, which ascends to the east from the eastern end of the plain. A male weapon grave is also known from Rossavik.

\subsection{Research strategies and progress of the excavation}

Subsequent to the 1980 discovery of the settlement remains below one of the excavated cairns, the Museum of Archaeology in Stavanger decided to finance further fieldwork within its own budget. Money for research was limited, but the director of the Museum of Archaeology at that time decided that a reasonable part of the museum's funding should be allocated to the investigations at Forsandmoen. By 1984, the large size and long duration of the settlement was documented. It was decided that the excavation campaign should continue until 1990.

The Cultural Heritage Act of 1978 allows the responsible museums to carry out excavations for research purposes. However, it was necessary to find strategies that also satisfied the needs of landowners in terms of being able to produce a reasonable crop yield from their land, even though they were compensated economically for their loss of potential crops. Forsandmoen is used today for production of grass fodder for domestic animals. Taking large areas out of grass production due to excavations could have had serious consequences for the farmers, as grass is not always easily available for purchase. The progress of the excavations was therefore not always the best from an archaeological point of view. Still, most of the areas with high phosphate values have been excavated. One small part of the area with low phosphate values was excavated, but without results. This suggests that the most important areas of the settlement area were excavated, even though some areas west of Area C (Fig. 4) were not accessible due to modern disturbances.

Also, an area between the Areas A and C, with the highest phosphate values and a good potential for houses, could regrettably not be excavated due to lack of funding. Aside from the houses and their indoor features, many cooking pits, hearths and some waste pits have been found. In addition, two cremation burials without any visible indication were situated near by one of the many burial mounds within the settled area. No trackways, wells or fences have been registered within the excavated area.

\subsection{Summary of excavation progress 1981-90}

The excavations at Forsandmoen from 1981 up to and including 1990 were concentrated in five different areas, $\mathrm{A}-\mathrm{E}$, containing settlement traces and two smaller areas without such traces (Fig. 4).

Area $E$ is the largest area and is located in the southwest. A total of $39600 \mathrm{~m}^{2}$ have been unearthed in that area, but there is an additional approximately 17200 $\mathrm{m}^{2}$ situated in $19 \mathrm{~m}$ wide strips between the trenches. In such intermediate areas, only small houses can be missing (in addition to parts of houses already partly documented in the excavated trenches). Within a $61,600 \mathrm{~m}^{2}$ area, the project has acquired an almost complete knowledge of the number and types of houses in the area.

Area $D$ is situated to the north-west and is a much smaller area, measuring $4000 \mathrm{~m}^{2}$ in three excavation trenches and $1600 \mathrm{~m}^{2}$ in between the three trenches. This area gives us a fairly good impression of the history of the settlement here. With the benefit of hindsight, it would have been better to have had a more contiguous excavated area without it being divided by the unearthed $10 \mathrm{~m}$ wide strips; this could mean that the short-lived Bronze Age and Pre-Roman Iron Age houses may still be hiding in the unexcavated areas between the trenches.

Area $A$ and Area $C$ together comprise the second largest excavation area and are situated in the northeast, consisting of a contiguous area (A) measuring 250 x 60-100 $\mathrm{m}\left(15,800 \mathrm{~m}^{2}\right)$ and some scattered areas (C) to the south-west measuring $3300 \mathrm{~m}^{2}$, in total $19100 \mathrm{~m}^{2}$. 
Area $B$ is situated in the south-east part of the plain, and consists of $7250 \mathrm{~m}^{2}$ of excavated area, and an additional approximately $2000 \mathrm{~m}^{2}$ between the trenches. This area likely does not contain any other houses than those excavated.

In addition, in the phosphate-enriched area just east of Steinberg, two trenches totalling $2600 \mathrm{~m}^{2}$ were excavated. Also, to the west of Steinberg, a 1,500 $\mathrm{m}^{2}$ trench was investigated. These areas $\left(4,100 \mathrm{~m}^{2}\right)$, however, did not contain settlement remains.

In total, $74000 \mathrm{~m}^{2}$ of the plain was investigated during the eleven years of excavation. There are still $20.800 \mathrm{~m}^{2}$ of areas that have not yet been investigated located in strips a maximum of $19 \mathrm{~m}$ wide in between the excavated areas. These areas probably only contain a few small houses. Most trenches were laid out in areas with a high content of phosphate in the subsoil. One such trench, just to the east of the hill called Steinberg, did not contain any traces of settlement activity in spite of the very high content of phosphate in the area. Another $100 \times 20 \mathrm{~m}$ large trench situated $30 \mathrm{~m}$ west of the main excavation area in the southwest (E) also had no settlement traces. However, this was not surprising, since the phosphate content in this area was so low that the area was supposed to be outside the settlement area. In the south-east area (B), a large early Roman Iron Age farm covered the highcontent phosphate area. Further to the east was a small settlement area, containing ten houses, situated on the southern, small part of a medium-enriched phosphate area, which was otherwise nearly vacant of settlement traces. As far as Forsandmoen is concerned, one can conclude that, with one exception, a high content of phosphate corresponds with settlement activity.

\section{0-1984}

This period saw the excavation of a major part of the western portion of the planned cultivation area $(6300$ $\mathrm{m}^{2}$ ) and one $100 \times 10 \mathrm{~m}$ trench to the north of that area in formerly cultivated land. The purpose of this trench was to examine whether or not settlement traces had been preserved in land cultivated without the use of a mechanical digger.

\section{5}

As a result of the extensive phosphate mapping undertaken in 1983-84, the main goal for the season was to excavate five large trial trenches in the most phosphateenriched areas. As a test, one of the $100 \times 10 \mathrm{~m}$ trenches was intended to reach areas with less phosphate so as to see if such areas also contained traces of a settle- ment. Two of the trenches were situated NE of Forsand School, which was in the same area as the municipality had wanted the museum to investigate a large area on the site of a planned new building.

\section{6-1988}

During this time, project resources were primarily allocated to the phosphate-enriched area to the NE, underneath the steep hillside to the north, and partly sheltered by the protruding hill, Odda, to the east. An area of $11000 \mathrm{~m}^{2}$ was excavated. In addition, a large trial trench was opened up just east of Steinberg hill and another at Hestamoen, where an expansion of the sand quarry was planned. More importantly, the excavation in 1988 also returned to the original area. Two $100 \times 20 \mathrm{~m}$ trenches were laid out on each side of the long trench in the cultivated area north of the planned cultivation area, giving a $100 \times 50 \mathrm{~m}$ area on very phosphate-enriched soil, which bordered the initial 6,300 $\mathrm{m}^{2}$ area from 1981-84. Investigations were also started in the phosphate-enriched area at the south-east corner of the plain, where three barrows strongly indicated a settlement area. Initially, one trial trench was laid out right over the most phosphate-enriched area, and the north-eastern end of a longhouse came to light.

\section{9}

The work continued to unearth new areas to the east and north in the north-eastern main excavation area. In the south-western excavation area, another two $100 \mathrm{x}$ $20 \mathrm{~m}$ trenches were laid out with the intention to document whether the western border of the settlement site coincided with the border of the most phosphateenriched soil. A $100 \times 100 \mathrm{~m}$ area was then excavated in addition to the $100 \times 75 \mathrm{~m}$ area in the original planned cultivation area. The third area excavated in 1989 was in the south-east part of the plain, where the investigated area covered a total of $60 \times 60 \mathrm{~m}$ and contained a $50 \mathrm{~m}$ long farmhouse. Due to funding restrictions not all houses could be excavated in full.

\section{0}

The main goal for the final excavation season was to investigate the size of the late Roman Iron Age / Migration Period settlement in the south-western part of the plain. In addition, two trenches were opened in the north-western part of the site, where only a $10 \mathrm{~m}$ wide search trench had been excavated in 1985. The third main excavation area in this season was in the outermost south-east part of the plain, where three $60 \times 20 \mathrm{~m}$ trenches and some areas in between were 
excavated on a low gravel ridge due to future plans for a sand quarry in this area. Somewhat further to the north, a small excavation was carried out on a dry ridge in the autumn due to agricultural plans.

\subsection{Further settlement excavations 1992-95, 2007}

The plans of establishing a sand quarry in the SE part of the plain quickly became a reality. Large areas nearby, where excavations had taken place in 1990, had to be investigated (Area B). In 1992, large areas totalling $4,700 \mathrm{~m}^{2}$ were stripped of topsoil in a trench system, and an additional approximately $2000 \mathrm{~m}^{2}$ between the trenches (Hemdorff 1992). Only three more houses were uncovered. However, one structure, consisting of one pair of postholes, has been dated as early as Bronze Age Period II, showing that this area was taken into use as a settlement area as early as the sheltered area west of Odda.

In 1994, school development plans led to the excavation of a long strip bordering one of the large trial trenches from 1985, Area C. Topsoil stripping unearthed an area of $2700 \mathrm{~m}^{2}$ (Rønne \& Løken 1998). The advantage of this excavation was that several houses that had only been partly investigated in the old trench could now be fully unearthed and investigated. At the northern end, it was also possible to connect the old trench and the new trench to the western end of the large continuous excavation area in the north-east part of the plain.

In total, these two excavations increased the investigated settlement area at Forsandmoen by $7400 \mathrm{~m}^{2}$ and by $2000 \mathrm{~m}^{2}$ in between trenches, resulting in a total of $81400 \mathrm{~m}^{2}$ and $22,800 \mathrm{~m}^{2}$, respectively, on the plain.

Due to a huge demand for sand and moraine gravel, the sand quarry needed to expand further in the late 1990s and into the new millennium. After a prolonged hearing, all area south of the E-W main road through the plain (Fig. 4 and 6) was committed to the sand industry. As a consequence, the as yet unexcavated settlement areas and four large burial cairns had to be excavated.

In 2007, a large excavation took place, where 11.000 $\mathrm{m}^{2}$ of settlement area, situated partly in between areas that had been previously stripped $\left(3200 \mathrm{~m}^{2}\right)$ but mostly in unexplored areas $\left(7900 \mathrm{~m}^{2}\right)$, were excavated (eastern part of Area E, Fig. 4) (Dahl 2008). This increased the total excavated area on the plain to $89600 \mathrm{~m}^{2}$ and reduced the unexplored areas in between the trenches by $6000 \mathrm{~m}^{2}$ to $16.800 \mathrm{~m}^{2}$. In addition, 13 trenches $3-4$ $\mathrm{m}$ wide (20-100 m long) were dug further east, where the content of phosphate was low, but fluctuating. Only the trench bordering the excavated settlement areas revealed two large Migration Period houses. During this campaign, several partly excavated houses were unearthed in their entirety. Furthermore, 2-3 additional late Roman Iron Age or Migration Period farms were uncovered, increasing our knowledge of the village substantially.

The results of the development-led excavation undertaken after the closing of the excavations included in the original research project are included in this publication by kind permission from Rønne, Hemdorff and Dahl.

\subsection{Excavations of burial mounds and cairns 1980-2001}

This chapter will give a brief overview of the results of the excavations of eight burial cairns at Forsandmoen during the last 25 years. The excavated graves provide important supplementary material when the settlement is interpreted as part of the larger society, not only in the Lysefjord and the Høgsfjord areas, but also when the settlement is interpreted as part of Rogaland. In Rogaland, there are few municipalities where such a high number of burial cairns have been professionally excavated over the last decades. Therefore, it is important to give a description of the results, which until now have only been presented individually.

As described above, the project started with the excavation of a small burial cairn. The cairn Id $14502^{1}$ was situated in the NW corner of the 1981 excavation area (Fig. 4: no. 1). It was slightly oval, $5.6 \mathrm{~m} \mathrm{~N}-\mathrm{S}$ and $4.2 \mathrm{~m} \mathrm{E}-\mathrm{W}$ and $0.5 \mathrm{~m}$ high, consisting of mainly small stones. There were no finds from the cairn, but during the initial settlement fieldwork, a cruciform brooch and a knife with no traces of a funeral pyre were found right outside the cairn and may derive from a grave plundering event. The brooch dates the cairn to the Migration Period (Bårdsgård 1980a, Bårdsgård et al. 1980).

Id 71854 was situated approximately $140 \mathrm{~m}$ to the south-west of the above-mentioned cairn (Fig. 4: no. 2) and at the edge of the plain (Bårdsgård 1980b). This cairn was slightly larger and circular, measuring $6 \mathrm{~m}$ in diameter and $0.5 \mathrm{~m}$ in height. The centre of the cairn had been plundered. A small stone cist was situated 
near the outer edge. The cist contained a layer of burnt bones at the bottom. Among the stones outside the cist, a double-conical spindle whorl with collars was found, which dates the cairn to the late Roman Iron Age or Migration Period (Hofseth 1985).

In 1981, an oval stone setting/cairn was found when removing the topsoil near the southern edge of the plain (Fig. 4: no. 3). It was excavated two years later but did not produce datable finds. The cairn was oval, measuring $7.1 \times 6 \mathrm{~m}$, and was only $0.25 \mathrm{~m}$ high (Løken 1992c:112-113).

Three cairns on the plain were excavated due to plans for the cultivation of fields and development plans for a gravel quarry in 1992 (Hemdorff \& Kjeldsen 1992). At the eastern end of the plain, there was a long barrow that was $30.4 \mathrm{~m}$ long and $5 \mathrm{~m}$ wide, with a carefully built kerb of hewn stones with a vertical front all around (Fig. 4: no. 4). It had no primary grave, only an upright, standing stone (menhir, bauta) in the central axis of the cairn. Just inside the kerbstones, there was a cremation pit with some pottery sherds and a pair of tweezers that dated the grave to the late Roman Iron Age or Migration Period (Hemdorff \& Kjeldsen 1992).

Adjacent to the main settlement area, two circular cairns were excavated (Fig 4: no. 5-6) (Kjeldsen 1992). A cairn that was $7 \mathrm{~m}$ wide and $0.7 \mathrm{~m}$ high and built of pebbles covered two cremation patches near the edge of the cairn. A pit from grave plundering had disturbed the centre of the cairn.

One of the cremation patches contained an undecorated bucket-shaped pot. In addition, there were blue and red glass beads and melted glass from beads, two bronze needles, a bronze pendant and a decorated three-layer bone comb, suggesting a female grave. The bucket-shaped pot belongs typologically to the transition between the late Roman Iron Age and Migration Period (Hemdorff \& Kjeldsen 1992, Kristoffersen \& Magnus 2010). A ${ }^{14} \mathrm{C}$ date of charcoal from the pyre dates the grave to the Migration Period (1590 $\pm 80 \mathrm{BP}$, AD 390-570, T-10703).

The other grave in the cairn, also from the Migration Period, was marked with a large boulder and contained the remains of a bucked-shaped pot, a decorated bone comb and some human bones (Hemdorff \& Kjeldsen 1992).

Only one half of the second cairn, also built of pebbles, was preserved. The diameter was $11 \mathrm{~m}$ and the height $0.5 \mathrm{~m}$. A $2 \mathrm{~m}$ wide cremation patch contained $500 \mathrm{~g}$ of human bones, an iron hook, tweezers, sherds from bucket-shaped pottery and a vessel with a handle, probably a male grave. A Migration Period date is sup- ported by a ${ }^{14} \mathrm{C}$ date from the pyre to $1620 \pm 70 \mathrm{BP}, \mathrm{AD}$ 350-540 (T-10704).

When the gravel quarry was expanded closer to the remaining two burial cairns at the eastern end of the plain in 2000, one of the largest mounds in the area had to be examined (Fig. 4: no. 7) (Gellein 2000, Gellein \& Skjelstad 2001). This cairn was situated $25 \mathrm{~m}$ from the southern end of a $50 \mathrm{~m}$ long house dated to the early and middle Roman Iron Age. It was supposed that the monument had been erected in connection with the habitation period of the house. The circular cairn measured $14 \mathrm{~m}$ in diameter and $1.9 \mathrm{~m}$ in height at most. A deep pit, $4 \mathrm{~m}$ wide, from plundering in the middle had taken away the original top of the cairn. Based on the recorded curvature, the cairn probably measured $2.5 \mathrm{~m}$ in height. The cairn consisted of at least two phases. First, a cairn consisting of a mixture of stone and earth, $8 \mathrm{~m}$ wide and $1 \mathrm{~m}$ high, was constructed and delimited by a stone kerb. At the centre and near the original surface, there were many fire-cracked stones and large pieces of charcoal. This can be interpreted as waste material from the nearby settlement or as remains from funeral ceremonies. There were no finds to date this cairn.

Above and around this cairn, a much larger cairn, consisting only of stones, was erected. A stone cist 3 $\mathrm{m}$ long and oriented $\mathrm{N}-\mathrm{S}$ was dug halfway into the original cairn. There was a 3-4 $\mathrm{m}$ wide circular stone setting around the cist, marking the centre. A spindle whorl, fragment of a silver buckle, late Roman Iron Age / Migration Period pottery and cremated human bones, suggest that a woman was probably buried in the cist. To the east of the cist, a male warrior was buried without any recognisable marking. The grave contained a lance and spear with remains of oak shafts, a shield boss, five iron arrowheads, scissors with remains of a case made of rowan, an iron handle from a casket and pottery, both ordinary earthenware as well as an asbestos-tempered bucket-shaped pot. What make this grave outstanding at Forsand are a small golden finger ring and a gilded silver clasp with niello inlay. In total, the grave is the most richly furnished grave known from the plain (Fig. 5). It is tempting to connect it with the nearby and longest farmhouse on the plain $(50 \mathrm{~m})$. However, since the graves from the second building phase are dated to the Migration Period (Gellein \& Skjelstad 2001) due to the bucket-shaped pottery, the weapons and the silver clasp, and the farm belongs to the early Roman Iron Age or beginning of the late Roman Iron Age, the settlement and this grave cannot be contemporaneous. It is, however, a possibility that 


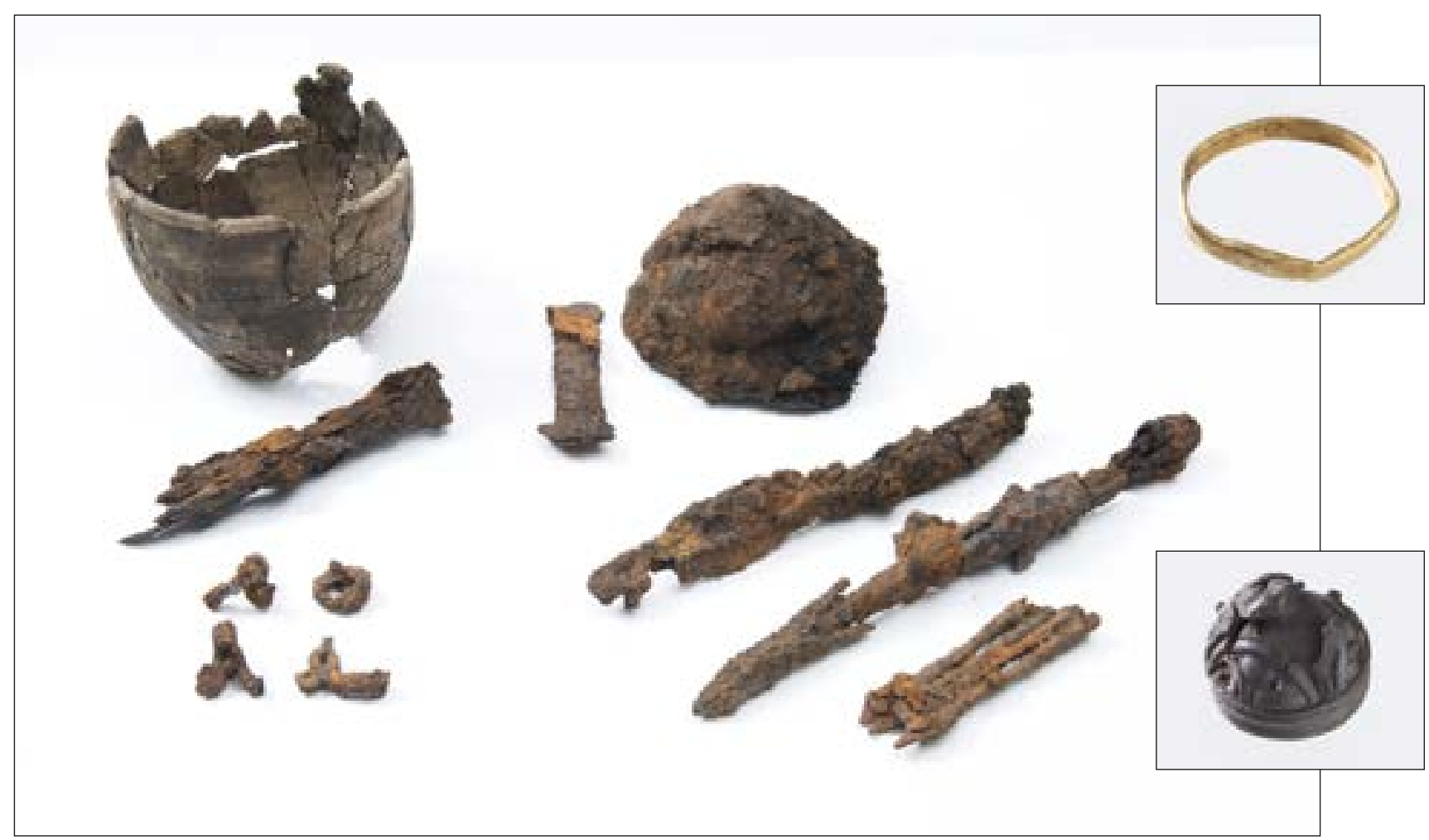

Fig. 5. SII865: Inventory from a warrior's grave from the Migration Period, including a small golden finger ring and a gilded silver clasp with niello inlay (photo: T. Treit, AM, UiS).

the earliest construction phase of the cairn was contemporary with the house.

The last burial cairn to be excavated was also $14 \mathrm{~m}$ in diameter and was originally only $1.3 \mathrm{~m}$ in height (Fig. 4:no 8). Due to plundering, it has been reduced to $1 \mathrm{~m}$ in height (Sørheim 2007). The monument had a $1.5 \mathrm{~m}$ wide flat border of stone paving around the approximately $10 \mathrm{~m}$ wide cairn proper. The cairn covered a cremation patch that was E-W oriented and $3 \times 2.2 \mathrm{~m}$ wide, which - in addition to charcoal and burnt bones - included a spindle whorl and crushed pottery from a female grave. Midway and directly east, between the centre and the fringe of the cairn, a small cist had been built. The cist contained a fragment of a blue glass bead, tiny fragments of a bone comb, burnt bones and charcoal. The cist had clearly been plundered since a fragment of a similar glass bead, a crushed decorated earthen vessel, burnt bones and charcoal were found on top of the cairn. The central cremation grave can only be dated generally to the late Roman Iron Age or Migration Period, while the earthenware likely dates from the Migration Period (Sørheim 2007:7). 


\section{Methods and source criticism}

\subsection{Conditions for preservation of the settlement site}

There appears to have been no settlements on the Forsandmoen plain in modern times before the beginning of the $20^{\text {th }}$ century. The plain was common pasture and an area for gathering heather for the two historic farms Forsand and Berge, situated at Forsand proper. Using heather as fodder for cattle and sheep/ goats, either by grazing or collected as winter fodder, requires that the heather is burnt regularly. If not, the heather grows too old to serve as fodder (Kaland 1979:46). Such land-use would not affect possible cultural deposits or features below the humid topsoil. Before new farms were established on the plain and modern cultivation began, one would therefore expect that the cultural deposits were undamaged by agriculture. Most areas, where the phosphate analysis indicated settlement activity, were already cultivated at the beginning of the project. This type of cultivation was originally conducted in an old fashioned way, by lifting the largest stones with a stone clearing device (a tripod, Norwegian: steinbukk) while most stones were gathered directly on sledges or wagons and tipped down the steep slope at the southern edge of the plain. This type of clearance of the fields did little or no harm to the subsurface settlement traces. However, the subsequent ploughing could easily have removed large wedging stones from the postholes. In the 1960s and 1970s, mechanical diggers did more harm, since they turned over both the soil and the uppermost gravel layer, removing as many stones as possible. In addition, holes were struck into the iron pan in the top of the subsoil to improve the drainage.

Our trenches showed that the two types of cultivation had damaged the settlement remains, but nowhere so severely that an interpretation of the features in the subsoil was impossible.

The only two areas that were not cultivated prior to 1980 were the area where the excavation started in 1980 (the south-western part of Area E) and the large north-eastern excavation area (Area A). Here, there was a possibility of finding preserved cultural deposits. Removing the topsoil mechanically would potentially remove everything of scientific value there. When the project started, we wanted to investigate if cultural deposits were preserved and see how many and what types of artefacts were present. Several test squares were therefore dug by hand from top to bottom in the south-western part of Area E.

The investigation gave a clear answer; even in areas with no modern cultivation, intact prehistoric cultural deposits were not preserved above the subsoil. The reason for this is probably that the prehistoric farmers used the settlement areas as fields after the settlement had moved. Traces from scratch ploughs in many settlement areas support this explanation. The artefact finds from the test squares were also very scarce; only a few sherds of coarse-tempered pottery and some pieces of burnt clay were found. It was therefore deemed not worthwhile to excavate larger areas of the topsoil manually, especially since the artefacts, due to later agricultural activity, no longer were preserved in situ and therefore could not be connected with certainty to the underlying features.

The excavation managers searched for artefacts in the washed top of the spoil heaps in the different excavation areas, finding very few artefacts. We also regularly examined the exposed sections along the trenches and concluded that preserved cultural layers were absent. The conclusion is that the sample results obtained in 1981 were valid in general for the whole area investigated.

Searching with metal detectors, prior to or during mechanical topsoil removal, was not carried out due to limited experience with this method in Rogaland in the initial phase of the project, and lack of trained metal detectorists.

The plain is nearly perfectly level, rising at the southern edge from 38 m.a.s.l. to 57 m.a.s.l. at the base of the Esmark moraine, $1.4 \mathrm{~km}$ to the north, which is a height difference of only $1.35 \mathrm{~m} / 100 \mathrm{~m}$. This implies that there has not been any significant natural erosion, which could have affected the settlement traces after the landscape situation had stabilised at the end of the late Weichselian (Ice Age). In general, the natural conditions for the preservation of settlement traces 
are therefore stable throughout the excavation areas. Running water from the melting ice created height differences in the subsoil at the south-east settlement and also at the eastern part of the south-west settlement (cf. chapter 2.2). In the eastern part of Area E, the houses from the Migration Period were positioned on top of low ridges and were more exposed to disturbance from ploughing than houses situated further to the west, where there are no ridges. Some of these houses on the ridges were so affected by clearance activity or ploughing that it was difficult to interpret the layout of the houses properly.

\subsection{Excavation by mechanical topsoil stripping}

Løken, Pilø and Hemdorff have published the background and description of how mechanical topsoil stripping developed as a method during the 1980s at Forsandmoen (Løken et al. 1996). It is thus not necessary to describe this in detail here, and the 1996 publication contains a comprehensive summary in English. However, the houses and the finds are the main topics of this monograph, and this body of evidence was in many ways formed by a method that was still undergoing development at the time of excavation. It is therefore reasonable to describe the main stages in the development of this method and especially to point to the weaknesses of the different methodological choices.

\section{Developing the method at Forsandmoen}

A combination of a mechanical digger and a shovel dozer was used to remove the topsoil at the start of the Forsandmoen excavation in 1980. These were the only earth-moving machines available locally at the time. The shovel dozer was able to expose a contiguous area, but caused much damage to the underlying structures, and its use was discontinued after the 1981 field season. The mechanical digger did not have caterpillars and had to move by using the bucket to pull itself to the next position. It was less efficient than the shovel dozer, but also less damaging to the underlying structures. In this initial phase, a relatively small contiguous area was exposed, uncovering a large and wide longhouse with curved walls (House 2).

During a visit in 1983 the director of the Vorbasse project, Steen Hvass, recommended the use of a mechanical digger to remove the soil in $10 \mathrm{~m}$ wide trenches, instead of a contiguous area. This system of mechanical topsoil stripping by way of trenching had proven to be very efficient in the sandy soils of Jutland. The trench method turned out to be efficient on the coarse gravel at Forsandmoen as well. In the period from 1983-87, we still only had a mechanical digger at our disposal, which had to be moved by using the bucket to pull the digger. During this time, we continued to excavate 10 $\mathrm{m}$ wide trenches, putting the earth to one side, making it possible to open another $10 \mathrm{~m}$ trench adjacent to it, producing a $20 \mathrm{~m}$ wide trench. Cleaning of the exposed subsoil only took place after the mechanical digger had moved away from the trench. This allowed for a cleaned area per person of $50 \mathrm{~m}^{2}$ per day, i.e. it was very labour-intensive.

A new mechanical digger with caterpillars was introduced in 1988, which could move easily between two adjacent trenches. This made it possible to uncover two adjacent $10 \mathrm{~m}$ trenches simultaneously, exposing a 20 $\mathrm{m}$ wide trench in one go. This allowed for simultaneous surface cleaning by the crew in one $10 \mathrm{~m}$ trench when the excavator had moved to the other $10 \mathrm{~m}$ trench. The topsoil removal and subsequent subsoil cleaning process became much more efficient, since the soil from the cleaning process no longer had to be carried out by hand, increasing the cleaned surface to $400 \mathrm{~m}^{2}$ per person per day in 1990. This new procedure is described in detail by Løken et al. (1996:24f) and will therefore not be described further here.

This final development was the main reason why the excavation costs per ha were reduced by $50 \%$ from $1984-87$ to $1988-89$, and by another $50 \%$ in 1990 (Løken 1992c: 10-15).

Another reason for the low cost per area unit in 1990 was the changes in the excavation strategy. The first priority that year was to establish if there had been a $300 \times 150$ m Migration Period village in Area E. Three times more trenches $\left(31500 \mathrm{~m}^{2}\right)$ than each of the two previous years $\left(9250 \mathrm{~m}^{2}\right)$ were excavated. This could be done because many houses were only documented on the master plan level, and just the central hearth(s) and 1-3 postholes were excavated. The time-consuming collection and sieving of macrofossil samples was also reduced to a minimum, giving more labour capacity for opening additional trenches. This combination of a much more efficient method of topsoil stripping and surface cleaning - in addition to the different excavation strategy employed in 1990 - allowed for a great expansion of investigated areas in the last phase of the main excavation period.

\section{Documentation of the excavation area}

During the first years, we tried out several different ways of documenting the excavation areas: a photo 
tower, a 3 x 3 m drawing frame (Løken et al. 1996:30ff) and a Topometer (Hertz et al. 1980-92:E7, Wessel 1982). However, it became apparent that a less complicated procedure using measuring tape and folding rulers with an overall grid as a basis was the most efficient. Using trenches 10 or $20 \mathrm{~m}$ wide, this method turned out to be quite efficient in a decade where modern, computerised measuring was not available.

In 1988, a laser theodolite became available to the project through a grant from the Research Council of Norway. This made it possible for project staff to establish precise grid points for the trenches, instead of relying on the availability of land surveyors. The Forsandmoen project used the official Norwegian coordinate system at the time (NGO).

\subsection{Phosphate analysis}

The Museum of Archaeology has long experience in undertaking phosphate analysis, going back to 1960. At that time, the only Norwegian laboratory for scientific analyses of archaeological samples was established by Provan $(1968,1971)$ and Mauritzen (1970) at the Museum of Archaeology in 1967. In the late half of the 1970s, Bakkevig (1980, 1981a, 1981b, 1982b, 1983) introduced a spot test method, which had the advantage that the samples could, if needed, be analysed in the field, even though the more stable conditions at the indoor laboratory were considered to give more reliable results. Based on prior experience with phosphate analysis, it was natural to implement this method in the investigation of the Forsandmoen settlement. Such analysis could be used in large-scale mapping to delimit the settlement area as well as for detailing the distribution of phosphate in connection with individual houses.

\section{Method}

The spot test method has been presented and discussed by Bakkevig in a number of papers (Bakkevig 1980, 1981a, 1981b, 1982b, 1983). It is therefore necessary only to give a brief description here. At settlement sites, the main source of organic accumulated phosphate is bone. However, meat, fish, plants, animal urine, dung and ashes can also contribute to a high P content. Small soil samples were collected using a 2-centimetre-wide auger at $10 \mathrm{~cm}$ intervals down to a depth of $60 \mathrm{~cm}$ and analysed in the museum laboratory. Approximately 50 $\mathrm{mg}$ of soil was placed on a filter paper and two drops of solution containing hydrochloric acid and ammonium molybdate dissolved in distilled water were added. After half a minute, two drops of a reducing reagent of ascorbic acid were added and the filter paper turned more or less blue according to the amount of phosphate in the soil sample. The amount of blue-coloured substance on the filter paper is proportional to the $\mathrm{P}$ content dissolved by the extraction agent. The results were assessed visually using six values $(0-5)$, where $0-1$ indicates a natural $\mathrm{P}$ content not influenced by man, 2-3 indicates a natural $\mathrm{P}$ content in P-rich soils or anthropogenic $\mathrm{P}$ and $4-5$ indicates anthropogenic $\mathrm{P}$. These six spot test colour values were calibrated using double-blind spot tests on 143 phosphate samples with known absolute ppm values, collected and analysed with ordinary laboratory procedures in the1960-70s (Bakkevig \& Løken 1985). This analysis showed that a spot test value of 2 would have an average value of 130 ppm, a spot test value of 3 would be approximately 320 ppm, a spot test value of 4 being $350 \mathrm{ppm}$ while a spot test value of 5 could be as high as $650 \mathrm{ppm}$. Spot test analysis could therefore be highly valuable for assessing the size of settlement area as well as the amount of phosphate in the different areas at Forsandmoen.

\section{Phosphate analysis used as an indicator of settlement areas}

Several series of phosphate samples were analysed in and around the $1300 \mathrm{~m}^{2}$ excavation area in 1981. Further sampling around this area showed that the area with a high phosphate content extended well outside the excavation area. It was therefore decided to implement large-scale phosphate mapping, covering the whole of Forsandmoen. Samples were collected in a $50 \times 50 \mathrm{~m}$ grid (based on the official Norwegian grid). To reduce the importance of occasional variation in the soil at the grid point, four samples were collected in a square at a distance of 1 metre from each grid point. The average value from the different $10 \mathrm{~cm}$ layers of these four samples represents the value at the grid point. Samples were taken from the whole plain during the autumn of 1983 and 1984, with supplementary samples in 1985-86 (Løken 1984a). Thanks to the extensive sampling work, a very informative map (Fig. 6) depicting the variation in the phosphate content in the subsoil could be constructed (Løken 1987b). It showed that the central, western end of the plain contained a large phosphate-enriched area, with spot test values of 4 or higher, measuring $12 \mathrm{ha}(550 \mathrm{~m}$ SSW-NNE x 250 m ESE-WNW). Three narrow phosphate-enriched areas that stretch eastwards from the main phosphate area are interpreted as indications of cattle paths towards pastures. In addition, phosphateenriched areas were situated east of the Steinberg hill 


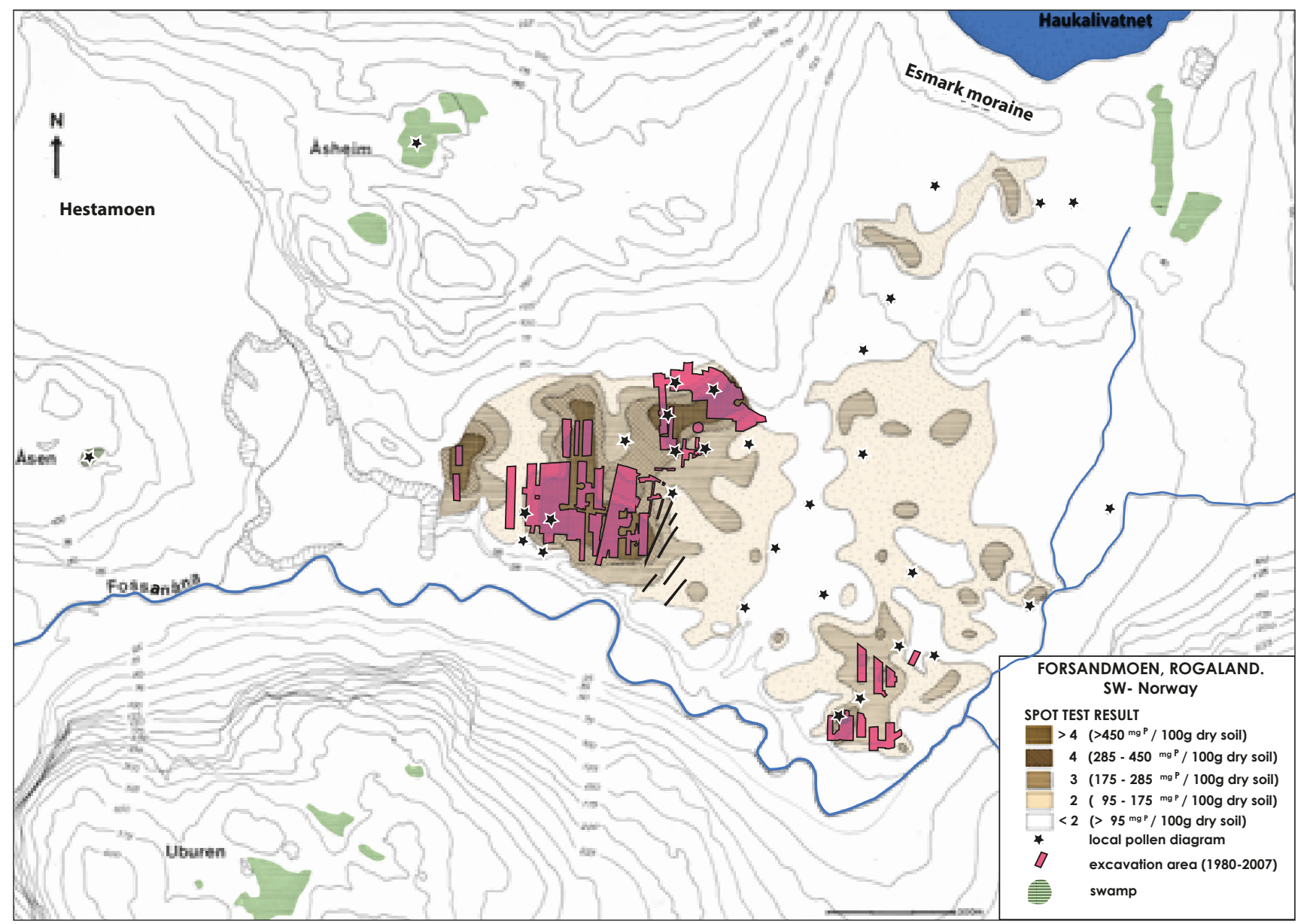

Fig. 6. Map showing the variation in the phosphate content in the subsoil throughout the Forsandmoen plain (based on PrøschDanielsen \& Simonsen 1988, Prøsch-Danielsen 200I).

( 1 ha) and in the south-east corner of the plain (0.5 ha). The clear results of the phosphate mapping guided the project in the choice of excavation areas, especially since the prehistoric burial cairns, indicating human occupation, were located in the phosphate-enriched areas. It was also known that there had not been any modern agricultural settlement at the plain that could have obscured the prehistoric pattern.

In 1986-87, due to plans for extending the sand quarryat Hestamoen, samples were taken at Hestamoen using the same grid system as at Forsandmoen. The phosphate levels in the soil were, however, considerably lower there, indicating a low probability of finding settlement traces. Two trial trenches in very coarse gravel failed to uncover any prehistoric features.

\section{Phosphate from houses}

In 1981, samples were also collected in a $3 \times 3 \mathrm{~m}$ grid at the gravel surface in the northern half of the excavation area, covering houses 2 and 3. Most samples showed that the phosphate content was at the maximum value for the spot test (level 5). The horizontal distribution of these results did not coincide with the extent of the houses, so it was difficult to use the spot test analysis in a horizontal mapping of possible differences caused by certain activities. A third result was that the phosphate content in the topsoil was low (level 0-1), while the content was high from the top of the gravel surface down to $50 \mathrm{~cm}$ below that surface. Because of the lack of high content of phosphate in the gravel outside the settled area, the phosphate in the gravel appears to be old, most likely prehistoric.

In 1982, we investigated possible phosphate variations in different parts of houses 2 and 3. Phosphate samples were collected in two rows inside the houses, from the gravel at the edge of the already excavated roof-bearing postholes, down to a depth of $70 \mathrm{~cm}$ below the gravel surface. House 2 had higher phosphate values in the subsoil in the western half than in the eastern half. Since the hearths in house 2 were situated in the western half, indicating the dwelling area, it was likely that large amounts of phosphate from rubbish and 
ashes had been deposited in the dwelling area, while a lesser amount of phosphate from the less phosphoruscontaining cattle dung and urine filtered down into the gravel in the eastern part of the house, where the byre most likely was located.

In house 3, the results were not so clear. However, also here there were higher values of phosphate in the western end where the hearths were located, lower amounts in the central part and somewhat higher again in the eastern part, where a hearth was also situated. The interpretation was that, most likely, the part with low values of phosphate was the byre.

Similar phosphate samples have been collected from other houses during the excavation period, but without as clear results as from the two houses in 1982. The houses sampled in 1982 were situated in an area without preceding settlement activity and were thus well suited for analysis. This was not the case with the other sampled houses, which were situated in areas with settlement activities pre-dating and/or post-dating the sampled houses. Most likely, phosphate from other activities obscured the pattern from the other sampled houses.

\subsection{Macrofossil analysis}

Analysis of charred grains from an excavation of an agricultural-based settlement was accomplished for the first time in SW Norway in 1968-69 at the Migration Period farm Ullandhaug, near Stavanger (Lundeberg 1972, Myhre 1980, Rindal 2011). Material from the central hearths was soaked in a bucket of water and floating, carbonised grains of hulled barley (Hordeum vulgare var. vulgare) and oat (Avena) were retrieved. Bakkevig (1982a) developed a technique, which is easily obtainable, cheap and not harmful to the environment, to retrieve wet charred grains based on the use of saturated calcium chloride $\left(\mathrm{CaCl}_{2}\right)$.

Samples were gathered at Forsandmoen in 1983 from different levels in a series of hearths and analysed according to the method proposed by Bakkevig. No grains were found, most probably because the samples were collected from the lower levels of the hearths, where the grains could not survive due to high temperature. In autumn 1983, Bakkevig and Løken participated in a workshop where the results from macrofossil analysis from postholes at Gene in northern Sweden were presented (Ramqvist 1983). The following year, a research programme was initiated with the aim of retrieving macrofossils from the contents of the roofbearing postholes at Forsandmoen. During the years
1984-1990, more than 1000 samples from 103 different houses were collected and analysed (Bakkevig 1991, 1992, 1995, 1998).

\section{Method}

The method used at Forsandmoen was based on experiments conducted by Bakkevig (1982a, 1991, Løken et al. 1996:61f), where a bucket of moist samples were first soaked with water overnight and then the charred grains and seeds were separated by lowering a part of the sample into a bucket with a saturated solution of calcium chloride. The specific gravity of 1.4 of the saturated solution is high enough to separate wet charred grains and seeds, which will float, while most of the charred wood fragments and uncharred plant remains are found in the residue at the bottom. Two types of sieves were used: one with a $0.71 \mathrm{~mm}$ mesh to collect seeds from a small part of the sample and a coarser one with a $1.39 \mathrm{~mm}$ mesh to sieve the larger part of the sample for retrieving the cereal grains.

\section{The material}

Charred cereal grains were found in 75 houses, and in another 22 houses, only different species of seeds were retrieved. The remaining six houses lacked finds from grains or seeds. In 49 houses, only a small amount of charred grains (1-9) were found. These have not as yet been properly analysed. The material from the remaining 27 houses, containing samples with more than ten charred grains or fragments of grain found in each house have been analysed by Prøsch-Danielsen and Soltvedt (2011). Table 1 shows the time and species distribution of this material, which consists of 13172 grains or fragments of grains. From one large find, only 554 of approximately 6000 grains are included in this analysis. The total material comprises therefore approximately 18,600 grains or fragments of grains. Nearly $15 \%$ of the 13172 grains are either undetermined or fragments and will not be included in the following evaluation (see chapter 16).

\section{Summary of crop development}

Most of the material from the Bronze Age derives from three sacrificial depositions, while from the other periods, the less abundant material has been collected from several postholes in the houses, probably reflecting the actual consumption of cereals. The overall development shown in this material (Fig. 7) is that, in the Early Bronze Age, the two species of barley (Hordeum vulgare var. nudum and $H$. vulgare var. vulgare) dominate, 
Table I. Time and species distribution of determined cereal grains. Material retrieved from Prøsch-Danielsen \& Soltvedt 20II, table 2 .

\begin{tabular}{|c|c|c|c|c|c|c|c|c|c|c|c|c|c|c|c|}
\hline Period & $\begin{array}{l}\text { Naked } \\
\text { barley } \\
\text { Hordeum } \\
\text { vulgare } \\
\text { var. } \\
\text { nudum }\end{array}$ & $\%$ & $\begin{array}{c}\text { Hulled } \\
\text { barley } \\
\text { Hordeum } \\
\text { vulgare var. } \\
\text { vulgare }\end{array}$ & $\%$ & $\begin{array}{c}\text { Unspec. } \\
\text { barley } \\
\text { Hordeum } \\
\text { sp. }\end{array}$ & $\%$ & $\begin{array}{c}\text { Wheat } \\
\text { Triticum } \\
\text { sp. }\end{array}$ & $\%$ & $\begin{array}{l}\text { Oat } \\
\text { Avena }\end{array}$ & $\%$ & Sum & $\%$ & $\begin{array}{l}\text { Undet. } \\
\text { grain }\end{array}$ & $\begin{array}{l}\text { Frag- } \\
\text { ments }\end{array}$ & Sum \\
\hline Early Bronze Age & $|55|$ & 16.2 & 7243 & 76.0 & 423 & 4.3 & 291 & 3.1 & 3 & 0.4 & 9511 & 100 & 629 & & 10140 \\
\hline Late Bronze Age & 208 & 50.7 & 56 & 13.7 & 12 & 2.9 & 134 & 32.7 & 0 & 0.0 & 410 & 100 & 220 & & 630 \\
\hline Pre Roman Iron Age & 95 & 30.9 & 58 & 18.9 & 63 & 20.5 & 53 & 17.3 & 38 & 12.4 & 307 & 100 & 183 & 174 & 664 \\
\hline Early Roman Iron Age & 5 & 6.5 & 12 & 15.6 & 8 & 10.4 & 4 & 5.2 & 48 & 62.3 & 77 & 100 & 14 & 33 & 124 \\
\hline Late Roman Iron Age & I & 0.8 & 34 & 26.4 & 12 & 9.3 & 0 & 0.0 & 82 & 63.6 & 129 & 100 & 25 & 18 & 172 \\
\hline Migration Period & 0 & 0,0 & 330 & 35,6 & 14 & 1,5 & 3 & 0,3 & 576 & 62,4 & 923 & 100 & 504 & 15 & 1442 \\
\hline Sum & 1860 & & 7733 & & 532 & & 485 & & 747 & & 11357 & 100 & 1575 & 240 & 13172 \\
\hline
\end{tabular}

Fig. 7. Circle diagrams showing the time and species distribution of determined charred cereal species (based on Prøsch-Danielsen \& Soltvedt 201I, table 2).

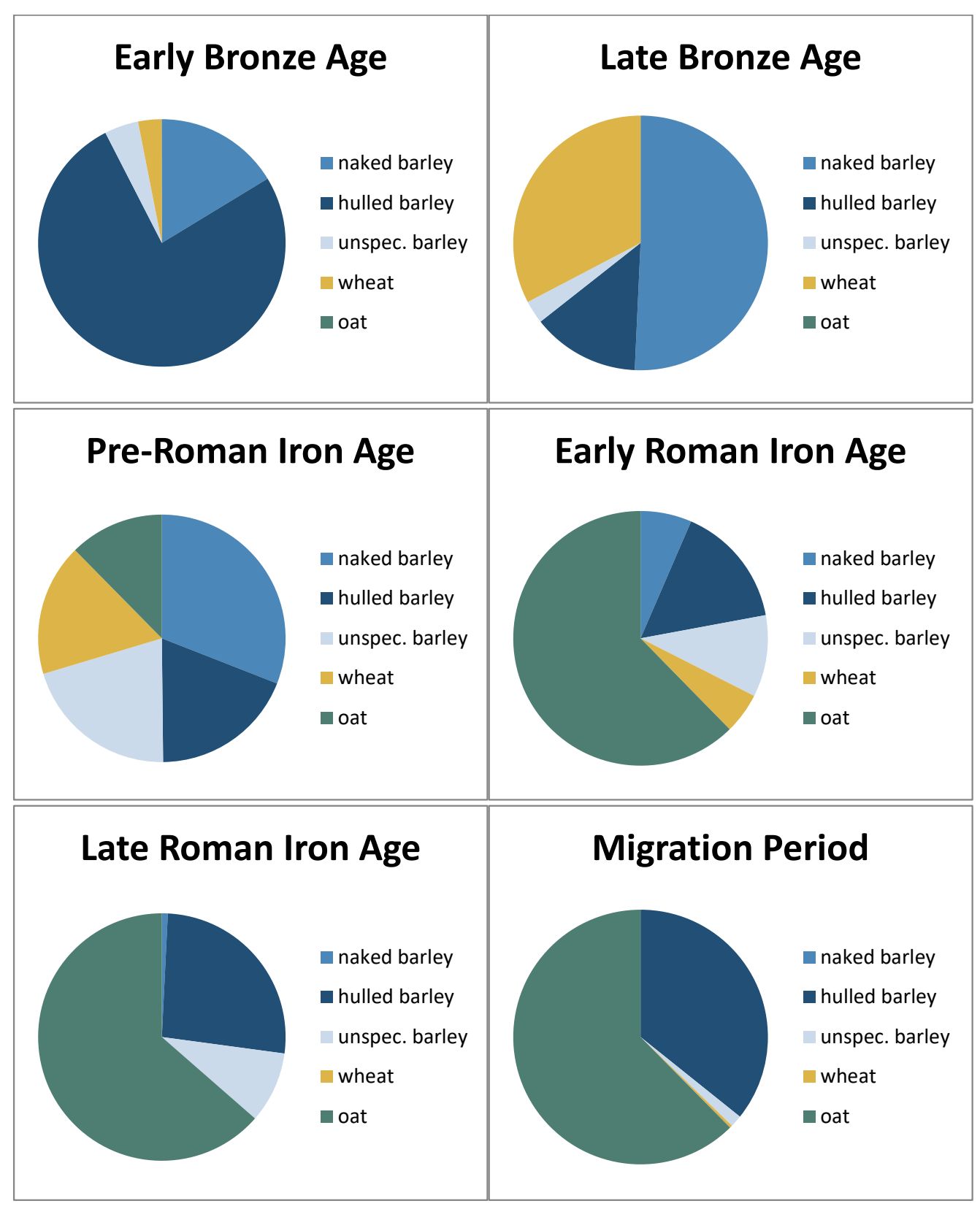


and wheat (Triticum) has scarcely been found. The 18/82 \% proportion between naked and hulled barley (Hordeum vulgare var. nudum and $H$. vulgare var. vulgare) of species-determined grains from the Early Bronze Age probably does not reflect the ratio between the species actually grown, due to the fact that the two comprehensive and contemporary finds are very different concerning the type of barley (Hordeum sp.); one of the finds is five times larger than the other and is dominated by hulled barley (Hordeum vulgare var. vulgare), while in the other find, naked barley (Hordeum vulgare var. nudum) dominates. In both finds, a small proportion of wheat (Triticum) is found, but since the two finds seem to represent a crop from a field of either naked or hulled barley (Hordeum vulgare var. nudum or $H$. vulgare var. vulgare), it is difficult to assess the importance of wheat (Triticum) cultivation. In the Late Bronze Age, $33 \%$ of the grains are determined as wheat (Triticum) and the remaining material is dominated by naked barley (Hordeum vulgare var. nudum) over hulled barley (Hordeum vulgare var. vulgare) (85/15\%). In the Pre-Roman Iron Age, this proportion is altered to 60/40 $\%$, but this only amounts to $70 \%$ of the period's total determined grains. The remaining material consists of nearly $20 \%$ wheat (Triticum) and $10 \%$ oat (Avena), as a new species. In both periods of the Roman Iron Age and the Migration Period, barley (Hordeum sp.) counts close to $33 \%$ and oat (Avena) $66 \%$. It must be mentioned that the amount of determined grains from the two Roman periods is restricted to \pm 100 specimens, making the proportions between the different species uncertain.

The overall development is that naked barley (Hordeum vulgare var. nudum) gives way to hulled barley (Hordeum vulgare var. vulgare) through time and that the proportion of barley (Hordeum) diminishes over time to be of minor importance in the Roman Iron Age and Migration Period. Wheat has a certain importance in the Late Bronze Age and the Pre-Roman Iron Age, but is nearly completely absent after AD 1 . Oat (Avena) are introduced in the late part of the Pre-Roman Iron Age and become the main species in the later periods.

\subsection{Pollen analysis}

A major field in the interdisciplinary research at the Museum of Archaeology is pollen analysis. This method has been practised at the Museum of Archaeology since late 1960s (Simonsen 1968, 1969, 1971). In 1980, pollen samples were collected by the geologist Asbjørn Simonsen from the layers in the burial cairn Id14502 as an integrated part of the excavation. When the first small trial trenches in the settlement were excavated, Simonsen participated by analysing samples from the topsoil and subsoil. He concluded that the soil contained pollen from crop cultivation [barley (Hordeum sp.), oat (Avena)] and from weeds from fields, and that tilled fields must have existed on site or nearby.

\section{Bog investigations}

There are no bogs at the rather flat outwash plain that can be used to construct a local pollen diagram. Coring was done in a suitable small infill basin at Åsheim north of Hestamoen and in a bog at the small hill Åsen (Selsing 1982) (Fig. 6). These two sites are situated 750 $\mathrm{m} \mathrm{NW}$ and $1000 \mathrm{~m} \mathrm{~W}$ of the settlement site. The actual sampling and analysis from the two bog sites was done by Helge Høeg (1999). The bog from Åsheim was selected to date the important changes in vegetation and to find out when human impact occurred in the area surrounding Forsandmoen. Table 2 (end of table) shows the result from nine samples covering a period from 9280-8700 BC to AD 1300-1440. That part of the table includes a short characterisation of the main changes in species at that time.

The pollen diagrams show that wood was burnt at Forsand immediately after the ice had retreated from the area (9000 BC), probably intentionally by hunter/ gatherers (Selsing 2016:38). The first traces of grazing, recorded by the appearance of ribwort plantain (Plantago lanceolata), occurred at 2500-2300 BC, in the late Middle Neolithic. Crop production appears in the pollen records for the first time around 1200-1100 BC. At the same time, the forest was also partly cleared, indicating the presence of an agricultural settlement some time prior to this. This is more than 200 years later than the dated charred macro remains of grains from wheat (Triticum sp.) and barley (Hordeum sp.) found in postholes from the oldest three-aisled houses on the plain (Løken 1998b). This delay is probably due to the remote location of the pollen sites as compared to the area for the prehistoric settlement site. From around $1000 \mathrm{BC}$ onwards, the forests were gradually replaced by heathland. Crop production was present but with varying intensity from 1000-800 BC to around the time of the Black Death (AD 1349). From the late Pre-Roman Iron Age (200 BC) until the present, heathland dominated the area. The most intensive use of the landscape happened in the time interval between the last century of the late Pre-Roman Iron Age and the end of the Migration Period. This conclusion fits well with the results from the excavations (see synthesis, chapter 16). 
Table 2. List of the 264 radiocarbon dates from Forsandmoen, ordered after increasing house number. At the bottom, the list includes dates from bog and clearance cairn investigations.

\begin{tabular}{|c|c|c|c|c|c|c|c|c|c|c|c|}
\hline T-nr. & Year & $\begin{array}{l}\text { Find } \\
\text { number }\end{array}$ & $\begin{array}{l}\text { House } \\
\text { number }\end{array}$ & $\begin{array}{l}\text { Feature } \\
\text { number }\end{array}$ & Feature type & Species & $\begin{array}{l}\text { Weight } \\
\text { (gram) }\end{array}$ & $\begin{array}{l}{ }^{14} \mathrm{C}- \\
\text { date } \\
\text { BP }\end{array}$ & $\begin{array}{l}\text { I Sd } \\
\text { I } \sigma\end{array}$ & $\begin{array}{l}\text { Cal age } \\
\text { from } \\
B C-A D\end{array}$ & $\begin{array}{l}\text { Cal age } \\
\text { to } \\
B C-A D\end{array}$ \\
\hline 4326 & 1981 & 152 & 1 & 1 & roof-bearing posthole & oak & 0.3 & 1940 & 170 & -170 & 320 \\
\hline 4325 & 1981 & 148 & I & 41 & central hearth & birch/alder & 8.6 & 1650 & 70 & 260 & 540 \\
\hline 4324 & 1981 & 169 & 1 & 42 & hearth & birch/alder & 7.7 & 1790 & 80 & 130 & 340 \\
\hline 5385 & 1983 & 207 & 2 & 25 & ember pit & deciduous & 3.6 & 1600 & 50 & 410 & 540 \\
\hline 4800 & 1982 & 228 & 2 & 34 & central hearth & birch/alder & 8.0 & 1440 & 50 & 560 & 660 \\
\hline 4801 & 1982 & 342 & 2 & 35 & ditch & birch/alder & 1.8 & 1770 & 80 & 130 & 390 \\
\hline 5387 & 1983 & 247 & 2 & 57 & pit & deciduous & 1.9 & 3020 & 90 & -1400 & -1120 \\
\hline 4805 & 1982 & 332 & 3 & 10 & hearth & deciduous & 1.8 & 1730 & 90 & 180 & 430 \\
\hline 4802 & 1982 & 291 & 3 & 26 & central hearth & deciduous & 2.5 & 1950 & 100 & -60 & 220 \\
\hline 5724 & 1984 & 484 & 3 & 26 & central hearth & birch/alder & 5.2 & 1720 & 70 & 240 & 410 \\
\hline 4803 & 1982 & 279 & 3 & 27 & central hearth & deciduous & 8.3 & 1470 & 80 & 440 & 660 \\
\hline 4804 & 1982 & 298 & 3 & 55 & hearth & deciduous & 1.4 & 3130 & 120 & -1530 & -1210 \\
\hline 4807 & 1982 & 307 & 3 & 89 & hearth & deciduous & 8.4 & 1520 & 50 & 430 & 610 \\
\hline 4806 & 1982 & 315 & 3 & 93 & wall ditch & deciduous & 5.6 & 1660 & 80 & 250 & 540 \\
\hline 5384 & 1983 & 324 & 3 & 97 & central hearth & deciduous & 4.6 & 1700 & 70 & 250 & 430 \\
\hline 5386 & 1983 & 325 & 3 & 98 & ember pit & pine & 6.2 & 1580 & 70 & 410 & 570 \\
\hline 5388 & 1983 & 411 & 3 & 128 & hearth & lime & 9.3 & 1590 & 70 & 390 & 560 \\
\hline 5379 & 1983 & 529 & 5 & 26 & central hearth & birch/alder & 2.7 & 1420 & 90 & 530 & 760 \\
\hline 5378 & 1983 & 542 & 5 & 27 & central hearth & pine & 6.9 & 1550 & 70 & 420 & 600 \\
\hline 5380 & 1983 & 561 & 5 & 84 & central hearth & pine/birch & 3.7 & 1660 & 50 & 260 & 440 \\
\hline 5389 & 1983 & 372 & 6 & 3 & pit & birch/alder & 1.1 & 2080 & 100 & -350 & 50 \\
\hline 8551 & 1989 & 515 & 6 & 18 & central hearth & rowan & 3.4 & 1640 & 60 & 260 & 540 \\
\hline 5381 & 1983 & 522 & 6 & 21 & central hearth & birch/alder & 4.3 & 1390 & 70 & 560 & 770 \\
\hline 5382 & 1983 & 554 & 6 & 63 & central hearth & pine/birch & 3.0 & 1850 & 70 & 80 & 250 \\
\hline 5383 & 1983 & 389 & 7 & 6 & pit & deciduous & 4.3 & 2140 & 80 & -360 & -50 \\
\hline 6395 & 1985 & 356 & 10 & 4 & central hearth & alder & 3.6 & 1830 & 50 & 90 & 250 \\
\hline 5903 & 1984 & 594 & 10 & 10 & central hearth & birch/alder & 4.2 & 1760 & 70 & 130 & 390 \\
\hline 5907 & 1984 & 752 & 10 & 80 & central hearth & deciduous & 4.1 & 1270 & 80 & 660 & 860 \\
\hline 6393 & 1985 & 794 & 10 & 124 & central hearth & birch & 3.9 & 1640 & 80 & 260 & 540 \\
\hline 5902 & 1984 & 573 & 11 & 23 & central hearth & birch & 5.5 & 1560 & 70 & 420 & 600 \\
\hline 5906 & 1984 & 699 & II & 47 & central hearth & birch & 4.0 & 1540 & 40 & 430 & 600 \\
\hline 8555 & 1989 & 834 & II & 95 & central hearth & rowan/birch & 6.5 & 1590 & 40 & 420 & 540 \\
\hline 6389 & 1985 & 1129 & 12 & 100 & central hearth & birch & 1.7 & 1720 & 90 & 210 & 430 \\
\hline 8250 & 1988 & 1985 & 13 & 23 & central hearth & birch & 7.0 & 1760 & 50 & 220 & 390 \\
\hline 5909 & 1984 & 839 & 14 & 76 & central hearth & bich & 1.0 & 1540 & 80 & 430 & 600 \\
\hline 5905 & 1984 & 690 & 16 & 21 & central hearth & birch & 5.7 & 1710 & 70 & 240 & 420 \\
\hline 5904 & 1984 & 674 & 17 & 7 & central hearth & birch & 4.2 & 1570 & 70 & 410 & 570 \\
\hline 8552 & 1989 & 725 & 18 & I & roof-bearing posthole & pine & 6.0 & 1640 & 80 & 260 & 540 \\
\hline 8249 & 1988 & 1983 & 19 & 8 & roof-bearing posthole & birch & 5.9 & 2140 & 70 & -360 & -50 \\
\hline 8248 & 1988 & 1970 & 20 & 26 & central hearth & birch/alder & 7.0 & 1750 & 70 & 210 & 400 \\
\hline 8246 & 1988 & 1954 & 21 & 36 & central hearth & hazel/birch & 6.7 & 2140 & 70 & -360 & -50 \\
\hline
\end{tabular}




\begin{tabular}{|c|c|c|c|c|c|c|c|c|c|c|c|}
\hline T-nr. & Year & $\begin{array}{l}\text { Find } \\
\text { number }\end{array}$ & $\begin{array}{l}\text { House } \\
\text { number }\end{array}$ & $\begin{array}{l}\text { Feature } \\
\text { number }\end{array}$ & Feature type & Species & $\begin{array}{l}\text { Weight } \\
\text { (gram) }\end{array}$ & $\begin{array}{l}{ }^{14} \mathrm{C}- \\
\text { date } \\
\text { BP }\end{array}$ & $\begin{array}{l}\text { I Sd } \\
\text { I } \sigma\end{array}$ & $\begin{array}{l}\text { Cal age } \\
\text { from } \\
B C-A D\end{array}$ & $\begin{array}{l}\text { Cal age } \\
\text { to } \\
\text { BC-AD }\end{array}$ \\
\hline 5908 & 1984 & 832 & 22 & 9 & central hearth & rowan/birch & 3.4 & 1530 & 50 & 430 & 600 \\
\hline 9534 & 1990 & 836 & 23 & 3 & central hearth & birch/alder & 3.5 & 1565 & 50 & 420 & 550 \\
\hline 6391 & 1985 & 1024 & 24 & 94 & central hearth & rowan/birch & 2.6 & 1640 & 90 & 260 & 540 \\
\hline 6388 & 1985 & 865 & 25 & 9 & central hearth & oak & 0.4 & 2410 & 160 & -780 & -380 \\
\hline 6392 & 1985 & 883 & 26 & I & roof-bearing posthole & williow & 0.7 & 1470 & 140 & 410 & 690 \\
\hline 13835 & 1994 & 11 & 26 & 41 & central hearth & hazel/birch & 5.4 & 2255 & 45 & -390 & -200 \\
\hline 6394 & 1985 & 887 & 27 & 12 & central hearth & birch & 1.8 & 2280 & 100 & -490 & -170 \\
\hline 6390 & 1985 & 913 & 29 & 22 & central hearth & birch & 1.5 & 1700 & 80 & 240 & 430 \\
\hline 8548 & 1989 & 1507 & 29 & 39 & central hearth & birch/alder & 6.0 & 1780 & 70 & 130 & 340 \\
\hline 8549 & 1989 & 1492 & 29 & 41 & central hearth & birch/alder & 7.3 & 1550 & 70 & 420 & 600 \\
\hline 8556 & 1989 & 1496 & 29 & 42 & central hearth & birch/alder & 5.0 & 1860 & 70 & 70 & 240 \\
\hline 8239 & 1988 & 1862 & 30 & 14 & pit & birch/alder & 1.6 & 1680 & 100 & 240 & 540 \\
\hline 7076 & 1986 & 927 & 32 & 11 & central hearth & birch & 4.3 & 1640 & 80 & 260 & 540 \\
\hline 306 & 1991 & 106 & 32 & 29 & roof-bearing posthole & grain: barley & & 3230 & 65 & -1580 & -1445 \\
\hline 307 & 1991 & 107 & 32 & 30 & roof-bearing posthole & grain: barley & & 3150 & 65 & -1495 & -1395 \\
\hline 308 & 1991 & 108 & 32 & 33 & entrance posthole & grain: barley & & 3135 & 65 & -1480 & -1365 \\
\hline 429 & 1991 & 109 & 32 & 49 & roof-bearing posthole & grain: barley & & 3245 & 60 & -1610 & -1430 \\
\hline 309 & 1991 & 110 & 32 & 52 & roof-bearing posthole & grain: barley & & 3125 & 65 & -1470 & -1350 \\
\hline 310 & 1991 & 111 & 32 & 56 & internal posthole & grain: barley & & 3015 & 65 & -1380 & -1120 \\
\hline 422 & 1991 & 105 & 32 & 75 & roof-bearing posthole & grain: barley & & 3185 & 65 & -1530 & -1390 \\
\hline 418 & 1991 & 101 & 32 & 75 & roof-bearing posthole & grain: barley & & 3175 & 50 & -1520 & -1400 \\
\hline 419 & 1991 & 102 & 32 & 75 & roof-bearing posthole & grain: barley & & 3210 & 45 & -1520 & -1435 \\
\hline 420 & 1991 & 103 & 32 & 75 & roof-bearing posthole & grain: barley & & 3185 & 45 & -1515 & -1410 \\
\hline 421 & 1991 & 104 & 32 & 75 & roof-bearing posthole & grain: barley & & 3080 & 50 & -1410 & -1260 \\
\hline 8240 & 1988 & 1884 & 32 & 75 & roof-bearing posthole & pine & 11.0 & 2990 & 70 & -1380 & -1120 \\
\hline 311 & 1991 & 112 & 32 & 76 & entrance posthole & grain: barley & & 3275 & 65 & -1680 & -1450 \\
\hline 312 & 1991 & 113 & 32 & 77 & entrance posthole & grain: barley & & 3070 & 75 & -1430 & -1210 \\
\hline 313 & 1991 & 114 & 32 & 78 & roof-bearing posthole & grain: barley & & 3040 & 65 & -1400 & -1130 \\
\hline 7077 & 1986 & 941 & 33 & 12 & central hearth & hazel/birch & 2.3 & 2890 & 80 & -1220 & -930 \\
\hline 6386 & 1985 & 1115 & 34 & 13 & central hearth & birch & 1.1 & 1910 & 70 & 20 & 220 \\
\hline 126 & 1990 & 2975 & 35 & 19 & roof-bearing posthole & grain & & 1580 & 60 & 410 & 560 \\
\hline 19350 & 2007 & $2007 / 6-123$ & 35 & & central hearth & birch/hazel & 6.0 & 1530 & 65 & 440 & 615 \\
\hline 9514 & 1990 & 2845 & 37 & 30 & roof-bearing posthole & oak & 8.9 & 2245 & 65 & -390 & -200 \\
\hline 6387 & 1985 & 1095 & 44 & 2 & roof-bearing posthole & birch & 0.5 & 2000 & 160 & -210 & 220 \\
\hline 7074 & 1986 & 1131 & 45 & 10 & roof-bearing posthole & birch/alder & 2.1 & 3140 & 90 & -1520 & -1260 \\
\hline 7075 & 1986 & 1148 & 48 & 6 & roof-bearing posthole & $\begin{array}{l}\text { birch/bird } \\
\text { cherry }\end{array}$ & & 2790 & 75 & -1010 & -830 \\
\hline 7071 & 1986 & 1188 & 50 & 23 & central hearth & birch/alder & 3.4 & 1750 & 60 & 230 & 390 \\
\hline 8557 & 1989 & 1189 & 50 & 24 & central hearth & birch/alder & 1.6 & 1940 & 70 & -50 & 140 \\
\hline 8547 & 1989 & 1233 & 50 & 26 & central hearth & birch/alder & 6.0 & 1800 & 70 & 120 & 330 \\
\hline 8554 & 1989 & 1289 & 50 & 59 & central hearth & birch/alder & 3.0 & 1920 & 70 & 0 & 220 \\
\hline 8546 & 1989 & 1539 & 50 & 61 & central hearth & birch/alder & 6.0 & 1980 & 70 & -60 & 130 \\
\hline 7081 & 1986 & 1160 & 52 & I & central hearth & birch & 4.6 & 2960 & 90 & -1310 & -1020 \\
\hline 7080 & 1986 & 1192 & 54 & 22 & central hearth & birch/alder & 5.9 & 2120 & 90 & -360 & 0 \\
\hline
\end{tabular}




\begin{tabular}{|c|c|c|c|c|c|c|c|c|c|c|c|}
\hline T-nr. & Year & $\begin{array}{l}\text { Find } \\
\text { number }\end{array}$ & $\begin{array}{l}\text { House } \\
\text { number }\end{array}$ & $\begin{array}{l}\text { Feature } \\
\text { number }\end{array}$ & Feature type & Species & $\begin{array}{l}\text { Weight } \\
\text { (gram) }\end{array}$ & $\begin{array}{l}{ }^{14} \mathrm{C}- \\
\text { date } \\
\text { BP }\end{array}$ & $\begin{array}{l}\text { I Sd } \\
\text { I } \sigma\end{array}$ & $\begin{array}{l}\text { Cal age } \\
\text { from } \\
\text { BC-AD }\end{array}$ & $\begin{array}{l}\text { Cal } \\
\text { age to } \\
\text { BC-AD }\end{array}$ \\
\hline 7078 & 1986 & 1248 & 55 & 30 & pit & birch & 1.6 & 2330 & 100 & -800 & -200 \\
\hline 7070 & 1986 & 1375 & 57 & 1 & wall ditch & birch & 0.9 & 2820 & 160 & -1260 & -820 \\
\hline 7079 & 1986 & 1390 & 58 & 1 & roof-bearing posthole & hazel/birch & 3.1 & 2370 & 80 & -760 & -370 \\
\hline 7068 & 1986 & $130 \mid$ & 59 & 4 & roof-bearing posthole & hazel/birch & 2.5 & 2390 & 110 & -760 & -380 \\
\hline 315 & 1991 & $13 \mid$ & 59 & 80 & pit & grain: barley & & 2725 & 60 & -920 & -810 \\
\hline 581 & 1991 & 120 & 59 & 2 & roof-bearing posthole & grain: barley & & 2265 & 70 & -400 & -200 \\
\hline 314 & 1991 & 121 & 59 & 4 & roof-bearing posthole & grain: barley & & 2555 & 65 & -810 & -540 \\
\hline 582 & 1991 & 122 & 59 & 9 & roof-bearing posthole & grain: barley & & 2620 & 60 & -900 & -590 \\
\hline 428 & 1991 & 124 & 59 & 11 & roof-bearing posthole & grain: barley & & 2655 & 60 & -900 & -790 \\
\hline 583 & 1991 & 129 & 59 & 16 & roof-bearing posthole & grain: barley & & 2495 & 60 & -780 & -520 \\
\hline 7892 & 1987 & 1449 & 59 & 74 & hearth & birch & 1.4 & 2330 & 80 & -800 & -200 \\
\hline 305 & 1991 & 119 & 59 & 92 & pit & grain: barley & & 3115 & 85 & -1500 & -1260 \\
\hline 303 & 1991 & 117 & 59 & 92 & pit & grain: barley & & 3030 & 95 & -1410 & -1120 \\
\hline 301 & 1991 & 115 & 59 & 92 & pit & grain: barley & & 2995 & 85 & -1380 & -1090 \\
\hline 302 & 1991 & 116 & 59 & 92 & pit & grain: barley & & 2900 & 90 & -1260 & -940 \\
\hline 304 & 1991 & 118 & 59 & 92 & pit & grain: barley & & 2815 & 85 & -1110 & -830 \\
\hline 7069 & 1986 & 1516 & 59 & 92 & pit & birch/alder & 1.7 & 2780 & 100 & -1050 & -820 \\
\hline 7880 & 1987 & 1797 & 60 & 9 & roof-bearing posthole & birch & 1.7 & 2340 & 150 & -800 & -200 \\
\hline 7897 & 1987 & 1639 & 61 & 29 & roof-bearing posthole & birch & 1.3 & 2030 & 80 & -160 & 60 \\
\hline 7886 & 1987 & 1591 & 62 & 14 & roof-bearing posthole & oak & 1.9 & 1940 & 100 & -50 & 220 \\
\hline 7893 & 1987 & 1800 & 62 & $13 \mid$ & pit & hazel/birch & 5.9 & 2210 & 70 & -380 & -190 \\
\hline 7889 & 1987 & 1546 & 63 & 4 & roof-bearing posthole & birch & 2.2 & 1440 & 100 & 430 & 690 \\
\hline 7882 & 1987 & 1552 & 65 & & roof-bearing posthole & birch & & 2090 & 80 & -340 & 10 \\
\hline 7885 & 1987 & 1684 & 72 & 5 & hearth & birch & 4.1 & 2740 & 80 & -980 & -800 \\
\hline 7884 & 1987 & 1683 & 72 & 5 & hearth & birch & 3.2 & 2620 & 60 & -900 & -590 \\
\hline 7887 & 1987 & 1693 & 73 & 8 & roof-bearing posthole & birch & 2.7 & 2870 & 110 & -1260 & -900 \\
\hline 7896 & 1987 & 1659 & 74 & 10 & roof-bearing posthole & birch & 1.6 & 2600 & 80 & -900 & -540 \\
\hline 7890 & 1987 & 1681 & 76 & 2 & roof-bearing posthole & birch & 1.0 & 2320 & 120 & -800 & -200 \\
\hline 7898 & 1987 & 1763 & 80 & 46 & wall posthole & birch & 0.8 & 1880 & 130 & -40 & 330 \\
\hline 7881 & 1987 & 1740 & 81 & 12 & roof-bearing posthole & birch & & 2050 & 70 & -170 & 30 \\
\hline 7899 & 1987 & 1780 & 82 & 6 & roof-bearing posthole & birch & 0.5 & 1860 & 130 & 0 & 340 \\
\hline 7891 & 1987 & 1725 & 86 & 5 & hearth & birch & 3.7 & 2820 & 50 & -1050 & -900 \\
\hline 7894 & 1987 & 1749 & 89 & 14 & hearth & birch & 2.0 & 2100 & 70 & -340 & 0 \\
\hline 424 & 1991 & 134 & 90 & 3 & roof-bearing posthole & grain: barley & & 3155 & 60 & -1520 & -1320 \\
\hline 423 & 1991 & 133 & 90 & 3 & roof-bearing posthole & grain: barley & & 3115 & 80 & -1500 & -1260 \\
\hline 425 & 1991 & 135 & 90 & 3 & roof-bearing posthole & grain: barley & & 3150 & 60 & -1500 & -1320 \\
\hline 427 & 1991 & 137 & 90 & 3 & roof-bearing posthole & grain: barley & & 3145 & 55 & -1500 & -1310 \\
\hline 426 & 1991 & 136 & 90 & 3 & roof-bearing posthole & grain: barley & & 2930 & 70 & -1260 & -1010 \\
\hline 7883 & 1987 & 1801 & 90 & 3 & roof-bearing posthole & grain: undeterm. & 3.4 & 2400 & 150 & -770 & -380 \\
\hline 8236 & 1988 & 1835 & 99 & 2 & roof-bearing posthole & hazel/birch & 5.2 & 2440 & 40 & -760 & -400 \\
\hline 7888 & 1987 & 1766 & 100 & 6 & roof-bearing posthole & birch & & 2490 & 75 & -770 & -510 \\
\hline 8235 & 1988 & 1830 & 102 & 4 & roof-bearing posthole & willow/birch & 2.1 & 3030 & 110 & -1420 & -1120 \\
\hline 8711 & 1989 & 1906 & 104 & 23 & central hearth & birch/alder & 4.0 & 1730 & 80 & 220 & 420 \\
\hline
\end{tabular}




\begin{tabular}{|c|c|c|c|c|c|c|c|c|c|c|c|}
\hline T-nr. & Year & $\begin{array}{l}\text { Find } \\
\text { number }\end{array}$ & $\begin{array}{l}\text { House } \\
\text { number }\end{array}$ & $\begin{array}{l}\text { Feature } \\
\text { number }\end{array}$ & Feature type & Species & $\begin{array}{l}\text { Weight } \\
\text { (gram) }\end{array}$ & $\begin{array}{l}{ }^{14} \mathrm{C}- \\
\text { date } \\
\text { BP }\end{array}$ & $\begin{array}{l}\text { I Sd } \\
\text { I } \sigma\end{array}$ & $\begin{array}{l}\text { Cal age } \\
\text { from } \\
B C-A D\end{array}$ & $\begin{array}{l}\mathrm{Cal} \\
\text { age to } \\
\mathrm{BC}-\mathrm{AD}\end{array}$ \\
\hline 8241 & 1988 & 1870 & 105 & 22 & central hearth & birch & 4.8 & 1580 & 80 & 400 & 600 \\
\hline 8706 & 1989 & 2179 & 105 & 32 & central hearth & birch/alder & 2.6 & 1680 & 80 & 240 & 440 \\
\hline 8238 & 1988 & 1859 & 106 & 35 & central hearth & hazel/birch & 6.2 & 1570 & 50 & 430 & 540 \\
\hline 8550 & 1989 & 2104 & 106 & 36 & central hearth & birch/alder & 5.5 & 1570 & 70 & 410 & 570 \\
\hline 8242 & 1988 & 1896 & 107 & 21 & central hearth & birch/alder & 6.9 & 1800 & 40 & 130 & 320 \\
\hline 8243 & 1988 & 1915 & 107 & 25 & central hearth & birch & 5.7 & 1770 & 70 & 130 & 380 \\
\hline 8237 & 1988 & 1857 & 108 & 26 & central hearth & birch & 6.1 & 1620 & 40 & 390 & 540 \\
\hline 8244 & 1988 & 1926 & 109 & 11 & central hearth & birch & 6.6 & 1370 & 70 & 600 & 770 \\
\hline 8252 & 1988 & 2017 & 110 & 6 & roof-bearing posthole & birch & 2.7 & 2260 & 80 & -400 & -200 \\
\hline 8712 & 1989 & 1901 & III & 20 & central hearth & birch/alder & 6.4 & 1765 & 70 & 130 & 390 \\
\hline 83 & 1989 & 2105 & 113 & 16 & central hearth & birch/alder & & 2535 & 115 & -810 & -510 \\
\hline 8697 & 1989 & 2167 & 116 & 23 & central hearth & birch/alder & 2.6 & 1800 & 65 & 130 & 330 \\
\hline 8709 & 1989 & 1925 & 118 & 5 & central hearth & oak & 4.0 & 1910 & 80 & 0 & 220 \\
\hline 84 & 1989 & 2295 & 119 & 34 & roof-bearing posthole & birch/alder & & 2245 & 100 & -400 & -170 \\
\hline 8245 & 1988 & 1951 & 120 & 33 & hearth & hazel/birch & 5.1 & 1830 & 40 & 130 & 240 \\
\hline 8695 & 1989 & 2249 & 123 & 28 & central hearth & birch/alder & 5.0 & 1835 & 85 & 70 & 320 \\
\hline 8247 & 1988 & 1960 & 124 & & posthole & birch/alder & 1.1 & 2110 & 80 & -350 & 0 \\
\hline 8254 & 1988 & 2068 & 127 & 15 & central hearth & birch/alder & 5.2 & 2230 & 70 & -390 & -200 \\
\hline 8253 & 1988 & 2046 & 129 & 5 & central hearth & birch & 6.8 & 2150 & 70 & -360 & -60 \\
\hline 8710 & 1989 & 2050 & 130 & 4 & roof-bearing posthole & bark & 3.0 & 1730 & 65 & 240 & 400 \\
\hline 8698 & 1989 & 2118 & 132 & 23 & central hearth & birch/alder & 2.0 & 1620 & 80 & 340 & 540 \\
\hline 13837 & 1994 & 63 & 134 & 43 & central hearth & rowan/birch & 4.5 & 1290 & 75 & 650 & 860 \\
\hline 8713 & 1989 & 2090 & 135 & 6 & central hearth & birch/alder & 4.0 & 1720 & 80 & 230 & 430 \\
\hline 8708 & 1989 & 2086 & 135 & 6 & central hearth & birch/alder & 6.2 & 1730 & 65 & 240 & 400 \\
\hline 8690 & 1989 & 2121 & 139 & 33 & central hearth & birch/alder & 4.4 & 1910 & 70 & 20 & 220 \\
\hline 8717 & 1989 & 2125 & 140 & 19 & central hearth & birch/alder & 4.8 & 2005 & 70 & -100 & 80 \\
\hline 8696 & 1989 & 2145 & 141 & 22 & central hearth & birch/alder & 2.5 & 1595 & 50 & 420 & 540 \\
\hline 8705 & 1989 & 2119 & 142 & 6 & hearth & birch/alder & 4.0 & 1875 & 75 & 60 & 240 \\
\hline 8699 & 1989 & 2184 & 144 & 11 & central hearth & birch/alder & 7.7 & 1770 & 70 & 130 & 380 \\
\hline 8703 & 1989 & 2178 & 145 & 11 & central hearth & birch/alder & 4.9 & 1740 & 80 & 210 & 410 \\
\hline 2990 & 1990 & & 150 & 1 & roof-bearing posthole & sheep-coprolite & & 1775 & 45 & 215 & 335 \\
\hline 2991 & 1990 & & 150 & 8 & roof-bearing posthole & sheep-coprolite & & 1985 & 45 & -25 & 75 \\
\hline 8691 & 1989 & 2372 & 150 & 116 & central hearth & birch/alder & 5.5 & 1980 & 70 & -60 & 130 \\
\hline 2989 & 1990 & 2349 & 150 & 117 & central hearth & birch & & 1980 & 55 & -35 & 80 \\
\hline 15195 & 1990 & 2356 & 150 & 118 & central hearth & birch/alder & 5.5 & 1830 & 35 & 135 & 240 \\
\hline 9521 & 1990 & 2347 & 150 & 119 & central hearth & birch/alder & 4.0 & 1885 & 85 & 20 & 240 \\
\hline 8700 & 1989 & 2359 & $15 \mid$ & 46 & central hearth & pine & 3.9 & 1795 & 85 & 120 & 350 \\
\hline 8707 & 1989 & 2365 & $|5|$ & 48 & hearth & birch/alder & 3.5 & 1825 & 80 & 80 & 330 \\
\hline 8716 & 1989 & 2225 & 155 & 31 & central hearth & birch/alder & 5.7 & 1820 & 80 & 80 & 330 \\
\hline 8692 & 1989 & 2333 & 156 & 24 & central hearth & birch/alder & 5.6 & 1760 & 70 & 130 & 390 \\
\hline 8693 & 1989 & 2322 & 157 & 30 & central hearth & birch/alder & 7.3 & 1785 & 70 & 130 & 340 \\
\hline 8714 & 1989 & 2324 & 157 & 31 & central hearth & birch/alder & 0.7 & 1670 & 75 & 250 & 530 \\
\hline 8694 & 1989 & 2258 & 158 & 30 & central hearth & birch/alder & 4.5 & 1705 & 80 & 240 & 430 \\
\hline
\end{tabular}




\begin{tabular}{|c|c|c|c|c|c|c|c|c|c|c|c|}
\hline T-nr. & Year & $\begin{array}{l}\text { Find } \\
\text { number }\end{array}$ & $\begin{array}{l}\text { House } \\
\text { number }\end{array}$ & $\begin{array}{l}\text { Feature } \\
\text { number }\end{array}$ & Feature type & Species & $\begin{array}{l}\text { Weight } \\
\text { (gram) }\end{array}$ & $\begin{array}{l}{ }^{14} \mathrm{C}- \\
\text { date } \\
\text { BP }\end{array}$ & $\begin{array}{l}\text { I Sd } \\
\text { I } \sigma\end{array}$ & $\begin{array}{l}\text { Cal age } \\
\text { from } \\
B C-A D\end{array}$ & $\begin{array}{l}\text { Cal } \\
\text { age to } \\
\text { BC-AD }\end{array}$ \\
\hline 8715 & 1989 & 2332 & 158 & 31 & central hearth & birch/alder & 4.0 & 1835 & 80 & 80 & 320 \\
\hline 8701 & 1989 & 2316 & 159 & 19 & central hearth & birch/alder & 6.3 & 1805 & 70 & 120 & 330 \\
\hline 8824 & 1989 & 2300 & 160 & 20 & central hearth & oak & 5.0 & 1550 & 65 & 430 & 600 \\
\hline 8702 & 1989 & 2248 & 163 & 23 & central hearth & birch/alder & 3.6 & 1790 & 80 & 130 & 340 \\
\hline 8704 & 1989 & 2358 & 165 & 10 & central hearth & birch/alder & 2.0 & 1915 & 75 & 0 & 220 \\
\hline 9500 & 1990 & 2445 & 169 & 32 & central hearth & birch/alder & 4.1 & 1830 & 50 & 90 & 250 \\
\hline TUa-7010 & 2007 & $2007 / 6-9$ & 169 & & cooking pit & rowan/birch & 2.3 & 1740 & 30 & 250 & 375 \\
\hline 9515 & 1990 & 2430 & 170 & 5 & roof-bearing posthole & birch & 0.3 & 2235 & 165 & -550 & 0 \\
\hline 9526 & 1990 & 2437 & 171 & 18 & central hearth & birch/alder & 3.7 & 1640 & 50 & 340 & 540 \\
\hline 9498 & 1990 & 2460 & 172 & 15 & central hearth & birch & 1.5 & 1675 & 60 & 250 & 430 \\
\hline 9525 & 1990 & 2463 & 173 & 5 & central hearth & birch/alder & 3.1 & 1525 & 80 & 430 & 610 \\
\hline 9503 & 1990 & 2450 & 174 & 29 & central hearth & birch/alder & 5.1 & 1510 & 65 & 430 & 640 \\
\hline 9502 & 1990 & 2655 & 176 & 21 & central hearth & birch & 3.5 & 1670 & 80 & 250 & 530 \\
\hline 19341 & 2007 & $2007 / 6-39$ & 177 & & central hearth & alder & 3.4 & 1550 & 80 & 420 & 605 \\
\hline 9519 & 1990 & 2650 & 179 & 14 & central hearth & birch/alder & 6.0 & 2430 & 45 & -760 & -400 \\
\hline 9505 & 1990 & 2567 & 180 & 70 & central hearth & birch & 4.2 & 1825 & 70 & 80 & 320 \\
\hline 9509 & 1990 & 2494 & 180 & 72 & central hearth & birch/alder & 4.3 & 1720 & 65 & 240 & 410 \\
\hline 9536 & 1990 & 2512 & 181 & 18 & central hearth & birch/alder & 3.4 & 1680 & 80 & 240 & 440 \\
\hline 9501 & 1990 & 2523 & 182 & 15 & central hearth & birch & 4.0 & 1885 & 70 & 60 & 230 \\
\hline 9524 & 1990 & 2509 & 184 & 9 & central hearth & birch/alder & 3.7 & 1635 & 65 & 340 & 540 \\
\hline 9522 & 1990 & 2587 & 185 & 6 & roof-bearing posthole & birch/alder & 2.5 & 2535 & 80 & -800 & -520 \\
\hline 9533 & 1990 & 2538 & 185 & 8 & posthole & birch/alder & 2.6 & 2400 & 45 & -760 & -390 \\
\hline 9517 & 1990 & 2553 & 188 & 10 & roof-bearing posthole & pine & 2.3 & 2455 & 105 & -760 & -400 \\
\hline 9518 & 1990 & 2920 & 190 & 15 & roof-bearing posthole & birch & 2.0 & 2260 & 85 & -400 & -200 \\
\hline 9506 & 1990 & 2915 & 191 & 13 & central hearth & birch & 3.7 & 1920 & 80 & -20 & 220 \\
\hline 9537 & 1990 & 2660 & 194 & 12 & central hearth & birch/alder & 3.0 & 1780 & 80 & 130 & 350 \\
\hline 9507 & 1990 & 2946 & 198 & 19 & central hearth & birch/alder & 3.0 & 1675 & 60 & 250 & 430 \\
\hline 9497 & 1990 & 2659 & 200 & 23 & central hearth & birch/alder & 4.5 & 1665 & 45 & 260 & 430 \\
\hline 9532 & 1990 & 2931 & 201 & 90 & central hearth & birch/alder & 5.0 & 1835 & 70 & 80 & 320 \\
\hline 9539 & 1990 & 2689 & 203 & 9 & central hearth & birch/alder & 4.1 & 1700 & 70 & 250 & 430 \\
\hline 9504 & 1990 & 2692 & 205 & 14 & central hearth & birch/alder & 2.8 & 1600 & 35 & 420 & 540 \\
\hline 19344 & 2007 & $2007 / 6-100$ & 205 & & central hearth & birch/alder & 4.4 & 1595 & 50 & 420 & 545 \\
\hline TUa-70II & 2007 & $2007 / 6-11$ & 205 & & cooking pit & alder & 2.7 & 1660 & 30 & 385 & 425 \\
\hline 9508 & 1990 & 2694 & 206 & 16 & central hearth & birch/alder & 3.6 & 1610 & 65 & 380 & 540 \\
\hline 19338 & 2007 & $2007 / 6-13$ & 207 & & cooking pit & birch/alder & 4.8 & 1535 & 75 & 430 & 620 \\
\hline TUa-70I3 & 2007 & $2007 / 6-124$ & 207 & & central hearth & alder & & 1410 & 30 & 540 & 605 \\
\hline 9499 & 1990 & 2696 & 208 & 27 & central hearth & birch/alder & 3.5 & 1590 & 65 & 400 & 560 \\
\hline 19339 & 2007 & $2007 / 6-26$ & 208 & & cooking pit & alder & 6.0 & 1540 & 65 & 435 & 610 \\
\hline 9527 & 1990 & 2698 & 209 & 17 & central hearth & birch/alder & 3.8 & 1575 & 80 & 410 & 600 \\
\hline 9513 & 1990 & 2668 & 212 & 13 & roof-bearing posthole & birch & 0.5 & 2870 & 110 & -1260 & -900 \\
\hline 9530 & 1990 & 2688 & 213 & 9 & roof-bearing posthole & birch/alder & 2.5 & 2260 & 65 & -400 & -200 \\
\hline 9512 & 1990 & 2742 & 215 & II & roof-bearing posthole & birch & 1.4 & 2620 & 115 & -920 & -520 \\
\hline 9523 & 1990 & 2916 & 216 & & hearth & oak/birch & 1.8 & 2325 & 100 & -800 & -200 \\
\hline
\end{tabular}




\begin{tabular}{|c|c|c|c|c|c|c|c|c|c|c|c|}
\hline T-nr. & Year & $\begin{array}{l}\text { Find } \\
\text { number }\end{array}$ & $\begin{array}{l}\text { House } \\
\text { number }\end{array}$ & $\begin{array}{l}\text { Feature } \\
\text { number }\end{array}$ & Feature type & Species & $\begin{array}{l}\text { Weight } \\
\text { (gram) }\end{array}$ & $\begin{array}{l}{ }^{14} \mathrm{C}- \\
\text { date } \\
\text { BP }\end{array}$ & $\begin{array}{l}\text { I Sd } \\
\text { I } \sigma\end{array}$ & $\begin{array}{l}\text { Cal age } \\
\text { from } \\
B C-A D\end{array}$ & $\begin{array}{l}\text { Cal } \\
\text { age to } \\
\text { BC-AD }\end{array}$ \\
\hline 9529 & 1990 & 2893 & 218 & 11 & door post & birch/alder & 0.9 & 2405 & 80 & -760 & -390 \\
\hline 9538 & 1990 & 2782 & 219 & 1 & roof-bearing posthole & birch/alder & 0.5 & 2340 & 130 & -800 & -200 \\
\hline 9510 & 1990 & 2777 & 220 & 46 & central hearth & birch/alder & 3.3 & 1700 & 80 & 240 & 430 \\
\hline 9535 & 1990 & 2775 & 221 & 7 & central hearth & birch/alder & 5.9 & 2480 & 85 & -770 & -410 \\
\hline 9520 & 1990 & 2904 & 223 & 6 & roof-bearing posthole & oak, pine & 3.5 & 1945 & 60 & -20 & 130 \\
\hline 9516 & 1990 & 2922 & 229 & 20 & pit & birch/alder & 2.3 & 2220 & 60 & -380 & -200 \\
\hline 9528 & 1990 & 2919 & 231 & 9 & central hearth & birch/alder & 4.2 & 1630 & 70 & 340 & 540 \\
\hline 9531 & 1990 & 2936 & 232 & 5 & roof-bearing posthole & birch/alder & 0.7 & 2260 & 110 & -410 & -110 \\
\hline 9511 & 1990 & 5 & 234 & 17 & central hearth & birch & 3.7 & 1605 & 65 & 390 & 540 \\
\hline 9610 & 1991 & 2981 & 235 & 6 & central hearth & birch & 3.7 & 2275 & 85 & -410 & -200 \\
\hline 10706 & 1992 & 2 & 237 & 3 & roof-bearing posthole & willow/birch & 2.1 & 2775 & 85 & -1010 & -820 \\
\hline 611 & 1992 & 1 & 238 & 4 & roof-bearing posthole & hazel/birch & & 2605 & 60 & -840 & -560 \\
\hline 10707 & 1992 & 3 & 238 & 7 & roof-bearing posthole & willow & 1.8 & 2395 & 90 & -760 & -390 \\
\hline 10708 & 1992 & 5 & 239 & 1 & roof-bearing posthole & oak & 3.3 & 3215 & 110 & -1680 & -1320 \\
\hline 13833 & 1994 & 56 & 242 & 4 & roof-bearing posthole & birch & 1.8 & 2235 & 105 & -410 & -160 \\
\hline 2267 & 1994 & 39 & 242 & 9 & central hearth & birch & & 2355 & 65 & -760 & -260 \\
\hline 13836 & 1994 & 44 & 243 & 5 & roof-bearing posthole & hazel/birch & 1.9 & 1255 & 80 & 680 & 880 \\
\hline 2268 & 1994 & 48 & 245 & 2 & roof-bearing posthole & birch & & 1470 & 65 & 530 & 650 \\
\hline 13834 & 1995 & 1 & 247 & 48 & central hearth & birch & 1.9 & 2405 & 55 & -760 & -390 \\
\hline 19342 & 2007 & $2007 / 6-54$ & 247 & & central hearth & birch & 6.0 & 1715 & 65 & 250 & 420 \\
\hline 19340 & 2007 & $2007 / 5-35$ & 248 & & central hearth & alder & 4.6 & 1630 & 80 & 350 & 540 \\
\hline 19611 & 2007 & $2007 / 6-33$ & 248 & & central hearth & birch/alder & 2.5 & 1595 & 80 & 400 & 555 \\
\hline 19612 & 2007 & $2007 / 6-79$ & 248 & & cooking pit & hazel/birch & 6.3 & 1610 & 80 & 390 & 550 \\
\hline 19343 & 2007 & $2007 / 6-69$ & 249 & & roof-bearing posthole & alder & 3.1 & 1595 & 65 & 410 & 550 \\
\hline TUa-7428 & 2007 & $2007 / 6-68$ & 249 & & roof-bearing posthole & $\begin{array}{l}\text { alder, hazel, } \\
\text { rowan }\end{array}$ & 0.5 & 1630 & 30 & 410 & 440 \\
\hline 19345 & 2007 & $2007 / 6-105$ & 250 & & central hearth & birch/alder & 3.9 & 1535 & 75 & 430 & 620 \\
\hline 19346 & 2007 & $2007 / 6-106$ & 250 & & central hearth & alder & 4.4 & 1700 & 80 & 250 & 425 \\
\hline 19347 & 2007 & $2007 / 6-109$ & 250 & & central hearth & birch/alder & 3.2 & 1545 & 80 & 425 & 610 \\
\hline 19348 & 2007 & $2007 / 6-110$ & 250 & & central hearth & alder & 3.9 & 1625 & 80 & 350 & 540 \\
\hline 19349 & 2007 & $2007 / 6-114$ & 250 & & central hearth & birch/alder, hazel & 3.2 & 1625 & 65 & 390 & 540 \\
\hline 19337 & 2007 & $2007 / 6-10$ & 250 & & cooking pit & alder & 4.1 & 1730 & 65 & 240 & 410 \\
\hline TUa-7009 & 2007 & $2007 / 6-3$ & 251 & & roof-bearing posthole & deciduous & & 1620 & 30 & 415 & 445 \\
\hline 19352 & 2007 & $2007 / 6-167$ & 252 & & central hearth & birch/alder & 6.0 & 1710 & 70 & 250 & 420 \\
\hline 19351 & 2007 & $2007 / 6-136$ & $253 \mathrm{~A}$ & & central hearth & birch/alder & 6.0 & 1615 & 65 & 395 & 545 \\
\hline 19353 & 2007 & $2007 / 6-208$ & $253 B$ & & central hearth & alder & 1.7 & 1750 & 80 & 220 & 405 \\
\hline TUa-70I2 & 2007 & $2007 / 6-119$ & 254 & & central hearth & birch/alder & & 2145 & 30 & -195 & -115 \\
\hline $495 I A$ & 1982 & & & & bog & peat & & 9240 & 160 & -8700 & -9280 \\
\hline $5100 \mathrm{~A}$ & 1982 & & & & bog & peat & & 8490 & 120 & -7610 & -7350 \\
\hline $4952 \mathrm{~A}$ & 1982 & & & & bog & peat & & 7990 & 100 & -7060 & -6760 \\
\hline $5099 \mathrm{~A}$ & 1982 & & & & bog & peat & & 5760 & 100 & -4720 & -4490 \\
\hline $4953 \mathrm{~A}$ & 1982 & & & & bog & peat & & 4200 & 80 & -2900 & -2670 \\
\hline $4949 A$ & 1982 & & & & bog & peat & & 3450 & 80 & -1890 & -1660 \\
\hline
\end{tabular}




\begin{tabular}{|c|c|c|c|c|c|c|c|c|c|c|c|}
\hline T-nr. & Year & $\begin{array}{l}\text { Find } \\
\text { number }\end{array}$ & $\begin{array}{l}\text { House } \\
\text { number }\end{array}$ & $\begin{array}{l}\text { Feature } \\
\text { number }\end{array}$ & Feature type & Species & $\begin{array}{l}\text { Weight } \\
\text { (gram) }\end{array}$ & $\begin{array}{l}{ }^{14} \mathrm{C} \text {-date } \\
\text { BP }\end{array}$ & $\begin{array}{l}\text { I Sd } \\
\text { I } \sigma\end{array}$ & $\begin{array}{l}\text { Cal age } \\
\text { from } \\
B C-A D\end{array}$ & $\begin{array}{l}\text { Cal age to } \\
B C-A D\end{array}$ \\
\hline $5097 \mathrm{~A}$ & 1982 & & & & bog & peat & & 2050 & 50 & -160 & 10 \\
\hline 4950 & 1982 & & & & bog & peat & & 1590 & 70 & 400 & 560 \\
\hline 5098 & 1982 & & & & bog & peat & & 550 & 70 & 1300 & 1440 \\
\hline$|3| 1$ & 1995 & $95 / 622 C$ & & & burnt layer & oak & & 3210 & 65 & -1520 & -1410 \\
\hline 1312 & 1995 & $95 / 622 D$ & & & burnt layer & birch & & 3210 & 65 & -1520 & -1410 \\
\hline 1313 & 1995 & $85 / 320-39$ & & & cultivation layer & birch & & 1390 & 65 & 620 & 680 \\
\hline $1310 \mathrm{~A}$ & 1995 & $95 / 622 \mathrm{~A}$ & & & between stones & humus & & 455 & 65 & 1415 & 1485 \\
\hline 8251 & 1988 & 2009 & Heia & & central hearth & birch & 5.4 & 1550 & 80 & 420 & 600 \\
\hline TUa-7427 & 2007 & $2007 / 6-51$ & & & clerance cairn & $\begin{array}{l}\text { deciduous, } \\
\text { not oak }\end{array}$ & & 2190 & 30 & -355 & -190 \\
\hline
\end{tabular}

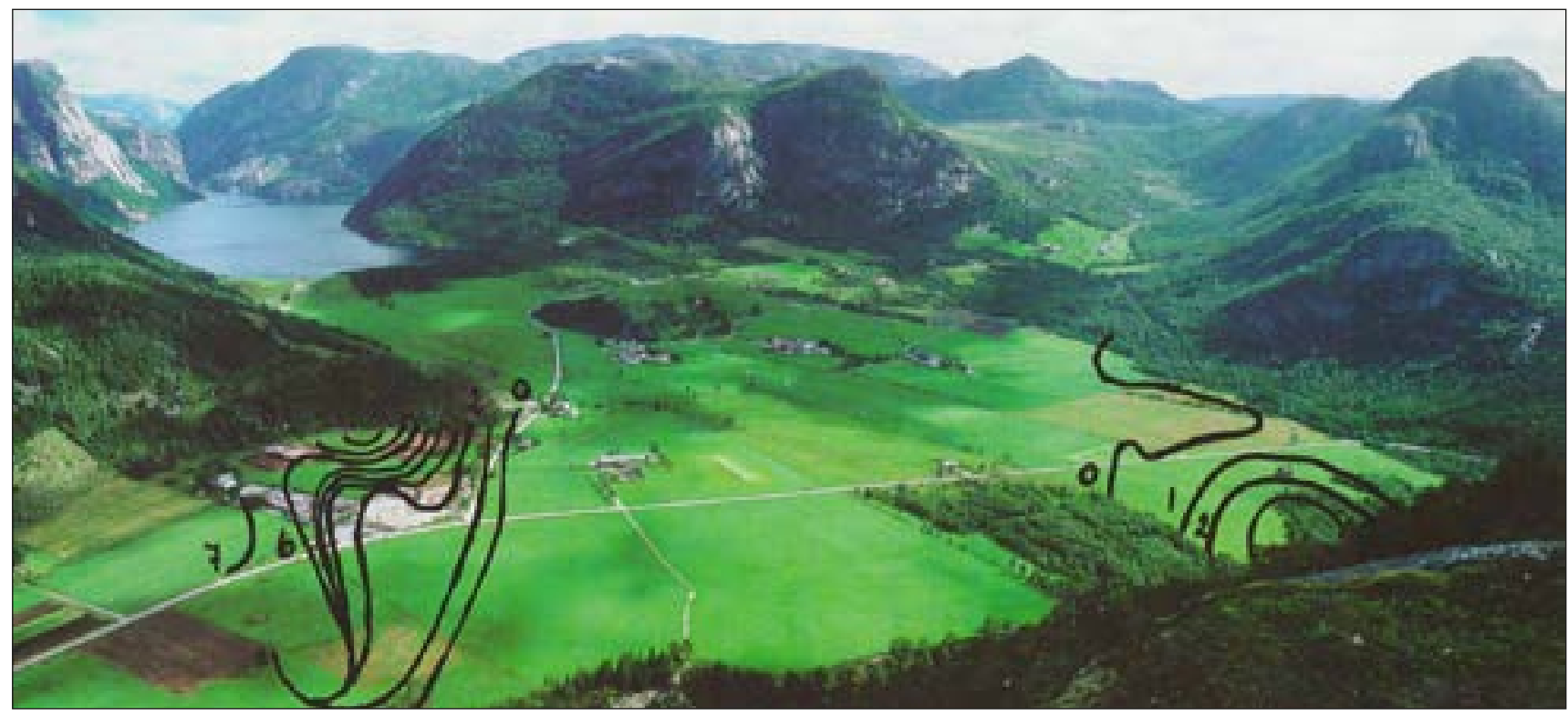

Fig. 8. View towards NE from the northern slope of the mountain Uburen at Forsandmoen, showing where the intensively used farmland was located in an early phase of the settlement period (Prøsch-Danielsen 200I:3I).

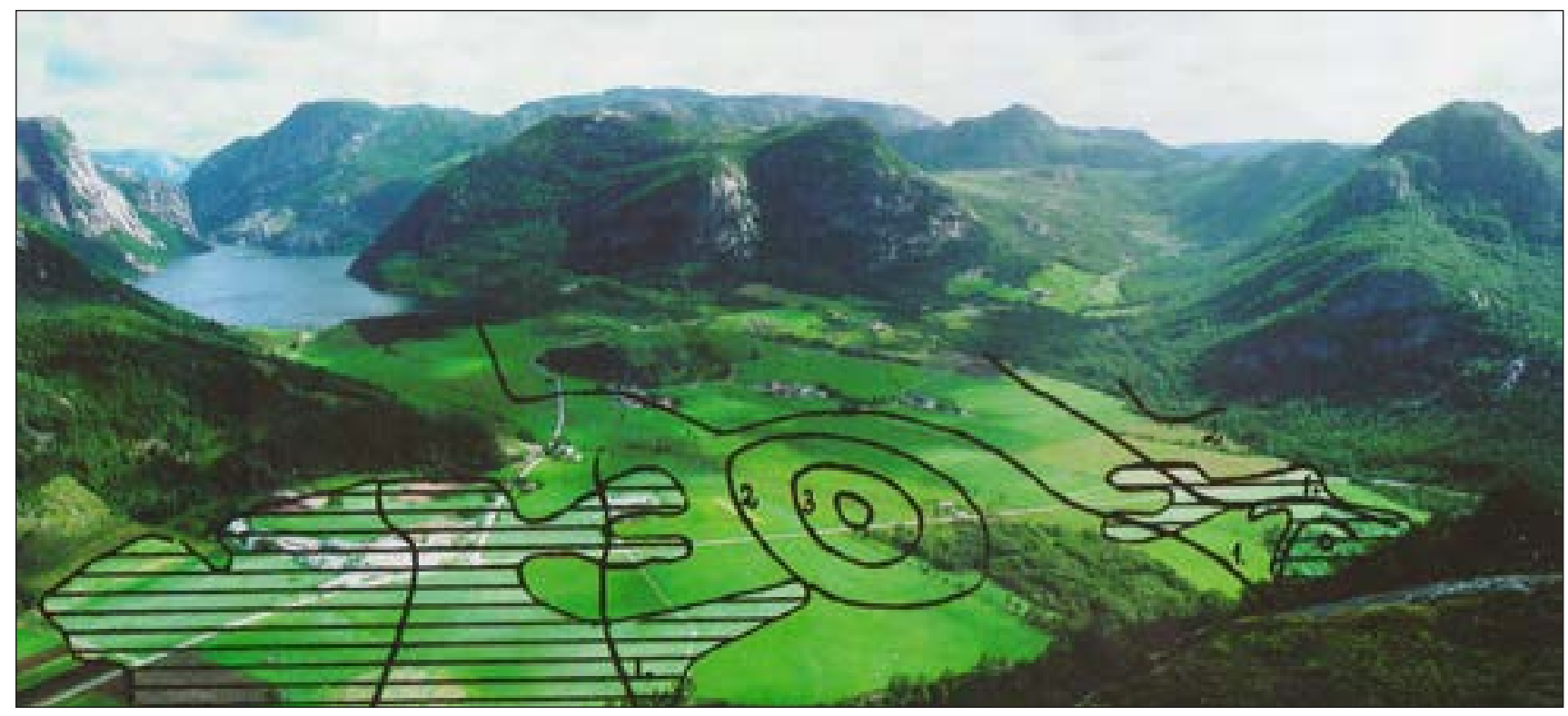

Fig 9. View towards NE from the northern slope of the mountain Uburen at the Forsandmoen, showing where the intensively used farmland and pastures were located in a late phase of the settlement period (Prøsch-Danielsen 2001:32). 


\section{Investigations of soil profiles}

When the archaeological investigations started at Forsandmoen in 1980, pollen was found to be well preserved in the soils on the outwash plain. These circumstances were to a degree the result of two factors: 1) the transition to heathland at the end of the settlement period, creating acid soil conditions; 2) the moist conditions caused by a dense iron pan, preventing the water from evaporating (Prøsch-Danielsen \& Simonsen 1988). Pollen samples were collected in different structures on the habitation site and from a cross-section near the border of the plain (Hjelle 1984, Selsing 1983). The pollen analysis confirmed that there had been crop production in the area, with the main crop being barley (Hordeum sp.).

However, it would also be beneficial to obtain information concerning the horizontal land-use patterns at Forsandmoen throughout time - not only the vertical time-depth situation. Such an investigation had previously been done during the large excavation by mechanical topsoil stripping at Flögeln, north of Bremerhafen, Germany. This investigation was situated in a geest landscape containing a series of late glacial dead ice depressions, which later turned into small lakes or bogs (Zimmermann 1992). At Flögeln, pollen diagrams from many bogs were collected. The results concerning the vegetation history at Flögeln were very convincing and inspired a similar strategy in the Forsandmoen project.

The pollen analysis at Forsandmoen has been analysed in detail and published in a number of papers (Prøsch-Danielsen 1988, 1996, Prøsch-Danielsen \& Bakkevig 1990, Prøsch-Danielsen \& Simonsen 1988), and it is therefore not necessary to describe the methods and results in detail here. The goal was to reveal the changing land-use patterns throughout prehistory - to determine where fields, meadows and pastures had been situated.

Pollen samples were collected from 28 soil profiles in areas where the soil was undisturbed by modern agricultural activity (Prøsch-Danielsen 1986). However, west of the settlement, there were no longer any undisturbed deposits. Even so, such cross-sections could be located underneath burial cairns, fences and in uncultivated areas.

A multivariate analysis divided the pollen samples into three stratigraphic groups, which represented a relative time sequence where the uppermost layer represented the youngest heathland phase dating back to the early Roman Iron Age (Prøsch-Danielsen \& Simonsen 1988, Prøsch-Danielsen 1996:12). The two other stratigraphic layers represented the prehistoric settlements. The low- ermost level (Fig. 8) showed a large area of intense crop production in the main settlement area (the lines in the left part of Fig. 8, Areas A and E) and eastwards towards a little brook, and also an area of crop production around the settlement in Area B (the lines in the right part of the figure). In between and to the north, there had been meadows and pastures in deciduous forest. The uppermost level showed less intense crop production in smaller areas around the main settlement areas A and E, and the same was true for Area B. Pastures were now concentrated to an area near to and around the brook; i.e. located around the water supply (Fig. 9). Cattle paths are indicated by narrow areas of high phosphate values between the main settled areas $A$ and $E$ and the pasture areas. (See also Fig. 6) where three narrow phosphate-enriched areas stretch eastwards from the main phosphate area.) The previously mentioned N-S oriented ancient stone fence situated at the western side of the brook (approximately where the phosphate paths end), which constituted a border between uncleared areas with many visible stones to the east and cleared areas to the west, probably confirms the interpretation based on the pollen analysis.

\section{Clearance cairns}

Clearance cairns were only preserved in the south-east part of the plain, but investigations of these monuments were not included in the project plan. However, approximately 70 such cairns were removed without permission from the cultural heritage authorities, in violation of the Cultural Heritage Act. In connection with the investigation and subsequent trial, it became necessary to gain more information about their construction and date.

Løken and Hemdorff (1996) excavated a small clearance cairn, $5 \mathrm{~m}$ in diameter and $0.5 \mathrm{~m}$ in height. Prøsch-Danielsen (1996) analysed the pollen samples from a sample sequence in the cross-section. The analysis showed that, after clearing the forest by burning (dated to $3210 \pm 65$ BP, 1520-1410 BC (Ua-1311)), the bottom layer of stones from clearing was laid directly on top of the burnt twigs and ashes. Pollen from cereal production occurred from bottom to top in the cross-section taken from the cairn, except for the heath turf on the upper $15 \mathrm{~cm}$ of the cairn. Thus, it was confirmed that cereal production and clearing of the fields took place from approximately $1500 \mathrm{BC}$ onwards. The ${ }^{14} \mathrm{C}$ date of the bottom layer is contemporary with the oldest dates from house remains to the south-east, as well as those from the large settlement area to the west. 


\subsection{Radiocarbon analysis}

It was obvious right from the beginning of the project that artefacts that could date the structures and houses precisely were few and far between. The exception was the occurrence of bucket-shaped pottery, which could date houses to within the $4^{\text {th }}-6^{\text {th }}$ century, but otherwise, pottery could seldom help to date structures with much accuracy. Thus, we had to rely on radiocarbon dating to determine the chronology of the site and the individual houses. The approximately 250 radiocarbon dates from Forsand represented the largest number of samples from one site ever in the early 1990s.

Charcoal samples were therefore collected from all structures where charcoal occurred in contexts that could be used as a basis for ${ }^{14} \mathrm{C}$ dates. Charcoal can with some methodological limitations - be used to date a house if collected from either postholes belonging to the house or from hearths situated symmetrically within the roof-bearing construction of the house. However, in both instances, it can be problematic to know what is really being dated.

The Forsand project took place during the 1980s and only conventional dating methods were available at the National Laboratory for Age Determination at the Norwegian University of Science and Technology in Trondheim, labelled T-no. Only in the last years of that decade was an agreement established with the Svedberg Laboratory in Uppsala, Sweden, giving Norwegian researchers the opportunity to date a few samples at a reasonable price with the accelerator mass spectrometry technique (AMS), labelled TUa-no. It was necessary to use as large samples as possible, as this would allow for the use of the laboratory's largest counters and consequently help in obtaining as narrow a standard deviation as possible. Because of this situation, it was not possible to date charred grains from postholes during the main excavation period, a method that has been the preferred way of dating settlement structures later on. In this publication, all radiocarbon dates are presented with one standard deviation, $1 \sigma$, and rendered as calibrated years $\mathrm{BC}$ and/or AD.

There are numerous problems associated with determining the origin of charcoal and charred cereals in postholes and with linking this origin beyond reasonable doubt to the lifetime of a specific building (Gjerpe 2008b:86f, Gustafson 2005a:54f). An obvious solution is to date in situ remains of a charred post i.e. the physical remains of the actual building. However, the remains of the preferred oak (Quercus) and pine (Pinus) from the roof-bearing posts at Forsandmoen can be several hundred years older than the actual use of the house. This can be caused either by the age of the timber itself or because the timber was reused. A good situation for dating buildings more precisely by means of their building materials is when the surface of a posthole reveals a circle of charred material. This is caused by the charring of natural round timber to delay the decaying process. In such a situation, the problem of the actual age of the timber is eliminated; reuse could, however, still present a problem. Unfortunately, this situation was only seen twice during the Forsand project. If the charred material does not describe a full circle, it could be that the timber was from a reused, hewn post with the possible consequence that we could end up dating an old part of the post.

A more common situation is when a large piece or a concentration of charcoal is found in the central part of a posthole, where the post had been placed previously. This central space in the posthole most probably was filled up within a short time period after the demolition of the house. If this charcoal consists of one type of short-lived wood, like birch (Betula) or alder (Alnus), it is reasonable to assume that it originates from activities belonging to the demolished house. If there are no other house remains that interfere, this type of charcoal might be the most reliable type of charcoal sample from which to date a house from postholes.

One way of obtaining ${ }^{14} \mathrm{C}$ dates that belong to the occupation period is to take samples from centrally located hearths inside the buildings. At Forsand, this normally implied that the hearth was situated on the central axis, and preferably also in the middle between two trestles. In the late Roman Iron Age and the Migration Period, there were often two hearths along the axis. These hearths are regarded as well suited for dating purposes. The samples to be dated from the hearths were generally wood from short-lived deciduous trees like birch (Betula) and alder (Alnus). In some instances, however, pine (Pinus) or oak (Quercus) were used for dating when short-lived deciduous trees were absent, with the usual associated old wood problems.

The hearths at Forsand normally consist of a 10-15 $\mathrm{cm}$ layer of charcoal and fire-cracked stones at the bottom of the hearth pit and a layer with less charcoal and more fire-cracked stones and earth on top. Occasionally, more than one charcoal layer occurred, probably due to reuse of the hearth. The samples were always collected from the bottom layer to prevent the possibility of contamination from later activities. One would think that such samples dated the first use of the hearth and thus earliest phase of the house, but this 
is not necessarily the case. The hearths were probably cleaned out regularly, considering how much waste a hearth used on a daily basis would have produced. Most likely, dates from the bottom layers of the hearths represent the last period of occupation in the houses.

In addition to charcoal, charred grains can also contribute to date structures. In 1967-68, charred seeds from barley (Hordeum sp.) and oat (Avena) were found in the hearths in one of the longhouses at the Iron Age farm at Ullandhaug near Stavanger. The advantage of charred grains is that they are annuals, which prevents uncertainty related to the time of growth represented by the charcoal. Ramqvist's (1983) thesis on the site at Gene showed that charred grain could be sifted out of the posthole material. Following this method, such material was collected from most buildings at Forsand (Bakkevig 1992, 1995, 1998), both from houses with hearths and from houses without hearths, where charred grains then facilitated dating. Charred grains found in a posthole are likely to be related to the use of the house or from shortly after the house was abandoned (Gjerpe 2008, Gustafson 2005a). If so, they were likely deposited into the postholes after an accidental fire in stored grains, as an offering or as remnants from daily consumption. Large amounts of grains may be regarded as remnants from a fire in a stored crop, while small amounts $(1-15 / 20)$ of charred grains were more likely mixed into the soil, eventually ending up in the fill around the posts when the buildings were constructed or torn down. If this is the case, it is not methodologically sound to date houses situated in a multi-phased settlement site by choosing one charred grain from a posthole. Houses with 2-7 charred grains probably only reflect the content of the soil during the construction of the four-post houses - not the habitation phase of the house.

In total, 724 charcoal samples were collected during the Forsand project. Since this was a research project with very limited external funding, we were eligible to apply for funding from the Research Council of Norway to finance most of the costs for the ${ }^{14} \mathrm{C}$ dates. However, dating capacity at the National Laboratory for Age Determination was limited and consequently the number of approved radiocarbon dates was also limited. Altogether, 183 conventional tests and 13 AMS tests were granted. In addition, 29 AMS dates were analysed in a project where the goal was to investigate the chronological distribution of charred grains in three houses from the Bronze Age (Bakkevig 1998). Four AMS dates derive from the clearance cairn investigation in 1995 and nine conventional dates from the
Table 3. Survey of the different house types, their number and the number of dated houses.

\begin{tabular}{|c|r|r|r|r|r|r|r|}
\hline \multicolumn{10}{|l|}{ Longhouses } \\
\hline $\begin{array}{l}\text { House } \\
\text { type }\end{array}$ & $\begin{array}{l}\text { Number } \\
\text { of houses }\end{array}$ & $\begin{array}{l}\text { Number } \\
\text { of dates }\end{array}$ & $\begin{array}{l}\text { Dated } \\
\text { houses }\end{array}$ & $\begin{array}{l}\text { House } \\
\text { type }\end{array}$ & $\begin{array}{l}\text { Number } \\
\text { of houses }\end{array}$ & $\begin{array}{l}\text { Number } \\
\text { of dates }\end{array}$ & $\begin{array}{l}\text { Dated } \\
\text { houses }\end{array}$ \\
\hline 1 & 4 & 36 & 4 & 5 & 4 & 5 & 4 \\
\hline 2 & 2 & 1 & 1 & 6 & 4 & 2 & 2 \\
\hline 3 & 38 & 34 & 32 & 11 & 10 & 3 & 3 \\
\hline 7 & 7 & 12 & 7 & 12 & 4 & 3 & 3 \\
\hline 8 & 7 & 16 & 7 & 13 & 3 & 2 & 2 \\
\hline 9 & 44 & 65 & 42 & 14 & 3 & 1 & 1 \\
\hline 10 & 36 & 42 & 32 & 15 & 9 & 1 & 1 \\
\hline & & & & 16 & 7 & 2 & 2 \\
\hline & & & & 17 & 3 & 2 & 3 \\
\hline & & & & 18 & 63 & 8 & 6 \\
\hline Total & 138 & 206 & 125 & & 110 & 29 & 27 \\
\hline
\end{tabular}

Åsen pollen cores. At the time, the 238 dates were the largest series of ${ }^{14} \mathrm{C}$ dates from one site in Norway.

Due to the establishment of a gravel quarry, another excavation was undertaken in 2007 (Dahl 2008), and another 26 radiocarbon dates from 14 different houses - including nine newly discovered houses were analysed. The amount of radiocarbon dates from Forsandmoen has thus increased to 264 (Table 2).

The intention of the radiocarbon dating programme was to obtain at least one ${ }^{14} \mathrm{C}$ date from each house, even if three or four dates would give a better indication of the house's lifetime. Due to the restricted laboratory capacity, combined with a lack of suitable dating material, only 152 houses out of 274 were dated (Table 3). Consequently, the date of several house types is difficult to assess. Similarly, there are also difficulties in determining the number of houses in the different periods, making it harder to evaluate the settlement development through time.

The normal situation when conducting settlement investigations today is that each house is dated by a series of ${ }^{14} \mathrm{C}$ dates (Børsheim \& Soltvedt 2002, Soltvedt et al. 2007). This allows for a better understanding of the absolute dating of the house and the time span during which the house existed. If one of the dates is inconsistent with all the other dates, it may be rejected due to a number of reasons: it may contain old wood, it may be contaminated or the feature from which it was collected does not originate from the house in question. With only one date from a house one cannot be certain that the date really reflects the occupation of the house. However, when a date is in accordance with the normal time span of this type of house, this 
strengthens the reliability of the individual date. The total time span for the use of a certain house type will be determined by how many single houses are dated; the more dates, the more reliable is the estimate of the time span. Unfortunately, several house types only have a few radiocarbon dates, resulting in an uncertain time span for that house type. As an example, only nine of the 63 so-called four-post houses (granaries) are ${ }^{14} \mathrm{C}$ dated, mainly due to the lack of hearths in such buildings. The result is that there is great uncertainty as to which period the granaries belong (chapter 7.1).

A total of 117 houses are dated by one single sample, while 30 houses have more than one ${ }^{14} \mathrm{C}$ date. Of these 30 houses, 17 have been dated by two ${ }^{14} \mathrm{C}$ dates, and 13 houses have been dated by $3-16$ samples. This has given us the opportunity to estimate how long a house with more than one building phase existed (cf. chapter 13).

As previously described, macrofossil material from more than 1000 postholes was collected from 1984 onwards. In connection with research on this material in the mid-1990s (Bakkevig 1998:55), 25 charred grains were dated from the Bronze Age houses 32B, 59 and 90 , in which large quantities of grains were found. The purpose was to investigate if the bulk of the grain from one posthole/pit in each house had a similar date as the solitary grains from other postholes in the same house - and if these dates coincided with the dates from the deciduous tree charcoal found in the same postholes. The results are discussed in detail in relation to the actual houses (chapter 4). Here, I can briefly state that the five grain dates from each of the large collections were contemporaneous. However, in two of the sample collections, one sample was so different from the other that one could not use the combined procedure in the OxCal programme to calculate a combined date for all five dates. Since all the grains originate from a single context, this discrepancy is likely to be due to the measuring procedures.

With 232 radiocarbon dates from houses, Table 2 shows that there was a continuous settlement spanning $2,200$ years ( $1500 \mathrm{BC}-\mathrm{AD} 700)$, but it is difficult to recognise from such a table how the number of dates has changed through the long duration of the settlement.

My initial method to explore if the number of dates could give better insight into these changes, was to record how many dates had at least 35 years of their calibrated $1 \sigma$ [standard deviation (68.2\%)] dating interval in each half century. The sum could then be transferred to a graph showing changes in the number of dates throughout the settlement period (Fig. 10). This is to provide a graphical representation of the

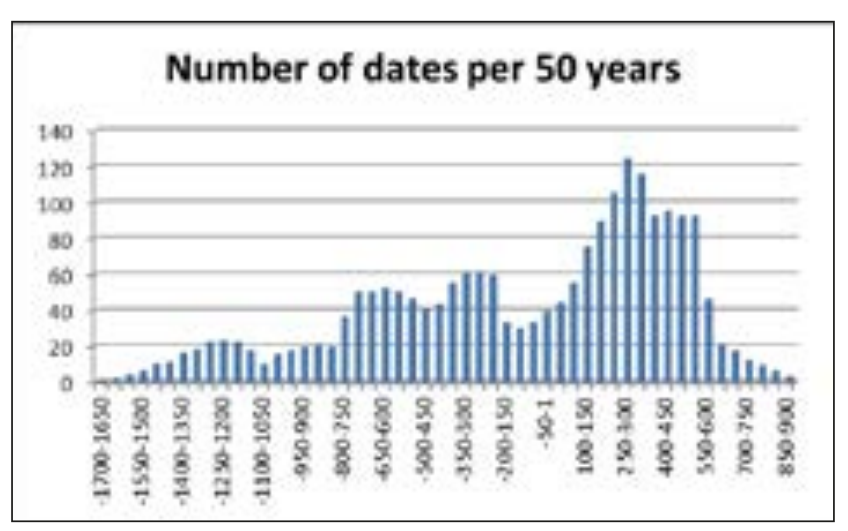

Fig. 10. Graphical representation of 210 radiocarbon dates from Forsandmoen, using I standard deviation, recorded in 50-years intervals.

uncertainty margin of the dates, so a dating is not only represented in one time interval.

Regarding how the extent of the settlement has changed throughout the settlement period, it should be noted that the figure does not take into account that, during this time, there are four plateaus in the calibration curve that affect the possibility of specifying both the age of the buildings and the size of the settlement at different times. I am also aware that Bayesian modelling could improve our understanding of the lifetime of the different house types, in addition to helping to assess when changes in the size of the settlement occurred and when the settlement was nearly abandoned in the $6^{\text {th }}$ century, but such an analysis was not available to me after my retirement in 2010.

We can see that the size of the settlement, expressed in the number of dates within each 50-year time unit is fluctuating and low, with approximately 20 dates in each 50 -year period in the Bronze Age until approximately $800 \mathrm{BC}$, after which the number of dates increases by $150 \%$ to about $50-60$ dates until approximately 200 BC. Apparently, the settlement suffers through a period of fewer dates in the late Pre-Roman Iron Age but then increases rapidly through the Roman Iron Age to a maximum of 100-120 dates every 50 years in the period AD 200-350. In the period AD 350-550, the quantity of dates stabilises at a slightly lower level $(90$ dates) and then is reduced by half (45) in the period AD $550-600$ and is further reduced in the beginning of the Migration Period to less than 20 dates.

After an expansion until the early 300s, there must have been factors that caused the settlement to become slightly smaller, but stable in scope, for 200 years. In this context, there is good reason to mention the exploitation of the area since the area could hardly have had sufficient grazing areas for the putative bovine population. In addition, prolonged grain culti- 
vation on the plain could easily have created a shortage of essential trace elements and consequently poor harvests. Nevertheless, the settlement could have been maintained as a community of at least 14 to 16 farm units. The large reduction in the number of dates and thus the destruction of the villages at Forsandmoen occurs in the transition between periods AD 500-550 and AD 550-600. From AD 600, there are only one or two farms, which endure until the beginning of the early AD 700s.

\subsection{Finds from the Forsand project}

The Forsand project collected 3042 finds during 11 years of excavation, each normally containing several artefacts or several types of samples. The finds are described in a database stored in the University of Stavanger's computer system and available in the Museum of Archaeology's object database (MUSIT). The following is a brief review of the main find groups, starting with iron and bronze objects, then ceramics and soapstone, glass, larger stone artefacts, flint finds, bone material and different types of charcoal samples. Grave finds from the Forsand area that were found prior to or after the excavations are not discussed in this section, see chapters 2.3 and 2.4.

\section{Iron and bronze objects}

A curved knife for scraping hides (house 55) and a wellpreserved bridle (Fig. 11) (house 19) belong to the first half of the Pre-Roman Iron Age. A part of a knife (house 180) dates to the late Roman Iron Age. A well-preserved knife was found in a disturbed cultural deposit NW of house 2 and a cruciform brooch from the Migration Period was found in the same area; these are probably the remains of a looted burial mound in the area, cf. chapter 2.8.

Three iron nails have been found. They have a partially preserved stem $(0.5-3.5 \mathrm{~cm})$ and rectangular or round head (houses $2,180,200$ ). In addition, a rhombic rivet head (house 5) and three fragments of rivet stems were found in houses 5 and 11. All nail remains are from houses of type 9 and are dated by context to the late Roman Iron Age and Migration Period. There are also eleven small iron fragments in the shape of small plates or round or rectangular rods that may have been parts of a needle or awl. All these eleven finds were also found in type 9 houses $(2,5,11,108,132,158$ and 180) from the same period as the rivets. It is notable that, in the unprecedented broad and well-built house 2 , there are finds of iron in three different post-holes for roofbearing posts as well as two finds in a central scrap-
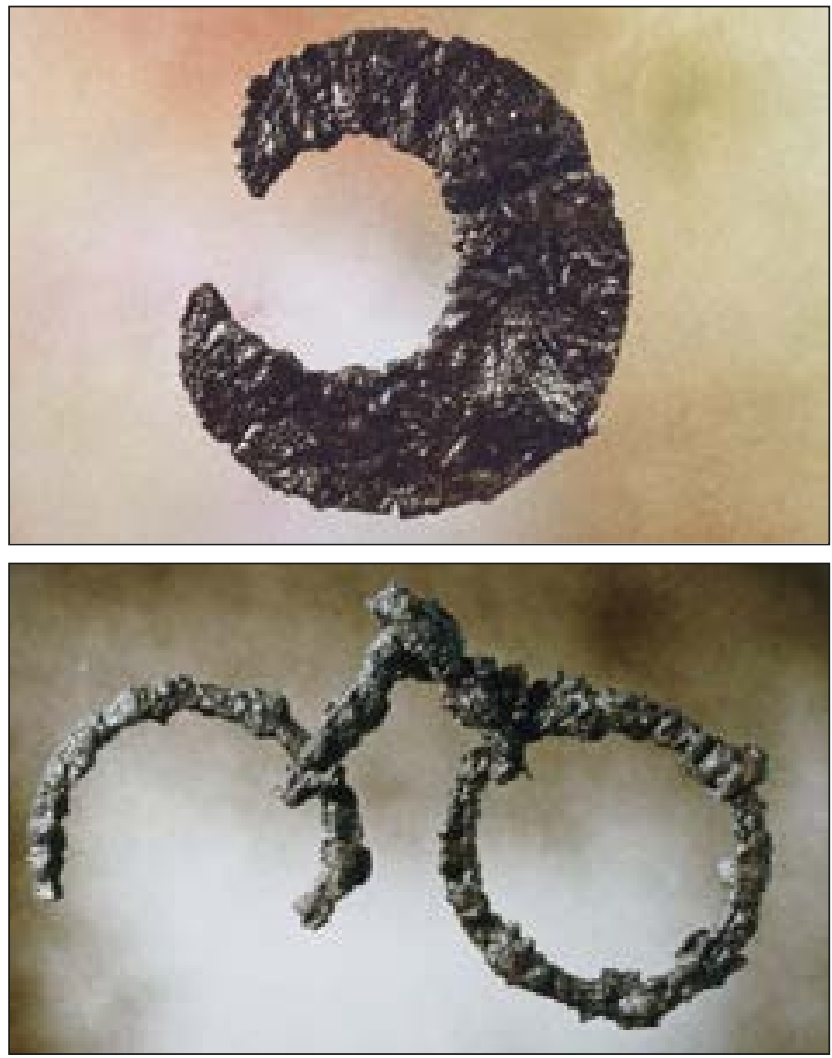

Fig. II. The curved knife (SI0479) for scraping hides and the bridle (SI30I7), dated respectively to the early and the middle Pre-Roman Iron Age, are the most well-preserved iron objects from the Forsandmoen excavations (photo: $\AA$. Pedersen and T. Treit, AM, UiS).

ing; there are also four such finds in the neighbouring house 5 . House 2 also distinguishes itself because the majority of fine, burnished decorated pottery from Forsand was found there. A small fragment of copper alloy, found just NE of house 2, must also be seen in connection with this house.

\section{Pottery}

There are 706 finds of pottery sherds from Forsand with a total weight of $14,447 \mathrm{~g}$, which are distributed between 2,551 sherds (3.6 sherds per find), averaging 5.7 g per sherd.

There are 159 finds with 321 sherds of bucket-shaped pottery with a total weight of $1.121 \mathrm{~g}$. The median weight per sherd is $3.4 \mathrm{~g}$, the average is $7.1 \mathrm{~g}$. Only one find weighs more than $50 \mathrm{~g}(166.3 \mathrm{~g})$ and only 32 finds more than $10 \mathrm{~g}$. The 31 finds (i.e. the 32 finds of more than $10 \mathrm{~g}$ minus the one find of $166.3 \mathrm{~g}$ ) weigh a total of $479.2 \mathrm{~g}$, with an average weight of $15.5 \mathrm{~g}$. The remaining 136 finds have an average weight of $3.5 \mathrm{~g}$ (median 2.7 g). They weigh $476.3 \mathrm{~g}$, which is as much as the 31 finds mentioned above. The low median weight, compared to the average for the finds under $10 \mathrm{~g}$ indicates that there are relatively many small sherds in relation to the 


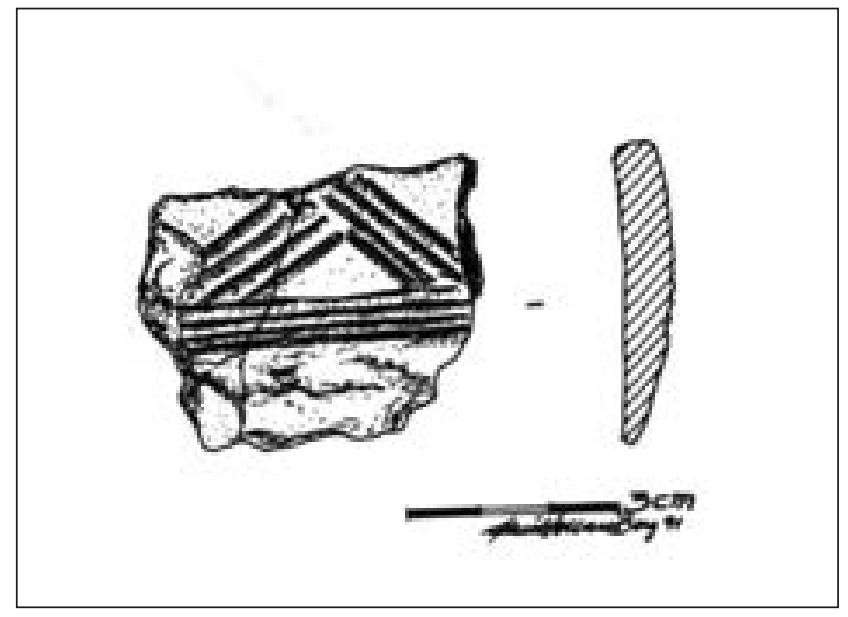

Fig. 12. Decorated sherd from a bucket-shaped vessel (SI0479) (drawing: A. H. Berg, AM, UiS).

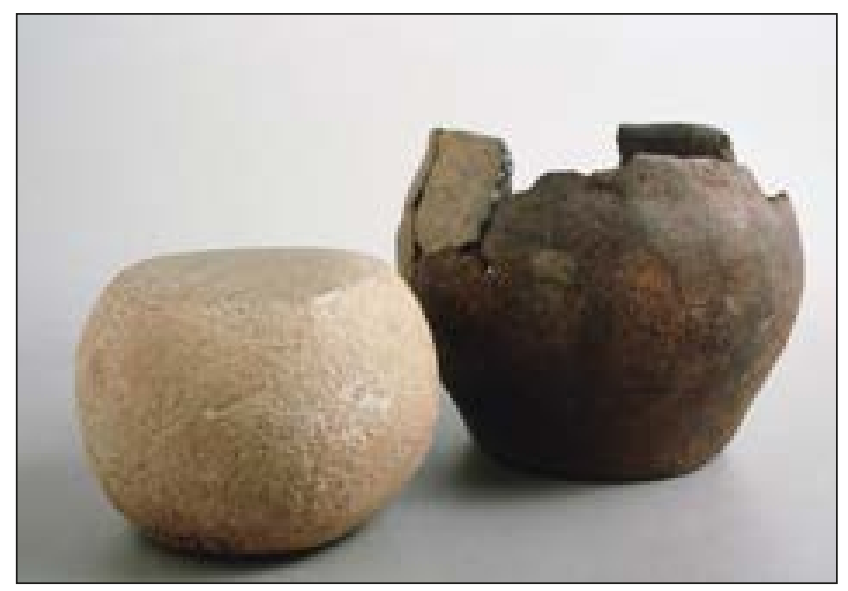

Fig. 13. The small, curved earthenware and the grinding stone (SI3I0I.I-2) probably a foundation sacrifice in connection with the building of house 119 in the years around BC/AD (photo: T. Tveit, AM, UiS).

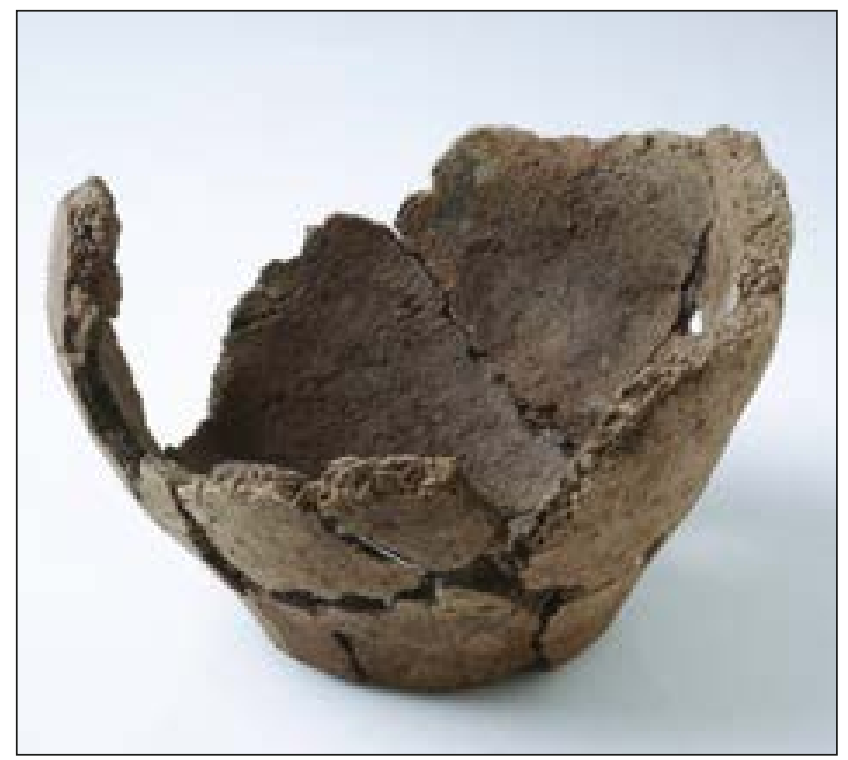

Fig. 14. This pot (SI0479) nearly filled the bottom of a small posthole, probably offered there when the house was torn down (photo: T. Tveit, AM, UiS). number of finds up to $10 \mathrm{~g}$. The sherd material must as a whole be characterised as highly fragmented with limited possibilities for placing the bucket-shaped pottery within typological or narrow chronological limits. Fig. 12 shows the largest of the most decorated sherds. There are 514 finds consisting of 2,169 sherds of coarse ware, weighing a total of $13069 \mathrm{~g}$, with an average weight of $6 \mathrm{~g}$ (median $4.3 \mathrm{~g}$ ) per sherd. Of these, 22 finds contain more than $100 \mathrm{~g}$, of which nine are more than $250 \mathrm{~g}$. The largest find weighs in at 3,745 g with 389 sherds from more than three vessels. The number of sherds per find ranges from 1-389, on average $4.2 \mathrm{~g}$ per sherd (median $1 \mathrm{~g}$ ); 327 finds have only one sherd, 66 have two sherds, 37 have three sherds and eleven have four sherds.

A nearly complete small vessel was found together with a grinding stone in one of the postholes from the central extended trestle in house 119 (Fig. 13). This is obviously an offering from when the house was built in the late Pre-Roman Iron Age or early Roman Iron Age.

Another vessel (Fig. 14), where only the rim was missing, was placed in the bottom of a roof-bearing posthole belonging to house 58 (type 11), probably when the house was deserted in Bronze Age Period VI or early Pre-Roman Iron Age.

Most of a vessel rim (diameter: $16 \mathrm{~cm}$ ) was found together with the curved knife (Fig. 11) in house 55. 15 of the finds consist of 35 sherds of fine, burnished, decorated ware, weighing $114.6 \mathrm{~g}$, with an average weight of $3.3 \mathrm{~g}$ per sherd (median $1 \mathrm{~g}$ ). Most of these sherds were found in house 2 . Ten of the finds consist of 14 sherds tempered with plant material, weighing $100.1 \mathrm{~g}$, with a $7.1 \mathrm{~g}$ average weight per sherd.

One asbestos-tempered pottery sherd (13.7 g) was recovered from a cooking pit that is stratigraphically older than house 80 from the early Roman Iron Age. Due to the early date, this sherd is not likely to be of the bucket-shaped type. A soapstone-tempered sherd, found in house 158 from the late Roman Iron Age / Migration Period, is not of the bucket-shaped type of pottery.

\section{Soapstone}

Four soapstone sherds, among them two rim sherds, were found in four different houses $(55,58,89$ and 185 ) and another four were found in a hearth near the Bronze Age house 59. All sherds are dated to Bronze Age Period VI and/or Pre-Roman Iron Age.

\section{Glass}

Two shards of glass beakers were found in a hearth/ pit in the houses 123 and 169. The shard $(3.1 \mathrm{~cm}$ long 


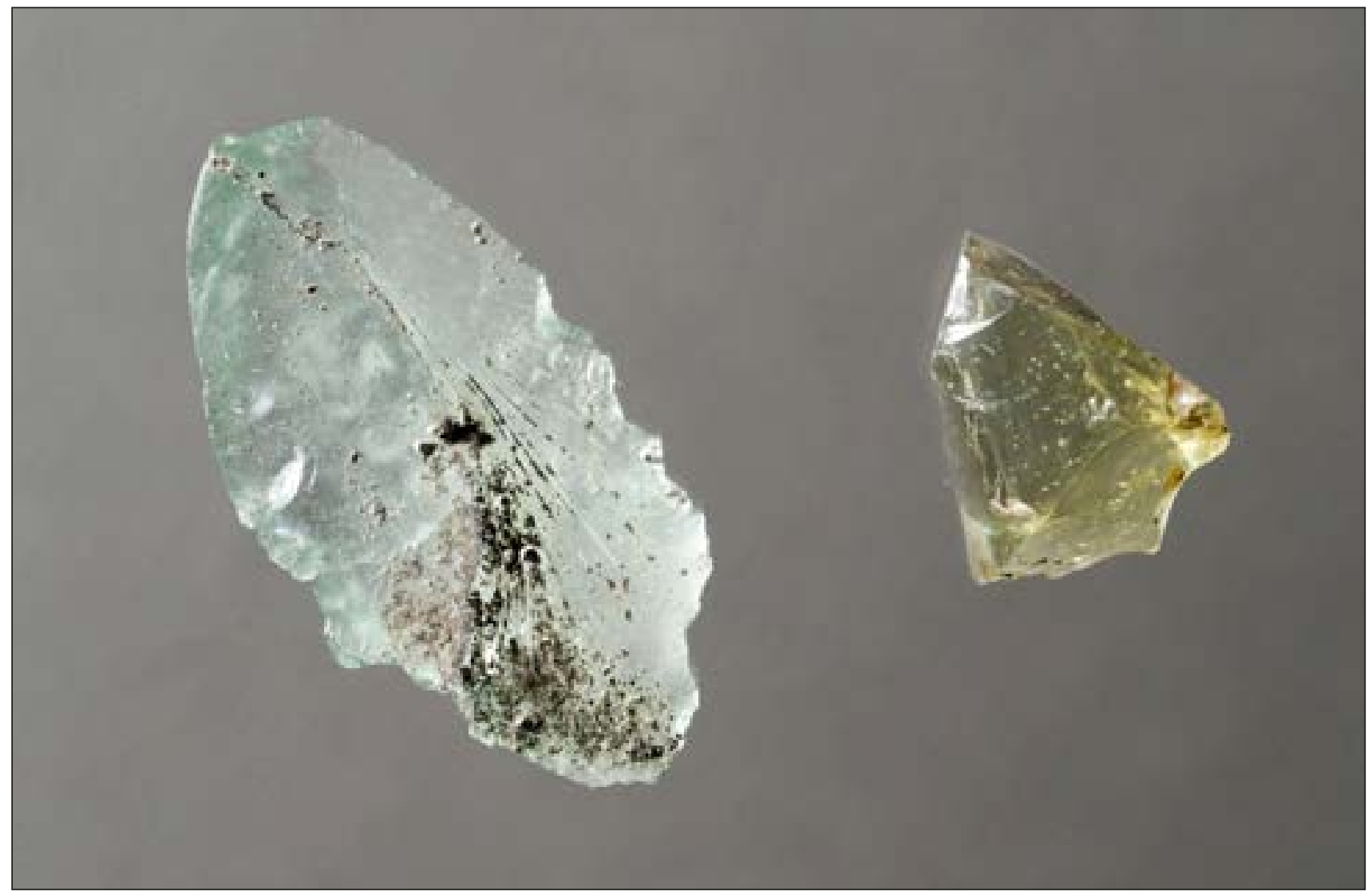

Fig. 15. SI0479: The shards from a thick-walled, light bluish glass beaker (left) and bottom shard from a coned greenish beaker (right) show that glass-beakers were used at Forsandmoen in the Roman Iron Age as well as the Migration Period (photo: $\AA$. Pedersen, AM, UiS).

and $3.4 \mathrm{~g}$ ) from house 123 was a thick-walled, light bluish glass, which, based on its colour, is probably from the early Roman Iron Age (Fig. 15). The ${ }^{14} \mathrm{C}$ date from the house (AD 20-320) is consistent with this. The second shard $(1.5 \mathrm{~cm}$ long and $1.7 \mathrm{~g}$ ) from house 169 is a bottom shard from a coned greenish beaker of the type Straume 1987, tafel 7, dated to AD 350-450 (Fig. 15). The ${ }^{14} \mathrm{C}$ date (AD 90-250) from the central hearth in the house is not compatible with this assessment. However, in the same feature where the glass shard was discovered, five sherds of a decorated bucket-shaped vessel were also found, thus confirming the dating of the glass to the transition between the late Roman Iron Age and the Migration Period.

Three whole or fragmented glass beads are all without any certain context to any house. A dark blue double pearl was found in the topsoil in the same area as the cruciform brooch and an iron knife and likely belong to a grave in the nearby looted cairn. A fragmented greenish pearl and a dark blue one probably belong to houses 17 and 156-158 from the late Roman Iron Age / Migration Period. One possible ceramic bead was found in a posthole from a roof-bearing post in house 59, dated to Bronze Age Periods IV-V.

\section{Objects of stone}

There were ten whetstones, four possible whetstones and a rough-out (blank) found in eleven different houses. In addition, there were three stray finds. All whetstones are greater or smaller fragments, disrupted in one or both ends, or split (cleaved). Six whetstones measure between 10 and $21 \mathrm{~cm}$ in length while a smaller group of four possible hones measure less than $5 \mathrm{~cm}$ each. Their total weight is $3.155 \mathrm{~g}$, while the maximum and minimum weights are $1,865 \mathrm{~g}$ and $3.3 \mathrm{~g}$, respectively. Two whetstones are made of quartzite and slate, the other has not been geologically determined. One hone has served as a needle hone.

Two equal sized fish sinkers $(9.4$ to $9.9 \mathrm{~cm}$ in length and 730.4 to $816.7 \mathrm{~g}$ ), made from oval beach rocks, have carved grooves along the longitudinal edge and one with an additional furrow along the shortest circumference. These sinkers were found in postholes for roof-bearing posts in the dwelling area of the nearby parallel houses 5 and 6 from the late Roman Iron Age and Migration Period. These houses are situated the closest to the access from the settlement and down to the sea.

Eight round-oval hammer stones, with crush marks in one or both ends, were found in houses 57 and 59 
Fig. 16. A complete two-piece mould (SI3065) for a socketed axe proves that metal technology, based on copperalloy, was present in the late Bronze Age (photo: Å. Pedersen, AM, UiS).

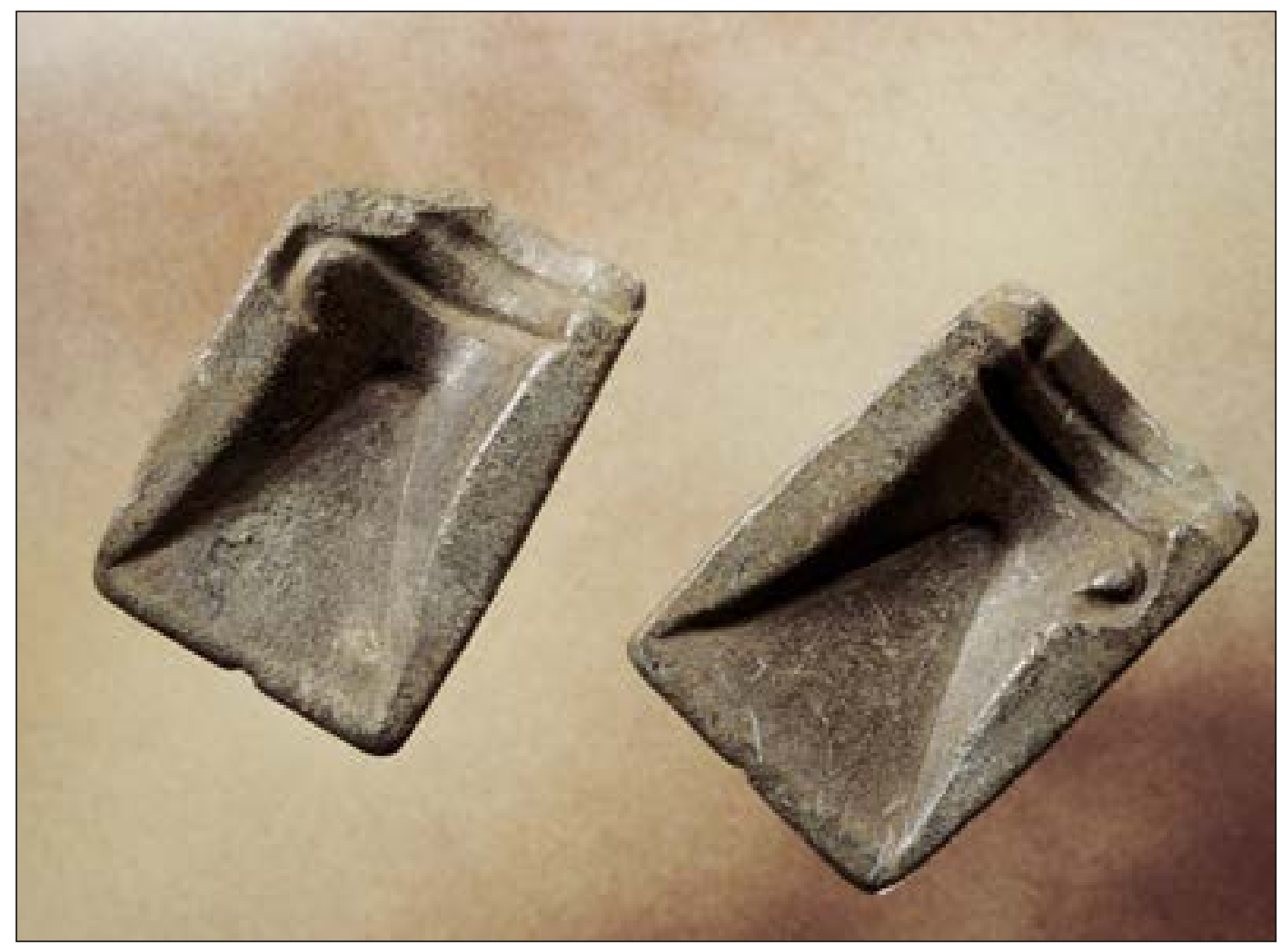

from the Bronze Age Periods III-IV, house 75 from the Bronze Age Periods V-VI and houses 5 and 106 from the late Roman Iron Age / Migration Period. The stones are between 6.1 and $16.5 \mathrm{~cm}$ long and weigh, with one exception, between 114 and $485 \mathrm{~g}$. In addition, a $10 \mathrm{~cm}$ hammer stone $(634 \mathrm{~g})$ from house 190 has been dated to the middle of the Pre-Roman Iron Age and has crush marks along the length of the edge.

Two spindle whorls found in houses 29 and 156 date from the late Roman Iron Age / Migration Period. One was made of soapstone and the other was carved out of a sherd from a bucket-shaped vessel. Both have a diameter of $3.3 \mathrm{~cm}$, the soapstone whorl weighs 24.7 $\mathrm{g}$, about three times as much as the pottery whorl $(8.7$ g). The great weight difference implies that they were likely used for the spinning of different kinds of yarn.

A complete two-piece soapstone mould for a socketed axe of type C3 (Baudou 1960) from the Late Bronze Age Periods V-VI was found in a posthole in house 75 (Fig. 16). The mould is $7.1 \mathrm{~cm}$ long and a total of $3.6 \mathrm{~cm}$ thick, with a total weight of $210.1 \mathrm{~g}$. A 5.8 $\mathrm{cm}$ long chisel of grey-green, fine-grained rock (30.2 g) was also found in the same posthole as the mould. The discovery of the mould is the most important artefact find from the Bronze Age as it proves that metal technology based on copper-alloy was used in the settlement, although actual bronze artefacts were not found during the excavation.
A polished edge fragment from a stone axe as well as a whole stone axe $(12.6 \mathrm{~cm}$ long and $382 \mathrm{~g})$ were found in association with two of the oldest houses in Forsand (32B and 45), both dated to Bronze Age Period II, while another edge fragment from a stone axe (green schist) was found in a post hole of a house from Bronze Age Period VI.

A soapstone loom weight with rounded trapezoidal shape $(10.2 \mathrm{~cm}$ long and $332 \mathrm{~g})$ was found in a posthole for a roof-bearing post close to the western gable of house 3 and dated to the late Roman Iron Age / Migration Period. This may indicate that this area just west of the main entrance to the residential part, served as a weaving workshop, among other activities.

\section{Querns}

A total of eleven different saddle querns, of which only one is not fragmented, weigh between 3,800 and $29,400 \mathrm{~g}$, with an average of $11467 \mathrm{~g}$ (median 10,900 g). Their overall length is between 20 and $50 \mathrm{~cm}$ (average $30 \mathrm{~cm}$ ). Three are from the Pre-Roman Iron Age; there is one each from the early and the late Roman Iron Age; seven are from the late Roman Iron Age / Migration Period.

There are eight fragments from rotary querns, either upper or lower stones, originating from six different rotary grinders, weighing between 380 and $14000 \mathrm{~g}$, with an average of $5410 \mathrm{~g}$ (median $3900 \mathrm{~g}$ ). The rotary 
querns were found in six different houses, all dating to the late Roman Iron Age / Migration Period. The diameter varies between $19.5 \mathrm{~cm}$ and $42 \mathrm{~cm}$, of which four querns were between 19.5 and $21.5 \mathrm{~cm}$, while the two remaining querns, each with two fragments, were 36 and $42 \mathrm{~cm}$ respectively.

The five saddle querns as well as the fragments of the rotary querns were reused as wedge stone in postholes.

\section{Grinding stones}

There are 24 grinding stones, weighing on average 4,108 g. Their overall length is between 6.5 and $39.5 \mathrm{~cm}$ (average $22.5 \mathrm{~cm}$ ). Few of the grinding stones are from the Bronze Age (1 from Periods III-IV) or the Pre-Roman Iron Age (2), while four are from the early Roman Iron Age and as many as nine are from the late Roman Iron Age / Migration Period; the remaining grinding stones have not been dated.

\section{Polishing stones}

There are 24 polishing stones, weighing a total of $12050 \mathrm{~g}$, on average $524 \mathrm{~g}$ (median $215 \mathrm{~g}$ ) and measuring between 1.8 and $22 \mathrm{~cm}$ in length, on average 9.2 $\mathrm{cm}$ (median $8.5 \mathrm{~cm}$ ). Unlike grinding stones, stones with polishing marks are hardly represented in the Migration Period (only two items), while nearly half of the stones (eleven) are from the Bronze Age. The PreRoman Iron Age and Roman Iron Age are also well represented with five and six finds, respectively.

A small fragment of pumice with abrasive tracks $(1.8$ $\mathrm{cm}$ and $3.8 \mathrm{~g}$ ) was found in a posthole for a roof-bearing post in house 59 from Bronze Age Periods IV-V.

\section{Mica schist}

A total of 62 finds consist of larger or smaller fragments of mica schist. Mica schist does not occur naturally in inner southern Ryfylke, and must have been obtained from the northern part of the Stavanger peninsula or Strand municipality, where such stone occurs. Flagstones in general were not formed in the local bedrock and are also not found in the moraine deposits, so they must have been obtained from other areas. Many of the mica schist fragments are scorched. The flagstones made of mica schist were probably used in connection with food preparation, like a small charred bread discovered in house 190, dated to the early Pre-Roman Iron Age.

There are 221 fragments of mica schist registered in 62 finds, in total about 300 fragments. The finds weigh between 0.2 and $1857 \mathrm{~g}$, in total $5698 \mathrm{~g}$, with an average of $95 \mathrm{~g}$ (median $8.5 \mathrm{~g}$ ) per find. Mica schist is found in
20 different houses, of which 17 combined dwelling/ byre houses and two storage houses are dated. The houses are distributed fairly evenly throughout the settlement periods, with three finds each from the periods Bronze Age Periods V-VI, early Pre-Roman Iron Age, late Pre-Roman Iron Age, early Roman Iron Age and late Roman Iron Age; Bronze Age Period II-IV only has one find and the Migration Period has four finds. Fragments of mica schist are found in all parts of the settlement area. One can conclude that flagstones made of mica schist probably were an integral part of the food preparation and other heating functions from the Bronze Age Period IV and onwards.

\section{Wedging stones}

Four wedging stones which framed a rectangular post in posthole 20 were collected from house 50 . From posthole 1 in the same house, a clearly intentionally split wedging stone was also recorded as a find. Similarly cleaved wedging stones collected from houses 11 and 26 and unwrought wedging stones from houses 34 and 59 were sampled as examples of materials used in the construction of the lining around the posts.

\section{Flint}

There are 47 finds of flint with a total of 130 objects and a total weight of $222.3 \mathrm{~g}$. One find consists of 16 flakes and 54 splinters, eight finds have two flint artefacts, three have three objects, the other has one object only. There are 33 finds with a total of 59 flint flakes, of which one has a retouch, two have been invasively retouched and seven more are probably remains from invasive retouching. The material also contains two scrapers: a flake scraper and a discoid scraper, three cores (one with three platforms - of which two are opposite - one opposed platform core and a core with five sides), a blade with possible edge retouch and a tip of an object. Only five finds contain burnt flint.

House 32B from Bronze Age Period II has the most finds, with 75 artefacts, mostly splinters from invasive retouching. House 59 from Bronze Age Period IV has seven finds (nine flints, weight $28.7 \mathrm{~g}$ ), including two flake remains from invasive flaking. Four flakes were found in house 80 from the Roman Iron Age, a blade and a flake in house 81 from the late Pre-Roman Iron Age and three flakes from house 29 dated to the early Roman Iron Age. There were 16 other houses that had finds of one or two flint flakes as well as some flakes from the soil layers above the houses. The invasively retouched sickle-like tip was found in house 73 from Bronze Age Periods III-IV, while the flake scraper was 
found in an undated storage house. None of the cores were located in structures that belonged to a house. A flake from invasive retouching, found in house 48 , is dated by context to Bronze Age Period IV. Since $70 \%$ of the lithic finds from the houses are dated to Bronze Age Periods II-IV, and all four discoveries of stone axes/ chisels are also dated to this period, combined with the fact that flint finds only occur sporadically later, this suggests that stone technology was phased out during the Bronze Age.

\section{Burnt bones}

There are 147 finds with 984 fragments of burnt bones, weighing a total of $285.7 \mathrm{~g}$. They were collected from 62 different houses. There were 25 finds in house 59, dated to Bronze Age Period IV; these finds comprise 45 fragments $(9.7 \mathrm{~g})$ and include limb bones from sheep and pig. Unfortunately, the largest collection of bone fragments $(50 \mathrm{~g})$, which consists only of undeterminable bones from mammals, was found in a cooking pit stratigraphically older than house 80, dated to the Roman Iron Age. Of the 984 bones, five fragments have been determined to be toe joints from cattle, eight as toe joints or limb bones, one limb bone, a by-jowl and three vertebrae from sheep/goat, in addition to eleven fragments of limb bones from sheep/goat. Four bones are probably from pig, while no horse bones have been identified. There are three bones from birds that have been impossible to identify as to species and may represent chicken or wild birds. Two bones probably from deer and one each from fish and possible hare, in addition to a seal bone, represent hunting and fishing.

The bones from sheep/goats were found in contexts from the transition of the Early to the Late Bronze Age and thereafter in all periods to the beginning of the Merovingian Period ( $7^{\text {th }}$ century). Finds of charred sheep coprolites, in house 32B from Bronze Age Period II and house 150 from the early Roman Iron Age, show that sheep/goats are present at Forsand throughout the duration of the settlement. Bones from pig are known from Bronze Age Period IV and throughout the Roman Iron Age and Migration Period. Cattle are only found in a house from the Migration Period, but the discoveries of stall boxes and barn aisle cattle paths show the occurrence of stalled cattle from Bronze Age Period III and further throughout the settlement period. Bird bones are known only from the late Roman Iron Age and Migration Period. The bones of deer and seal together with sheep/goat are found in a fire pit that was stratigraphically older than a posthole in house 80 , dated to the Roman Iron Age, while another deer bone, one hare, two bird and one fish bone, from houses 24, 123 and 144, are dated to the late Roman Iron Age or Migration Period.

\section{Charcoal samples}

A total of 1315 charcoal samples with a total weight of $96,950 \mathrm{~g}$ were collected. Four samples from burnt roofbearing posts [houses 14, 59 and 150 (2)] were found in postholes and two other fragments from posts were found in hearths (houses 3 and 24). The charred oak post in house 59 was buried to a depth of $44 \mathrm{~cm}$, while a pine post in house 150 was rectangular with dimensions of $15 \times 25 \mathrm{~cm}$.

Five charcoal samples with cutting marks were found in four houses (1, 11, 24 and 116). All houses are dated to the late Roman Iron Age and/or Migration Period. Nine other pieces of charcoal are characterised as worked, probably carved by axe or knife. Two of these from a depression older than house 62, dated to the middle of the Pre-Roman Iron Age, are circular pieces (diameter $2.5 \mathrm{~cm}$ ), which are carved out of two different oak (Quercus) pieces with very different tree-ring patterns (which run across the round cross-section) (Fig. 71, chapter 13). These pieces have probably been part of two different wooden nails from slow-growth oak (Quercus) and pine (Pinus), judging from the very close growth rings. The remaining pieces were collected from houses 15, 17 and 158, all of which date to the late Roman Iron Age / Migration Period, while two were found in soil layers over houses 1 and 3. Worked charcoal pieces are, excluding the fragments of wooden nails, dated to the last 3-400 years of the settlement period.

\subsection{The houses}

During the years 1980-1990, 1992 and 1995 the uncovered structures from the Forsandmoen excavations were interpreted as belonging to 247 different house structures, each of them given a number from 1-247 as the main identification number. It proved later that seven of these numbers did not contain structures from a house, resulting in 240 different house numbers. However, as many of the houses had more than one phase different from the other in size, layout or orientation, the 240 house numbers comprise as many as 264 houses, dating from $1400 \mathrm{BC}$ to AD 700.

In addition, a development-led excavation was initiated in 2007 due to gravel quarrying. This resulted in an additional eight house numbers containing ten house phases (Dahl 2007). The results of this excava- 
tion will be evaluated together with the data from the original research project.

Due to the premises mentioned earlier, the large amount of house remains has made it possible to divide the data into different types of identical or nearly identical houses, based on structural patterns and traces of interior occupation activities dug down in the gravel on the plain. The houses can be divided into two different groups: 138 longhouses mainly intended for human occupation, combined with a byre or workshop, and 110 shorter houses intended mainly as workshops, storage houses or for human occupation (Table 3). During the excavation period, the houses were divided into 18 different types. Later, type 4 was withdrawn, and the houses originally classified as belonging to type 4 were transferred to type 3 . Table 3 shows the number of houses assessed to the different types. It has been possible to determine to a certain type as many as 248 of the total 274 houses, while the remaining 26 houses consisted either of small parts of a house, which continued outside the excavation trench, or of scattered postholes and hearths.

Four of the types (3, 9, 10 and 18) distinguish themselves from the others because each type comprises at least 30 houses, while none of the other types include more than ten houses. Six of the types have only three or four houses and it is therefore reasonable to question whether these should be classified as types. However, they share many features and overall layout and, so far, they are regarded as real types.

The following analysis will focus on the four house types that are represented with many specimens, since they represent the two main combined dwelling and byre type of houses (types 3 and 9) and the most important workshop and storage buildings (type 10 and 18). Together, types 3 and 9 cover the entire duration of the settlement period, but while type 3 was built right from the first settlement and was the preferred dwelling house type during the Late Bronze Age and the Pre-Roman Iron Age - and was also built in the Roman
Iron Age - type 9 was the preferred house type in the Roman Age, the Migration Period and the beginning of the Merovingian Period. Likewise, storage house type 18 was used throughout the duration of the settlement period, while workshop house type 10 was used during the same period as type 9 . All the other house types were built during a much shorter period and will therefore be given less attention. Types 7 and 8 also represent the combined dwelling and byre type but belong only to the short period of the late Pre-Roman Iron Age and Roman Iron Age. Types 5-6 and 11-16 are dated to the Late Bronze Age and the Pre-Roman Iron Age. Types 5-6 are interpreted as small dwelling houses, while types 11-16 seem to have functioned as storage buildings. Lastly, type 17, a small workshop building, is linked to the type 9 and 10 houses of the late Roman Iron Age and Migration Period.

The following features have been used to distinguish the house material into the above-mentioned types from the Forsandmoen excavations:

- Rows of postholes: straight or curved

- Trestles: pattern of the distances between the trestles in a house

- Postholes/imprints of posts: horizontal shape (circular, rectangular or oval), vertical shape, size

- Width of a house/trestle: the actual size and the relation between the two measures (TQ)

- Walls: straight or curved, made of wall postholes or ditches or missing

- Wall postholes: size of postholes, distance between them, content of clay

- Gable walls: straight or semi-circular, distance between them, corner post, central gable post

- Entrances: location along the walls, type of posthole, size of the posthole and the door width, recess from the wall course, and two entrances opposite each other

- Hearths: presence or not, location in relation to trestle pattern and entrances, horizontal and vertical shape, content 


\section{Types 1 and 2: Dwelling houses with wide-spaced trestles}

Type 1-2 consists of only six houses, among which four belong to the larger type 1 and only two shorter ones to type 2 .

The longhouses of types 1 and 2 at Forsand (Fig. 17) are defined by the distance between the posts in a pair at the middle of the house of 3.4-4 $\mathrm{m}$ and a house width larger than $7.3 \mathrm{~m}$. Such a large trestle width and house width are not found in the other house from the Bronze Age and the Pre-Roman Iron Age at Forsand. With a 7.9 m mean width for type 1 houses, this results in a mean $2.1 \mathrm{TQ}$ (i.e. a balanced roof construction). Likewise, type 2 houses with a $7.3 \mathrm{~m}$ width also have

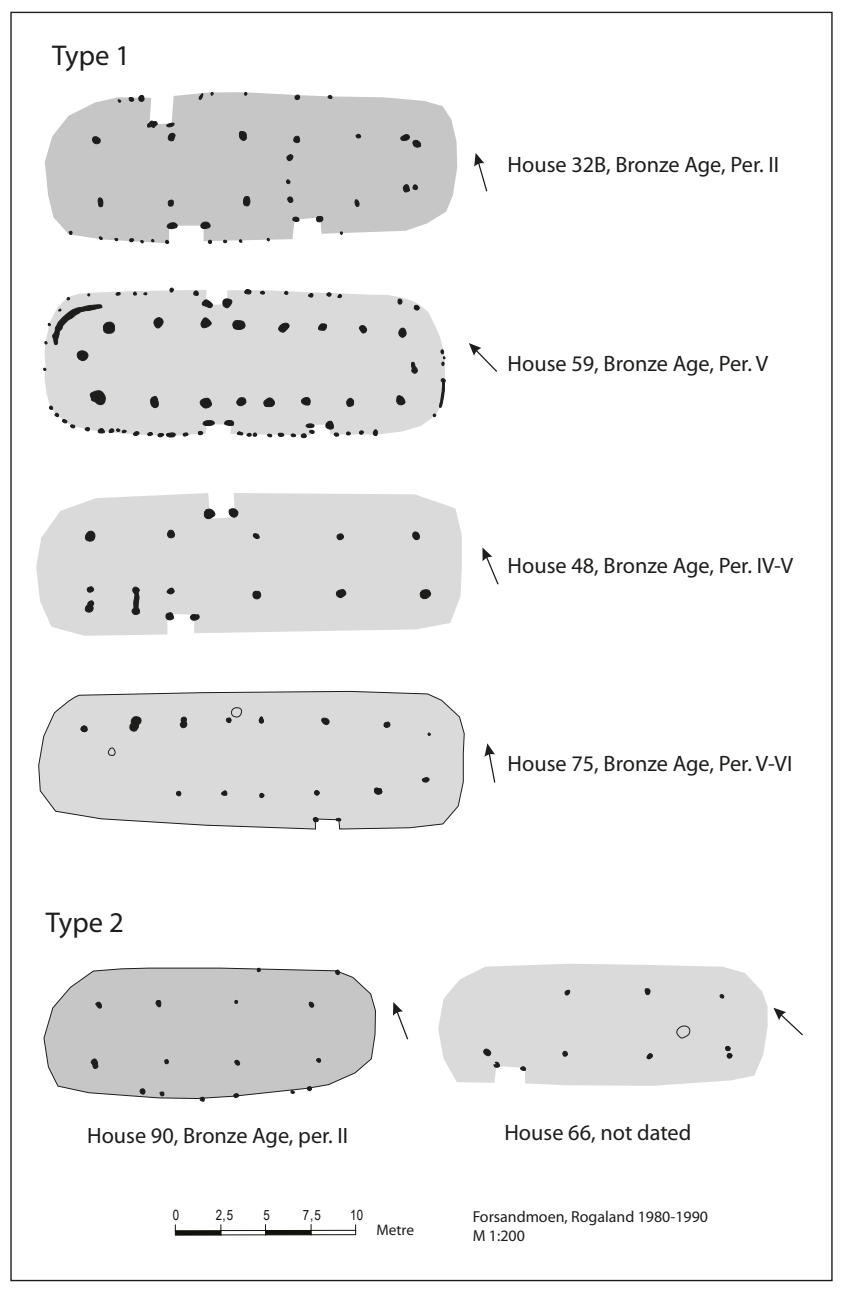

Fig. 17. House plans of type I and 2 houses. Notice the equal size of the type I houses. a balanced roof. These two types of houses are the only Bronze Age and Pre-Roman Iron Age houses from Forsandmoen with such a roof construction. The larger type 1 has one or more entrance(s) while type 2 lacks any such traces. The roof-bearing construction in type 1 is different from house to house, while the construction in type 2 has even spaces between the trestles.

Three of the type 1 houses have been radiocarbon dated to, respectively, Bronze Age Period II (house 32B: combined date to $1430-1410 \mathrm{BC}$ from five charred grains from different postholes), Period IV (house 48: 1010-830 BC) and Period V (house 59: combined date from four charred grains to 813-792 BC). The last type 1 house (75) has been dated to Bronze Age Periods V-VI by a soapstone casting mould of type C1B/C3 (Baudou 1960). One of the type 2 houses (90) is also radiocarbon dated to Bronze Age Period II, while house 66 could not be dated. Thus, it is clear that the wide and large type 1 houses were in use over an astonishingly long period of time. It appears that there was a need to build such a house only a few times, at intervals of 200 to 400 years during the Bronze Age, probably due to a special situation caused by an economic, social or demographic event. Most of the recorded measurements concerning the sizes and shapes of the type 1-2 houses are presented in Table 4.

\subsection{The distribution of type 1-2 houses and their orientation}

All type 1-2 houses are located in Area A (Fig. 18), in the NE corner of the settlement area - an area which has the best local climate due to the best sun exposure on the plain and shelter from the easterly winter winds. The two Bronze Age Period II houses (32B and 90), representing the initial settlement on the plain, have obviously been carefully placed in Area A.

The houses have a mean orientation of $330^{\circ} \mathrm{NW}$, but the orientation varies between 310 and $350^{\circ}$. Compared to the nearly approximate E-W orientation of the type 3 houses $\left(277-346^{\circ}\right.$, mean $310^{\circ}$, cf. Fig. 
Table 4. Presentation of retrieved measurements from type I-2 houses. Measurements in metres (m).

\begin{tabular}{|c|c|c|c|c|c|c|c|c|c|c|c|c|c|c|c|c|c|c|}
\hline \multirow{2}{*}{ 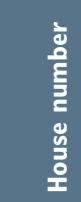 } & \multirow{2}{*}{ 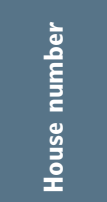 } & \multirow{2}{*}{ 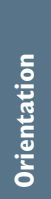 } & \multirow{2}{*}{ 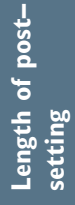 } & \multirow{2}{*}{ 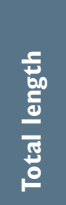 } & \multirow{2}{*}{$\frac{5}{\frac{5}{3}}$} & \multirow{2}{*}{ 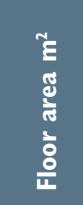 } & \multirow{2}{*}{ 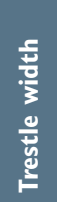 } & \multirow[b]{2}{*}{$\stackrel{\circ}{\circ}$} & \multicolumn{2}{|c|}{ 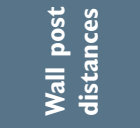 } & \multicolumn{8}{|c|}{ Distances between trestles } \\
\hline & & & & & & & & & N & $S$ & $4-3$ & $3-2$ & $2-1$ & Entrance room & $I-2$ & $2-3$ & $3-4$ & $4-5$ \\
\hline \multicolumn{19}{|l|}{ Type I } \\
\hline $32 B$ & $X X X I I B$ & 317 & 17.0 & 21.0 & 8.1 & 170.1 & 3.7 & 2.2 & 0.6 & 0.8 & & & 4.0 & 4.1 & 3.2 & 3.7 & 2.6 & \\
\hline 48 & XLVII & 326 & 18.3 & 22.3 & 7.4 & 165.0 & 3.4 & 2.2 & & & & 2.5 & 1.9 & 4.8 & 4.7 & 4.4 & & \\
\hline 59 & LIX & 350 & 16.6 & 22.1 & 8.0 & 176.8 & 4.4 & 1.8 & 0.8 & 0.6 & & 2.8 & 2.9 & 1.8 & 2.0 & 2.1 & 2.4 & 2.5 \\
\hline 75 & LXXV & 314 & 19.1 & 23.3 & 8.0 & 184.8 & 4.I & 2.0 & & & 2.8 & 2.6 & 2.5 & 2.0 & 3.3 & 3.5 & 2.4 & \\
\hline Mean & & 327 & 17.8 & 22.2 & 7.9 & 174.2 & 3.9 & 2.1 & 0.7 & 0.7 & 2.8 & 2.6 & 2.8 & 3.2 & 3.2 & 3.4 & 2.5 & 2.5 \\
\hline \multicolumn{19}{|l|}{ Type 2} \\
\hline 90 & $x C$ & 324 & 12.0 & 16.6 & 7.3 & 121.8 & 3.4 & 2.2 & 0.9 & & & & 3.6 & 4.1 & 4.3 & & & \\
\hline 66 & LXVI & 353 & 13.2 & 17.2 & 7.2 & 123.8 & 3.5 & 2.1 & & & & & 4.3 & 4.6 & 4.3 & & & \\
\hline Mean & & 339 & 12.6 & 16.9 & 7.3 & 122.8 & 3.5 & 2.2 & & & & & 4.0 & 4.4 & 4.3 & & & \\
\hline
\end{tabular}

23), the type 1-2 houses have a more NW-SE orientation. However, looking at the orientation of type 3 houses located in Area A (18 houses), one can see that they have a mean orientation of $320^{\circ}$, while the other half of the type 3 houses on the more open area of the plain SW of Area A (Areas B, C and D) have a mean orientation of $300^{\circ}$. The conclusion is that it was more convenient to orient the houses in Area A in a more NW-SE direction than was preferred in the other areas, likely due to the orientation of the border between the plain and the base of the mountain, and that the orientation did not differ significantly between the two house types 1-2 and 3 in Area A. The slightly NW-SE orientation preferred in the more sun-exposed and wind-sheltered Area A might also be the result of a wish to catch more heat from the afternoon sun on the southern façade.

\subsection{Analysis of house features}

\section{The size of the houses}

The four type 1 houses (32B, 48, 59 and 75) consist of two slightly curved rows of six or eight pairs of roofbearing posts. The curvature of each row is between 0.25 and $0.35 \mathrm{~m}(1.5-1.8 \%)$. The length of the row of posts is between 16.6 and $19.1 \mathrm{~m}$ (mean $17.8 \mathrm{~m}$ ). The two houses with only six trestles have mainly large bays (3.2-4.7 $\mathrm{m}$ ), while in the two houses with eight trestles, the bays measure only $2.4-3.5 \mathrm{~m}$. Only house 59 has preserved gable walls, showing that the house was $22.1 \mathrm{~m}$ in length. The length of the other houses, considering the mean size of the gable room in type 3 , can be estimated to between 21 and $23 \mathrm{~m}$ and the mean house length would then be $22.5 \mathrm{~m}$. Compared to the Bronze Age type 3 houses (mean length 15.2 $\mathrm{m})$ the type 1 houses are $7.4 \mathrm{~m}$ longer than an average type 3 house. Taking into consideration the larger width of the type 1 houses $(7.9 \mathrm{~m}$ versus $6.1 \mathrm{~m})$, the floor area is doubled $\left(174 \mathrm{~m}^{2}\right)$ compared to the type 3 Bronze Age houses $\left(88 \mathrm{~m}^{2}\right)$. These houses therefore probably represent another type of household and/or economy.

The type 2 houses consist of only four straight trestles divided into three nearly equally sized bays, measuring 12-13 m in length. One house (90) has remains of the curved wall, which shows that the house was 7.2 $\mathrm{m}$ wide and probably $16.6 \mathrm{~m}$ long, resulting in a roofed area of $122 \mathrm{~m}^{2}$, two-thirds of that of the type 1 houses.

\section{The walls}

House 59 had a nearly completely preserved row of wall posts, showing slightly curved long walls and slightly 


\begin{tabular}{|c|c|c|c|c|c|c|c|c|c|c|c|c|c|c|c|}
\hline \multirow{2}{*}{\multicolumn{2}{|c|}{$\begin{array}{l}\text { Door } \\
\text { width }\end{array}$}} & \multirow{2}{*}{\multicolumn{2}{|c|}{$\begin{array}{l}\text { Door } \\
\text { recess }\end{array}$}} & \multicolumn{6}{|c|}{ Roof-bearing postholes } & \multicolumn{6}{|c|}{ Entrance postholes } \\
\hline & & & & \multirow[t]{2}{*}{ Number } & \multirow{2}{*}{$\begin{array}{l}\text { Shape } \\
\text { I:round } \\
\text { 2:oval }\end{array}$} & \multicolumn{2}{|c|}{ Surface dimension } & \multicolumn{2}{|c|}{ Depth } & \multirow[t]{2}{*}{ Number } & \multirow{2}{*}{$\begin{array}{l}\text { Shape } \\
\text { I:round } \\
\text { 2:oval }\end{array}$} & \multicolumn{2}{|c|}{ Surface dimension } & \multicolumn{2}{|c|}{ Depth } \\
\hline $\mathbf{N}$ & s & $\mathbf{N}$ & $s$ & & & Min-max & Mean & Min-max & Mean & & & Min-max & Mean & Min-max & Mean \\
\hline 1.0 & 1.8 & 1.4 & 0.9 & $\begin{array}{l}10 \\
1\end{array}$ & $\begin{array}{l}1 \\
2\end{array}$ & $\begin{array}{l}0.23-0.50 \\
0.30 \times 0.50\end{array}$ & $\begin{array}{l}0.37 \\
0.30 \times 0.50\end{array}$ & $\begin{array}{l}0.06-0.50 \\
0.25\end{array}$ & $\begin{array}{l}0.30 \\
0.25\end{array}$ & 4 & 2 & $\begin{array}{l}0.27 \times 0.42- \\
0.35 \times 0.50\end{array}$ & $0.32 \times 0.46$ & $0.22-0.30$ & 0.28 \\
\hline 1.3 & 1.3 & & & $\begin{array}{l}7 \\
2\end{array}$ & $\begin{array}{l}1 \\
2\end{array}$ & $\begin{array}{l}0.30-0.40 \\
0.25 \times 0.35- \\
0.40 \times 0.50\end{array}$ & $\begin{array}{l}0.36 \\
0.33 \times 0.43\end{array}$ & $\begin{array}{l}0.30-0.60 \\
0.44-0.60\end{array}$ & $\begin{array}{l}0.46 \\
0.52\end{array}$ & $\begin{array}{l}1 \\
4\end{array}$ & $\begin{array}{l}1 \\
2\end{array}$ & $\begin{array}{l}0.25 \times 0.36- \\
0.50 \times 0.60\end{array}$ & $\begin{array}{l}0.50 \\
0.30 \times 0.50\end{array}$ & $0.29-0.40$ & $\begin{array}{l}0.40 \\
0.33\end{array}$ \\
\hline 1.2 & 1.2 & 0.6 & 0.6 & $\begin{array}{l}11 \\
5\end{array}$ & $\begin{array}{l}1 \\
2\end{array}$ & $\begin{array}{l}0.40-0.60 \\
0.35 \times 0.46- \\
0.60 \times 0.80\end{array}$ & $\begin{array}{l}0.50 \\
0.45 \times 0.61\end{array}$ & $\begin{array}{l}0.38-0.55 \\
0.36-0.56\end{array}$ & $\begin{array}{l}0.41 \\
0.46\end{array}$ & $\begin{array}{l}1 \\
5\end{array}$ & $\begin{array}{l}1 \\
2\end{array}$ & $\begin{array}{l}0.22 \times 0.43- \\
0.49 \times 0.70\end{array}$ & $\begin{array}{l}0.40 \\
0.39 \times 0.58\end{array}$ & $0.17-0.32$ & $\begin{array}{l}0.11 \\
0.27\end{array}$ \\
\hline & 1.3 & 1.0 & 0.8 & 11 & I & $0.28-0.50$ & 0.36 & $0.22-0.52$ & 0.29 & & & & & & \\
\hline 1.2 & 1.4 & 0.8 & 0.7 & $\begin{array}{r}39 \\
8\end{array}$ & $\begin{array}{l}1 \\
2\end{array}$ & & $\begin{array}{l}0.41 \\
0.40 \times 0.55\end{array}$ & & $\begin{array}{l}0.36 \\
0.39\end{array}$ & $\begin{array}{r}2 \\
13\end{array}$ & $\begin{array}{l}1 \\
2\end{array}$ & & $\begin{array}{l}0.45 \\
0.34 \times 0.52\end{array}$ & & $\begin{array}{l}0.26 \\
0.32\end{array}$ \\
\hline & & & & 8 & I & $0.26-0.36$ & 0.31 & $0.12-0.39$ & 0.24 & & & & & & \\
\hline & 1.5 & & & 7 & $\mathrm{I}$ & $0.25-0.30$ & 0.28 & $0.19-0.35$ & 0.28 & & & & & & \\
\hline & & & & 15 & 1 & & 0.30 & & 0.26 & & & & & & \\
\hline
\end{tabular}

curved gable walls with rounded corners. House 32B had remains from similar long walls, while the other two type 1 houses lacked remains from the walls. The walls consisted of small, rounded postholes placed at a different average distance in different parts of the house $(0.6,0.75,0.85$ and $0.95 \mathrm{~m}$ intervals). The wall posts are set closest together in the southern wall.

\section{The entrances}

Three houses (32B, 48 and 59) had two opposed and recessed entrances located west of the midpoint of the house. In house 32B, they were located on either side of a trestle. The northern and southern entrances in houses $32 \mathrm{~B}$ and 48 are displaced $0.9-2 \mathrm{~m}$ in an E-W direction in relation to each other. The entrances are recessed between $0.5-0.6 \mathrm{~m}$ (house 59) or 0.9-1.4 m (house 32B) from the wall course (mean for all: 0.75 $\mathrm{m}$ ). The door width is between 1-1.8 m (mean $1.2 \mathrm{~m}$ in the northern wall and $1.4 \mathrm{~m}$ in the southern wall). The difference in entrance width is normally within $0.2 \mathrm{~m}$ in an individual house. The entrance room can be narrow $(1.9-2.1 \mathrm{~m}$, house 59,75$)$ or wide (4.1-4.8 $\mathrm{m}$, house $32 \mathrm{~B}, 48$ ). The width of the narrow entrance room differs from the other distances between the trestles, which are 2.3-3.4 m (mean $2.7 \mathrm{~m}$ ), while the wide entrance rooms (mean $4.5 \mathrm{~m}$ ) are substantially wider than the mean distance between the trestles (mean $3.3 \mathrm{~m}$ ).

Three of the houses have an additional entrance in the eastern part of the south wall. House 32B has an interior door located in the first trestle to the west of the entrance. This may indicate special activities in this part of the house.

\section{Shape and size of postholes and the roof-bearing posts}

Only $13 \%$ of the documented roof-bearing postholes from the types 1-2 was oval; the others were circular. Concerning the entrance postholes, the ratios were nearly the opposite and only $20 \%$ were circular. The ratios are in full accordance with the numbers found from the contemporary type 3 houses. It is obvious that the rectangular entrance posts were intended to emphasise the importance of the entrance of the house in relation to all the other less worked up interior posts. The mean measures of oval posts (size: $0.40 \times 0.55 \mathrm{~m}$, depth: $0.39 \mathrm{~m}$ ) and circular roof-bearing posts (diam.: $0.41 \mathrm{~m}$, depth: $0.36 \mathrm{~m}$ ), as well as entrance posts (size: $0.34 \times 0.52 \mathrm{~m}$, depth: $0.26 \mathrm{~m}$ ) in the type 1 postholes were slightly larger and deeper compared to the contemporary type 3 houses, probably reflecting the larger width and size of the type 1 house. 


\section{Forsandmoen, Forsand municipality Map of settlement area}

$C D$ House feature with preserved wall remains House feature without wall remains

Type 1

Type 2

Gravemound / cairn

$\bigcirc \quad$ Excavated gravemound / cairn

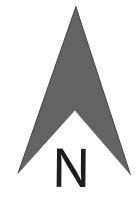

TGB/TL 2009/2014
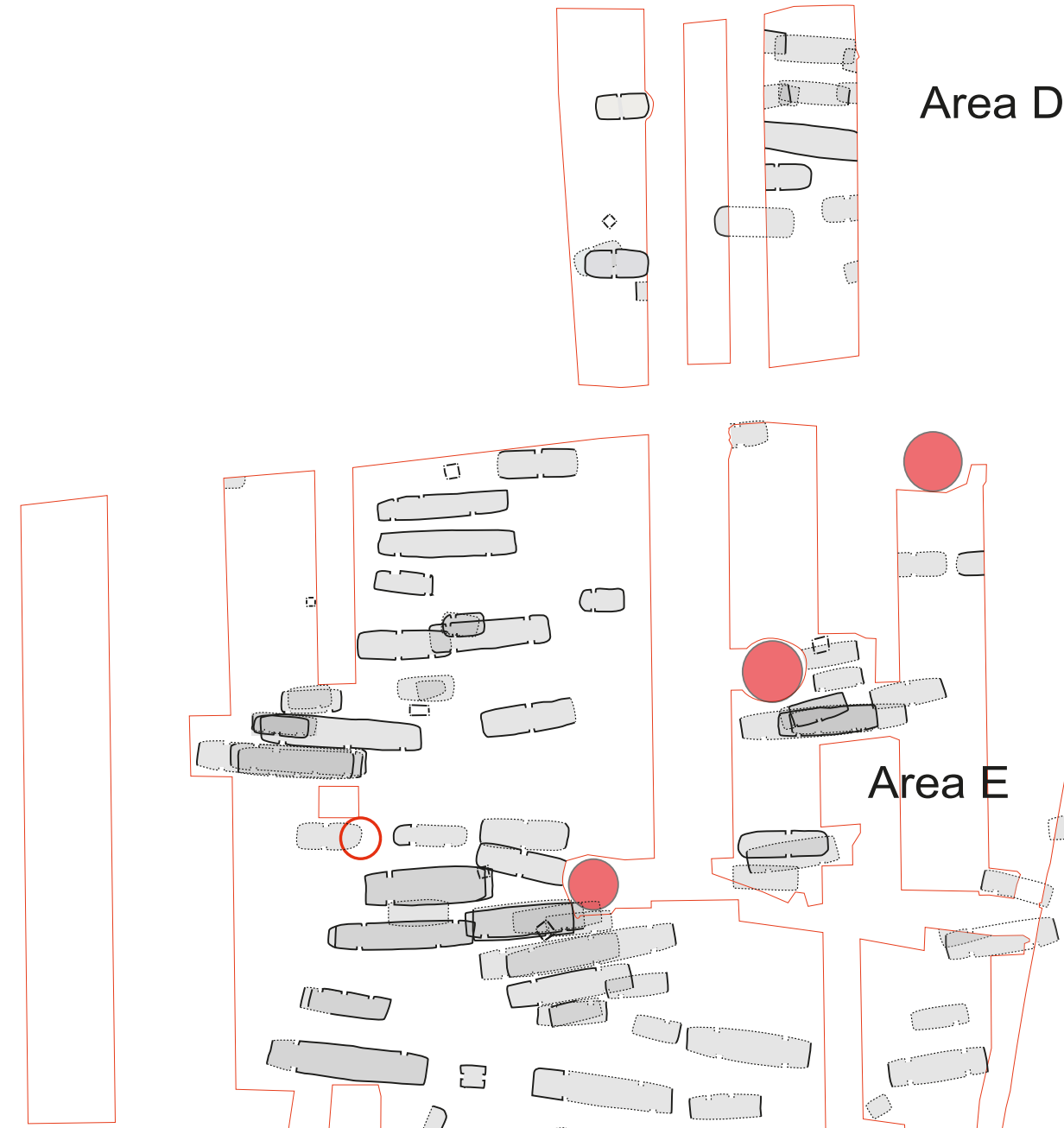

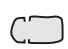
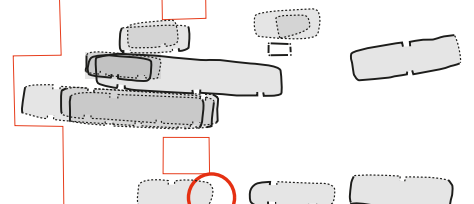

O
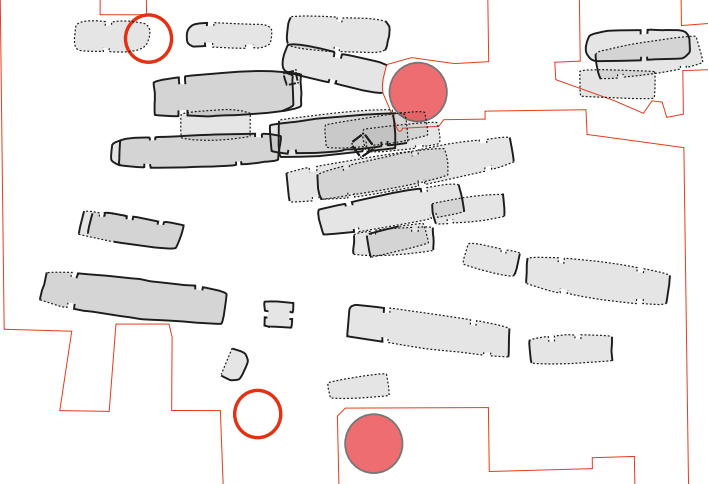

$\bigcirc$

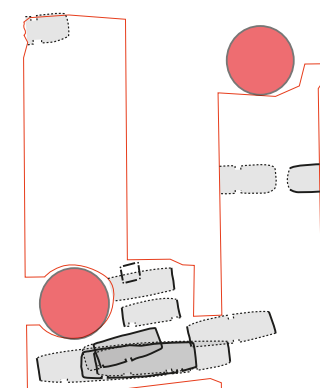

Area E
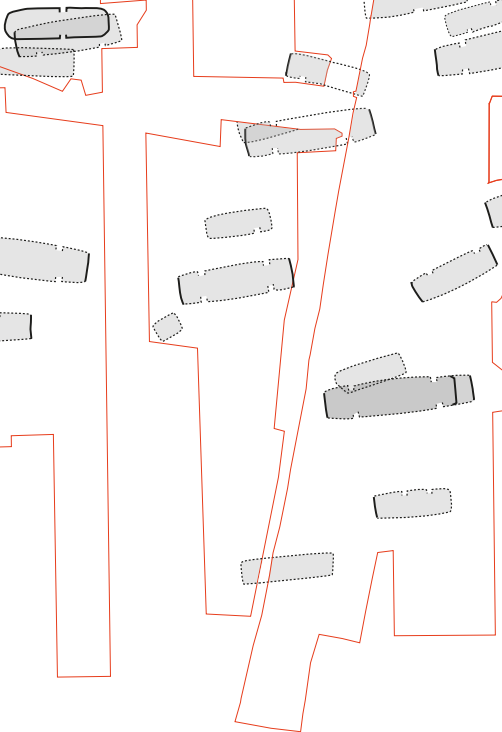


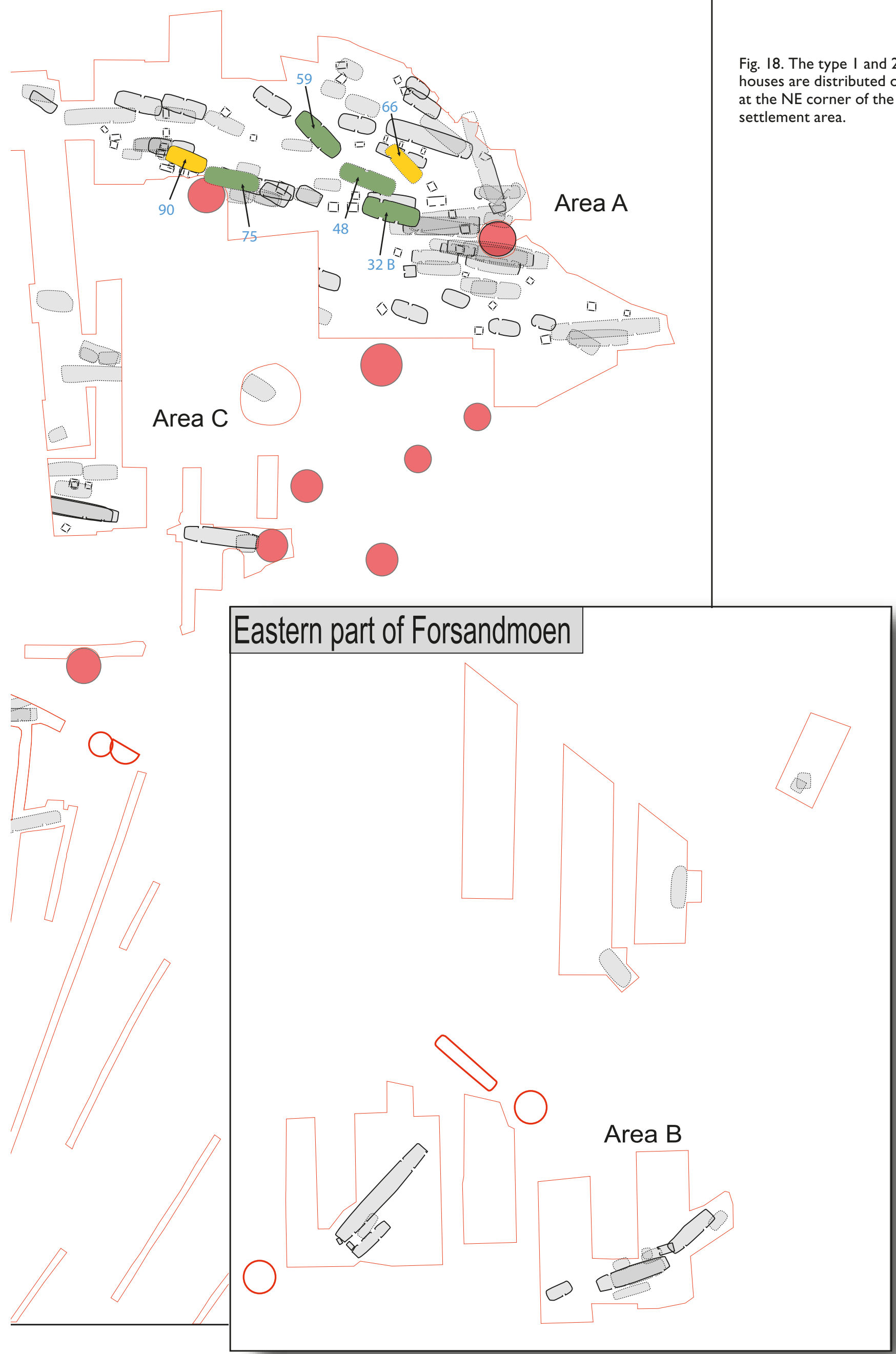


The posthole size and depth of the smaller type 2 houses (diam.: $0.3 \mathrm{~m}$, depth: $0.26 \mathrm{~m}$ ) was similar to those from type 3 (cf. Table 4 and Table 5 , folder).

The size of the circular imprints of the posts could be measured in six of the type 1 postholes. In house 59 , one post impression measured $16-18 \times 20-22 \mathrm{~cm}$, another $20 \times 20 \mathrm{~cm}$, while a third measured a maximum of $18 \mathrm{~cm}$. In house 75, two impressions measured 22 and $24 \mathrm{~cm}$, respectively. In seven postholes in house 75 , the posts could have measured a maximum of $26-28 \mathrm{~cm}$, due to the narrow postholes. Lastly, in house $32 \mathrm{~B}$, the remains of a charred, pointed post was $28 \mathrm{~cm}$ in diameter. These measurements are within the size range that was found for the largest part of the measurements from type 3 houses (cf. chapter 5.2)

\section{The layout of the type 1 houses}

The type 1 houses have two different layouts. House 32B has five equally large bays between the six trestles, an entrance to three of the bays and an interior door that divides the two eastern bays from the western part. House 48 is similar to house 32B with six trestles, and with the doors not positioned directly opposite each other. House 59 and house 75 have eight trestles with two large bays in the western and eastern end of the house, respectively, and shorter ones in the middle part of the house. Just as house 32B, house 59 has three entrances, two of which are located opposite each other in a small bay near the centre of the house. The third entrance is located near the eastern end, as in house 32B. In house 75, the only entrance is found in the eastern end, placed the same way at the eastern entrances in house $32 \mathrm{~B}$ and 59 . A narrow bay $(2 \mathrm{~m})$ in the middle of house 75 , as in house 59 , may indicate the location of two opposed entrances. It is possible that the two houses 32B and 59 - and probably house 75 as well - had a layout divided in three sections.

\subsection{Find distribution}

The central entrance room in the type 3 houses in the Bronze Age and Pre-Roman Iron Age, with a pair of opposed recessed doors, have normally been interpreted as the partition between a dwelling room for people to one side and a byre/storage area to the other. The much larger type 1 houses at Forsand, with two opposite or nearly opposite entrances in the western half and another entrance in the south-eastern wall indicate that these houses have been used in a different way. The significantly larger roofed area indicates that they could have contained more people and/or cattle or that the houses could have served other functions. There were no certain traces of stall boxes or wear depressions from cattle, so unlike some of the Danish houses (Bjerre, Hemmed, Brd. Gram IV, and Legård: Bech 2003, Boas 1991, Ethelberg 2000, Mikkelsen 2012) stalling of cattle is not proven in the Rogaland houses. However, since they have the same three-part layout, it is reasonable to assume that they had some space for stalling cattle. Likewise, there are no traces of cooking pits/sunken hearths in the type 1 houses in the Forsand material, but a cluster of three cooking pits was situated in the western end of Austbø house I (Hundvåg, Rogaland) (cf. Juhl 2001), as is often found in the mentioned Danish material.

The find distribution of house 32B can shed some additional light on where activities took place. Five postholes belonging to the eastern part, including postholes for entrances, interior divisions and roof-bearing posts, contained more than 2100 charred grains. This dispersed pattern may indicate that the house caught fire at one point rather than representing sacrifices. The same postholes also contained 75 pieces of burnt and unburnt flakes and splints from the making of flaked arrowheads, chaff from grain, three coprolites from sheep/goat and one undecorated sherd of pottery. This part of the house may have been used to thresh and store grain, make tools and perform other daily activities and even used as a sheep shed. In the western end, only one charred find of a phalanx III (toe bone) from a cloven-footed animal together with eight fragments from undetermined mammals may indicate that this was an area for food preparation and consumption, like in the Austbø houses.

House 48, interpreted as being of the same type as house $32 \mathrm{~B}$, has a find distribution, comprising one grinding stone, 20 undecorated sherds of pottery, one flint flake and $2.1 \mathrm{~g}$ of undetermined burnt bone from mammals, which is restricted to the western part of the house. This seems to confirm that at least the western part was an area for human occupation.

The number of finds in house 59 was much greater than in house 32B. They show a varied distribution pattern related to the different types of objects. Nearly all pottery sherds (96\%), all flint and quartzite flakes and clay found in the postholes from the roof-bearing posts, were located at the western end of the house; in the same area, there was also a piece of pumice with abrasive tracks and a grinding stone, as well as a pit containing raw clay near the SW entrance. In total, this strongly indicates that this part of the house was a dwelling area for people. However, the distribution 
of burnt bone is different. There were 134 fragments of burnt bones $(8.4 \mathrm{~g})$, including one limb bone from sheep/goat and one from a larger mammal (pig/ox), as well as finds of charred grains, found in the postholes throughout the entire house. Throughout the eastern part of the house, there were 24 fragments of hazelnuts (Corylus) (1.5 g) and 66 fragments (190 g) of mica schist (phyllite). The mica schist fragments are probably remains from baking sheets, and thus represent food preparation in the eastern part.

In house 75 - in many ways similar to house 59 - all objects were found in the western part of the house, where two pits containing raw clay were also located. Both halves of a steatite mould for casting a bronze socketed axe, a stone chisel ground on all four sides, a hammer stone, a flint flake and one piece of mica schist point to this part of the house as the dwelling area. The narrow space between trestles three and four from the west indicates an entrance room there, and the additional entrance near the eastern end, as in house 59, makes it possible to assume that the two houses had a similar organisation of activities.

Concerning the type 2 houses, the finds are restricted to 7,800 carbonised grains from three postholes in house 90. A combined dating of five grains of barley (Hordeum) shows that the house is contemporary with house 32B. On the basis of these findings and the layout of the houses, it is not possible to say whether the houses were storage houses or dwellings for people.

\subsection{Comparative houses from Norway and Denmark}

Two wide and large houses from Bronze Age Period II were excavated at Austbø, in the municipality of Stavanger in the years 1987-90 (Juhl 2001:41f). House 1 at Austbø (21.8 x 6 m) (Juhl 2001:46) has many similarities with Forsand house 32B, especially the tripartite layout, the location of the several entrances and interior doors as well, as many charred grains, but Austbø I lacks any remains of the walls. A cluster of cooking pits was located near the western end as well as near the eastern gable. The house is dated to Bronze Age Period II, 1500-1300 BC, somewhat younger than house 32B.

House II at Austbø $(23.1 \times 7.8 \mathrm{~m})$ is more similar to Forsand house 59 with the many densely set small wall posts. But while Forsand house 59 is dated to Bronze Age Period V, the Austbø house II is contemporary with Austbø house I, dated to Bronze Age Period II.

Two more type 1 houses have been excavated at Kleppe, in Klepp municipality (Berge 2007). Both houses had six trestles, but no traces of entrances or walls. The roof-bearing construction measured $19.9 \mathrm{x}$ $3.5 \mathrm{~m}$ and $19.3 \times 4.6 \mathrm{~m}$, which indicates a house size of $24 \times 7-7.5 \mathrm{~m}$. In one house, dated to Bronze Age Period IV, the trestles are quite evenly distributed throughout the construction, and a large hearth indicates an occupation area in the NW part. In the second house, the distance between the three eastern trestles was $2.6 \mathrm{~m}$, while the other three distances were $4.7 \mathrm{~m}$ each. This indicates that there may have been different activity areas in the house, but this does not necessary imply a byre. Two interior postholes, $2 \mathrm{~m}$ apart and $2.9 \mathrm{~m}$ to the west of trestle three from the west, might be a wide doorway, delimiting the western house area. The house is dated by means of a combined date from three radiocarbon charcoal dates to Bronze Age Period I (1610-1530 BC). Although these houses lack remains from entrances and walls, they are comparable with the type 1 houses at Forsand, because of their wide trestles and their large size $\left(180 \mathrm{~m}^{2}\right.$ roofed area), and may be regarded as houses belonging to the same building tradition as the houses from Forsand and Austbø.

From Sandved, Skeiane, in Sandnes municipality, a house with 4-4.3 m wide trestles may be of type 1 (Berntsen \& Pilskog 1998). The house consists of six trestles and the rows of roof-bearing posts are slightly convex. The roof-bearing structure measured $10.7 \mathrm{~m}$, so the total length of the house was likely $15 \mathrm{~m}$, and the width, given side aisle widths of 1.5-1.7 m, was slightly less than $8 \mathrm{~m}$. The two western bays measure $2.6-2.8 \mathrm{~m}$, while the other three measure $1.6-1.9 \mathrm{~m}$. A probable interpretation is that the house was a small type 1 house, comparable in size to the type 2 house 90 at Forsand, with a dwelling area in the western part, a narrow entrance room in the middle and a possible byre with space for eight cattle in the eastern half. The charred macrofossils from three postholes add nothing to such an interpretation (Sandvik 1999:5f). A ${ }^{14} \mathrm{C}$ sample of a charred grain from a posthole dates the house to Bronze Age Period II, 1520-1420 BC.

In the southern part of Rogaland, at Tengesdal, in the municipality of Bjerkreim, another type 1 house was found in 2015 (Reiersen 2015). The house consists of eight trestles and had straight rows of roof-bearing posts with a $3 \mathrm{~m}$ trestle width. The roof-bearing structure measured $17.6 \mathrm{~m}$, so the total length of the house was likely $21-22 \mathrm{~m}$. Two central bays measure $4.3-4.5$ $\mathrm{m}$, while four other bays measure $1.5-2.1 \mathrm{~m}$. The house was probably a somewhat narrow type 1 house with a dwelling area with a wide entrance room in the southern end. A pit with charred grains was found near the 
southern gable wall, reminiscent of similar finds in houses 32B, 59 and 90 at Forsand and, based on the distribution of charred grains in the southern part of the house, this area can be interpreted as a dwelling area. The northern end is interpreted as a byre area because of the narrow distances between the trestles, together with an entrance and finds of seeds from the meadows found in the postholes. Based on Persicaria (knotweeds) seeds from one posthole, the central section of the house has been interpreted as a barn where the grain crop was stored (Reiersen 2015:65f). Five radiocarbon dates show that the house can be dated to 1380-1310 BC.

Similar houses have also been found in different parts of the Jutland peninsula in Denmark. The custom of erecting a three-aisled building can be traced back to the transition to Bronze Age Period I in Southern Jutland (Ethelberg 2000:174, house II), but is more commonly found in Bronze Age Period II, where several Høggård houses (I, II, XIV, XXVII) (Ethelberg 2000:175ff) and the Trappendal house in Southern Jutland (Boysen \& Andersen 1983) are good examples. Most of these houses are similar in size to the two Norwegian house types, although some were more than $30 \mathrm{~m}$ in length. Højgård, house XXXI has interior walls showing an even longer house (51 m), which was divided into four rooms. At Brd. Gram (Ethelberg 2000:191f), there were three 30-50 m similarly divided houses also dated to Bronze Age Period II and the beginning of Bronze Age Period III.

Further to the north, there are two similar houses (II, V) dated to the middle of Bronze Age Period II, found at Hemmed in Djursland (Boas 1991). From the Limfjord area, two houses (III, IX) were excavated at Legård (Mikkelsen 2012:54f) and another at Bjerre, which were also dated to Broze Age Period II (Beck 2003). All these houses were divided into three sections of almost equal size, where the middle part often consisted of traces of a byre. The frequent occurrance of clusters of cooking pits in the gable rooms, as in Southern Jutland, have led to an interpretation of the houses as being built for two households (Kristiansen 1999, Mikkelsen 2012). This shows that the tradition of building three-aisled houses had rapidly expanded to the northern tip of Jutland, and the material from Rogaland also shows that this tradition crossed the North Sea to Rogaland at least in the middle of Bronze Age Period II, according to the combined ${ }^{14} \mathrm{C}$ dates from Forsand. The combined date from the houses at Kleppe suggests perhaps that this already started happening in the last part of Bronze Age Period I.

The main differences between the material from Rogaland and Jutland is that the Forsand, Austbø, Kleppe and
Tengesdal houses have sizes $(22-24 \times 7-8 \mathrm{~m})$ that are only comparable with the smaller part of the Jutlandish corpus, which in total covers house lengths between 20 and $50 \mathrm{~m}$. Most of the Jutlandish houses have walls set with larger posts and longer distances between the posts than is the case in Rogaland, although the wall traces from Trappendal are very similar to the walls from Austbø II and Forsand 32B and 59.

On the basis of the different structures and find distributions found in the type 1 houses at Forsand, it is difficult to interpret what sort of activities took place in the different sections. However, all four houses seem to have had a dwelling area in the western end, and two houses $(32 \mathrm{~B}, 59)$ also have traces of food preparation and an extra entrance in the eastern end, which indicates that there was a dwelling area in that part of the house as well. There are no certain traces from stalling cattle in these houses, but the short distances between the trestles in the central section in house 59 might represent a byre area, as is also indicated in the Tengesdal house (Reiersen 2015:65). The findings of bone fragments from sheep/goats and sheep coprolites in the middle part of the house probably mean that sheep/goats may have been kept there, at least in part of the winter, to shield them from cold or predators, or to safeguard the animals during lambing, shearing/plucking, slaughtering and mating, as Oma (2016:45) argues regarding the Bronze Age in Rogaland.

Although no certain bones have been found from cattle at Forsandmoen, this does not preclude, as Oma (2016) also points out, that the type 3 houses from the Bronze Age, such as house 45 from Bronze Age Period II, had a byre area adapted for stalling cattle. Wear depressions along the centre axis of houses from Bronze Age Periods III and IV as well as in the early and late Pre-Roman Iron Age, in addition to the lack of finds of objects, hearths, clay floors and a denser post-setting in those parts of the house, nevertheless suggest that stalled cattle were a part of the agricultural activity on the plain.

My conclusion is that the three section layout from Austbø I and Forsand 32B, 59 and 48, as well the less preserved houses from Kleppe, Sandved and Tengesdal, represents the same idea of how to build a proper home for an agricultural settlement, which was established in the southern part of Jutland at the turn of Bronze Age Period I to Period II. While the settlements in Jutland had the resources to build large houses, such as Brd. Gram IV $(50 \times 10 \mathrm{~m})$, covering $500 \mathrm{~m}^{2}$, the smaller settlements in Rogaland erected houses with a roofed area no larger than $170-180 \mathrm{~m}^{2}$. 


\section{Type 3: Dwelling/byre house with opposed, recessed entrances at the middle of the house}

The defining criterion for this type of longhouse is that two opposed and recessed entrances provide access to a narrow entrance room that is located between the middle pairs of posts. The type consists of two straight or slightly curved rows with 5-11 pairs of roof-bearing postholes. Depending on the number of pairs, the length of the roof-bearing structure is $6.5-19.7 \mathrm{~m}$. The distance between the posts in a pair at the middle of the house is $1.8-3 \mathrm{~m}$. The door width is $0.9-1.4 \mathrm{~m}$ (mean $1.2 \mathrm{~m}$ ) both in the northern and southern wall. The walls consist of small, rounded posts placed with a mean distance between 0.6 and $1.1 \mathrm{~m}$. The longitudinal walls are slightly curved, $0.1-0.3 \mathrm{~m}$ between the middle of the house and the outermost pair of roof-bearing posts. The gables are semi-circular or straight with rounded corners. The width of the houses is $5.8-6.8 \mathrm{~m}$ (mean $6.5 \mathrm{~m}$ ), and the TQ of this type is $2.2-2.8$ (mean 2.5).

The type can be divided into three sub-groups according to the number of pairs of posts:

- Type 3.1: Main type with 6 pairs of posts (15 houses)

- Type 3.2: Short type with 5 pairs of posts (7 houses)

- Type 3.3: Long type with 7-11 pairs of posts (10 houses)

In addition, six type 3 houses are not entirely excavated and can therefore not be determined to any subgroup. Originally, this group was divided into type 3 and type 4 , based on the amount of circular or oval roof-bearing postholes in the different house. However, further analysis showed that the percentage of the two shapes in the houses only differed through time, increasing from most circular in the Early Bronze Age to most oval in the Roman Iron Age. So, now it is considered only one type.

Fig. 19 and 20 shows a collection of the different subtypes dated to all the prehistoric periods when such houses were built.

In total, the type consists of 38 houses divided into three subtypes, 3.1-3.3. Six houses are classified as uncertain type 3.1 , because they are only partly unearthed due to the excavation trench system. The

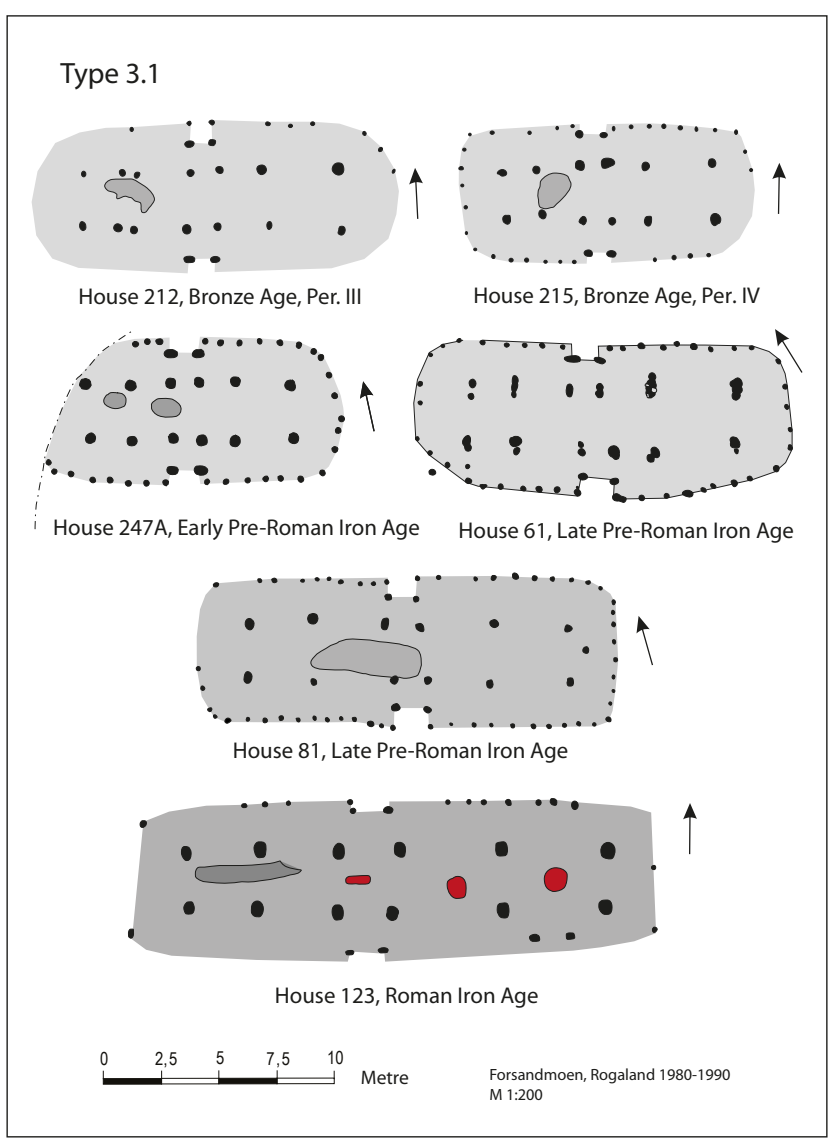

Fig. 19. House plans of a selection of the type 3.1 houses.

three subtypes will be analysed separately and compared, and the partly excavated houses will also be considered when they have features that may contribute to the analyses. All different features, such as orientation, wall post distance, etc., will primarily be analysed in each subtype and compared with the other subtypes. Thereafter the houses of the three subtypes will be analysed as a whole and compared to the other subtypes. The development of the house type will be analysed according to five chronological periods: Early, Middle and Late Bronze Age, early and late Pre-Roman Iron Age and Roman Iron Age (see p. 6).

Features that will be analysed are orientation, length of roof-bearing construction, house width, trestle width and curvature, TQ, wall post distances, shape of the gables, the location pattern of the trestles, entrance 


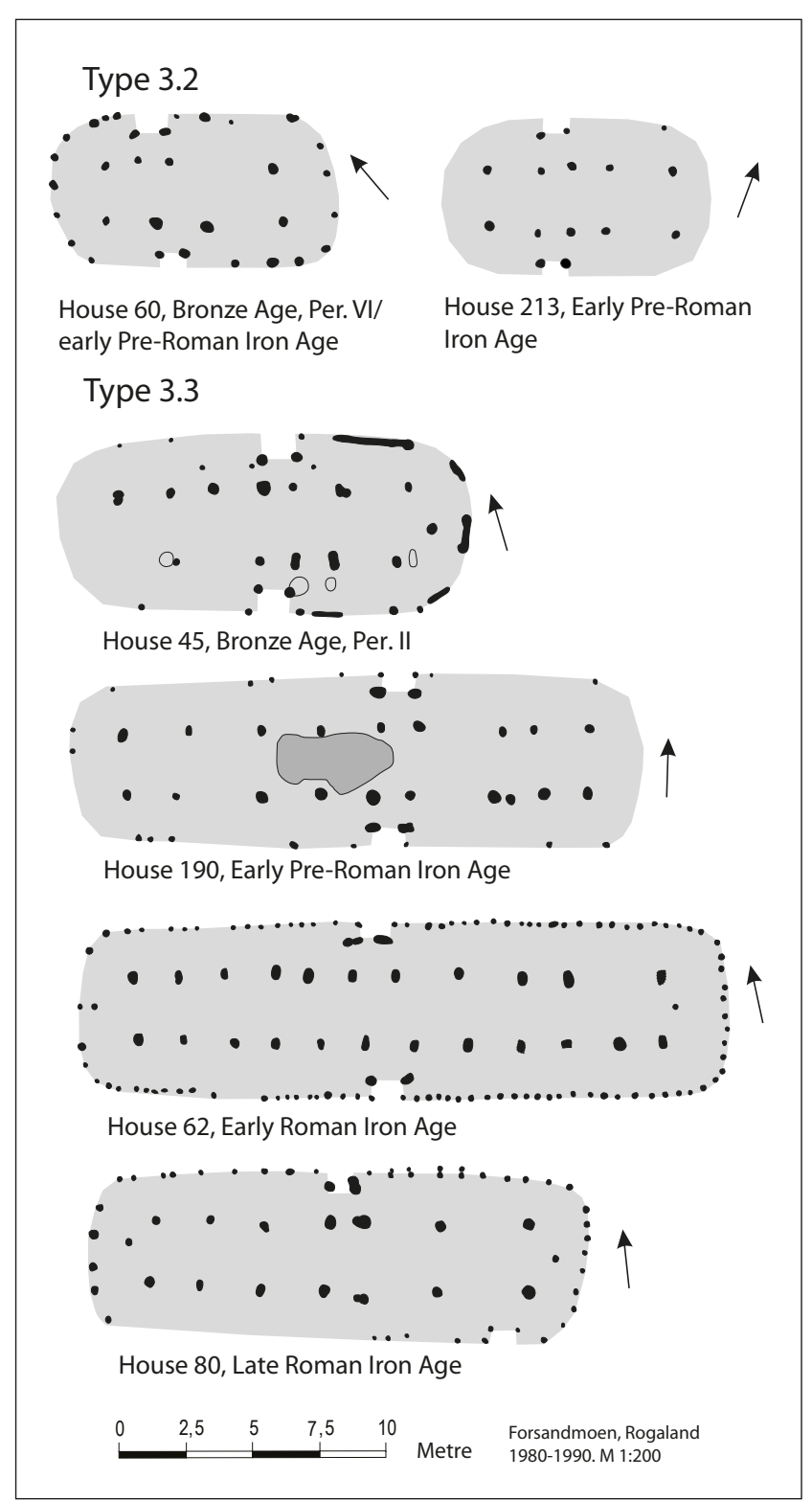

Fig. 20. House plans of a selection of the type 3.2-3.3 houses.

width and recess from the main wall. Also shape and size/depth of the postholes, the shape and size of the posts (both the roof-bearing and the entrance posts) and the date of the houses will be investigated.

\subsection{The distribution of type 3 houses and their orientation}

Fig. 21 shows how the different subtypes are distributed throughout the excavated settlement area. Type 3 houses do not occur in the south-east, Area B, and the southernmost part of the western excavation areas, Area E, that were mainly settled in the Roman Iron Age and Migration Period. Only three out of ten type 3.1.1 are situated outside the north-east settlement area, Area A and C. In contrast, three out of four of the larger type 3.1.2 are located in the western part of Area E. The types "probable 3.1", 3.2 and 3.3 are nearly evenly distributed except in the southern and eastern parts of Area E and Area B. In Area E, eight out of ten type 3 houses are large type 3.1.2 and 3.3 houses. On the other hand, most of the small type 3.1.1 and 3.2 houses are situated at north-east Areas A and C. One conclusion we can draw is that the smaller houses type 3.1.1 and 3.2 are mainly located in the north-east area and the northernmost part of the western area. The larger houses 3.1.2 and 3.3 are nearly exclusively located in the central western part and quite densely clustered in the western part of the north-east area. However, since this northern $250 \times 70 \mathrm{~m}$ part was settled through more than 2000 years, one cannot infer that these houses represent a clustered habitation during the period when the type 3 houses were built. The much more spacious type 3 pattern in the western area can more likely be interpreted as one or more farms shifting their location when new farmhouses had to be erected.

Fig. 22 shows how the type 3 houses are distributed during the main settlement periods. The houses from each of the four periods are quite dispersed and cannot support any other conclusion than the following: the settlement consisted of individually situated farmsteads. The only exception might be in the western end of the north-east area. Area A, where the late PreRoman Iron Age houses 61 and 81 are situated $30 \mathrm{~m}$ apart. They have the same ${ }^{14} \mathrm{C}$ date $(170 \mathrm{BC}-\mathrm{AD} 60$ and $170 \mathrm{BC}-\mathrm{AD} 30$, respectively) makes it likely that the two houses were contemporary. House 89 immediately to the west of house 81 is older ( $340 \mathrm{BC}-\mathrm{AD} 1$ ) than these two, and they are followed in the same area by a similar pattern since the two houses 80 and 82 both are dated to $40 \mathrm{BC}-\mathrm{AD} 330$ and $\mathrm{AD} 1-340$. These dates offer the possibility that the two houses are not contemporary and, between the two late Pre-Roman Iron Age houses and the two from early the Roman Iron Age, house 62, $50 \mathrm{BC}-\mathrm{AD} 140$. In conclusion, it is possible to interpret the settlement pattern here as consisting of six type 3.1/3.3 houses following in a sequence from $300 \mathrm{BC}$ to AD 300 with an agglomerated settlement of two farms in two phases around AD 1.

In the central part of the western area, Area E, two large houses (13: type 3.1.2, 12: type 3.3), situated partly on top of each other, are dated to the late Roman Iron Age (AD 210-430 and AD 220-390, respectively). Given that the two houses succeeded each other, which is considered very likely, is it possible to observe how the inhabitants of a farm changed the layout of a house when a new farmhouse was erected. Table 5 (folder) 
shows that, apart from the westernmost trestle span, all spans in house 12, including the entrance room, are narrow $(1.8-2.1 \mathrm{~m})$, while in house 13 they are, including the entrance room, between 2.5 and $3.5 \mathrm{~m}$ wide. Since such wide entrance rooms only occur in the Roman Iron Age, I find it possible that house 13 is the youngest. A hearth located centrally in the entrance room indicates a new function compared to other type 3 houses that lack such a hearth. If so, the younger house has reduced the habitable area both in the dwelling area as well as in the byre. The space of the entrance room is doubled, which is reminiscent of the large entrance rooms in the contemporary type 9 houses. The byre is estimated to have been reduced by four stall boxes, from 16 to 12 (Table 5, folder). Interestingly, both houses have the dwelling area in west; together with the unusual organisation, this supports that there was continuity between the two houses, maybe even with the same inhabitants.

In the northernmost part of the western area, Area D, four Bronze Age and two early Pre-Roman Iron Age houses are situated within a $50 \times 30 \mathrm{~m}$ area. They are all ${ }^{14} \mathrm{C}$ dated between Bronze Age Periods III/IV (1260-900 $\mathrm{BC})$ and the early Pre-Roman Iron Age (400-200 BC (two houses). Three other houses are dated to 920-520 BC, 760-390 BC and 800-200 BC. Bearing in mind that these quite similar results are caused by the plateaus in the calibration curve at 800-400 and 400-200 $\mathrm{BC}$ ) it is, however, likely that none of the houses were contemporaneous. The interpretation of this partly excavated settlement area is therefore that a farm was probably located here between 1100/1000-400/300 BC. During this period, three different type 3 houses were built: in the earliest phase, small houses of type 3.1.1 and 3.2 were built, while the younger houses 38 and 219, which are not totally excavated, must have been larger, probably type 3.1.2 and/or 3.3.

As can be seen in Table 5 (folder) - the mean orientation of the three subtypes and the uncertain houses is nearly similar, between $306^{\circ}$ and $310^{\circ}$ north of due west. Only nine of the 38 houses have an orientation that differs more than $\pm 20^{\circ}$ from the mean orientation and Fig. 23 shows that the orientation is distributed as a Gaussian curve around $310^{\circ}\left(400^{\circ}\right.$ system). The figures illustrate that there was a strong expectation in society that these types of dwellings should have an E-W orientation. Whether this was due to purely functional or symbolic reasons is unclear. Since two of the houses (55A and 60) were situated along the protruding rock Odda and were probably oriented parallel to the base of the rock, there are only two houses on the plain that have a diverging orientation. All these four houses are dated to Bronze Age Period VI or the Pre-Roman Iron Age, as most of the other type 3 houses. Table 6 shows that the mean orientation within five phases from the Early Bronze Age to the Roman Iron Age is nearly the same at around $310^{\circ}$, differing $\pm 5^{\circ}$. This signifies that the same conditions existed through nearly 2000 years, resulting in the construction of type 3 houses with a preferred $310^{\circ}$ orientation, visualised in Fig. 24. A similar orientation is demonstrated in Bronze Age houses at Fosie IV as well as in 110 Bronze Age houses from Scania and Denmark (Björhem \& Säfvestad 1993:113115). Björhem and Säfvestad interpret this orientation as indicating that the house direction was based on the sunset between vernal and autumn equinox, when the houses were most likely built. It is also the case that in the Early Iron Age, houses are oriented in a more westerly direction. At Forsand, Fig. 22 shows that houses with a WNW orientation are located in Area A, while houses in Areas C, D and E are oriented towards W. Houses from all four settlement periods occur in Area $\mathrm{A}$ as well as the western areas $\mathrm{D} / \mathrm{E}$, so the difference between the two areas is not caused by a change in orientation through time. It is therefore possible to put forward a different explanation for the orientation than that presented by Björhem and Säfvestad. The NE area is sheltered from the cold eastern and north-west winds by a protruding rock to the east and north-east and the steep hills of the Berge mountain to the north and north-west (M. Nitter, personal communication 2009). Therefore, a functionalistic explanation could be that the houses were given a WNW orientation in order to catch as much heat as possible from the sun in the winter. On the other hand, there are the houses in the western area, which are exposed to the prevailing easterly and westerly winds. Thus, the best orientation is parallel to these directions. In addition, those houses are located near to the steep mountain Uburen located to the south of the settlement. Here, the sun is absent for several months during the winter (Wishman 1990). There would be no need for a WNW orientation here. It is worth mentioning here that the same orientation pattern is found in the analysis of the Roman Iron Age and Migration Period type 9 and 10 houses (see chapter 10 and 11).

\subsection{Analysis of house features}

The size of the houses differs somewhat within each subtype and between the subtypes since the number of trestles in the houses is a main classification criterion. 


\section{Forsandmoen, Forsand municipality Map of settlement area}

$\subset$ House feature with preserved wall remains House feature without wall remains

$\square$ Type 3.1.1.

$\square$ Probable type 3.1.

$\square$ Type 3.1.2.

$\square$ Type 3.2.

Gravemound / cairn $\square$ Type 3.3.

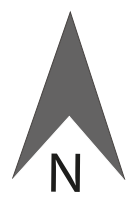

$\bigcirc \quad$ Excavated gravemound / cairn
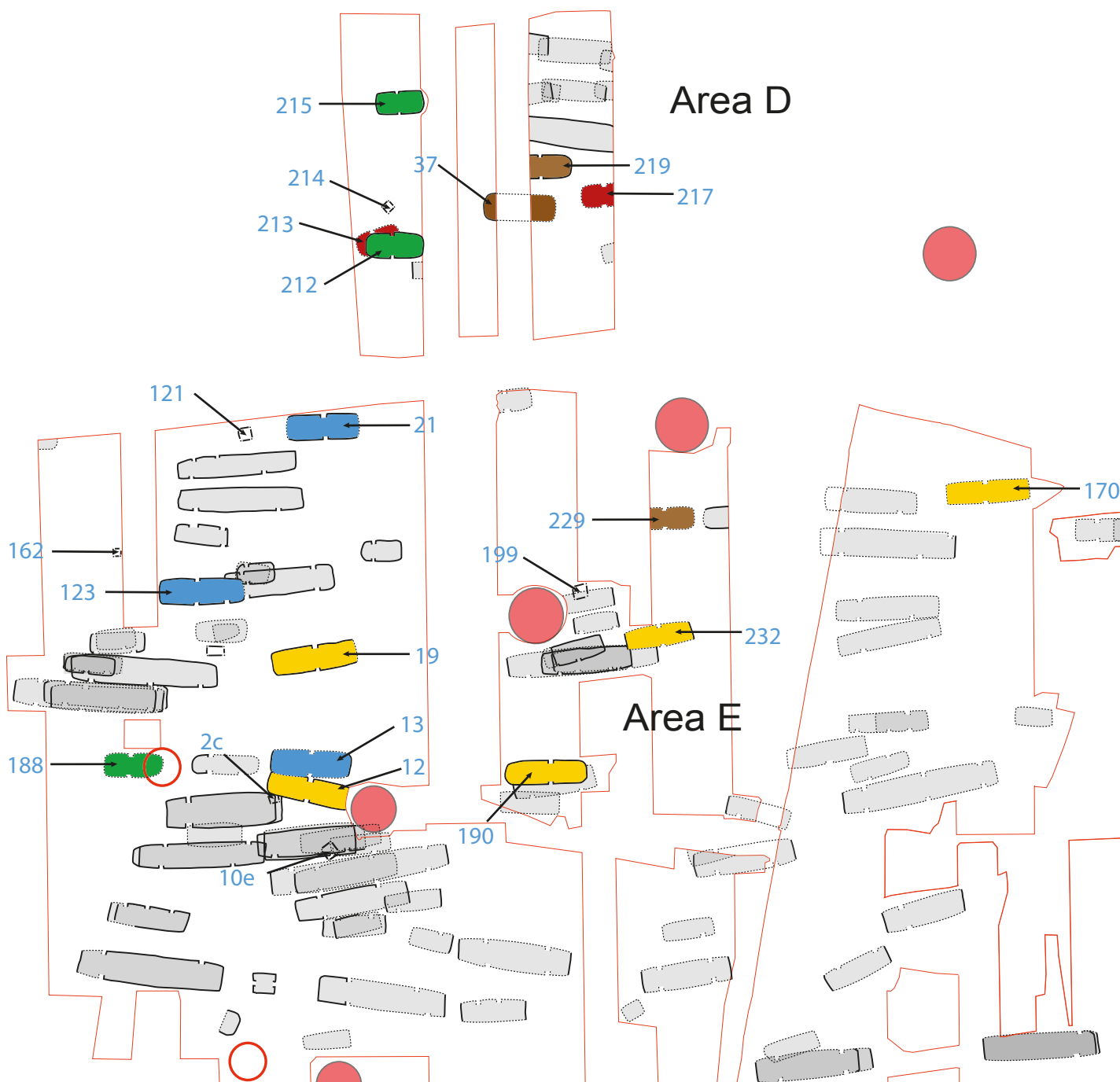

$\bigcirc$
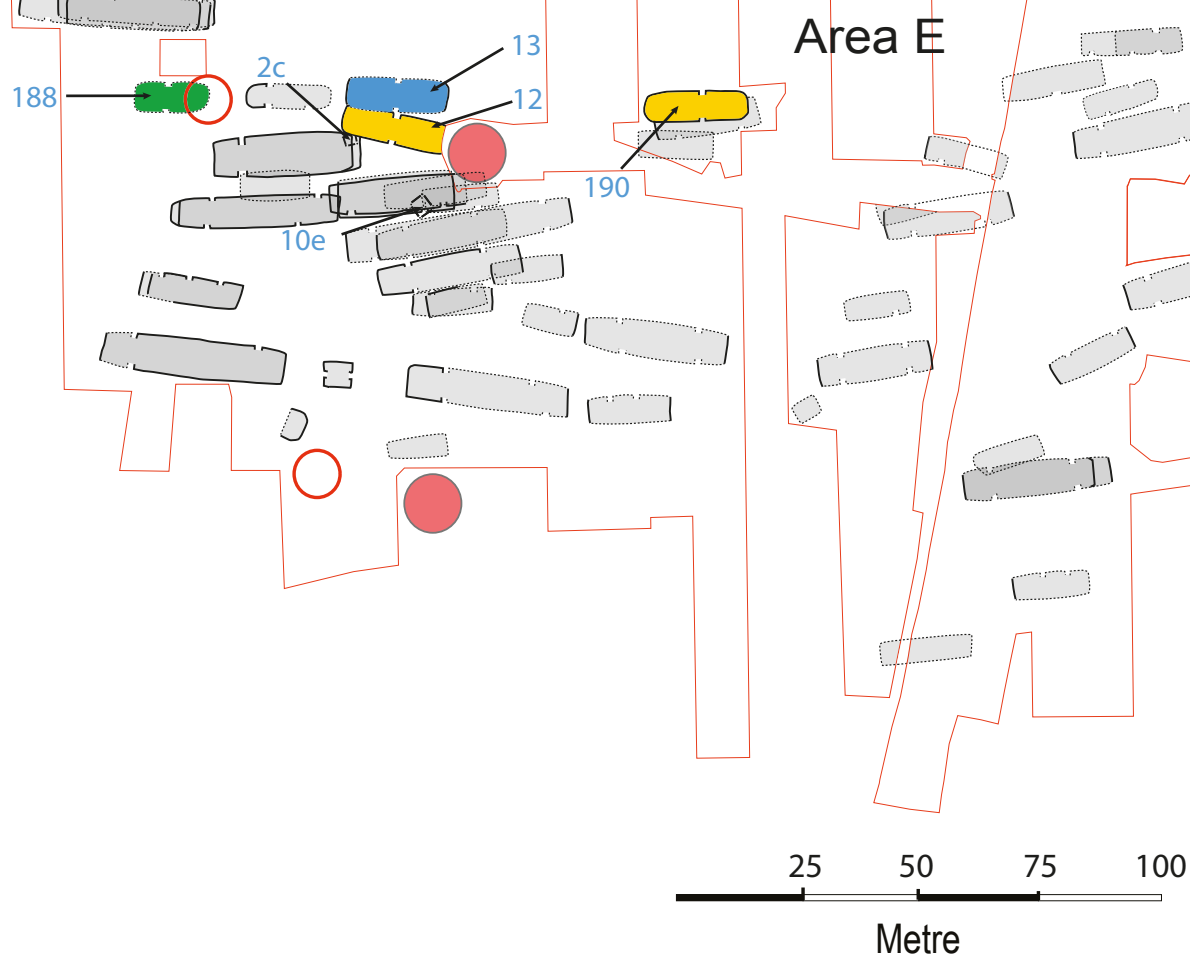


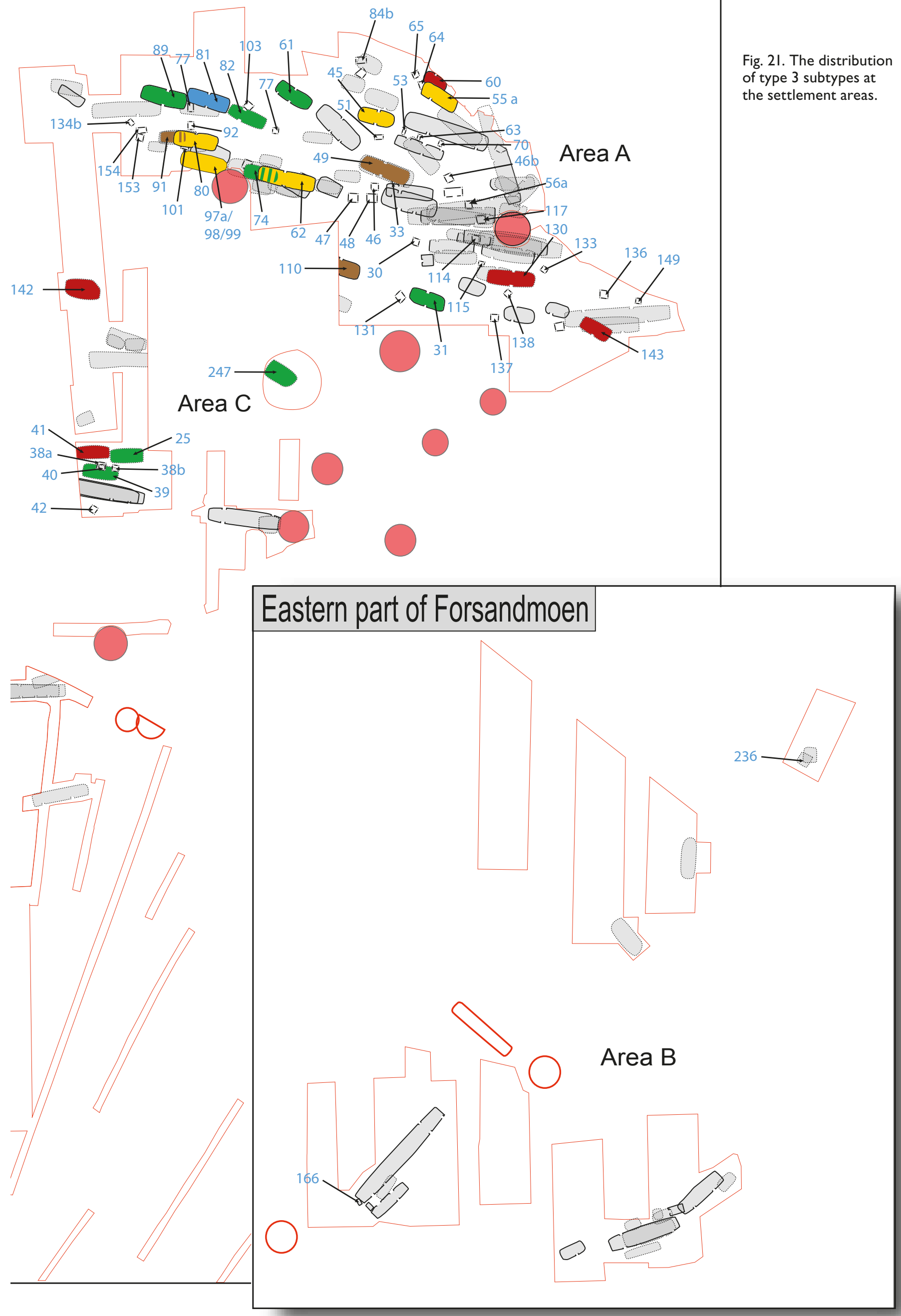




\section{Forsandmoen, Forsand municipality Map of settlement area}

Type 3 houses:

$\square$ Bronze Age II-V

a PRIA

$\square$ Bronze Age VI

$\square$ ERIA

¿ LRIA

$C$ House feature with preserved wall remains House feature without wall remains

Gravemound / cairn

Excavated gravemound / cairn

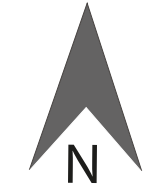

TGB/TL 2009/2014
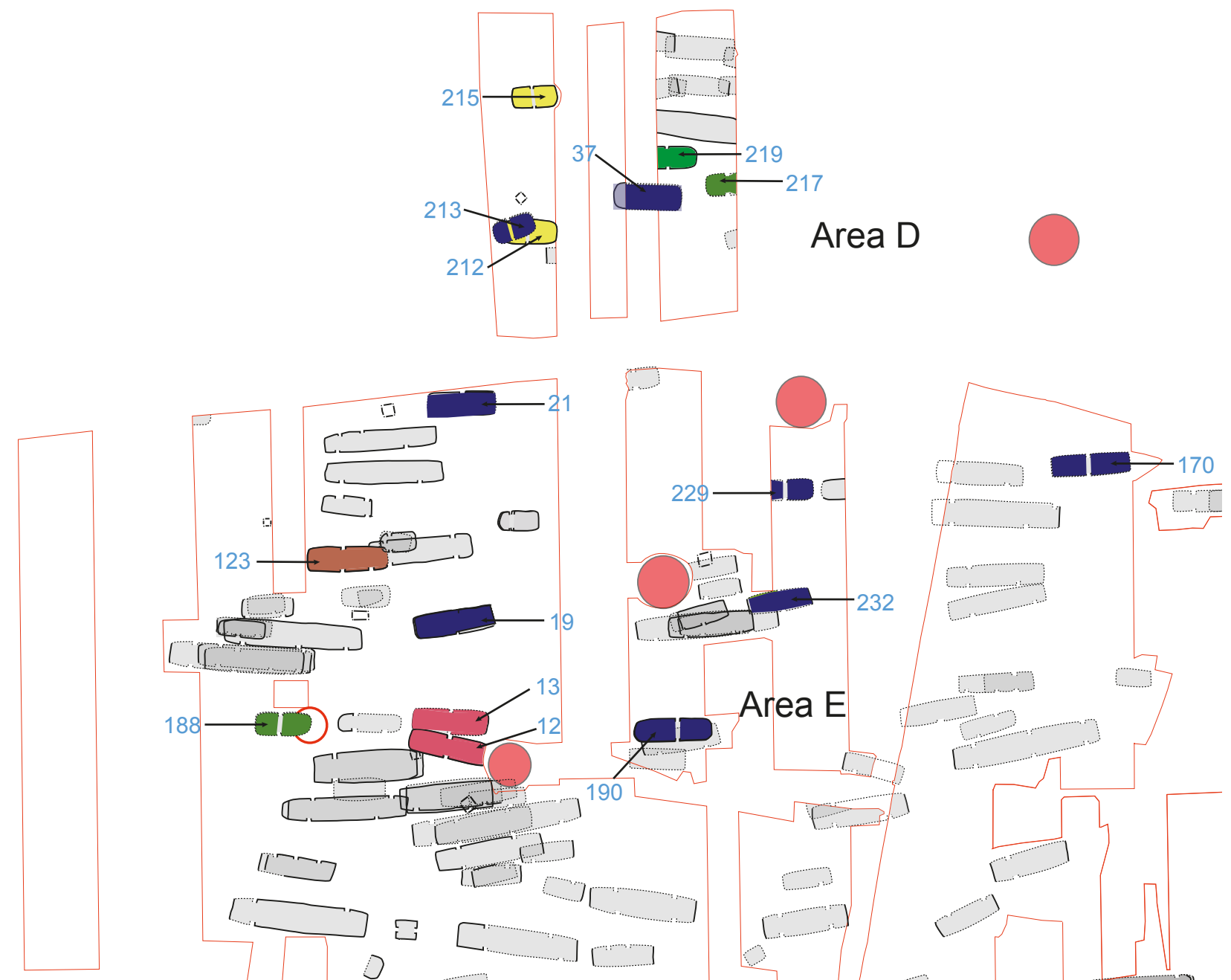

$\bigcirc$

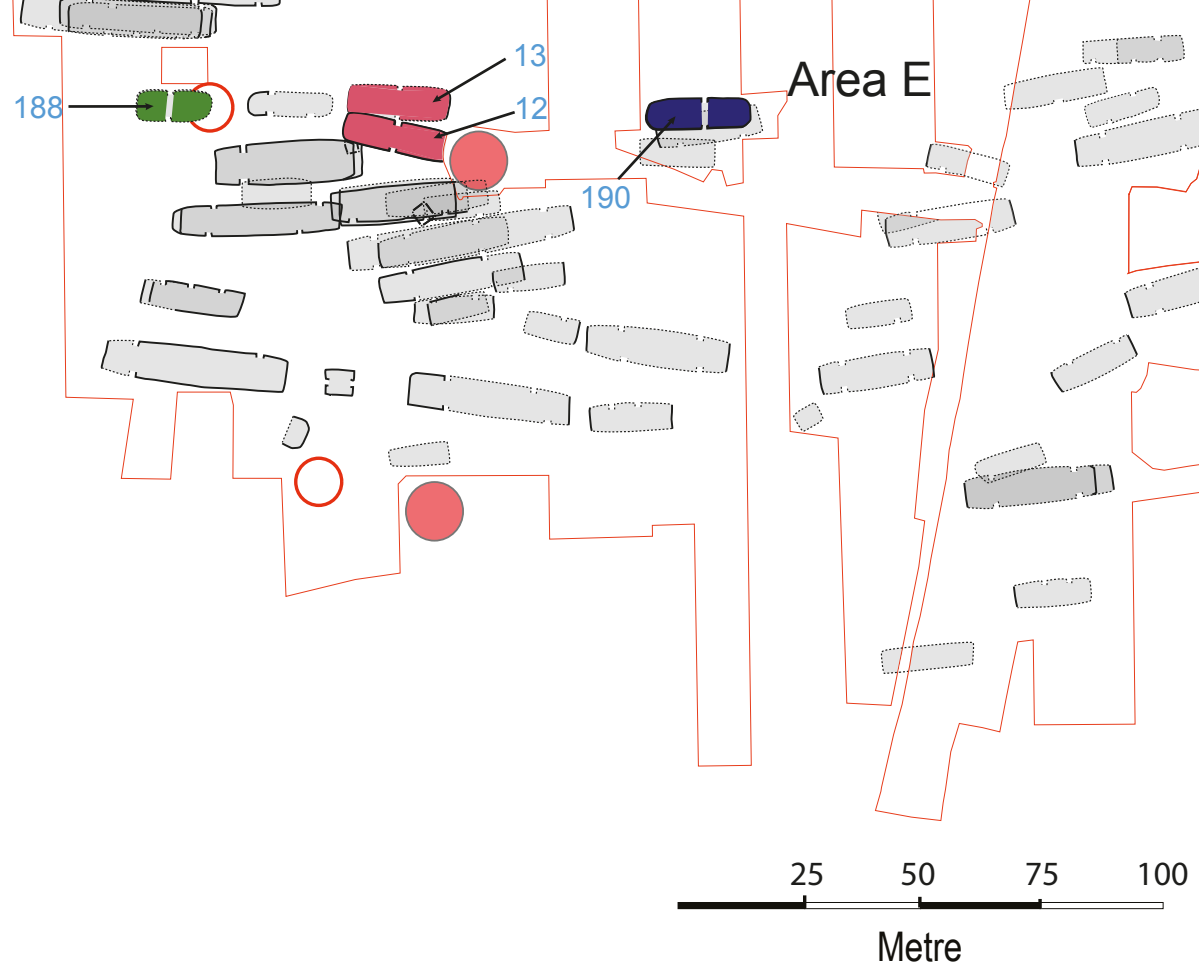




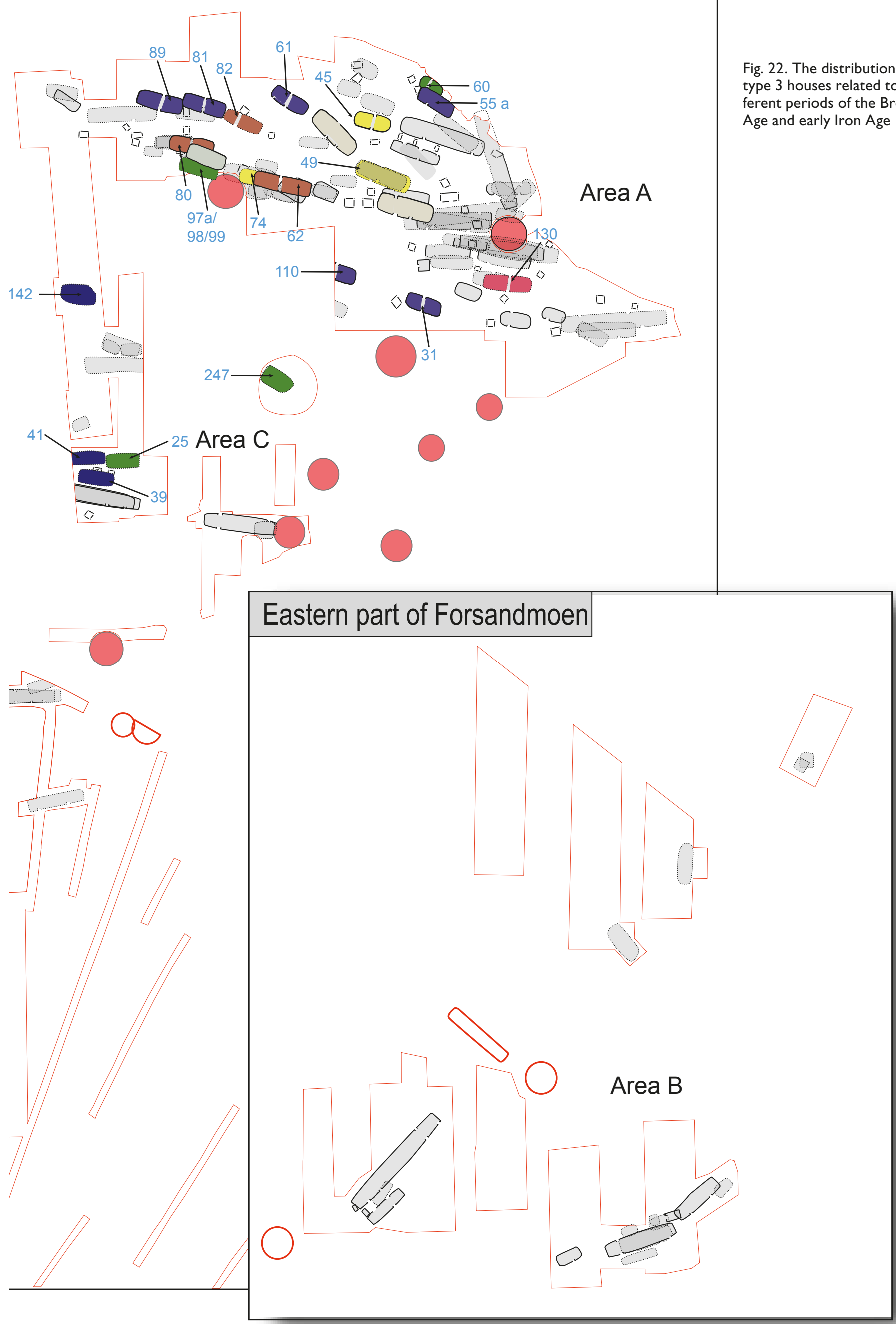


Table 6. The average orientation of type 3 houses in five time-periods and in total.

\begin{tabular}{|c|c|c|}
\hline \multicolumn{3}{|c|}{ Forsand, type 3 houses: orientation according to age } \\
\hline Age BC-AD & Number of houses & Mean orientation \\
\hline $1500-900$ & 2 & 311 \\
\hline $900-500$ & 7 & 310 \\
\hline $500-200$ & 10 & 304 \\
\hline $200-1$ & 6 & 309 \\
\hline I-400 & 7 & 312 \\
\hline Not dated & 6 & 315 \\
\hline Total & 38 & 310 \\
\hline
\end{tabular}

Table 7. The variation in length and the average length of the different type 3 houses. Measurements in metres (m).

\begin{tabular}{|l|c|c|c|}
\cline { 2 - 4 } \multicolumn{1}{c|}{} & $\begin{array}{c}\text { Length, } \\
\mathrm{min}\end{array}$ & $\begin{array}{c}\text { Length, } \\
\mathrm{max}\end{array}$ & $\begin{array}{c}\text { Mean } \\
\text { length }\end{array}$ \\
\hline Type 3.2 & 10.3 & 13.8 & 12.8 \\
\hline Type 3.1.1 & 12.6 & 16.0 & 14.7 \\
\hline Type 3.1.2 & 18.0 & 22.4 & 19.6 \\
\hline Type 3.3 & 15.2 & 24.1 & 19.9 \\
\hline
\end{tabular}

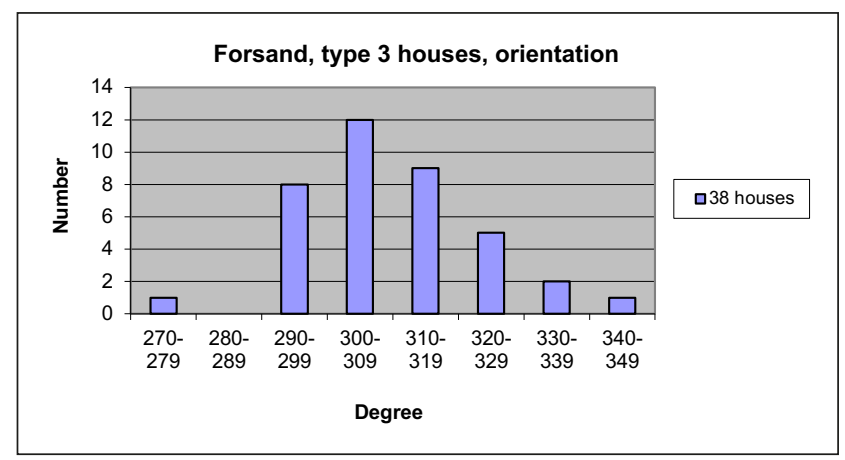

Fig. 23. The orientation of type 3 houses within $10^{\circ}$ intervals, which shows a Gaussian distribution.

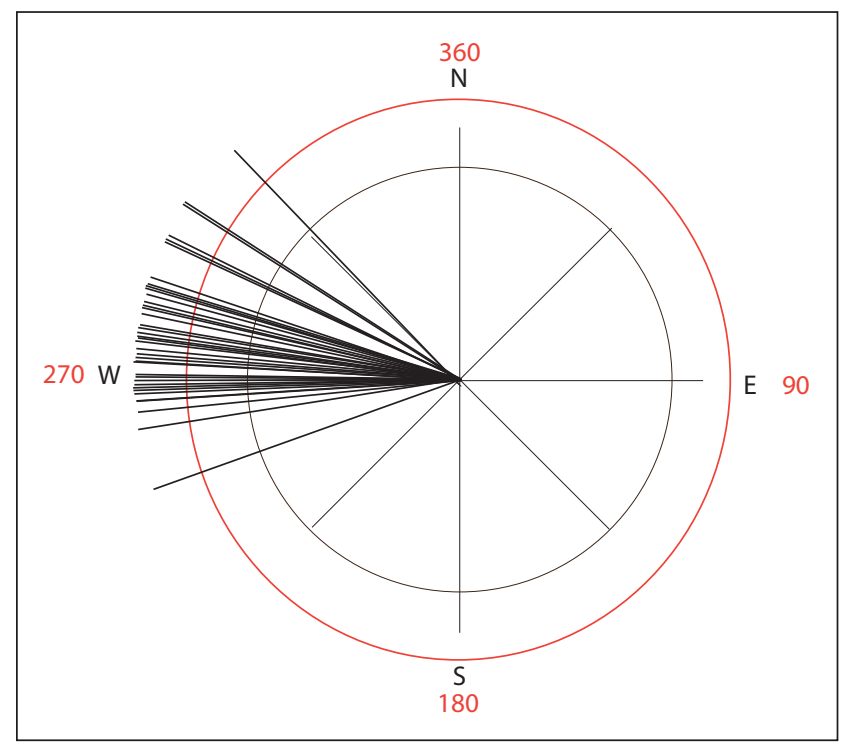

Fig. 24. Orientation of type 3 houses.

\section{Length}

The roof-bearing construction of the 15 type 3.1 houses, built with six trestles, measures between $8.8-18.2 \mathrm{~m}$ (Table 5, folder). Eleven houses (type 3.1.1), which are smaller houses and less than $11.6 \mathrm{~m}$ long, constitute the majority, while four houses (type 3.1.2) measure between 13.9-18.2 m. These longer houses have each at least two trestle spans longer than $3.3 \mathrm{~m}$, while such a length only occurs twice among other houses. The length of the four longer houses is comparable with the mean length of the type 3.3 houses, while the length of the two shortest 3.1.1 houses $(9 \mathrm{~m})$ is comparable with type 3.2 houses.

The roof-bearing construction of six type 3.2 houses, built with five trestles, measures between 6.5 and 9.7 $\mathrm{m}$, with $7.6 \mathrm{~m}$ being the average length. In addition, there is one such house that is $14.9 \mathrm{~m}$ long and built with unusually long trestle spans, comparable in length with type 3.3 houses. Only the second longest house has a length that is comparable to the type 3.1 houses.

The roof-bearing construction of ten type 3.3 houses, consisting of seven to eleven trestles, measures between 11.1 and $19.7 \mathrm{~m}$ (mean $15.7 \mathrm{~m}$ ), depending on the number of trestles. Only two houses are less than $14 \mathrm{~m}$ in length, similar to type 3.1 in length.

Among the probable type 3.1 houses, only two (49, 91/93) have been entirely unearthed. However, they lack some features to make certain identification to the type. The central part of one (37) has not been excavated. But considering the length of the roof-bearing construction (11.6-13.6 m) and six trestles in two of the houses, they seem reasonable indications suggesting that they are type 3.1 houses. Among the remaining three houses that are not entirely excavated, two $(219 ; 229)$ consist of five trestles with only two to the west of the entrance room, where the unexcavated part is situated. The last one (110) only had the eastern half excavated, including the entrances. It cannot be ruled out that these three houses belong to type 3.2 or 3.3 as well as type 3.1. Judged from the length of the unearthed five-trestle construction $(8.2 \mathrm{~m})$, the length, including one normal (approximately $2 \mathrm{~m}$ ) extra trestle span would result in a $10.2 \mathrm{~m}$ long roof-bearing construction that is comparable with four medium sized type 3.1 houses. The house (110), only half unearthed, is obviously a well-built, large house. The eastern half measures $8.8 \mathrm{~m}$ and, as a symmetrical six-trestle house, its length will exceed the total length of type 3.1 houses. On the other hand, the sizes with either five or seven trestles will also be longer than the type 3.2 or 3.3 houses. My conclusion is therefore that the 
most frequent type 3 house at Forsandmoen is the sixtrestle house (21 houses), while other varieties are less common.

As the mean length values show (Table 7), the house length increases according to the number of trestles, but the five-trestle houses are much shorter than expected, and the difference between the six- and seven-trestle houses is smaller than expected, considering the extra trestle span. Fig. 25 shows the distribution of the length of the roof-bearing construction and the total length for the type 3 houses. The most frequent size of the post-setting is $10-12 \mathrm{~m}$, and twice as many are longer than smaller than this size. The distribution does not show a Gaussian curve, indicating that the sizes were dependent on factors other than a random size around the preferred type 3.1 house with six trestles. The total length expresses the same size distribution; only 4 metres longer than the post-setting, as the total length is a function of the additional 2-2.1 $\mathrm{m}$ distance to the gable.

Type 3 houses had more or less rounded gables marked by small posts. In 25 gables, the distance from the outmost trestle to the gable wall could be measured and, except for two distances, the remaining differed between 1.8 and $2.4 \mathrm{~m}$, with a $2.1 \mathrm{~m}$ mean value in both gables. There is no difference in this distance depending on the date of the houses. Where traces of the gables

Table 8. Development of the average type 3 houses. Length of the roof-bearing construction in five time periods.

Measurements in metres (m).

\begin{tabular}{|r|c|c|}
\hline \multicolumn{2}{|c|}{ Forsand, type 3 houses: length according to age } \\
\hline Age BC-AD & Number of houses & $\begin{array}{c}\text { Average length of post } \\
\text { setting }\end{array}$ \\
\hline $1500-900$ & 2 & 11.1 \\
\hline $900-500$ & 7 & 10.3 \\
\hline $500-200$ & 9 & 11.7 \\
\hline $200-1$ & 6 & 14.0 \\
\hline $1-400$ & 6 & 15.8 \\
\hline Not dated & 6 & 10.3 \\
\hline
\end{tabular}

Table 9. Average house width, trestle width and TQ for the different type 3 house subtypes. Measurements in metres (m).

\begin{tabular}{|r|c|c|c|c|}
\multicolumn{1}{|l|}{ House type } & Total width & $\begin{array}{c}\text { Min. trestle } \\
\text { width }\end{array}$ & $\begin{array}{c}\text { Max trestle } \\
\text { width }\end{array}$ & TQ \\
\hline 3.2 & 5.8 & 2.2 & 2.5 & 2.3 \\
\hline 3.1 .1 & 6.0 & 2.1 & 2.5 & 2.5 \\
\hline Probably 3.1 & 6.4 & 2.5 & 2.8 & 2.3 \\
\hline 3.3 & 6.4 & 2.3 & 2.6 & 2.5 \\
\hline 3.1 .2 & 6.6 & 2.4 & 2.7 & 2.5 \\
\hline
\end{tabular}

have not survived, the total house length can safely be calculated with an additional $4.2 \mathrm{~m}$ to the length of the roof-bearing construction. One late Roman Iron Age house (13) had a different gable construction, which is normal in the house types 9 and 10: two corner posts set at a $4.2 \mathrm{~m}$ distance between each other and $2.7 \mathrm{~m}$ from the easternmost trestle.

The length of the type 3.2 houses then differs from 10.3 to $13.8 \mathrm{~m}$ (mean $12.8 \mathrm{~m}$ ) via the type 3.1.1 houses that measure from 12.6 to $16 \mathrm{~m}$ (mean $14.7 \mathrm{~m}$ ), the type 3.1.2 houses measuring from 18 to $22.4 \mathrm{~m}$ (mean 19.6 $\mathrm{m}$ ) and the type 3.3 houses at 15.2 to $24.1 \mathrm{~m}$ (mean 19.9 $\mathrm{m})$.

In seven of the houses $(37,45,61,80,81,110,241 / 242)$, there is an additional post in the central axis, either near one or - in three instances - near both gables. They are located $0.5-1.5 \mathrm{~m}$ outside the outmost trestle and at a distance of $0.6-1.8 \mathrm{~m}$ to the gable wall. Because these postholes are observed in less than $20 \%$ of the houses, the posts probably did not serve a crucial function in the construction of this house type. Nevertheless, the most probable function must have been related to the attachment between the roof, the roof-bearing construction and the walls.

Table 8 shows that the mean length of the roof-bearing construction increases by $60 \%$ from a minimum in the Late Bronze Age Periods V-VI to the Roman Iron

Table 10. The average TQ value during the settlement period. Measurements in metres $(\mathrm{m})$.

\begin{tabular}{|l|c|c|}
\hline Period & Number of houses & TQ \\
\hline Early Bronze Age & 2 & 2.55 \\
\hline Late Bronze Age & 2 & 2.40 \\
\hline Early Pre-Roman Iron Age & 9 & 2.40 \\
\hline Late Pre-Roman Iron Age & 5 & 2.60 \\
\hline Roman Iron Age & 4 & 2.30 \\
\hline
\end{tabular}

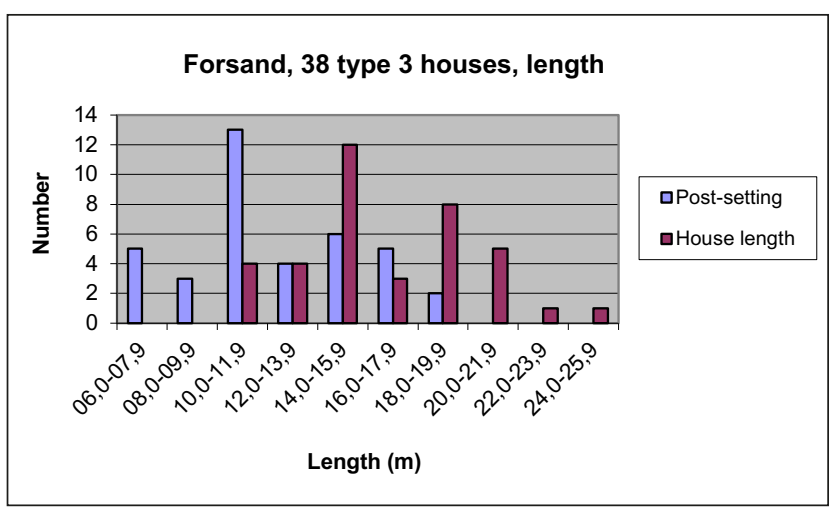

Fig. 25. The length distribution of the roof-bearing construction compared with the total house length of type 3 houses. 
Table II. Four periods of average feature values of type 3 houses. Measurements in metres $(\mathrm{m})$. Estimated measurements in italics.

\begin{tabular}{|c|c|c|c|c|c|c|c|c|c|c|c|c|c|c|c|}
\hline \multirow[t]{2}{*}{ Period } & \multirow{2}{*}{ 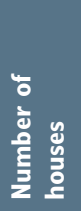 } & \multirow{2}{*}{ 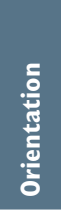 } & \multirow{2}{*}{ 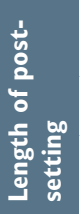 } & \multirow{2}{*}{ 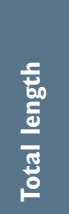 } & \multirow[b]{2}{*}{$\frac{5}{5}$} & \multirow{2}{*}{ 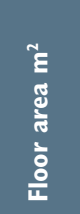 } & \multirow{2}{*}{ 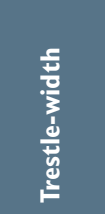 } & \multirow[b]{2}{*}{$\stackrel{\circ}{\circ}$} & \multicolumn{2}{|c|}{ 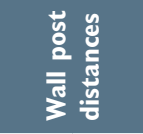 } & \multicolumn{5}{|c|}{ Distances between trestles } \\
\hline & & & & & & & & & N & $\mathbf{S}$ & $6-5$ & $5-4$ & 4-3 & $3-2$ & $2-1$ \\
\hline Mean, Bronze Age & 9 & 310 & 10.5 & 14.6 & 6.0 & 88.1 & $2.1-2.5$ & 2.4 & 0.9 & 1.0 & & & 2.1 & 2.2 & 2.2 \\
\hline Mean, early Pre-Roman Iron Age & 10 & 304 & 11.7 & 16.0 & 6.2 & 96.9 & $2.3-2.6$ & 2.4 & 0.8 & 0.8 & & 2.1 & 2.5 & 1.7 & 2.0 \\
\hline Mean, late Pre-Roman Iron Age & 6 & 309 & 14.0 & 18.3 & 6.5 & 117.4 & $2.3-2.6$ & 2.6 & 0.8 & 0.9 & & 1.9 & 1.8 & 2.3 & 2.7 \\
\hline Mean, Roman Iron Age & 7 & 312 & 15.8 & 20.1 & 6.3 & 124.0 & $2.4-2.7$ & 2.3 & 0.8 & 0.6 & 1.6 & 1.9 & 2.5 & 2.6 & 2.7 \\
\hline Mean, undated & 6 & 315 & 10.3 & 14.5 & 6.2 & 91.0 & $2.3-2.7$ & 2.2 & & & & & & 1.8 & 2.4 \\
\hline
\end{tabular}

Age. The number of houses is, of course, restricted and must be treated with caution, but such a change is also seen elsewhere in southern Scandinavia. The mean length of the two Early Bronze Age houses might indicate that the house length was reduced from the Early Bronze Age to the Late Bronze Age. Such a view is well documented in Denmark and is supported by the presence of a small group (cf. type 1) of houses no more than 22 metres long - also at Forsand in the Early Bronze Age.

\section{Width}

The trestles are normally wider at the centre of the house than near the gables. Looking at the mean values from the three subtypes, the trestle widths near the gables are $2.2-2.3 \mathrm{~m}$, while at the centre, the widths are $2.5-2.6 \mathrm{~m}$, and the difference within each subtype is 0.3 $\mathrm{m}$. Only one type 3.1 house has a trestle width (1.2-1.8 $\mathrm{m})$ that is beyond normal variation, which is $2-2.6 \mathrm{~m}$ near the gables and 2.3-3 $\mathrm{m}$ at centre. The differences in trestle width between the three subtypes are not significant, but the somewhat larger differences between the subtypes 3.1.1 (2.1-2.5) and 3.1.2 (2.4-2.7), regarded in connection with the larger mean house width (6 and $6.6 \mathrm{~m}$, respectively) and the length, show that larger houses are larger in most features. However, one must conclude that the builders of the houses had the same idea of how the roof-bearing construction should look. The symmetrical and curved construction also shows that the person in charge had a fully developed concept of the building, adapted to the needed roofed space, before the house plan was marked out on the ground.
In all, sufficient remains have been preserved of the long walls of 24 of the houses to measure the total width (Table 9). Type 3.1.2 has the largest mean width (6.6 $\mathrm{m})$, while type 3.3 is somewhat narrower $(6.4 \mathrm{~m})$. The three type 3.2 houses with preserved wall traces only measured $5.9 \mathrm{~m}$ in width, while type 3.1 .1 is slightly broader $(6 \mathrm{~m})$. These differences are in accordance with the differences in the trestle width in the same subtypes, and probably express a fixed proportion of 2.5 (TQ) between the total width and the trestle width. There are, of course, some differences - between 2.1 and 2.8 in TQ - but the large majority $\left(23\right.$ of $32{ }^{14} \mathrm{C}$ dated houses) have a TQ between 2.3-2.7. A total of 23 of the houses with remains of the long walls have been dated to the Early Bronze Age Period II until the Roman Iron Age. Table 10 shows that the differences in TQ value are modest throughout this period, which does not support any other conclusion than that type 3 houses were built using the same concept, with a slightly under-balanced roof.

The consequence of the convex longitudinal walls is that the house widths at the outermost trestles are normally $0.3-0.4 \mathrm{~m}$ smaller than at the centre. The walls consist of postholes $0.10-0.20 \mathrm{~m}$ in size, set with a mean distance of 0.8-0.9 m apart. As can be seen in (Table 5, folder), the mean distance does not differ from subtype to subtype. Also, the distances in the Bronze Age are $20 \mathrm{~cm}$ longer than in the later periods. The actual mean distance in a house differs little between the two long walls and might be as little as 0.6 and up to $1.15 \mathrm{~m}$. A small content of clay in many such postholes indicates, together with the tiny posthole dimensions 
postholes were nearly universal. This is a very different pattern from the roof-bearing postholes, where $85 \%$ of the postholes in the Bronze Age and $60 \%$ in the early Pre-Roman Iron Age were circular and with 40 $\%$ circular postholes still being dug in the late PreRoman Iron Age and Roman Iron Age. The interpretation might be that, despite all the extra work required to make rectangular posts - especially before the introduction of iron in the middle of the Pre-Roman Iron Age - there was an idea that the entrance posts should be marked out as more elaborate than the rest of the roof-bearing construction. This could also have been to ensure the stability of the doorframe, since the posts, judged from the lengthwise orientation of the postholes, would have been more stable than circular posts. One must certainly not rule out the possibility that important culturally significant meanings were tied to the entrance to the domestic sphere (Eriksen 2015, Hodder 1982, Moore 1986).

The two entrances might have served different practical or symbolic functions, which could be mirrored in the shape or size of the postholes, the width of the entrance or differences between the two entrances in a house. But overall, the postholes at the two entrances are reasonably equal, considering the conditions of digging them in prehistory and excavating them in the 1980s. In seven houses, there are possibly intentional differences. The most striking example is from house 49 , where the northern entrance postholes were circular and quite large, $0.55 \mathrm{~m}$ in diameter and 0.40 $m$ deep, whereas the southern ones were oval, much smaller $(0.20 \times 0.37 \mathrm{~m})$ and only $0.10 \mathrm{~m}$ deep. In house $241 / 242$, the same differences occur, but with an even depth. An interpretation could be that the southern entrance with a decorated and superficially founded doorframe was intended for people, while the northern, wider entrance with deep founded, large circular posts served as the cattle entrance. In the other five houses, a common pattern is hard to find. One has circular postholes with different sizes in the two entrances, while the depth is equal. The other four consist partly of oval, equally large postholes where the depth differs - shallower in the north than in south in one house and the opposite in the other and two, where the northern postholes are the largest but the greatest depth is found at the northern entrance in one house and the southern entrance in the other. The conclusion that can we can draw from these seemingly random differences, and given the fact that most of the houses have two fairly identical entrances, may be that no special activities can be assigned on the basis of the archaeological data gathered on the entrances.

\section{The roof-bearing construction}

The roof-bearing post construction normally has a narrow entrance room at the centre of the house. The data described below can be found in (Table 5 , folder).

Type 3.1 can be divided into two groups. A small group of four houses (type 3.1.2) has at least two long trestle spans (3.3-4.5 m), so the total post-setting is larger than $13.9 \mathrm{~m}$. The other group (type 3.1.1, eleven houses) has in total only two trestle spans that exceed $3.3 \mathrm{~m}(3.6-3.7 \mathrm{~m})$, resulting in houses with post-settings of less than $11.5 \mathrm{~m}$. This subtype has the smallest entrance room (mean $1.3 \mathrm{~m}$ ), while the entrance rooms of the two subtypes $3.2-3.3$ are somewhat wider $(1.6-1.9 \mathrm{~m})$ and as much as $2.3 \mathrm{~m}$ in subtype 3.1.2. At each side of the entrance room in subtype 3.1.1, there are two trestles spans, which to the west measure an average of 1.9 and $2.2 \mathrm{~m}$, respectively. It is important to note that only three spans measure more than $2.3 \mathrm{~m}$, indicating a firm concept of how this part of the house should be organised. To the east of the entrance room, the first room has a size comparable with the two on the western side, while the eastern room is much larger, in mean $2.7 \mathrm{~m}$, measuring with one exception between 2.5 and $3.7 \mathrm{~m}$. Three of the houses $(25,74$, and 82$)$ have a large room adjacent to the entrance room. Thus, all these eleven type 3.1.1 houses have one large span in the eastern part of the house, while the remaining spans measure approximately $2 \mathrm{~m} \pm 0.2 \mathrm{~m}$. The full interpretation of this will be dealt with later on, but if one accepts the view often argued that the part with the larger span represents the dwelling area for people, the type 3.1.1 houses had their living quarters in the eastern part of the house. Also, five of the six probable type 3.1 houses have a large room between the two easternmost trestles, and the sixth has a large room west of the entrance room.

A small group (3.1.2) with a wide entrance room has in mean nearly equal sized trestle spans, measuring $3.2-3.4 \mathrm{~m}$ to each side of the entrance room. Two have the largest span in the western half and two in the eastern half. Two houses are dated to the late Pre-Roman Iron Age and the other two to the Roman Iron Age. In contrast to this, six of the nine dated houses in subtype 3.1.1 belong to the Bronze Age or the early Pre-Roman Iron Age. The long type 3.1 houses seem therefore to be younger than the shorter ones, even though both types exist in the late Pre-Roman Iron Age and Roman Iron Age. It is also worth mentioning here that there is 
also one type 3.2 longhouse with a $3.8 \mathrm{~m}$ wide entrance room dated to the late Roman Iron Age.

This situation is not equally clear when it comes to types 3.2 and 3.3. In 15 out of 18 houses, the entrances are located in a narrow room similar to type 3.1.1, while three houses have an entrance room measuring 2.1-3.8 $\mathrm{m}$. However, still we can conclude that a type 3 house concept included a central, quite narrow entrance room, only $1.2-1.7 \mathrm{~m}$ wide. As Table 11 shows, the mean width of the entrance room is nearly identical $(1.4-1.5 \mathrm{~m})$ in the three earliest periods, increasing to $2.3 \mathrm{~m}$ in the Roman Iron Age.

All but one of the type 3.2 houses have their widest trestle span east of the entrance room. The one with a differing pattern is not fully unearthed so, besides having had a large room to the west of the entrance room, we do not know the complete layout of the house.

Concerning type 3.3, the pattern is inconclusive. Looking at the mean size of the different trestle spans, there is not a single span that is marked out as larger than the other. However, the five houses with seven or eight trestles have their longest span in the eastern half, and four of them in the easternmost trestle span. The last one (55A) has two $1.2 \mathrm{~m}$ spans to the west and four nearly equal sized $(1.8-2.3 \mathrm{~m})$ spans to the east. The dwelling area must have been in the eastern part since there is so little room to the west. The two nine-trestle houses $(12,232)$ have one large room to the west of the entrance room, and six similar small rooms partly further to the west and partly to the east, indicating a room for human occupation in the western half. Another nine-trestle house (190) has equally large spans to each side of the entrance room, while the two houses with the most trestles (ten and twelve, respectively) do not have any especially long trestle span, which makes it hard to use the trestle layout to interpret the location of the living room. However, they both have two somewhat longer spans $(2.2-2.3 \mathrm{~m}$ ) east of the entrance room than elsewhere, probably a hint of where the living room was situated.

Based on the trestle span layout, we may conclude that 17 of 21 type 3.1-3.2 houses had the human occupation zone in the eastern half, while the opposite location was found in three cases. Two houses have the longest (and same sized) span on each side of the entrance. Also, seven of the type 3.3 houses probably had the dwelling area in the eastern part, with only two in the western part, while one is uncertain.

This pattern is also visible among the probable type 3.1 houses, as three definitely have their longest span in the east and one in the west.
In total, there can be no doubt that the trestle layout strongly indicates that the human occupation zone at Forsandmoen in the type 3 houses from the Bronze Age to the Roman Iron Age was generally in the eastern half. This is not in accordance with the accepted interpretation of this type of house in Denmark and Sweden, where the living room in most cases was situated in the western end. This will be discussed further in chapter 15 .

The trestle construction is without exception convex, with a difference in trestle width between the middle and the end of the house between 0.1 and $0.7 \mathrm{~m}$, with $0.35 \mathrm{~m}$ as the mean value. There are small mean value differences between the subtypes, but type 3.3 has many nearly straight houses as well as some of those most convex houses. The curvature does not change significantly through the settlement period, but the Bronze Age houses are the most convex.

Fig. 26 shows that both the minimum and the maximum type 3 house trestle widths are evenly distributed with 2.26 and $2.62 \mathrm{~m}$ as the mean minimum and maximum trestle width. All subtypes have houses within the normal distribution range except for the small subgroup 3.1.2, where the trestles are among the widest ones, consequently resulting in the widest houses. In mean, the probable 3.1 houses have the widest trestles ( 2.5 and $2.8 \mathrm{~m} \mathrm{~min} / \mathrm{max}$, respectively) and type 3.1.1 houses have the narrowest trestle widths ( 2.1 and $2.5 \mathrm{~m} \mathrm{~min} / \mathrm{max}$, respectively). The differences in trestle width may indicate that the house had a more or less balanced roof construction, or that the overall width of the house differs. Table 9 shows that house widths are divided into two groups: the short houses 3.2 and 3.1.1 are also narrow $(5.8-6 \mathrm{~m})$, while the long houses 3.1.2 and 3.3 are wider (6.4-6.6 m). In spite of this division, the TQ is approximately the same. In mean, all the subtypes are clearly underbalanced although there are differences in the TQ of individual houses from nearly balanced (2.1) to very under-balanced (2.8).

Fig. 27, however, shows that a group of six houses had a balanced roof, while the remaining 27 houses are distributed normally around the mean and median TQ value of 2.5. The houses with the balanced roof are not connected to one subtype, but three such houses belong to the uncertain probable 3.1 type. It is also important to note that no houses were over-balanced despite the fact that part of the material derives from the Bronze Age and early Pre-Roman Iron Age, a period when over-balanced constructions were common (Herschend 1989:84). 


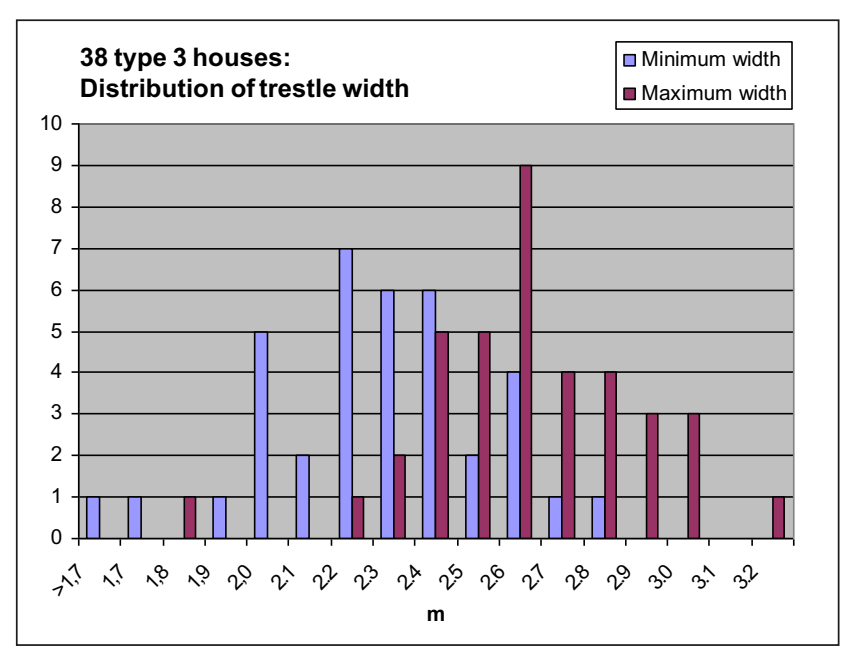

Fig. 26. Distribution minimum and maximum trestle width (metres) in type 3 houses.

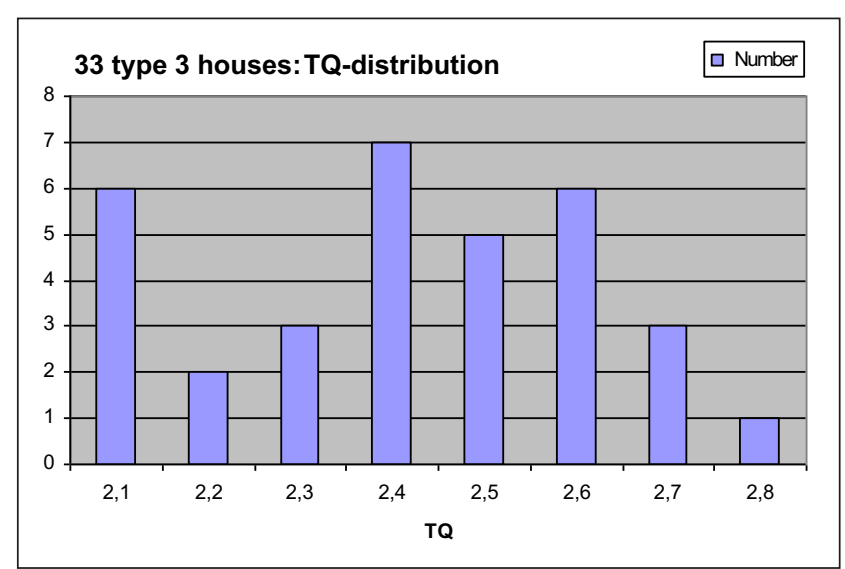

Fig. 27. Distribution of TQ values in type 3 houses.

Since a small part of this house material seems to have been deliberately built with a balanced roof it will be worth-while exploring diachronically the same features as above. Table 12 skal stå 5.8 shows that the total width increases from the Bronze Age to the late Pre-Roman Iron Age and then drops in the latest settlement period. The trestle width also increases during the settlement period, so the TQ value differs within a narrow, slightly under-balanced range.

The conclusion is that, at Forsandmoen, there is no change from over- to under-balanced roof construction in the period from the Early Bronze Age to the Roman Iron Age. The total material shows a normal distribution around TQ 2.5 (slightly under-balanced) and, in addition, there is a small group of balanced houses. During all periods at Forsandmoen, people built balanced as well as more or less under-balanced houses.

\section{The walls}

Remains of the walls are recorded in 24 houses (Table 5 , folder), but the long walls as well as the gables were
Table 12. The average house width, minimum and maximum trestle width and TQ in the four settlement periods when type 3 houses were built. Measurements in metres (m).

\begin{tabular}{|l|c|c|c|c|}
\hline $\begin{array}{l}\text { Settlement } \\
\text { period }\end{array}$ & $\begin{array}{c}\text { House } \\
\text { width }\end{array}$ & $\begin{array}{c}\text { Min. trestle } \\
\text { width }\end{array}$ & $\begin{array}{c}\text { Max trestle } \\
\text { width }\end{array}$ & TQ \\
\hline Bronze Age & 6.0 & 2.1 & 2.5 & 2.4 \\
\hline $\begin{array}{l}\text { Early Pre-Roman } \\
\text { Iron Age }\end{array}$ & 6.2 & 2.3 & 2.6 & 2.4 \\
\hline $\begin{array}{l}\text { Late Pre-Roman } \\
\text { Iron Age }\end{array}$ & 6.5 & 2.3 & 2.6 & 2.6 \\
\hline Roman Iron Age & 6.3 & 2.4 & 2.7 & 2.3 \\
\hline Not dated & 6.2 & 2.3 & 2.7 & 2.2 \\
\hline
\end{tabular}

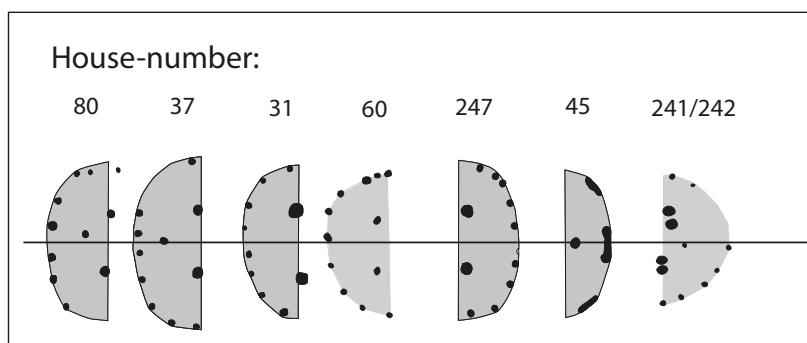

House-number:

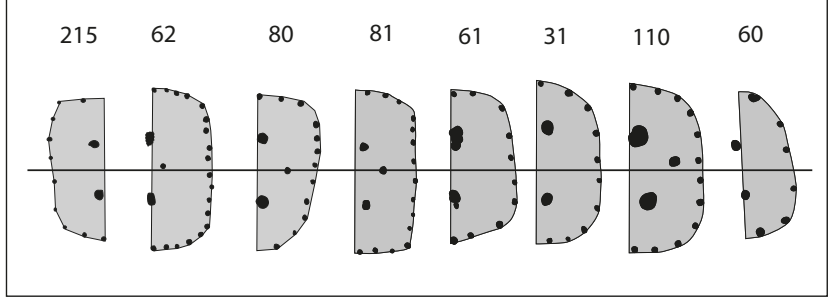

Fig. 28. I5 well-preserved gable plans with symmetrical wall post construction from type 3 houses.

well preserved only in eight houses. The long walls are, as the rows of roof-bearing posts, slightly convex, which must have been the result of a roof with a fixed incline and a curved purlin. The remains of the long wall consist of rows of small postholes. Their size differs from $10-30 \mathrm{~cm}$ in the four periods and there are no size differences between the periods. No post dimension is documented. Since the different subtypes are present in these periods, there are consequently no size differences connected to the subtypes. The posts were dug into the gravel ground to approximately the same depth, mainly $5-9 \mathrm{~cm}$, but in three houses, they are from 10 to $23 \mathrm{~cm}$ deep. Judging from these measurements, the type of walls was the same throughout the period of time that type 3 houses were built. The TQ value and the total house width do not differ much. This indicates that the roof weight from the slightly under-balanced roof was approximately constant, thus one should expect the same wall traces. However, the distance between the wall posts differs from 0.60 to 1.15 $\mathrm{m}$, indicating different solutions in the wall plate. There 
is a tendency that the widest and deepest postholes are combined with the longest post distances $(0.90-1.15)$ and the shortest distances $(0.60-0.70 \mathrm{~m})$ with the smaller postholes. The small posthole dimensions and short post distances, together with clay often recorded in the wall postholes, suggest that a wattle and daub wall interpretation is more likely than a vertical plank wall (bole wall, in Norwegian sleppverk, skiftesverk).

14 houses lack any remains from walls. Many of these are among the smallest and their small and shallow roof-bearing postholes, compared with the posthole depth of the larger houses, are probably the explanation for the lack of wall postholes. Most likely, all type 3 houses had wattle and daub walls.

The gable walls are mainly of two types: semi-circular (or nearly semi-circular) and straight with rounded corners. The two types occur in all periods except for the Roman Iron Age, where there were only two houses where the gables are straight with rounded corners. The two types can also be combined into one house. The distance from the outmost trestle to the gable differs very little and the same pattern occurs in the different subtypes. On average, this distance is $2.10 \mathrm{~m}$ to the western gable (13 measurements) and $2.15 \mathrm{~m}$ to the eastern (14 measurements). Only two measurements have a larger divergence from $2.1 \mathrm{~m}$ than $0.2 \mathrm{~m}$, indicating that $2.1 \pm 0.2 \mathrm{~m}$ was essential in the gable/roof construction. The distances from the outermost roofbearing posts to the long wall are also nearly constant and $1.8 \mathrm{~m}$ in mean. The proportion 1:1.17 $(1.8 \mathrm{~m} / 2.1 \mathrm{~m})$ between the distance to the long wall and gable must be regarded as a decisive part of the construction of the roof. Herschend (1987) has shown that the proportion 1:1 indicates a hipped roof and that the proportion 1:2 indicates a saddle roof. The solution here may be a partly hipped roof with proportions in between. The type 3 proportion is so near 1:1 that the roofs were most likely hipped. Herschend (1987) proposes that the proportion 1:1 implies a convex gable wall with rounded ( $1 / 4$ circle) corners. The fact that all type 3 houses, with one exception, have rounded corners confirms his view. One third of 21 well-preserved gables have a straight wall line between the rounded corners, while only one house (81) has nearly right-angled corners. In five houses, straight and convex wall lines are combined, while two other houses have convex gable walls at either end. However, most curved walls are so slightly curved that it is difficult to regard them as another type of wall than straight.

Looking in more detail at the gable walls, it is apparent that they were often constructed according to a fixed plan. In fifteen gable walls (Fig. 28), the posts were arranged symmetrically around the central axis of the house. Many of them have a curved line consisting of six wall posts inside the rounded corners. House 81 had nine posts, including the corner posts. Since seven out of ten well-preserved symmetrical gable walls were built with six posts, this suggests that this was the preferred way of constructing the gable. This amount of posts must have been sufficient to construct a stable wattle and daub curved gable wall. The straight wall (81) with a more dense post pattern might, due to the lack of strength that the curved shape would provide, need more posts in the gable.

In five houses $(37,45,80,81,110)$, a solitary post is located in or nearby the central axis and $0.8-1.4 \mathrm{~m}$ outside the gable trestle. Komber (1998:51) has interpreted such posts in connection with the reconstruction of the Bronze Age Period IV house 59 at Forsand as having a lengthwise stabilising function for the roof-bearing construction.

\section{Shape and size of the postholes}

In Table 5 (folder), the variation of horizontal and vertical size is given for each house, and then a mean value for each house is calculated. A mean size and depth for all houses within each subtype is also calculated. The table shows that the postholes in type 3.2 almost exclusively consist of circular postholes (90\%). In type 3.1, the small houses (3.1.1) also nearly exclusively have circular postholes (92), while among the long houses (3.1.2), there is a large majority of oval postholes (83 $\%$ ). The postholes in the probable type 3.1 are split in nearly equal proportions, while $65 \%$ of the postholes in type 3.3 are oval.

Fig. 29 shows how the proportion between circular and oval postholes changes through time, from mainly (85\%) circular postholes in the Bronze Age to a more even proportion (60/40) in favour of circular postholes in the early Pre-Roman Iron Age. In both the late Pre-Roman Iron Age and Roman Iron Age, there is a preferred use of oval postholes (62\%). The shape of the postholes is mostly dependent on two aspects: the shape of the post and the technique used to raise the post. As I will show below, the shape of the post is rarely documented, but a few have been identified as circular. One conclusion below is also that all type 3 houses follow one coherent building tradition where the method of erecting the roof-bearing construction might have been the same through more than 1000 years. The differences between the postholes might therefore reflect a change in the preferred shape of the post, from circular 
to rectangular; many rectangular posts have been documented in oval postholes in the type 7 and 9 houses from the Roman Iron Age and Migration Period.

This change can possibly be connected to the important change in axe technology from small bronze socketed axes - or even stone axes still in use as some such finds at the settlement area indicate - to the use of iron at least by the late Pre-Roman Iron Age, when iron was used as a tool, as documented at the Forsandmoen settlement (bridle and a leather knife). When people were dependent on stone or bronze technology, it is likely that they chose appropriately large trees for circular posts as often as possible. This would have resulted in as little work as possible to split trunks; splitting trunks could, of course, not be totally avoided, result-

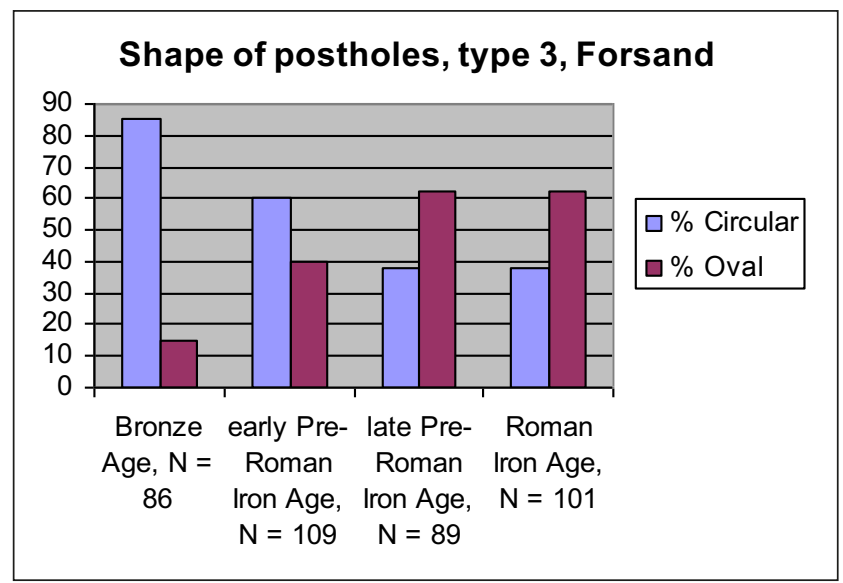

Fig. 29. The shape of type 3 postholes changes throughout the settlement periods.

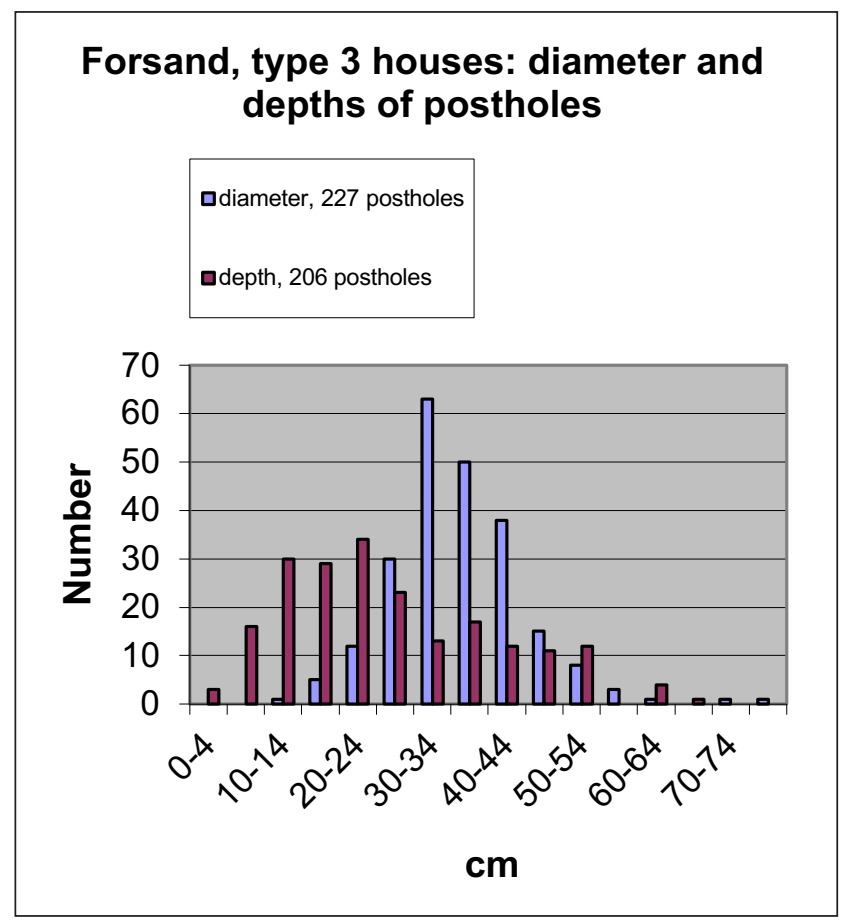

Fig. 30. Distribution of diameter and depth in type 3 postholes. ing in a small proportion of oval postholes where rectangular posts would have been erected. I suggest that the increasing proportion of oval postholes from the early Pre-Roman Iron Age mirrors a transition to Iron Age tools in general and an increasing access to improved axe technology throughout the Early Iron Age. Early Pre-Roman Iron Age remains from the extraction of bog iron or from a smithy show that the settlement could produce iron for internal needs at the time when the proportion of oval postholes increased. Another important aspect is that, as the settlement size increased in the Late Bronze Age and the PreRoman Iron Age, the amount of sufficiently large trees for posts decreased, which in turn forced people to split larger trees for rectangular posts.

The mean circular postholes in each group differ very little $(0.37-0.44 \mathrm{~m})$ in size, but when it comes to the depth, subtype 3.3 is much shallower than the three other groups $(0.18 \mathrm{~m}$ versus $0.26-0.30 \mathrm{~m})$. It is important to keep in mind that the mean values for each house differ slightly within and between groups. The great majority of values are in the range from 0.30 to $0.38 \mathrm{~m}$ in diameter, while the depths vary much more, from 0.13 to $0.35 \mathrm{~m}$; see Fig. 30, which is based on measurements from more than 260 postholes - an average of ten for each house.

We see from Fig. 30 that the size of the postholes describes a Gaussian curve with half of the measurements within the interval $30-39 \mathrm{~cm}$, while the depth distribution has its main point between $10 \mathrm{~cm}$ to $24 \mathrm{~cm}$ with a tail towards depths of up to $60 \mathrm{~cm}$ or more. This tail is dependent on two houses (91/93 and 110), both of which had a $50 \mathrm{~cm}$ mean depth. If those two houses were excluded, the remaining houses would have been distributed more in accordance with the Gaussian curve.

If we look at the size though time (Table 11), the circular posthole size increases gradually from $0.34 \mathrm{~m}$ in the Bronze Age to $0.44 \mathrm{~m}$ in the Roman Iron Age. If this larger size reflects larger posts, this can relate to the greater length and width of the houses, which brought about a need for stronger constructions. There is no apparent increase in the trestle span size that could have caused a need for heavier posts. The depth of the circular postholes is stable through time, even though the late Pre-Roman Iron Age houses, which had the largest mean house width $(6.5 \mathrm{~m})$, are a few centimetre deeper $(0.28 \mathrm{~m})$ than those from other settlement periods $(0.22-0.24 \mathrm{~m})$.

In addition to circular postholes, there is a varying proportion of oval postholes, from $8 \%$ in type 3.1.1 to $83 \%$ in type 3.1.2 houses. The size of the oval postholes 
does not show a clear distribution when looking at the different types, except that the subtypes 3.1 and 3.1.2 are larger than the other subtypes (approximately 0.43 $\mathrm{x} 0.56 \mathrm{~m}$ as opposed to $0.30 \mathrm{x} 0.40 \mathrm{~m}$ ). The depth shows the same pattern: the small postholes have a shallower depth (approximately $0.15-0.19 \mathrm{~m}$ ) than the large ones $(0.30 \mathrm{~m})$. Both size and depth increase through time, from $0.32 \times 0.41 \mathrm{~m}$ in the Bronze Age to $0.36 \times 0.52 \mathrm{~m}$ in the Roman Iron Age. The lengths of the postholes increase more than the width, indicating that the posts had a stable width but a greater length in the late PreRoman Iron Age and Roman Iron Age compared with before. This is in accordance with the need for stronger posts in the wider houses in these two periods than in previous periods. The depth increases by $0.05 \mathrm{~m}$ from $0.17 \mathrm{~m}$ in the Bronze Age to later periods, which may be a result of the increased mean width from the Bronze Age to the early Pre-Roman Iron Age.

\section{Shape and size of the posts}

From ten type 3 houses, there are documented traces of posts in 20 postholes. These traces consist of either a well-defined core of clay or dark soil with charcoal, clearly different from the surrounding material. Also, vertical stones with an even side facing the centre of the posthole that once lined the post are considered traces of posts. Fig. 31 shows how the diameters of the traces of the posts are distributed with a onecentimetre interval. The size has often been given as an interval (like 16-18 cm), and in these instances the mean value has been calculated. Even though the number of posts is few, they seem to cluster in three sizes (mean 13.5, 17.5 and $24 \mathrm{~cm}$ ). But three of the four smallest sizes $(12-14 \mathrm{~cm})$ derive from postholes where the post dimension is measured between two lining stones. The stones looked like they were in an original position, but can easily have been moved by frost activity, especially when the posts had decayed or were removed. So those small observations are less reliable than those that originate from measuring the dark core in the postholes. Fig. 31 can therefore be interpreted as the post dimensions divided into two dimensions: approximately $17-18 \mathrm{~cm}$ and nearly $25 \mathrm{~cm}$. One could expect that the different dimensions belonged to different houses. But from six houses, where there are two or three measurements, the measurements in each house differ significantly: two houses from $14-22 \mathrm{~cm}$ and another two from $17-24 / 26 \mathrm{~cm}$. What is interesting then is that, even though the numbers are small, the mean values are quite similar, around $18-19 \mathrm{~cm}$, which is also near to the overall mean diameter $(20 \mathrm{~cm})$. One conclusion is tempting: that the preferred size of posts in type 3 houses was $20 \pm 3-4 \mathrm{~cm}$. Finally, a few of the traces showed that the post had been circular, confirming the conclusion drawn from the large majority of circular postholes.

Only five of ten houses with traces of the posts have been dated; two date to the Late Bronze Age Period VI, two to the early and middle Pre-Roman Iron Age and one to the late Pre-Roman Iron Age. Looking at the connection between the size of the posts and the dated houses, the differences in such a small sample are too insignificant to reach any conclusions concerning a possible change in post dimensions through time.

A final observation is that a layer of small stones occurs now and then at the bottom of the postholes. Also, flagstones are placed at the bottom, as supporters for the posts. In many cases, there were random finds of stones with an even side in the posthole fill, showing that the posts had been wedged into place.
Fig. 3I. Distribution of circular post dimensions in type 3 houses.

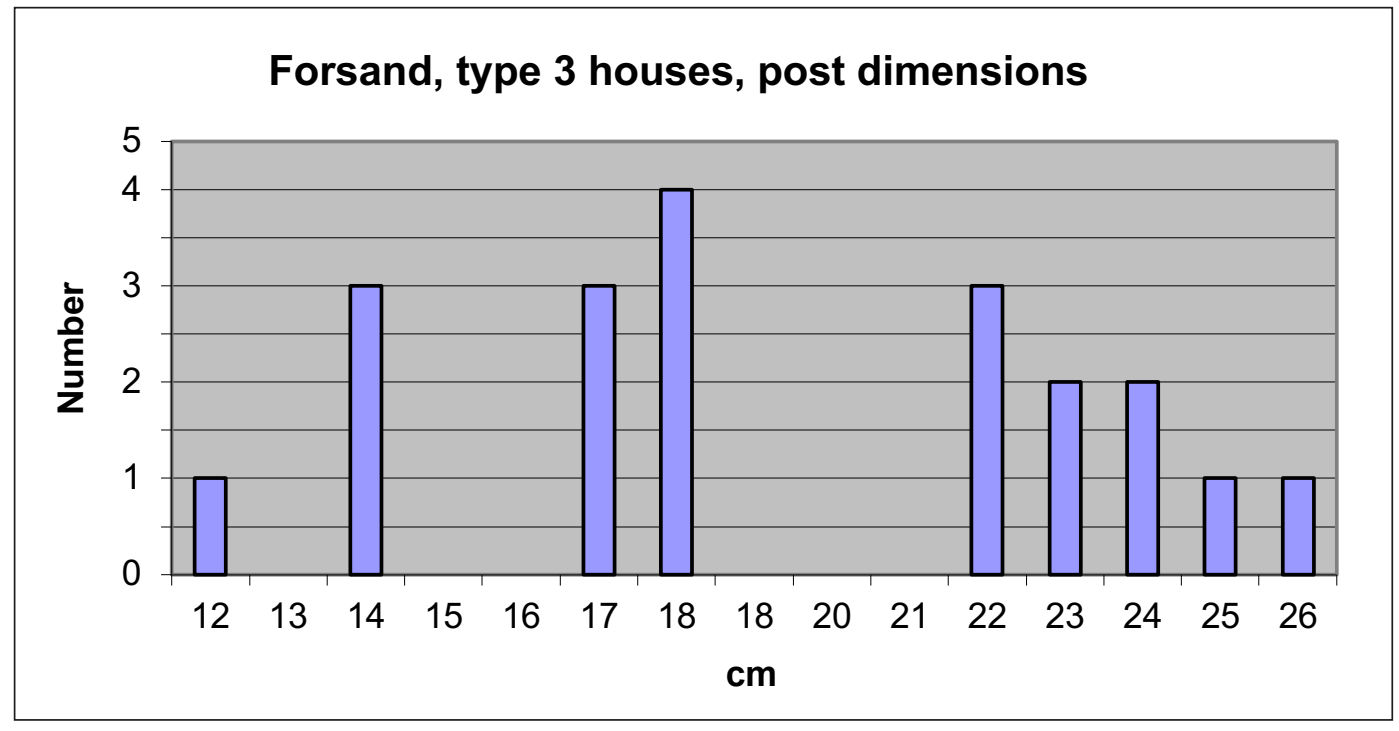




\subsection{Comparative houses from Norway}

The type 3 dwelling-byre house is well known throughout Sweden, Denmark, north-west Germany and the Netherlands. Such houses are also present in a few examples in Eastern, Western and Central Norway, and show that the house type was spread throughout the southern half of the country. In my opinion, it is difficult to use the restricted and widely spread material in questions such as what constituted normal sizes, construction, the normal location of dwelling and byre and the like. In the following, the Norwegian material is presented; beginning with other settlements in Rogaland, then turning to the west coast, up to Trøndelag, and finally to the eastern lowland (see also Table 13, where the most vital measurements are given). The presentation will be restricted to houses where a full house plan is known, only briefly mentioning partly excavated houses.

The oldest type 3.1.1 from Rogaland was found at Kvåle, Time municipality (Soltvedt et al. 2007:45f). The house from Kvåle was $18 \mathrm{~m}$ long, $5.7 \mathrm{~m}$ wide and had a narrow, $1.6 \mathrm{~m}$ entrance room, a possible occupation area with two $3.3 \mathrm{~m}$ long bays to the north-west, and two somewhat smaller bays to the south (2.8 $\mathrm{m})$. The long walls were well preserved with a $0.9 \mathrm{~m}$ mean distance between the postholes. The gables were not preserved. Plant remains gave no indications of a byre function in the south-eastern part. The house is dated to Bronze Age Period I (1750-1665 BC), based on a combined ${ }^{14} \mathrm{C}$ date (three samples). This house is as early as the earliest three-aisled houses at Højgård in Southern Jutland (Ethelberg 2000:184), and may indicate that the change to a three-aisled construction took place simultaneously with the change from twoaisled to three-aisled houses in southern Scandinavia (Soltvedt et al. 2007:60). In Rogaland, another threeaisled type 3 house from Kleppe, Klepp municipality, has been dated to the last part of Bronze Age Period I, with a combined $1610-1530 \mathrm{BC}$ date from three ${ }^{14} \mathrm{C}$ samples (Berge 2007).

The large development-led excavation at Gausel, Stavanger in Rogaland revealed three complete and three probable type 3 houses from the Pre-Roman Iron Age and early Roman Iron Age (Børsheim \& Soltvedt 2002). The complete ones were type 3.3 with 7-9 trestles. They measured $16-18.5 \times 5.6-6.4 \mathrm{~m}$ and the walls were partly marked by small postholes, partly by ditches. The dwelling and byre area were approximately the same size and the byre in all three houses had space between the trestle spans for twelve cattle. In one house, the stall boxes were marked by small postholes, and in the two other houses the byre had a 5-6 m stone-paved wear depression along the central aisle, but not in the gable room. The gable rooms measured slightly more than $2 \mathrm{~m}$, and three of four entrance rooms were 1.3-1.4 $\mathrm{m}$, while the last was $3.5 \mathrm{~m}$ wide. Together, these houses fit well into the pattern of type 3 from Forsand. Most interesting are the marked stall boxes in one house and that the paved wear depressions did not extend into the gable room. This proves that this part of the house was not used to stall cattle. The dates of the six certain and probable type 3 houses at Gausel fit well with the later part of the period of use at Forsand. Most important is that the youngest house belonged to the early Roman Iron Age.

At Sandved, Skeiane, Sandnes municipality, three type 3 houses were excavated (Berntsen \& Pilskog 1998, Sandvik 1999). A type 3.2 house with only four trestles (house VII) measured $11.5 \times 5 \mathrm{~m}$ and is dated to the early Pre-Roman Iron Age $(420-250 \mathrm{BC})$ by three ${ }^{14} \mathrm{C}$ samples. A much larger house was house IV, with eight trestles (type 3.3), measuring $18 \times 5.5-6 \mathrm{~m}$. The N-S oriented house had an $11 \mathrm{~m}$ long dwelling area with bays measuring $2.4-2.7 \mathrm{~m}$. It had a hearth to the south and a narrow entrance room $(1.3 \mathrm{~m})$ as well as two 1.9metre wide bays to the north, which would have been well suited as stalls for eight cattle. Three ${ }^{14} \mathrm{C}$ samples gave the house a combined date to the early Pre-Roman Iron Age (400-230 BC). House II, oriented N-S, was also a type 3.3 house with a $3.1 \mathrm{~m}$ wide entrance room in the middle and an additional entrance to the west, a $9 \mathrm{~m}$ long dwelling area with a long hearth to the south and a $9.5 \mathrm{~m}$ long byre with a wear depression to the north. In total, the house measured $21.5 \times 6.5 \mathrm{~m}$ and was dated by three ${ }^{14} \mathrm{C}$ samples to the Late Bronze Age Period VI (760-510 BC). House I at the same site, with more than $4 \mathrm{~m}$ wide trestles and no traces of the entrances has been dated to Bronze Age Period II (1520-1430 BC) and was discussed in connection with type 1.

Nearby, at Skadberg, Sola municipality, two well preserved type 3.1 houses and one type 3.2 house are situated parallel to each other at a distance of 12-18 m (Bjørlo 2011). They measure between 11 and $17.5 \mathrm{~m}$ in length and $6.5 \mathrm{~m}$ in width. They have wall posts at the normal $0.7 \mathrm{~m}$ distance and gables with rounded corners. The houses are preliminary dated to the PreRoman Iron Age.

At Søra Bråde, Revheim, Stavanger municipality, a type 33 house dated to the Pre-Roman Iron Age, $17 \mathrm{~m}$ long and $6.5 \mathrm{~m}$ wide with eight trestles, revealed wear depressions in the central aisle in both halves and the 
entrance room (Sørheim et al. 2004:5). The byre part, with three spans of $1.9-2.1 \mathrm{~m}$ and one only $1.1 \mathrm{~m}$ in width, which would have had room for a maximum of 14 cattle, was divided from the entrance room by a wall-ditch. A ditch between two entrance posts may represent a threshold or a drainage ditch. Two ditches, parallel to and one metre inside the long wall in the dwelling area, may have functioned as parts of benches or a raised floor. Densely set $(0.5-0.7 \mathrm{~m})$ small postholes different places in the wall showed that the house had parallel wattle and daub walls. The holes for the roof-bearing posts were circular and measured $0.3-0.5$ $\mathrm{m}$ in diameter. There are several post- and stake holes inside the house, probably from another house, but a series of small holes are situated at a metre's distance between the roof-bearing posts in the byre, and can possibly represent a division of stall boxes.

At the furthest end of the 38-kilometre-long Lysefjord, in Nerabø, Forsand municipality, a $16.8 \mathrm{~m}$ type 3.1.1 house has been found (Løken et al. 1996:85, Måge 1993). The trestle width was $2.5-2.6 \mathrm{~m}$ and the distance between the two northern entrance postholes and the one that survived of the southern one was 5.6 $\mathrm{m}$, indicating a $6.5 \mathrm{~m}$ house width. The postholes were circular and the posts in three holes seem to have been replaced with new ones. Three charcoal samples from postholes were ${ }^{14} \mathrm{C}$ dated. At least two of the samples were contaminated, giving dates from AD 1500-1600, and even later than AD 1800. The last was from the Viking Period, AD 775-955. It is of course possible that the type 3.1.1 house was still in use in the Viking Period, but due to the two erroneous dates, this is not likely. On the other hand, we know from a series of grave finds that the farm at Lysebotn was settled in the Roman Iron Age and Migration Period, so the house may originate from that period (Løken 2001a:16).

Further north along the western coast, three-aisled longhouses have been reported at several sites, but most houses cannot be categorised as type 3 houses since they do not have the opposed entrances in the middle of the house (Diinhoff 2005a:80-81), or they are so badly preserved that the important details are missing (Diinhoff 2005b). But Late Bronze Age and Pre-Roman Iron Age houses from Sogn og Fjordane and Sunnmøre measure 14-16 x 5-6 m, have walls marked by densely placed posts with rounded gables, recessed entrance, a large room in one end and quite dense post-setting in the other end, probably marking stall boxes (Diinhoff 2006:figs. 5-6). I suggest they represent the same basic house concept as type 3. I have reinterpreted houses I and V from Mo, Ørsta as basically type 3.3 houses in order to be used as comparative material. At Hornnes, Sogn og Fjordane (Diinhoff 1996), two approximately 16-17 m houses from late Pre-Roman Iron Age and early Roman Iron Age, respectively, may have been type 3 houses with one entrance centrally located as a division between the dwelling and byre areas. From Berge, there is a documented house plan from a small type 3.4 house (Diinhoff 2006:79, fig. 14), showing that such small houses, which are often found in Jutland, also occur in Western Norway.

In Central Norway (Trøndelag) there have been some large excavations over the last decade or so. The first project, at Hovde, Ørlandet, a $27 \mathrm{~m}$ long six pair house with a small entrance room in the middle shows a great resemblance to type 3.1.1 at Forsand. Taking into account the drainage ditch along the northern long wall and the $5 \mathrm{~m}$ distance between the corner posts, the house width was most likely around $9 \mathrm{~m}$. Due to the size, the large distances between the trestles, hearths in both halves as well as in the entrance room and corner posts instead of curved gables, the house probably served other purposes than as a dwelling/byre peasant home. The house has been dated to the late Pre-Roman Iron Age (160 BC-AD 30) and is interpreted as a chieftain's hall by Grønnesby (1999). Two large projects in Melhus and at Kvenild near Trondheim revealed a series of three-aisled houses with opposed and recessed entrances near the centre, densely set wall posts with rounded gables, which were dated to the Bronze Age and Pre-Roman Iron Age. In these respects, they can be characterised as type 3 houses, but only a few fit well into the subtypes. In the Melhus area (Rønne 2005), the houses measure as much as $26 \mathrm{~m}$ as early as in the Early Bronze Age, and the prevalent size was as much as $25-32 \mathrm{~m}$ in the Pre-Roman Iron Age. These houses have parts with a large span between the trestles (dwelling area), but also parts where the distance is around one metre, indicating that the cattle were stalled in stall boxes already from Bronze Age Period III. At Kvenild (Grønnesby 2006) the houses measure 10-19 m, and have one or two centrally located entrance(s), densely set wall posts with rounded gables and large trestle spans to the east, as well as approximately $1 \mathrm{~m}$ spans in the west. Even though Grønnesby (2006:99) rejects that the western part was a byre, on the basis of one or two hearths located in that part, my interpretation is that, at Kvenild, the dwelling area was in the spacious eastern part, while the cattle were stalled in the west.

In my opinion, the material from Western and Central Norway shows that the basic concept with a tripartite 
entrance room dividing the byre and dwelling area are spread throughout the area and, as the dates from the Trøndelag area show, were already in use in Bronze Age Period III. The densely set trestles (1 m apart) in many houses along the coast and as far north as Trøndelag, support the conclusion from Forsand, that stalling cattle ordinarily took place from some time in the Early Bronze Age. However, the material found in that area also shows much more diversity in the layout than found at Forsand. Looking at the two large projects in Trøndelag (Melhus and Kvenild) - the only other excavations where most of the house plans have been preliminarily published - it seems that, within each settlement site, the houses had a homogeneous layout. Based on this basic concept, it is therefore probable that local or regional building traditions were developed as a result of environmental, economic or social preferences. The rather large houses, especially at Melhus, compared with those at Forsand and along the western coast may be explained by the more northerly and inland location with a longer and harsher winter, and thus a greater need for stalling both large and small cattle, than what was needed on the west coast.

Lastly, concerning the Norwegian material, it must be mentioned that publications from Eastern Norway are so far restricted to a very small number of house plans that have sufficient features to be labelled as type 3 houses. In the following, a few houses are presented.

At Moer, Akershus, several three-aisled houses were investigated, but only two with a preserved plan (Guttormsen 1998). House I, Phase A is a type 3.2 with five trestles and two opposed entrances, but also with corner posts at each gable, and curved ditches (interpreted as wall foundations) along the long walls and straight gables. The roof-bearing construction measured $15 \mathrm{~m}$, with $20.6 \mathrm{~m}$ between the corner posts. The $9.5 \mathrm{~m}$ width between the $0.6 \mathrm{~m}$ wide ditches that also run 1.2-1.7 m outside along the corner posts (both lengthwise and transverse) indicate that they served as drainage ditches rather than wall-foundation ditches. Judging from the entrances at the centre, the house was $6.4 \mathrm{~m}$ wide. The house had another entrance in the southern part and shows traces of a room division there. Even though the house can be labelled as a type 3 house, the curved ditches, corner posts and additional entrance are features that point to another building tradition. The house is dated to the late Roman Iron Age, as could be expected from these features, but what is important is the occurrence of a regular type 3 roof-bearing construction as late as this in Eastern Norway.
In connection with the E6 development-led project, only one out of ten houses at Vestre Borge, Råde, Østfold, seem to be a type 3.3 house, although only one entrance was recorded (Bårdseth \& Sandvik 2007a:57ff). House 1 was a N-S oriented nine-trestle house with circular posts, $0.20-0.25 \mathrm{~m}$ in diameter. A narrow $(1.8 \mathrm{~m})$ entrance room divided the house into a short, three-bay northern part and a long, four-bay southern part. The location of the $1.8 \mathrm{~m}$ wide eastern entrance and a few wall postholes indicates that the house was $7 \mathrm{~m}$ wide. The trestle construction measured $20 \mathrm{~m}$ and was convex, $2.3-3 \mathrm{~m}$ in width. The house existed for some time, as evidenced by three renewed posts. The wide bays to the south are connected to pottery finds in the house. That part must therefore have been the dwelling area, and the byre and storage area located north of the entrance. This approximate $24 \mathrm{x}$ $6.5 \mathrm{~m}$ house $\left(155 \mathrm{~m}^{2}\right)$, dated to the late Pre-Roman Iron Age by two ${ }^{14} \mathrm{C}$ dates (Bårdseth \& Sandvik 2007a:69) matches nicely with similar, contemporary houses in Rogaland.

At Årum, Fredrikstad, Østfold, a type 3.2 house (12.5 × $6 \mathrm{~m}$ ) has been excavated (Vikshåland \& Sandvik 2007a:9f). As many of the houses in the E6 project, this house had drainage ditches all around the house and no traces of the walls. One $1.1 \mathrm{~m}$ wide entrance in the north wall divided the house into a two-bay occupation zone with a hearth to the west and a $2.2 \mathrm{~m}$ long trestle bay to the east. The postholes were circular, and the size indicates that the posts measured $0.20-0.25 \mathrm{~m}$ across. A combined analysis of four ${ }^{14} \mathrm{C}$ dates resulted in a Bronze Age Period VI date to 750-510 BC.

At Bustgård, Sarpsborg, Østfold, a partly preserved type 3 house was also found (Vikshåland \& Sandvik 2007c:143f). Judging from the wall posts, two opposite entrances divided the house into two halves. Only three trestles were preserved, but the house most certainly consisted of six trestles that measured $17.4 \times 7.9 \mathrm{~m}$. The house had rectangular $(0.18-0.36 \mathrm{~m})$ roof-bearing posts, while the widely spaced wall posts (mean $1.7 \mathrm{~m}$ ) were $0.12-0.22 \mathrm{~m}$ across. The large distance and the size and depth of the wall postholes show that the wall had a bole construction. An offered small pottery vessel was found in one of the wall postholes and a roofbearing posthole contained several fragments from a decorated clay hearth pavement. Three ${ }^{14} \mathrm{C}$ dates of barley (Hordeum) have a combined date to AD 130-250 (Vikshåland \& Sandvik 2007c:151).

The three type 3 houses from Østfold show, in addition to those that define type 3 houses, many characteristics in common with the material from Rogaland; 
finds and hearths are connected to wide trestle bays to one side of the central entrance, posts change shape from circular to rectangular somewhere around AD 1, different subtypes are present in the restricted house material and they cover the period from Late Bronze Age Period VI to the Roman Iron Age.

In fact, the late Roman Iron Age and Migration Period are also represented in Eastern Norway, but from Vestfold, on the other side of the Oslofjord. At Ringdal, Larvik municipality (Gjerpe \& Østmo 2008:39ff), three such houses were found at a farmstead consisting of ten dwelling longhouses, three storage houses and at least six granaries (four-post constructions). Three of the longhouses are type 3 houses with 6-8 trestles and opposed entrances at the middle of the house. They lack traces of the long walls except for a $6 \mathrm{~m}$ ditch near the gable in house 6 . Unlike the type 3 houses at Forsand, two of the houses have corner postholes. House 5, a short type 3.3. house, $17.6 \mathrm{~m}$ long - including $2 \mathrm{~m}$ to the gables - and $6.5 \mathrm{~m}$ wide, had access to a $2 \mathrm{~m}$ wide entrance room through 1.6-1.8 m wide doors (Gjerpe \& Østmo 2008:71f). A partition wall located at the third trestle from the south divided this part in two. The trestle spans differ between 2 and $2.5 \mathrm{~m}$ and do not allow for an interpretation as to where the dwelling area was located, nor is there a hearth to give us an indication. The two houses (houses 6 and 7) with corner posts, type 3.1.2 and 3.3, respectively, both have an unusually wide $(3.5 \mathrm{~m})$ entrance room as well as doors (1.5-2.1 m) (Gjerpe \& Østmo 2008:75-85). In both houses, the trestle spans are quite even, mainly $3.2-3.5 \mathrm{~m}$, giving no indication as to where the dwelling area was located. Both houses are somewhat longer than similar houses at Forsand, probably reflecting the general tendency in the southern half of Scandinavia to build longer houses in the late Roman Iron Age and Migration Period than in the late Pre-Roman Iron Age and early Roman Iron Age. House 7 has been dated to the late Roman Iron Age by two ${ }^{14} \mathrm{C}$ samples (Gjerpe \& Østmo 2008:85) while the houses 5 and 6 have been dated to Migration Period (Gjerpe \& Østmo $2008: 75,81$ ) by several ${ }^{14} \mathrm{C}$ samples, showing that the type 3 organisation of houses probably lasted longer in the eastern part of Norway than in Rogaland.

\subsection{Comparison between Forsand and the Norwegian type 3 houses}

The collected data from the Norwegian material is presented in Table 13. Nearly all these houses, including those from Rogaland, were built with more than six trestles (type 3.3), as opposed to the majority of type 3.1 houses at Forsand. Concerning the three areas Rogaland, Western Norway and Sør-Trøndelag, there are so many houses that it is possible to compare these areas to Forsand. The type 3.3 houses from Rogaland are, due to a lesser number of trestles than in type 3.3 at Forsand, on average $2.5 \mathrm{~m}$ shorter than the equivalent houses at Forsand. However, the average distance between the trestles is equivalent in both the dwelling and byre part in these houses, indicating corresponding activities. These houses could therefore accommodate six people and eleven cattle, while the similar type 3.3 houses at Forsand had space for 7-8 people and 15 cattle. The houses from the two other areas (Western Norway, Sør-Trøndelag) differ more from the Forsand houses. Most noteworthy is that the distances between the trestles in the byre part are only 1.2-1.3 m as opposed to $2 \mathrm{~m}$ in type 3.3 houses at Forsand. The narrowly spaced trestles indicate that there was room for only one cow between two trestles. Due to this construction in the byre, these houses could only on average accommodate seven and 9-10 cattle, respectively, which is comparable with the small type 3.1 houses at Forsand. These two groups of houses are also 4 and $2.5 \mathrm{~m}$ shorter, respectively, than the type 3.3 houses at Forsand. The house width was also smaller, so the floor area $\left(88\right.$ and $\left.95.4 \mathrm{~m}^{2}\right)$ was $30-36 \mathrm{~m}^{2}$ smaller than for the type 3.3 houses at Forsand $\left(124 \mathrm{~m}^{2}\right)$. The size of the dwelling area (40 and $47 \mathrm{~m}^{2}$, respectively) could accommodate a household of 5-6 adults while the same house type (3.3) at Forsand had space for 7-8 people. The household size of 5-6 people is the same as that found in the type 3.1 house at Forsand. Therefore, the type 3.3 houses from Western Norway and Sør-Trøndelag represent the smallest type of farm at Forsand in terms of capacities for both people and cattle.

\subsection{Comparative houses from southern Scandinavia, Germany and the Netherlands}

We know that three-aisled houses were introduced at the turn to Bronze Age Period II in Southern Jutland. They occur in the Jæren area at nearly the same time. We also know that such houses are older in north-west Germany and the Netherlands. Fokkens (1999:36) states that the three-aisled longhouse dates back to the $18^{\text {th }}$ and $17^{\text {th }}$ century BC. In the following, the Forsand houses will be compared with the excavated houses further south. 
Table 13. Compiled measurements from features of type 3 houses from Norway (Forsand excluded). Measurements in metres ( $\mathrm{m}$ ).

\begin{tabular}{|c|c|c|c|c|c|c|c|c|c|c|c|c|c|c|c|}
\hline \multirow[b]{2}{*}{ Site/ type } & \multirow{2}{*}{ 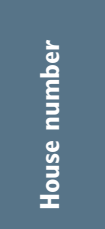 } & \multirow{2}{*}{ 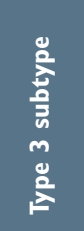 } & \multirow{2}{*}{ 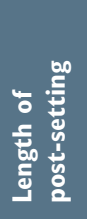 } & \multirow{2}{*}{ 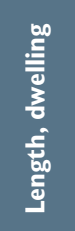 } & \multirow{2}{*}{ 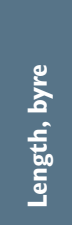 } & \multirow{2}{*}{ 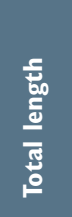 } & \multirow{2}{*}{$\frac{\frac{5}{5}}{\frac{0}{3}}$} & \multirow{2}{*}{ 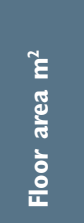 } & \multirow{2}{*}{ 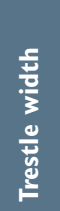 } & \multirow[b]{2}{*}{$\stackrel{\circ}{\vdash}$} & \multicolumn{5}{|c|}{ Distances between trestles } \\
\hline & & & & & & & & & & & $6-5$ & $5-4$ & $4-3$ & $3-2$ & $2-1$ \\
\hline Gausel sør & $\mathrm{VI}$ & 3.3 & 11.1 & 4.9 & 4.9 & 14.5 & 5.8 & 84.1 & 2.2 & 2.6 & & & 1.4 & 1.9 & 1.6 \\
\hline Gausel nord & 1 & 3.3 & 12.4 & 7.5 & 7.4 & 16.3 & 5.9 & 96.2 & 2.4 & 2.5 & & & & 2.0 & 3.7 \\
\hline Gausel nord & 2 & 3.3 & 12.5 & 7.2 & 7.6 & 16.1 & 6.1 & 98.2 & 2.6 & 2.3 & & & 2.2 & 1.2 & 1.8 \\
\hline Søra Bråde & 1 & 3.3 & 13.7 & 7.5 & 8.7 & 17.5 & 6.5 & 113.8 & 2.6 & 2.5 & & & & 2.7 & 2.9 \\
\hline Sandved & IV & 3.3 & 14.1 & 11.0 & 5.8 & 18.1 & 5.5 & 99.6 & 2.4 & 2.3 & & 2.0 & 2.2 & 2.8 & 1.9 \\
\hline Gausel sør & IV & 3.3 & 14.9 & 8.3 & 6.4 & 18.4 & 6.4 & 117.8 & 2.8 & 2.3 & & & & 3.0 & 3.2 \\
\hline Sandved & II & 3.3 & 17.5 & 9.0 & 9.5 & 21.5 & 6.5 & 139.8 & 2.7 & 2.4 & & & 2.7 & 1.9 & 2.3 \\
\hline Rogaland (7) & & 3.3 & 13.7 & 7.9 & 7.2 & 17.5 & 6.1 & 107.0 & 2.5 & 2.4 & & 2.0 & 2.1 & 2.2 & 2.5 \\
\hline Nerabø & 1 & 3.1 .1 & 12.8 & 7.2 & 6.9 & 16.8 & 6.5 & 109.2 & 2.6 & 2.5 & & & & 2.3 & 2.7 \\
\hline Kvåle & 3 & 3.1 .1 & 13.7 & 10.6 & 9.3 & 21.8 & 5.7 & 124.3 & 2.7 & 2.1 & & & & 3.3 & 3.2 \\
\hline Rogaland (2) & & 3.1 .1 & 13.3 & 8.9 & 8.1 & 19.3 & 6.1 & 116.7 & 2.7 & 2.3 & & & & 2.8 & 3.0 \\
\hline Sandved & VII & 3.4 & 7.5 & 5.3 & 4.0 & 11.0 & 5.0 & 55.0 & 1.8 & 2.8 & & & & & 3.3 \\
\hline Mo, Møre og Romsdal & V & 3.3 & 8.6 & 4.8 & 7.6 & 13.7 & 5.6 & 76.7 & 2.3 & 2.4 & & & 0.9 & 0.9 & 0.9 \\
\hline Mo, Møre og Romsdal & 1 & 3.3 & 12.0 & 7.9 & 7.8 & 15.7 & 6.0 & 94.2 & 2.3 & 2.6 & & & 2.7 & 2.1 & 1.2 \\
\hline $\begin{array}{l}\text { Hornnes, Sogn og } \\
\text { Fjordane }\end{array}$ & 1 & 3.3 & 12.5 & 6.7 & 4.7 & 16.5 & 5.5 & 90.8 & 2.4 & 2.3 & & & 1.9 & 2.8 & 2.1 \\
\hline $\begin{array}{l}\text { Hornnes, Sogn og } \\
\text { Fjordane }\end{array}$ & II & 3.3 & 12.5 & 8.0 & 7.1 & 16.4 & 5.5 & 90.2 & 2.0 & 2.8 & & & 1.2 & 1.2 & 3.6 \\
\hline W-Norway (4) & & 3.3 & 11.4 & 6.9 & 6.8 & 15.6 & 5.7 & 88.0 & 2.3 & 2.5 & & & 1.7 & 1.8 & 2.0 \\
\hline Berge? & 1 & 3.2 & 7.9 & 3.8 & 5.3 & 11.1 & 6.0 & 66.6 & 2.7 & 2.2 & & & & & 2.1 \\
\hline Melhus & VII:B & 3.3 & 9.0 & 4.8 & 6.5 & 13.0 & 5.8 & 75.4 & 2.0 & 2.9 & & & & & 2.6 \\
\hline Kvenild & O & 3.3 & 9.4 & 4.9 & 5.5 & 12.8 & 5.6 & 71.7 & 2.3 & 2.4 & & & & 1.6 & 1.4 \\
\hline Søberg & XVII2:I & 3.3 & 9.8 & 4.9 & 6.7 & 12.6 & 4.7 & 59.2 & 2.1 & 2.2 & & & 1.7 & 0.9 & 0.9 \\
\hline Søberg & XVl:I & 3.3 & 12.5 & 8.4 & 5.7 & 15.6 & 5.2 & 81.1 & 2.0 & 2.6 & & & 2.6 & 2.2 & 2.1 \\
\hline Kvenild & A & 3.3 & 13.0 & 10.2 & 5.6 & 17.1 & 5.8 & 99.2 & 2.4 & 2.4 & 1.2 & 1.4 & 1.4 & 2.6 & 1.7 \\
\hline Kvenild & M & 3.3 & 14.8 & 9.9 & 7.3 & 18.7 & 6.0 & 112.2 & 2.9 & 2.1 & & 3.0 & 1.8 & 1.4 & 1.4 \\
\hline Kvenild & B & 3.3 & 15.5 & 11.4 & 5.9 & 18.6 & 5.5 & 102.3 & 2.1 & 2.6 & 2.3 & 2.6 & 1.6 & 2.0 & 1.5 \\
\hline Søberg & III:VI & 3.3 & 17.2 & 7.6 & 11.8 & 21.0 & 5.6 & 117.6 & 2.3 & 2.4 & & 1.7 & 1.2 & 1.5 & 1.2 \\
\hline Søberg & III:II & 3.3 & 20.8 & 14.2 & 9.5 & 25.5 & 5.5 & 140.3 & 2.2 & 2.5 & 3.0 & 1.7 & 2.2 & 2.5 & 2.3 \\
\hline Sør Trøndelag (9) & & 3.3 & 13.6 & 8.5 & 7.2 & 17.2 & 5.5 & 95.4 & 2.3 & 2.5 & 2.2 & 2.1 & 1.8 & 1.8 & 1.7 \\
\hline Hovde, Sør Trøndelag & & 3.1 .1 & 21.9 & 12.3 & II.I & 27.0 & 9.0 & 243.0 & 3.4 & 2.6 & & & & 3.3 & 6.7 \\
\hline Ringdal & 13:6 & 3.3 & 19.2 & 10.8 & 8.6 & 22.9 & 6.8 & 155.7 & 3.3 & 2.1 & & 3.4 & 2.5 & 1.3 & 2.0 \\
\hline Borge, vestre & 19:1 & 3.3 & 20.0 & 12.8 & 9.2 & 24.0 & 6.5 & 156.0 & 3.0 & 2.2 & & 2.0 & 2.7 & 3.1 & 3.0 \\
\hline Ringdal & 13:5 & 3.3 & 13.6 & 8.8 & 6.5 & 17.6 & 6.5 & 114.4 & 3.4 & 1.9 & & & 2.5 & 2.3 & 2.0 \\
\hline East Norway (3) & & 3.3 & 17.6 & 10.8 & 8.1 & 21.5 & 6.6 & 142.0 & 3.2 & 2.0 & & 2.7 & 2.6 & 2.2 & 2.3 \\
\hline Årum. øvre & $21: 1$ & 3.2 & 8.5 & 4.8 & 4.1 & 11.5 & 6.6 & 75.9 & 2.6 & 2.5 & & & & 2.0 & 2.0 \\
\hline Moer & II & 3.2 & 14.8 & 6.4 & 10.1 & 20.6 & 6.4 & 131.8 & 3.2 & 2.0 & & & & & 3.6 \\
\hline Ringdal & 13:7 & 3.2 & 14.3 & 5.7 & 9.1 & 18.5 & 6.2 & 114.7 & 3.5 & 1.8 & & & & 3.7 & 3.6 \\
\hline East Norway (3) & & 3.2 & 12.5 & 5.6 & 7.8 & 16.9 & 6.4 & 107.5 & 3.1 & 2.1 & & & & 2.9 & 3.1 \\
\hline
\end{tabular}




\begin{tabular}{|c|c|c|c|c|c|c|c|c|c|c|c|c|c|c|c|c|c|}
\hline \multicolumn{9}{|c|}{ Distances between trestles } & \multirow{3}{*}{ 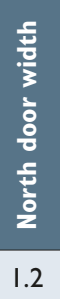 } & \multirow{3}{*}{ 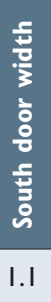 } & \multirow{3}{*}{ 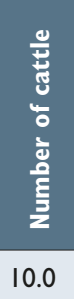 } & \multirow{3}{*}{ 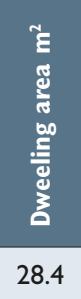 } & \multirow{3}{*}{ 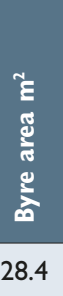 } & \multirow{2}{*}{\multicolumn{2}{|c|}{ Age BC-AD }} & \multirow{3}{*}{$\begin{array}{l}\text { Period } \\
\text { A IV/ E. PRIA }\end{array}$} & \multirow{3}{*}{$\begin{array}{c}\text { Location of } \\
\text { dwelling }\end{array}$} \\
\hline $\begin{array}{c}\text { Entrance } \\
\text { room }\end{array}$ & $1-2$ & $2-3$ & $3-4$ & 4-5 & $5-6$ & 6-7 & $7-8$ & $8-9$ & & & & & & & & & \\
\hline 1.2 & 2.0 & 1.0 & 1.6 & & & & & & & & & & & -700 & -300 & & \\
\hline 1.4 & 1.9 & 2.5 & 1.0 & & & & & & 1.2 & 1.2 & 10.0 & 44.3 & 43.7 & I & 200 & E. RIA & dwelling in $S$ \\
\hline 1.3 & 1.8 & 3.0 & 1.2 & & & & & & 1.4 & 1.4 & 12.0 & 43.9 & 46.4 & -500 & -200 & E. PRIA & dwelling in $N$ \\
\hline 1.4 & 2.1 & 1.8 & 1.9 & 1.0 & & & & & 1.3 & 1.4 & 14.0 & 48.8 & 56.6 & & & E. IA & dwelling in SE \\
\hline 1.3 & 1.9 & 1.9 & & & & & & & I.I & I.I & 8.0 & 60.5 & 31.9 & -400 & -230 & E. PRIA & dwelling in S \\
\hline 3.5 & 1.6 & 2.2 & 1.7 & & & & & & 1.5 & 1.3 & 12.0 & 53.1 & 41.0 & -700 & -300 & LBA IV/ E. PRIA & dwelling in W \\
\hline 3.1 & 3.3 & 2.1 & 2.1 & & & & & & 1.3 & 1.2 & 14.0 & 58.5 & 61.8 & -760 & -510 & LBA VI & dwelling in S \\
\hline 1.9 & 2.1 & 2.1 & 1.9 & 1.0 & & & & & 1.3 & 1.2 & 11.4 & 48.2 & 44.2 & & & & \\
\hline 2.9 & 2.2 & 2.7 & & & & & & & 1.6 & & 10.0 & 46.8 & 44.9 & & & E. IA & no byre traces \\
\hline 1.5 & 2.8 & 2.7 & & & & & & & 1.2 & 1.2 & & 60.4 & 53.0 & -1780 & -1620 & EBA I & \\
\hline 2.2 & 2.5 & 2.7 & & & & & & & 1.4 & 1.2 & 10.0 & 53.6 & 48.9 & & & & \\
\hline 1.7 & 2.8 & & & & & & & & 1.4 & 1.1 & 6.0 & 26.5 & 20.0 & -420 & -250 & E. PRIA & no byre traces \\
\hline 1.3 & 1.0 & 0.9 & 1.0 & 1.7 & & & & & I.I & & 10.0 & 26.9 & 42.6 & -760 & -400 & LBA VI/E. PRIA & dwelling in W \\
\hline 1.0 & 1.0 & 1.0 & 1.4 & 1.6 & & & & & I.I & I.I & 10.0 & 47.4 & 46.8 & -760 & -400 & LBA VI/E. PRIA & dwelling in $E$ \\
\hline 3.0 & 1.3 & 1.4 & & & & & & & I.I & & & 36.9 & 25.9 & 145 & 330 & L. RIA & \\
\hline 1.4 & 1.3 & 1.2 & 1.2 & 1.4 & & & & & I.I & & 8.0 & 44.0 & 39.1 & -200 & -1 & L... PRIA & \\
\hline 1.7 & 1.2 & I.I & 1.3 & 1.5 & & & & & I.I & & 9.0 & 38.8 & 38.6 & & & & \\
\hline 2.0 & 1.6 & 2.2 & & & & & & & 1.2 & & 7.0 & 22.8 & 31.8 & -800 & -780 & LBAV & \\
\hline 1.5 & 1.6 & 0.9 & 1.2 & 1.2 & & & & & 1.3 & 1.3 & 10.0 & 27.8 & 37.7 & -370 & -200 & PRIA & dwlling in S \\
\hline 1.5 & 0.9 & I.I & 0.9 & 0.9 & 1.1 & & & & 1.2 & 1.3 & 10.0 & 27.4 & 30.8 & -385 & -200 & E. PRIA & dwelling in $E$ \\
\hline 1.0 & 1.3 & 1.3 & 1.0 & 0.8 & 0.9 & & & & 0.9 & 0.9 & 10.0 & 23.0 & 31.5 & -110 & 10 & L. PRIA & \\
\hline 1.4 & 1.2 & 1.0 & I.I & 0.9 & & & & & 0.9 & & 8.0 & 43.7 & 29.6 & 150 & 350 & L. RIA & dwelling in $S$ \\
\hline 1.2 & 1.2 & 1.3 & 1.0 & & & & & & & 1.4 & 6.0 & 59.2 & 32.5 & -900 & -800 & L. BAV & dwelling in $\mathrm{E}$ \\
\hline 1.6 & I.I & I.I & 1.2 & 1.1 & 1.1 & & & & 1.2 & 1.3 & 10.0 & 59.4 & 43.8 & -400 & -200 & E. PRIA & dwelling in $\mathrm{E}$ \\
\hline 1.3 & 1.2 & 0.9 & 0.9 & 1.2 & & & & & I.4 & & 8.0 & 62.7 & 32.5 & -375 & -115 & L. PRIA & dwelling in $\mathrm{E}$ \\
\hline 1.4 & 0.9 & I.I & 0.8 & 1.2 & 1.0 & 1.0 & 1.7 & 2.5 & 1.4 & & 16.0 & 42.6 & 66.1 & -820 & -540 & L. BA V-VI & dwelling in $N$ \\
\hline 1.7 & 1.0 & 1.0 & 1.1 & 1.0 & 1.2 & 2.1 & & & 1.2 & & 14.0 & 78.1 & 52.3 & -1310 & -1000 & E. BA III-IV & dwelling in S \\
\hline 1.4 & 1.2 & 1.1 & 1.0 & 1.1 & 1.1 & 1.6 & 1.7 & 2.5 & 1.2 & 1.2 & 10.2 & 47.1 & 39.6 & & & & \\
\hline 3.5 & 5.2 & 3.2 & & & & & & & 1.6 & 1.0 & & 210.6 & & -160 & -30 & L. PRIA & no byre traces \\
\hline 3.4 & 3.2 & 3.4 & & & & & & & 1.5 & 1.5 & 14.0 & 73.4 & 58.5 & 430 & 550 & MP & dwelling in SW \\
\hline 2.0 & 2.5 & 2.4 & 2.3 & & & & & & 1.7 & & & 83.2 & 59.8 & -355 & -65 & L. PRIA & no byre traces \\
\hline 2.3 & 2.5 & 2.0 & & & & & & & 1.8 & 1.6 & & 57.2 & 42.3 & 430 & 560 & MP & dwelling in $E$ \\
\hline 2.6 & 2.7 & 2.6 & 2.3 & & & & & & 1.7 & 1.6 & 14.0 & 71.3 & 53.5 & & & & \\
\hline 2.5 & 2.0 & & & & & & & & 1.3 & & & 31.7 & 27.1 & -800 & -400 & L. BA V-VI & no byre traces \\
\hline 4.2 & 3.6 & 3.4 & & & & & & & 1.9 & 2.0 & & 41.0 & 64.6 & 215 & 370 & L. RIA & no byre traces \\
\hline 3.6 & 3.4 & & & & & & & & I.7 & 2.1 & & 35.3 & 56.4 & 250 & 425 & L. RIA/E. MP & no byre traces \\
\hline 3.4 & 3.0 & 3.4 & & & & & & & 1.6 & 2.1 & & 36.0 & 49.4 & & & & \\
\hline
\end{tabular}


Table 14. Compiled measurements from features of type 3 houses in Northern Jutland in Bronze Age. Measurements in metres (m).

\begin{tabular}{|c|c|c|c|c|c|c|c|c|c|c|c|c|c|c|}
\hline \multirow[b]{2}{*}{ Site/ type } & \multirow{2}{*}{ 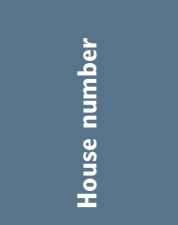 } & \multirow{2}{*}{ 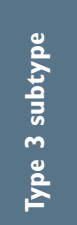 } & \multirow{2}{*}{ 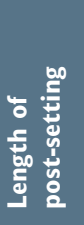 } & \multirow{2}{*}{ 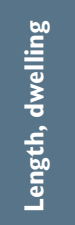 } & \multirow{2}{*}{ 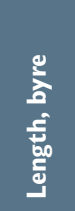 } & \multirow{2}{*}{ 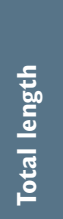 } & \multirow[b]{2}{*}{ 咅 } & \multirow{2}{*}{ 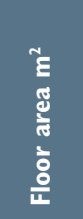 } & \multirow{2}{*}{ 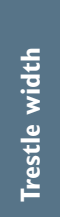 } & \multirow[b]{2}{*}{$\stackrel{O}{\square}$} & \multicolumn{4}{|c|}{ Distances between trestles } \\
\hline & & & & & & & & & & & $3-2$ & $2-1$ & $\begin{array}{l}\text { Entrance } \\
\text { room }\end{array}$ & $\mathrm{I}-2$ \\
\hline N-Jutland & Verdens & 3.1 .1 & 9.6 & 5.8 & 5.0 & 12.3 & 5.2 & 64.0 & 2.4 & 2.2 & 2.9 & 1.5 & 1.5 & 1.9 \\
\hline N-Jutland & Tastrum & 3.1 .2 & 15.9 & 7.8 & 8.8 & 19.6 & 6.3 & 123.5 & 2.7 & 2.3 & 3.1 & 2.8 & 3.0 & 3.4 \\
\hline N-Jutland & Jegstrup & 3.2 & 13.1 & 9.0 & 6.4 & 18.7 & 5.8 & 108.5 & 2.4 & 2.4 & 3.4 & 2.6 & 3.3 & 3.8 \\
\hline N-Jutland & Heltborg & 3.2 & 13.2 & 7.2 & 7.9 & 17.8 & 7.2 & 128.2 & 2.9 & 2.5 & & 4.6 & 2.7 & 2.9 \\
\hline N-jutland & Hellerup & 3.2 & 15.2 & 7.7 & 9.3 & 19.7 & 7.2 & $|4| .8$ & 2.6 & 2.8 & & 5.7 & 2.7 & 3.8 \\
\hline N-Jutland & Aas VII & 3.2 & 14.1 & 7.0 & 10.0 & 20.3 & 7.7 & 156.3 & 3.0 & 2.6 & & 5.0 & 3.3 & 3.0 \\
\hline N-Jutland & Bjerre 2:2 & 3.2 & 14.5 & 10.0 & 7.4 & 19.5 & 7.0 & 136.5 & 2.6 & 2.7 & 4.0 & 3.4 & 2.1 & 5.0 \\
\hline Mean & North Jutland & 3.2 & 14.0 & 8.2 & 8.2 & 19.2 & 7.0 & 134.3 & 2.7 & 2.6 & 3.7 & 4.3 & 2.8 & 3.7 \\
\hline N-Jutland & Bjerre 2:3 & 3.3 & 15.0 & 7.8 & 9.8 & 19.0 & 6.0 & 114.0 & 2.2 & 2.7 & 3.9 & 1.8 & 1.4 & 2.8 \\
\hline N-Jutland & Jegstrup & 3.3 & 19.1 & 8.0 & 12.4 & 23.8 & 5.7 & 135.7 & 2.4 & 2.4 & 3.5 & 2.2 & 3.4 & 1.8 \\
\hline Mean & North Jutland & 3.3 & 17.1 & 7.9 & 11.1 & 21.4 & 5.9 & 124.8 & 2.3 & 2.6 & 3.7 & 2.0 & 2.4 & 2.3 \\
\hline N-Jutland & Aas II & 3.4 & 10.2 & 7.6 & 5.0 & 14.8 & 6.9 & 102.1 & 2.7 & 2.6 & & 5.4 & 2.2 & 2.6 \\
\hline N-Jutland & Aas IX & 3.4 & 9.0 & 5.0 & 5.4 & 12.6 & 5.8 & 73.1 & 3.4 & 1.7 & & 2.9 & 2.2 & 3.9 \\
\hline N-Jutland & Stagstrup I & 3.4 & 9.2 & 6.8 & 4.6 & 13.8 & 6.9 & 95.2 & 2.5 & 2.8 & & 4.2 & 2.4 & 2.6 \\
\hline Mean & North Jutland & 3.4 & 9.5 & 6.5 & 5.0 & 13.7 & 6.5 & 90.1 & 2.9 & 2.3 & & 4.2 & 2.3 & 3.0 \\
\hline
\end{tabular}

location of hearth

In those areas, there are so many excavations with well-preserved house plans that the comparative material must be restricted to a small group of sites where there are sufficient numbers of houses to allow for a statistical analysis of them. The sites were chosen to include different parts of southern Scandinavia and Northern Germany and also the different time periods within the time span that type 3 houses occur at Forsandmoen (Tables 14-22).

The chosen settlement sites have all more or less been completely investigated, so it is possible to interpret fully excavated houses and analyse them as an entity. Sites excavated in connection with roads, gas or water pipes or the like were initially excluded because this often results in many partly unearthed houses, which are difficult to use in comparisons. However, in order to present a comparable data set of houses from all the periods represented at Forsand, data from smaller excavations has been collected from northern Jutland and South Sweden. The following sites areas have been chosen: North Jutland and South Sweden from the Bronze Age, Grøntoft, Hodde, Flögeln from the Pre-Roman Iron Age and South Sweden from the PreRoman Iron Age and the Roman Iron Age.

The analysed houses comprise 106 type 3 houses distributed between the similar sub-types as those at Forsand. In addition, 64 smaller type 3 houses (3.4) with only four trestles are included in the tables.

North Jutland is the nearest southern Scandinavian area to Rogaland and Forsand. Most likely, the type 3 concept of a combined dwelling/byre house originated in that area. Twelve type 3 Bronze Age houses from that area have been analysed to compare with the Forsand houses (Table 14). The subtype 3.2 is most frequently represented and, compared to subtype 3.2 at Forsand, the Jutlandish houses are much larger (total length 19.2 $\mathrm{m}$ compared to $12.8 \mathrm{~m}$ ) due to a much longer trestle span. They could accommodate seven people and eleven cattle compared to four people and seven cattle at Forsand. These numbers are approximately what have 


\begin{tabular}{|c|c|c|c|c|c|c|c|c|c|}
\hline \multicolumn{4}{|c|}{ Distances between trestles } & \multirow{2}{*}{ 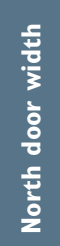 } & \multirow{2}{*}{ 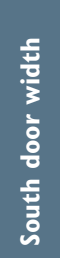 } & \multirow{2}{*}{ 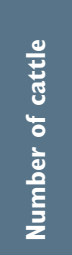 } & \multirow{2}{*}{ 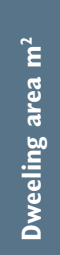 } & \multirow{2}{*}{ 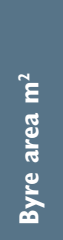 } & \multirow[b]{2}{*}{ Period } \\
\hline $2-3$ & $3-4$ & 4-5 & $5-6$ & & & & & & \\
\hline 1.8 & & & & 1.3 & 1.1 & 8.0 & 30.2 & 26.0 & BA III-IV \\
\hline \multirow[t]{2}{*}{3.6} & & & & & 1.7 & 16.0 & 49.1 & 55.4 & BA III-VI \\
\hline & & & & 1.6 & 1.4 & 8.0 & 52.2 & 37.1 & BAV \\
\hline 3.0 & & & & 0.9 & & 12.0 & 51.8 & 56.9 & BA IV-VI \\
\hline 3.0 & & & & 1.1 & & 14.0 & 55.4 & 67.0 & BA III \\
\hline \multirow[t]{2}{*}{2.8} & & & & 1.2 & 0.9 & 12.0 & 53.9 & 77.0 & BA IV-VI \\
\hline & & & & 1.5 & 1.1 & 10.0 & 70.0 & 51.8 & BA II \\
\hline 3.6 & & & & 1.3 & I.I & 11.2 & 56.7 & 58.0 & BA II-V \\
\hline 3.2 & 1.9 & & & 1.0 & 1.4 & 16.0 & 46.8 & 58.8 & BA II \\
\hline 2.0 & 2.0 & 1.6 & 2.6 & 1.1 & 1.2 & 22.0 & 45.6 & 70.7 & BAV \\
\hline \multirow[t]{5}{*}{2.6} & 2.0 & 1.6 & 2.6 & 1.1 & 1.3 & 19.0 & 46.2 & 64.7 & \\
\hline & & & & 0.9 & 0.9 & 6.0 & 52.4 & 34.5 & BA IV-V \\
\hline & & & & & & 10.0 & 29.0 & 31.3 & BA V-VI \\
\hline & & & & 1.1 & I.I & 6.0 & 46.9 & 31.7 & BA IV-VI \\
\hline & & & & 1.0 & 1.0 & 7.3 & 42.8 & 32.5 & BA IV-VI \\
\hline
\end{tabular}

been found for the long type 3.1.2 house, which has one more trestle in the construction. The dwelling area in the North Jutland houses was located in the western part of the house, so the opposite pattern at Forsand has not been adopted from this area.

From South Sweden, 20 type 3.1.1-3.1.3 and 3.3 Bronze Age houses have been analysed (Table 15). Type 3.2 is also more frequent in this area compared to the subtypes 3.1 and 3.3 than is the case for the Forsand material. In general, the type 3.1 and 3.3 houses in South Sweden are larger than the similar houses at Forsand, for instance the average size of type 3.1 houses in South Sweden is $17.8 \times 7 \mathrm{~m}\left(124 \mathrm{~m}^{2}\right)$ compared to $14.3 \times 5.9$ $\mathrm{m}\left(89 \mathrm{~m}^{2}\right)$ at Forsand; for type 3.3 houses, the South Swedish houses measured $21.2 \times 7 \mathrm{~m}\left(148.9 \mathrm{~m}^{2}\right)$ compared to $17.1 \times 6.4 \mathrm{~m}\left(108 \mathrm{~m}^{2}\right)$ at Forsand. In both cases, the roofed area at Forsand represents only $72 \%$ of the South Swedish area. Consequently, each farmstead at Forsand could accommodate only approximately $2 / 3$ the number of inhabitants and stalled cattle of what was possible in South Sweden in the Bronze Age, i.e. seven people and ten cattle versus five people and eight cattle in type 3.1 houses and eight people and 16 cattle versus 6-7 people and 14 cattle in type 3.3 houses. The average size of type 3.2 houses in South Sweden $\left(14.2 \times 6.6 \mathrm{~m}, 93 \mathrm{~m}^{2}\right)$ is also larger $\left(12.8 \times 5.8 \mathrm{~m}, 74 \mathrm{~m}^{2}\right)$ compared to the same type at Forsand.

If we turn to the house types 3.1 and 3.3 in the PreRoman Iron Age, we can see that the length of the houses still is shorter at Forsand (approximately $80 \%$ ). However, the house width was larger at Forsand during that period, resulting in approximately the same roofed area in the two house types, which means space for five people and 8-9 cattle in type 3.1 and 7-8 people and 16 cattle in type 3.3. The conclusion from these figures is that the farmsteads at Forsand developed from being $2 / 3$ of the size of comparable houses in South Sweden in the Bronze Age to being equal size in the Pre-Roman Iron Age. The figures also indicate that, in South Sweden, both house types were made smaller in the Pre-Roman Iron Age than in the Bronze Age, while in Forsand, the size of type 3.1 was unchanged and type 3.3 increased by $20 \%$ from the Bronze Age to the Pre-Roman Iron Age. This can be regarded as a development from a newly established settlement with limited human and agricultural resources to a settlement similar to those in southern Scandinavia.

The type 3 houses from North Jutland and South Sweden have one feature in common that is not shared at Forsand: all the hearths found in these southern Scandinavian Bronze Age houses were situated in the western half of the house. At Forsand, all the hearths from the Bronze Age and the Pre-Roman Iron Age were situated in the eastern half and - with the exception of a few houses from the Roman Iron Age, where the dwelling area was located in the western part - all the other houses are interpreted as having the dwelling area in the eastern part. This odd habit compared to southern Scandinavia can probably be explained by local weather conditions.

From the Pre-Roman Iron Age, the excavations at Grøntoft and Hodde from the southern part of Jutland (Tables 16 and 17) have been analysed. The overall impression is that the type 3 houses there are smaller than those at Forsand due to the scarcity of type 3.1 and 3.3 houses but with many type 3.2 houses and, most importantly, also many houses with only four trestles (type 3.4). At both sites, traces of hearths are always found in the western part and, with a few exceptions at Hodde, the traces of the stall boxes were located in the eastern part. 
Table 15. Compiled measurements from features of type 3 houses in South Sweden in different periods. Measurements in metres (m).

\begin{tabular}{|c|c|c|c|c|c|c|c|c|c|c|c|c|c|}
\hline Site/type & $\begin{array}{l}\text { House } \\
\text { number }\end{array}$ & $\begin{array}{l}\text { Type } 3 \\
\text { subtype }\end{array}$ & $\begin{array}{l}\text { Length of } \\
\text { post-setting }\end{array}$ & $\begin{array}{l}\text { Length, } \\
\text { dwelling }\end{array}$ & $\begin{array}{l}\text { Length, } \\
\text { byre }\end{array}$ & $\begin{array}{l}\text { Total } \\
\text { length }\end{array}$ & Width & $\begin{array}{c}\text { Floor } \\
\text { area } \mathbf{m}^{2}\end{array}$ & $\begin{array}{l}\text { Trestle } \\
\text { width }\end{array}$ & TQ & $4-3$ & $3-2$ & $2-1$ \\
\hline Järrestad SU:2 & 15 & 3.1 .2 & 13,4 & 6.9 & 8.0 & 17.3 & 7.0 & 121.1 & 4.0 & 1.8 & & 2.2 & 2.7 \\
\hline Fosie & 91 & 3.1 .2 & 19,4 & 7.0 & 12.0 & 21.7 & 7.0 & 151.9 & 3.6 & 1.9 & & 5.0 & 4.8 \\
\hline Svågertorp 8B-C & 1 & 3.1 .2 & 14,4 & 10.6 & 5.0 & 18.5 & 7.0 & 129.5 & 3.2 & 2.2 & 3.4 & 2.2 & 2.8 \\
\hline Pryssgården & 210 & 3.1 .1 & 11,3 & 8.2 & 5.6 & 15.3 & 6.6 & 101.0 & 3.2 & 2.1 & & 3.5 & 2.7 \\
\hline Pryssgården & 195 & 3.1 .1 & 12,2 & 9.6 & 5.0 & 16.2 & 7.2 & 116.6 & 4.0 & 1.8 & & 3.9 & 3.6 \\
\hline Mean (5) & & & 14,1 & 8.5 & 7.1 & 17.8 & 7.0 & 124.0 & 3.6 & 1.9 & & 3.4 & 3.3 \\
\hline Köpinge area & $\mathrm{B} \mid 3: 2$ & 3.2 & 9,0 & 5.6 & 5.7 & 13.4 & 6.7 & 89.8 & 3.1 & 2.2 & & & 3.4 \\
\hline Köpinge area & $\mathrm{B} \mid 3: 3$ & 3.2 & 10,9 & 7.3 & 6.0 & 14.5 & 6.5 & 94.3 & 3.4 & 1.9 & & & 5.5 \\
\hline Köpinge area & BI4:III & 3.2 & 10,4 & 6.0 & 6.3 & 14.3 & 7.0 & 100.1 & 3.1 & 2.3 & & & 4.8 \\
\hline Köpinge area & BI4:I & 3.2 & 10,3 & 7.3 & 5.6 & 14.1 & 7.0 & 98.7 & 3.8 & 1.8 & & & 5.2 \\
\hline Köpinge area & B26:I & 3.2 & 11,0 & 6.4 & 6.6 & 15.9 & 6.7 & 106.5 & 3.8 & 1.8 & & & 4.2 \\
\hline Pryssgården & 187 & 3.2 & 10,2 & 8.2 & 4.0 & 13.4 & 6.6 & 88.4 & 4.2 & 1.6 & & 3.8 & 3.2 \\
\hline Pryssgården & 161 & 3.2 & 10,2 & 9.0 & 3.8 & 14.3 & 6.2 & 88.7 & 3.8 & 1.6 & & 3.7 & 3.2 \\
\hline Pryssgården & 179 & 3.2 & 9,9 & 5.0 & 7.4 & 13.9 & 6.0 & 83.4 & 2.6 & 2.3 & & & 3.0 \\
\hline Pryssgården & 201 & 3.2 & 9,6 & 8.0 & 4.3 & 13.7 & 6.6 & 90.4 & 3.5 & 1.9 & & 4.2 & 1.8 \\
\hline Mean (9) & & 3.2 & 10,2 & 7.0 & 5.5 & 14.2 & 6.6 & 93.4 & 3.5 & 1.9 & & 3.9 & 3.8 \\
\hline Fosie & 75 & 3.3 & 18,9 & 8.5 & 12.6 & 23.1 & 8.0 & 184.8 & 4.7 & 1.7 & & 3.0 & 3.4 \\
\hline Elinelund $2 \mathrm{~A}$ & I & 3.3 & 20,1 & 10.0 & 10.6 & 23.8 & 7.0 & 166.6 & 3.5 & 2.0 & & 4.3 & 4.0 \\
\hline Pryssgården & 189 & 3.3 & 18,1 & 11.0 & 11.5 & 23.8 & 7.2 & 171.4 & 3.8 & 1.9 & & 4.4 & 3.7 \\
\hline Pryssgården & 172 & 3.3 & 15,2 & 7.2 & 10.1 & 18.8 & 6.4 & 120.3 & 2.8 & 2.3 & & 3.2 & 2.0 \\
\hline Pryssgården & 150 & 3.3 & 18,1 & 9.8 & 11.1 & 22.1 & 6.6 & 145.9 & 2.8 & 2.4 & 2.8 & 2.9 & 2.1 \\
\hline Pryssgården & 211 & 3.3 & 12,8 & 7.5 & 7.0 & 15.8 & 6.6 & 104.3 & 3.3 & 2.0 & & 3.7 & 3.0 \\
\hline Mean (6) & & 3.3 & 17,2 & 9.0 & 10.5 & 21.2 & 7.0 & 148.9 & 3.5 & 2.0 & 2.8 & 3.6 & 3.0 \\
\hline Rydebäck & 1 & 3.1 .1 & 11,9 & 7.6 & 5.0 & 15.5 & 5.5 & 85.3 & 2.9 & 1.9 & & 2.1 & 3.7 \\
\hline Pryssgården & 171 & 3.1 .2 & 13,0 & 10.3 & 6.5 & 19.2 & 6.0 & 115.2 & 3.2 & 1.9 & & 2.9 & 3.9 \\
\hline Köpinge area & B29:I & 3.1 .1 & 13,7 & 8.0 & 7.0 & 18.0 & 5.4 & 97.2 & 2.6 & 2.1 & & 2.8 & 3.1 \\
\hline Klörups backar & III & 3.1 .2 & 18,0 & 8.5 & 9.7 & 21.9 & 4.4 & 96.4 & 2.2 & 2.0 & & 3.2 & 3.5 \\
\hline Mean (4) & & & 14,2 & 8.6 & 7.1 & 18.7 & 5.3 & 98.5 & 2.7 & 2.0 & & 2.8 & 3.6 \\
\hline Grevie & & 3.3 & 17,2 & 10.8 & 11.5 & 25.1 & 5.9 & 148.1 & 3.0 & 2.0 & & 3.3 & 2.9 \\
\hline Hilleshög & 3 & 3.3 & 18,1 & 9.2 & 11.2 & 23.7 & 5.6 & 132.7 & 2.7 & 2.1 & & 3.3 & 3.7 \\
\hline Rydebäck & 3 & 3.3 & 16,2 & 11.2 & 6.6 & 20.3 & 5.5 & 111.7 & 2.8 & 2.0 & 2.6 & 3.2 & 3.4 \\
\hline Ramlösa IA:7 & II & 3.3 & 17,9 & 7.6 & 9.5 & 20.9 & 5.6 & 117.0 & 2.8 & 2.0 & & 2.9 & 3.1 \\
\hline Annelöv SUI4:V & 10 & 3.3 & 21,1 & 10.2 & 11.3 & 24.9 & 6.0 & 149.4 & 2.2 & 2.7 & & 4.9 & 3.3 \\
\hline Mean (5) & & 3.3 & 18,1 & 9.8 & 10.0 & 23.0 & 5.7 & 131.8 & 2.7 & 2.1 & 2.6 & 3.5 & 3.3 \\
\hline Böljenamosse & 1 & 3.2 & 14,8 & 10.3 & 7.5 & 21.1 & 5.5 & 116.1 & 2.2 & 2.5 & & 4.1 & 3.5 \\
\hline Köpinge area & BI4:IV & 3.2 & 12,5 & 6.8 & 8.0 & 17.0 & 5.6 & 95.2 & 1.7 & 3.3 & & & 4.5 \\
\hline Köpinge B6 & 1 & 3.2 & 19,4 & 8.0 & 11.6 & 23.5 & 5.0 & 117.5 & 2.2 & 2.3 & & & 6.0 \\
\hline Mean (3) & & 3.2 & 15,6 & 8.4 & 9.0 & 20.5 & 5.4 & 109.6 & 2.0 & 2.7 & & 4.1 & 4.7 \\
\hline Köpinge area & BI4:II & 3.4 & 8,7 & 7.0 & 4.5 & 12.7 & 6.6 & 83.8 & 3.2 & 2.1 & & & 5.3 \\
\hline Köpinge area & $\mathrm{BI} 4: \mathrm{VIII}$ & 3.4 & 8,3 & 6.9 & 3.8 & 12.0 & 6.8 & 81.6 & 3.3 & 2.1 & & & 5.0 \\
\hline Köpinge area & B26:II & 3.4 & 11,9 & 6.3 & 4.0 & 13.5 & 7.4 & 99.9 & 3.5 & 2.1 & & & 5.6 \\
\hline Hilleshög 3:6 & 5 & 3.4 & 8,6 & 5.4 & 3.6 & 12.4 & 5.6 & 69.4 & 2.4 & 2.3 & & & 3.4 \\
\hline Köpinge area & BI4:IX & 3.4 & 13,4 & 7.2 & 6.6 & 18.1 & 5.8 & 105.0 & 1.9 & 3.1 & & & 4.7 \\
\hline Mean (5) & & 3.4 & 10,2 & 6.6 & 4.5 & 13.7 & 6.4 & 87.9 & 2.9 & 2.3 & & & 4.8 \\
\hline
\end{tabular}




\begin{tabular}{|c|c|c|c|c|c|c|c|c|c|c|c|c|c|}
\hline \multicolumn{6}{|c|}{ Distances between trestles } & \multirow[b]{2}{*}{$\begin{array}{c}\text { North } \\
\text { door width }\end{array}$} & \multirow[b]{2}{*}{$\begin{array}{l}\text { South door } \\
\text { width }\end{array}$} & \multirow[b]{2}{*}{$\begin{array}{l}\text { Number } \\
\text { of cattle }\end{array}$} & \multirow[b]{2}{*}{$\begin{array}{l}\text { Dweeling } \\
\text { area } \mathrm{m}^{2}\end{array}$} & \multirow{2}{*}{$\begin{array}{c}\text { Byre } \\
\text { area } \\
\mathbf{m}^{2}\end{array}$} & \multirow[b]{2}{*}{ Period } & \multirow{2}{*}{\multicolumn{2}{|c|}{$\begin{array}{l}\text { Age } \\
\text { BC-AD }\end{array}$}} \\
\hline $\begin{array}{l}\text { Entrance } \\
\text { room }\end{array}$ & $\mid-2$ & $2-3$ & $3-4$ & 4-5 & $5-6$ & & & & & & & & \\
\hline 2.4 & 3.1 & 3.0 & & & & & 1.6 & 12 & 48.3 & 56.0 & Early BA & -1500 & -1100 \\
\hline 2.7 & 3.2 & 3.7 & & & & 1.2 & 1.3 & 14 & 49.0 & 84.0 & Late BA & -1100 & -500 \\
\hline 2.9 & 3.1 & & & & & 1.0 & 1.1 & 6 & 74.2 & 35.0 & Late BA & -1100 & -500 \\
\hline 1.5 & 1.9 & 1.7 & & & & & & 8 & 54.1 & 37.0 & Late BA & -1100 & -500 \\
\hline 1.6 & 1.5 & 1.6 & & & & & 1.5 & 8 & 69.1 & 36.0 & Late BA & -1100 & -500 \\
\hline 2.2 & 2.6 & 2.5 & & & & 1.1 & 1.4 & 10 & 58.9 & 49.6 & Bronze Age & & \\
\hline 2.1 & 1.7 & 1.8 & & & & 1.1 & 1.1 & 8 & 37.5 & 38.2 & Early BA & -1500 & -1100 \\
\hline 1.2 & 1.8 & 2.4 & & & & 1.0 & 0.9 & 8 & 47.5 & 39.0 & Early BA & -1500 & -1100 \\
\hline 2.0 & 1.7 & 1.9 & & & & & 1.5 & 8 & 42.0 & 44.1 & Early BA & -1500 & -1100 \\
\hline 1.2 & 1.9 & 2.0 & & & & & & 8 & 51.1 & 39.2 & Late BA & -1100 & -500 \\
\hline 2.9 & 2.0 & 1.9 & & & & 1.6 & 1.2 & 8 & 42.9 & 44.2 & Late BA & -1100 & -500 \\
\hline 1.2 & 2.0 & & & & & & 1.3 & 4 & 54.1 & 26.4 & Late BA & -1100 & -500 \\
\hline 1.5 & 1.8 & & & & & & 1.1 & 4 & 55.8 & 23.6 & Late BA & -1100 & -500 \\
\hline 1.5 & 2.4 & 3.0 & & & & & 0.9 & 12 & 30.0 & 44.4 & Late BA & -1100 & -500 \\
\hline 1.4 & 2.2 & & & & & & 1.0 & 4 & 52.8 & 28.4 & Late BA & -1100 & -500 \\
\hline 1.7 & 1.9 & 2.2 & & & & 1.2 & 1.1 & $7-8$ & 46.0 & 36.4 & Bronze Age & & \\
\hline 2.0 & 2.0 & 4.9 & 3.6 & & & 2.2 & & 24 & 68.0 & 100.8 & Early BA & -1500 & -1100 \\
\hline 3.2 & 1.7 & 2.4 & 2.3 & 2.2 & & 1.6 & 1.5 & 16 & 70.0 & 74.2 & Early BA & -1500 & -1100 \\
\hline 1.3 & 1.8 & 1.7 & 1.9 & 2.0 & 1.3 & 1.1 & & 12 & 79.2 & 82.8 & Late BA & -1100 & -500 \\
\hline 1.5 & 1.8 & 1.8 & 1.8 & 1.5 & 1.6 & & 1.2 & 20 & 46.1 & 64.6 & Late BA & -1100 & -500 \\
\hline 1.2 & 1.7 & 1.7 & 1.7 & 1.8 & 2.2 & & 1.4 & 16 & 64.7 & 73.3 & Late BA & -1100 & -500 \\
\hline 1.3 & 2.0 & 1.6 & 1.2 & & & & 1.2 & 10 & 49.5 & 46.2 & Late BA & -1100 & -500 \\
\hline 1.8 & 1.8 & 2.4 & 2.1 & 1.9 & 1.7 & 1.6 & 1.3 & $16-17$ & 62.9 & 73.7 & Bronze Age & & \\
\hline 2.9 & 1.7 & 1.5 & & & & 1.2 & 1.2 & 8 & 41.8 & 27.5 & Early Pre-Roman IA & -500 & -200 \\
\hline 2.4 & 2.0 & 1.8 & & & & 1.3 & & 8 & 61.8 & 39.0 & Early Pre-Roman IA & -500 & -200 \\
\hline 3.0 & 2.0 & 2.8 & & & & 1.1 & & 10 & 43.2 & 37.8 & Late Pre-Roman IA & -200 & -1 \\
\hline 3.7 & 3.8 & 3.8 & & & & 1.5 & & 16 & 37.4 & 42.7 & Early Roman IA & I & 200 \\
\hline 3.0 & 2.4 & 2.5 & & & & 1.3 & 1.2 & 11 & 46.0 & 36.7 & Pre- and Roman IA & & \\
\hline 2.8 & 2.8 & 2.9 & 2.5 & & & 1.3 & 1.4 & 18 & 63.7 & 67.9 & Early Pre-Roman IA & -500 & -200 \\
\hline 3.3 & 1.9 & 2.8 & 3.1 & & & & 1.4 & 16 & 51.5 & 62.7 & Early Pre-Roman IA & -500 & -200 \\
\hline 2.5 & 2.4 & 2.1 & & & & 1.2 & 1.2 & 8 & 61.6 & 36.3 & Early Pre-Roman IA & -500 & -200 \\
\hline 3.8 & 4.2 & 2.1 & 1.8 & & & 1.3 & 1.3 & 16 & 42.6 & 53.2 & Late Pre-Roman IA & -200 & -1 \\
\hline 3.4 & 2.3 & 3.5 & 3.7 & & & 1.3 & 1.4 & 20 & 61.2 & 67.8 & Late Roman IA & 200 & 400 \\
\hline 3.2 & 2.7 & 2.7 & 2.8 & & & 1.3 & 1.3 & $15-16$ & 56.1 & 57.6 & Pre- and Roman IA & & \\
\hline 3.3 & 3.9 & & & & & 1.1 & 1.3 & & 56.7 & 41.3 & Roman IA & 1 & 400 \\
\hline 2.2 & 1.9 & 3.9 & & & & & & 12 & 38.1 & 44.8 & Late Roman IA & 200 & 400 \\
\hline 3.9 & 3.7 & 5.8 & & & & & 1.2 & & 40.0 & 58.0 & Late Roman IA & 200 & 400 \\
\hline 3.1 & 3.2 & 4.8 & & & & I.I & 1.3 & & 44.9 & 48.0 & Roman IA & & \\
\hline 1.2 & 2.2 & & & & & 0.8 & 1.0 & 4 & 46.2 & 29.7 & Late BA & -1100 & -500 \\
\hline 1.3 & 2.0 & & & & & 0.9 & 0.8 & 4 & 46.9 & 25.8 & Late BA & -1100 & -500 \\
\hline 3.2 & 3.1 & & & & & & 1.1 & 6 & 46.6 & 29.6 & Late BA & -1100 & -500 \\
\hline 3.4 & 1.8 & & & & & 1.0 & & 4 & 30.2 & 20.2 & Early Pre-Roman IA & -500 & -200 \\
\hline 4.3 & 4.4 & & & & & & 1.0 & 10 & 41.8 & 38.3 & Late Roman IA & 200 & 400 \\
\hline 2.7 & 2.7 & & & & & 0.9 & 1.0 & $5-6$ & 42.3 & 28.7 & Multi period & & \\
\hline
\end{tabular}


Table 16. Compiled measurements from features of type 3 houses at Hodde in Jutland in the Pre-Roman Iron Age. Measurements in metres $(\mathrm{m})$.

\begin{tabular}{|c|c|c|c|c|c|c|c|c|c|}
\hline Site & House number & Type 3 subtype & Orientation & Length of post-setting & Total length & Width & Floor area $\mathrm{m}^{2}$ & Trestle width & TQ \\
\hline Hodde & $\mathrm{XVII}$ & 3.1 .1 & 290 & 9.2 & 12.2 & 5.2 & 63.4 & 2.9 & 1.8 \\
\hline Hodde & $X \mathrm{~L}$ & 3.1 .1 & 290 & 9.4 & 12.4 & 5.4 & 67.0 & 3.2 & 1.7 \\
\hline Hodde & $\mathrm{XXI}$ & 3.1 .1 & 295 & 11.2 & 14.2 & 5.0 & 71.0 & 2.7 & 1.9 \\
\hline Hodde & XII & 3.1 .1 & 295 & 12.1 & 15.1 & 4.8 & 72.5 & 2.8 & 1.7 \\
\hline Hodde & XXXVIIb & 3.1 .1 & 293 & 14.2 & 17.2 & 5.2 & 89.4 & 3.1 & 1.7 \\
\hline Hodde & $X V$ & 3.1 .1 & 300 & 14.6 & 17.6 & 5.2 & 91.5 & 2.8 & 1.9 \\
\hline Mean & & & 294 & 11.8 & 14.8 & 5.1 & 75.8 & 2.9 & 1.8 \\
\hline Hodde & $X X V a$ & 3.2 & 297 & 9.8 & 12.8 & 5.2 & 66.6 & 3.1 & 1.7 \\
\hline Hodde & XLVIla & 3.2 & 296 & 11.0 & 13.0 & 5.0 & 65.0 & 3.0 & 1.7 \\
\hline Hodde & IV & 3.2 & 287 & 10.0 & 13.0 & 5.2 & 67.6 & 2.7 & 1.9 \\
\hline Hodde & XIII & 3.2 & 291 & 10.2 & 13.2 & 5.4 & 71.3 & 3.0 & 1.8 \\
\hline Hodde & LXVIII & 3.2 & 290 & 10.4 & 13.4 & 5.4 & 72.4 & 3.0 & 1.8 \\
\hline Hodde & XXXIIIb & 3.2 & 298 & 10.5 & 13.5 & 5.4 & 72.9 & 2.8 & 1.9 \\
\hline Hodde & $X X V b$ & 3.2 & 300 & 10.8 & 13.8 & 5.2 & 71.8 & 2.8 & 1.9 \\
\hline Hodde & XXIIIb & 3.2 & 295 & 11.4 & 14.4 & 5.2 & 74.9 & 3.1 & 1.7 \\
\hline Hodde & XXVla & 3.2 & 297 & 11.6 & 14.6 & 5.3 & 77.4 & 2.9 & 1.8 \\
\hline Hodde & XXII & 3.2 & 291 & 13.0 & 15.0 & 5.5 & 82.5 & 2.8 & 2.0 \\
\hline Hodde & LVI & 3.2 & 298 & 12.7 & 15.7 & 5.6 & 87.9 & 3.2 & 1.8 \\
\hline Hodde & $\mathrm{Lb}$ & 3.2 & 321 & 12.8 & 15.8 & 5.3 & 83.7 & 2.8 & 1.9 \\
\hline Hodde & $X a$ & 3.2 & 295 & 14.4 & 17.4 & 5.6 & 97.4 & 3.2 & 1.8 \\
\hline Hodde & XLVla & 3.2 & 302 & 15.3 & 18.3 & 5.5 & 100.7 & 3.3 & 1.7 \\
\hline Mean & & & 297 & 11.7 & 14.6 & 5.3 & 78.0 & 3.0 & 1.8 \\
\hline Hodde & $x X X$ & 3.3 & 300 & 10.2 & 13.2 & 5.2 & 68.6 & 3.0 & 1.7 \\
\hline Hodde & $\mathrm{lb}$ & 3.3 & 298 & 19.5 & 22.5 & 5.6 & 126.0 & 3.2 & 1.8 \\
\hline Hodde & la & 3.3 & 298 & 24.0 & 27.6 & 5.6 & 154.6 & 3.2 & 1.8 \\
\hline Mean & & & 299 & 17.9 & 21.1 & 5.5 & 116.4 & 3.1 & 1.7 \\
\hline Hodde & $\mathrm{La}$ & 3.4 & 306 & 6.4 & 9.4 & 4.8 & 45.1 & 2.6 & 1.8 \\
\hline Hodde & XXIV & 3.4 & 300 & 6.8 & 9.8 & 4.6 & 45.1 & 2.6 & 1.8 \\
\hline Hodde & XVIII & 3.4 & 299 & 7.1 & 10.1 & 5.0 & 50.5 & 2.8 & 1.8 \\
\hline Hodde & XIX & 3.4 & 286 & 7.8 & 10.8 & 5.2 & 56.2 & 2.9 & 1.8 \\
\hline Hodde & XLIV & 3.4 & 301 & 8.0 & 11.0 & 5.0 & 55.0 & 3.2 & 1.6 \\
\hline Hodde & LV & 3.4 & 308 & 8.4 & 11.4 & 4.8 & 54.7 & 2.7 & 1.8 \\
\hline Hodde & VII & 3.4 & 294 & 8.6 & 11.6 & 5.3 & 61.5 & 3.0 & 1.8 \\
\hline Hodde & XXVIII & 3.4 & 289 & 8.7 & 11.7 & 5.3 & 62.0 & 3.1 & 1.7 \\
\hline Hodde & LXIII & 3.4 & 303 & 8.7 & 11.7 & 5.3 & 62.0 & 3.0 & 1.8 \\
\hline Hodde & $\mathrm{XXXVI}$ & 3.4 & 298 & 8.8 & 11.8 & 5.4 & 63.7 & 2.6 & 2.1 \\
\hline Hodde & XXIIla & 3.4 & 294 & 8.8 & 11.8 & 5.0 & 59.0 & 2.7 & 1.9 \\
\hline Hodde & $\mathrm{XI}$ & 3.4 & 293 & 8.9 & 11.9 & 5.2 & 61.9 & 2.8 & 1.9 \\
\hline Hodde & LXI & 3.4 & 289 & 9.2 & 12.2 & 5.0 & 61.0 & 2.9 & 1.7 \\
\hline Hodde & LXIV & 3.4 & 300 & 9.3 & 12.3 & 5.5 & 67.7 & 3.2 & 1.7 \\
\hline Hodde & VIII & 3.4 & 298 & 9.3 & 12.3 & 5.1 & 62.7 & 2.8 & 1.8 \\
\hline Hodde & XXXVIla & 3.4 & 293 & 9.4 & 12.4 & 5.5 & 68.2 & 3.2 & 1.7 \\
\hline Hodde & XLVIIIb & 3.4 & 317 & 9.4 & 12.4 & 5.3 & 65.7 & 3.2 & 1.7 \\
\hline Hodde & $X X X V b$ & 3.4 & 298 & 9.4 & 12.4 & 5.0 & 62.0 & 2.8 & 1.8 \\
\hline Hodde & XLVIb & 3.4 & 302 & 9.6 & 12.6 & 5.4 & 68.0 & 3.2 & 1.7 \\
\hline Hodde & IX & 3.4 & 294 & 9.9 & 12.9 & 5.3 & 68.4 & 2.7 & 2.0 \\
\hline Hodde & $\mathrm{Xb}$ & 3.4 & 293 & 10.4 & 13.4 & 5.0 & 67.0 & 2.8 & 1.8 \\
\hline Mean & & & 298 & 8.7 & 11.7 & 5.1 & 60.4 & 2.9 & 1.8 \\
\hline
\end{tabular}




\begin{tabular}{|c|c|c|c|c|c|c|c|c|c|c|c|c|c|}
\hline \multicolumn{10}{|c|}{ Distances between trestles } & \multirow[b]{2}{*}{ North door width } & \multirow[b]{2}{*}{ South door width } & \multirow[b]{2}{*}{$\begin{array}{c}\text { Number of } \\
\text { cattle }\end{array}$} & \multirow[b]{2}{*}{ Comments } \\
\hline $4-3$ & $3-2$ & $2-1$ & $\begin{array}{l}\text { Entrance } \\
\text { room }\end{array}$ & $\mathrm{I}-2$ & $2-3$ & $3-4$ & $4-5$ & $5-6$ & $6-7$ & & & & \\
\hline & & 2.6 & 2.4 & 1.8 & 1.6 & 0.8 & & & & 1.2 & 1.3 & 12 & byre in east \\
\hline & 1.3 & 1.6 & 2.6 & 2.9 & 1.0 & & & & & 1.4 & 1.4 & 12 & byre in east \\
\hline & & 2.5 & 2.5 & 2.4 & 1.6 & 2.2 & & & & 1.1 & 1.0 & 14 & byre in east \\
\hline & 2.4 & 1.6 & 3.4 & 2.8 & 1.8 & & & & & & & 12 & byre in east \\
\hline & & 3.2 & 2.2 & 3.2 & 2.2 & 3.4 & & & & 1.2 & 1.2 & 16 & byre in east \\
\hline & 3.0 & 1.6 & 3.9 & 3.0 & 3.1 & & & & & 1.2 & 1.3 & $>2$ & byre in west \\
\hline & 2.2 & 2.2 & 2.8 & 2.7 & 1.9 & 2.1 & & & & 1.2 & 1.2 & 13 & \\
\hline & & 3.3 & 2.2 & 2.1 & 2.2 & & & & & 1.3 & & 0 & no byre traces \\
\hline & 3.4 & 2.5 & 2.7 & 2.4 & & & & & & 1.3 & 1.1 & 16 & byre in west \\
\hline & & 3.2 & 3.0 & 2.5 & 1.3 & & & & & 1.4 & 1.2 & 0 & no byre traces \\
\hline & & 3.2 & 2.9 & 2.7 & 1.4 & & & & & 1.4 & 1.2 & 16 & byre in east \\
\hline & & 2.8 & 2.4 & 2.6 & 2.6 & & & & & 1.4 & 1.2 & 12 & byre in east \\
\hline & & 3.9 & 2.5 & 2.6 & 1.5 & & & & & 1.4 & 1.2 & 10 & byre in east \\
\hline & & 2.5 & 3.1 & 2.6 & 2.6 & & & & & 1.2 & 1.2 & 12 & byre in east \\
\hline & & 3.0 & 2.2 & 2.8 & 3.4 & & & & & 1.4 & 1.2 & 14 & byre in east \\
\hline & & 3.2 & 3.0 & 2.9 & 2.5 & & & & & 1.4 & 1.5 & 8 & byre in east \\
\hline & & 3.4 & 3.5 & 2.8 & 3.3 & & & & & 1.2 & 1.1 & 20 & byre in east \\
\hline & & 2.9 & 3.4 & 3.2 & 3.2 & & & & & 1.2 & 1.2 & 18 & byre in east \\
\hline & 3.2 & 3.0 & 3.4 & 3.2 & & & & & & 1.4 & 1.4 & 8 & byre in east \\
\hline & 3.9 & 3.2 & 3.5 & 3.8 & & & & & & 1.5 & 1.4 & 0 & no byre traces \\
\hline 3.3 & 4.7 & 2.4 & 2.3 & 2.6 & & & & & & 1.4 & 1.0 & 24 & byre in west \\
\hline \multirow[t]{27}{*}{3.3} & 3.9 & 2.7 & 2.5 & 2.4 & 2.4 & & & & & 1.4 & 1.2 & $11-12$ & \\
\hline & & 2.5 & 2.7 & 0.7 & 1.8 & 0.8 & 0.8 & 0.8 & & 1.3 & 1.2 & 12 & byre in east \\
\hline & 3.4 & 3.6 & 4.0 & 3.3 & 1.6 & 1.2 & 2.0 & & & 1.5 & 1.6 & 22 & byre in east \\
\hline & 3.4 & 3.6 & 4.0 & 3.3 & 1.6 & 1.2 & 2.0 & 3.2 & 1.8 & 1.5 & 1.6 & 28 & byre in east \\
\hline & 3.4 & 3.2 & 3.6 & 2.4 & 1.7 & 1.1 & 1.6 & 2.0 & 1.8 & 1.4 & 1.5 & $20-21$ & \\
\hline & & 2.2 & 2.2 & 2.0 & & & & & & & 1.2 & 0 & no byre traces \\
\hline & & 2.5 & 2.3 & 2.0 & & & & & & 1.4 & 1.2 & 0 & no byre traces \\
\hline & & 2.7 & 2.3 & 2.1 & & & & & & 1.3 & 1.5 & 0 & no byre traces \\
\hline & & 2.7 & 2.2 & 2.9 & & & & & & 1.2 & & 0 & no byre traces \\
\hline & & 3.1 & 2.4 & 2.5 & & & & & & 1.2 & 1.2 & 6 & byre in east \\
\hline & & 2.6 & 2.7 & 3.1 & & & & & & 1.4 & 1.3 & 0 & no byre traces \\
\hline & & 3.2 & 2.7 & 2.7 & & & & & & 1.4 & 1.1 & 6 & byre in east \\
\hline & & 2.9 & 2.4 & 3.4 & & & & & & 1.2 & 1.2 & 8 & byre in east \\
\hline & & 2.9 & 2.2 & 3.6 & & & & & & 1.0 & 1.1 & 8 & byre in west \\
\hline & & 2.6 & 3.0 & 3.2 & & & & & & & 1.2 & 8 & byre in east \\
\hline & & 3.2 & 3.4 & 2.2 & & & & & & & 1.3 & 0 & no byre traces \\
\hline & & 2.6 & 3.0 & 3.3 & & & & & & 1.0 & 1.2 & 12 & byre in east \\
\hline & & 3.4 & 2.7 & 3.1 & & & & & & 1.3 & & 8 & byre in east \\
\hline & & 3.4 & 2.6 & 3.2 & & & & & & 1.3 & & 8 & byre in east \\
\hline & & 3.6 & 2.5 & 3.2 & & & & & & 1.4 & & 0 & no byre traces \\
\hline & & 3.2 & 3.0 & 3.2 & & & & & & 1.1 & 1.3 & 10 & byre in east \\
\hline & & 3.1 & 2.9 & 3.4 & & & & & & 1.2 & 1.4 & 8 & byre in east \\
\hline & & 3.2 & 2.8 & 3.4 & & & & & & 1.3 & 1.2 & 0 & no byre traces \\
\hline & & 2.7 & 3.7 & 3.2 & & & & & & 1.3 & 1.2 & 0 & no byre traces \\
\hline & & 3.1 & 2.9 & 3.9 & & & & & & 1.4 & 1.6 & 8 & byre in east \\
\hline & & 3.8 & 3.6 & 3.2 & & & & & & 1.5 & 1.4 & 6 & byre in east \\
\hline & & 3.0 & 2.7 & 3.0 & & & & & & 1.3 & 1.3 & $8-9$ & \\
\hline
\end{tabular}




\section{Trond Løken}

Table 17. Compiled measurements from features of type 3 houses at Grøntoft in Jutland in the Pre-Roman Iron Age. Measurements in metres $(\mathrm{m})$.

\begin{tabular}{|c|c|c|c|c|c|c|c|c|c|}
\hline Site & House number & Type 3 subtype & $\begin{array}{l}\text { Length of post- } \\
\text { setting }\end{array}$ & $\begin{array}{l}\text { Length, } \\
\text { dwelling }\end{array}$ & $\begin{array}{l}\text { Length, } \\
\text { byre }\end{array}$ & $\begin{array}{l}\text { Total } \\
\text { length }\end{array}$ & Width & $\begin{array}{c}\text { Floor area } \\
\mathrm{m}^{2}\end{array}$ & $\begin{array}{l}\text { Trestle } \\
\text { width }\end{array}$ \\
\hline Grøntoft II & $C X i b$ & 3.1 .1 & 10.7 & 4.8 & 6.0 & 13.0 & 5.0 & 65.0 & 2.6 \\
\hline Grøntoft III & EVIII & 3.1 .1 & 10.8 & 5.7 & 6.2 & 13.6 & 5.7 & 77.5 & 3.3 \\
\hline Grøntoft III & E XII c & 3.1 .1 & 11.0 & 5.4 & 6.3 & 13.7 & 5.0 & 68.5 & 2.6 \\
\hline Grøntoft III & $\mathrm{B} \| \mathrm{a}$ & 3.1 .1 & 10.2 & 6.4 & 5.8 & 13.8 & 5.4 & 74.5 & 3.5 \\
\hline Mean (4) & & 3.I.I. & 10.7 & 5.6 & 6.1 & 13.5 & 5.3 & 71.4 & 3.0 \\
\hline Grøntoft III & $B \times b$ & 3.2 & 7.9 & 3.4 & 5.7 & 10.6 & 4.3 & 45.6 & 2.4 \\
\hline Grøntoft III & $B \vee b$ & 3.2 & 7.9 & 2.7 & 5.8 & 10.6 & 4.3 & 45.6 & 2.4 \\
\hline Grøntoft III & $E X X$ & 3.2 & 7.2 & 3.6 & 4.1 & 10.0 & 5.5 & 55.0 & 2.8 \\
\hline Grøntoft IVB & A III c & 3.2 & 8.9 & 4.8 & 5.6 & 12.0 & 5.3 & 63.6 & 2.6 \\
\hline Grøntoft II & KIX & 3.2 & 8.8 & 4.1 & 6.1 & 11.5 & 5.0 & 57.5 & 2.2 \\
\hline Grøntoft II & D XIII & 3.2 & 10.0 & 4.3 & 6.0 & 13.2 & 5.4 & 71.3 & 3.2 \\
\hline Grøntoft IVB & $A X V I I b$ & 3.2 & 10.6 & 4.4 & 6.7 & 13.4 & 5.3 & 71.0 & 2.4 \\
\hline Grøntoft II & $\mathrm{HXXI}$ & 3.2 & 10.0 & 5.0 & 6.1 & 13.1 & 5.4 & 70.7 & 2.9 \\
\hline Grøntoft III & $\mathrm{DIb}$ & 3.2 & 10.4 & 5.0 & 5.7 & 13.8 & 5.0 & 69.0 & 2.8 \\
\hline Grøntoft III & $E X X V$ & 3.2 & 11.9 & 5.4 & 6.8 & 14.0 & 4.9 & 68.6 & 3.2 \\
\hline Grøntoft II & GVI & 3.2 & 12.5 & 4.8 & 7.8 & 15.7 & 6.2 & 97.3 & 3.6 \\
\hline Grøntoft IVA & A Vib & 3.2 & 13.1 & 5.6 & 8.5 & 17.0 & 5.5 & 93.5 & 2.5 \\
\hline Grøntoft II & $\mathrm{PV} \mathrm{b}$ & 3.2 & 11.9 & 5.3 & 7.2 & 15.3 & 4.7 & 71.9 & 2.7 \\
\hline Mean (I3) & & 3.2 & 10.1 & 4.5 & 6.3 & 13.1 & 5.1 & 67.7 & 2.7 \\
\hline Grøntoft IVB & $A$ III b & 3.3 & 12.4 & 4.8 & 8.6 & 15.2 & 5.3 & 80.6 & 2.5 \\
\hline Grøntoft II & $\mathrm{PVI}$ & 3.3 & 20.1 & 10.8 & 10.8 & 23.0 & 5.5 & 126.5 & 3.3 \\
\hline Mean (2) & & 3.3 & 16.3 & 7.8 & 9.7 & 19.1 & 5.4 & 103.5 & 2.9 \\
\hline Grøntoft III & A XVIII & 3.4 & 4.8 & 3.3 & 3.2 & 7.8 & 4.3 & 33.5 & 2.2 \\
\hline Grøntoft III & $B \times I$ & 3.4 & 5.4 & 3.0 & 3.0 & 7.4 & 3.9 & 28.9 & 2.1 \\
\hline Grøntoft III & $\mathrm{BV}$ a & 3.4 & 5.4 & 2.6 & 3.3 & 7.6 & 4.2 & 31.9 & 2.3 \\
\hline Grøntoft III & $B \times a$ & 3.4 & 5.9 & 3.4 & 3.7 & 7.4 & 4.5 & 33.3 & 2.4 \\
\hline Grøntoft III & B III & 3.4 & 6.0 & 3.2 & 4.4 & 9.1 & 4.0 & 36.4 & 1.8 \\
\hline Grøntoft II & $\mathrm{D} \times \mathrm{V}$ & 3.4 & 6.0 & 3.2 & 3.2 & 9.2 & 4.6 & 42.3 & 2.2 \\
\hline Grøntoft III & E XXXIII & 3.4 & 6.0 & 3.6 & 3.4 & 8.7 & 4.6 & 40.0 & 2.7 \\
\hline Grøntoft III & $\mathrm{P} \| \mathrm{a}$ & 3.4 & 6.3 & 3.6 & 3.2 & 9.2 & 4.2 & 38.6 & 2.3 \\
\hline Grøntoft III & E XXIV & 3.4 & 6.4 & 3.5 & 3.3 & 8.4 & 4.5 & 37.8 & 2.5 \\
\hline Grøntoft III & $\mathrm{BIX} a$ & 3.4 & 6.8 & 3.3 & 4.2 & 9.9 & 4.6 & 45.5 & 2.5 \\
\hline Grøntoft III & $E X X X$ & 3.4 & 6.8 & 3.6 & 3.6 & 8.9 & 4.6 & 40.9 & 3.2 \\
\hline Grøntoft II & $\mathrm{KV}$ & 3.4 & 6.9 & 3.6 & 4.9 & 10.4 & 4.8 & 49.9 & 2.2 \\
\hline Grøntoft II & $D X X$ & 3.4 & 7.2 & 3.8 & 3.4 & 11.5 & 4.4 & 50.6 & 2.1 \\
\hline Grøntoft III & $E X X X I X$ & 3.4 & 7.3 & 3.7 & 4.2 & 9.8 & 4.3 & 42.1 & 2.4 \\
\hline Grøntoft III & $\mathrm{EIXb}$ & 3.4 & 7.4 & 3.4 & 5.1 & 10.8 & 4.0 & 43.2 & 2.1 \\
\hline Grøntoft IVA & $\mathrm{PXI} a$ & 3.4 & 7.4 & 3.9 & 4.2 & 10.0 & 5.2 & 52.0 & 2.3 \\
\hline Grøntoft IVA & $A X$ & 3.4 & 7.4 & 3.8 & 4.5 & 9.8 & 5.3 & 51.9 & 2.7 \\
\hline Grøntoft II & FXVII & 3.4 & 7.7 & 3.6 & 5.9 & 12.0 & 4.8 & 57.6 & 2.4 \\
\hline Grøntoft III & D XXIV & 3.4 & 7.9 & 4.0 & 4.1 & 11.2 & 5.0 & 56.0 & 2.9 \\
\hline Grøntoft II & FXIII & 3.4 & 8.0 & 4.0 & 5.8 & 11.8 & 4.6 & 54.3 & 2.1 \\
\hline Grøntoft III & EVII a & 3.4 & 8.1 & 4.4 & 4.5 & 10.7 & 4.1 & 43.9 & 2.4 \\
\hline Grøntoft III & $D X$ & 3.4 & 8.1 & 4.0 & 4.8 & 11.0 & 4.6 & 50.6 & 2.8 \\
\hline Grøntoft IVA & $\mathrm{PX}$ & 3.4 & 8.1 & 5.4 & 5.6 & 10.8 & 5.2 & 56.2 & 2.6 \\
\hline Grøntoft II & $\mathrm{H} \times \mathrm{V}$ & 3.4 & 8.4 & 4.7 & 4.4 & 11.7 & 5.0 & 58.5 & 2.3 \\
\hline Grøntoft III & EXXVI & 3.4 & 8.6 & 4.0 & 4.5 & 10.6 & 4.5 & 47.7 & 2.9 \\
\hline Grøntoft III & EV & 3.4 & 8.6 & 4.4 & 4.8 & 11.1 & 4.7 & 52.2 & 2.8 \\
\hline
\end{tabular}

\section{byre area}




\begin{tabular}{|c|c|c|c|c|c|c|c|c|c|c|c|c|c|}
\hline \multirow[b]{2}{*}{ TQ } & \multicolumn{8}{|c|}{ Distances between trestles } & \multirow{2}{*}{$\begin{array}{l}\text { North door } \\
\text { width }\end{array}$} & \multirow{2}{*}{$\begin{array}{l}\text { South door } \\
\text { width }\end{array}$} & \multirow{2}{*}{$\begin{array}{l}\text { Number } \\
\text { of cattle }\end{array}$} & \multirow{2}{*}{$\begin{array}{l}\text { Dwelling } \\
\text { area } \mathbf{m}^{2}\end{array}$} & \multirow{2}{*}{$\begin{array}{c}\text { Byre } \\
\text { area } \mathrm{m}^{2}\end{array}$} \\
\hline & $4-3$ & $3-2$ & $2-1$ & Entrance room & $I-2$ & $2-3$ & $3-4$ & $4-5$ & & & & & \\
\hline 1.9 & & 1.9 & 1.4 & 2.5 & 2.5 & 2.4 & & & 1.1 & 1.0 & 12 & 24.0 & 30.0 \\
\hline 1.7 & & 2.4 & 1.8 & 1.6 & 2.0 & 3.0 & & & 1.2 & 1.4 & 10 & 32.5 & 35.3 \\
\hline 1.9 & & 2.4 & 1.8 & 2.1 & 2.2 & 2.5 & & & 1.4 & 1.3 & 14 & 27.0 & 31.5 \\
\hline 1.5 & & 2.9 & 1.7 & 1.7 & 2.0 & 1.9 & & & 1.6 & 1.4 & 10 & 34.6 & 31.3 \\
\hline 1.8 & & 2.4 & 1.7 & 2.0 & 2.2 & 2.5 & & & 1.3 & 1.3 & $11-12$ & 29.5 & 32.0 \\
\hline 1.8 & & & 1.8 & 1.4 & 2.8 & 1.9 & & & 1.2 & 1.1 & 10 & 14.6 & 24.5 \\
\hline 1.8 & & & 1.7 & 1.8 & 2.1 & 2.3 & & & 1.4 & 1.2 & 14 & 11.6 & 24.9 \\
\hline 2.0 & & & 2.2 & 2.3 & 1.5 & 1.2 & & & 1.3 & 1.2 & 6 & 19.8 & 22.6 \\
\hline 2.0 & & & 3.2 & 2.3 & 1.9 & 1.5 & & & 1.2 & 1.2 & 10 & 25.4 & 29.7 \\
\hline 2.3 & & & 2.4 & 1.8 & 1.8 & 2.8 & & & 1.2 & 1.2 & 12 & 20.5 & 30.5 \\
\hline 1.7 & & & 2.9 & 2.6 & 1.7 & 2.8 & & & 1.1 & 1.4 & 12 & 23.2 & 32.4 \\
\hline 2.2 & & & 2.8 & 3.1 & 2.8 & 1.9 & & & 1.3 & 1.2 & 12 & 23.3 & 35.5 \\
\hline 1.9 & & & 3.5 & 2.0 & 1.9 & 2.6 & & & 1.1 & 1.1 & 10 & 27.0 & 32.9 \\
\hline 1.8 & & & 3.1 & 2.9 & 1.7 & 2.7 & & & 1.3 & & 14 & 25.0 & 28.5 \\
\hline 1.5 & & & 4.2 & 2.6 & 1.8 & 3.3 & & & 1.5 & 1.4 & 14 & 26.5 & 33.3 \\
\hline 1.7 & & & 3.5 & 3.2 & 3.0 & 2.8 & & & 1.3 & 0.9 & 18 & 29.8 & 48.4 \\
\hline 2.2 & & & 3.9 & 2.6 & 3.4 & 3.2 & & & 1.2 & 1.3 & 18 & 30.8 & 46.8 \\
\hline 1.7 & & & 3.7 & 2.8 & 2.7 & 2.7 & & & 1.4 & 1.6 & 14 & 24.9 & 33.8 \\
\hline 1.9 & & & 3.0 & 2.4 & 2.2 & 2.4 & & & 1.3 & 1.2 & $12-13$ & 23.3 & 32.6 \\
\hline 2.1 & & 1.2 & 2.2 & 2.4 & 1.8 & 1.6 & 1.5 & 1.7 & 1.2 & 1.2 & 18 & 25.4 & 45.6 \\
\hline 1.7 & 2.8 & 2.8 & 2.8 & 3.6 & 2.6 & 2.8 & 2.7 & & 1.2 & 1.4 & 22 & 59.4 & 59.4 \\
\hline 1.9 & 2.8 & 2.0 & 2.5 & 3.0 & 2.2 & 2.2 & 2.1 & 1.7 & 1.2 & 1.3 & 20 & 42.4 & 52.5 \\
\hline 2.0 & & & 1.8 & 1.4 & 1.6 & & & & 1.2 & 1.2 & 4 & 14.2 & 13.8 \\
\hline 1.9 & & & 1.8 & 1.3 & 2.3 & & & & 1.1 & 1.2 & 6 & 11.7 & 11.7 \\
\hline 1.8 & & & 1.7 & 1.7 & 2.0 & & & & 1.3 & 1.4 & 6 & 10.9 & 13.9 \\
\hline 1.9 & & & 1.7 & 1.5 & 2.7 & & & & 1.2 & 1.2 & 6 & 15.3 & 16.7 \\
\hline 2.2 & & & 1.7 & 1.5 & 2.8 & & & & 1.4 & 1.4 & 6 & 12.8 & 17.6 \\
\hline 2.1 & & & 1.8 & 1.8 & 2.4 & & & & 1.0 & 1.3 & 8 & 14.7 & 14.7 \\
\hline 1.7 & & & 2.4 & 1.6 & 2.0 & & & & 1.1 & 1.1 & 6 & 16.6 & 15.6 \\
\hline 1.8 & & & 2.4 & 2.2 & 1.7 & & & & 1.2 & 1.4 & 6 & 15.1 & 13.4 \\
\hline 1.8 & & & 2.5 & 1.5 & 2.4 & & & & 1.3 & 1.3 & 6 & 15.8 & 14.9 \\
\hline 1.8 & & & 1.7 & 2.4 & 2.7 & & & & 1.2 & 1.2 & 6 & 15.2 & 19.3 \\
\hline 1.4 & & & 2.5 & 1.7 & 2.6 & & & & 1.2 & 1.3 & 6 & 16.6 & 16.6 \\
\hline 2.2 & & & 2.2 & 1.9 & 2.8 & & & & 1.3 & 1.3 & 10 & 17.3 & 23.5 \\
\hline 2.1 & & & 2.4 & 2.2 & 2.6 & & & & 1.1 & 1.2 & 6 & 16.7 & 15.0 \\
\hline 1.8 & & & 2.5 & 1.8 & 3.0 & & & & I.I & 1.1 & 6 & 15.9 & 18.1 \\
\hline 1.9 & & & 2.4 & 3.2 & 1.8 & & & & 1.0 & 1.3 & 8 & 13.6 & 20.4 \\
\hline 2.3 & & & 2.3 & 2.6 & 2.5 & & & & 1.2 & 1.1 & 6 & 20.3 & 21.8 \\
\hline 2.0 & & & 2.5 & 1.7 & 3.2 & & & & 1.3 & 1.3 & 8 & 20.1 & 23.9 \\
\hline 2.0 & & & 2.2 & 2.9 & 2.6 & & & & 1.1 & 1.2 & 10 & 17.3 & 28.3 \\
\hline 1.7 & & & 2.4 & 3.0 & 2.5 & & & & 1.1 & 1.3 & 6 & 20.0 & 20.5 \\
\hline 2.2 & & & 2.4 & 2.6 & 3.0 & & & & 1.2 & & 12 & 18.4 & 26.7 \\
\hline 1.7 & & & 2.8 & 2.7 & 2.6 & & & & 1.3 & 1.3 & 8 & 18.0 & 18.5 \\
\hline 1.6 & & & 2.5 & 2.3 & 3.3 & & & & 1.4 & 1.2 & 10 & 18.4 & 22.1 \\
\hline 2.0 & & & 2.9 & 1.8 & 3.4 & & & & 1.2 & 1.4 & 8 & 28.1 & 29.1 \\
\hline 2.2 & & & 3.0 & 2.5 & 2.9 & & & & 1.2 & I.I & 12 & 23.5 & 22.0 \\
\hline 1.6 & & & 2.9 & 2.7 & 3.0 & & & & 1.3 & 1.4 & 8 & 18.0 & 20.3 \\
\hline 1.7 & & & 3.0 & 2.9 & 2.7 & & & & 1.3 & 1.3 & 8 & 20.7 & 22.6 \\
\hline
\end{tabular}




\begin{tabular}{|c|c|c|c|c|c|c|c|c|c|}
\hline Site/type & House number & Type 3 subtype & $\begin{array}{l}\text { Length of post- } \\
\text { setting }\end{array}$ & $\begin{array}{l}\text { Length, } \\
\text { dwelling }\end{array}$ & $\begin{array}{l}\text { Length, } \\
\text { byre }\end{array}$ & $\begin{array}{l}\text { Total } \\
\text { length }\end{array}$ & Width & $\begin{array}{l}\text { Floor area } \\
\mathrm{m}^{2}\end{array}$ & $\begin{array}{l}\text { Trestle } \\
\text { width }\end{array}$ \\
\hline Grøntoft IVB & A XII a & 3.4 & 8.6 & 4.8 & 5.4 & 11.9 & 5.2 & 61.9 & 2.9 \\
\hline Grøntoft IVB & DVIII & 3.4 & 8.6 & 4.8 & 5.4 & 12.0 & 5.4 & 64.8 & 3.1 \\
\hline Grøntoft IVB & $\mathrm{A} \times \mathrm{VII}$ a & 3.4 & 8.7 & 4.4 & 5.0 & 11.7 & 5.3 & 62.0 & 2.4 \\
\hline Grøntoft II & GI & 3.4 & 8.8 & 4.6 & 5.7 & 12.0 & 5.1 & 61.2 & 2.3 \\
\hline Grøntoft II & $F X$ & 3.4 & 9.3 & 4.7 & 5.7 & 13.3 & 4.7 & 62.5 & 2.6 \\
\hline Grøntoft III & EVI & 3.4 & 9.4 & 4.5 & 5.6 & 12.0 & 5.6 & 67.2 & 2.6 \\
\hline Grøntoft III & EXXI & 3.4 & 9.6 & 4.6 & 5.4 & 11.8 & 4.9 & 57.8 & 3.3 \\
\hline Grøntoft III & $E X X X I$ a & 3.4 & 10.3 & 5.2 & 5.4 & 13.9 & 4.9 & 68.1 & 3.0 \\
\hline Grøntoft III & E XXIII & 3.4 & 10.6 & 4.7 & 6.0 & 13.4 & 4.7 & 63.0 & 2.9 \\
\hline Grøntoft III & EXXIII & 3.4 & 10.6 & 4.7 & 6.0 & 13.4 & 4.7 & 63.0 & 2.9 \\
\hline Mean (35) & & 3.4 & 7.6 & 4.0 & 4.5 & 10.5 & 4.7 & 49.8 & 2.5 \\
\hline Grøntoft III & E XIX & 3.5 & 3.5 & 2.3 & 2.6 & 6.4 & 4.2 & 26.9 & 2.3 \\
\hline Grøntoft IVB & A II & 3.5 & 5.0 & 3.0 & 2.8 & 7.6 & 5.3 & 40.3 & 2.8 \\
\hline Grøntoft III & EIX a & 3.5 & 4.2 & 3.4 & 2.6 & 7.4 & 4.0 & 29.6 & 2.1 \\
\hline Grøntoft III & D XXIII & 3.5 & 5.4 & 3.7 & 3.1 & 7.5 & 4.5 & 33.8 & 2.5 \\
\hline Grøntoft III & $D X X V$ & 3.5 & 4.9 & 3.0 & 3.4 & 7.7 & 4.4 & 33.9 & 2.3 \\
\hline Grøntoft II & DVII & 3.5 & 5.1 & 4.0 & 3.6 & 7.6 & 4.0 & 30.4 & 2.0 \\
\hline Grøntoft III & D XIV & 3.5 & 5.9 & 3.4 & 3.5 & 8.3 & 4.2 & 34.9 & 2.2 \\
\hline Grøntoft III & E XXXVIII & 3.5 & 7.3 & 3.0 & 2.8 & 9.2 & 4.2 & 38.6 & 2.3 \\
\hline Mean (8) & & 3.5 & 5.2 & 3.2 & 3.1 & 7.7 & 4.4 & 33.5 & 2.3 \\
\hline
\end{tabular}

This shows that the Forsand tradition of situating the dwelling part in the eastern part of the house and the byre in the western part must be an adaption to local conditions when the inhabitants of Forsand, most probably inspired by influence from visits to or from Jutland, began to build this type of house in Bronze Age Period II.

There are four type 3.1 houses from Grøntoft and Hodde, these have been compared to six such houses from the Pre-Roman Iron Age at Forsand (Table 18). The houses at each of the Grøntoft/Hodde sites measured an average of $14 \times 5.3 \mathrm{~m}$, had a total area of 72-75 $\mathrm{m}^{2}$ and could accommodate four people and twelve cattle. The Forsand houses (type 3.1.1.) were somewhat larger: they measured on average $15 \times 6 \mathrm{~m}$, had a total area of $91 \mathrm{~m}^{2}$ and could accommodate six people but only eight cattle. In addition, four of the longer type 3.1.2 houses measured an average of $19.6 \times 6.6 \mathrm{~m}$, had a total area of $122 \mathrm{~m}^{2}$ that could accommodate seven people and twelve cattle. The relatively large roofed area in the Forsand houses seems to give room for fewer cattle than the Danish ones.

This might be caused by a different calculation method: in the houses at Grøntoft/Hodde, the number of preserved cattle stalls has been counted, giving a stall width of $0.8 \mathrm{~m}$. In Forsand, without such traces in the type 3 houses, the distances between the trestles, normally $\pm 2 \mathrm{~m}$ or $\pm 3 \mathrm{~m}$, give room for two or three cattle between two trestles, and thus more room for each cow and a lower capacity in the same area. In total, the type 3.1 houses at Grøntoft/Hodde could accommodate fewer people and more cattle than those at Forsand.

At Grøntoft, there are only two larger type 3.3 houses with more than six trestles and the short phase (Ib) from the chieftain's farm at Hodde can be compared with four such houses dated to the Pre-Roman Iron

Table 18. Comparison of Pre-Roman Iron Age type 3.I.I houses between the settlements at Grøntoft, Hodde and Forsandmoen. Measurements in metres $(\mathrm{m})$.

\begin{tabular}{|l|c|c|c|c|c|c|c|}
\hline Site & House type & $\begin{array}{c}\text { Number of } \\
\text { houses }\end{array}$ & House length & House width & Area m & $\begin{array}{c}\text { Calculated number } \\
\text { of persons }\end{array}$ & $\begin{array}{c}\text { Calculated number } \\
\text { of cattle }\end{array}$ \\
\hline Grøntoft & Type 3.I.I & 4 & 13.5 & 5.3 & 71.4 & 4 \\
\hline Hodde & Type 3.I.I & 4 & 14.5 & 5.3 & 74.6 & 4 \\
\hline Forsandmoen & Type 3.I.I & 6 & 15.0 & 6.0 & 91.1 & $12-13$ \\
\hline
\end{tabular}




\begin{tabular}{|c|c|c|c|c|c|c|c|c|c|c|c|c|c|}
\hline \multirow[b]{2}{*}{ TQ } & \multicolumn{8}{|c|}{ Distances between trestles } & \multirow{2}{*}{$\begin{array}{l}\text { North door } \\
\text { width }\end{array}$} & \multirow{2}{*}{$\begin{array}{l}\text { South door } \\
\text { width }\end{array}$} & \multirow{2}{*}{$\begin{array}{l}\text { Number } \\
\text { of cattle }\end{array}$} & \multirow{2}{*}{$\begin{array}{l}\text { Dwelling } \\
\text { area } \mathbf{m}^{2}\end{array}$} & \multirow{2}{*}{$\begin{array}{c}\text { Byre } \\
\text { area } \mathbf{m}^{2}\end{array}$} \\
\hline & $4-3$ & $3-2$ & $2-1$ & Entrance room & $I-2$ & $2-3$ & $3-4$ & $4-5$ & & & & & \\
\hline 1.8 & & & 3.5 & 1.4 & 3.7 & & & & 1.3 & 1.3 & 8 & 25.0 & 28.1 \\
\hline 1.7 & & & 3.1 & 2.8 & 2.7 & & & & 1.2 & 1.0 & 8 & 25.9 & 29.2 \\
\hline 2.2 & & & 2.8 & 3.1 & 2.8 & & & & 1.3 & 1.2 & 8 & 23.3 & 26.5 \\
\hline 2.2 & & & 2.9 & 3.0 & 2.9 & & & & 1.2 & 1.2 & 14 & 23.5 & 29.1 \\
\hline 1.8 & & & 3.3 & 3.5 & 2.5 & & & & 1.2 & 1.2 & 12 & 22.1 & 26.8 \\
\hline 2.2 & & & 3.2 & 3.5 & 2.7 & & & & 1.4 & 1.3 & 10 & 25.2 & 31.4 \\
\hline 1.5 & & & 3.4 & 2.6 & 3.6 & & & & 1.2 & 1.3 & 10 & 22.5 & 26.5 \\
\hline 1.6 & & & 3.4 & 3.2 & 3.7 & & & & 1.4 & 1.2 & 10 & 25.5 & 26.5 \\
\hline 1.6 & & & 3.6 & 3.3 & 3.7 & & & & 1.4 & 1.2 & 12 & 22.1 & 28.2 \\
\hline 1.6 & & & 3.6 & 3.3 & 3.7 & & & & 1.4 & 1.2 & 12 & 22.1 & 28.2 \\
\hline 1.9 & & & 2.6 & 2.3 & 2.7 & & & & 1.2 & 1.2 & $8-9$ & 18.9 & 21.5 \\
\hline 1.8 & & & & 2.2 & 1.3 & & & & 1.3 & 1.4 & 4 & 9.7 & 10.9 \\
\hline 1.9 & & & & 3.3 & 1.7 & & & & 1.2 & 1.2 & 4 & 15.9 & 14.8 \\
\hline 1.9 & & & & 1.9 & 2.3 & & & & I.I & 1.2 & 6 & 13.6 & 10.4 \\
\hline 1.8 & & & & 2.9 & 2.5 & & & & 1.1 & 1.2 & 6 & 16.7 & 14.0 \\
\hline 1.9 & & & & 3.2 & 1.7 & & & & & 1.2 & 6 & 13.2 & 15.0 \\
\hline 2.0 & & & & 2.9 & 2.1 & & & & 1.0 & 1.2 & 6 & 16.0 & 14.4 \\
\hline 1.9 & & & & 3.3 & 2.6 & & & & 1.2 & 1.3 & 6 & 14.3 & 14.7 \\
\hline 1.8 & & & & 4.7 & 2.6 & ? & & & 1.0 & 1.0 & 4 & 12.6 & 11.8 \\
\hline 1.9 & & & & 3.1 & 2.1 & & & & I.I & 1.2 & $5-6$ & 14.0 & 13.2 \\
\hline
\end{tabular}

Age at Forsand (Table 19). Like the type 3.1 houses, the 3.3 houses at Grøntoft/Hodde could, due to the smaller dwelling area and longer byre area than at Forsand, accommodate fewer people (5-6 compared to 7-8) and more cattle (20-25 compared to 16$)$.

The smaller type 3.2 house, with only five trestles (Table 20), is more common at both Grøntoft and Hodde than at Forsand and can be compared with the house types with six or more trestles. The average sizes in Table 20 are therefore more trustworthy than those in the Tables 18 and 19. We find, however, the same pattern as in the two previous tables, with space for more people and fewer cattle at Forsand compared to the Grøntoft/Hodde sites.

The house material from the German site Flögeln (Zimmermann 1992), dated to the Roman Iron Age, can also be compared with the Forsand type 3 material. The Flögeln material consists of 23 type $1 \mathrm{a}-\mathrm{b}$ houses in the Zimmermann type system, which can be compared with the house types 3.1, 3.2 and 3.3 at Forsand (Table 21). Unfortunately, only seven type 3 houses were built in the Roman Iron Age at Forsand, since new house types (7-10) dominated the building material at that time. The Flögeln material consists of an equal number of house types 3.1 and 3.3, and fever type 3.2. The Forsand material consists of three houses of type 3.1 and 3.3, and only one type 3.2 house. In order to make a comparison with the five 3.2 houses at Flögeln, I have included four 3.2 Forsand houses dated to the late Pre-Roman Iron Age in Table 22. Table 22 shows that the sizes of the houses in each of the subtypes is distributed fairly even between the two sites and that they could accommodate approximately the same number of people and cattle. Compared with the Danish and Forsand type 3 houses from the Pre-Roman Iron Age, these Roman Iron Age subtypes are larger. Densely set

Table 19. Comparison of Pre-Roman Iron Age type 3.3 houses between the settlements at Grøntoft, Hodde and Forsandmoen. Measurements in metres $(\mathrm{m})$.

\begin{tabular}{|l|c|c|c|c|c|c|c|}
\hline Site & House type & $\begin{array}{c}\text { Number of } \\
\text { houses }\end{array}$ & House length & House width & Area $\mathbf{m}^{2}$ & $\begin{array}{c}\text { Calculated number } \\
\text { of persons }\end{array}$ & $\begin{array}{c}\text { Calculated number } \\
\text { of cattle }\end{array}$ \\
\hline Grøntoft & Type 3.3 & 2 & 19.1 & 5.4 & 104 & 5 & 20 \\
\hline Hodde & Type 3.3 & 1 & 22.5 & 5.6 & 126 & 6 & 22 \\
\hline Forsandmoen & Type 3.3 & 5 & 20.1 & 6.3 & 124 & $7-8$ & 14 \\
\hline
\end{tabular}


Table 20. Comparison of Pre-Roman Iron Age type 3.2 houses between the settlements at Grøntoft, Hodde and Forsandmoen. Measurements in metres $(\mathrm{m})$.

\begin{tabular}{|c|c|c|c|c|c|c|c|}
\hline Site & House type & $\begin{array}{l}\text { Number of } \\
\text { houses }\end{array}$ & House length & House width & Area $\mathrm{m}^{2}$ & $\begin{array}{c}\text { Calculated number } \\
\text { of persons }\end{array}$ & $\begin{array}{c}\text { Calculated number } \\
\text { of cattle }\end{array}$ \\
\hline Grøntoft & Type 3.2 & 13 & 13.1 & 5.1 & 68 & $3-4$ & 13 \\
\hline Hodde & Type 3.2 & 9 & 14.4 & 5.4 & 77 & $3-4$ & 13 \\
\hline Forsandmoen & Type 3.2 & 7 & 12.8 & 5.9 & 74 & $4-5$ & 7 \\
\hline
\end{tabular}

Table 22. Comparison of Roman Iron Age type 3.I-3.3 houses between the settlements at Flögeln and Forsandmoen. Measurements in metres $(\mathrm{m})$.

\begin{tabular}{|l|c|c|c|c|c|c|c|}
\hline Site & House type & $\begin{array}{c}\text { Number of } \\
\text { houses }\end{array}$ & House length & $\begin{array}{c}\text { House width } \\
\text { Calculated number } \\
\text { of cattle }\end{array}$ & $\begin{array}{c}\text { Area m } \\
\text { Calculated number } \\
\text { of persons }\end{array}$ \\
\hline Flögeln & Type 3.I & 9 & 18.3 & 5.5 & 101 & 6 \\
\hline Forsandmoen & Type 3.I & 3 & 19.3 & 6.3 & 122 & $7-8$ \\
\hline Flögeln & Type 3.3 & 9 & 22.7 & 5.5 & 127 & $7-8$ \\
\hline Forsandmoen & Type 3.3 & 3 & 21.3 & 6.4 & 136 & 8 \\
\hline Flögeln & Type 3.2 & 5 & 15.9 & 5.5 & 87 & 5 \\
\hline Forsandmoen & Type 3.2 & 5 & 13.5 & 5.9 & 78 & 5 \\
\hline
\end{tabular}

Table 21. Compiled measurements from features in type 3 houses at Flögeln in Germany in the Roman Iron Age. Measurements in metres $(m)$.

\begin{tabular}{|c|c|c|c|c|c|c|c|c|c|c|c|c|}
\hline Site/type & $\begin{array}{l}\text { House } \\
\text { number }\end{array}$ & $\begin{array}{l}\text { Type } 3 \\
\text { subtype }\end{array}$ & $\begin{array}{l}\text { Length of } \\
\text { post-setting }\end{array}$ & $\begin{array}{l}\text { Length, } \\
\text { dwelling }\end{array}$ & $\begin{array}{c}\text { Length, } \\
\text { byre }\end{array}$ & $\begin{array}{c}\text { Total } \\
\text { length }\end{array}$ & Width & $\begin{array}{l}\text { Floor area } \\
\mathbf{m}^{2}\end{array}$ & $\begin{array}{l}\text { Trestle } \\
\text { width }\end{array}$ & TQ & $4-3$ & $3-2$ \\
\hline Flögeln Ib & 81 & 3.1 .1 & 11.8 & 7.0 & 5.3 & 15.4 & 6.1 & 93.9 & 3.4 & 1.8 & & 3.2 \\
\hline Flögeln Ia & 93 & 3.1 .1 & 12.5 & 6.8 & 6.9 & 16.5 & 5.6 & 92.4 & 2.8 & 2.0 & & \\
\hline Flögeln Ia & 21 & 3.1 .1 & 12.6 & 6.6 & 8.2 & 17.6 & 5.8 & 102.1 & 2.8 & 2.1 & & \\
\hline Flögeln Ib & 150 & 3.I.I & I5.I & 11.4 & 4.7 & 18.3 & 4.8 & 87.8 & 2.9 & 1.7 & & 4.5 \\
\hline Flögeln Ia & 105 & 3.1 .1 & 16.0 & 9.9 & 5.3 & 18.6 & 5.0 & 93.0 & 2.8 & 1.8 & & 3.6 \\
\hline Flögeln Ia & 36 & 3.1 .1 & 13.4 & 7.4 & 7.9 & 18.7 & 5.6 & 104.7 & 2.7 & 2.1 & & \\
\hline Flögeln Ia & 60 & 3.1 .1 & 13.7 & 10.0 & 6.9 & 18.8 & 5.4 & 101.5 & 2.9 & 1.9 & & \\
\hline Flögeln Ia & 15 & 3.1 .1 & 13.2 & 9.7 & 7.0 & 19.3 & 5.8 & 111.9 & 3.3 & 1.8 & & \\
\hline Flögeln Ia & 6 & 3.1 .1 & 14.5 & 9.4 & 9.1 & 21.3 & 5.6 & 119.3 & 3.2 & 1.8 & & \\
\hline Mean & & & 13.6 & 8.7 & 6.8 & 18.3 & 5.5 & 100.7 & 3.0 & 1.9 & & 3.8 \\
\hline Flögeln Ia & 66 & 3.2 & 10.0 & 6.7 & 4.9 & 14.3 & 5.2 & 74.4 & 2.7 & 1.9 & & \\
\hline Flögeln Ia & 94 & 3.2 & 10.2 & 7.1 & 6.8 & 15.8 & 5.4 & 85.3 & 2.9 & 1.9 & & \\
\hline Flögeln Ia & 61 & 3.2 & 7.7 & 6.9 & 6.9 & 15.8 & 5.2 & 82.2 & 2.9 & 1.8 & & \\
\hline Flögeln Ia & 29 & 3.2 & 12.2 & 7.4 & 6.3 & 16.2 & 5.8 & 94.0 & 3.1 & 1.9 & & \\
\hline Flögeln Ib & 18 & 3.2 & 11.7 & 9.8 & 4.4 & 17.6 & 5.7 & 100.3 & 3.1 & 1.8 & & 4.4 \\
\hline Mean & & & 10.4 & 7.6 & 5.9 & 15.9 & 5.5 & 87.2 & 2.9 & 1.9 & & 4.4 \\
\hline Flögeln Ib & 79 & 3.3 & 13.2 & 8.6 & 6.9 & 17.9 & 5.4 & 96.7 & 2.8 & 1.9 & & 3.4 \\
\hline Flögeln Ia & 63 & 3.3 & 13.8 & 9.4 & 8.6 & 19.6 & 5.5 & 107.8 & 2.8 & 2.0 & & \\
\hline Flögeln Ia & 4 & 3.3 & 17.2 & 7.5 & 7.4 & 21.6 & 5.5 & 118.8 & 3.1 & 1.8 & & \\
\hline Flögeln Ib & 3 & 3.3 & 17.9 & II.I & 8.8 & 22.7 & 5.9 & 133.9 & 3.0 & 2.0 & & 4.6 \\
\hline Flögeln Ia & 14 & 3.3 & 18.4 & 12.6 & 8.2 & 23.1 & 5.5 & 127.1 & 2.8 & 2.0 & & 4.8 \\
\hline Flögeln Ia & 35 & 3.3 & 14.9 & II.I & 10.6 & 23.3 & 5.5 & 128.2 & 2.5 & 2.2 & & \\
\hline Flögeln Ib & 58 & 3.3 & 17.5 & 13.4 & 7.1 & 23.8 & 5.5 & 130.9 & 2.9 & 1.9 & 3.1 & 2.7 \\
\hline Flögeln Ib & 25 & 3.3 & 19.5 & 12.6 & 10.1 & 25.7 & 6.4 & 164.5 & 3.4 & 1.9 & & 2.6 \\
\hline Flögeln Ib & 49 & 3.3 & 23.3 & 9.8 & 15.6 & 26.7 & 5.0 & 133.5 & 2.8 & 1.8 & & 4.9 \\
\hline Mean & & & 17.3 & 10.7 & 9.3 & 22.7 & 5.6 & 126.8 & 2.9 & 1.9 & 3.1 & 3.8 \\
\hline
\end{tabular}


trestles in the eastern part, as well as centrally situated hearths in the western part, show that, at Flögeln, as at Grøntoft/Hodde and contrary to Forsand, the dwelling area was located in the western part and the byre to the east.

The comparative material shows that the use of the types 3.1-3 at Forsand is part of a common building tradition during the Bronze Age and Early Iron Age in southern Scandinavia and Northern Germany. There are differences concerning the ratio in the use of the different subtypes between the areas in the different periods as well as the sizes of the houses and the possible number of people and cattle they housed. There are certainly also differences in many other features in the construction of this house type (such as type and shape of walls, balanced or under-/over-balanced roof construction, and construction of the entrance).

It is my conclusion that the use of the different type 3 houses as the main combined dwelling/byre house at
Forsand in the Bronze Age, the Pre-Roman Iron Age and to a certain extent also the Roman Iron Age is in accordance with the building tradition in southern Scandinavian and Northern Germany. However, in all these areas, people also built other types of houses - smaller as well as larger - in different periods. At Forsand, the type 1 house represents a larger house type that is also well known in Denmark (Trappendal, Gram and Højgård). In addition, the Forsand types 5, 6 and 11 (see below) represent contemporary dwelling houses without room for cattle.

To the north and east of Forsand, the Norwegian material showed - even if approximately 20 type 3 houses were recorded there (Table 13) along with many houses of different types - that the influence of southern Scandinavian building traditions must have been weaker than what is indicated in the Forsand material.

\section{Distances between trestles}

\begin{tabular}{|c|c|c|c|c|c|c|c|c|}
\hline $2-1$ & Entrance room & $I-2$ & $2-3$ & $3-4$ & $4-5$ & $5-6$ & $6-7$ & $7-8$ \\
\hline 2.1 & 3.1 & 1.6 & 1.8 & & & & & \\
\hline 4.5 & 2.8 & 2.0 & 1.8 & 1.4 & & & & \\
\hline 3.9 & 2.8 & 2.2 & 2.0 & 1.7 & & & & \\
\hline 5.2 & 2.2 & 1.6 & 1.6 & & & & & \\
\hline 5.0 & 3.4 & 2.2 & 1.8 & & & & & \\
\hline 4.6 & 3.4 & 1.9 & 1.8 & 1.7 & & & & \\
\hline 5.0 & 1.9 & 2.0 & 1.3 & 1.7 & 1.8 & & & \\
\hline 5.3 & 2.6 & 1.7 & 1.9 & 1.7 & & & & \\
\hline 5.9 & 2.8 & 1.8 & 2.1 & 1.9 & & & & \\
\hline 4.6 & 2.8 & 1.9 & 1.8 & 1.7 & 1.8 & & & \\
\hline 3.9 & 2.7 & 1.7 & 1.7 & & & & & \\
\hline 4.9 & 1.9 & 1.8 & 1.6 & & & & & \\
\hline 2.2 & 2.0 & 1.7 & 1.8 & & & & & \\
\hline 4.6 & 2.5 & 2.1 & 3.0 & & & & & \\
\hline 1.7 & 3.4 & 2.2 & & & & & & \\
\hline 3.5 & 2.5 & 1.9 & 2.0 & & & & & \\
\hline 1.8 & 2.4 & 1.9 & 1.8 & 1.9 & & & & \\
\hline 5.3 & 1.6 & 1.8 & 2.1 & 1.4 & 1.6 & & & \\
\hline 3.7 & 6.7 & 1.7 & 1.7 & 1.7 & 1.7 & & & \\
\hline 5.1 & 2.8 & 1.8 & 1.7 & 1.9 & & & & \\
\hline 5.5 & 2.3 & 2.1 & 2.0 & 1.7 & & & & \\
\hline 4.6 & 1.6 & 1.4 & 1.7 & 2.1 & 1.5 & 2.0 & & \\
\hline 2.4 & 3.3 & 1.7 & 1.9 & 2.4 & & & & \\
\hline 6.4 & 3.0 & 2.1 & 1.9 & 1.8 & 1.7 & & & \\
\hline 3.3 & 1.3 & 2.4 & 1.9 & 2.2 & 1.6 & 2.2 & 1.7 & 1.8 \\
\hline 4.2 & 2.8 & 1.9 & 1.9 & 1.9 & 1.6 & 2.1 & 1.7 & 1.8 \\
\hline
\end{tabular}

\begin{tabular}{|c|c|c|c|c|}
\hline $\begin{array}{l}\text { North door } \\
\text { width }\end{array}$ & $\begin{array}{l}\text { South door } \\
\text { width }\end{array}$ & $\begin{array}{l}\text { Number } \\
\text { of cattle }\end{array}$ & $\begin{array}{l}\text { Dweeling } \\
\text { area } \mathbf{m}^{2}\end{array}$ & Byre area $\mathrm{m}^{2}$ \\
\hline & & 8 & 42.7 & 32.3 \\
\hline \multirow[t]{3}{*}{0.9} & 0.9 & 10 & 38.1 & 38.6 \\
\hline & & 12 & 38.3 & 47.6 \\
\hline & & 8 & 54.7 & 22.6 \\
\hline \multirow[t]{3}{*}{ I.I } & 0.9 & 10 & 49.5 & 26.5 \\
\hline & & 12 & 41.4 & 44.2 \\
\hline & & 14 & 54.0 & 37.3 \\
\hline \multirow[t]{2}{*}{1.2} & 1.2 & 12 & 56.3 & 40.6 \\
\hline & & 12 & 52.6 & 51.0 \\
\hline I.I & 1.0 & $10-11$ & 47.5 & 37.9 \\
\hline \multirow[t]{2}{*}{1.4} & 1.3 & 8 & 34.8 & 25.5 \\
\hline & & 8 & 38.3 & 36.7 \\
\hline 1.4 & & 8 & 35.9 & 35.9 \\
\hline \multirow[t]{2}{*}{1.3} & & 10 & 42.9 & 36.5 \\
\hline & & ? & 55.9 & 25.1 \\
\hline \multirow[t]{2}{*}{1.4} & 1.3 & $8-9$ & 41.6 & 31.9 \\
\hline & & 12 & 46.4 & 37.3 \\
\hline \multirow[t]{2}{*}{1.2} & I.I & 14 & 51.7 & 47.3 \\
\hline & & 16 & 41.3 & 40.7 \\
\hline 1.2 & 1.2 & 12 & 65.5 & 51.9 \\
\hline \multirow[t]{4}{*}{1.2} & 1.2 & 12 & 69.3 & 45.1 \\
\hline & & 18 & 61.1 & 58.3 \\
\hline & & 12 & 73.7 & 39.1 \\
\hline & & 16 & 80.6 & 64.6 \\
\hline 1.2 & 1.3 & 30 & 49.0 & 78.0 \\
\hline 1.2 & 1.2 & $15-16$ & 59.8 & 51.4 \\
\hline
\end{tabular}




\section{Small dwelling houses}

\subsection{Type 5: Small dwelling house with a central wide-spanned trestle}

This type consists of four houses (124, 127, 128 and 185), of which three are shown in Fig. 32. The house type is constructed with three trestles in two straight rows with circular postholes for roof-bearing posts. In addition, one trestle has a larger span than the other two trestles. The western bay is longer $(3.4-5 \mathrm{~m})$ than the eastern bay $(2.3-2.6 \mathrm{~m})$. One or two entrances are located directly east of the western trestle. The house type has densely set wall posts $(0.75-0.8 \mathrm{~m})$ both in the long walls and the gables. The gables are either semicircular or straight with rounded corners.

All measurements taken from the excavations have been systematised, see Table 23, folder. In addition to the above definition the following characteristics can be underlined:

The three well-preserved houses of the type measure between 9.5 and $12.3 \mathrm{~m}$ in length (mean $10.8 \mathrm{~m}$ ), between 5.5 and $6.2 \mathrm{~m}$ in width (mean $5.6 \mathrm{~m}$ ) and have a floor area between 50 and $76 \mathrm{~m}^{2}$ (mean $61 \mathrm{~m}^{2}$ ). The extended trestle is situated either outside the second trestle from the west - and thus seems to serve as an additional roof support in connection with the trestle - or, in one house (124), it is situated in the eastern bay as some sort of support around the hearth. The two houses 127 and 128, situated only $5 \mathrm{~m}$ apart, have in common that they also have an additional narrow trestle $0.6-0.8 \mathrm{~m}$ west of the eastern trestle. House 124 has an additional trestle $0.5 \mathrm{~m}$ west of the central trestle. Considering their modest length, all the houses have a relatively high number of trestles to support the roof, but this can be the result of repairs to the house.

One house (124) has a more complicated layout, with an extra entrance in the western semi-circular gable and another, narrow entrance in the NE corner of the house. There is also an interior post situated inside the opposite SE corner, a location comparable with the eastern entrance post in the NE corner.

All houses have a certain content of clay in many of the postholes from roof-bearing and wall posts, and in all parts of the house. It seems likely that the houses

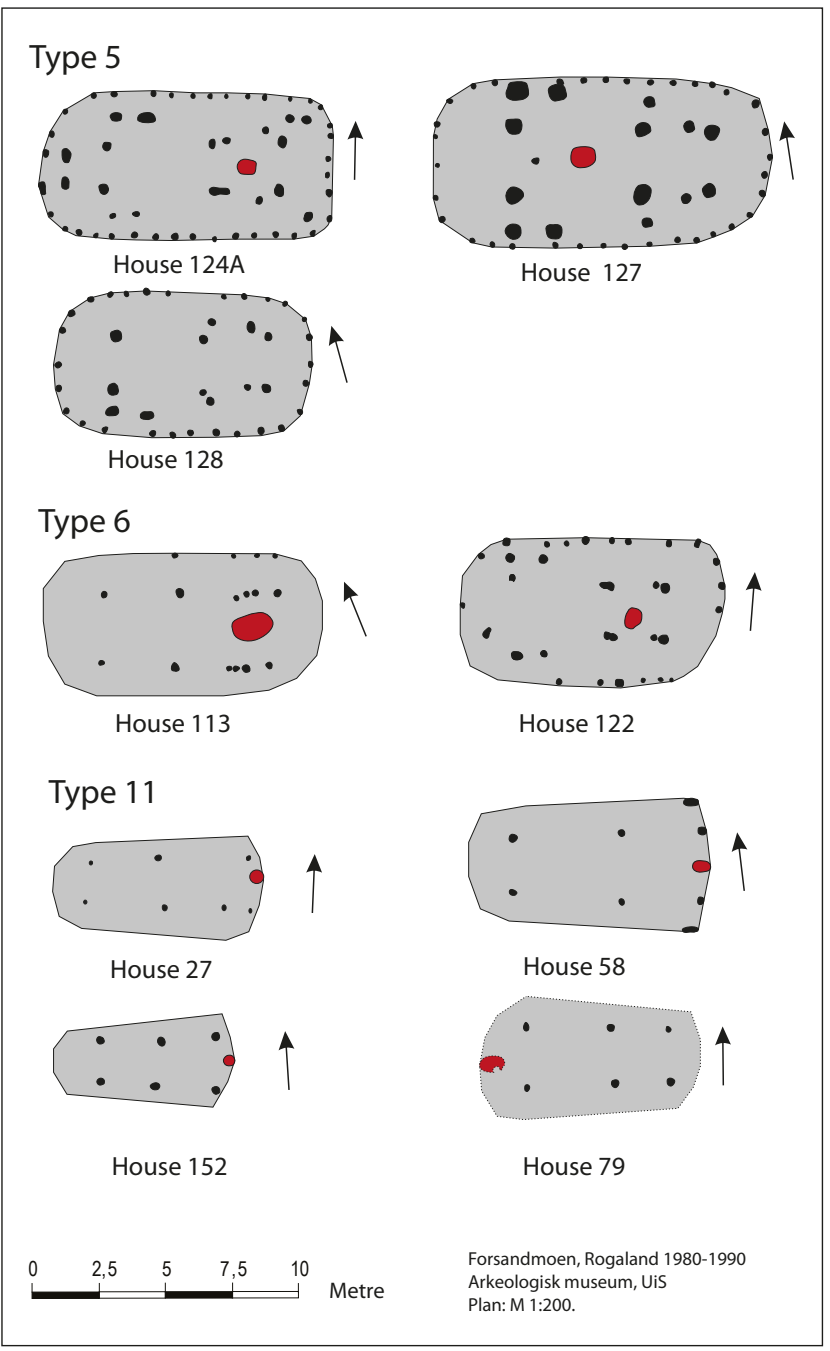

Fig. 32. House plans of a selection of type 5, 6 and II houses.

had a clay floor throughout the interior. The small distances between the wall posts $(0.75-1 \mathrm{~m})$ combined with the content of clay indicate wattle and daub walls.

All postholes are circular. Those from house 127 are larger (mean diameter 0.64 and $0.49 \mathrm{~m}$ in depth) than those from the three other houses (mean diameter 0.39 and $0.28 \mathrm{~m}$ in depth). This might be explained by the $1 \mathrm{~m}$ larger width of house 127 compared to the others. The postholes from the widely spaced trestles are smaller and shallower compared to the ones from roofbearing posts. The few observations of the possible size of the roof-bearing posts range from $0.16 \times 0.18 \mathrm{~m}$ via 


\section{Forsandmoen, Forsand municipality \\ Map of settlement area}

$\square$ House feature with preserved wall remains

House feature without wall remains
Type 5
D Type 11
- Type 6
D Type 12

Gravemound / cairn

Excavated gravemound / cairn

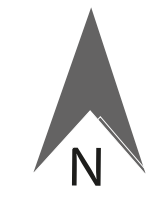

TGB/TL 2009/2014

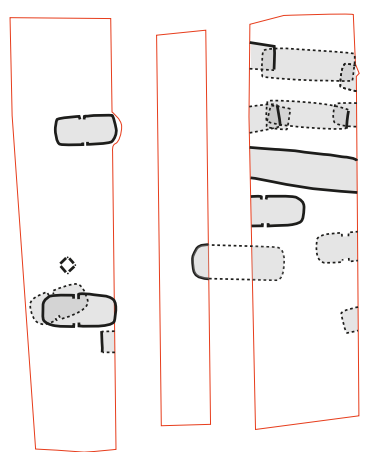

Area D
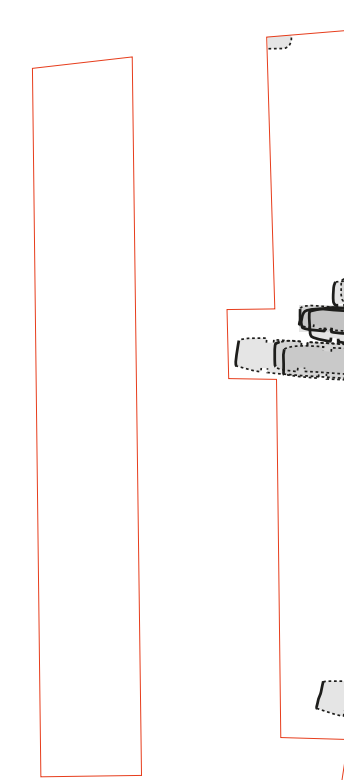

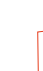

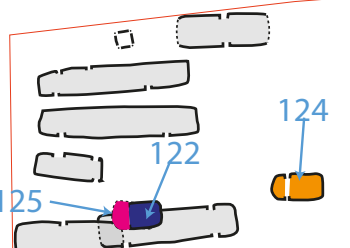

$-125$

(

O

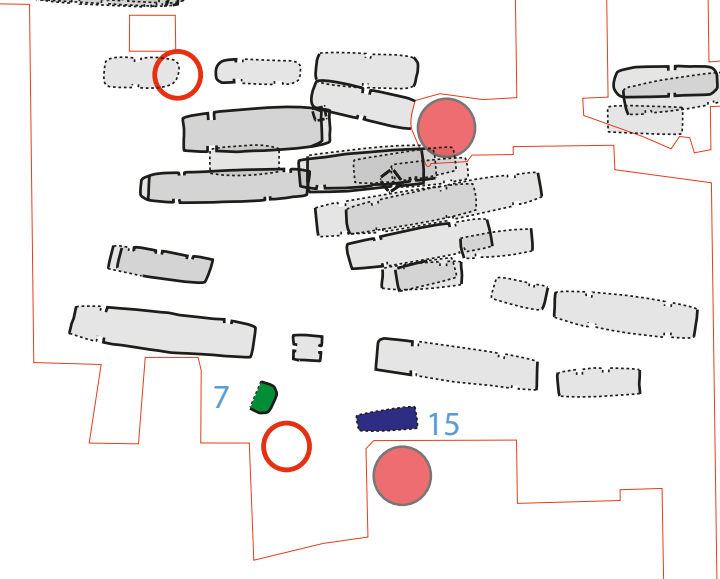

Area $\mathrm{E}$

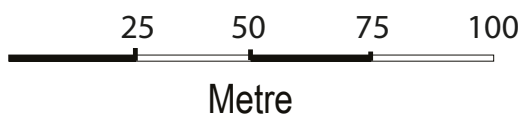


0.20 to $0.25-0.30 \mathrm{~m}$ in diameter. One entrance post measured $0.35 \mathrm{~m}$ in diameter. This in accordance with the sizes found in type 3 houses (Fig. 31).

Three of the houses are oriented slightly WNW-ESE, as most longhouses are, but house 185 at the SE corner of the plain has a SW-NE orientation, as is normal in this settlement area.

Three of the houses are ${ }^{14} \mathrm{C}$ dated to $2110 \pm 80 \mathrm{BP}$, 350-1 BC (T-8247, 124), $2230 \pm 70$ BP, 400-200 BC (T-8254, 127) and $2400 \pm 45$ BP, 800-400 BC (T-9533, 185), respectively. This time span is nearly the same as the three ${ }^{14} \mathrm{C}$ dates covered by the type 6 houses, so it is likely that these two, quite similar house types, belong to the same period of the settlement, which is most probably Bronze Age Period VI and the early PreRoman Iron Age.

The four type 5 houses are widely distributed in the settlement areas (Fig. 33). Two houses (127 and 128) are situated close to each other in the easternmost part of Area A, while the two houses 185 and 124 are found in Area B and Area E, respectively. Houses, similar to type 6 (see below), were also found near these three locations.

These well-built houses, with a floor area comparable to the dwelling area of types 3.1.2 and 3.3, and with remains of a central hearth within two of the houses, most likely served only for human occupation.

\subsection{Type 6: Small dwelling house with a circular hearth with a clay foundation}

This type consists of four houses: 15, 113, 122 and 179, of which two are shown in Fig. 32. The house type has two straight rows of circular postholes for roof-bearing posts and 3-4 trestles. The trestle construction measures 5.9-6.4 $\mathrm{m}$ in length. It has a circular hearth with a clay foundation, covering reddish (ochre) gravel, between the easternmost trestles. The walls had wall posts set at distances varying between $0.80-1.30 \mathrm{~m}$.

All measurements taken from the excavations have been systematised, see Table 23, folder. In addition to the above definition, the following characteristics can be underlined: The trestle width in three of the houses is narrow (1.8-2.3 m), while one house (113) has much wider trestles $(2.7 \mathrm{~m})$. Based on the preserved wall posts, the houses measured 4.9-5.3 (mean $5.2 \mathrm{~m}$ ) in width. The length could only be measured in house 122 (9.7 $\mathrm{m}$ ) and, judging from the distances from the outermost trestles to the gables here and in the in many features similar to type 5 houses, the total length of the other three houses may have been 9.7-10.2 m. Consequently, the floor area of these houses, between 49 and $53 \mathrm{~m}^{2}$ (mean $51 \mathrm{~m}^{2}$ ), would have been nearly the same as in type 5. Three of the houses had a TQ between 2-2.3, meaning a balanced roof, while the last one, with the narrowest trestles, had an under-balanced roof (TQ = 2.8) (Komber 1989:124f).

Concerning the structure of the bays, the houses can be divided into two groups, where two houses (15 and 113) have three fairly even bays, between 2 and $2.5 \mathrm{~m}$ wide. The two others $(122,179)$ have a wide bay to the west $(3-3.5 \mathrm{~m})$ and a shorter one to the east (2.3-2.5 $\mathrm{m}$ ). The shorter bay has been divided with an additional trestle only $0.6 \mathrm{~m}$ west of the eastern trestle; this structure is similar to the one in the type 5 houses. These densely set trestle posts might be the result of a renovation of the trestles.

Only house 122 has preserved entrances. These were situated adjacent to and east of the trestle, as is also the case in type 5 houses. The door width (1.1-1.3 m) is typical, but the southern door is recessed deeper (1 $\mathrm{m})$ than is normally seen. These entrances were located similarly to the entrances in the type 5 houses.

The postholes for roof-bearing posts are nearly all circular. The mean surface dimension in the individual houses differs between 0.20 and $0.30 \mathrm{~m}$, with a total mean value of $0.25 \mathrm{~m}$. The mean depths are similarly between $0.07-0.16 \mathrm{~m}$ in the individual houses, with a total mean value of $0.12 \mathrm{~m}$, except for four deep postholes belonging to house 189 , which measured $0.25 \mathrm{~m}$ in mean. Traces of the post were found in two postholes, indicating a circular post with a diameter of 0.18 and $0.20 \mathrm{~m}$, respectively. The diameters of the postholes indicate that the roof-bearing posts in this house type were between 0.15 and $0.20 \mathrm{~m}$ in diameter.

The mean orientation of the houses is straight $\mathrm{E}-\mathrm{W}$, but this mean value obscures the fact that two of the houses are oriented nearly WSW-ENE and WNWESE, respectively. Such a deviation in orientation is also seen in types 5 and 11, and this is also in accordance with the differences in orientation seen in the contemporary type 3 houses.

Raw or burnt clay was regularly found in the postholes. In connection with the type 3 houses, it was argued that the areas with clay represent the dwelling area in the houses. Based on the same argument, the houses in type 6 - in many respects similar to type 5 dwelling houses - are also interpreted as solely dwelling houses.

The type 6 houses are distributed widely throughout the settlement area (Fig. 33). Two houses (15 and 122) are situated near the western fringes of Area $\mathrm{E}$ with a 
$110 \mathrm{~m}$ internal distance, while one (113) is situated 450 $\mathrm{m}$ to the NE, near the north-eastern corner of Area A. The last one (179) is found in the little settlement of Area B, $800 \mathrm{~m}$ to the SE of Area A.

Three of the houses are ${ }^{14} \mathrm{C}$ dated to $2430 \pm 45 \mathrm{BP}$, 760-400 BC (T-9519, 179), $2535 \pm 115$ BP, 810-510 BC (TUa-83, 113) and $2150 \pm 70$ BP, 360-60 BC (T-8253, 129), respectively. Thus, it appears likely that type 6 belongs to Late Bronze Age Periods V-VI and the PreRoman Iron Age.

The house type is not connected to a certain part of the settlement area, and the undated houses 15 and 122 are situated in Area E, where there are only two other houses (type 3.2, 188, Fig. 22 and type 6, 124, Fig. 33) dated to the periods in question (BA VI; PRIA).

House 179 is situated in Area $B$, in a row with two other small houses, among which one type 5 house (185) is dated to Bronze Age Period VI, and the type 11 house 178 was also normally used in the same period or the early Pre-Roman Iron Age. A small settlement with other types of houses than the ordinary type 3 must for a short period have been situated in Area B in the Late Bronze Age and the transition to Pre-Roman Iron Age.

The last house (129), situated in Area A, was the nearest neighbour to two type 5 houses $(127,128)$; one of them (127) is dated to the early Pre-Roman Iron Age. Since types 5 and 6 have many features in common, it is likely that the houses represent a continuous special purpose part of the settlement, situated at the fringe of Area A in the Late Bronze Age and early Pre-Roman Iron Age.

\subsection{Conclusion type 5 and type 6}

The houses belonging to types 5 and 6 have a widespread distribution in the settlement area:

- The type 5 house 124 is situated in Area E and is only $25 \mathrm{~m}$ east of type 6 house 122 and $130 \mathrm{~m}$ north of type 6 house 15 .

- The type 5 houses 127 and 128 are located in Area A and are only 10 and $25 \mathrm{~m}$ ESE of the type 6 house 113 and 60 m east of type 6 house 129 .

- The type 5 house 185 is located in Area B and is $30 \mathrm{~m}$ ENE of the type 6 house 179.

This shows that houses of type 5 and type 6 are closely connected in space, situated in three different outskirts of the settlement at Forsandmoen. Both the house types have dates to Bronze Age Period VI or the PreRoman Iron Age. The two houses $(124,122)$ in Area E have been dated to $400-200 \mathrm{BC}$, and they can either be
Table 24. Comparison between the average sizes and roofed area of the different type 5, 6 and II houses, when the houses 5, 6 and II.I are supposed to have had long walls and gable walls. Measurements in metres $(\mathrm{m})$.

\begin{tabular}{|l|c|c|c|c|}
\hline & $\begin{array}{c}\text { Length, post- } \\
\text { structure }\end{array}$ & $\begin{array}{c}\text { Total } \\
\text { length }\end{array}$ & Width & $\begin{array}{c}\text { Roofed } \\
\text { area } \text { m }^{2}\end{array}$ \\
\hline Type 5 & 6.80 & 10.80 & 5.60 & 6 I \\
\hline Type 6 & 6.20 & 9.90 & 5.20 & 51 \\
\hline Type II.I & 6.20 & 10.20 & 4.40 & 45 \\
\hline $\begin{array}{l}\text { Type II.2 with } \\
\text { outer walls }\end{array}$ & 5.00 & 5.00 & 4.50 & 23 \\
\hline $\begin{array}{l}\text { Type II.2 without } \\
\text { outer walls }\end{array}$ & 5.00 & 5.00 & 2.40 & 12 \\
\hline
\end{tabular}

contemporaneous or succeed each other. Concerning the three houses in Area A $(113,127,128)$, of which two are dated to $800-400$ and $400-200 \mathrm{BC}$, respectively, it is tempting to suggest a sequence of the three buildings in the Late Bronze Age and the early Pre-Roman Iron Age. Since the type 6 houses have dates only to the period $800-400 \mathrm{BC}$, it is also tempting to suggest a two-phased type 5-6 house at the western fringe of Area E in the Late Bronze Age and the early Pre-Roman Iron Age.

These houses are small, compared to the contemporary longhouses of type 3 , and have no indications of stalled cattle. These buildings are likely to represent something other than the normal agricultural households of the period, but neither the structure of the houses nor the finds give information supporting alternative functions of the houses.

\subsection{Type 11: Small dwelling house with a hearth and diverging trestles}

This type consists of six houses: 27A, 58, 79, 96, 152 and 178, of which four are shown in Fig. 32. In addition, four houses have, with some uncertainty due to poor preservation or only partly uncovered structures, been interpreted as belonging to this type: 125, 129, 175 and 244 . Type 11 houses consist of two straight rows, each with three circular postholes for roof-bearing posts. The rows are diverging towards one end, where a circular hearth made of clay, covered by gravel, possibly containing red-burnt ochre, is situated on the central axis of the house and outside the nearest trestle.

The houses, with one exception (175), are oriented directly $\mathrm{E}-\mathrm{W}$ or a few degrees towards $\mathrm{N}$, in mean $301^{\circ}$. Except for two partly preserved houses, the roofbearing construction of the remaining eight measures between 4.1 and $7.1 \mathrm{~m}$ in length (mean $5.5 \mathrm{~m}$ ). Seven of the houses have an increasing trestle width from west 
$(1.8 \mathrm{~m})$ to east $(2.2 \mathrm{~m})$, while in two houses, the trestle width increases the other way, from $1.8 \mathrm{~m}$ to $2.5 \mathrm{~m}$.

Traces of the wall construction are almost absent in these houses. Only house 58 has two short ditches located $1.1 \mathrm{~m}$ outside the widest roof-bearing postholes, indicating a house width of $4.7 \mathrm{~m}$. In a feature belonging to house 129 , a piece of clay lining with imprints of $2 \mathrm{~cm}$ thick twigs was found. This may originate from a wattle and daub wall. House 129 also has an uncertain entrance $2 \mathrm{~m}$ north of the central axis. If this entrance was recessed by $0.3-0.4 \mathrm{~m}$ from the long wall, as is normal in the Pre-Roman Iron Age, the house width would have been 4.6-4.8 m. Based on these two measurements, the general house width of this house type may be calculated to $2.2 \mathrm{~m}$ broader than the widest trestle. If this were the case, houses of this type would have had house widths from 4.2-4.7 m (mean $4.5 \mathrm{~m}$ ), and consequently a roofed area of 18-33 $\mathrm{m}^{2}$ (mean $25 \mathrm{~m}^{2}$ ), not including areas in possible gables outside the roof-bearing construction. It is, however, also a possibility that at least some of these houses were constructions without outer walls or that longitudinal walls were attached to the roof-bearing construction. If so, the roofed areas would only have been $5-18 \mathrm{~m}^{2}$ (mean $10.4 \mathrm{~m}^{2}$ ).

The postholes are circular, measuring in mean 0.25 $\mathrm{m}$ in diameter and $0.15 \mathrm{~m}$ in depth. The holes are quite similar in size, seldom above $0.30 \mathrm{~m}$ in diameter and $0.20 \mathrm{~m}$ in depth. The postholes in house 58 have been dug so narrow and vertical that the diameter of the posts in the postholes in the eastern end could not have exceeded $0.20 \mathrm{~m}$, while the other four posts would have had a maximum diameter of $0.15 \mathrm{~m}$.

The distinguishing feature of this house type is the location of the hearth, which is on the central axis, but outside the roof-bearing construction elements at the widest trestle. There are three possible interpretations of this location:

1. A wall did not close the gable where the hearth was situated. In this case, the construction was probably an open workshop shed, very much like three-trestle storage buildings still in use in Western Norway.

2. Another possibility, as in the case of house 58 , is that they only had long walls.

3. The houses had long walls and gable walls, but with such shallowly dug postholes that no traces of the postholes are preserved today.

Based on the third interpretation, the roofed area should be increased by approximately $18 \mathrm{~m}^{2}$ (2 gables $x 4.5 \times 2 \mathrm{~m})$, so that the roofed area would have varied between 36 and $51 \mathrm{~m}^{2}\left(\right.$ mean $\left.43 \mathrm{~m}^{2}\right)$.

The hearths are either circular or oval and measure from $0.4-0.75 \mathrm{~m}$ in diameter when circular (mean 0.55 $\mathrm{m}$ ) and $0.4 \times 0.6-0.7 \times 1 \mathrm{~m}$ when oval (mean $0.55 \times 0.85$ $\mathrm{m})$. Five out of nine hearths consisted of a 0.04-0.06 $\mathrm{m}$ thick layer of burnt clay covering a layer of redcoloured gravel. The red colour derives from burning or by adding ochre. The other four hearths were only seen as red-coloured gravel, where ploughing probably destroyed the covering clay sheet. In addition to the burnt clay, an up to $0.07 \mathrm{~m}$ thick layer of charcoal on top of the clay sheet in house 27A confirms that fires were made on top of the sheet.

A small clay vessel containing raw clay was found in a pit underneath the clay sheet in house 129. This can be interpreted as an offering made when building the house. The hearth also contained much charred grain (200 grains from one sample) and burnt bones, probably from household activities. Three other large versions of this house type have sherds of pottery in the postholes or hearths, in addition to flint, soapstone sherds, a smoothing stone and a piece of slag. In total, these houses have similar finds as recovered from habitation houses (type 3 ) from the same period. On the other hand, it is more likely that the smaller version of this type of house, which has no finds, may have been constructed to shelter activities that required a hearth.

The three large houses (27A, 58 and 79) are interpreted as having long walls and gable walls 1.1 and 2 $\mathrm{m}$ outside the roof-bearing construction, respectively. They would have had a $45 \mathrm{~m}^{2}$ mean roofed area, which is only $5-6 \mathrm{~m}^{2}$ less than for type 6 houses. This small size difference between the two groups of houses supports interpreting the three (four if 129 is included) type 11.1 houses as small houses for habitation, while the remaining type 11.2 houses may have been workshops without walls outside the roof-bearing construction. In Table 24, this interpretation is shown in the floor area column as an alternative mean floor area (45 $\mathrm{m}^{2}$ ). Also in Table 24, type 11.2 is primarily shown as if the floor area of the house had long walls $1.1 \mathrm{~m}$ outside the roof-bearing construction and, alternatively, the preferred interpretation with a mean floor area value $\left(12 \mathrm{~m}^{2}\right)$ if the shed did not have any walls outside the roof-bearing construction.

Type 11 is widely distributed throughout the settlement area (Fig. 33). The majority (7) are situated in the eastern half of Area A, while one is found in Area B, another one at the southern part of Area $\mathrm{E}$ and the last 


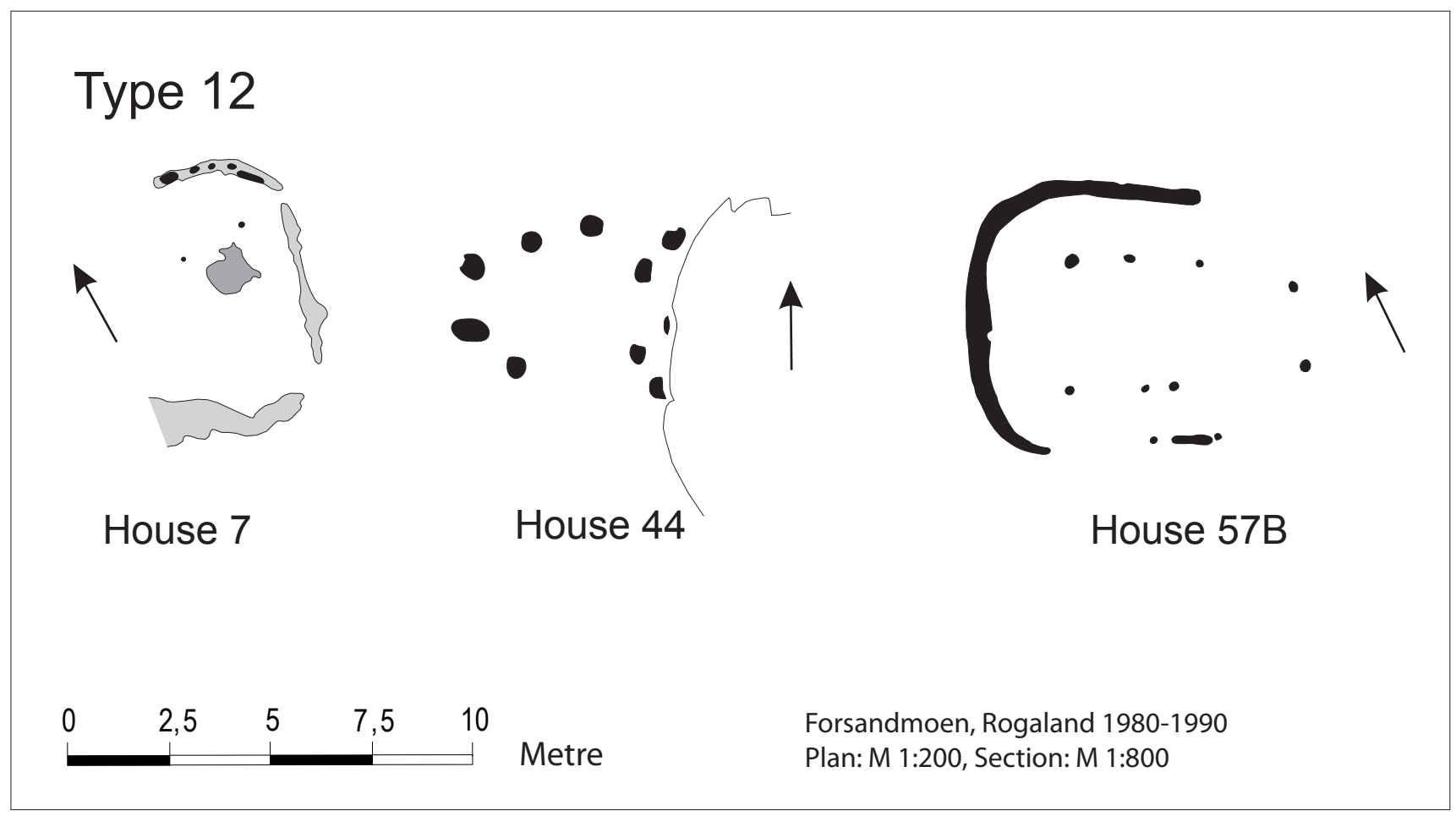

Fig 34. House plans of the type 12 houses.

house at the same spot as the type 6 house (122) near the western fringe of Area E. The four possible houses for habitation (27A, 58, 79 and 129) are all situated in Area A, which is the location of the densest settlement area in Bronze Age Period VI and the Pre-Roman Iron Age.

Three of the ten houses are ${ }^{14} \mathrm{C}$ dated, and the dates cover Late Bronze Age Period VI and the early and middle Pre-Roman Iron Age. In addition, house 178 is between and parallel to the two type 5 and 6 houses 185 and 179, both dated to the period 800-400 BC. It seems reasonable to believe that house 178 belongs to the same period as these two houses.

The type 5 and 6 houses have five ${ }^{14} \mathrm{C}$ dates, which cover the same period as the three dates for type 11 . One may conclude that these three types of small houses belong to Bronze Age Period VI and the early and middle Pre-Roman Iron Age. They probably represent small houses for habitation, where there would not have been space to stall cattle (at most a few sheep). Smaller versions may have been sheds or open workshops. These 18 houses must be seen as additional buildings to the prevailing type of habitation house in that period, namely the type 3 house with a dwelling area and a byre area divided by a small entrance room in the middle. The analysis of these houses as well as the storage houses with 4-12 posts has shown that the Late Bronze Age and Pre-Roman Iron Age has a complex structure with a series of different houses for different requirements.

\subsection{Comparison and interpretation of the house types 5, 6 and 11}

The houses consist of two parallel rows - or towards one end diverging rows - of circular postholes. Type 5 has larger postholes $(0.39 \mathrm{~m}$ in diameter, $0.28 \mathrm{~m}$ in depth) than the two other types $(0.25 \mathrm{~m}$ in diameter, and $0.15 \mathrm{~m}$ in depth). Except for one type 5 house (0.25-0.30 $\mathrm{m}$ in diameter), all measured post dimensions were between 0.15 and $0.20 \mathrm{~m}$ in diameter. The preferred orientation was straight E-W, except for three houses (one from each type) situated at the SE corner of the plain (Area B), which had a mean $270^{\circ}$ orientation.

Types 5 and 6 have entirely or partly preserved long walls and gable walls consisting of densely set postholes, while only one type 11 house has two short wall foundation ditches. All type 5 and 6 houses also have a certain content of clay in the roof-bearing wall postholes, while only four out of ten type 11 houses contained clay in a few postholes. Entrances are also present in type 5 and 6 houses and they are absent in type 11 houses. In many respects, type 5 and 6 can be described with the same features. The main difference is that, in type 5 houses, an extended trestle is added in the eastern part of the house, either outside a normal trestle or between two trestles.

A feature that is common for the three types is the occurrence of a hearth located on top of the gravel. The 
hearth consisted of a sheet of clay on which the fire was lit. However, especially in type 11 houses, the only remains of the hearth is ochre and reddish gravel.

Concerning the size of the houses, the conclusion of the above analysis of house type 11 is that type 11 probably can be divided into two sub-groups: 11.1 as houses intended for habitation with outer walls and 11.2 as sheds without outer walls or with walls attached to the roof-bearing construction and intended for workshop activities that needed a hearth. Type 11.1 is interpreted as having long walls $1 \mathrm{~m}$ outside the widest trestle and the total length is the length of the roof-bearing structure and $2 \mathrm{~m}$ added out to the gables. The mean distance from the nearest trestle to the gable found in the contemporary types 3-6 at Forsand is $2 \mathrm{~m}$. Table 23 (folder) summarise the sizes of the four house groups into which the material has been divided. Four partly excavated type 11 houses (125 and 244: type 11.2 and 129 and 175: 11.3) are not included in this table.

Table 23 shows that the length of the roof-bearing structure is approximately identical for types 5, 6 and 11.1, while the width seems to be reduced from type 5 to type 11.1 - and consequently also the roofed area. The size of the houses interpreted as houses for human habitation only is comparable to the area interpreted as the dwelling area in the type 3 houses from the same time. These three house types might therefore have been the home to similar sized households as those who also had their livestock under the same roof.

It is important to point out that type 11.2 houses, if interpreted with both long walls and gable walls would also have been of a size $\left(41 \mathrm{~m}^{2}\right)$ that was sufficient for a similar household. However, since the finds are different from the houses in type 11.1, the type 11.2 houses are interpreted as sheds at least without gable walls. I believe that the most likely interpretation of the houses in type 11.2 is that they had no outer walls and were used as small sheds for activities requiring a hearth, whether it be cooking, baking, pottery production, bronze casting, an iron forge or anything else that could need both a hearth and shelter.

As Fig. 33 shows, types 5, 6 and 11 occur in three areas: Areas A, E and B. It is not surprising that 10 houses are found in Area A because this was the main settlement area in the Bronze Age and Pre-Roman Iron Age. Here, the houses can be seen in connection with combined dwelling houses for people and cattle, where there also could be households without cattle, as well as sheds for undertaking activities dependent on a hearth or - as the concentrated succession of type 5 and 6 houses at the SE part of this area - special purpose houses of some sort.
The three type 5, 6 and 11 houses in the middle of Area $\mathrm{E}$ are also situated in between farmhouses for people and cattle, dated to the Pre-Roman Iron Age. The well-preserved houses 122 and 124 fit well into a small settlement, consisting of at most two farmhouses at a time (see Fig. 22), as houses for special purposes or as dwellings for a household without cattle to stall. At the southern fringe of the SW settlement area, the type 6 and 11 houses, 15 and 175 respectively, are situated at the border of the plain, with the Forsand river valley to the south, which provides the easiest access to the sheltered bay of Høgsfjord, $800 \mathrm{~m}$ to the SW. The houses are located on each side of the easiest access from the valley to the plain, and the small houses can easily be interpreted as houses belonging to shepherds or a shepherd household, where their main occupation was to herd the cattle in the valley pastures - or as houses used by guardsmen from the settlements whenever needed.

More surprising is the occurrence of three houses, one each of types 5, 6 and 11 at the SE corner of the plain (Area $B$ ), where there are no other settlement traces, like type 3 houses. However, in the excavation areas to the north of this settlement, there are a few badly preserved houses with ${ }^{14} \mathrm{C}$ date intervals that cover the period from Bronze Age Period II down to the middle of the Pre-Roman Iron Age. Later, a proper farm settlement was situated here in the Roman Iron Age and the early days of the Migration Period. Relatively small areas have been excavated here, so there is a possibility that there were further settlements that together constituted a continuous settlement to which the three small houses belonged. Another possibility is that this area was used now and then, for instance as a guard settlement at the access to the plain from Rossavik at Høgsfjord. The type of house, which was only intended for human habitation, can be in favour of such an interpretation or it could have been used in connection with herding cattle in the large pastures towards Rossavik.

One can conclude that types 5, 6 and 11 are distributed in Areas A and E, which were the main habitation areas in house 148 dated to Bronze Age Period VI and the Pre-Roman Iron Age. In addition, such houses were located at two strategic points, Area B and the southern part of Area E, where people could maintain control over their herds at the main pastures on the hillsides outside the plain. The two locations were also strategic for spotting any foreigners that might ascend to the plain, because two other possibilities - from the NW and NE, respectively - were rendered difficult by ravines to the NW and a lake with steep shores to the $\mathrm{N}$ of the terminal moraine Vassrygjen. 


\subsection{Type 12: Small U-shaped features/buildings}

This type consists of four buildings (7, 44, 57B, 148), three of which are shown in Fig. 34. Their location is shown in Fig. 33, in Areas E, C and A, respectively. The only feature these four constructions have in common is a U-shaped outline, shown either as a ditch or, in one case, as a curved row of postholes. In other aspects, they are different from each other and they will only be commented on as unique constructions.

The U-shaped ditch in house 7 is the only feature that with certainty belongs to this construction. A narrow and shallow ditch with a few tiny stake holes and lack of postholes in the area inside the "U" makes it unlikely that the structure represents a house. A sheltering fence around a large central pit may be a more likely interpretation. The contents of the pit indicate a function as a garbage pit, but large parts of a pot may have been intentionally placed in the central pit.

The size of the U-shaped ditch, $4.1 \times 6.4 \mathrm{~m}$, is comparable to two structures from Sweden, which are interpreted as cult houses. At Fosie IV, a 5.9 x $4.8 \mathrm{~m}$ U-shaped structure consisting of postholes and with a large central pit with settlement garbage is interpreted as a cult house (Björhem \& Säfvestad 1993:101, 110). Kaliff $(1996,1997: 54)$ has excavated a similar but smaller $(3 \times 5.5 \mathrm{~m})$ house at Ringeby, where a pit with fire-cracked stones and a possible stone altar was situated inside the walls. The similarities with the alleged Swedish cult houses make it possible that the structure at Forsand has served some religious purposes.

House 7 is dated to the middle or late Pre-Roman Iron Age, which is somewhat later than the two Swedish cult houses, which are dated to Bronze Age Period VI or the early Pre-Roman Iron Age. The other three type 12 structures are more likely to have been houses or sheds open towards the open end of the U-shape.
House 44, measuring $4.8 \times 3.5 \mathrm{~m}$, consists of 9 large and deep postholes appearing as a U-like structure. However, since the structure seems to continue towards east underneath a burial mound, the U-shape may not be real. The house may have consisted of seven large postholes in the U-shape and with a trestle set $4.2 \mathrm{~m}$ from the western, rounded gable. Slag from ironworking and pieces from a forge show that it was probably a smithy at the turn to the Roman Iron Age. One of the wall postholes is stratigraphically older than a wall posthole belonging to house 34 , which dates the house at latest to the beginning of the early Roman Iron Age.

House 57B consists of a U-shaped ditch measuring $6.4 \mathrm{~m}$ in width and $5 \mathrm{~m}$ in depth. Two rows with small postholes are situated inside the ditch, making four trestles of a converging structure. The trestle width near the bottom of the $\mathrm{U}$ measures $3 \mathrm{~m}$, decreasing to $1.8 \mathrm{~m}$ at the outer end. House 148 is a similar, but smaller construction with two trestles of posts inside the U-shaped ditch.

U-shaped houses/constructions have been found at several locations in Rogaland. The oldest one, dated as early as Bronze Age Period I, is a somewhat similar construction as house 44, consisting of two pairs of postholes inside a row of postholes in the shape of a U. This was discovered at Løbrekk in Strand Municipality, not far from Forsand (Løken 2009). Other U-shaped constructions have been found in the Jæren area. They are dated to the Late Bronze Age or the Pre-Roman Iron Age (Bårdsgård 1982, Haavaldsen 1984, 1985, Juhl 2001).

The existence of these U-shaped constructions, together with the type 11 houses, which also had a hearth, show that there had been some type of activities that needed a sheltered but open room in the Late Bronze Age and the Pre-Roman Iron Age. 


\section{Storage buildings (granaries)}

A total of 80 storage buildings have been found at Forsandmoen. The buildings range in size from four to twelve posts set in 2-6 trestles. The buildings lack any trace of features such as wall posts, entrances and with a few exceptions - also hearths. Due to the lack of a hearth, they have therefore been considered not to have been used as dwellings. Most likely, their purpose was to store agricultural crops. The material has been divided into five house types $(13-16,18)$ on basis of the number of trestles and the shape of the layout. The rectangular or square four-post buildings (type 18) are the most common type, comprising 58 buildings, of which nine are dated from the Early Bronze Age to the Migration Period. Types 13 and 14, which consist of two-trestles with either a trapezoid or diverging layout, are each represented by three Bronze Age or early Pre-Roman Iron Age buildings. None of the nine rectangular three- or four-trestle buildings of type 15 have been ${ }^{14} \mathrm{C}$ dated, but some are tentatively dated to the Early Bronze Age as well as the Roman Iron Age and/or Migration Period, due to their proximity to houses from these periods. The seven five- or six-trestle buildings of type 16 were probably used in connection with the type 9 and 10 houses from the Roman Iron Age and/or Migration Period.

\subsection{Type 18: Four-post buildings}

58 rectangular or square four-post buildings were discovered at Forsandmoen. They differed significantly in size, from $1.3 \times 1.1 \mathrm{~m}$ up to $4.5 \times 3.9 \mathrm{~m}$ (Table 25). Fig. 35 illustrates nine different house plans for these fourpost houses. This house type was scattered throughout the entire settlement area (Fig. 36) but was concentrated in Area A, where most type 3 houses were also situated. There were relatively few four-post houses in Area E, where the large late Roman Iron Age and Migration Period village was situated. Thus, it appears that four-post granaries were usually not a part of the farm in these periods.

Dating by radiocarbon analysis, artefacts and context The four-post house type has elements in the layout that can be used to divide them into subtypes and to date them. We tried to collect charcoal samples to
Fig. 35. House plans of the type 18 houses.

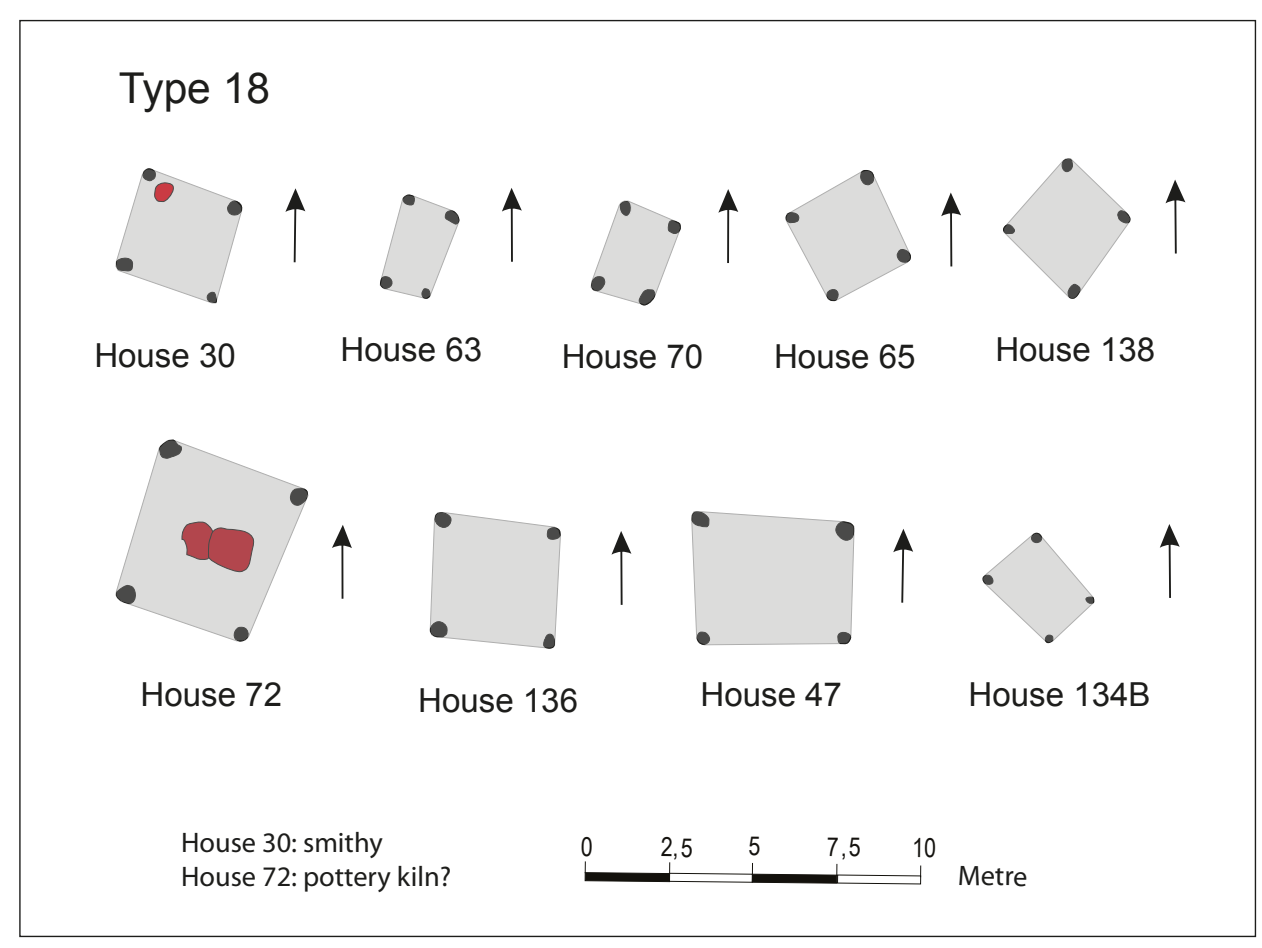


Table 25. Presentation of compiled features from type 18 houses (four-post buildings). Measurements in metres (m).

\begin{tabular}{|c|c|c|c|c|c|c|c|c|c|c|c|c|c|c|c|}
\hline \multirow{3}{*}{ 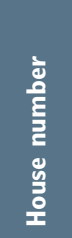 } & \multirow{3}{*}{ 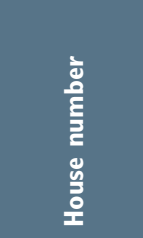 } & \multirow{3}{*}{$\stackrel{\Xi}{\grave{\Sigma}}$} & \multirow{3}{*}{ 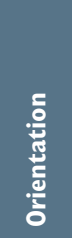 } & \multirow{3}{*}{ 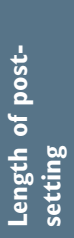 } & \multirow{3}{*}{$\begin{array}{l}\frac{5}{5} \\
\frac{0}{3} \\
\frac{\pi}{2}\end{array}$} & \multirow{3}{*}{ 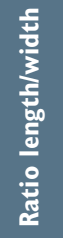 } & \multirow{3}{*}{ 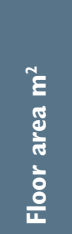 } & \multirow{3}{*}{ 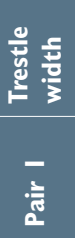 } & \multirow{3}{*}{ 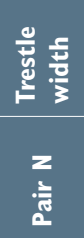 } & \multicolumn{6}{|c|}{ Roof-bearing postholes } \\
\hline & & & & & & & & & & \multirow{2}{*}{ 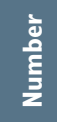 } & \multirow{2}{*}{$\begin{array}{l}\text { Shape } \\
\text { I:round } \\
\text { 2:oval }\end{array}$} & \multicolumn{2}{|c|}{ Surface dimension } & \multicolumn{2}{|c|}{ Depth } \\
\hline & & & & & & & & & & & & Min-max & Mean & Min-max & Mean \\
\hline 148 & CXLVIII & 18 & 272 & 1.30 & 1.10 & 1.15 & 1.5 & 1.15 & 1.50 & $\begin{array}{l}2 \\
2\end{array}$ & $\begin{array}{l}1 \\
2\end{array}$ & $\begin{array}{l}0.21-0.26 \\
0.23 \times 0.43- \\
0.28 \times 0.35\end{array}$ & $\begin{array}{c}0.24 \\
0.26 \times 0.39\end{array}$ & $0.08-0.24$ & 0.14 \\
\hline 46 & $\mathrm{XLVI}$ & 18 & 300 & 2.95 & 2.80 & 1.05 & 8.3 & 2.85 & 2.80 & 4 & 1 & $0.40-0.46$ & 0.44 & $0.31-0.33$ & 0.32 \\
\hline 47 & XLVII & 18 & 303 & 4.30 & 3.40 & 1.26 & 14.6 & 3.55 & 3.25 & 4 & 1 & $0.40-0.46$ & 0.43 & $0.26-0.38$ & 0.32 \\
\hline 51 & $\mathrm{LI}$ & 18 & 297 & 3.50 & 1.80 & 1.94 & 6.3 & 1.80 & 1.80 & 3 & 1 & $0.25-0.50$ & 0.42 & $0.03-0.26$ & 0.17 \\
\hline $56 \mathrm{~B}$ & LVI B & 18 & 368 & 3.45 & 2.90 & 1.19 & 10.0 & 2.95 & 2.90 & 4 & 1 & $0.25-0.35$ & 0.30 & & \\
\hline 67 & LXVII & 18 & 304 & 4.00 & 3.55 & 1.27 & 14.2 & 3.60 & 3.55 & 4 & I & $0.30-0.40$ & 0.35 & $0.30-0.40$ & 0.33 \\
\hline $84 B$ & LXXXIV B & 18 & 292 & 4.40 & 2.55 & 1.73 & 11.2 & 2.55 & 2.55 & 2 & I & & 0.25 & $0.12-0.13$ & 0.13 \\
\hline 102 & Cll & 18 & 229 & 3.55 & 3.45 & 1.03 & 12.2 & 3.45 & 3.45 & 4 & I & $0.28-0.32$ & 0.31 & $0.17-0.35$ & 0.24 \\
\hline 214 & CCXIV & 18 & 247 & 2.35 & 2.35 & 1.00 & 5.5 & 2.35 & 2.35 & 3 & 1 & $0.25-0.30$ & 0.27 & $0.05-0.06$ & 0.05 \\
\hline 33 & XXXIII & 18 & 292 & 3.00 & 3.00 & 1.00 & 9.0 & 3.00 & 3.00 & 4 & I & $0.30-0.38$ & 0.34 & $0.25-0.35$ & 0.31 \\
\hline $164 B$ & CLXIV B & 18 & 302 & 4.40 & 2.40 & 1.85 & 10.7 & 2.15 & 2.65 & 4 & 1 & $0.40-0.50$ & 0.45 & $0.05-0.12$ & 0.09 \\
\hline 72 & LXXII & 18 & 222 & 4.50 & 3.90 & 1.15 & 17.6 & 4.10 & 3.70 & 4 & I & $0.44-0.58$ & 0.49 & $0.28-0.46$ & 0.37 \\
\hline 183 & CLXXXIII & 18 & 383 & 2.90 & 2.10 & 1.38 & 6.1 & 2.10 & 2.10 & 3 & 1 & $0.40-0.46$ & 0.43 & $0.14-0.28$ & 0.21 \\
\hline 64 & LXIV & 18 & 285 & 3.20 & 3.10 & 1.03 & 9.9 & 3.20 & 3.00 & 3 & 1 & & 0.45 & $0.34-0.42$ & 0.38 \\
\hline $38 \mathrm{~A}$ & XXXVIII A & 18 & 310 & 3.35 & 3.20 & 1.05 & 10.7 & 3.20 & 3.15 & 3 & 1 & $0.40-0.45$ & 0.42 & $0.4 I-0.54$ & 0.47 \\
\hline $38 \mathrm{~B}$ & XXXVIII B & 18 & 310 & 2.40 & 2.30 & 1.04 & 5.5 & 2.35 & 2.25 & 4 & I & $0.30-0.47$ & 0.40 & $0.26-0.37$ & 0.30 \\
\hline 40 & $X L$ & 18 & 295 & 2.45 & 2.30 & 1.07 & 6.0 & 2.45 & 2.30 & 3 & 1 & $0.30-0.38$ & 0.33 & $0.20-0.28$ & 0.25 \\
\hline 137 & CXXXVII & 18 & 300 & 3.20 & 2.90 & 1.10 & 9.3 & 2.85 & 2.95 & 4 & I & $0.35-0.55$ & 0.46 & $0.10-0.18$ & 0.16 \\
\hline 138 & CXXXVIII & 18 & 245 & 2.60 & 2.45 & 1.06 & 6.4 & 2.25 & 2.65 & 4 & 2 & $\begin{array}{l}0.30 \times 0.34 \\
0.42 \times 0.48\end{array}$ & $0.34 \times 0.41$ & $0.15-0.22$ & 0.20 \\
\hline$|3|$ & CXXXI & 18 & 362 & 3.90 & 3.65 & 1.07 & 14.2 & 3.65 & 3.65 & 3 & 1 & $0.32-0.36$ & 0.34 & $0.22-0.29$ & 0.26 \\
\hline 199 & CXCIX & 18 & 392 & 3.65 & 3.15 & 1.16 & 11.5 & 3.05 & 3.24 & 4 & 1 & $0.25-0.35$ & & $0.08-0.15$ & 0.11 \\
\hline 236 & CCXXXVI & 18 & 218 & 2.80 & 2.20 & 1.27 & 6.2 & 2.10 & 2.25 & 4 & I & $0.26-0.32$ & 0.30 & $0.06-0.13$ & 0.10 \\
\hline 65 & LXV & 18 & 272 & 2.55 & 2.50 & 1.02 & 6.4 & 2.50 & 2.45 & 4 & 1 & $0.45-0.55$ & 0.53 & $0.23-0.25$ & 0.24 \\
\hline 121 & CXXI & 18 & 290 & 3.00 & 2.90 & 1.03 & 8.7 & 2.85 & 3.00 & 4 & I & $0.30-0.40$ & 0.34 & $0.22-0.27$ & 0.25 \\
\hline 103 & CIII & 18 & 345 & 3.10 & 2.80 & 1.11 & 8.7 & 2.80 & 2.80 & 4 & I & $0.28-0.32$ & 0.30 & $0.29-0.40$ & 0.34 \\
\hline 136 & CXXXVI & 18 & 308 & 3.30 & 3.20 & 1.03 & 10.6 & 3.20 & 3.20 & $\begin{array}{l}1 \\
3\end{array}$ & $\begin{array}{l}1 \\
2\end{array}$ & $\begin{array}{l}0.45 \\
0.35 \times 0.53- \\
0.60 \times 0.70\end{array}$ & $\begin{array}{c}0.45 \\
0.45 \times 0.61\end{array}$ & $\begin{array}{c}0.43 \\
0.12-0.31\end{array}$ & $\begin{array}{l}0.43 \\
0.24\end{array}$ \\
\hline 142 & CXLII & 18 & 290 & 3.80 & 3.30 & 1.15 & 12.5 & 3.05 & 3.50 & 4 & 1 & $0.31-0.35$ & 0.34 & $0.11-0.29$ & 0.20 \\
\hline 149 & CXLIX & 18 & 306 & 2.25 & 2.00 & 1.13 & 4.5 & 2.00 & 2.00 & 4 & 1 & & 0.25 & & 0.05 \\
\hline
\end{tabular}




\begin{tabular}{|c|c|c|c|c|}
\hline \multicolumn{2}{|c|}{ Attached to house number } & \multicolumn{2}{|c|}{ Age BC-AD } & \multirow[t]{3}{*}{ Date 2} \\
\hline & & -1500 & -1100 & \\
\hline & & -1500 & -1100 & \\
\hline $32 B / 48$ & $\begin{array}{l}\text { XXXII B / } \\
\text { XLVIII }\end{array}$ & -1500 & -900 & \\
\hline $32 B / 48$ & $\begin{array}{l}\text { XXXII B / } \\
\text { XLVIII }\end{array}$ & -1500 & -900 & \\
\hline $45 / 59$ & XLV / LIX & -1500 & -900 & \\
\hline $32 B / 48$ & XXXII B /XLVIII & -1500 & -900 & \\
\hline $32 B / 48$ & XXXII B /XLVIII & -1500 & -900 & \\
\hline \multirow[t]{2}{*}{$45 / 52 / 59$} & XLV / LII / LIX & -1500 & -900 & \\
\hline & & -1400 & -1100 & $\begin{array}{l}3030 \pm \text { I I0 BP, cal. BC } \\
\text { 1420-I I } 20 \text { (T-8235) }\end{array}$ \\
\hline \multirow[t]{3}{*}{$212 / 213$} & CCXII / CCXIII & -1300 & -300 & \\
\hline & & -1200 & -900 & $\begin{array}{l}2890 \pm 80 \text { BP, cal. BC } \\
1260-940 \text { (T-7077) }\end{array}$ \\
\hline & & -1100 & -300 & \\
\hline 74 & LXXIV & -900 & -700 & $\begin{array}{l}2620 \pm 60 \mathrm{BP}, \mathrm{cal} B C \\
900-590(\mathrm{~T}-7884)\end{array}$ \\
\hline $179 / 185$ & $\begin{array}{l}\text { CLXXIXI } \\
\text { CLXXXV }\end{array}$ & -900 & -500 & \\
\hline \multirow[t]{4}{*}{54} & LIV & -800 & -200 & \\
\hline & & -500 & -300 & \\
\hline & & -500 & -300 & \\
\hline & & -500 & -300 & \\
\hline 127 & CXXVII & -500 & -300 & \\
\hline 127 & CXXVII & -500 & -300 & \\
\hline 31 & $X X X I$ & -500 & -1 & \\
\hline \multirow[t]{2}{*}{232} & CCXXXII & -500 & -1 & \\
\hline & & -400 & -200 & $\begin{array}{l}2275 \pm 85 \text { BP, cal. BC } \\
410-205 \text { (from house } \\
235 \text { ) }\end{array}$ \\
\hline 60 & LX & -300 & -1 & $\begin{array}{l}2090 \pm 80 \mathrm{BP}, \mathrm{cal} \mathrm{BC} \\
340-10(\mathrm{~T}-7882 \\
\text { TUa-7882) }\end{array}$ \\
\hline $21 / 119$ & XXI / CXIX & -300 & -1 & \\
\hline 81 & $L X X X I$ & -200 & -1 & \\
\hline \multirow[t]{2}{*}{140} & $C X L$ & -100 & 200 & \\
\hline & & -100 & 200 & \\
\hline 139 & CXXXIX & 1 & 200 & $\begin{array}{l}1875 \pm 75 \mathrm{BP}, \mathrm{cal} . \mathrm{AD} \\
60-240(\mathrm{~T}-8705)\end{array}$ \\
\hline 139 & CXXXIX & I & 200 & \\
\hline
\end{tabular}

date the houses during the excavation. Useful samples could, however, only be collected from postholes in three buildings, as other contexts were deemed too uncertain (Løken et al. 1996). In addition, four hearths inside buildings were regarded as contemporary with the construction and the charcoal from these was therefore acceptable as dating material.

A charred grain is a type of find that is more likely to be related to the use of the four-post buildings. The soil samples contained a small amount of charred grains in eight of the 36 sampled four-post buildings. This could support the traditional interpretation that the four-post buildings served as a granary. If so, they were likely deposited into the postholes after an accidental fire in either the stored grain or in the construction. But the amount of charred grains is small; except for 20 grains in one building, only two to seven grains are found in the other seven houses. The 20 grains may be regarded as remnants from a fire in a stored crop, while in the other houses, the charred grains were more likely mixed into the soil, eventually ending up in the fill around the posts when the buildings were constructed or torn down. If this is the case, it is not methodologically sound to date houses situated in a multi-phased settlement site by choosing one charred grain from a posthole.

A significant amount of oak (Quercus) or pine (Pinus) charcoal in the centre of the posthole or charred vertical remains from a post can be an acceptable evidence of a building fire. Such charcoal findings are not reported from the four-post buildings, indicating that none of the houses burnt down. There are small charcoal amounts in three or four of the postholes in 26 (46\%) of these houses. In five houses, there are only small amounts in one or two of the postholes. No charcoal was documented in eight houses. Concerning the last 17 four-post houses, the presence of charcoal is not reported, largely because the postholes were not excavated. In six of the eight houses with finds of charred grains, the postholes are reported to contain small amounts of charcoal, while only one is said to be without charcoal. The seven houses with 2-7 charred grains probably only reflect the content of the soil during the construction of the four-post houses - not the habitation phase of the house.

Table 25 shows that only seven ${ }^{14} \mathrm{C}$ samples could be used to date four-post buildings directly. In addition, due to its solitary location together with house 235 , on a low ridge $60 \mathrm{~m}$ from the nearest longhouse, house 236 is very likely to be contemporary with the dated house 235, and the date from house 235 was therefore used 


\begin{tabular}{|c|c|c|c|c|c|c|c|c|c|c|c|c|c|c|c|}
\hline \multirow{3}{*}{ 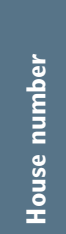 } & \multirow{3}{*}{ 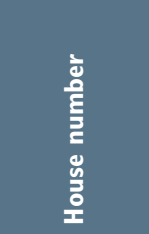 } & \multirow[b]{3}{*}{ 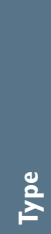 } & \multirow{3}{*}{ 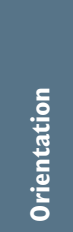 } & \multirow{3}{*}{ 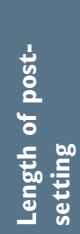 } & \multirow{3}{*}{$\begin{array}{l}\frac{5}{3} \\
\frac{3}{3} \\
\frac{x}{2} \\
\frac{0}{2}\end{array}$} & \multirow{3}{*}{ 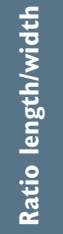 } & \multirow{3}{*}{ 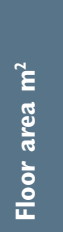 } & \multirow{3}{*}{ 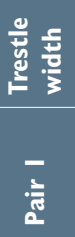 } & \multirow{3}{*}{ 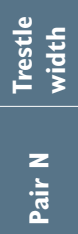 } & \multicolumn{6}{|c|}{ Roof-bearing postholes } \\
\hline & & & & & & & & & & \multirow{2}{*}{$\begin{array}{l}\text { है } \\
\text { है } \\
\text { है }\end{array}$} & \multirow{2}{*}{$\begin{array}{l}\text { Shape } \\
\text { I:round } \\
\text { 2:oval }\end{array}$} & \multicolumn{2}{|c|}{ Surface dimension } & \multicolumn{2}{|c|}{ Depth } \\
\hline & & & & & & & & & & & & Min-max & Mean & Min-max & Mean \\
\hline \multirow[t]{2}{*}{166} & CLXVI & 18 & 368 & 2.20 & 1.50 & 1.47 & 3.3 & 1.50 & 1.50 & 3 & I & $0.20-0.33$ & 0.27 & $0.20-0.33$ & 0.27 \\
\hline & CLXVI & & & & & & & & & I & 2 & $0.29 \times 0.37$ & & 0.27 & \\
\hline $87 B$ & LXXXVII B & 18 & 315 & 2.90 & 1.90 & 1.53 & 5.5 & 1.80 & 1.90 & 3 & I & $0.24-0.29$ & 0.26 & $0.26-0.35$ & 0.31 \\
\hline 53 & LIII & 18 & 220 & 2.70 & 1.10 & 2.45 & 3.0 & 1.15 & 1.10 & 2 & 2 & & & & \\
\hline \multirow[t]{2}{*}{70} & LXX & 18 & 225 & 2.35 & 1.55 & 1.52 & 3.6 & 1.55 & 1.55 & 2 & I & $0.48-0.52$ & 0.50 & $0.27-0.30$ & 0.29 \\
\hline & & & & & & & & & & 2 & 2 & $\begin{array}{l}0.35 \times 0.40 \\
0.35 \times 0.50\end{array}$ & $0.35 \times 0.45$ & $0.18-0.23$ & 0.21 \\
\hline 77 & LXXVII & 18 & 306 & 2.40 & 2.25 & 1.07 & 5.4 & 2.25 & 2.25 & 4 & I & $0.28-0.38$ & 0.33 & $0.18-0.30$ & 0.22 \\
\hline 92 & XCII & 18 & 400 & 3.20 & 2.30 & 1.39 & 7.4 & 2.30 & 2.30 & 4 & I & $0.31-0.36$ & 0.34 & $0.12-0.20$ & 0.18 \\
\hline 133 & CXXXIII & 18 & 340 & 2.50 & 2.20 & 1.36 & 5.5 & 2.20 & 2.25 & 4 & $\mathrm{I}$ & $0.25-0.30$ & 0.28 & $0.08-0.14$ & 0.10 \\
\hline 161 & CLXII & 18 & 302 & 1.80 & 1.80 & 1.00 & 3.2 & 1.80 & 1.80 & 3 & I & $0.25-0.28$ & 0.26 & $0.18-0.19$ & 0.18 \\
\hline $2 \mathrm{C}$ & $\| \mathrm{C}$ & 18 & 384 & 2.70 & 2.15 & 1.26 & 5.8 & 1.90 & 2.40 & 4 & I & $0.40-0.60$ & 0.45 & $0.15-0.50$ & 0.38 \\
\hline IOD & $X D$ & 18 & 362 & 3.75 & 3.50 & 1.07 & 13.1 & 3.50 & 3.50 & 4 & 1 & $0.22-0.26$ & 0.24 & $0.11-0.18$ & 0.14 \\
\hline 30 & $X X X$ & 18 & 324 & 2.80 & 2.70 & 1.04 & 7.6 & 2.70 & 2.70 & 4 & I & $0.32-0.46$ & 0.39 & $0.23-0.34$ & 0.28 \\
\hline $27 B$ & $X X V I I I$ & 18 & 314 & 2.60 & 2.60 & 1.00 & 6.8 & 2.60 & 2.60 & 4 & I & $0.15-0.23$ & 0.21 & $0.16-0.24$ & 0.20 \\
\hline $27 C$ & XXVII C & 18 & 210 & 3.50 & 3.40 & 1.03 & 11.9 & 3.40 & 3.40 & 4 & I & $0.30-0.32$ & 0.31 & $0.18-0.34$ & 0.25 \\
\hline 27D & $X X V \| D$ & 18 & 302 & 2.85 & 2.15 & 1.33 & 6.1 & 2.15 & 2.15 & 4 & I & $0.12-0.27$ & 0.21 & $0.06-0.16$ & 0.09 \\
\hline 42 & XLII & 18 & 365 & 2.90 & 2.75 & 1.05 & 8.0 & 2.80 & 2.70 & 4 & I & $0.40-0.48$ & 0.46 & $0.31-0.35$ & 0.34 \\
\hline 233 & CCXXXIII & 18 & 334 & 3.05 & 2.55 & 1.20 & 7.8 & 2.55 & 2.55 & 3 & I & $0.22-0.28$ & 0.25 & $0.10-0.26$ & 0.16 \\
\hline 115 & CXV & 18 & 310 & 2.20 & 1.60 & 1.38 & 3.5 & 1.60 & 1.60 & 4 & I & $0.20-0.43$ & 0.32 & $0.11-0.24$ & 0.16 \\
\hline 114 & CXIV & 18 & 310 & 3.20 & 2.80 & 1.14 & 9.0 & 2.80 & 2.80 & 4 & I & $0.70-1.06$ & 0.89 & $0.13-0.23$ & 0.19 \\
\hline 63 & LXIII & 18 & 220 & 2.55 & 1.30 & 1.96 & 3.3 & 1.40 & 1.25 & 4 & 1 & $0.40-0.56$ & 0.48 & $0.26-0.34$ & 0.29 \\
\hline $134 \mathrm{~B}$ & CXXXIV B & 18 & 356 & 2.45 & 1.80 & 1.36 & 4.4 & 1.65 & 1.90 & 3 & I & $0.24-0.47$ & 0.29 & $0.07-0.09$ & 0.09 \\
\hline 246 & CCXLVI & 18 & 344 & 3.85 & 2.00 & 1.93 & 7.7 & 2.00 & 2.00 & 2 & I & $0.22-0.30$ & 0.26 & $0.13-0.20$ & 0.16 \\
\hline $56 \mathrm{~A}$ & LVIA & 18 & 397 & 3.30 & 2.70 & 1.22 & 8.9 & 2.95 & 2.50 & 4 & I & $0.30-0.40$ & 0.37 & $0.14-0.25$ & 0.18 \\
\hline 88 & LXXXVIIII & 18 & 398 & 3.90 & 2.00 & 1.95 & 7.8 & 2.05 & 2.00 & 3 & I & $0.32-0.35$ & 0.34 & $0.16-0.19$ & 0.18 \\
\hline & & & & & & & & & & I & 2 & $0.24 \times 0.30$ & 0.19 & & \\
\hline 94 & XCIV & 18 & 310 & 3.20 & 2.65 & 1.21 & 8.5 & 2.30 & 2.30 & 4 & I & $0.30-0.36$ & 0.33 & $0.20-0.29$ & 0.25 \\
\hline 95 & $X C V$ & 18 & 312 & 2.55 & 2.30 & 1.11 & 5.9 & 2.30 & 2.30 & 4 & I & $0.30-0.44$ & 0.40 & $0.18-0.32$ & 0.24 \\
\hline $97 B$ & XCVII B & 18 & 320 & 2.20 & 2.10 & 1.05 & 4.6 & 2.10 & 2.10 & 3 & I & $0.20-0.25$ & 0.22 & $0.08-0.14$ & 0.12 \\
\hline 101 & $\mathrm{Cl}$ & 18 & 314 & 3.30 & 2.80 & 1.18 & 9.2 & 2.75 & 2.80 & 3 & I & $0.20-0.25$ & 0.23 & $0.19-0.29$ & 0.22 \\
\hline 117 & CXVII & 18 & 390 & 3.20 & 3.20 & 1.00 & 10.2 & 3.20 & 3.20 & 4 & I & $0.30-0.34$ & 0.31 & $0.16-0.24$ & 0.20 \\
\hline 153 & CLIII & 18 & 313 & 3.00 & 2.50 & 1.20 & 7.5 & 2.35 & 2.70 & 4 & I & $0.24-0.38$ & 0.32 & $0.07-0.11$ & 0.09 \\
\hline 154 & CLIV & 18 & 292 & 4.05 & 2.05 & 1.97 & 8.3 & 2.00 & 2.10 & 4 & I & $0.30-0.34$ & 0.33 & $0.22-0.32$ & 0.29 \\
\hline
\end{tabular}




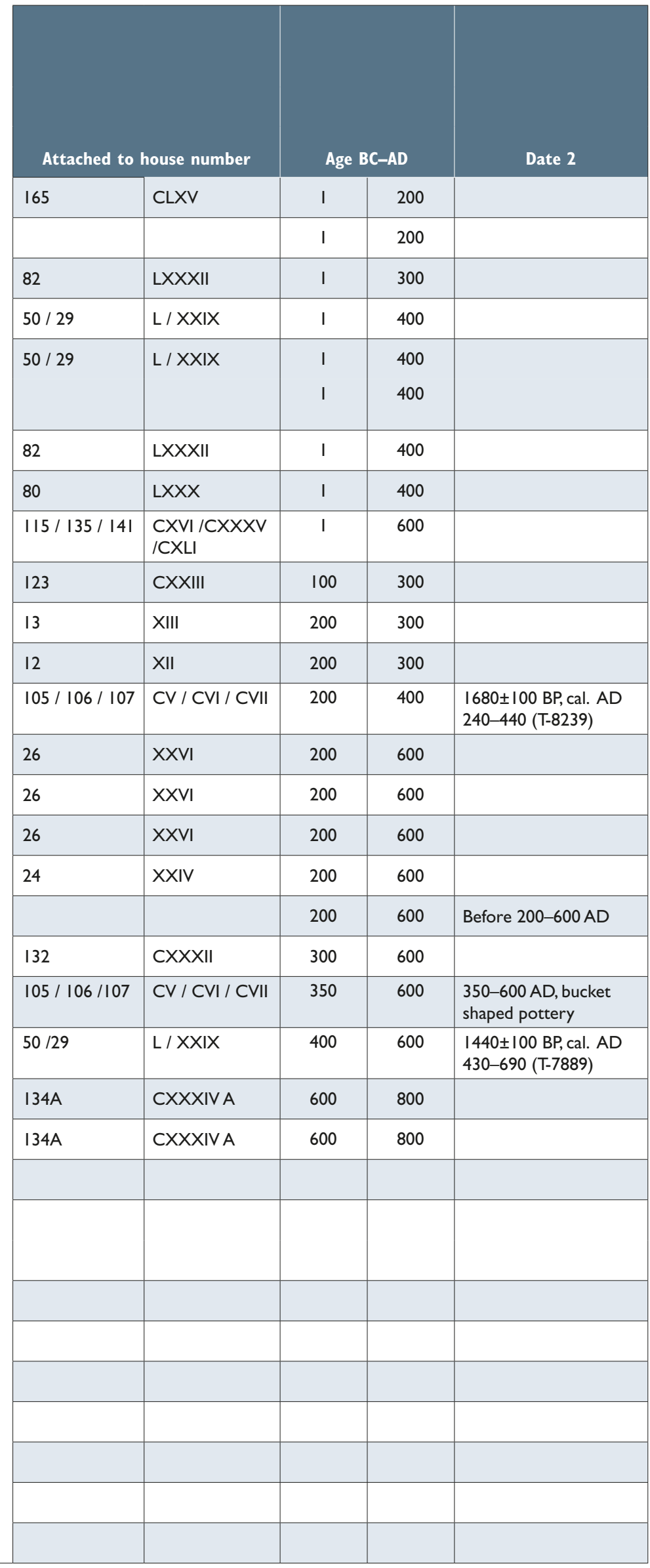

for 236. These eight dates are quite evenly distributed throughout the whole habitation period, with one date to the Early, Middle and Late Bronze Age, respectively, and one from the early and late Pre-Roman Iron Age. The same pattern continues into the early and late Roman Iron Age and, finally, there is one date from the Migration Period. The conclusion must be that four-post buildings were used for storage purposes through more than 2000 years of settlement. However, compared to the number of dwelling houses from the different periods, the four-post granaries are less frequently used after AD 1 than before.

Eight dates from 58 buildings is a too small number to draw conclusions about their date. What artefacts from postholes in these eight ${ }^{14} \mathrm{C}$ dated buildings can add to our understanding of the period of use in these houses? Only three of these houses provided finds. One house (102 from the Early Bronze Age) yielded two side sherds of coarse-tempered pottery. House 72 from the Late Bronze Age produced one rim sherd and three side sherds from similar un-datable pottery. Slag and partly glazed, burnt clay lining (coating) from a furnace may correspond to the ${ }^{14} \mathrm{C}$ date of AD $240-440$ from charcoal sampled from the furnace in house 30.

Among the nine other houses with artefacts, there is only one (house 114) that is datable to a specific period. One sherd from a bucket-shaped pot, decorated with four parallel, vertical lines, dates the house to late Roman Iron Age or Migration Period. Seven other houses only had one or a few sherds of coarsetempered pottery. They are mostly side sherds as well as only three rim sherds, none of them with dating elements. A fragment of a crucible (or a hearth lining) was found in the last of the four-post buildings with finds. None of these finds, except for the sherd from a bucket-shaped pot, can help to date the houses within the settlement period. The small amount of finds, in fewer than $20 \%$ of the houses, indicates that the finds in the four-post houses are mainly old sherds scattered in the earth. They may have been secondarily deposited in a posthole by chance, and not as a result of activities in the four-post houses.

The buildings may also be dated by the size and shape of the ground plan, changes through time in the posthole constellation, or the posts themselves. Also, the orientation of the house and its association with other houses - especially the longhouses - is important for the dating.

Looking towards Jutland, it is well known that fourpost houses from the Iron Age in Jutland are often situated in enclosed farmyards, at a short distance to 


\section{Forsandmoen, Forsand municipality Map of settlement area}

$\subset$ House feature with preserved wall remains House feature without wall remains

$\square$ House possibly connected to a nearby granary

- Four-post granary

Gravemound / cairn

$\bigcirc \quad$ Excavated gravemound / cairn

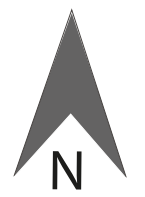

TGB/TL 2009/2014
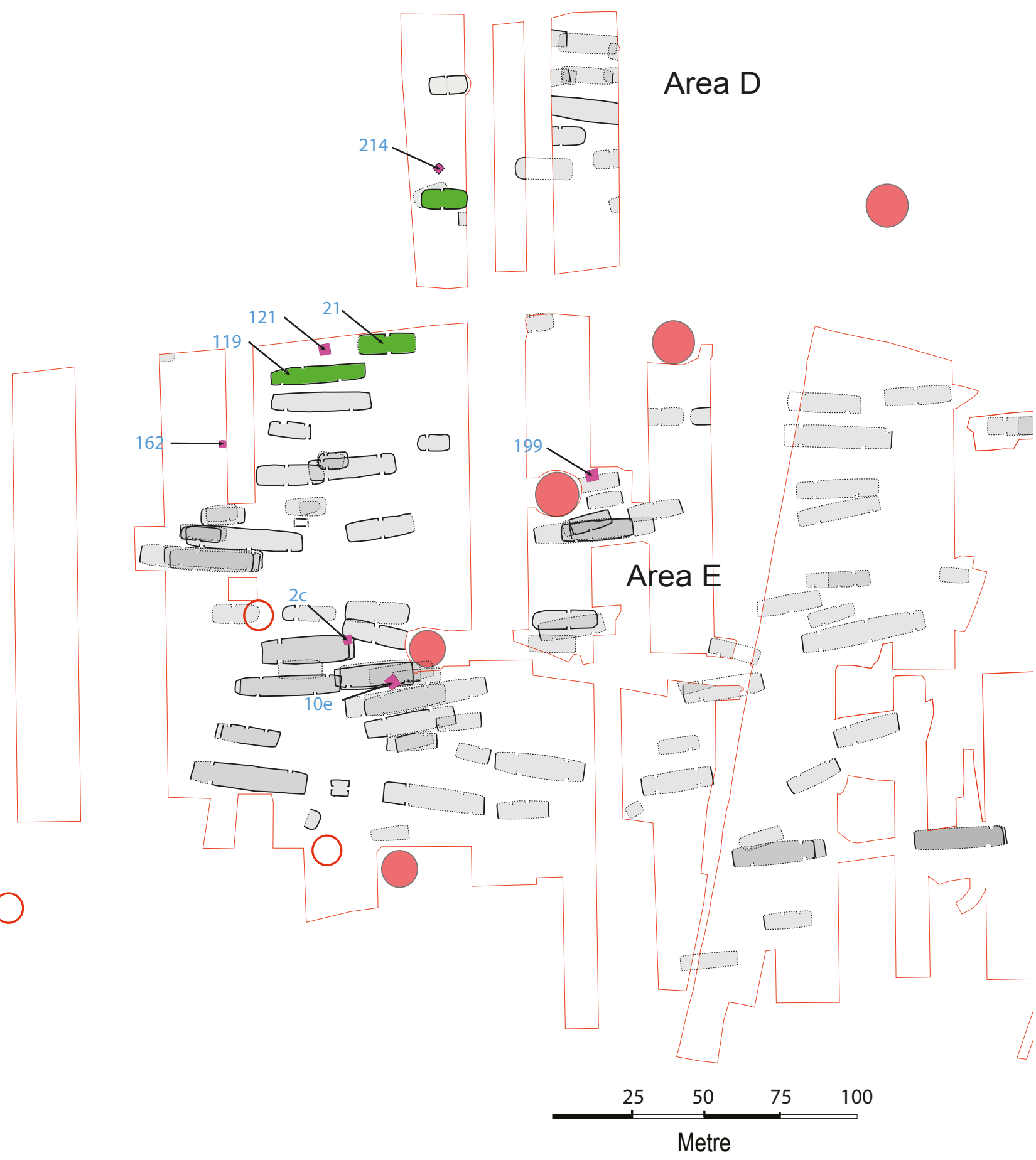

Area $\mathrm{E}$

$\bigcirc$ 
Table 26. Comparison of differences in orientation between four-post granaries and longhouses of the types I, 3, 7, 8 and 9.

\begin{tabular}{|c|c|c|c|c|c|}
\hline \multirow{2}{*}{\multicolumn{2}{|c|}{ Orientation }} & \multicolumn{2}{|c|}{$\begin{array}{l}\text { Four-post } \\
\text { buildings }\end{array}$} & \multicolumn{2}{|c|}{ Longhouses } \\
\hline & & Number & $\%$ & Number & $\%$ \\
\hline $200-233$ & SSW-NNE & 8 & 13 & 0 & 0 \\
\hline $234-266$ & SW-NE & 2 & 5 & 2 & 2 \\
\hline $267-299$ & WSW-ENE & 10 & 17 & 35 & 38 \\
\hline $300-333$ & WNW-ESE & 22 & 38 & 50 & 54 \\
\hline $334-366$ & NW-SE & 8 & 13 & 5 & 5 \\
\hline \multirow[t]{2}{*}{$367-399$} & NNW-SSE & 8 & 13 & I & 1 \\
\hline & & 58 & 99 & 93 & 100 \\
\hline
\end{tabular}

the main farmhouse. This can be seen for instance at Hodde (Hvass 1985) and Grøntoft (Becker 1968, 1971, Rindel 1997) in the Pre-Roman Iron Age, and at Vorbasse (Hvass 1979) and Nørre Snede (Hansen 1987) in the Roman Iron Age and Migration Period. A fence encloses each single farm in many of the Iron Age settlements. This allows for the conclusion that the enclosed buildings are contemporary. Four-post houses are also known at settlement sites from the Bronze Age (Bertelsen et al. 1996).

The relationship between a four-post building and the nearest main farmhouse often gives a tentative date of the four-post house. Such an approach could be applied where two types of houses were situated closely together, but at a distance to other longhouses. Even in such a situation, the combination of houses is not certain. Therefore, such combinations must be treated with care. When many buildings were situated close to each other, one has to be even more cautious.

The relationship between four-post buildings and associated dated longhouses represent another possibility to tentatively date some of the four-post buildings. The surroundings and stratigraphical information for every four-post building have therefore been analysed in order to connect the four-post building to the most probable longhouse. Table 25 shows most of the relevant data for the 58 four-post houses, including a link to one or more main longhouses with which they could have been associated, with a date of the longhouses based on ${ }^{14} \mathrm{C}$ dates and/or artefacts. The table has been sorted by age before present, with nine houses at the bottom that have no dates or possible associated longhouses. The most certain association of four-post houses and longhouses can be seen in Fig. 36. Three such houses (53, 65 and 70) are found in Area A, situated in a narrow farmyard between the dwelling/byre house 50 and the workshop house 29. Another reliable example of the analysis is granary 214 , which was

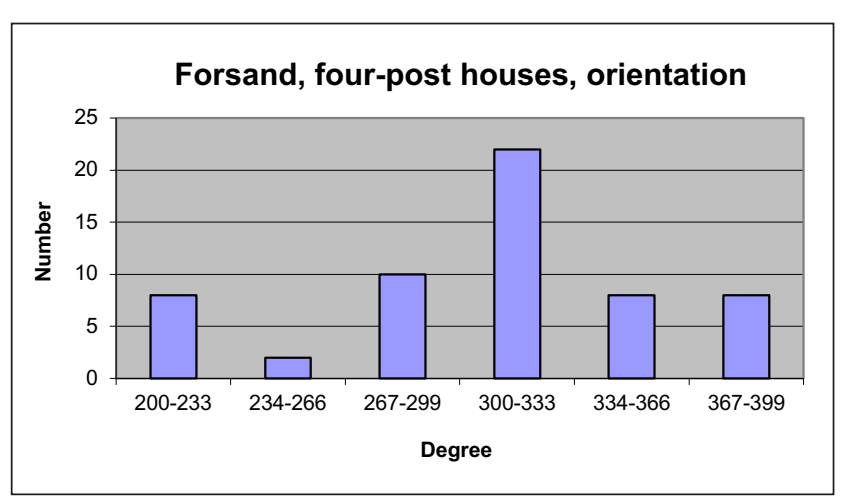

Fig. 37. Graph showing the orientation distribution of the 57 four-post granaries.

probably used together with the type 3 house 212 Area D, cf. also Løken 1989b:113f). Others are granary 131, associated with the type 3 house 31 (Area A); granary 137, associated with the type 3 house 127 (Area A) and granary 121, associated with the type 3 house 21 or the type 7 house 119 (Area E).

The analysis shows that 13 four-post houses appear to belong to the Bronze Age, eleven to the Pre-Roman Iron Age, 22 to the Roman Iron Age and Migration Period and two to the Merovingian Period. No suggestions could be made for nine houses. Per century, this gives 1.3 houses in the Bronze Age, 2.4 in the Pre-Roman Iron Age, 3.5 in the Roman Iron Age and Migration Period and 1 in the Merovingian Period. This seems to point to an increasing use of four-post houses through time. However, such numbers do not take into account the development of the number of settlement units/farms - each at least consisting of a dwelling/byre house - from 1-2 farms or settlement units in the Early Bronze Age via $3-5$ in the Late Bronze Age and 6-8 during the Pre-Roman Iron Age to 10-16 during the Roman Iron Age and Migration Period (Løken 2001a:13). Against this background, the use of four-post houses associated with a farm/settlement unit has been most frequent in the Early Bronze Age, while they were seldom used in the Roman Iron Age and Migration Period.

The four-post houses are not evenly distributed throughout the settlement area (Fig. 36). Only twelve buildings are located outside the densely occupied Area A. It is striking that none of the late Roman Iron Age and Migration Period farms in the large village in the SW corner of the central habitation area (Area E) have associated four-post buildings, and this is also the case with the two farms from the same period in Area B. In Area A, nine four-post buildings are tentatively ascribed to a house from the late Roman Iron Age, Migration Period or even the Merovingian Period. 
However, in all these cases the four-post buildings are situated in areas with many older longhouses, which makes such an association uncertain. The remaining four-post building tentatively dated to the Roman Iron Age and Migration Period belongs to longhouses from the early Roman Iron Age, and there are also a few examples of four-post buildings and early Roman Iron Age longhouses in the SW corner.

The only four-post house with bucket-shaped pottery in the postholes (114) is situated inside a three-phased longhouse area from the late Roman Iron Age and Migration Period, confirming the date given by the pottery. When the location of the houses is taken into consideration, the conclusion must be that four-post buildings to some degree were a part of the Roman Iron Age and Migration Period farms.

On the basis of the presented interpretation of the main longhouses and the different four-post buildings with which they have been associated, it is possible to analyse other attributes of the four-post buildings mentioned above and to investigate whether or not there are differences in features such as the orientation of the houses, their size and shape and their post construction through the 2000 years of settlement history at Forsandmoen.

\section{Orientation of the four-post buildings}

The trestles in the houses are defined as the pairs of posts that have the shortest distances between the posts. The direction is measured along the central axis between the trestles between $200^{\circ}$ and $399^{\circ}$. Due to the restricted number of houses, the material is divided into only six groups to make it possible to recognise a pattern. As can be seen in Table 26 and Fig. 37, the four-post buildings are oriented in all directions: $55 \%$ are oriented between WSW and WNW and 5-15\% of the houses are oriented in the four other directions. This pattern can be compared with the orientation of five types of longhouses (1, 3, 7, 8 and 9) from the entire

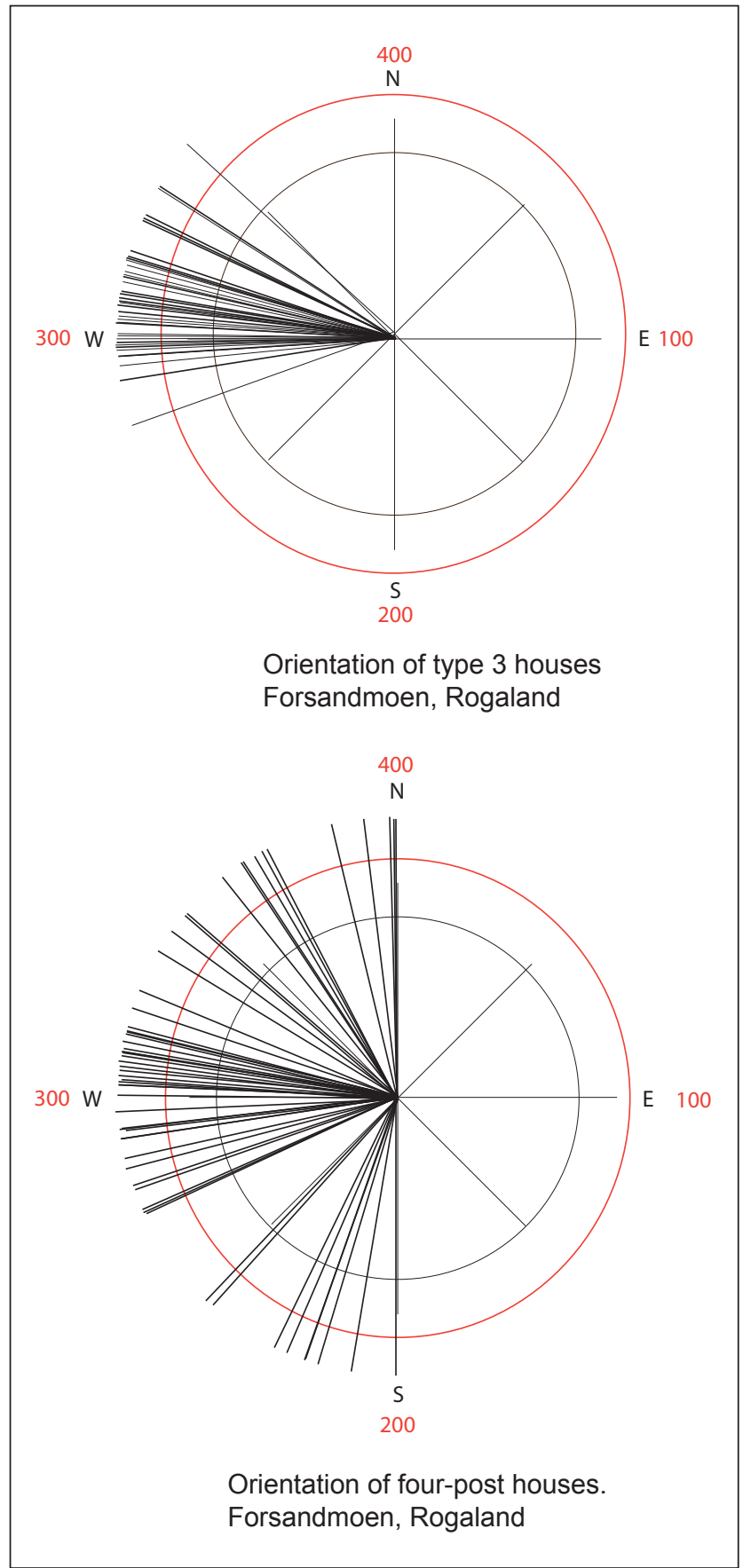

Fig 38. Orientation of four-post granaries.

Table 27. Orientation distribution of four-post granaries compared to longhouses during the Bronze Age, Pre-Roman Iron Age and Roman Iron Age / Migration Period.

\begin{tabular}{|c|c|c|c|c|c|c|c|c|c|c|c|c|}
\hline \multirow[t]{2}{*}{ Orientation } & \multicolumn{2}{|c|}{$\begin{array}{l}\text { Four-post, } \\
\text { Bronze Age }\end{array}$} & \multicolumn{2}{|c|}{$\begin{array}{l}\text { Longhouse, } \\
\text { Bronze Age }\end{array}$} & \multicolumn{2}{|c|}{$\begin{array}{l}\text { Four-post, } \\
\text { Pre-Roman Iron Age }\end{array}$} & \multicolumn{2}{|c|}{$\begin{array}{l}\text { Longhouse, } \\
\text { Pre-Roman Iron Age }\end{array}$} & \multicolumn{2}{|c|}{$\begin{array}{l}\text { Four-post, } \\
\text { Roman Iron Age/ } \\
\text { Migration Period }\end{array}$} & \multicolumn{2}{|c|}{$\begin{array}{l}\text { Longhouse, } \\
\text { Roman Iron Age/ } \\
\text { Migration Period }\end{array}$} \\
\hline & Number & $\%$ & Number & $\%$ & Number & $\%$ & Number & $\%$ & Number & $\%$ & Number & $\%$ \\
\hline $200-279$ & 4 & 31 & 0 & 0 & 3 & 25 & I & 5 & 4 & 17 & 2 & 4 \\
\hline $280-299$ & 3 & 23 & 2 & 13 & 3 & 25 & 6 & 29 & I & 4 & 26 & 47 \\
\hline $300-319$ & 4 & 31 & 8 & 50 & 3 & 25 & 10 & 47 & 9 & 37 & 25 & 44 \\
\hline \multirow[t]{2}{*}{$320-399$} & 2 & 15 & 6 & 37 & 3 & 25 & 4 & 19 & 10 & 42 & 3 & 5 \\
\hline & 13 & 100 & 16 & 100 & 12 & 100 & 21 & 100 & 24 & 100 & 56 & 100 \\
\hline
\end{tabular}


Table 28. Measured features from seven four-post houses with recorded post dimensions. Measurements in centimetres (cm).

\begin{tabular}{|c|c|c|c|c|c|c|}
\hline House number & Orientation & House size & Posthole & Post & Date BC-AD & Attached to house \\
\hline 63 & 220 & $255 \times 130$ & $40-56$ & $30-35$ & $200-400$ AD & 50 and 29 \\
\hline 77 & 306 & $240 \times 225$ & $28-38$ & $15-16$ & I-400 AD & 82 \\
\hline $27 B$ & 314 & $260 \times 260$ & $15-23$ & $12-14$ & $200-400$ AD & 26 \\
\hline 33 & 292 & $300 \times 300$ & $30-38$ & $14-15$ & BC I $200-900$ & \\
\hline 64 & 285 & $320 \times 310$ & 45 & 15 & BC 300-1 & 54 \\
\hline $10 D$ & 362 & $375 \times 350$ & $22-26$ & 15 & $200-300$ AD & 12 \\
\hline 67 & 304 & $400 \times 355$ & $30-40$ & $18-19$ & BC I500-900 & $32 B$ \\
\hline
\end{tabular}

settlement period (Table 26). More than $90 \%$ of those houses are oriented between WSW and WNW, showing a quite different pattern compared to that of the four-post houses. The difference in orientation between the four-post granaries and the type 3 houses is shown in Fig. 38. However, since the four-post buildings are in most cases nearly square, those oriented $\mathrm{N}-\mathrm{S}$ can be regarded as also have an orientation perpendicular to the prevailing $\mathrm{E}-\mathrm{W}$ orientation of the longhouses. In fact, most of the longhouses (62\%) have an orientation within $10^{\circ}$ to each side of due west $\left(300^{\circ}\right)$, varying from the Bronze Age with 31 \%, 61 \% in the Pre-Roman Iron Age and $71 \%$ in Roman Iron Age and Migration Period. Only $43 \%$ of the four-post houses have an orientation within $10^{\circ}$ to each side of straight west and north. The conclusion is that the four-post houses have a more varied orientation than the longhouses. The orientation of the four-post houses may have been determined by some other factors than those that dictated the orientation of the longhouses. Many researchers have argued that the preferred E-W or WNW-ESE of the longhouses was chosen because such an orientation gives a maximum sun exposure to the southern long wall and consequently into the house. Since the four-post houses are nearly square, it does not matter which side is exposed to the sun. Maybe the stored grain or hay gains more drying effect from the sun if two of the sides are sun-exposed during the central part of the day? Or

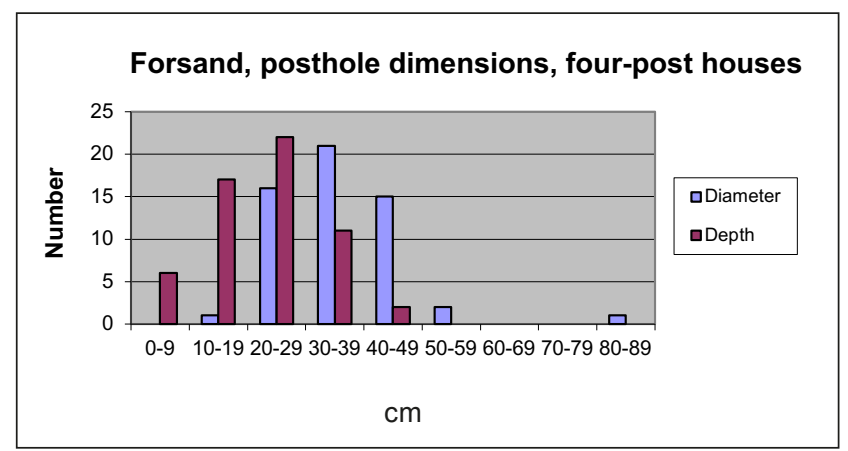

Fig. 39. Average posthole dimensions (diametre, depth) from four-post houses. could it have something to do with the prevailing wind directions at the spot for each four-post house: to gain as much drying effect as possible from the wind?

During 2,200 years of continuous habitation, the preferred orientation may have changed. If there were changes in the orientation of the four-post buildings through time, it could give information of how the houses were used. The number of houses in each of the three main settlement periods was, however, so few $-13,12$ and 24, respectively - that it was necessary to divide them into only four orientation groups. Two of the groups represented $20^{\circ}$ to each side of due $\mathrm{W}$, while the two other groups covered the rest of the directions to due $\mathrm{S}$ and N, respectively. In Table 27, the distribution of the 49 tentatively dated four-post buildings is compared to the total 93 longhouses from the same periods.

Of the four-post buildings, $40-50 \%$ in each of the three periods have an orientation within $20^{\circ}$ to each side of due W. Approximately $50 \%$ have an orientation to each side of due W in the Bronze Age and Pre-Roman Iron Age. In contrast as many as $80 \%$ are oriented $\mathrm{N}$ of due $\mathrm{W}$ in the Roman Iron Age and Migration Period. The conclusion is that the four-post buildings in total have a slightly WNW orientation, probably regarded as the best or right orientation of a house. Such a pattern is confirmed by the orientation of the Roman Iron Age and Migration Period longhouses, which also are evenly distributed around due W, with $91 \%$ within $40^{\circ}$ around due W in the Roman Iron Age / Migration Period. In the earlier periods, the longhouses are not oriented so evenly towards E-W. A smaller proportion of longhouses have their orientation within the $\pm 20^{\circ}$ from due W, and as much as 70-90\% of the houses have an orientation NW of E-W, as opposed to the Roman Iron Age and Migration Period houses.

The conclusion is therefore that the orientation of four-post houses contains two different patterns compared with the longhouses; in total, the orientation is much more widely dispersed and there is a smaller 
number with an orientation within $\pm 20^{\circ}$ from due W. Their orientation is evenly distributed to each side of $\mathrm{E}-\mathrm{W}$ in the Bronze Age and Pre-Roman Iron Age. Most of the houses in the Roman Iron Age and Migration Period are, however, oriented to the NW. Nevertheless, this tendency is not clear enough to use as a means of dating the nine four-post buildings without a tentative date, because only two of these buildings have an orientation that varies beyond the $\pm 20^{\circ}$ from due W. This tendency is confirmed in Table 25, where the mean orientation in the five settlement periods increases from $293^{\circ}$ to $313^{\circ}$ in the Roman Iron Age.

\section{The size of the posts}

Table 25 shows that postholes from four-post houses are relatively small compared with postholes from longhouses (cf. type 3 houses, chapter 5 ). They are nearly all circular on the cleaned surface. Table 25 lists the mean diameter of the postholes in each building. Fig. 39 shows that both diameter and depth vary according to a Gaussian curve, indicating that there was a consistent idea of what the posthole dimensions should be. The mean posthole diameter in the three main periods of habitation is nearly identical in all three periods: $36 \mathrm{~cm}$ in the Bronze Age, $39 \mathrm{~cm}$ in the Pre-Roman Iron Age and $36 \mathrm{~cm}$ in the Roman Iron Age and Migration Period. Concerning the depth, the same situation is observed; the mean depth in the Pre-Roman Iron Age is $27 \mathrm{~cm}$, while the depth in the two other periods is $22 \mathrm{~cm}$. The nine four-post buildings that are not tentatively dated have approximately the same posthole dimensions: 32 $\mathrm{cm}$ in diameter and $20 \mathrm{~cm}$ in depth in mean. The fourpost buildings were probably constructed in the same way throughout more than 2000 years.

The very dominant use of circular postholes points strongly to the use of circular posts. Table 28 shows information from seven four-post buildings where the shape and size of the posts are recorded. These seven four-post buildings are, in most respects, ordinary houses. They have orientations between $220^{\circ}$ and $314^{\circ}$. They differ in size from one of the smallest four-post buildings $(2.55 \times 1.30 \mathrm{~m})$ to one of the largest $(4 \times 3.55$ $\mathrm{m})$. They are dated from the Early Bronze Age to the late Roman Iron Age. The mean size $(34 \mathrm{~cm})$ and depth $(27 \mathrm{~cm})$ of these postholes is comparable with the entire group of type 18 houses $(35 \mathrm{~cm}$ and $23 \mathrm{~cm}$ ). The size at the cleaned surface is average, while the depth is $5 \mathrm{~cm}$ $(20 \%)$ greater than average.

In six of the seven houses, the posts (between one and four in each house) were circular. The seventh house only shows the $\mathrm{N}-\mathrm{S}$ length of the post, not the

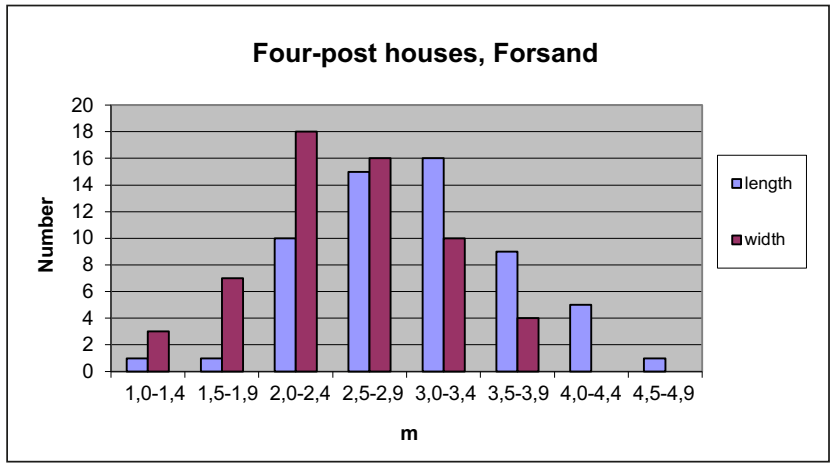

Fig. 40. Distribution of length and width in four-post houses.

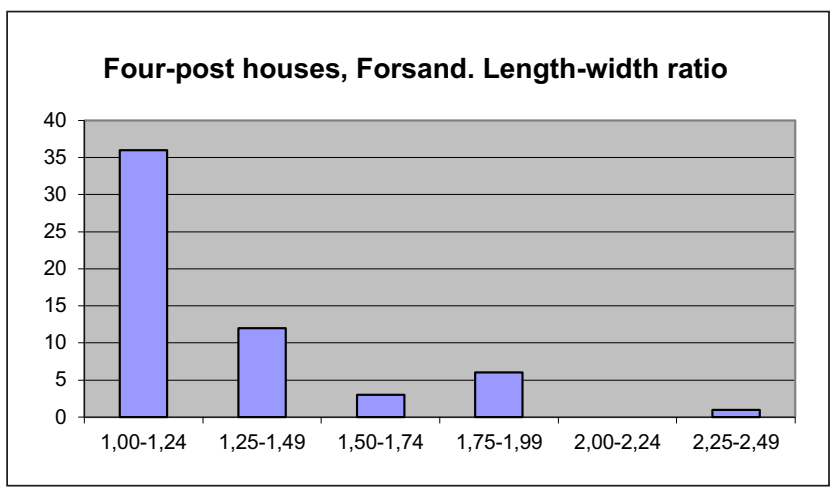

Fig. 4I. Distribution of length/width ratio in four-post houses.

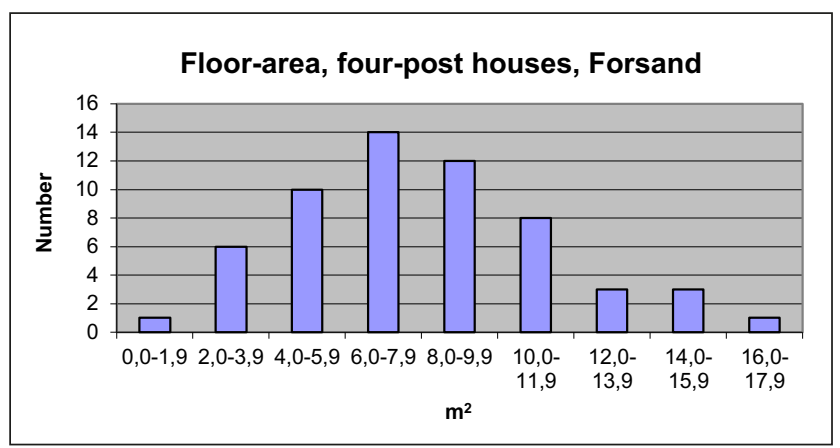

Fig. 42. Distribution in floor area in four-post houses.

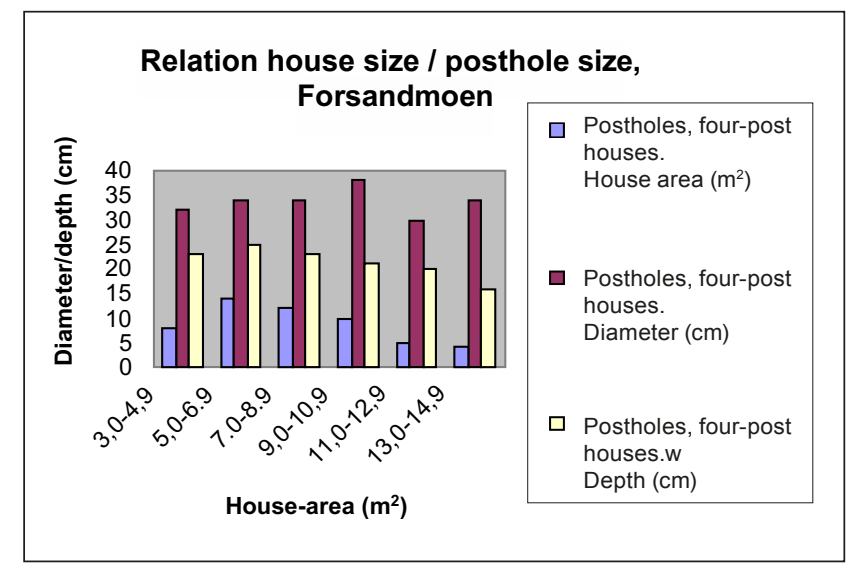

Fig. 43. Relationship between the house size and posthole sizes (diameter/depth) in four-post houses. 
cross-section. Given the circular shape of nearly all the postholes, it is therefore reasonable to conclude that the posts in these houses were indeed circular - even in the Roman Iron Age and Migration Period, when the postholes for roof-bearing posts were normally oval or rectangular.

There is some information regarding the size of the posts in all these seven houses. As can be seen in Table 28, the dimensions with one exception differ between $12-14 \mathrm{~cm}$ and $18-19 \mathrm{~cm}$, with $15-16 \mathrm{~cm}$ as the most frequent size. The largest dimension (18-19 $\mathrm{cm})$ was used in the largest building $(4 \times 3.55 \mathrm{~m})$, while the dimension $15-16 \mathrm{~cm}$ was used in houses ranging in size from $2.40 \times 2.25 \mathrm{~m}$ to $3.75 \times 3.50 \mathrm{~m}$. The smallest dimension $(12-14 \mathrm{~cm})$ was used in one of the smaller $(2.60 \times 2.60 \mathrm{~m})$ of the six houses. When building these houses, the dimensions of the posts were, not surprisingly, adapted to the size of the house and consequently to the weight of the roof that the four posts were to carry. The small size of the posts indicates, together with the size of the structures, that they only held up the roof and not a raised floor for storing grain or hay.

One of the seven houses varies from this pattern. House 63 is the smallest one, only $2.55 \times 1.30 \mathrm{~m}$, but has the largest post dimension $(30-35 \mathrm{~cm})$. The large post dimension is surprising compared to the dimensions of the other six houses, and out of normal proportions for such a small building. The house has a special location in a narrow courtyard between the main longhouse (house 50) and the workshop (house 29), together with two similar sized four-post buildings (63: $2.70 \times 1.10 \mathrm{~m}$, and 70: $2.35 \times 1.55 \mathrm{~m}$ ) in the same courtyard. These two four-post buildings have large postholes that are similar to those in house 63 . These three houses were probably constructed differently to the normal four-post buildings, or served functions other than storage of crops or hay. One possibility is that the large posts only had a height of $0.5-1 \mathrm{~m}$ above the ground and served as support for a small storage house with an elevated floor built on the posts. Such an interpretation is often presented in north-western Germany (Haarnagel 1979, Zimmermann 1992) when the posts are more densely set than in the normal four-post houses. A similar interpretation has also been put forward by Björhem and Säfvestad (1993:294) concerning two houses from the Viking Period and by Rostovány and Hydén (2002:30) where a nine-post Early Bronze Age granary was discussed.

The lack of entrance postholes in the normal fourpost granaries show that they did not have outer walls
(Ethelberg 2003:190), and this house type is interpreted as an open shed with the four corner posts carrying a double-hipped roof (Ethelberg 2003:315) without a raised floor or any type of walls between the posts. The manner in which the crop was stored must have protected the grains from being eaten by rodents or other animals, with the roof supplying protection from rain and moisture.

\section{The size and shape of the ground plan}

The four-post houses are small buildings. Fig. 40 shows that they do not exceed $5 \mathrm{~m}$ in length and $4 \mathrm{~m}$ in width, and that they are as small as $1.3 \mathrm{~m}$ by $1.1 \mathrm{~m}$. However, $90 \%$ measure within 2-3.9 $\mathrm{m}$ in length and 1.5-3.4 $\mathrm{m}$ in width. These are sizes comparable with the length between the posts within a trestle and between trestles in Bronze Age and Pre-Roman Iron Age houses. Fig. 41 also shows that length and width distribution constitute regular Gaussian curves around the mean length (3.06 $\mathrm{m})$ and width $(2.51 \mathrm{~m})$ values. The four-post houses are seldom square, but as Fig. 41 shows, they are slightly rectangular as only $10 \%$ exceed a 1.5 length/width ratio and $60 \%$ have a ratio less than 1.25 . The ratio distribution constitutes a typical exponential curve.

The floor area (Fig. 42) shows a large variation in square metres and consequently storage capability. The variation, between 1.1 and $17.6 \mathrm{~m}^{2}$, is so large that it is reasonable to suggest that this type of house served a variety of purposes; the smallest ones can hardly have been used to store hay or unthreshed grain. The size distribution constitutes a Gaussian curve with its peak at $6-7.9 \mathrm{~m}^{2}$, while the mean size for all 58 houses is 8 $\mathrm{m}^{2}$.

The distribution of these features as a whole, combined with the regular distribution curves, indicates that the four-post houses were constructed within a consistent template as to what they should look like and which purposes they should serve. If this is not the case, one could expect that the distribution curves would have more than one peak. However, the houses were built during a 2000-year period, and it is therefore possible that changes could have taken place during such a long period of time. Table 29 shows the grouped mean values of the central measurements from four-post houses at Forsand, divided into five periods. A sixth group comprises undated houses. Even if we are dealing with small number of houses in each period, one can suggest a few tendencies. Both length and width are smaller in the Roman Iron Age and Migration Period than in the earlier periods - also resulting in a marked difference in the floor area, decreasing from $8.5-9.9 \mathrm{~m}^{2}$ to $6.5-6.9$ 
Table 29. The average size of seven different features in four-post houses, distributed between five prehistoric periods. Measurements in metres ( $\mathrm{m})$.

\begin{tabular}{|c|c|c|c|c|c|c|c|c|}
\hline Period & $\begin{array}{l}\text { Number } \\
\text { of houses }\end{array}$ & $\begin{array}{l}\text { Orientation, } \\
\text { degrees }\end{array}$ & $\begin{array}{l}\text { Length of } \\
\text { post-setting }\end{array}$ & Max width & $\begin{array}{c}\text { Ratio } \\
\text { length/width }\end{array}$ & Floor area $\mathrm{m}^{2}$ & Posthole & $\begin{array}{l}\text { Posthole, } \\
\text { depth }\end{array}$ \\
\hline Mean EBA & II & 291 & 3.38 & 2.66 & 1.32 & 9.4 & 0.35 & 0.22 \\
\hline Mean LBA/E PRIA & 8 & 300 & 2.99 & 2.71 & 1.11 & 8.5 & 0.43 & 0.26 \\
\hline Mean L PRIA & 6 & 315 & 3.28 & 2.97 & 1.11 & 9.9 & 0.36 & 0.25 \\
\hline Mean RIA & 14 & 318 & 2.76 & 2.25 & 1.32 & 6.5 & 0.33 & 0.22 \\
\hline Mean L RIA/ MP & 10 & 307 & 2.92 & 2.30 & 1.34 & 6.9 & 0.37 & 0.19 \\
\hline Mean, not dated & 9 & 338 & 3.19 & 2.51 & 1.27 & 7.9 & 0.32 & 0.20 \\
\hline Mean all four-post houses & 58 & 310 & 3.06 & 2.51 & 1.27 & 8.0 & 0.35 & 0.22 \\
\hline
\end{tabular}

$\mathrm{m}^{2}$. Such a difference between the dated earlier and younger buildings might reflect a prehistoric situation. The measurements from the undated buildings group together in the middle of those from the earlier and later periods, indicating that they may belong to the entire settlement period.

The mean sizes of the postholes do not seem related to the differences in mean floor area during the habitation period. The small changes in the mean diameter and depth cannot have had any consequence for what post-dimension was used since the posts were less than half the diameter of the posthole. Looking at the relationship between house-size and diameter and depth below the cleaned surface of all four-post houses (Fig. 43, it is clear that none of the elements increase with increasing floor area, in spite of what it may seem from Table 28. This indicates that the post dimensions increased from 12-14 to $20 \mathrm{~cm}$ from the smallest to the largest houses. The mean depths decreased evenly between 5 and $15 \mathrm{~m}^{2}$ roofed area, which indicates no need for deeper founding of the posts in the larger houses. The stability must have been adjusted above the ground using bracing members (diagonal braces).

\section{Comparative material in Norway \\ Rogaland}

Few four-post granaries have been found in Rogaland outside Forsandmoen. From Hafsøy, Eigersund (Steen 1995) a granary measuring $2.5 \times 2.5 \mathrm{~m}$ and dated to approximately $1700 \mathrm{BC}$, was encompassed by a nearly circular drainage ditch that was $5 \mathrm{~m}$ wide. This granary shows the need for storage facilities already in the earliest phase of sedentary agricultural settlements in Rogaland, and it may indicate that growing cereal was an important part of the subsistence economy. At the same site - and contemporary with a late Roman Iron Age and Migration Period farm with two parallel longhouses - three four-post granaries are dated to the late Roman Iron Age.
A few other - but much later - granaries with drainage ditches have been found in Stavanger municipality. At Gausel (Børsheim \& Soltvedt 2002:167f), an open drain around three sides of a granary served to prevent water from flooding into the granary. The granary measured $2.5 \times 2.2 \mathrm{~m}$ and the drainage ditch was $4 \mathrm{~m}$ across. Charcoal from the ditch dated the construction to the Early Neolithic (BC 2340-1910), but the granary is situated in an area with houses from the Late Iron Age. Børsheim and Soltvedt's conclusion is that the ${ }^{14} \mathrm{C}$ date is not reliable (Børsheim \& Soltvedt 2002:171). Two ordinary four-post granaries were also situated nearby.

On the island of Hundvåg, two four-post granaries surrounded by a circular ditch have been found at the farms Skeie and Husabø. They are somewhat larger than those mentioned above $(3 \times 3 \mathrm{~m})$ and the ditches are 6-6.5 $\mathrm{m}$ across. The Skeie granary, which had been rebuilt twice, is dated to the Merovingian Period (Børsheim \& Soltvedt 2002:171) by two ${ }^{14} \mathrm{C}$ samples from charred grain from a posthole and the ditch, respectively, while the Husabø granary (house III), which was rebuilt once using new postholes, is tentatively dated to the Late Iron Age. At Husabø, there was also a granary (house I) with a ditch around three sides of the construction, like the one at Gausel, together with one granary (house II) with a central posthole (Aakvik 2001).

At the farm Austbø on Hundvåg, two four-post granaries have been found. A $3 \times 3$ m house (VII) was situated $7 \mathrm{~m}$ north of the eastern end of house IV (Austbø west), which has been dated to the late Roman Iron Age C1a-b (Hemdorff 2006:10). Also at Austbø, but close to the seashore, there was a similar solitary fourpost construction, measuring $3.3 \times 3.3 \mathrm{~m}$; it had burnt down. It was dated to the Viking Period (Juhl 2001:77) by heather sprigs from the postholes. This house was likely used to store heather gathered from the heathland and shows that these houses might have served different storage purposes. 
A still later four-post granary, from AD 1100-1200, is found at Veien in Eastern Norway (Gustafson 2005a:50) and is so far the latest four-post house excavated in Norway.

At the Tastarusta IIa settlement in Stavanger, five undated four-post granaries were situated 3-8 $\mathrm{m}$ from two 15-20 m longhouses dated to the Merovingian Period. They measured from $2.5 \times 2.5 \mathrm{~m}$ to $3 \times 3 \mathrm{~m}$. Two longhouses from the late Pre-Roman Iron Age were also situated in the same area. Even if the distance between the four-post granaries and the late Pre-Roman Iron Age houses is greater $(15 \mathrm{~m})$ we cannot exclude a possible late Pre-Roman Iron Age date for one or more of the granaries.

In Rogaland, the granaries with a surrounding drainage ditch seem to belong to the Late Iron Age, except for the one from Hafsøy which is dated to the Early Bronze Age. Another such construction from Missingen, Østfold (see below) is dated to the early Roman Iron Age. This widespread distribution of dates indicates that digging ditches to protect the stored crops was done more frequently than these few examples would indicate. The granaries without ditches found scattered throughout Rogaland confirm findings from Forsand: four-post granaries were used from early sedentary settlements using post-built longhouses until at least the end of the Viking Period.

A few four-post granaries are found at settlement sites outside Rogaland, and new ones are being found at an increasing pace. As few of the settlement excavations have been extensively published beyond short, preliminary papers, the following two sections can only be regarded as random examples excavated prior to 2010 .

\section{Sogn og Fjordane and Trøndelag}

At Hornnes in Sogn og Fjordane, two four-post granaries have been dated to the Late Bronze Age or the beginning of the Pre-Roman Iron Age (Diinhoff 1996:34f, 44f) and one to the late Roman Iron Age (Diinhoff 1996:40f). The two from the Late Bronze Age are in all respects similar to contemporary granaries at Forsand. The latest is compatible with Roman Iron Age houses that have wide and shallow postholes.

At Hovde in Trøndelag, there are at least two published structures that can be interpreted as four-post granaries, although such an interpretation has not been presented (Grønnesby 1999). If my interpretation is accepted, they should belong to the late Pre-Roman Iron Age and Roman Iron Age, as indicated by several ${ }^{14} \mathrm{C}$ dates from the longhouses.
A four-post granary from Kvenild in Sør-Trøndelag has been dated to Bronze Age Periods V-VI. The approximately 100 charred grains from barley give a fairly good indication as to the grain storage function of the construction (Grønnesby 2006:103f). The granary had wider and deeper postholes $(0.6 \mathrm{~m}$ in diam. and $0.4 \mathrm{~m}$ in depth) than is normally found at Forsand; this may indicate a more stable construction in an area that has different environmental conditions than in Rogaland, for instance more snow.

\section{Østfold and Vestfold}

In the south-eastern part of Norway, a $3.6 \times 3.6 \mathrm{~m}$ granary was found at Kjølberg in Østfold, together with five longhouses dated to AD 400-700 (Martens 2007:104). Three or four such houses were also found at Moer, Akershus, where three longhouses have been dated to the Roman Iron Age and Migration Period (Gustafson 2005b:118f). The $2.4 \times 2.7 \mathrm{~m}$ granary house IV at Moer had a post imprint that measured $0.19 \mathrm{~m}$. It is situated $8 \mathrm{~m}$ east of house I, which has been dated to the late Roman Iron Age and Migration Period (Guttormsen 1998:22f). House V (2.2 x $2.5 \mathrm{~m})$, stratigraphically older than AD 415-600, was situated $17 \mathrm{~m}$ south of house I, and house VI ( $1.5 \times 1.5 \mathrm{~m})$ was situated by itself. At Missingen in Østfold, a $3.5 \times 3.5$ m four-post granary was encircled by a ditch measuring $6.5 \times 6 \mathrm{~m}$ (Bårdseth \& Sandvik 2007b:158f). Compared with the size of the four-post construction, the postholes were rather modest at only $0.28 \mathrm{~m}$ in diameter and $0.20 \mathrm{~m}$ in depth. The ditch is interpreted as a drain. At Bustgård in Østfold, there is a $1.9 \times 5.5 \mathrm{~m}$ rectangular four-post construction, which is larger than average for four-post buildings; situated close to a $25 \mathrm{~m}$ long Migration Period farmhouse, it is more likely a small house than a granary. At Molteberg in Østfold, a four-post granary was situated in an area with ard marks and a cooking pit. The area also contained a bronze axe from Bronze Age Periods I-II, 1700-1300 BC, together with flint cores and flakes, pottery, bones from mammals and grinding stones, all dated to the Late Neolithic or Early Bronze Age (Vikshåland \& Sandvik 2007b:47f).

At least six four-post granaries are known from a settlement dated to the late Roman Iron Age and Migration Period from Ringdal, Vestfold (Gjerpe \& Østmo 2008:98f). In mean, five buildings have a $315^{\circ}$ orientation $\left(305-329^{\circ}\right)$ and one is oriented nearly $\mathrm{N}-\mathrm{S}$ $\left(395^{\circ}\right)$. They differ in size from $2.3 \times 2.5 \mathrm{~m}$ to $3.8 \times 3.8$ $\mathrm{m}$ (mean $3.1 \times 3.3 \mathrm{~m}$ ) and floor areas differ between 5.75 and $14.4 \mathrm{~m}^{2}$ (mean $10.3 \mathrm{~m}^{2}$ ). While the Forsand granaries have quite varying orientations, all these 
houses - with one exception - are oriented nearly $\mathrm{E}-\mathrm{W}$ or slightly to the WNW, which is a rotation of $90^{\circ}$ compared with the longhouses at the settlement. The Ringdal four-post houses are more concentrated in size and larger $\left(7.2 \mathrm{~m}^{2}\right)$ than the mean total floor area at Forsand, a size that is only comparable with 13 Roman Iron Age and Migration Period houses from Forsandmoen. The larger sizes at Ringdal probably express a larger storage requirement at Ringdal than seen in Rogaland and also south of the North Sea (see below).

\section{Conclusion}

We can conclude that four-post granaries are reported both in Rogaland as well as in other parts of South and Central Norway. Since most of the sites are restricted in size, only 1-4/5 granaries have been excavated at each site. According to ${ }^{14} \mathrm{C}$ dates, they were used from the transition between the Late Neolithic II and Early Bronze Age until the Late Iron Age, but so far the material is so scarce that no conclusions can be drawn as to whether there were periods with more frequent use than others.

\section{Comparative houses: Scandinavian, German and Dutch four-post granaries from the Bronze Age and Early Iron Age}

Four-post granaries have not received much attention in settlement analyses in Scandinavian archaeology, but are treated in more detail in German and Dutch archaeology.

\section{Scandinavian four-post granaries: The Bronze Age}

Outside Norway, reported granaries are nearly absent in the Scandinavian material, and investigations and evaluations have concentrated primarily on longhouses. Granaries are not reported from Højgård, Southern Jutland (Ethelberg 1993). The same is the case in a synthesis concerning the agricultural history of Southern Jutland in the Late Stone Age and Bronze Age (Ethelberg 2000). Further to the north in Jutland, five granaries were found at the Bronze Age site Bjerg B (Becker 1980:135f). Bronze Age four-post buildings are also found at Spjald, Jutland (Becker 1972), central and north-western Jutland (Bertelsen et al. 1996) and Sealand (Tornbjerg 1985). The impression based on published excavations is that four-post granaries are not frequent at Danish Bronze Age sites.

In Sweden, Tesch (1993:170f) has published a few Bronze Age houses with two trestles, but most of them have partially preserved wall posts, so they probably belong to another house type than those discussed here. One of them seems to have three entrances, which indicates an outer wall around the four-post construction.

The concluding publications from the project $S k a ̊ n s k a$ spår - arkeologi längs Västkustbanan [Scanian Traces Archaeology Along the Western Coastline] (Artursson 2005a, 2005b), are mainly concentrated on longhouses, but when turning to the Bronze Age farms, there are a few instances of four-post houses. Also in connection with the large project Öresundsförbindelsen [The Öresund Connection], at least two four-post granaries have been reported and dated to the Bronze Age (Hadevik \& Gidlöf 2003:134f, Rudin \& Brink 2002:50,). This project also documented four nine-post granaries, three dated to Bronze Age Periods II-III (Berggren \& Celin 2004:61, Rudin \& Brink 2002:52f) and one to Late Bronze Age Period VI (Rostovány \& Hydén 2002:29). They show that the nine-post granaries found in the German and Dutch areas in the Roman Iron Age have a much longer history - back to the Bronze Age - and that the type was also part of the southern Scandinavian building tradition. At Elp in the Netherlands, a six-phased isolated farm from Bronze Age Periods II-IV has 2-3 granaries in connection with each phase (Müller-Wille 1977:173f, Waterbolk 1964:99) and shows that such houses were also a part of the Dutch and German farms (Zimmermann 1992:243).

\section{Scandinavian four-post granaries: The Iron Age}

Small outbuildings in Southern Jutland are new phenomena in the Iron Age according to Ethelberg (2003:148). He distinguishes between small houses consisting of 2-3 pairs of posts and remains from entrances, walls and/or hearths and buildings with four or more posts without such features, which are called staklade, speicher, hjelm, rutenberger or granary in different languages. The illustrations from many farm sites (Ethelberg 2003) show that the four-post or larger storage houses do not occur frequently at the farms in southern Jutland in the Early Iron Age, mostly due to outbuildings being placed along the palisade that surrounds the farmyard.

Among the 200 houses at the site, only six four-post and two six-post granaries from the Pre-Roman Iron Age I-II were excavated at Grøntoft, Jutland (Rindel 1997:134). Such houses are therefore only seldom associated with a farm at this settlement. However, the 36 four-post granaries from the last part of the PreRoman Iron Age (Hvass 1985) that have been excavated 
Fig. 44. Distribution of the floor size of houses within 2 $\mathrm{m}^{2}$ intervals at six sites in the Northern European area.

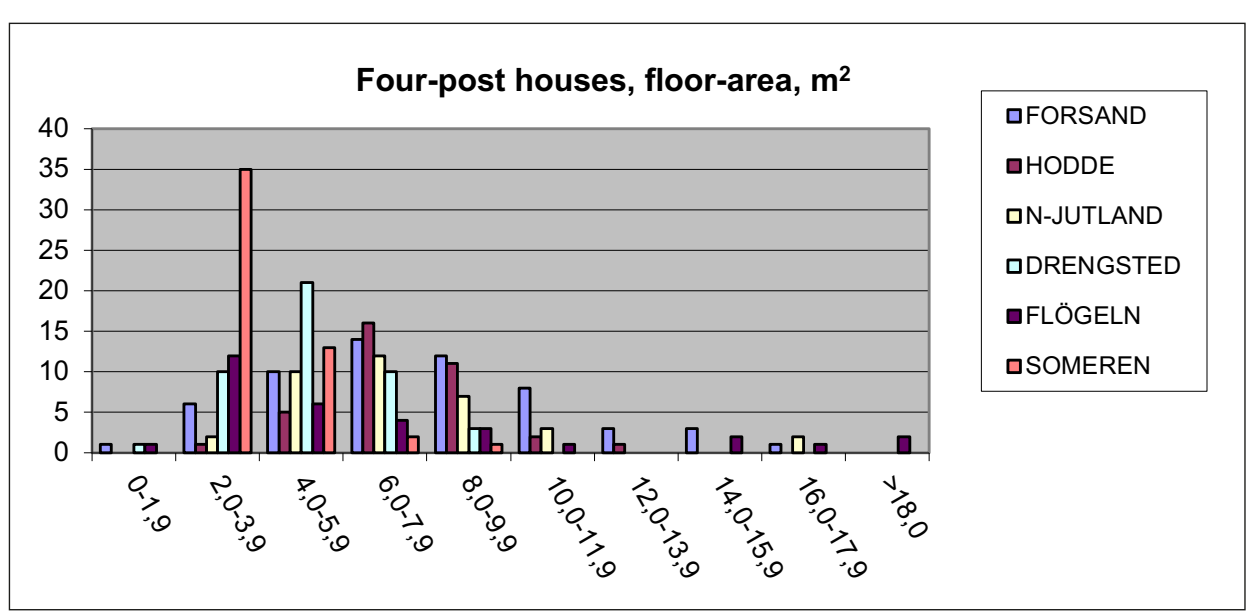

Table 30. Distribution of the floor size of four-post houses with $2 \mathrm{~m}^{2}$ intervals at six sites in the Northern European area.

\begin{tabular}{|l|c|c|c|c|c|c|c|c|c|c|c|c|}
\hline & \multicolumn{2}{|c|}{ Forsandmoen } & \multicolumn{2}{|c|}{ Hodde } & \multicolumn{2}{c|}{ Nord-Jylland } & \multicolumn{2}{c|}{ Drengsted } & \multicolumn{3}{c|}{ Flögeln } & \multicolumn{2}{c|}{ Someren } \\
\hline Area $\mathrm{m}^{2}$ & Number & $\%$ & Number & $\%$ & Number & $\%$ & Number & $\%$ & Number & $\%$ & Number & $\%$ \\
\hline $0-1.9$ & 1 & 3 & & & & & 1 & 2 & 1 & 3 & & \\
\hline $2.0-3.9$ & 6 & 10 & 1 & 3 & 2 & 6 & 10 & 22 & 12 & 38 & 35 & 69 \\
\hline $4.0-5.9$ & 10 & 17 & 5 & 14 & 10 & 28 & 21 & 47 & 6 & 19 & 13 & 25 \\
\hline $6.0-7.9$ & 14 & 23 & 16 & 44 & 12 & 33 & 10 & 22 & 4 & 13 & 2 & 4 \\
\hline $8.0-9.9$ & 12 & 20 & 11 & 30 & 7 & 19 & 3 & 7 & 3 & 9 & 1 & 2 \\
\hline $10,0-11.9$ & 8 & 14 & 2 & 6 & 3 & 8 & & & 1 & 3 & & \\
\hline $12.0-13.9$ & 3 & 5 & 1 & 3 & & & & & & & & \\
\hline $14.0-15.9$ & 3 & 5 & & & & & & & 2 & 6 & & \\
\hline $16.0-17.9$ & 1 & 3 & & & 2 & 6 & & & 1 & 3 & & \\
\hline$>18.0$ & & & & & & & & & 2 & 6 & \\
\hline Sum & 58 & 100 & 36 & 100 & 36 & 100 & 45 & 100 & 32 & 100 & 51 & 100 \\
\hline
\end{tabular}

at Hodde indicate a more frequent use of such houses around AD 1. At the settlement at Priorsløkke in East Jutland (Kaul 1985), the second phase from the $2^{\text {nd }}$ century AD contains seven four-post buildings, which seems to be one for each main farmhouse at the site. At Nørre Snede (Hansen 1987:185f), as many as 75 four-post granaries indicate that one or more such houses belonged to nearly every farm. At Drengsted (Mikkelsen \& Nørbach 2003:34), such houses were also prevalent, as the 52 houses were clustered with up to 4-5 granaries associated with the different farmyards. This could give the impression of an increasing use of four-post granaries in Jutland, but at settlements such as Præstestien (Siemen 2000) and Vorbasse (Hvass 1979) such houses are rare, most probably because sheds along the fences were used for storage. The use of four-post buildings seems therefore to differ greatly from site to site in the Roman Iron Age and Migration Period in Jutland.

In Scania, Sweden, a few Early Iron Age four-post houses are associated with longhouses (Tesch 1993:fig. 16-17), but according to Tesch, there have been many other such houses in the chaos of postholes at the different sites in the Köpinge area.

Eight four-post houses were discovered at the settlement sites at Fosie and divided into three subtypes. The type A is the same type as houses 53, 63 and 70 from Forsand, and is interpreted as a building where the floor was located above the ground. They are from the middle part of the Late Bronze Age. The two other types of houses are dated respectively to the Pre-Roman Iron Age and the Viking Period (Björhem \& Säfvestad 1993:292f).

In the concluding publications from the project Skånska spår - arkeologi längs Västkustbanan (Artursson 2005a, 2005b) the four-post granaries are frequently documented as being from the Early Iron Age. The Öresundsförbindelsen project documented a few granaries from late Pre-Roman Iron Age, Roman Iron Age and Migration Period (Hadevik \& Gidlöf 2003:53ff, Nord \& Sarnäs 2005:103ff, Steinecke et al. 2005:58). It is also worth mentioning that a four-post granary in this project has been dated to the $12^{\text {th }}-13^{\text {th }}$ century (Olsson et al. 2005:72). At the Brogård site in 
Halland (Carlie 1992), the four-post houses are few compared to the number of longhouses, and they only occur in connection with Iron Age farms. Further to the north, nine four-post houses dated to the Late Bronze Age and Iron Age are found at Pryssgården, Østergötland (Borna-Ahlkvist 1998:49f). The houses have been divided into four types, among which type $\mathrm{D}$ is the same as Forsand type 17 and will be discussed later. Only type A, consisting of four postholes, is comparable with four-post houses at Forsand. In the publication Hus och Gård $i$ det förurbana samhället [Houses and Farms in Pre-urban Society] (Göthberg et al. 1995), seven examples are given of four-post granaries from different parts of Sweden, in addition to some from Fosie.

\section{German four-post granaries: The Roman Iron Age}

In contrast to the general impression that four-post houses do not frequently occur at settlement sites in southern Scandinavia, such houses are abundant at the Flögeln settlement in Germany, where as many as 123 four-post houses have been found (Zimmermann 1992:229ff). They were used throughout the entire settlement period from the $1^{\text {st }}$ to $6^{\text {th }}$ century AD. They are rectangular or square with a floor area between $1.5 \mathrm{~m}^{2}$ and $21.3 \mathrm{~m}^{2}$. The 24 square houses, shown in Zimmermann (1992:fig. 178-180), measure from 1.3 x $1.3 \mathrm{~m}$ to $4.6 \times 4.6$ $\mathrm{m}$, while seven rectangular houses range in size between $1 \times 1.6 \mathrm{~m}$ and $2.2 \times 3 \mathrm{~m}$. Furthermore, two rectangular four-post houses measure 5.6 and $6 \mathrm{~m}$, respectively, in the E-W direction and both are $3.4 \mathrm{~m} \mathrm{~N}-\mathrm{S}$. In addition to the four-post houses, there are also larger storage houses with six (20 houses), eight (13 houses), nine (twelve houses), twelve (five houses) and 20 (one house) posts. Altogether, there are 174 storage houses at Flögeln. The storage houses with more than four posts are dealt with in connection with the Forsand types 15 and 16.

At the wurt settlement, Feddersen Wierde, on the coastal marshes between the rivers Elbe and Weser in Germany, occupied between the $1^{\text {st }}$ and $5^{\text {th }}$ century $\mathrm{AD}$, as many as 147 storage houses were uncovered (Haarnagel 1979:148). However, only a minority (13 houses) are of the four-post type, while the most ordinary type (96 houses) has nine posts in three rows. In addition, there are a few houses with six and twelve posts. The building tradition of the storage houses appears to be quite different from the one at Flögeln on the sandy Geest, only $15 \mathrm{~km}$ to the east, even though the same types are present in both places. At Feddersen Wierde, a storage house was always situated close to the entrance that led to what is believed to be the working area of the housewife. Haarnagel (1979:149) concluded that the storage house was used for different types of food and other necessities in the daily life. Haarnagel (1979:150) also concluded that Feddersen Wierde is different from other settlements along the NW German and Dutch coastline because elsewhere storage houses are either absent or rare in the house material.

\section{Dutch four-post granaries: The Pre-Roman and Roman Iron Age}

Van Es (1967) has published a series of four-post granaries from Wijster in the Netherlands . They are regarded as storage houses for crops or hay and their sizes differed between 1.5 and $3.5 \mathrm{~m}^{2}$, and they are mostly square or somewhat rectangular (Van Es 1967:87f). In addition to the four-post granaries, there were also six-post and twelve-post buildings. The Wijster settlement was occupied in the late Roman Iron Age and early Migration Period, showing the use of the same types of granaries in Dutch areas at least during the same period as at Feddersen Wierde and Flögeln. At the late Pre-Roman Iron Age settlement at Someren in the southern Netherlands, as many as 51 four-post houses were situated within $25 \mathrm{~m}$ from the longhouses (Kortlang 1999), probably showing that each of the four phases of longhouses at the site had a series of four-post houses for storage.

\section{The function of the four-post houses}

In the literature referred to above, there is nearly a full consensus in favour of interpreting the four-post houses as having been used for storage, be it hay, heather, unthreshed or cleaned grain or used to store food and utensils in daily life. However, in the material from Forsandmoen, there are some four-post houses that may have served other functions.

Based on the overview of the storage houses given here, one can conclude that four-post houses are known in southern Scandinavia in the Bronze Age, but not in southern Jutland and northwestern Germany, and that such houses are present at most of the settlement sites all over that area in the Iron Age from $500 \mathrm{BC}$ to AD 600. So far, only a limited number of houses have been reported at the different settlements - and only at Hodde, Drengsted, Flögeln, Feddersen Wierde, Someren and Nørre Snede are a large number documented. Some of the sites, however, have a sufficient number of houses to allow a comparison with the Forsand material. Table 30 and Fig. 45 show the distribution of the size of houses within $2 \mathrm{~m}^{2}$ intervals at some of the sites. Feddersen Wierde is excluded 
Table 3I. Distribution of floor area $\left(\mathrm{m}^{2}\right)$ in two areas; a southern German/Dutch area compared to a northern Danish/ Norwegian area.

\begin{tabular}{|l|c|c|c|c|}
\hline Area $\mathrm{m}^{2}$ & $\begin{array}{c}\text { Forsandmoen, } \\
\text { N-Jutland, Hodde }\end{array}$ & $\%$ & $\begin{array}{c}\text { Drengsted, } \\
\text { Flögeln, Someren }\end{array}$ & $\%$ \\
\hline $0-1.9$ & $\mathrm{I}$ & $\mathrm{I}$ & 2 & 2 \\
\hline $2.0-3.9$ & 9 & 7 & 52 & 41 \\
\hline $4.0-5.9$ & 25 & 20 & 40 & 32 \\
\hline $6.0-7.9$ & 42 & 33 & 16 & 13 \\
\hline $8.0-9.9$ & 30 & 23 & 7 & 6 \\
\hline $10.0-11.9$ & 13 & 10 & 1 & 1 \\
\hline $12.0-13.9$ & 4 & 3 & 2 & 2 \\
\hline $14.0-15.9$ & 3 & 1 & 1 & 1 \\
\hline $16.0-17.9$ & 1 & 100 & 123 & 100 \\
\hline$>18.0$ & & & & 2 \\
\hline Sum & 128 & & & 12 \\
\hline
\end{tabular}

Table 32. Overviews of the change in average length/width size $(\mathrm{m}), \mathrm{L} / \mathrm{W}$ ratio and roofed area in square metres in four-post houses from 15 different sites/areas from southern Scandinavian and northern German/Dutch areas, divided into three main areas. Notice that the houses under the heading $\mathrm{N}$-Jutland were found at several Bronze Age settlement sites in Jutland (Bertelsen et al. 1996). Also notice that the houses from the publication Hus och gård i det förurbana samhället (Houses and farms in the pre-urban society) (Göthberg et al. 1995) comprise houses from different sites in Sweden, and that the houses under the heading "Malmö, Köpinge" cover three large excavations in Scania [Fosie IV (Björhem \& Säfvestad 1993), Öresundsförbindelsen (Björhem \& Magnusson Staaf 2006) and Köpinge area (Tesch 1993)].

\begin{tabular}{|c|c|c|c|c|c|}
\hline \multicolumn{2}{|c|}{ Four-post houses } & \multirow{2}{*}{$\begin{array}{c}\text { Number } \\
58 \\
\end{array}$} & \multirow{2}{*}{$\begin{array}{c}\text { Length } \mathrm{x} \\
\text { width } \\
3.05 \times 2.50\end{array}$} & \multirow{2}{*}{$\begin{array}{c}\text { L/W-ratio } \\
1.22\end{array}$} & \multirow{2}{*}{$\begin{array}{c}\text { Area } \mathrm{m}^{2} \\
7.6\end{array}$} \\
\hline 1 & Forsandmoen & & & & \\
\hline 2 & Hodde & 18 & $3.10 \times 2.40$ & 1.29 & 7.4 \\
\hline 3 & N-jutland & 7 & $3.10 \times 2.30$ & 1.35 & 7.1 \\
\hline 4 & Nørre Snede & 10 & $2.90 \times 2.80$ & 1.04 & 8.6 \\
\hline 5 & Priorsløkke & 7 & $3.10 \times 2.40$ & 1.29 & 7.4 \\
\hline 6 & Hus och gård & 9 & $2.85 \times 2.50$ & 1.14 & 7.1 \\
\hline 7 & Malmö. Köpinge & 13 & $3.50 \times 1.80$ & 1.94 & 6.3 \\
\hline 8 & Brogård & 5 & $3.80 \times 2.00$ & 1.90 & 7.6 \\
\hline \multicolumn{2}{|c|}{ Mean I-8 } & 127 & $3.10 \times 2.40$ & 1.24 & 7.4 \\
\hline 9 & Præstestien & 13 & $2.00 \times 1.80$ & 1.11 & 3.6 \\
\hline 10 & Drengsted & 45 & $2.50 \times 2.10$ & 1.19 & 5.1 \\
\hline 11 & Flögeln & 31 & $2.60 \times 2.00$ & 1.30 & 5.2 \\
\hline 12 & $\begin{array}{l}\text { Feddersen Wierde } \\
\text { (4-6 post) }\end{array}$ & 26 & $2.20 \times 1.80$ & 1.22 & 4.0 \\
\hline 13 & Someren & 51 & $2.10 \times 1.70$ & 1.24 & 3.6 \\
\hline \multicolumn{2}{|c|}{ Mean 9-13 } & 166 & $2.30 \times 1.90$ & 1.22 & 4.4 \\
\hline 14 & Flögeln (9-post) & 13 & $2.90 \times 2.60$ & 1.12 & 7.5 \\
\hline 15 & $\begin{array}{l}\text { Feddersen Wierde } \\
\text { (9-post) }\end{array}$ & 43 & $2.80 \times 2.40$ & 1.17 & 6.7 \\
\hline \multicolumn{2}{|c|}{ Mean $14-15$} & 56 & $2.80 \times 2.40$ & 1.16 & 6.9 \\
\hline
\end{tabular}

because most of the granaries are nine-post buildings. Nørre Snede is also excluded since only ten houses are published with information concerning their size. On the other hand, some smaller settlements in northern Jutland are gathered in one group in order to compare Forsand to the nearest area south of the North Sea.

The most striking differences between the size distribution is that, while $60-80 \%$ of the houses at Flögeln, Drengsted and Someren are less than $6 \mathrm{~m}^{2}$, this is only the case for $30 \%$ at Forsand, $34 \%$ in northern Jutland and $17 \%$ at Hodde. Both Flögeln and Forsand have a widespread distribution, while at Hodde, the size is clustered from $6 \mathrm{~m}^{2}$ to $9.9 \mathrm{~m}^{2}$. The distribution at Forsand, northern Jutland, Hodde and Drengsted reveal a Gaussian curve, while at Flögeln and Someren, it is clustered around 2-3.9 $\mathrm{m}^{2}$ and with a long "tail" up to $>18 \mathrm{~m}^{2}$. The conclusion is obvious: that people at the three sites put different demands on their fourpost buildings. Forsand has the most widespread size distribution, while the Someren four-post houses have the most clustered pattern. At Forsand and Hodde, the mean size is nearly the same $\left(7.2\right.$ and $\left.7.5 \mathrm{~m}^{2}\right)$, while at Flögeln, the size is only $4.7 \mathrm{~m}^{2}$. The similarity in the size distribution between Forsand and Hodde and the same mean size may indicate a similar type of use of the houses. At Hodde, $75 \%$ of the houses measured between $6-9.9 \mathrm{~m}^{2}$, while only $45 \%$ were the same size at Forsand. The seven four-post houses at Priorsløkke (Kaul 1985) have the same mean size $\left(7.5 \mathrm{~m}^{2}\right)$ as Hodde, maybe indicating that they were intended for the same function as at Hodde.

The houses from the three northern sites and the three southern sites, respectively, are gathered in two groups in Fig. 45 and Table 31, showing that a Gaussian curve is present in the northern group, while the southern group consists of an exponential curve. There can be no doubt that there must have been different demands in terms of the storage capacity in the two areas, with a preferred floor area in the north above 6-8 $\mathrm{m}^{2}$ and only $2-6 \mathrm{~m}^{2}$ in the south.

Three of the smallest four-post houses at Forsand were situated in a narrow courtyard between two longhouses making up a farm. Their location indicates that they are not intended for storing unthreshed crops or for hay and animals, but rather served as storage for food and equipment needed in daily life. This has also been suggested by Haarnagel (1979) concerning the four- and nine-post granaries adjacent to the houses at Feddersen Wierde.

The comprehensive excavations in the Öresundsförbindelsen project have revealed an important botanical 
material that is well suited for an interpretation of the houses. Several houses had burnt down, and charred grains and seeds are abundant in those houses. Such material is present in two nine-post houses, from Bronze Age Periods II-III and VI in such large quantities - and including grains, seeds and remains from threshing - that they have been interpreted as storage houses (granaries) (Berggren \& Celin 2004:61, Rostovány \& Hydén 2002:29). More than 2000 grains of mainly hulled barley (Hordeum vulgare var. vulgare) and smaller amounts of five other types of grain [(naked barley (Hordeum vulgare var. nudum), emmer (Triticum dicoccum), oat (Avena), millet (Panicum) and brome (Bromus)] were found in a Late Bronze Age house (Rostovány \& Hydén 2002:31). In the nine-post granary house 28 from Lockarp 7A (Rudin \& Brink 2002:53), the archaeobotanical material was dominated by grains and spikelet forks from emmer (Triticum dicoccum) and spelt (T. spelta) wheat. The conclusion was that Bronze Age Periods II-III houses had been used for storing the unthreshed crops rather than the cleaned crop. Since there are so few investigations that can shed light on the functions of this type of house, it is extraordinary that the storage function is documented as early as the Early Bronze Age. These excavations also revealed sufficient Iron Age botanical material to suggest that the fourpost houses were granaries, such as house 4 at Fosie $11 \mathrm{~A}$, dated to the Migration Period. Here, the analysis showed that mainly barley (Hordeum vulgare var. vulgare) and some club wheat (Triticum compactum) were stored in the building (Hadevik \& Gidlöf 2003:53).

Table 32 lists the number of four-post houses at a series of settlement sites, their mean size, length/width ratio and the roofed area in square metres. From Fosie IV, four large four-post houses (mean size $18,1 \mathrm{~m}^{2}$ ) dated to the Viking Period (Björhem \& Säfvestad 1993:293) have been excluded, since all the other four-post houses are dated to the Bronze Age and Early Iron Age. The six-post houses at Feddersen Wierde are included with the four-post houses because they have the same sizes. Note also that the nine-post houses from Flögeln and Feddersen Wierde are included in order to compare those houses with the Scandinavian four-post houses. The size of the houses has been measured between the centre of the postholes, and a mean value is given if the width differs between the trestles.

The material in Table 32 is divided into two groups: one from Norway, Sweden and northern and central Jutland consisting of relatively large four-post houses with a mean size of $6.3-8.4 \mathrm{~m}^{2}$, and a second group from southern Jutland and northern Germany and the
Netherlands with a mean size of $3.6-5.2 \mathrm{~m}^{2}$. The mean sizes from the different sites do not overlap with the other group. Except for the 13 houses in Scania, there is at least a $2 \mathrm{~m}^{2}$ area difference between the two groups. In mean size, the two groups have a $3 \mathrm{~m}^{2}$ difference (7.4 $\mathrm{m}^{2}$ versus $4.4 \mathrm{~m}^{2}$ ). The northern group is therefore on average $68 \%$ larger than the southern group. Within the northern group, the shape of the houses is similar in Jutland, Sweden (outside Scania) and Forsand (mean $3 \times 2.5 \mathrm{~m}$ ), while the Scanian houses are much more rectangular $(3.6 \times 1.9 \mathrm{~m})$. A possible conclusion is that the inhabitants of the settlements in southern Jutland and to the south-west built markedly smaller four-post houses than elsewhere in Scandinavia. However, the shape of the houses is quite similar with a length/width ratio of slightly above 1.2. It is possible that four-post houses in Scania were given a more rectangular shape than elsewhere (1.93 versus 1.23 ), but the low number of Scanian houses should be noted.

These differences in such simple houses were likely caused by different functional needs in terms of storage capacity. The Dutch/German interpretation is that the small storage houses had a building with a raised floor on top of short posts. This is possible, considering the short distance between the posts both in the four-post houses and in the nine-post houses (see Table 32, no. 14-15), which are smaller than the Scandinavian fourpost houses. These buildings served as a secure shelter for cereal grain, meat and other commodities. On the other hand, the distances between the tiny posts used in the Scandinavian four-post and larger storage houses are too large to have had a raised floor building (loft), indicating they stored unthreshed crops and hay.

Haarnagel (1979) has proposed that nine-post storage houses situated outside the entrance of a kitchen area served a similar purpose as an everyday storage

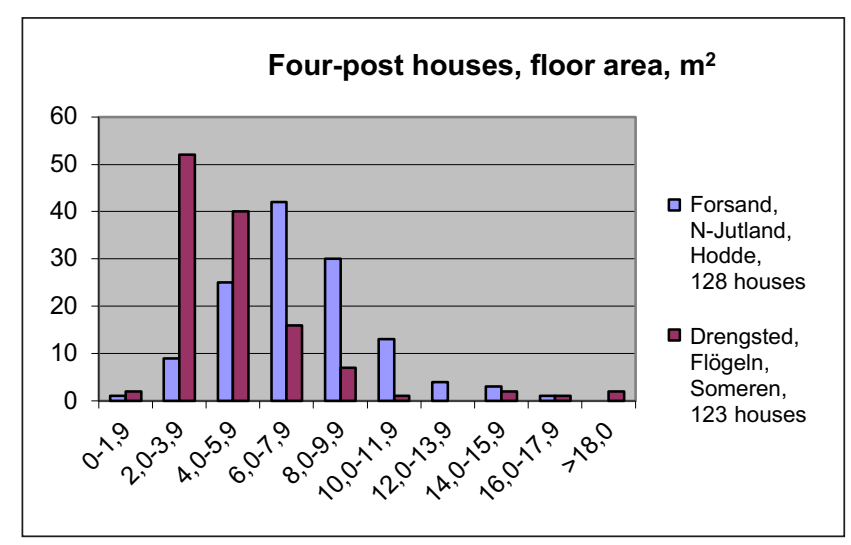

Fig. 45. Distribution of floor area in two areas; a southern German/Dutch area compared to a northern Danish/ Norwegian area. 


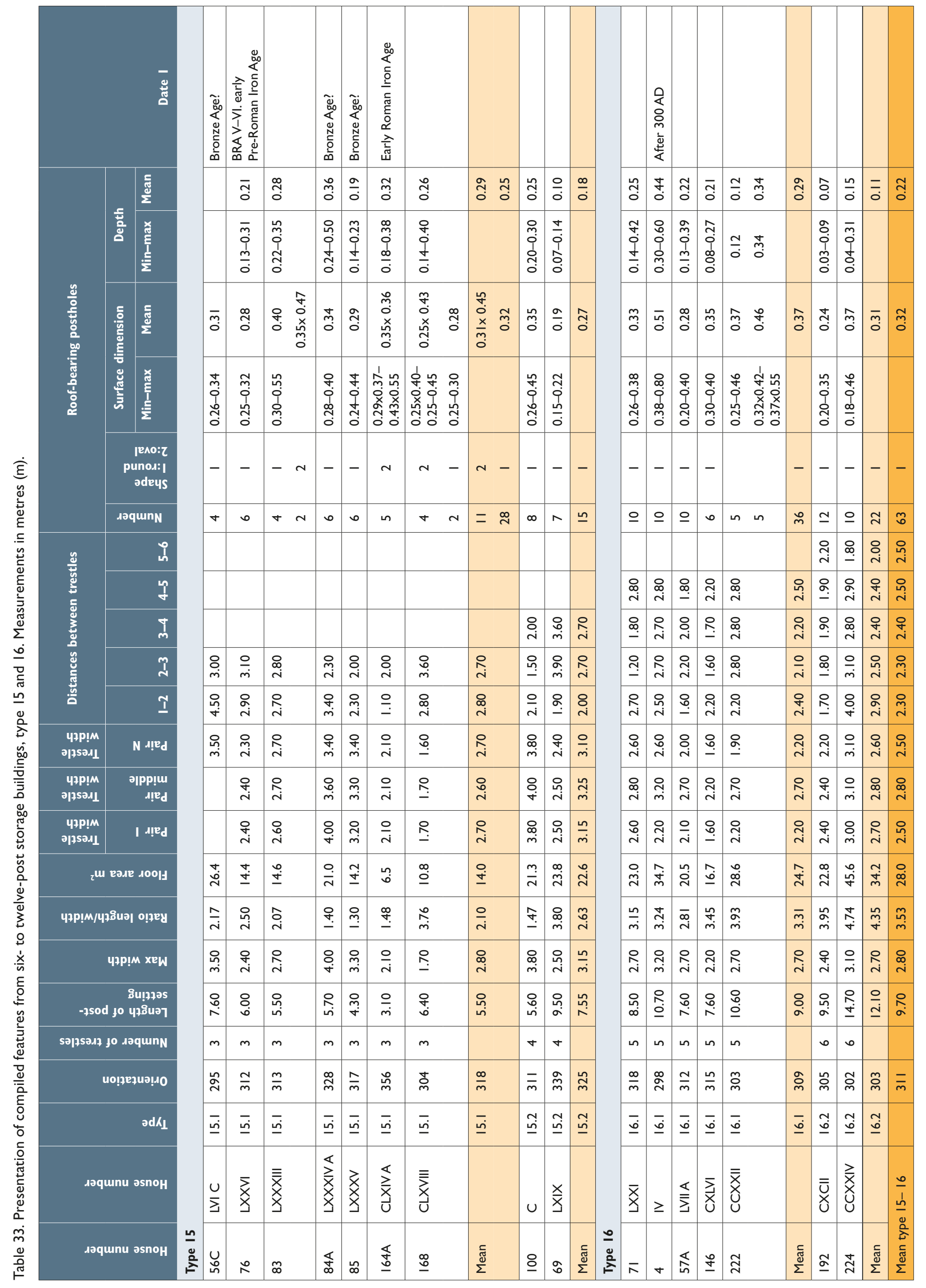


house at Feddersen Wierde. At Flögeln, the nine-post granaries have a size (mean size $7.8 \mathrm{~m}^{2}$ ) comparable with the four-post houses at Forsand and Hodde, and a hypothesis can therefore be that the nine-post houses at Flögeln served the same storage functions as have often been proposed for the Scandinavian four-post houses (storing crops and hay), and that the smaller four-post houses served other functions. However, looking at the distribution of the two types of storage house, the nine-post houses seem to be as closely associated with the longhouses as the four-post houses. Zimmermann (1978:161) states that some of the four-post houses were not used for storing grain, but rather for worked or unworked material in connection with leather craft production. Concerning the Forsand houses, some of the four-post houses interpreted as granaries are situated right outside the entrance of the dwelling house so they could be interpreted in the same way. Most of the four-post buildings are, however, withdrawn so much from the houses that a grain and hay storage house seem a more likely interpretation.

It is not possible to interpret what type of goods were stored from the size of the storage house; most likely, however, it was crops, grain and hay. Nevertheless, in houses situated near the entrance to the living area or workshops, other goods are a possibility.

\subsection{Type 13: Four-post buildings with a trapezoid layout}

This house type consists of two trestles with circular postholes to support the roof-bearing posts. The construction has a trapezoid shape, where the largest trestle width is $100 \%$ larger than the narrowest trestle. This house type has no traces of entrances or walls.

Depending on the ratio between the widest trestle and the length of the house, the houses are divided into two subtypes:

- Type 13.1: Length/width ratio is less than 1. A hearth is situated inside the construction (houses 86 and 235).

- Type 13.2: Length/width ratio is more than 1. A hearth is not present (house 165C).

The main type 13 consists of three houses $(86,165 \mathrm{C}$ and 235), all of which are shown in Fig. 46. Even though some of the four-post granaries also have a slightly trapezoidal shape (so little that it was probably not intentional), these three houses must have been deliberately given this outline. The houses are comparable in size to the largest houses in type 18 - the four-post granaries - and measure $2.6 \times 4.3 \mathrm{~m}$ and $3.4 \times 4.6 \mathrm{~m}$. The houses are widely distributed at the settlement site (Fig. 47), in Areas A, B and E.

Two of the houses (house 86, 235) have approximately the same short trapezoid outline, while the last one $(165 \mathrm{C})$ is more elongated, more closely resembling the type 11 houses. The two houses 86 and $165 \mathrm{C}$ have evenly sized circular postholes, but their depths differ substantially. The general impression is that these two houses were built with posts similar in size as to what has otherwise been documented for four-post houses (0.15-0.2 $\mathrm{m}$ in diameter). By contrast, house 235 has large oval postholes (mean $0.4 \times 0.6 \mathrm{~m}$, depth 0.19 $\mathrm{m})$ that are well suited for heavy, rectangular posts, although no traces of the posts have been documented.

Since there are no traces of entrances or walls, the houses probably consisted of no more than a roof sheltering the area within the post construction. The roofed area is calculated using the formula: (trestle width $1+$ trestle width 2) / $2 \times$ length of the house. The two type 13.1 houses are also nearly equal in size $\left(13.6 \mathrm{~m}^{2}\right.$ and $11.7 \mathrm{~m}^{2}$ ), and it is tempting to regard this as a house for special purposes similar to type 11. On the other hand, type 13.2 houses greatly resemble type 14 houses, with an elongated trapezoid outline made by relatively small and shallow postholes. However, house $165 \mathrm{C}$ is much smaller $\left(8.4 \mathrm{~m}^{2}\right)$ than the type 14 houses (mean roofed area $23 \mathrm{~m}^{2}$ ), so even though the most probable interpretation is that they were used as storage houses, it might have been for different types of goods. A very similar house with a trapezoid roof-bearing construction has been excavated at Løbrekk, Strand municipality (Løken 2009). That house is ${ }^{14} \mathrm{C}$ dated to Early Bronze Age Period I (3360 \pm 70 BP, 1740-1530 BC, T-7060) but such an early date is not likely considering all the other dates from houses and vegetation analyses. There is no supporting literature to help determine their function based on other settlement sites, since such trapezoid houses are not documented in major settlement literature in southern Scandinavia or northern Germany.

The two type 13.1 houses are ${ }^{14} \mathrm{C}$ dated, and the results show that the houses belong to widely dispersed periods: Late Bronze Age Period IV and the early PreRoman Iron Age. The youngest (235) is dated as contemporary with the type 11 houses, while the older date from house 86 is only contemporary with two dates of four-post houses with a hearth inside (33 and 102, cf. Fig. 46 and Table 25). It is maybe a possible conclusion that, in the Bronze Age settlement, the earliest special purpose houses were four-post houses - with at least two examples where a hearth was located inside. Later 


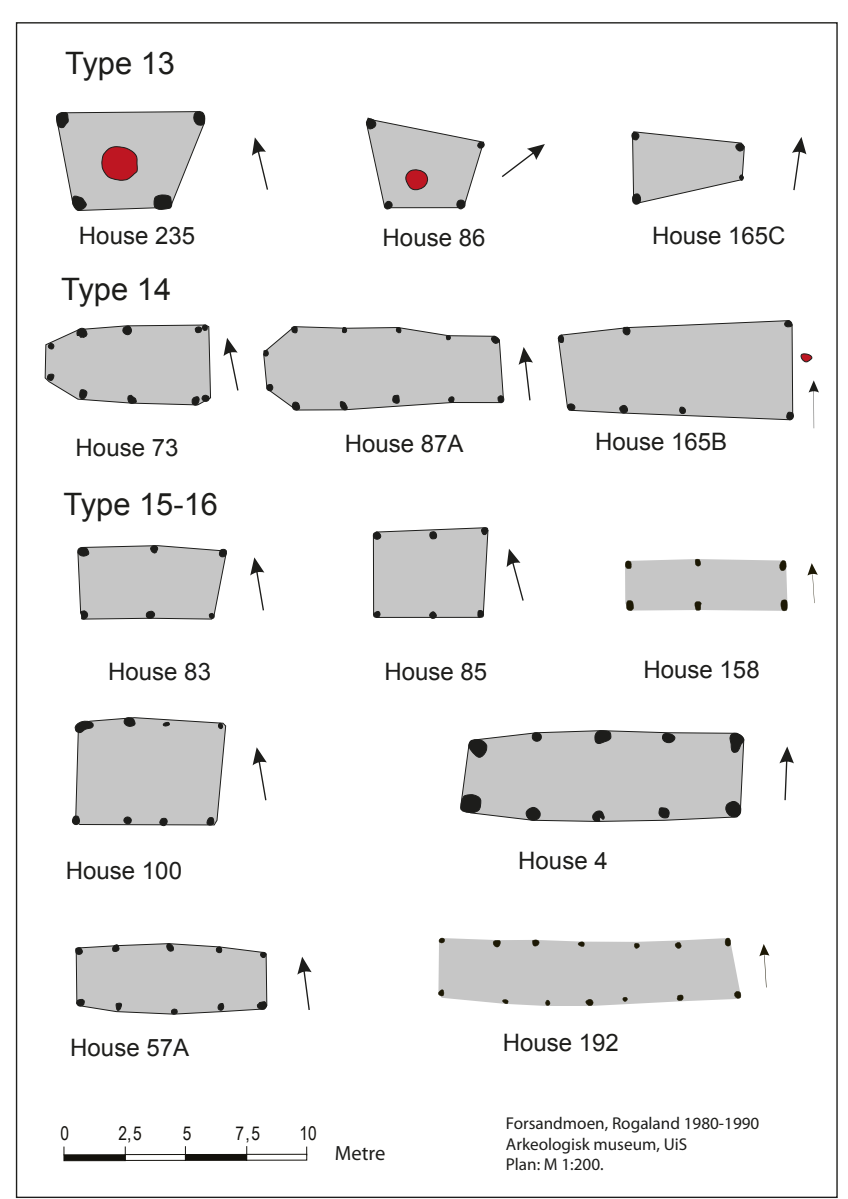

Fig. 46. House plans of type 13, 14,15 and 16 houses: 4-12-post storage houses.

on, in the last two periods of the Bronze Age, types 5, 6, 11 and 13 were added to the building types at Forsand.

The orientation of these houses, measured along the central axis and facing out from the widest trestle, varies from WSW via NW to NNE. House 235 is situated on a slight elevation near the SE corner of the plain and $60 \mathrm{~m}$ NNE of the nearest settlement area, while Bronze Age Period IV house 86 is situated only $15 \mathrm{~m}$ north of the large main longhouse 69 from the same period. The undated type 13.2 house is situated in between Roman Iron Age longhouses, which can be an indication of the age of the house.

\subsection{Type 14: Buildings with four to five diverging trestles}

Type 14 houses are minor buildings consisting of two diverging rows of four to five pairs of circular postholes, without any traces of walls, entrances or hearths.

The type consists of three houses (73, 87A and 165B), all of which are shown in Fig. 46-47. Fig. 47 shows that two of these houses are situated at the NW corner of Area A.
This type of house with a convex trestle structure is reminiscent of type 11, but they lack the traces of a hearth outside the wide gable and, apart from the size of house 73, they are larger and built with larger and deeper postholes. They also consist of four or five trestles, while type 11 has only three trestles.

The roof-bearing construction measures from $5.4 \mathrm{~m}$ to $9.4 \mathrm{~m}$; the largest trestle width is $2.9-3.7 \mathrm{~m}$ and the narrowest is $2.4-2.8 \mathrm{~m}$. Traces of the wall construction are absent, so the house widths are not known. The roofed area within the post structure is $17.6-29.9 \mathrm{~m}^{2}$ (mean $23 \mathrm{~m}^{2}$ ), which is more than twice as much as the same figure for type 11 houses $\left(10.4 \mathrm{~m}^{2}\right)$. Considering that the type 14 houses have wider trestles compared to type 11, if they did have outer long walls, they would have been approximately $5.2-6 \mathrm{~m}$ wide. Interpreted in such a way, the houses had a 27-50 $\mathrm{m}^{2}$ (mean $38 \mathrm{~m}^{2}$ ) roofed area - not including possible gable areas - compared to $18-33 \mathrm{~m}^{2}$ (mean $23 \mathrm{~m}^{2}$ ) for type 11 houses.

All postholes in these houses are circular. Two of the houses have one or two trestles with large and deep postholes, while the remaining postholes and those from the third house have the same size as is seen in type 11 . One impression from a burnt oak post measured 0,2 $\mathrm{m}$ in diameter, a size comparable with what is found in the other small houses (type 5, 6, 11, 18).

Two houses have their widest trestle to the east and one to the west, just as type 11 houses also are oriented either way. The houses are oriented slightly to the north of due west, as is also the case with type 11 .

Two of the type 14 houses $(73,87 \mathrm{~A})$ have a narrow trestle at the gable, in the widest or narrow end of the construction, respectively. The width of these trestles $(1.2-1.4 \mathrm{~m})$ is comparable to the average entrance width in type 3 houses. They are situated at a distance of $1.2 \mathrm{~m}$ from the gable trestles. Since this distance is the normal distance from the entrance postholes to the nearest row of postholes in type 3 houses, it is tempting to interpret the narrow trestles as entrance postholes at the short end of the houses. If we include gable rooms for these two houses, as has been proposed for type 11.1 houses, they have approximately the same floor area $\left(50 \mathrm{~m}^{2}\right)$ as type 11.1 and a comparable dwelling area as in type 3.1.1 houses. Altogether, considering the similarities in terms of trestle construction with type 11 - and that house 73 showed traces of human occupation (25 charred grains from wheat, eleven from barley and a fragment of a sickle) - the two houses have been interpreted as small houses for human occupation.

With its small and shallow postholes and wide post structure, is more natural to interpret House $165 \mathrm{~B}$ as a 
shed with a hearth in the open eastern gable, the same interpretation given for type 11.2 houses.

Type 14 houses are situated in two different areas (Fig. 47); houses 73 and 87 are located in the north-east corner, where there are four type 11 houses within a 10-15 m distance (cf. Fig. 33), and the last one is in the south-west area, also close to a type 11 house. The distribution fit with the overall distribution of houses in the Bronze Age and early Pre Roman Iron Age.

Only house 73 is dated: to the middle of Bronze Age Periods III-IV (1260-900 BC, T-7887). This is earlier than the three dates from type 11 houses, which are Bronze Age Period VI and the early Pre-Roman Iron Age. The small habitation houses types 5 and 6 also have such a date, so the single middle Bronze Age date for a type 14 house indicates that such small houses have a history further back in the Bronze Age than the cluster of dates from types 5, 6 and 11 indicates.

A conclusion near at hand is that when the type 3 house becomes the main type of home fitted for people and cattle, a smaller house would seem to be a dwelling intended only for human occupation or sheds for different settlement activities.

\subsection{Types 15-16: Six- to twelve-post storage buildings}

Type 15 and 16 houses consist of two straight or slightly curved rows of 6-12 circular or oval postholes set in 3-6 trestles and without traces of walls, entrances or hearths.

I have divided the description and analysis in this section according to the number of trestles in the houses (three, four, five and six), but I also compare the four different subtypes.

\section{Type 15.1: Six-post houses}

Seven houses $(56 \mathrm{C}, 76,83,84 \mathrm{~A}, 85,164 \mathrm{~A}$ and 168) measure 3.1-7.6 $\mathrm{m}$ in length (mean $5.5 \mathrm{~m}$ ) and 1.7-4 $\mathrm{m}$ in width (mean $2.8 \mathrm{~m}$ ), see Table 33. Three of these houses are shown in Fig. 46. They are quite different in shape, from short and narrow (house 83) to short and wide (house 85) or long and narrow (168) to long and wide houses (Table 33). This is reflected in the differences in the length/width ratio, which differs from 1.3 to 3.8 (mean 2.1), and also in the difference in floor area, which is between $6.5 \mathrm{~m}^{2}$ and $26.4 \mathrm{~m}^{2}$ (mean $14 \mathrm{~m}^{2}$ ). The two rows of posts are straight and, in each house, the distances between the trestles are quite even. The trestle width differs from 1.70 to $3.60 \mathrm{~m}$ as is also found in the four-post buildings. The six-post storage houses can therefore be regarded as two four-post square houses put together with a common central trestle. The mean size $\left(14 \mathrm{~m}^{2}\right)$ is also twice the mean size $\left(7.2 \mathrm{~m}^{2}\right)$ found in the four-post houses.

Five houses are situated in the NE settlement area adjacent to the Bronze Age houses (Fig. 47). Their mean orientation $\left(317^{\circ}\right)$ is comparable to the longhouses from the Bronze Age. Three of those six-post houses also have wide trestles $(3.2-4 \mathrm{~m})$, a width which is also comparable to the trestle width in the Bronze Age houses. One of the houses (76), which is ${ }^{14} \mathrm{C}$ dated to the period $800-200 \mathrm{BC}$, is located parallel to and just north of a longhouse (74) that is dated by a soapstone mould used to cast a period V-VI socketed bronze axe. Therefore, house 76 most probably belongs to the early half of the ${ }^{14} \mathrm{C}$ dated interval. The five six-post houses in this area are therefore tentatively dated to the Bronze Age, but no other house can be attached to a longhouse with any degree of certainty.

Due to their location, the two houses with the narrowest trestles (164A, 168), respectively 2.1 and $1.7 \mathrm{~m}$ wide, must be dated to the Roman Iron Age and/or Migration Period. House 164A was situated in an early Roman Iron Age farmyard in Area B and the other in the eastern part of the late Roman Iron Age / Migration Period village in Area E.

The dates are supported by the shape of the postholes; the tentatively dated Bronze Age houses have circular postholes, while the two Iron Age houses have oval ones, a shape that - in longhouses - is firmly connected to the late Pre-Roman Iron Age and later periods.

House 164A distinguishes itself from the other houses due to its location in a farmyard. Located at a right angle to and between the early Roman Iron Age houses 150 and 151 at the south-east corner of the plain, the house has a NW-SE $\left(356^{\circ}\right)$ orientation - since this farm has a NE-SW $\left(247^{\circ}\right)$ orientation - which is not seen elsewhere on Forsandmoen. The sizes ( $0.32 \mathrm{~m}$ in mean diameter) and depths $(0.25 \mathrm{~m}$ in mean depth) of the postholes are very similar to what could be calculated concerning the four-post houses (in total $0.37 \mathrm{~m}$ mean diameter and $0.23 \mathrm{~m}$ in depth) and confirms that the six-post houses were constructed using the same principles as the fourpost houses; they also probably served the same functions, mainly to store crops or fodder.

\section{Type 15.2: Eight-post houses}

Only two houses $(69,100)$ belong to this group (Fig. 46, Table 33). They measure 5.6-9.5 m (mean $7.55 \mathrm{~m}$ ) in length and 2.5-3.8 m (mean $3.15 \mathrm{~m}$ ) in width, and have therefore a quite different shape, which is reflected in 


\section{Forsandmoen, Forsand municipality Map of settlement area}

$\subset$ House feature with preserved wall remains House feature without wall remains

Type 13

- Type 15.1

Type 16.1

m.m. Type 14

- Type 15.2

Type 16.2

Gravemound / cairn

$\bigcirc \quad$ Excavated gravemound / cairn

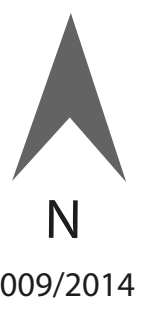

TGB/TL 2009/2014
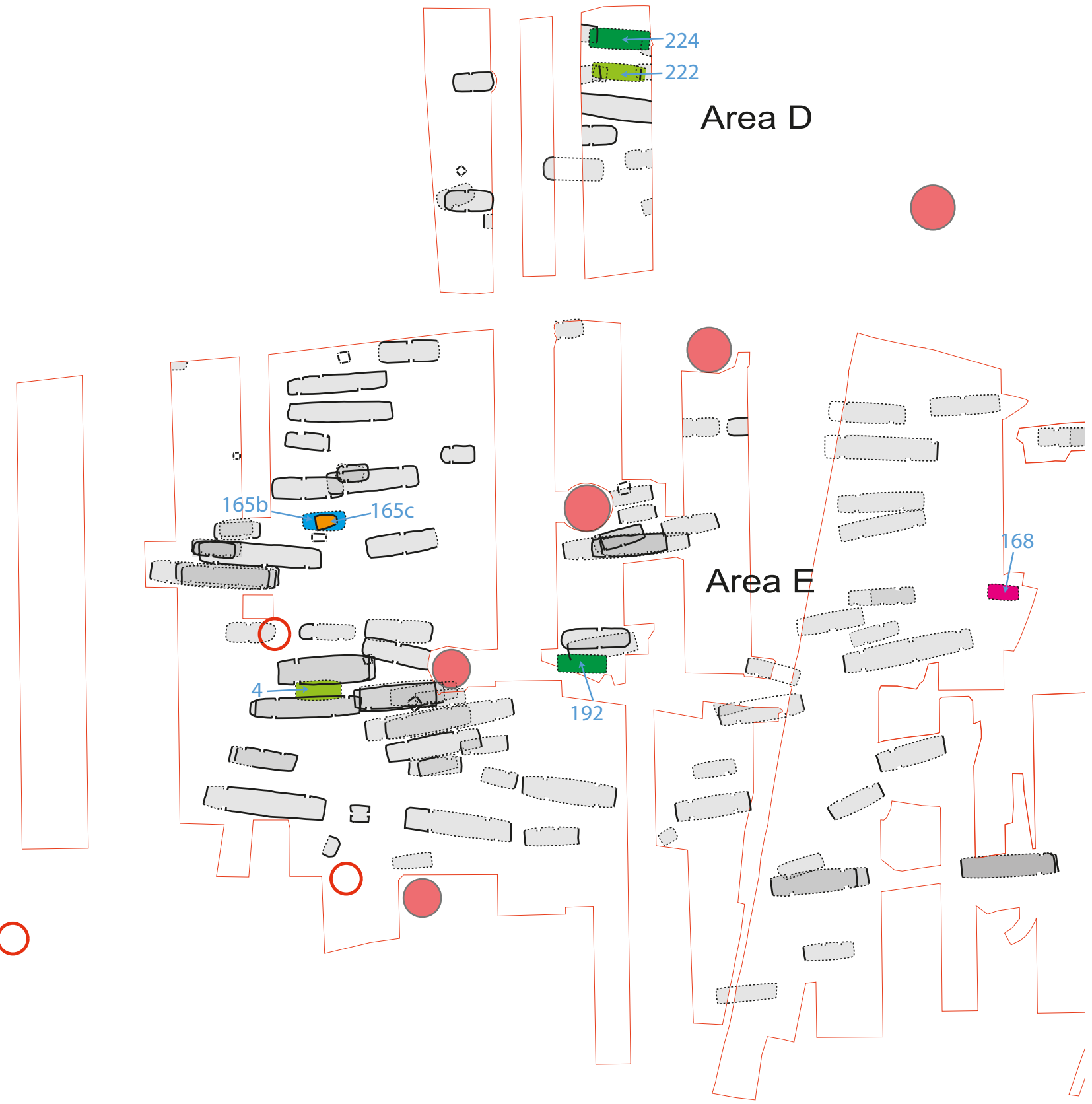

1...

○

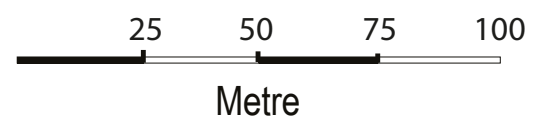




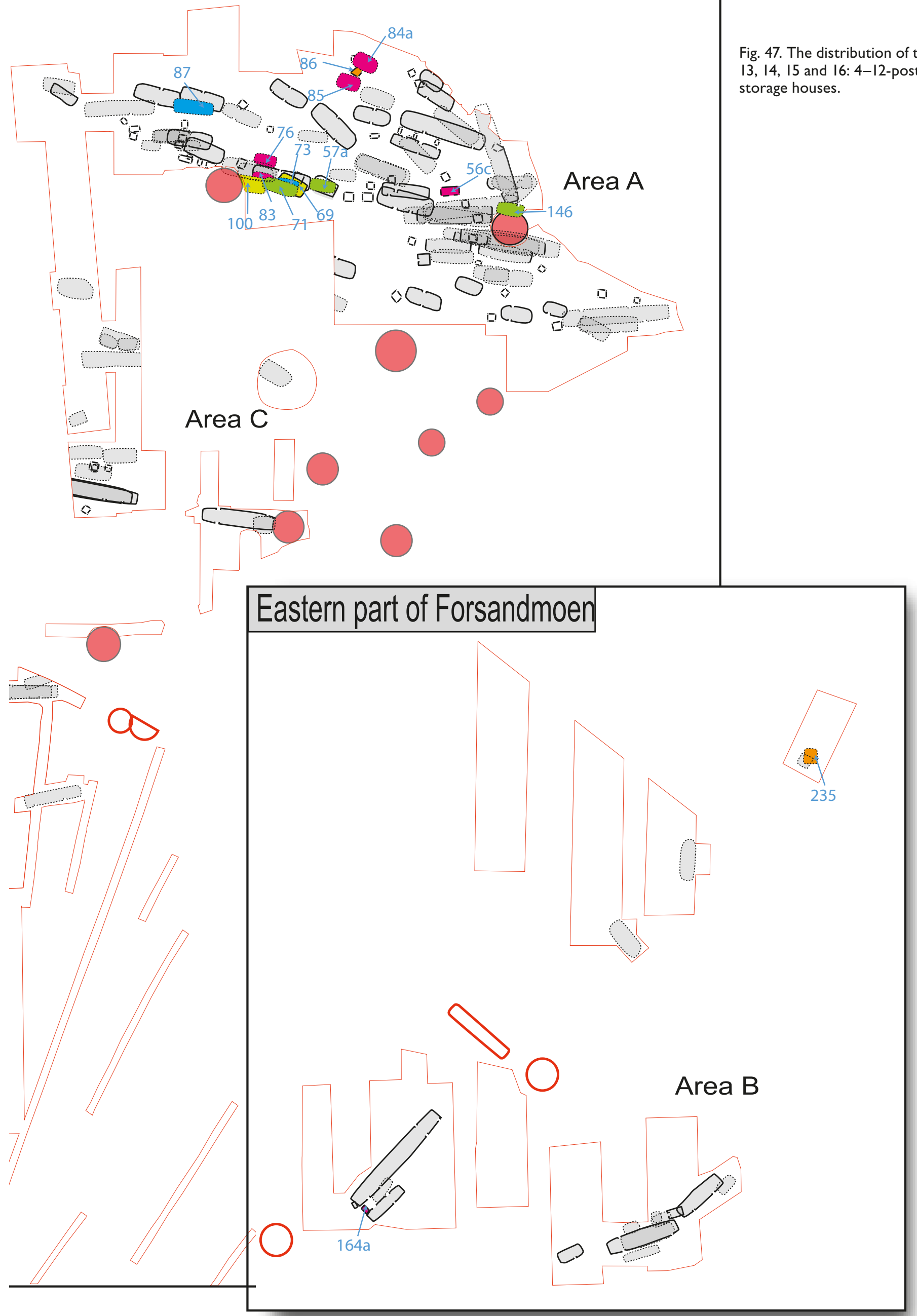


their different length/width ratio (1.5 and 3.8), while their floor area is nearly identical, $21.3 \mathrm{~m}^{2}$ and $23.8 \mathrm{~m}^{2}$. The two rows of posts are both straight, while the distance between the trestles is different. One house (100) has short distances between the trestles (around $2 \mathrm{~m}$ ), while the other house (69) has one similar distance and two measuring twice this distance.

The two houses are also, just as the six-post houses, situated nearby the main Bronze Age settlement area (Fig. 47), and have the same orientation angle as the Bronze Age houses. The large trestle width in house 100 is also an indication of a Bronze Age date of the house, and house 69 is stratigraphically older than house 62, ${ }^{14} \mathrm{C}$ dated by oak wood to the early Roman Iron Age. The house therefore most probably belongs to a period earlier than the late Pre-Roman Iron Age. It is not possible to connect the two houses to a longhouse.

Both houses have circular postholes, but of very different dimensions. Those in house 100 were normal sized $(0.35 \mathrm{~m}$ in diameter and $0.25 \mathrm{~m}$ in depth) while those in house 169 were very small and shallow $(0.19 \mathrm{~m}$ in diameter and $0.10 \mathrm{~m}$ in depth).

\section{Type 16.1: Ten-post houses}

The five houses (71, 4, 57A, 146 and 222) with ten posts measure 7.6-10.7 $\mathrm{m}$ (mean $9 \mathrm{~m}$ ) in length and 2.2-3.2 $\mathrm{m}$ (mean $2.7 \mathrm{~m}$ ) in width (Table 33). Two of the houses $(4,57 \mathrm{~A})$ are shown in Fig. 46. This subgroup also varies greatly in terms of length/width ratio (2.8-3.9) and the floor area $\left(16.7-34.7 \mathrm{~m}^{2}\right)$ varies as much as $100 \%$ from the smallest to the largest house. The rows of postholes are in all houses convex as opposed to the three other subgroups of storage houses with more than four posts, which are all straight. The mean difference between the outer trestles and the central one is as much as 0.5 $\mathrm{m}$ in these relatively short houses, which must reflect intentionally curved rows of posts.

The distances between the trestles are fairly similar. Except for five short ones, all the others are within 2-2.8 $\mathrm{m}$, which also is the normal variation for the four-post houses. This must indicate that these houses were also constructed in the same way as the four- and six-post houses. This is underlined by the fact that all ten-post houses have circular postholes and that the size is well known $(0.37 \mathrm{~m}$ in mean diameter and $0.27 \mathrm{~m}$ in mean depth). Based on the information from the four-post houses, there can be little doubt that the larger storage houses described so far had circular posts with a diameter within the range of $15-20 \mathrm{~cm}$.

When looking at the orientation of the five houses, they seem be divided into two groups. Three houses situated in the NE settlement area (A) (Fig. 47), including two of those $(57 \mathrm{~A}, 73)$ in the main Bronze Age settlement area, have a WNW-ESE orientation - as is known from the Bronze Age houses - while the two other houses $(4,222)$, oriented E-W, are located in the western settlement area (D and E) in close connection with late Roman Iron Age and Migration Period settlements. The possible Bronze Age houses are the shortest ones $(7.9 \mathrm{~m})$ as opposed to $10.7 \mathrm{~m}$ for the others, with the smallest floor area $\left(20.6 \mathrm{~m}^{2}\right.$ against $\left.31.7 \mathrm{~m}^{2}\right)$, their mean trestle distance is $2 \mathrm{~m}$ versus $2.7 \mathrm{~m}$, and their trestle width is $2.2 \mathrm{~m}$ versus $2.5 \mathrm{~m}$. Even though there are very few houses present in this small analysis, the clear differences in four vital measurements must indicate that the two groups of houses were built according to two different concepts.

The analysis of this group of ten-post houses seems to confirm that up to medium-sized storage houses $\left(20 \mathrm{~m}^{2}\right.$ in floor area) were used in connection with the Bronze Age or possibly the early Pre-Roman Iron Age in the NE settlement area, and that quite large such houses were used in connection with the Roman Iron Age and Migration Period farms in the western settlement area. These houses must be interpreted as additional storage houses for type 9 and 10 houses.

\section{Type 16.2: Twelve-post houses}

The largest storage houses, with twelve posts, comprise only two examples $(192,224)$, but only house 192 is shown in Fig. 46. They are both situated in the same area (D and E) as - and not far away from - the two Roman Iron Age and Migration Period houses with ten posts (Fig. 47). The date of these houses is also most probably from the late Roman Iron Age or Migration Period. They are rather different in size, as house 224 is $55 \%$ longer than $192(9.5-14.7 \mathrm{~m})$ and $100 \%$ larger in floor area $\left(22.8-44.6 \mathrm{~m}^{2}\right)$. Both houses have straight rows of postholes as opposed to the curved ten-post houses from the same period.

The short house 192 has very short and nearly equal distances $(1.7-2.2 \mathrm{~m})$ between the posts, indicating similar functions throughout the house, which was probably similar to the Bronze Age ten-post houses. House 224 is quite different, having three equal, $3 \mathrm{~m}$ trestle distances in the middle (equal to the distances in the late Roman Iron Age and Migration Period ten-post houses), a short $(1.8 \mathrm{~m})$ distance to the east (equivalent to the other group of ten-post houses), and as far as the storage houses are concerned, a long $(4 \mathrm{~m})$ distance to the east, similar to the spatial differences found in dwelling houses (type 3, chapter 5) with six 
trestles from the Late Bronze Age and Pre-Roman Iron Age. However, since there were no traces of entrances, walls or a hearth in connection with the house, and since the central bay where the entrance room should be was equal in size with the neighbouring bays, the house was interpreted as a large storage house. The $\mathrm{E}-\mathrm{W}$ orientation is also an argument against a type 3 interpretation, since most six-post dwelling houses have a slight inclination angle towards WNW-ESE.

Nearly all postholes in the two houses were circular. Those in house 192 were quite small (mean $0.24 \mathrm{~m}$ ) and shallow (mean $0.10 \mathrm{~m}$ ), while in house 224, the postholes had a normal diameter of $0.35 \mathrm{~m}$ in mean. Only three postholes from that house were excavated, and forge remains from an early Pre-Roman Iron Age smithy situated nearby date the house to later in the Pre-Roman Iron Age or Roman Iron Age. The circular shape of the postholes - and consequently the shape of the posts themselves - cannot be used as a dating means in connection with the storage houses since such houses have been dated by ${ }^{14} \mathrm{C}$ analysis to all settlement periods. These houses must most probably be interpreted as storage houses in connection with type 9 and 10 houses from the Roman Iron Age and Migration Period.

\section{Comparison between the six- to twelve-post and four-post storage houses}

Except for one house (164A) whose orientation was determined by its location in a farmyard, all other six- to twelve-post storage houses had an orientation between due E-W and WNW-ESE. This is a more concentrated distribution of the orientation than is found among the longhouses used as dwellings, not to mention the distribution among the four-post houses.

The mean length of the four groups of elongated storage houses (type 15.1-3,16) shows an increase in length according to the increased number of posts, from 5.5 to $12.2 \mathrm{~m}$, while the mean width of the roof-bearing structure is approximately the same in all four groups (2.7-3 m). As we therefore can expect, the length/width ratio and the floor area also increase according to the increase in the number of trestles. Since the trestle width is stable, the increase of these two measures is a function of the increase in the length of the house.

Because of the differences within the small groups of storage houses, it is difficult to pinpoint differences between the groups with any degree of certainty. However, one difference seems clear. The ten-post houses have a curved, convex roof-bearing construction, while the other groups have straight constructions. All four groups have a large majority of circular postholes, most often between $0.3-0.4 \mathrm{~m}$ in diameter and $0.2-0.3 \mathrm{~m}$ in depth. This indicates that - just as was the case with the four-post houses - the roofbearing posts measured $0.15-0.20 \mathrm{~m}$ in diameter. Two houses had smaller and shallower postholes, indicating an even lighter construction.

The floor area is five times larger in the twelve-post houses than the mean area found in the four-post houses (approximately 35 versus $7 \mathrm{~m}^{2}$ ), so the total roofed area (approximately $370 \mathrm{~m}^{2}$ ) from the six- to twelve-post houses is much larger than their small number (17) could indicate, compared to the total roofed area $\left(410 \mathrm{~m}^{2}\right)$ from the 58 four-post houses. The six- to twelve-post houses represent an $85 \%$ increase in roofed storage area, and consequently storage capacity, compared with the capacity of the four-post houses. The small number of six- to twelvepost storage houses was therefore a substantial part of the ability to store crops and/or fodder like hay in the different settlement periods.

Artefacts have been found in 9 of the 16 houses with six- to twelve-posts. Compared to the situation concerning the four-post houses, where artefacts are found in only eleven of the 58 houses; the proportion is thus quite different in the six- to twelve-post houses. This can be an indication in favour of interpreting some of the houses as dwellings, for instance house 71 . However, when looking at the finds, they are mostly small, single sherds of coarse-tempered pottery, a tiny burnt bone or one or two flint flakes. All the houses lack clay from a floor or a wattle and daub wall and more than half of the houses also lack a content of charcoal in the postholes. In addition to the seven houses with no finds, five out of six houses have finds that were most probably deposited in the postholes due to some kind of change. Among the remaining four houses, slag from iron working has been found in postholes belonging to houses 222 and 224, situated adjacent to an early Pre-Roman Iron Age smithy. Those finds must be regarded as contamination from the smithy. House 4 has been dated by pottery and 62 charred grains of barley (Hordeum) were found in three postholes in the last house (57A). Nine out of ten postholes in this house had a content of charcoal and three samples were collected. These finds can indicate that the house was a granary that burnt down. The analysis of the finds leads to the conclusion that the only find useful for interpreting the function of the house confirms the hypothesis of these houses as storage houses for crops or fodder.

Only two $(76,100)$ of the 16 storage houses with six- to twelve-posts have been dated by ${ }^{14} \mathrm{C}$ analysis, 
both to the Late Bronze Age. One house (4) is dated by bucket-shaped pottery to no earlier than the $4^{\text {th }}$ century $\mathrm{AD}$, while the remaining houses have not yielded dating material. The only possibility of placing these houses chronologically is by typology, by regarding their location in the settlement areas and by their connection with nearby dated longhouses. Such an interpretation has been undertaken in the evaluation of each house. The results can be summarised as follows, including the three well-dated houses: seven belong to the Late Bronze Age, three to the Late Bronze Age or Iron Age, three to the Pre-Roman Iron Age and three to the Roman Iron Age or Migration Period. Just as the four-post houses, the six- to twelve-post houses seem to belong to most of the settlement period. However, unlike the four-post houses, the six- to twelve-post houses did not exist in the Early Bronze Age. Taking into consideration that we are dealing with small numbers, one can also see a tendency that the six- and eight-post houses are mainly dated to the Bronze Age and Pre-Roman Iron Age (six out of nine houses), while only one of the ten- to twelve-post houses has a suggested Bronze Age date. This is probably a result of a demand for greater storage capacity as the main farmhouses grew larger during the Pre-Roman Iron Age. Only three of the 16 houses have been dated to periods after AD 1. The lesser use of separate storage houses in the last 600 years of the settlement period can probably be connected with the establishment of the much larger main farmhouses (type 9) as well as the new workshop houses (type 10), resulting in an area under roof that was 3-4 times greater than in a normal Bronze Age or Pre-Roman Iron Age farm.

\section{Comparison of six- to twelve-post houses in northern Europe}

The archaeological literature has paid little attention to storage houses with more than four posts. At settlement sites where preservation conditions for the houses were poor, wall and entrance postholes were seldom documented. Consequently, all houses with more than three trestles were automatically interpreted as dwelling houses (Björhem \& Säfvestad 1993:281). Björhem and Säfvestad suggest that some of the small six-post houses at Fosie IV cannot be interpreted as longhouses used as dwellings, but they do not discuss any alternative interpretations. In a summary of the houses from the Bronze Age, eight dwelling longhouses are listed in one row and four smaller houses in another (Björhem \& Säfvestad 1993:107, fig. 160). One of those has documented entrances and is probably a partly documented dwelling house, while the three other eight-post houses differ significantly from the dwelling houses in the size of the postholes, the distances between the trestles and the trestle-width. They obviously represent another type of building, but in the discussion of the function of the Bronze Age houses, they are not at all mentioned. Both six- and eight-post Iron Age houses have been documented with measurements that clearly distinguish them from the dwelling houses from the period. In fact, they have lengths (six-post: $5.4 \mathrm{~m}$, eight-post: 7.4 $\mathrm{m})$ that fit very well with those from Forsand (six-post: $5.5 \mathrm{~m}$, eight-post: $7.55 \mathrm{~m}$ ). An $8.9 \mathrm{~m}$ long ten-post house, corresponding nicely to similar $9 \mathrm{~m}$ long houses at Forsand, was probably also a storage house. Altogether, there might have been twelve six- to ten-post storage houses at Fosie, in addition to nine four-post houses.

It seems therefore that at Fosie IV, storage houses played a larger role throughout the settlement period than is discussed in the 1993 publication. Similar storage houses are present at Hodde (Hvass 1985) and Køpinge (Tesch 1993), but it seems from the publications that the number of large storage houses is very limited.

From the large excavations in connection with the Vestkystbanen railway line (Artursson 2005a, 2005b), a few six- to eight-post houses from the Bronze Age and Early Iron Age have been documented, while no such houses seem to have come to light at the excavations in connection with the Öresundsförbindelsen project.

Also at the Pryssgården settlement in Östergötland, eleven small houses have been reported as having six or eight posts and are interpreted as houses with different functions within different farms (Borna-Ahlkvist 1998:50). The houses have a partly straight, partly convex roof-bearing structure and the six-post trestle width is rather narrow - in mean only $2.4 \mathrm{~m}$ - while the houses with eight posts are $3.4 \mathrm{~m}$ wide. When studying the published ground plans, it is clear that most of them have hearths inside; some also have traces of entrances and walls. These houses, dated to the Roman Iron Age, are therefore more comparable with the workshop houses (type 10) at Forsand than the six- to twelve-post houses. However, one such house with 3.5 $\mathrm{m}$ wide trestles - probably from the Early Bronze Age - can be classified as an eight-post house.

In northern Jutland, seven six- to eight-post houses dated to the Bronze Age have also been excavated (Bertelsen et al. 1996).

At Priorsløkke (Kaul 1985:174-75), there are eight six- to eight-post houses dated to the $1^{\text {st }}$ to $2^{\text {nd }}$ century $\mathrm{AD}$ and without traces of walls and entrances - as 
opposed to eight similar houses with entrances - which are part of the farm area. The eight farms in the second phase seem to consist of the main farmhouse with 5-6 trestles, a workshop house with 2-3 trestles and a four-post granary. In addition, four farms have a six- or eight-post storage house; these storage houses are the same sizes as those at the Forsand site. At Priorsløkke, we can see the development towards the late Roman Iron Age large farms, with a larger area under the roof, but in the configuration of small, separate houses. At least seven six-post houses from the late Roman Iron Age and Migration Period have been excavated at Nørre Snede (Hansen 1987:186).

Also in southern Jutland, six ten-post houses are known from the early Roman Iron Age (Ethelberg 2003:190). Due to very good preservation conditions at some of the sites, Ethelberg is certain that they never had walls or entrances. He therefore interprets the buildings as saddle-roofed storage houses located in the farmyards. He also regards them as closely related to the four-post houses. Later in the Early Iron Age, such houses are uncommon because the saddleroofed fences (Ethelberg 2003:236ff) that surround the farms provided sufficient storage capacity.

At Flögeln (Zimmermann 1992:230ff), 33 six- to eight-post rectangular houses have been excavated in addition to 17 nine- or twelve-post square houses. I will not comment on the square houses here, since there are no comparable houses at Forsand. Concerning the six- and eight-post houses, their mean size $-4 \times 2.5 \mathrm{~m}$ $\left(10 \mathrm{~m}^{2}\right.$ roofed area) and $3.4 \times 2.1 \mathrm{~m}\left(7.1 \mathrm{~m}^{2}\right.$ roofed area), respectively - is markedly smaller than the corresponding houses at Forsand (Table 34). This seems to be in accordance with an overall tendency since the four-post houses at Flögeln were also smaller than at Forsand, see chapter 7.1. There is also a small number of six- to eightpost houses at Priorsløkke (Kaul 1985). They are similar in size to those at Forsand (Table 34) In addition to the two types of small storage houses already mentioned, there are also eleven so-called langgestreckte Speicher [long storage houses], with eight to ten posts. Those with eight posts are similar in size $\left(6.3 \times 3.1 \mathrm{~m}\right.$ and $21.3 \mathrm{~m}^{2}$ roofed area) to the eight-post houses at Forsand, while the ten-post houses $\left(11.9 \times 2.8 \mathrm{~m}, 32.7 \mathrm{~m}^{2}\right.$ roofed area) are markedly longer than the similar houses at Forsand.

Haarnagel (1979:148ff) has analysed the four- to six-post houses at Feddersen Wierde. Of a total of 147 granaries, the nine-post type comprises two thirds (97), while the most frequent types in Scandinavia (four- and six-posts houses) were seldom built (13 and 25 specimens, respectively). The houses are normally slightly rectangular and, in some cases, square. This is also the case for the six-post houses, which have, in fact, the same shape and size as the four-post houses, in mean $2.1 \times 1.9 \mathrm{~m}$ with a $4 \mathrm{~m}^{2}$ roofed area. The ninepost houses at Feddersen Wierde are somewhat larger than the four- and six-posts houses (in mean $2.8 \times 2.4$ $\mathrm{m}$ and a $6.7 \mathrm{~m}^{2}$ roofed area), and - in terms of size resemble the four-post houses at Forsand, Hodde and Priorsløkke. At Feddersen Wierde, one type of small storage house is connected to the main farmhouse and was situated right outside the entrance leading to the living room. Because of this location and that a surrounding wattle-work fence with an entrance sheltered the storage houses, Haarnagel interprets them as houses to store grain, meat, cloth and so forth - and even as a sleeping area, an interpretation inspired by the "loft" in Norway and Sweden (Haarnagel 1979:158). When the storage houses are situated in a group at some distance from the farm, they are interpreted as granaries. Because of the modest sizes of the four- to nine-post houses, he rejects the possibility that hay or dried leaves were stored in these houses.

The postholes in the storage houses at Feddersen Wierde had a depth of $0.8-1 \mathrm{~m}$, and the posts were made from radial split oak (Quercus) with the dimensions $0.20 \times 0.18-0.20 \mathrm{~m}$ (Haarnagel 1979:148). Haarnagel concludes that the foundation of the storage houses shows that the house was intended to carry heavy loads. He therefore reconstructed the storage houses in very much the same way as the Scandinavian "loft": on top of approximately $1 \mathrm{~m}$ high foundation posts is a solid

Table 34. Average size $(\mathrm{m})$ and roof area $\left(\mathrm{m}^{2}\right)$ from six- and eight-post storage houses from different sites in Norway, Sweden, Denmark and Germany.

\begin{tabular}{|l|c|c|}
\hline & Length $\mathbf{x}$ width & Area $\mathbf{~}^{2}$ \\
\hline Six-post houses & & 15.4 \\
\hline Forsandmoen & $5.5 \times 2.8$ & 14.4 \\
\hline Priorsløkke & $5.2 \times 2.8$ & 14.6 \\
\hline Pryssgården & $6.1 \times 2.4$ & 17.1 \\
\hline N-Jutland (BA) & $5.7 \times 3.0$ & 10.0 \\
\hline Flögeln & $4.0 \times 2.5$ & 4.0 \\
\hline Feddersen Wierde & $2.1 \times 1.9$ & 23.6 \\
\hline Eight-post houses & & 21.1 \\
\hline Forsandmoen & $7.6 \times 3.1$ & 24.1 \\
\hline Priorsløkke & $7.6 \times 2.8$ & 22.8 \\
\hline Pryssgården & $7.1 \times 3.4$ & 7.1 \\
\hline N-Jutland (BA) & $7.6 \times 3.0$ & 21.3 \\
\hline Flögeln & $3.4 \times 2.1$ & \\
\hline Flögeln. long type & $6.3 \times 3.1$ & \\
\hline
\end{tabular}


rectangular frame on which the actual storage house was constructed, probably with wattle work walls and a saddle roof (Haarnagel 1979:158).

Zimmermann (1992) is the other archaeologist who has made a thorough analysis of the storage houses. It is interesting that he refers to those houses as gestelzen Speicher, meaning a granary on stilts, and therefore concurs with Haarnagel's opinion. Zimmermann finds that such storage houses occur from Denmark to England in the Bronze Age, while in the Roman Iron Age they are only found on the Continent. The lack of storage houses at many settlement sites is because they were situated in clusters at some distance from the farmhouses. At Flögeln in the $2^{\text {nd }}-3^{\text {rd }}$ century, the storage houses were not connected to the single main farmhouse, but were situated near the northern border of the farmyards (Zimmermann 1992:244), a pattern quite different from what is seen at the same time at Feddersen Wierde, only $15 \mathrm{~km}$ to the west.

All types of four-to twelve-posthouses are interpreted as storage houses for different types of grain harvest including seed grain (Zimmermann 1992:243), where the grain was stored in large pottery vessels on a raised floor that prevented access by rodents and the like. The interpretation of these houses as granaries at Flögeln rests on two finds of charred grains, with 250 grains [rye (Secale), barley (Hordeum)] from the $2^{\text {nd }}$ and $3^{\text {rd }}$ century and 145 grains (barley (Hordeum), oat (Avena) and rye (Secale)) that are not dated in the publication. In addition, an analogy from recent times, regarding the widespread use of storage houses on stilts, confirms such an interpretation (Zimmermann 1992:243). Many finds of large quantities of grains in the four- to ninepost houses in Scania (for instance Rostovány \& Hydén 2002:29f) and also the finds at Forsandmoen led to the interpretation that the houses at least have been used to store harvested grain.

\subsection{Concluding remarks}

We have found that the Dutch and German four- to ninepost houses are much smaller than the Scandinavian ones, and at Feddersen Wierde, the posts are founded much deeper than in the Scandinavian examples. The sizes of the posts seem to be quite similar: at Feddersen Wierde split oak (Quercus) of $0.2 \times 0.2 \mathrm{~m}$ and at Forsand circular oak (Quercus) or pine (Pinus) $0.15-0.20 \mathrm{~m}$ in diameter. The Dutch and German archaeologists interpret the storage houses as built on stilts, while in Scandinavia, with the exception of the nine-post houses from Scania, the houses are interpreted without a raised, protective floor. These different interpretations are in fact reasonable. The small German storage houses, with densely set and deeply founded posts can be seen as stable base for a "loft" style storage house, while the larger Scandinavian houses with the same sized posts as in the German houses - but often shallowly founded in the subsoil - are less likely to provide enough support for a "loft" construction.

It is therefore reasonable to conclude that there were two different concepts when it came to building storage houses in Scandinavia compared to in Northern Germany and the Netherlands. To the south, the storage houses served "loft" functions or were used to store threshed grain, while the larger Scandinavian houses, not so closely situated to the farmhouse as those at Feddersen Wierde, served as bulk storage for crops before threshing or for hay and leaves.

The reason for such a difference may be found in the different weather conditions. In central Scandinavia, the crop harvest was in recent times dried and stored in a grain barn until the threshing took place during the winter. The four- to twelve-post houses could have been used for such intermediate storage when the houses did not have sufficient storage capacity. Another possibility is that, in Germany and at least the southern half of Jutland, the farms have fences with an open, roofed area inside, marking the border of the farmyard (Danish: halvtak, German: Zaunparallele Pfostenroste). These were well suited for storing the grain crop and hay and can explain how the small fourto nine-post houses might preferably have served the daily household needs. 


\section{Type 7: Large dwelling/byre houses with a central wide-spanned trestle}

After the discovery of a longhouse with a central, widely spaced trestle in 1985 (Løken 1985), similar features have also been discovered at a few other sites in Norway and Sweden. Some of the type 7 houses have been dealt with in a previous paper concerning the hall in the Early Iron Age (Løken 2001b). Even though the type is not common, the special interpretation requires a thorough analysis.

A type 7 house, see Fig. 48, is a longhouse that is primarily defined by the special construction of a centrally located trestle that has a larger span (3.4-4.2 m, mean $3.7 \mathrm{~m}$ ) than the other trestles in the house (with
Fig. 48. House plans of the type 7 houses.

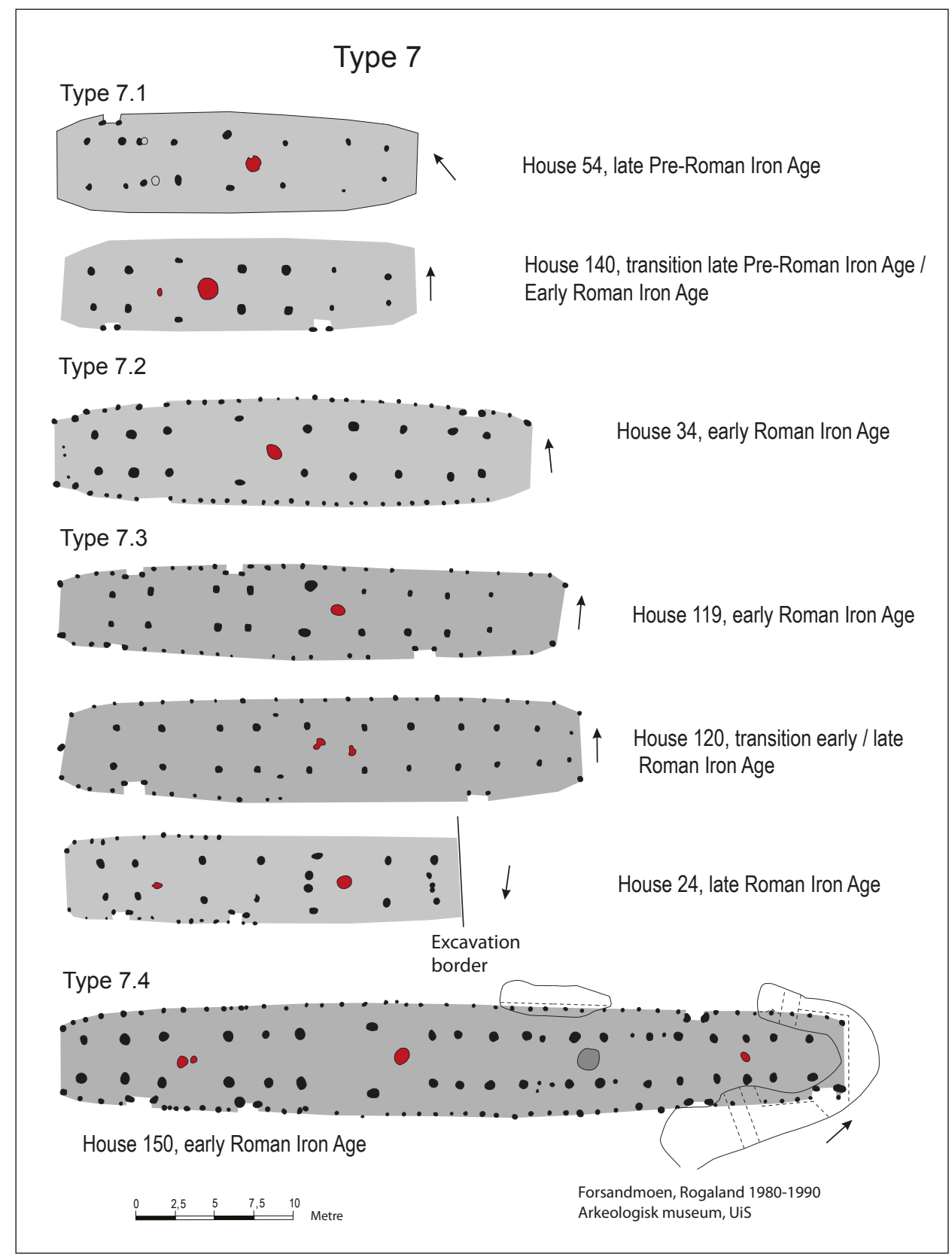




\section{Forsandmoen, Forsand municipality Map of settlement area}

House feature with preserved wall remains

-.... House feature without wall remains

Type 7 houses

Type 8 houses

Gravemound / cairn

Excavated gravemound / cairn
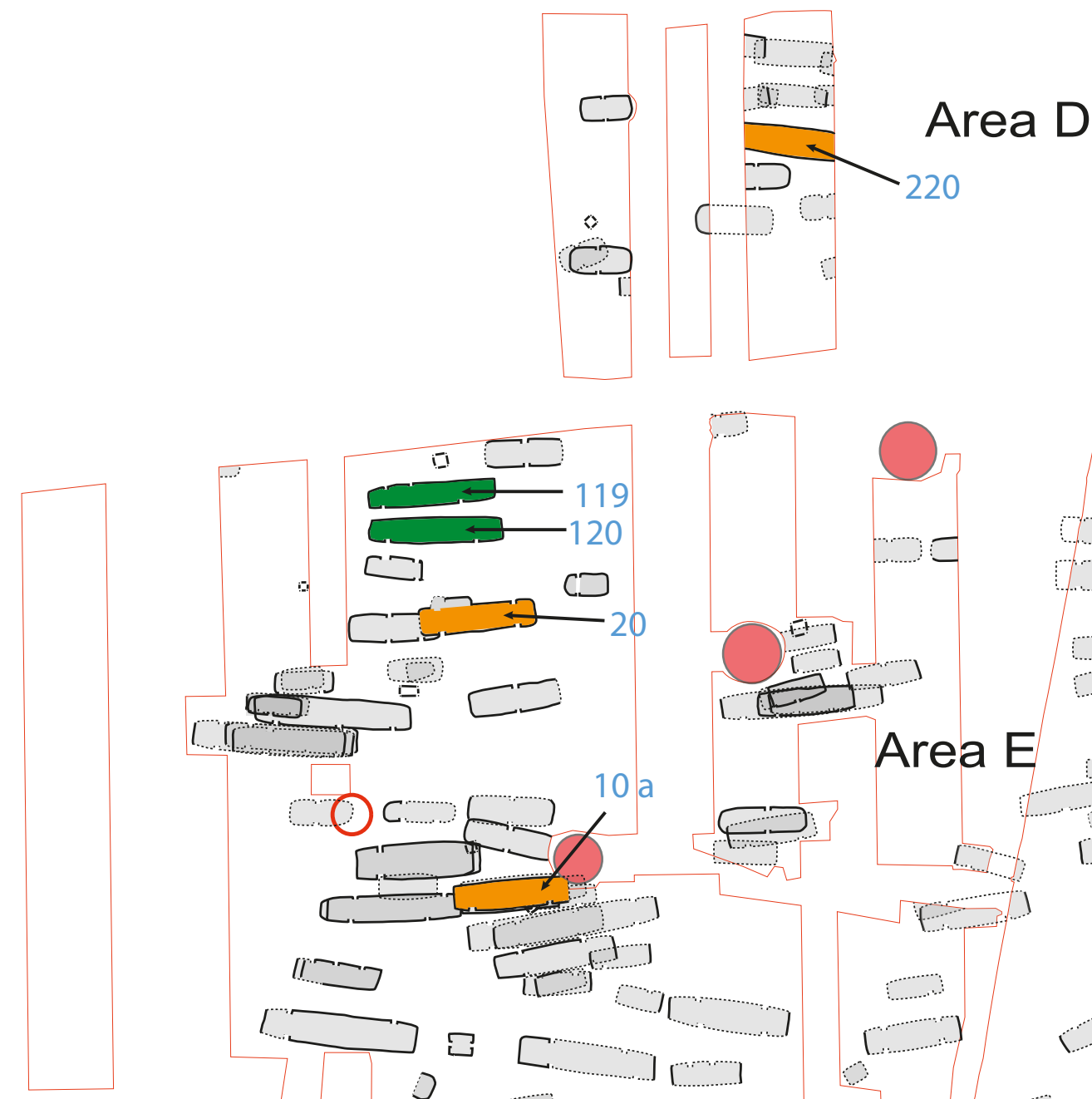

(1)
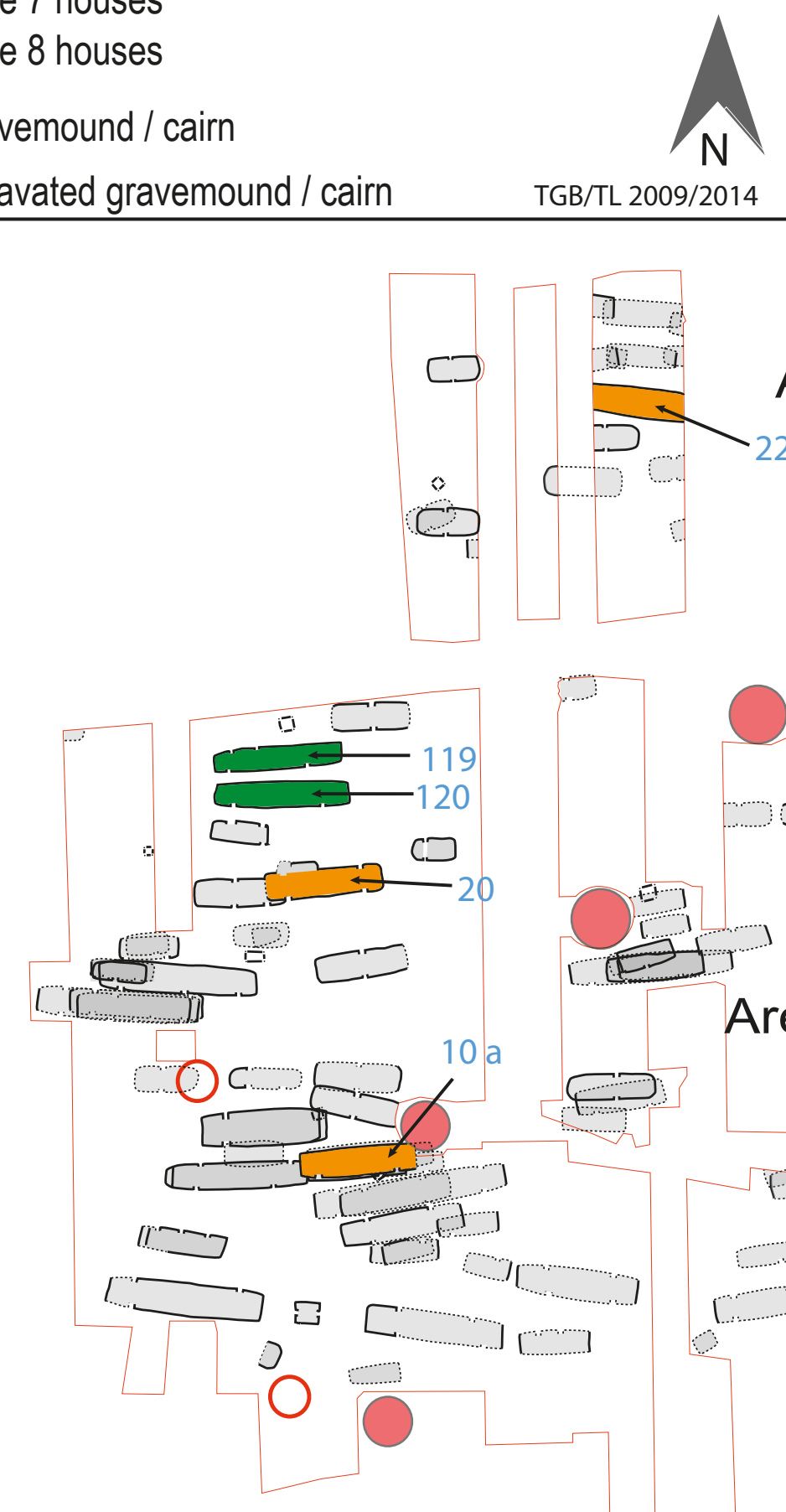

\section{Area E}

O
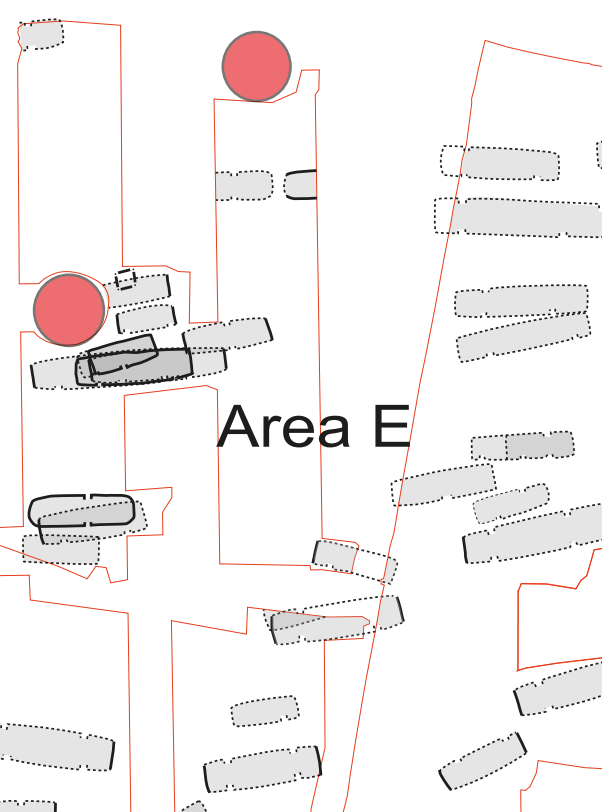


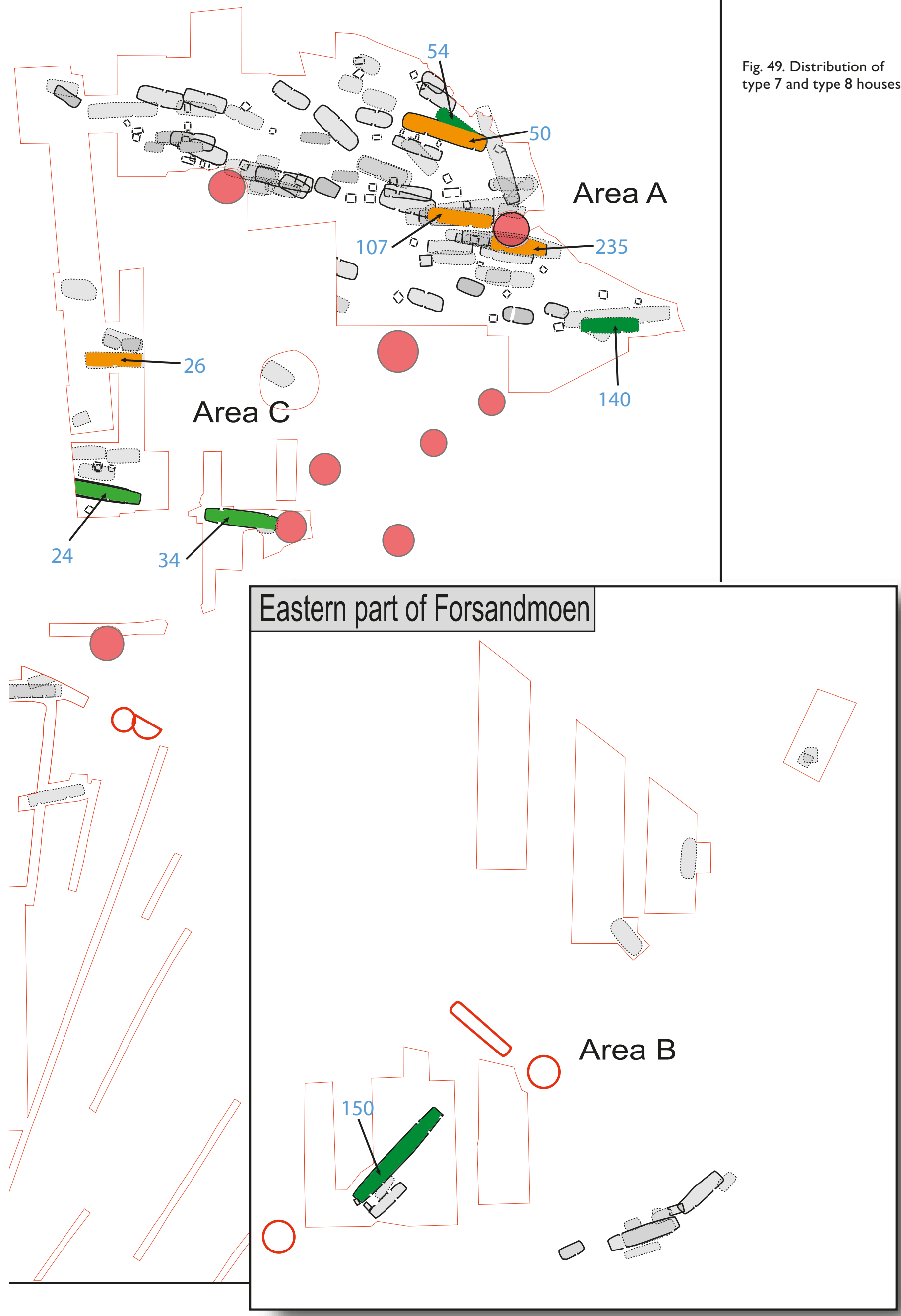


a trestle width near the middle of the house at 2.6-3.1 $\mathrm{m}$, mean $2.7 \mathrm{~m})$. Thus, in mean, these trestles have a width that is $1 \mathrm{~m}$ larger than the mean width of trestles near the centre of the houses, which implies that the postholes in these trestles are located $0.5 \mathrm{~m}$ closer to the wall than the nearest part of the roof-bearing row. The postholes in the trestle with a markedly larger span have their largest dimension parallel to the central axis, whereas all other postholes have their largest dimension at a right angle to the central axis. The trestle bays are largest on each side of the wide trestle compared to the other bays of the house. A central hearth is located to the east of the wide trestle. The type comprises houses of widely different sizes, with the length of the roof-bearing construction ranging from $16.4 \mathrm{~m}$ to 46.5 $\mathrm{m}$ (total house length 24.1-49.7 m).

This type comprises seven houses that have been divided into four subtypes (7.1-7.4), according to their length and the grouping of the bays. All recorded features are presented in Table 35, folder.

\section{Type 7.1}

Type 7.1 consists of two houses $(54,140)$, dated to 2120 $\pm 90 \mathrm{BP}, 360 \mathrm{BC}-\mathrm{AD} 1$ and $2005 \pm 70 \mathrm{BP}, 100 \mathrm{BC}-\mathrm{AD} 80$, and represents the introduction of type 7 at Forsand, see Fig. 48. They are the shortest and oldest of the type 7 houses. Their sizes are comparable with the larger type 3 houses from the same period and represent a new and alternative way of organising a home for a small household with a few cattle. The entrances are located near the gables and there is a $42 \mathrm{~m}^{2}$ heated hall room (approximately $7 \times 6 \mathrm{~m}$ ) located around the centre of the house, while a small byre area occupies the eastern end of the house.

\section{Type 7.2}

Type 7.2 consists of only one house (34), dated to 1910 $\pm 70 \mathrm{BP}, \mathrm{AD} 20-220$ and is likely slightly younger than the type 7.1 houses. The house is comparable in size (29 $\mathrm{m})$ to type 7.3, but lacks the additional larger room in the western end. Entrances are located in narrow bays at both gables, and there is a $60 \mathrm{~m}^{2}$ hall room in the centre of the house. A byre area that could accommodate 18 cattle at most is situated in the eastern part of the house.

\section{Type 7.3}

Type 7.3 comprises three houses $(24,119$ and 120$)$, and is dated to the Roman Iron Age. The house lengths exceed $30 \mathrm{~m}$ and the widths are 5.6-6.1 $\mathrm{m}$. In the western end, this type has four trestles organised into two groups, with short distances between the trestles (where entrances are located) within each group and a longer distance between the two groups. As the hearth is in the longer bay between the entrance bays in house 24 , the longer bays are interpreted as small dwelling rooms $\left(23-25 \mathrm{~m}^{2}\right)$, in addition to the central, large hall room that measured $42-44 \mathrm{~m}^{2}$ in all three houses. The byre area in houses 119 and 120 could, as in the similar sized type 7.2 house 34 , accommodate at most 18 cattle.

House 24 has the dwelling area with the two groups of postholes situated at the eastern end of the house. The house is not documented in its full length due to excavation restrictions, and the byre area is therefore missing. In Fig. 49, the ground plan of house 24 is mirrored to be able to compare it with the other houses.

\section{Type 7.4}

This subtype is a larger variant of type 7.3. Instead of two groups of two trestles, this type has two groups of three trestles in the western end, also with an entrance to each group. In the other end, there are many and very closely spaced trestles (12) compared to type 7.3 (maximum 6 trestles). The house length is $50 \mathrm{~m}$ and the width is $7.1 \mathrm{~m}$. This subtype consists of only one house (150), which has been dated by six radiocarbon samples to the early Roman Iron Age. Three dates are clustered, resulting in a combined age of $1982 \pm 31 \mathrm{BP}$, $5 \mathrm{BC}-\mathrm{AD} 60$ (58 \%) and the other three clusters produce a combined age of $1819 \pm 24$ BP, AD 135-235. The house was therefore most probably used in the early Roman Iron Age and the beginning of the late Roman Iron Age.

\subsection{The features of type 7 houses}

In the following sections, I will analyse the different features that constitute this house type (Table 35, folder) and compare them with the contemporaneous longhouse material, primarily type 9 houses, with which type 7 has many features in common. Type 7 also shares the extended trestle feature with the older type 5 (cf. chapter 6.1.).

\section{Orientation}

The mean orientation for five of these houses is due E-W $\left(300^{\circ}\right)$. The last two houses are oriented differently: SW-NE (150: $\left.346^{\circ}\right)$ and NW-SE (54: $\left.247^{\circ}\right)$, respectively. The pattern is in accordance with type 9 houses, in which most houses are within a few degrees around due E-W, and a few houses with a wider inclination. House 150, with its SW-NE orientation, is the genuine 
exception from this pattern. Due to high mountains to the east and south, the location of the house in the SW corner of the plain resulted in scarce sun exposure. In spring and autumn, the house would only receive sun exposure from the SE, so the SW-NE orientation of the house was probably due to a desire to ensure optimum sun exposure on the SE façade of the house.

\section{Length and shape of the post-setting}

The length of the post-setting in these houses is comparable to type 9 houses - between $17 \mathrm{~m}$ and $46.5 \mathrm{~m}$ - although the longest of these houses is $8 \mathrm{~m}$ longer than type 9 houses. The large difference in length in such a limited material makes it difficult to compare the houses. With one exception, the longest bays are to each side of the extended trestle, obviously to create a large room free of posts, where the central hearth was situated. The curvature of each row is between 0.2 and 0.35 $\mathrm{m}$ in the different houses, which gives the construction a clearly curved layout. In addition, the extended trestle was situated $0.5 \mathrm{~m}$ outside the curved row. This construction certainly presents challenges for the roofbearing construction, which will be discussed below in connection with the Norwegian comparative material.

\section{Shape and size of roof-bearing postholes}

Altogether, 133 holes for roof-bearing posts have been found in type 7 houses and constitute sufficient material for a reliable analysis of their size and shape. Only $57 \%$ have an oval shape, which is markedly less than the $73 \%$ in type 9 houses but corresponding to what was found for type 3 houses in the late Pre-Roman Iron Age and early Roman Iron Age. The distribution between oval and circular postholes is somewhat peculiar. Two houses $(119,140)$ have only oval postholes, house 34 has circular holes except for the extended ones and house 54 has a mixture of circular and oval postholes throughout the house. The last three (24, 120 and 150) share the same pattern: the oval postholes belong to the central dwelling area around the extended trestle, while the whole eastern half - including the dwelling area near the gable, as well as the dwelling area to the west - has almost entirely circular postholes. This difference supports the interpretation presented earlier (Løken 2001b) that the central dwelling area represents a special room: the hall. These three houses, together with house 119 with only oval postholes, are the largest of this type and marked out as high-status buildings using hewn rectangular post in important parts.

House 150 has postholes that are larger (oval 0.55 x $0.69 \mathrm{~m}$, circular $0.55 \mathrm{~m})$ and deeper $(0.32 \mathrm{~m})$ than the other type 7 houses (oval $0.39 \times 0.49 \mathrm{~m}$, circular $0.45 \mathrm{~m}, 0.20 \mathrm{in}$ depth). The posthole size of these six type 7 houses is comparable to type 3 houses from the same period and smaller than the contemporary type 9 houses. Only the high-status building 150 (Løken 2001b:66f) has a similar construction as type 9 houses, while the other type 7 houses belong in this respect to the old construction principles. But also the type 7.2-3 houses in Areas $C$ and $E$ must be regarded as wealthier farmhouses compared to the contemporaneous type 3 houses.

\section{Entrances and interior doors}

The entrances are located in each end of the building, between the first and second or the second and third trestles $(34,150)$ from each end. The entrances are recessed to a medium degree $(0.5-0.6 \mathrm{~m})$, a small degree $(0.2-0.4 \mathrm{~m})$ or not at all from the wall course (total mean $0.4 \mathrm{~m}$ ). The entrance widths are mainly between 0.9 and $1.4 \mathrm{~m}$ [mean $1.1 \mathrm{~m}(\mathrm{~S})$ and $1 \mathrm{~m}(\mathrm{~N})$ ]. Three entrances situated in the western end for human occupation in houses 34 and 150 measure $1.6-2.1 \mathrm{~m}$ and indicate functions other than normal use for people. The entrance postholes were $73 \%$ oval as compared to $85 \%$ in type 9 and $73 \%$ in type 3 houses. The type 7 entrance post construction resembles the older type 3 houses more than the younger type 9 houses. The oval postholes measure $0.39 \times 0.49 \mathrm{~m}$ and $0.23 \mathrm{~m}$ in depth, while the circular ones are $0.39 \mathrm{~m}$ in diameter and 0.25 $\mathrm{m}$ deep. There is a difference between the large house 150 , where all mean measurements are $0.10 \mathrm{~m}$ larger compared with all other type 7 houses - as was also seen in connection with the postholes for roof-bearing posts. The increase is somewhat smaller than the similar postholes in type 9, but the depth is equivalent and larger than what is found in type 3 houses.

The location of the entrances represents a new organisation of the entrances compared with the many houses of type 3 , with a shift from a central access to entrances near both gables of the longhouses. This change predates the same feature that characterises access to the type 9 houses.

Only two interior doors are recorded, both in the partly excavated youngest house 24 . One of these $(0.9$ $\mathrm{m}$ wide) is situated where the likely transition to the byre is located. The other, however, is situated between the extended trestle, consisting of two circular $(0.50 \mathrm{~m})$ and deep $(0.35 \mathrm{~m})$ postholes $0.8 \mathrm{~m}$ apart, unlike all other interior doors. An interior wall with a door located there would jeopardise the purpose of the extended trestle to make a large room for the household's central 
hearth. Another function, such as a foundation for a high seat, could be considered.

\section{Size and shape of posts}

In the western part of house 119, the central parts of the postholes for roof-bearing posts were filled with clay containing small amounts of charcoal. The size and shape of the imprints could be measured in six postholes. All were rectangular and measured $0.16-0.22 \mathrm{~m}$ in one direction and $0.30-0.34 \mathrm{~m}$ in the other (perpendicular to the central axis). The mean size was $0.19 \times 0.33 \mathrm{~m}$. Since the postholes, where these measurements were taken, are comparable with the postholes recorded in all type 7 houses - except house 150 - we can suppose that the posts in oval postholes in these houses had such dimensions. Only house 150, with approximately $0.10 \mathrm{~m}$ larger posthole dimensions - might have had larger posts, maybe as large as 0.30 $\mathrm{x} 0.40 \mathrm{~m}$ in the central area. The post size could also be measured in two entrance postholes belonging to house 119. Measuring $0.17 \times 0.28 \mathrm{~m}$, the dimensions were a little smaller than for the roof-bearing posts, as was also the posthole dimension. The only circular postholes in this house were in the eastern entrance to the byre area, with a $0.31 \mathrm{~m}$ diameter, indicating a post size of around $0.20 \mathrm{~m}$.

Based on the abundant occurrence of charcoal in the postholes for roof-bearing posts in house 150, this house most likely burnt down. In one instance, the charred post was preserved in the posthole. The $0.17 \mathrm{x}$ $0.25 \mathrm{~m}$ rectangular post was made from pine, like the charcoal in all other postholes in the house. The measured size was smaller than the mean clay imprint from house 119, but within the range of measurements. One should expect larger dimensions from the large house 150, judging from the post-hole dimensions. However, the charred post may have lost some of its size due to the fire.

\section{Walls}

The walls consist of circular postholes with a mean distance in the individual houses between 0.9 and 1.5 $\mathrm{m}-$ mostly $1.1-1.3 \mathrm{~m}$. The long walls in the approximately $30 \mathrm{~m}$ long house 34 are highly curved, $0.4-0.6$ m (1.5-2.2 \%, mean for 4 houses: $1.9 \%$, measured between the centre and the outermost roof-bearing trestle. House 150 (50 m long) has $1 \mathrm{~m}$ of curvature, which is also $2.2 \%$. This shows that type 7 houses were intentionally constructed with a curved layout. Five out of seven houses have preserved traces of the long walls, in contrast to only eight out of 44 type 9 houses. The spacing of the wall posts also differs from both type 9 and type 3 houses, which have between 0.5 and $0.9 \mathrm{~m}$ between the wall posts. The walls of house type 3 are of the wattle and daub type, and so are the type 9 walls with small postholes. In contrast, four of the type 7 walls were constructed with larger posts and large spacing - and they lack traces of clay. Three of the houses (24, 119 and 150) have 1.1-1.3 m spacing, while house 120 has a somewhat longer spacing (1.4-1.5 m) and house 24 has shorter spacing, measuring $0.9 \mathrm{~m}$. The wall postholes were normally $0.20-0.25 \mathrm{~m}$ in diameter and normally circular, indicating circular posts. The diameter and depth of all wall postholes in house 34 are regarded as being representative for type 7 walls. The mean size was $0.25 \mathrm{~m}$ in both long walls and the depth somewhat greater in the northern wall $(0.17 \mathrm{~m})$ than in the southern wall $(0.13 \mathrm{~m})$. This shows that the wall posts were dug down approximately $0.35 \mathrm{~m}$, considering $0.20 \mathrm{~m}$ of topsoil above the measured depths, which would have given posts of approximately 0.15 $\mathrm{m}$ in diameter a good base for the wall planking. The large house 150 had markedly larger and deeper wall postholes, measuring in mean 0.30 and $0.25 \mathrm{~m}$ in depth at the south-western and north-eastern dwelling area. In the area in between, the depth was only $0.10-0.15$ $\mathrm{m}$ indicating less secured wall posts in the byre area. The spacing - also in house 24 - is sufficiently wide to be interpreted as a bole wall with horizontal boards between the wall posts or alternatively with upright boards. A similar wall, but with wider-spaced $(3.4 \mathrm{~m})$ wall posts, has been documented in the type 9 house 6 as a further development of such a wall.

In house 150, burnt clay was found in six postholes in the western end ( 335.2 grams) and in three postholes in the eastern dwelling area (63.8 grams). Five of the clay finds from the western half comprise pieces with imprints of twigs, which had been $2-3.5 \mathrm{~cm}$ in diameter. In one instance, there are twig imprints on two opposed sides of the fragment divided by $1.4 \mathrm{~cm}$ of clay. Another piece has an imprint of bark. Many pieces, including some from the eastern living room, have a smoothed, straight surface; others have two parallel surfaces. These clay pieces with twig imprints most likely originate from a burnt wattle and daub wall. The charred roof-bearing posts found in the house leave no doubt that the house burnt down. There were very likely wattle and daub walls in the house. These imprints have been found in postholes on each side of the western entrance, at one side of the entrance to the main dwelling area and in a posthole representing the transition to the byre area. A possible interpretation of clay from 
wattle and daub in this location can be that these are remains from interior walls that delimited the more private areas from the more public entrance area as well as the main living room and the hall from the cattle. In the more numerous type 9 houses, there are traces of interior doors in connection with the western entrance room and between the living room and the byre area.

The other possible interpretation of these clay findings is that the long walls were not constructed as a bole wall, but as a wattle and daub wall consisting of three or four small, undocumented posts between the large ones. This interpretation has the advantage that the wall would have been built using a well-known technique, only altered to fit longer distances between the weight-bearing wall posts. An argument against this interpretation is that the wall posts in type 7 houses have a larger diameter than the equivalent posts in type 3 houses. This would have required a thicker wattle wall around these posts, thus increasing the amount of clay considerably without gaining a more stable wall. It is also possible that the wall posts, together with the trestle-posts, carried the weight of the roof, and that a wattle and daub wall was constructed inside the wall posts. Due to the lack of such additional postholes this solution is regarded as unlikely.

\section{House width and TQ}

Type 7 houses have a total width between 5.6 and 7.1 $\mathrm{m}$ (mean $6.2 \mathrm{~m}$ ), which is quite similar to type 9 and just as was the case with type 9 houses - the longer the house, the wider the house. The TQ is 2.2-2.4 (mean 2.3 ), as is seen in type 9 , but the extended trestle has a much lower TQ [1.6-1.9 (mean 1.7)].

\section{Construction of the gables}

The short walls are, with one exception, marked only with two corner postholes, set at a distance of 3.3-4.2 $\mathrm{m}$ (mean $4 \mathrm{~m}$ ). Compared to the house width at the nearest roof-bearing trestle, the corner postholes are set 1-1.5 m narrower than the house width. The distances from the outermost trestles to the corner posts vary from $1.2 \mathrm{~m}$ to $4.6 \mathrm{~m}$. The $4.6 \mathrm{~m}$ eastern gable room in house 119 may be caused by a missing trestle, indicated by the shallow depth of the nearest trestles. However, there are still larger differences in the size of the gable room in type 7 than we see in type 9 . This makes it difficult to estimate the house length for the two houses without any walls or corner posts $(54,140)$. However, in Table 35, folder, the gable room has been estimated to be approximately $2.6 \mathrm{~m}$, which is equivalent with the mean measured size in type 7 and also in type 9 .
Four of the houses have well-documented wall courses towards the gables. They show that the walls curved inward to adjoin the corner posts. Such a curve is a possible way to connect the long walls to the gable wall, given the interpretation of the long walls as a bole wall with short horizontal boards between the wall posts. This contrasts with the type 9 houses, where the walls (e.g. in house 2) seem to end up 0.5-1 m outside the corner posts. The explanation may be that the wooden sill beam to which the walls were attached could not be curved to meet the gable posts within that short distance.

\section{The hearths}

All type 7 houses have a hearth situated east of the extended trestle, and all but one were nearly circular, measuring 1-1.3 $\mathrm{m}$ across. They had a straight or slightly curved bottom filled with charcoal and some scattered burnt stones and were obviously intended for light and to heat the central room. In contrast to this, the main living room in type 9 houses often had two hearths; one for heat and light and one for food preparation. This difference underlines the special purpose of the central room in type 7 houses. An additional hearth is documented in the living room west of the central living room in houses 24 and 150, while the similar room in houses 119 and 120 lacks a hearth there. House 150 also had a hearth in the north-eastern area, indicating a dwelling area here. A fourth, $1.3 \mathrm{~m}$ wide circular hearth, also used for light and heat, was situated in a $1.9 \mathrm{~m}$ wide room in the byre area. This hearth has the youngest radiocarbon-date among the six dates from this house, indicating that, at the end of the habitation period, there was an altered use of the area, which - according to remains of stall boxes - was originally intended as a byre.

\section{Stall boxes}

Six stall boxes, indicated by small postholes in line with the rows of postholes for roof-bearing posts, are documented in three bays in the central part of house 150. In two of these, there are 2.9-3 m wide bays on each side of the central nave/aisle, dividing the bays in three $1 \mathrm{~m}$ wide sections. In addition, one such stall box posthole was situated in a $2 \mathrm{~m}$ wide neighbouring bay. Similarly situated small postholes are also documented in a few type 9 houses, also dividing up the bays into spaces $0.8-1 \mathrm{~m}$ wide. These postholes were probably attached to the long beam on top of the roofbearing posts, making a firm base for boards out to the long wall to divide off stall boxes. A similar house 
to house 150 has been excavated at Austbø, Stavanger (Hemdorff 2006). The same type of small posts divided each of the $3 \mathrm{~m}$ long bays into six stall boxes in the central part of that house, showing that this type of construction was adopted in a wider area. The interpretation as parts of a stall box construction is likely, since the width between these posts fits well with the normal width of stall boxes recorded at many PreRoman Iron Age and Roman Iron Age settlement sites in Jutland (Becker 1965, 1968, 1971, Ethelberg 1988, 2003, Hvass 1985).

The area between the central living room and the eastern, opposed entrances also contains two $2 \mathrm{~m}$ wide bays and one $1.6 \mathrm{~m}$ wide bay without traces of stall boxes. Given the stall box division of a $2 \mathrm{~m}$ bay, it must be regarded as likely that these two bays were part of the byre for stalling the cattle. The $1.6 \mathrm{~m}$ wide bay can have been part of the hall room since it was situated adjacent to that room. This interpretation is based on the occurrence of an interior door in the very similar house 1 at Veien (Gustafson 2000); that door was situated between the 1.6 and $2 \mathrm{~m}$ bays north of the hall room. The byre therefore provided room for a maximum of 28 cattle, or alternatively space for smaller animals if the number of cattle was smaller.

None of the other type 7 houses have traces of stall boxes, but it is possible to calculate the number of cattle likely to have been stalled in some of the houses. Between the eastern entrance and the central, heated living room, house 34 has three 3-3.2 m wide bays with space for 18 cattle. Houses 119 and 120 have one bay to one side of the eastern entrance and two on the other, which also could stall 18 cattle. All three houses belong to a 200-year period around AD 1, and are contemporaneous with the $50 \mathrm{~m}$ long house 150 . The smaller house $140(25 \mathrm{~m})$, also belonging to this period, only has two bays with space for 12-14 cattle. House 54, which is not so well documented, also has space for 12-14 cattle, while the last and much later house 24 lacks the byre area. Judging from the $22 \mathrm{~m}$ long dwelling area, with two heated rooms like house 150, the byre area could have been of a size similar to that found in houses 34, 119 and 120 , with room for at least 18 cattle.

\subsection{Finds}

In most of these houses the finds are scarce. Charcoal from the hearths has only been found in houses 54 and 140. In one of the extended postholes in house 119, a special find was made: a $9 \mathrm{~cm}$ high and $10.9 \mathrm{~cm}$ wide ceramic pot, together with a grinding stone (Fig. 13), placed at the bottom of a hole beside the post. The pot, weighing 260 grams, was complete with the exception of one tiny piece from the rim. This find was likely a foundation sacrifice in connection with the building of the house. From the other four houses, only two rims and 19 body sherds from undecorated pottery were found, with a total weight of 71.3 grams. All pottery was found in the western area of the houses, where the hearths are situated. This distribution supports the interpretation, based on the house structure, of this area as the dwelling area for people.

Small amounts of burnt bone (5 finds, 1.1 grams) were also found in this area in houses 24,34, and 120 . In house 150, a find (3.4 grams) of two bone fragments from sheep/goat and other bone-fragments of a size that would indicate sheep/goat was found in the possible dwelling area north-east of the byre entrances. In the same area, there were finds of two coprolites from sheep/goat, both dated to the early Roman Iron Age. These finds can indicate that this north-eastern area was a sheep byre instead of a dwelling area, as the centrally located hearth would indicate.

In the dwelling area of house 24, there were also 119 grams of burnt clay, either from crucibles or some sort of furnace. Except for a few finds in the eastern part, these scant finds point to the western area as the dwelling area in type 7 houses. This is the opposite area compared with the older and also contemporary type 3 houses and represents a shift in organising the interior of a house.

\subsection{Distribution in space and time}

The relatively few houses belonging to this house type are dispersed throughout all parts of the settlement area (Fig. 49). In the Areas A, D and E, a pair of houses is situated close to each other. In the western settlement area (E), the nearly identical houses 119 and 120 are located parallel to each other, only $5 \mathrm{~m}$ apart and with the western gables located in a N-S line. Since they are both large longhouses (31 and $33 \mathrm{~m}$, respectively) with space for people and cattle, and since they are situated so close together, the most likely interpretation is that they represent a time sequence rather than a farm with two equally large households.

Approximately $200 \mathrm{~m}$ to the NE (Area C), houses 24 and 34 are situated $30 \mathrm{~m}$ apart in a NNW-ESE oriented row. House 34 measures $30 \mathrm{~m}$ and the partly excavated house $24(23.3 \mathrm{~m})$ was probably about $32-35 \mathrm{~m}$ judging from the curved long walls, which are approximately the same size as houses 119 and 120. The third pair of such houses is situated in the north-eastern part (Area A). These houses are located at a somewhat greater 
distance $(80 \mathrm{~m})$ to each other than was the case in the two other pairs. They are also smaller in size $(24 \mathrm{~m})$, but equal to each other.

Due to the similar sizes in each pair of houses, the short distances between each pair and particularly the close, parallel location of houses 119 and 120, a possible interpretation is that all three pairs represent a farm in two succeeding phases.

The seventh of these houses does not follow this pattern. The $50 \mathrm{~m}$ long house 150 is situated by itself at the SE corner of the plain (Area B), only accompanied by a $21 \mathrm{~m}$ long workshop, with traces of a smithy. The house represents only one phase without any signs of maintenance, ending with a disastrous fire.

Three houses are ${ }^{14} \mathrm{C}$ dated to the $1^{\text {st }}$ and/or $2^{\text {nd }}$ century AD (early Roman Iron Age), while two belong to the period around AD 1. The other two houses differ from this well-defined period by having one date to the early/middle Pre-Roman Iron Age and one to the late Roman Iron Age and Migration Period (cf. type definition).

The oldest date $(2245 \pm 100 \mathrm{BP}, 400-170 \mathrm{BC})$ comes from house 119. The dated birch (Betula) charcoal was extracted from clay filling in a posthole from a roofbearing post. It was believed that the charcoal would date the period the clay was used in the house, but this is of course a dangerous assumption. Only $4 \mathrm{~m}$ south of house 119 is the nearby, parallel house 120 , which has been radiocarbon dated to $1830 \pm 40 \mathrm{BP}, \mathrm{AD} 130-240$. The layout of the two houses has so much in common that it is unlikely that the construction is separated by at least 300 years. I therefore regard house 119 as belonging to a period immediately before or after house 120 . However, considering the other contemporary farmhouses in the area, where the entrances were located in relation to the two houses and the small space between them, I find it most likely that house 119 antedated house 120 .

The latest date (1640 $\pm 90 \mathrm{BP}, \mathrm{AD} 260-540)$ was collected from a little hearth in the eastern living room in house 24 . As can be seen on the ground plan, the hearth does not satisfy the Forsandmoen project's requirements for reliable contexts of hearths in longhouses, since it is not situated in the house-axis and not centrally between the bays. This sample was dated before the western part of the house was excavated, which led to the discovery of the circular hearth in connection with the extended trestle. Due to restricted capacity at the lab, the suggested sample from this hearth was not given priority. The uncertainty concerning the age of this house makes it possible that the pair of houses
$(24,34)$ are more closely connected in time than the ${ }^{14} \mathrm{C}$ results indicate, also when taking into account the lack of finds of bucket-shaped pottery in house 24 and that none of the other six type 7 houses have ${ }^{14} \mathrm{C}$ dates younger than the transition between the early and late Roman Iron Age. There is no information on the relative chronology of the houses.

The third pair of houses has dates that fit well with each other (house 54: $2120 \pm 90 \mathrm{BP}, 360 \mathrm{BC}-\mathrm{AD}$ 1, house 140: $2005 \pm 70 \mathrm{BP}, 100 \mathrm{BC}-\mathrm{AD} 80$ ), giving a likely period of use in the late Pre-Roman Iron Age and earliest Roman Iron Age.

These two small houses are therefore regarded as the oldest ones and are succeeded by two 30-35 m long houses in Areas $\mathrm{C}$ and $\mathrm{E}$ within a 200 -year period. The two older houses have only one dwelling area in the western part, while three of the later houses have two living areas. At the same time, when these four houses were in use, the longhouse 150 was erected $800 \mathrm{~m}$ to the SW in Area B.

The conclusion is that at least six of the seven type 7 houses were erected within a 300-year period from $100 \mathrm{BC}$ to AD 200. They represent a short-lived adaptation to a demand for more space around a hearth that is located in the centre of the house. This solution is not seen before (type 3) or later (type 9), but a few other, special houses (type 8), dated to the early Roman Iron Age, also have a central hearth, but not the extended trestle in the centre of the house.

\subsection{The origin of type 7}

The special solution with an extended trestle at the centre of a longhouse is known only in a small number of houses elsewhere in Norway and they are from the same short period as those at Forsand. This type of structure has no predecessor in the near omnipresent combined dwelling/byre house (type 3) in the PreRoman Iron Age. However, there are a group of smaller houses that have such an extended trestle. Type 5 consists of four houses built with three pairs of roofbearing posts with the same trestle width, and there is an extended trestle closer to the long wall outside the central trestle or between the two easternmost trestles, where the hearth is located. The houses are only about $10 \mathrm{~m}$ long and did not have space for stalling cattle. This house type has therefore filled another function than type 7 but has, in the same way as in the type 7 - especially in house 124 (Fig. 32) - provided a wider post-free space surrounding the hearth. Type 5 houses can be considered residential buildings that 
are equivalent in size to the dwelling area in type 3 houses, and thereby to a household that does not have access to their own cattle. Alternatively, type 5 houses filled religious or social/political functions in a society where the preferred house type was unsuitable for such activities. The closely related type 6 houses also have three pairs of roof-bearing posts and an extra pair in conjunction with hearth, but without the trestle set closer to the wall.

Type 5 houses are located in same areas as type 7 and their dates to the Late Bronze Age and Pre-Roman Iron Age show that they are older than type 7 houses. It is possible that experimenting with an extended pair of roof-bearing posts produced a desired effect, which later was incorporated into the new type of longhouses that type 7 represents.

\subsection{The idea behind type 7 houses}

Type 7 represents a radical change in how the interior of a house is arranged, compared to the more than 1000-year-old two-solution type 3. The entrances for humans and animals are separated and located in each end of the building. A distinction between the human and animal world is created with all this implies in terms of self-understanding and people distancing themselves from the mucky animals. In addition, the main room is located in the middle of the house and with the round hearth in the middle between the three central trestles. The two oldest of these houses are still relatively small, but still as large as the largest among the type 3 houses. They have just one room with an entrance to the west of the large living room and a small byre to the east of it.

The later type 7 houses have several rooms west of the big residential room, preferably with an additional hearth. This structure shows a division of functions in the residential section: a distinction between rooms for daily tasks near the gable and the area in the centre of the house - a hall where important social activities and other types of activities could take place. The importance of the room is, in one instance, marked by a sacrifice in one of the extended postholes. The longest house (150) also has an area with a hearth at the other gable, where it is conceivable that servants, slaves or distant relatives could be located. Alternatively, judging from finds of sheep bones and sheep coprolites, this area was primarily a sheep shed.

Why did this change take place in the house concept in the late Pre-Roman Iron Age or the early Roman Iron Age? Did the inhabitants introduce new agricultural methods that resulted in other needs in terms of household organisation or was it a result of altered social conditions? I have previously dealt with the establishment of the Germanic hall (Løken 2001b). Here, however, I can briefly summarise that a change in funerary customs both in Denmark and in SW Norway testify to the establishment of a social elite (hierarchy) from the end of the Pre-Roman Iron Age. The chieftain's house at Hodde (Hvass 1980), which had twice as much living space and $50 \%$ more stable place than the other farms at that site, is interpreted by Hvass as a prestige building. The differences between the descriptions of the Germanic society provided by Caesar and later Tacitus indicate that social, political and religious institutions developed during the 100 years that passed between the two writers. The institutions described bear witness to a social organisation and activities that require space in which to meet. Bearing in mind the similar material culture and the three-aisled longhouses as the normal type of house in the Germanic areas east of the Rhine and in Scandinavia, it is reasonable to assume that social development in SW Norway also necessitated a "hall" at the time when type 7 houses start appearing. I have therefore interpreted the central compartment in type 7 houses as a hall, where deliberations, feasts, religious ceremonies and so on were held.

\subsection{Comparative houses}

So far, only three other type 7 houses have been excavated in Norway. A house similar to type 7 at Forsand (Tzigaridas 2001), but N-S oriented, was excavated in 1999 at the farm Austbø in Stavanger. The house has the same characteristics as the smaller houses of this type at Forsand, with a smaller hearth for light and heat just south of the extended trestle, a partly stone-paved area in the hall area and opposed entrances between the first and second pair of trestles from the north; the house was about 25 metres long, but traces of the walls were not preserved. South of the entrances there is also a large hearth; the two hearths suggest two different functional areas in the house's northern part, as described for the eastern part of house 150 from Forsand and the Veien house (see below). Three bays to the south of the hall room could, based on a stone-paved entrance path to the middle bay, provide room for stalling 12-14 cattle. The size and layout of the house is nearly identical to the contemporary house 140 at Forsand. The house at Austbø has by three radiocarbon samples been dated to the period $100 \mathrm{BC}$ to $\mathrm{AD} 100$. 
At Veien, Buskerud in Eastern Norway, a $47 \mathrm{~m}$ long N-S oriented building was excavated in 1995 (Gustafson 2000, 2001, 2005a, 2016), where only small details in the layout differ from house 150 at Forsand. Just as house 150 at Forsand, the Veien house also has two dwelling areas in one half, but in this case, there is an extended trestle associated with both hearths. There are two recessed, opposed entrances in the northernmost end, located slightly closer to the gable than is the case for house 150 . The northernmost part was probably a byre and storage area, judging from phosphate levels, macro fossils and finds. Gustafson (2000) has focused more on Veien as a ritual place and the function of the house in this context, rather than the house as an expression of power and status. She also thinks, due to interpretations of the results from a phosphate mapping of the floor area, that the primary stalling functions as a byre were given only modest space north of the northern entrances. The house has been radiocarbon dated to the early Roman Iron Age (Gustafson 2000:97, 2005a, 2016).

The Veien house is located very close to one of the largest and most richly furnished burial grounds from the Early Iron Age in the interior of Eastern Norway. The relationship with this high-status setting supports the interpretation of the large central area as the hall of the house. My interpretation is that, like house 150 at Forsand, the Veien house represents a farm for a chieftain and probably also a religious leader with a dwelling area, an exclusive hall and a byre with room for about 18-22 cattle.

The discovery of the $60 \mathrm{~m}$ longhouse Missingen 1 in Råde, Østfold, which has all the same elements as Forsand 150 and Veien 1, confirms that this idea was shared by other people in Eastern Norway in the early Roman Age (Bårdseth \& Sandvik 2007b:130f). The house also has a large dwelling and workshop area in the south, a hall area around the extended trestle in the middle and a byre/economy area to the north. The smaller house 2 (45 m long) with the same layout, but without the extended trestle at the centre of the house, was also erected in the same area as house 1 . They are both dated to the early Roman Iron Age, which is confirmed by a fragmented Roman denarius from the period AD 161-176 (Bårdseth \& Sandvik 2007b:150).

On the basis of the formal similarity between the three houses, I believe that the Veien and Missingen houses are an expression of the same ambition to make explicit and set the scene for a local elite in the early Roman Iron Age - just as house 150 at Forsand. The similarities between these three houses, over such great distances, are so great that they appear to have been shaped by a common understanding, an idea of how the new elite in landscapes around the coast to the south would convey their status. The longhouse Borg 2 in Lofoten (Herschend \& Mikkelsen 2003) is an example of this type of house - although without an extended trestle in the hall and even larger in size which was been built in a traditional elite environment in Northern Norway as late as the turn from early to Late Iron Age.

In Sweden, there are also a small number of houses with an extended trestle at the centre of the house: Tovsätter and Trogsta in Hälsingland. The $39 \mathrm{~m}$ long Roman Iron Age house from Trogsta has an extended trestle in the middle of an $11.5 \mathrm{~m}$ long room with two large oval hearths in the middle of the house (Liedgren 1992:55f). The room could serve as a hall, but other daily activities also had to be undertaken there because the house did not have another heated room, unlike many of the Norwegian type 7 houses. In addition to this hall feature, the house has a structure that is closely comparable to ordinary type 9 dwelling/byre houses at Forsand. This house, dated to the beginning of the late Roman Iron Age, is somewhat younger than the Norwegian houses.

The $47 \mathrm{~m}$ long house at Tovsätter (Liedgren 1992:45), situated on an artificial terrace, has a 12-m-long central hall with a stone-lined rectangular hearth in the middle of the extended trestle. At Hälsingland and north to Gene (Liedgren 1992, Ramqvist 1983), there are also a number of houses of 30-45 $\mathrm{m}$ in length that are constructed with a narrow central aisle and additional posts outside the trestles surrounding the heated hall room. The Roman Iron Age was clearly a time for testing new building designs; experiments with an extended trestle thus took place in different regions of Scandinavia.

The overall structure found in these houses is the same. An analysis by Karlenby (2007:150) of the development of farmhouses from the combined living room / hall function to an exclusive hall building in the Migration Period, uncovered that a similar type of large longhouse at various locations in Central Sweden. These were characterised by containing both a main living room (Swedish: storstuga), a hall and a byre/ storage area, and are dated to the late Pre-Roman Iron Age and early Roman Age (Skäggesta V, Norslunda Raä 136 house 2, Skämsta 1, Tibble C1, Ledinge I, Skavsta, Vaxmyre) (Fagerlund 2007, Göthberg 2000, Ulväng 1992, Wikborg \& Onsten-Molander 2007). 14 such houses are interpreted as the emerging elite buildings 
to highlight their position. It should, however, be pointed out that most of the houses are organised differently than the Norwegian examples, but they express the same ambitions as the type 7 houses. According to Karlenby's (2007) interpretation of the material, it was more common in Central Sweden in the late Roman Iron Age for the farms to have a shorter combined dwelling/byre/storage house and a separate hall building.

In the early Roman Iron Age, the way to create an elite physical environment was established on the basis of technological requirements as well as practical, social and religious conditions. Which features expressed great houses? It may be rights to the area, power, conservatism, comprehensive enterprise, a large household, a hall room, sense of form, balance between length, width and height of the building and decoration or aesthetics.

Karlenby (2007:124) describes my view very well: "Based on the development of the Nordic longhouse in the Roman Iron Age, there is good reason to assume that the sheer size was one of the principal means to express the inhabitant's social position. When the system was first developed, belonging to a particular type of house was enough to dictate that you should be treated in an particular way; it was possible to determine the status of the inhabitants by only looking at the building." 


\section{Type 8: Large dwelling and byre house with a dwelling area in the centre of the house}

Type 8 consists of eight house plans that have certain features that diverge from the older type 3 and type 7 houses and the contemporary type 9 houses. As can be seen in Fig. 50, seven of the houses have quite different shapes, and lack certain features, such as the central entrance room with the opposed entrances in type 3 , the extended central trestle in type 7 and the layout of the dwelling area in the western part of type 9. Therefore, type 8 must be regarded as a group of combined dwelling and byre houses that does not correspond to the three other such house types that were used in the Roman Iron Age, but without any defining criteria due to the different shapes. The two-phased house 35 is not included in Fig. 50 due to an uncertain layout in the eastern half of the house. For the same reason, the two phases of the house have not been recorded together with the other type 8 house in Table 36 , folder, but listed below the average values from the seven houses.

Two of the smaller houses (house 107 and 135) have the dwelling area in the eastern part of the house, where an entrance room divides the two heated rooms and probably a byre area in the western end. The much larger, partly excavated house 220 also has two heated rooms in the eastern dwelling area, from where an interior door gave access to what was likely a western byre. Such a location of the dwelling area is not part of the layout in types 7 and 9. The three larger, totally excavated houses $(50,10 \mathrm{~A}$ and 20$)$ have the heated room located near the centre of the house with more space to the west than is normal in type 9 houses. Both house 50 and 10A have a hearth in an entrance room, which has not been observed in types 7 and 9 . Nevertheless, the layout of house 20 is quite similar to the type 9 houses. All these houses are dated to the late Roman Iron Age, but house 50 has also been dated to the early Roman Iron Age with five radiocarbon dates. The layout of house 26B, dated to the late Migration Period / early Merovingian Period, probably represents a regression from the type 9 houses in the period when the settlement at Forsandmoen was laid waste.

\subsection{The features of the house type}

After a few years of excavations at Forsandmoen, it was evident from the ever-increasing house material that we could discern several types of houses - both combined dwelling and byre houses and smaller houses without space for livestock. Houses of types 3, 7 and 9 often appeared in the material, as well as workshops of type 10 and four-post storeage houses of type 18 . Once we began to systematise the material, it became apparent that there were a number of large houses with both a dwelling area and a byre area that did not fit into the definition of types 3, 7 or 9; these were then collected in a group called type 8 . As shown below, they do not have a common house plan. In fact, there seem to have been various ways of structuring the household activities in a longhouse with both dwelling and byre functions. The type 8 houses are contemporaneous with the houses of types 7 and 9 but must represent people who had specific structural requirements for their house, which differed from the majority of others in the Roman Iron Age and Migration Period.

\section{Orientation and distribution in space}

All the houses have a nearly E-W orientation (on average $303^{\circ}$ ) with the exception of house 50 , which has a more NW-SE orientation $\left(322^{\circ}\right)$ in accordance with many other houses in Area A (Fig. 49). Just as the type 7 houses, the type 8 were distributed throughout most of the excavation areas (A, C, D and E).

\section{Length and shape of the post-setting}

The length of the roof-bearing construction differs between 17.6 and $30.1 \mathrm{~m}$ (average $22.1 \mathrm{~m}$ ) (Table 36, folder). This is $2.5 \mathrm{~m}$ shorter than the average length of the contemporaneous type 9 houses. The two types of houses have had the same average width $(6.7 \mathrm{~m})$, which results in a $15 \mathrm{~m}^{2}$ smaller roofed area in type 8 compared to a $206 \mathrm{~m}^{2}$ roofed area in type 9. This must imply that the two types of houses were inhabited by the same type of household.

The two rows of postholes in the trestle construction were slightly curved, resulting in an average $3 \mathrm{~m}$ trestle 
width at the centre of the house compared to 2.4 and $2.5 \mathrm{~m}$ in the outmost trestles, respectively. These figures are slightly larger than the equivalent figures from the type 9 houses. The average length of the different bays in the type 8 houses was $3 \mathrm{~m}$, and unlike type 9 houses, the bays where the hearths were located were not especially long.

\section{Size and shape of the roof-bearing and entrance postholes}

Of the 130 roof-bearing and the entrance postholes, 90 $\%$ were oval and only $10 \%$ had a circular shape. This is an even smaller percentage of circular postholes than the $15 \%$ of such postholes in the contemporaneous type 9 houses. The sizes and depths of the oval type 8 postholes (Table 35 and Table 37, folder) were nearly $10 \mathrm{~cm}$ less than the similar type 9 postholes $(0.45 \mathrm{x}$ $0.61 \mathrm{~m} / 0.24 \mathrm{~m}$ versus $0.50 \times 0.70 \mathrm{~m} / 0.34 \mathrm{~m})$. These differences may be explained by the lack of 5-6 $\mathrm{m}$ long bays that were in the type 9 houses, which could have resulted in the use of smaller posts in the type 8 houses. Surprisingly, the average size and depths of the circular posts were identical in the two house types. There were no concrete observations of the size of the posts in the type 8 houses, but in six oval postholes, a ghost of a post indicated a $0.22-0.30 \mathrm{~m} \mathrm{~N}-\mathrm{S} \times 0.08-0.10 \mathrm{~m} \mathrm{E}-\mathrm{W}$ rectangular dimension near the bottom of the posthole, with the smallest dimension increasing towards the top of the posthole. In addition, two posts had 0.25 and $0.30 \mathrm{~m}$ as the longest $\mathrm{N}-\mathrm{S}$ measurement, and the E-W measurement of an entrance post increased from $0.16 \mathrm{~m}$ at the bottom to $0.22 \mathrm{~m}$ at the top of the posthole. These measurements seem to correspond well with measurements found in the type 9 houses.

\section{Entrances and interior doors}

The width of the entrances differs between 0.9 and $1.6 \mathrm{~m}$ (average $1.2 \mathrm{~m}$ ), when a $2.3 \mathrm{~m}$ entrance in house 135 has been excluded. The average figure is $0.2 \mathrm{~m}$ smaller than the entrances in type 9. Where it is possible to take measurements, the entrances are $0.7 \mathrm{~m}$ recessed from the wall line, as in type 9 houses. Two of the houses had an interior door, and in both houses (10A and 220), it was probably part of an interior wall between the dwelling area and the byre. In house 10A, the postholes were comparable in size with the wall posts with a $1.1 \mathrm{~m}$ entrance width, while in house 220 , the entrance post holes were comparable in size to the largest roof-bearing postholes in the house, giving a $1.6 \mathrm{~m}$ wide door. House 10 also had a posthole in the middle of the trestle to the west of the central hearth, indicating that the central heated room was sheltered on both sides of the room.

\section{Walls and gables}

Four of the type 8 houses had remains from the longitudinal walls. The best preserved walls, consisting of densely set, small postholes with an average of 0.6 $\mathrm{m}$ between them, were found in house 10A. House 20 also had a few remains at the eastern end from similarly spaced wall posts. The excavated part of house 220 had nearly completely preserved walls of equally placed postholes, although with a greater $(1.2 \mathrm{~m})$ distance between the posts. In house 50, which according to the radiocarbon dates and the traces of repairs, was used for a long time as indicated by the double wall post lines at different distances between the wall posts. The longest wall sequence in the northern wall has a $1.15 \mathrm{~m}$ average distance between the posts, which is similar to house 220 . However, the remains from the southern wall show much shorter distances between the posts. A section of similar wall shows that the house had a greater width during one phase of its long period of use. The walls with the 0.6 $\mathrm{m}$ distance between the posts were probably wattle and daub walls, while the posts with greater distances between them most probably imply a bole wall. Four of the houses had straight gables marked with corner posts. Furthermore, one of the gables in houses 10A and 135 was strengthened with a double-post in the middle of the corner posts.

Remains of interior walls are seldom documented at Forsandmoen, but three of these houses (10A, 26B and $220)$ seem to reveal such walls. House $10 \mathrm{~A}$ probably had an interior wall to each side of the central, heated dwelling room, if judged based on the postholes at the centre of the aisle between trestle postholes.

\section{Hearths}

Seven of the type 8 houses have 19 hearths, which are situated centrally within a bay and in the axis of the house, and are regarded as belonging to the different houses. They have a horizontal shape that is more or less oval (12 hearths), of which eight measure from $70 \mathrm{x}$ $90 \mathrm{~cm}$ to $110 \times 140 \mathrm{~cm}$ and have depths from $6-27 \mathrm{~cm}$; one was even larger $(155 \times 210 \mathrm{~cm})$, while three were quite small $(20 \times 30 \mathrm{~cm})$ - one of which is regarded as an ember pit. Six hearths were circular, measuring from $50 \mathrm{~cm}$ to $110 \mathrm{~cm}$ in diameter and from $6-18 \mathrm{~cm}$ in depth.

Ten of the hearths were bowl-shaped, consisting mainly of charcoal and scorched stones, while four had 


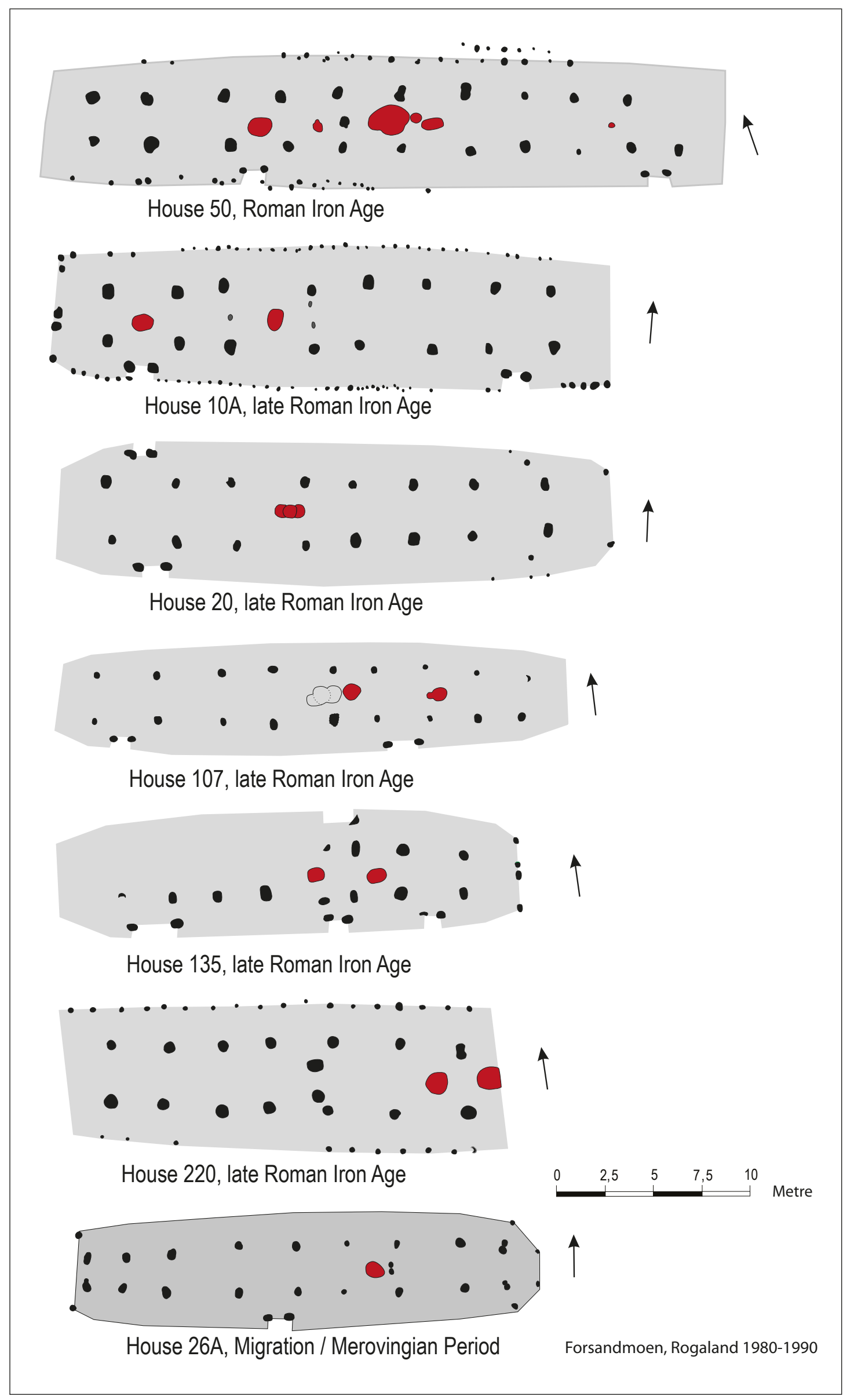

Fig. 50. House plans of type 8 houses. 


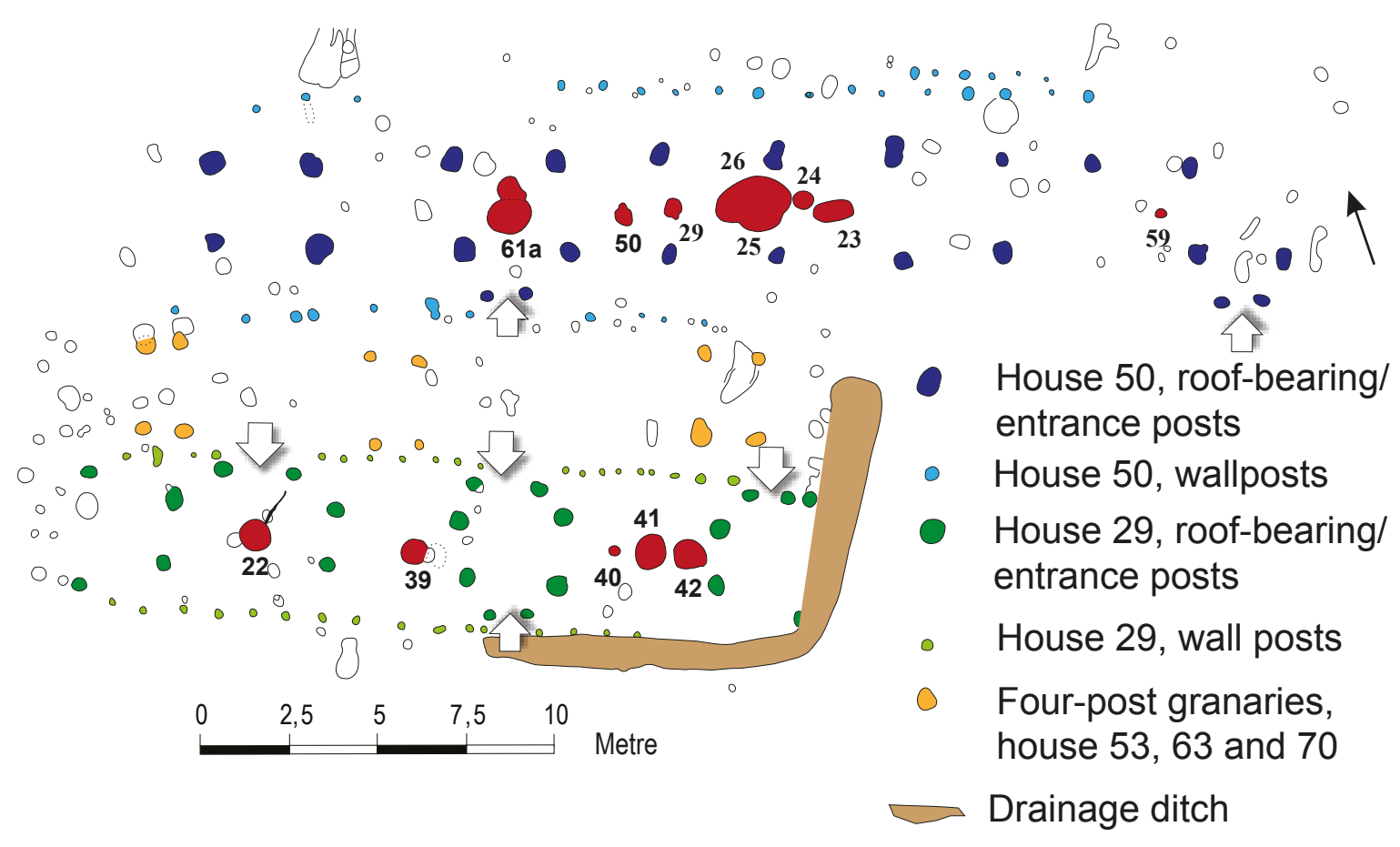

Atmospheric data from Stuiver et al. (1998); OxCal v3.9 Bronk Ramsey (2003); cub r:4 sd:12 prob usp[chron]

House 50, hearth $611980 \pm 70 \mathrm{BP}$

House 50, hearth $241940 \pm 70 \mathrm{BP}$

House 50, hearth $591920 \pm 70 \mathrm{BP}$

House 50, hearth $261800 \pm 70 \mathrm{BP}$

House 50, hearth $231750 \pm 60 \mathrm{BP}$
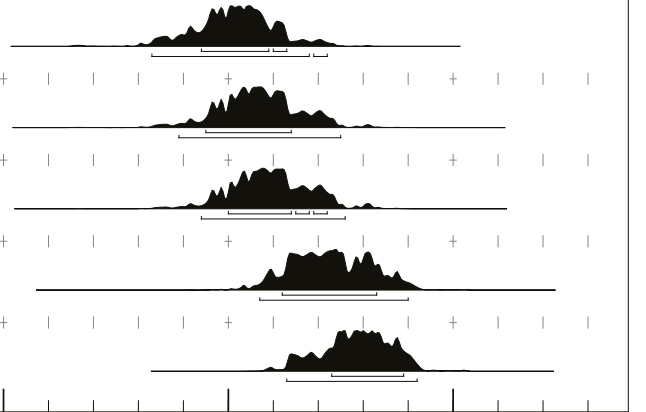

500CalBC CalBC/CalAD 500CalAD

Calibrated date

Atmospheric data from Stuiver et al. (1998); OxCal v3.9 Bronk Ramsey (2003); cub r:4 sd:12 prob usp[chron]

House 29, hearth $421860 \pm 70 \mathrm{BP}$

House 29 , hearth $391780 \pm 70 \mathrm{BP}$

House 29, hearth $221700 \pm 80 \mathrm{BP}$

House 29, hearth $411550 \pm 70 \mathrm{BP}$

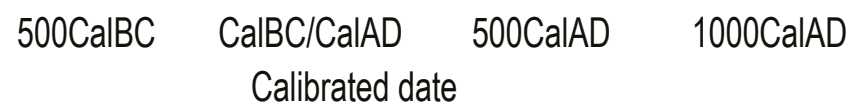

Forsandmoen, Rogaland 1980-1990. Arkeologisk museum, UiS. Plan: M 1:200.

Fig. 5I. Plan of the best documented farmyard: the dwelling/byre house 50, the workshop 29 and the three four-post granaries 53,63 and 70. The graphs illustrate time distribution of the nine radiocarbon dates from houses 50 and 29. 
vertical edges and a straight bottom and two hearths consisted of a thin charcoal layer on top of the gravel.

These differences in shape and size are in accordance with what was found during analyses of the type 9 houses (chapter 10) and therefore strengthen the conclusion that type 8 belongs to the same building tradition as type 9.

\section{Finds}

From all seven type 8 houses, there are only ten finds of coarse pottery between $3 \mathrm{~g}$ and $161 \mathrm{~g}$ (average $30 \mathrm{~g}$ ), in total $304 \mathrm{~g}$. The lack of finds from bucket-shaped pottery shows that these houses were abandoned before the introduction of that type of pottery. The distribution of the pottery, with only one or two finds in each house and when more than half of the material derives from a central hearth in house 50, sheds no light as to where the dwelling areas might have been apart from what the hearths signify. A find of $475 \mathrm{~g}$ of slag in a roof-bearing posthole in house 220 has probably nothing to do with this house, because there was a smithy in the same area at the beginning of the Pre-Roman Iron Age, from which some remains must have ended in the posthole. In addition to this, the finds consist only of one quarter of a rotary quern, one saddle quern and one fragment of a grinding stone.

\section{The byre}

Due to the small number of finds, the interpretation of the type 8 houses must therefore be based on the structure of the houses and the location of the hearths. Some have their dwelling area in the eastern part, where two small, heated rooms were separated by an entrance room while two others had a centrally located, larger dwelling room with a western entrance as in the type 9 houses. One house (50) had a large, heated central dwelling area containing four bays with hearths and two unheated bays west of the nearly centrally situated entrance. All these houses had, in the part opposite the dwelling area, a large area comprising 3-4 bays and an entrance near the gable, which most likely had been used as a byre and/or storage area. In my interpretation, these houses were divided into a $15 \mathrm{~m}$ long dwelling area and a $14 \mathrm{~m}$ long byre area. The bays measured $2.5-3 \mathrm{~m}$ in length. According to the analysis of the byre house (chapter 14) each such bay could accommodate six cattle and, on average, the type 8 houses could stall 18 cattle, compared to nine cattle in the Late Bronze Age and 13 in the larger Roman Iron Age type 3 houses. The size of the type 8 houses is on average $29 \times 6.7 \mathrm{~m}$, which is almost the same as the $31 \times 6.7 \mathrm{~m}$ size of the contemporaneous type 9 houses and - with my interpretation - they seem on average to accommodate the same number of cattle (17) that were found in type 9 houses in the Roman Iron Age as well as the Migration Period.

\section{A Roman Iron Age farm}

The workshop house 29, three four-post granaries (53, 63 and 70) and the type 8 longhouse 50 together constitute one of the best documented farmyards (tun) at Forsandmoen (Fig. 51). Houses 29 and 50 were located parallel to each other with the western gables located opposite each other, while the eastern gable in house 50 continued 13 m east of house 29 , making an inner and an outer farmyard. The inner farmyard measured $20 \times 4 \mathrm{~m}$ and, in that area, the three four-post granaries were positioned directly to the west of three entrances in the northern wall of house 29. House 29 also had access though the middle of the southern wall and, through the centrally located opposed entrances in the middle of the house, there was direct access to a southern entrance to the dwelling rooms in the central part of house 50. This must imply that access to this part was more sheltered, less public than the other areas of the farmyard. The many traces from erecting new posts in nearly the same postholes in house 50 and the double rows of wall posts show that this house existed for a long time. An assessment of the results from five radiocarbon dates (Fig. 51) indicates that house 50 must have been erected somewhere in the last part of the $1^{\text {st }}$ century AD and was still in use in the last part of the $3^{\text {rd }}$ century $\mathrm{AD}$, giving the house a lifespan of at least 200 years. The three oldest radiocarbon dates from house 29 - a house that does not show any traces of renewal of the construction - show that it was probably built at some point in the $2^{\text {nd }}$ century AD and was probably at least in use at least until the beginning of the $4^{\text {th }}$ century AD, after house 50 was abandoned. The centrally positioned hearth 41, dated to AD 420-600 indicates a still longer existence of the house.

The radiocarbon dates from the two houses show that the layout of the farm was probably not intentionally planned and established from the beginning of the farm. Instead, the layout represents a new development in the concept of the farm, where - in the case of house 50 and the type 7 house 150 (se chapter 8) - the workshop was added to the farmyard several decades (5-10) after the main house was built. In the last half of the early Roman Iron Age, six such workshop buildings were situated parallel to the larger longhouses of the types 7, 8 and 9, creating a farm concept that that 
was nearly absolute in the late Roman Iron Age and Migration Period at Forsandmoen.

\section{Conclusion}

Just as the type 7 houses, the type 8 houses represent an important change in how to create new physical and ideological conditions for a farming household; a change that took place around the beginning of our era. There are still a couple of examples of the main combined dwelling/byre house (type 3) used in the Bronze and Pre-Roman Iron Age in the early Roman Iron Age (4 houses) and the late Roman Iron Age (3 houses), but these are few compared to the type 7 and 8 houses $(7+7)$ and the large number of type 9 houses/ phases (23) dated to the Roman Iron Age. These new houses have a roofed area that is on average more than double the size as that of type 3 . In addition, most farms during this period also had a workshop attached to the main farm house, as is the case for houses 50 and 29. The change of house types around the beginning of our era therefore reflects a new farm concept in terms of how people organised daily life in the houses - including more rooms, probably larger households, a larger stock of animals and a more stratified society. 


\section{Type 9: Large dwelling/byre house with opposed recessed entrances at either end}

Two type 9 dwelling/byre houses were the first houses to be recognised when an area of 0.1 ha was stripped for the first time and the gravel surface cleaned. In the following years, as many as 44 such houses were uncovered (Fig. 52). Many analyses and thoughts concerning these houses and comparisons with house material from Norway and abroad have been launched in a number of published papers (Løken 1983, 1984a, 1984b, 1987b, 1991, 1992b, 1995, 1998a, 1999, 2001b).

According to the ${ }^{14} \mathrm{C}$ dates of nearly all of these houses, this type of house was built during a period spanning at least 800 years, from the last decades of the $1^{\text {st }}$ century $\mathrm{BC}$ until well into the $8^{\text {th }}$ century AD. Over such a long period of time, we would expect to see developments in the house type in terms of some of its features, and during the years of excavation it became clear that the type had to be divided into three subtypes. In addition, we found that the settlement also included another type of dwelling house (type 7, cf. chapter 8), as well as some houses with a specific layout (type 8 , cf. chapter 9). There were also a few instances of type 3 houses (chapter 5), with opposed entrances at the middle of the longitudinal walls from the Roman Iron Age. This mixture of dwelling houses from the Roman Iron Age and Migration Period necessitates a thorough analysis of the house material to establish a firm basis for interpreting the changes to and structure of the settlement over time. The main subtype has been described briefly in several papers (Løken 1983:85, 1987b:161, 1995, 1998a, 1999, 2001b).

\subsection{The features of type 9 houses}

Two opposed entrances that give access to the dwelling area are located within a trestle span at least $4 \mathrm{~m}$ wide, between trestles 1 and 2 from the west. Between trestles 2 and 3 from the west, with a span of at least $4.5 \mathrm{~m}$, 1-3 hearths are situated on the central axis. Further to the east, there are a minimum of two trestles that are $3 \pm 0.5 \mathrm{~m}$ apart. One or possibly two entrances either opposite to or giving access to two neighbouring trestle spans are located in or near the eastern end.
Altogether 44 houses satisfy this definition. Included in this number are ten houses that were altered so much during their existence (in terms of length, structure of the post-setting, location of entrances and orientation) that the altered version has been counted as a separate house (labelled A and B).

The basis for the division into subtypes is partly the house width. Types 9.1 and 9.3 are not wider than 7.2 $\mathrm{m}$, while type 9.2 has a width greater than or equal to $8 \mathrm{~m}$ at the centre of the house. Secondly, the subtype 9.3 is distinguished from 9.1 and 9.2 because an extra trestle is located west of the western entrance room. Within each subtype, the houses have been further divided into groups according to the number of roofbearing trestles, from five to eleven trestles into the types 9.1.1-9.1.7, from six to eleven trestles in the types 9.3.2-9.3.7 and from seven to eight trestles in the types 9.2.3 and 9.2.5. This has been implemented in order to explore if houses with the same number of trestles were constructed after a wanted and fixed size.

The type 9 houses consist of a lot of other features, but none of them are so frequent that they can contribute to the type definitions. In the following, the defining features will be analysed within each subtype and group. Then other features will be analysed, such as gable construction, long walls, entrances and interior doors, features in connection with the postholes (such as shape and size), contents, room division and extra hearths elsewhere in the house. The find-distribution is analysed in chapter $15 \mathrm{in}$ terms of the interpretation of activity areas in these houses.

\subsection{Orientation and length of the post-setting}

Table 37 and Table 38 (folder), and Fig. 53 show that the average orientation of the different subtypes varies between $290^{\circ}$ and $310^{\circ}$ and the total average value is nearly exactly E-W $\left(301^{\circ}\right)$. All these houses are situated on the central part of the plain, and the orientation has not been influenced by natural causes other than wind and sun exposure. Therefore, as much as $86 \%$ of the 


\section{Forsandmoen, Forsand municipality Map of settlement area}

House feature with preserved wall remains

House feature without wall remains

Gravemound / cairn

$\bigcirc \quad$ Excavated gravemound / cairn

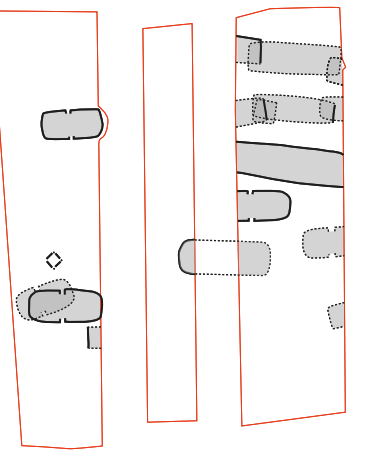

Area D byre house, type 9

Workshop, type 10

Houses from Roman Iron Age and

Migration Period
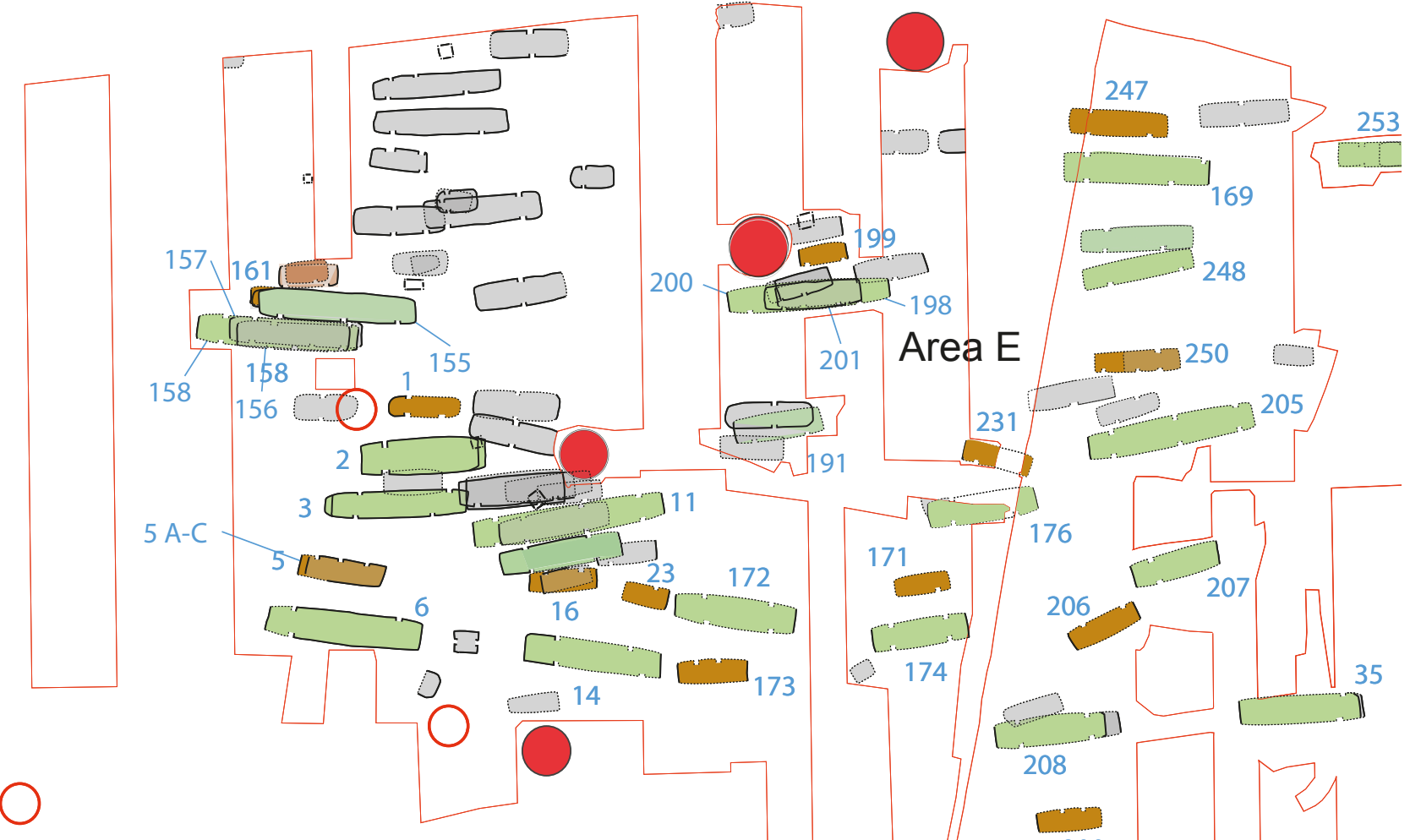

O
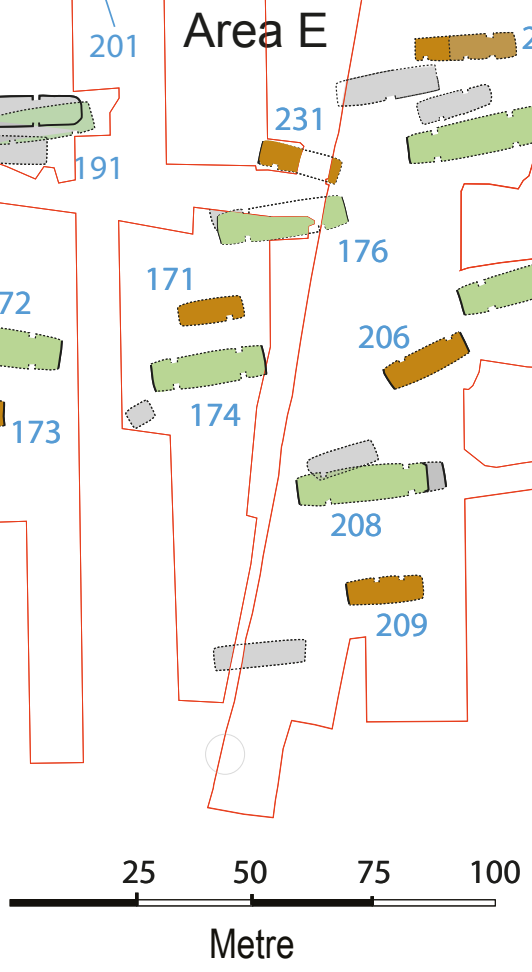
houses have an orientation within $\pm 10^{\circ}$ around $\mathrm{E}-\mathrm{W}$, probably in order to minimise the pressure from the prevailing eastern and westerly winds, due to the topography of Forsandmoen, and to achieve as much sun exposure as possible. Two houses clearly deviate from this pattern due to both adaptation and local conditions. House 144 , oriented nearly $\mathrm{N}-\mathrm{S}\left(378^{\circ}\right)$, is oriented along the western, steep side of the north-south oriented protruding rock Odda and thereby sheltered from westerly winds. House 182 , with a NE-SW orientation $\left(254^{\circ}\right)$, is situated on top of and parallel to a low gravel ridge. The house is also situated in the south-eastern corner of the plain, where due to the high and steep mountain Uburen to the south and south-west, most of the sun exposure in spring and autumn will only come from south-east during the first half of the day.

This highly uniform orientation differs distinctly from what is found in the hilly moor areas and in Ryfylke, where due to the topography, the houses have been oriented in all kinds of directions (Myhre 1980:fig. 117). On the lowlands of Jæren, $85 \%$ of houses are oriented more like at Forsand in NNW-ESE or NW-SE directions. These houses seem therefore to be oriented parallel to the prevailing wind directions (NW and SE) as the wind hits the gables (Myhre 1980:229). This also provides good sun conditions on the long side. In contrast, $75 \%$ of the houses at Ringdal in Vestfold are oriented NNE-SSW, i.e. rotated $100^{\circ}$ relative to Forsand, thereby minimising the sun exposure on the long sides (Gjerpe 2008:40f). The houses from the E6 project in Østfold (Bårdseth 2008:87, tab. 6.1) are from the Late Bronze Age and early Pre-Roman Iron Age and have

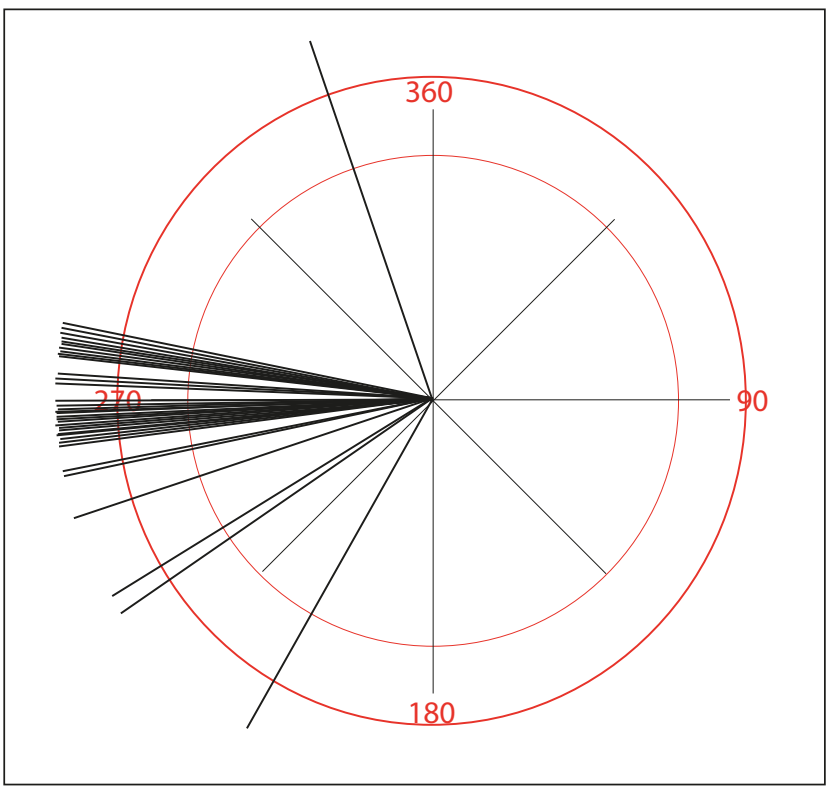

Fig. 53. Orientation for 44 type 9 houses. a predominantly $\mathrm{E}-\mathrm{W}$ orientation, while the orientation in the rest of the Iron Age is predominantly $\mathrm{N}-\mathrm{S}$. Probably, local factors such as the prevailing wind directions led to a $\mathrm{N}-\mathrm{S}$ preference for the orientation of the houses. This is highly unusual, compared with, for example the Iron Age houses from Fosie IV and a large number of houses from Scania, Zealand and Bornholm, that had the same tight distribution around E-W as in Forsand (Bjørhem \& Säfvestad 1993:figs. 162, 163). The houses in Jutland are also predominantly oriented approximately E-W, preferably with a centre of gravity slightly to WNW-ESE (Hansen 1987, Hvass 1979, 1980, Ravn 2009, Siemen 1985, 2000). We can ascertain that the houses at Forsand are oriented in the same manner as in the more southerly Scandinavian landscape, where the wind direction is predominantly E-W. The wind direction at Forsandmoen is the result of local conditions, where the shape of the surrounding mountains and valleys brings about winds from the east and west, despite the fact that the prevailing wind directions in Ryfylke are from the NW and SE.

Mostly the length increases according to the increasing number of trestles in the eastern part of the houses, as shown in Table 37 and Table 38 (folder). But the length is also dependent on increasing length in the two living sections in the western end and the addition of an eastern living section in some (twelve altogether) of type 9.1.3 and larger houses.

The mean subtype length of the roof-bearing construction varies from 15.5 to $38.4 \mathrm{~m}$. The same type of house can thus differ in size by as much as $250 \%$, indicating large differences in the household size from one farm to another. Table 38, folder, shows that the size of the western entrance room (trestle 1-2) increases from $3.9 \mathrm{~m}$ in type 9.1 .1 to $4.6 \mathrm{~m}$ in type 9.1 .3 , and then is fairly constant $(4.7-4.9 \mathrm{~m})$ in the remaining type 9.1 houses. Such a length is also found in type 9.2 houses. The same increase pattern occurs in the living section with the central hearth, where the types 9.1.1 and 9.1.2 have the smallest room (4.9-5.1 m), while the remaining types vary from 5.4 to $7.2 \mathrm{~m}$. The two types with the longest such room (9.2) are also the types that are defined because of a width as large as $8 \mathrm{~m}$ or more. The two smallest subtypes (9.1.1 and 9.1.2) are also narrower $(6.2 \mathrm{~m})$ than the other houses, which are at least $6.5 \mathrm{~m}$. Further to the east, Table 38 (folder) shows that the 3-4 nearest trestle spans measure on average $3 \pm 0.5 \mathrm{~m}$, and also that when the number of spans increase, they normally also measure on average approximately $3 \pm 0.5 \mathrm{~m}$.

A few houses (six) have a special post-setting pattern at the western gable. The feature is present in five 
different subtypes from six trestles (type 9.3.1) to eleven trestles (type 9.3.7). In addition to the described pattern, they have an extra pair of roof-bearing posts to the west of the entrance room, increasing the length of the western end by 2.1-2.6 m. However, this does not necessarily increase the house length, as type 9.3.1 has the same length as type 9.1.1, while the two longer types 9.3.2 and 9.3.3 are 2.1 and $3.9 \mathrm{~m}$ longer than types 9.1.2 and 9.1.3. The houses in type 9.3.6 are also $1.9 \mathrm{~m}$ longer than the type 9.1.6 house, while the type 9.3.7 house is as much as $11.2 \mathrm{~m}$ longer than the 9.1.7 house. This difference is caused by the unusual post-setting in the type 9.1.7 house, with short living section rooms in the western part and also small rooms in the eastern end, as opposed to a large room at both ends in the type 9.3.7 house.

The outermost bay in the eastern end of this house type is where the supposed cattle entrance in 16 of 44 houses is situated, either one (in twelve houses) or two (in four) opposed entrances (Table 39, subgroup 1 and Fig. 54:1). Only three of these houses exceed $30 \mathrm{~m}$ and $200 \mathrm{~m}^{2}$, while the remaining 13 houses vary between 18 and $27 \mathrm{~m}$ or between 106 and $175 \mathrm{~m}^{2}$. They constitute a small farmhouse, where 13 of the houses only have room for eight to 16 (mean 10.8) cattle in 1-4 bays west of the entrance, giving some storage capacity in the entrance and gable room. However, the three houses that are more than $30 \mathrm{~m}$ long could stall 22-24 cattle in $4-5$ bays, which indicates that these belong to the next group of farms.

Another eleven houses have an additional small room east of the eastern entrance(s), among which five houses have an additional entrance to that room. None of these eleven houses have had a hearth in this room, which indicates that they had a storage function (Table 39, subgroup 2 and Fig. 54:2). The extra rooms, including the gable room, measure $6 \mathrm{~m}$ in length and thus provided approximately $36 \mathrm{~m}^{2}$ of storage area for fodder, grain, etc. These houses $(33 \pm 3 \mathrm{~m})$ are an average of $5 \mathrm{~m}$ longer than the houses without an additional room, and the byre area had room for 10-24 cattle (mean 16).

Another five houses have a similar room in the east, but with a centrally situated hearth, indicating that this area was a room for human occupation (Table 39, subgroup 3 and Fig. 54:3). Two houses have an occupation zone consisting of two bays; one house has a direct entrance to the room, while two houses have an entrance adjacent to the bay with the hearth. This extra room has the same size as those mentioned above without a hearth. Four of these houses are similar in size (33-36 m), with room for 18-26 cattle (mean 20), while one is only $27 \mathrm{~m}$ long, with space for twelve stalls. On the whole, these houses are similarly constructed and similar in size to the above-mentioned eleven houses, but with an additional room with a hearth instead of a storage room. One could argue that the eleven houses had hearths that were not sufficiently deep to survive, but this is contradicted by the fact that only two of 44 houses lack the hearth in the western end. A loss of twelve hearths in 17 eastern gable rooms is therefore unlikely, and two types of activity must have taken place in the eastern end of these 17 houses.

Seven houses measure between 38 and $43 \mathrm{~m}$ in length (Table 39, subgroup 4, Fig. 54:4 and Table 40). All but one are built with eleven trestles and all have an equally sized human occupation area in each end of the house. Three of these houses (205, 11A and 158) have equally sized living sections with a storage room, a large entrance room and a large room with a hearth in each end of the house, as well as an entrance room in the middle of the house with either two or three having one small room to each side of the entrance. House 11A has stall boxes in the eastern three bays in the middle of the house, and another house (200, Table 39: subgroup 3) has stall boxes in the bay next to the western living room. These five central bays are therefore interpreted as a byre suitable for $24-27$ stall boxes. These houses have opposed entrances in the large eastern entrance room, indicating the same requirements in daily life here as in the western end. The four other equal sized houses have a somewhat different layout in the eastern end but still have what must be interpreted as a large occupation zone, comparable with the western dwelling area. In the middle, they also have one entrance giving access to $3-4$ additional bays that could house $18-22$ cattle.

It is tempting to interpret these seven houses as representing houses with two cooperative households, sharing a common central byre area, or in the two cases $(205,11 \mathrm{~A})$ with a separate two-span byre for each household. As the tables show, the dwelling areas in the western end measure 13-14 $\mathrm{m}$, which is an average of 1 $\mathrm{m}$ longer that the ones in the eastern end. The byre areas are for all practical purposes of similar size, measuring 13-15 $\mathrm{m}$ in length, and have space for maximum 18-24 stalled cattle. Even though these houses are the largest at Forsandmoen, this interpretation implies that each household had an area at its disposal (mean $135 \mathrm{~m}^{2}$ ) that is comparable to households in the two smallest house types (9.1.1 and 9.1.2: mean 124 and $142 \mathrm{~m}^{2}$ ).

Why was such a solution implemented? It may represent a close cooperation between two households, not 
Table 39. The type 9 houses organised after the type of additional room east of the byre entrance. Measurements in metres $(\mathrm{m})$. Estimated measurements in italics.

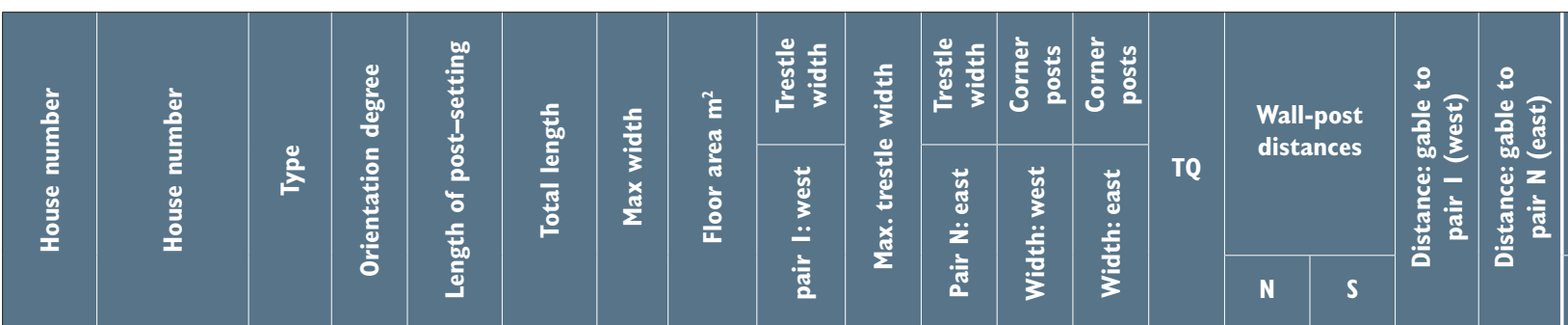

Distances between trestles

\begin{tabular}{|c|c|c|c|}
$0-1$ & $I-2$ & $2-3$ & $3-4$
\end{tabular}

\begin{tabular}{|c|c|c|c|c|c|c|c|c|c|c|c|c|c|c|c|c|c|c|c|c|c|}
\hline \multicolumn{22}{|c|}{ I: Houses without an additional eastern room } \\
\hline $132 \mathrm{~A}$ & CXXXIIA & 9.1 .1 & 312 & 14.4 & 18.2 & 6.0 & 106 & 2.3 & 3.0 & 2.6 & 3.6 & 4.0 & 2.0 & & & 1.3 & 2.5 & & 2.4 & 5.0 & 3.7 \\
\hline I32B & CXXXII B & 9.1 .1 & 312 & 16.6 & 21.8 & 6.0 & 126 & 2.5 & 3.0 & 2.6 & 4.1 & 4.0 & 2.0 & & & 2.7 & 2.5 & & 4.6 & 5.0 & 3.7 \\
\hline 182 & CLXXXII & 9.1 .1 & 254 & 15.0 & 21.5 & 6.3 & 129 & 2.4 & 2.8 & 2.4 & 3.9 & 4.5 & 2.3 & 0.66 & 0.65 & 2.8 & 3.6 & & 4.2 & 4.3 & 2.6 \\
\hline $180 \mathrm{~A}$ & CLXXXA & 9.1 .1 & 282 & 15.9 & 21.4 & 6.4 & 133 & 2.4 & 2.9 & 2.7 & 4.6 & - & - & & & 3.0 & 2.5 & & 4.3 & 4.8 & 2.8 \\
\hline $26 \mathrm{~B}$ & XXVI B & 9.3 .2 & 301 & 15.6 & 20.1 & 6.0 & 121 & 2.2 & 2.5 & 2.3 & 4.2 & & 2.2 & & & 2.0 & & 2.0 & 3.0 & 5.1 & 3.4 \\
\hline \multicolumn{2}{|l|}{ Mean } & & 292 & 15.5 & 20.6 & 6.1 & 123 & 2.4 & 2.8 & 2.5 & 4.1 & 4.2 & 2.1 & & & 2.4 & 2.8 & 2.0 & 3.7 & 4.8 & 3.2 \\
\hline 191 & $\mathrm{CXCl}$ & 9.1 .2 & 294 & 16.3 & 6.2 & 200 & 1.9 & 2.8 & 2.9 & 2.7 & 5.2 & & & & & 2.8 & & & 3.3 & 4.2 & 3.1 \\
\hline 174 & CLXXIV & 9.1 .2 & 292 & 18.3 & 23.6 & 6.1 & 139 & 2.0 & 2.6 & 2.0 & 4.0 & 4.2 & 2.3 & & & 2.5 & 2.8 & & 4.0 & 5.3 & 2.9 \\
\hline I44A & CXLIVA & 9.1 .2 & 378 & 18.8 & 23.7 & 6.0 & 142 & 2.2 & 2.6 & 2.6 & 3.9 & & 2.3 & 0.75 & 0.54 & 2.7 & & & 4.4 & 5.8 & 3.1 \\
\hline 176 & CLXXVI & 9.1 .2 & 292 & 20.1 & 26.3 & 6.3 & 144 & 2.6 & 3.0 & 2.4 & 4.4 & 4.2 & & & & 3.2 & 3.0 & & 4.7 & 5.2 & 3.9 \\
\hline 207 & CCVII & 9.1 .2 & 286 & 19.6 & 25.5 & 6.2 & 158 & 2.2 & 3.1 & 2.4 & 3.7 & 3.6 & & & & 3.2 & 2.7 & & 5.1 & 5.0 & 3.1 \\
\hline 156 & CLVI & 9.3 .2 & 308 & 20.5 & 27.3 & 6.4 & 175 & 2.3 & 2.9 & 2.8 & 5.4 & 4.6 & 2.2 & & & 4.1 & 2.7 & 2.3 & 4.3 & 4.7 & 3.0 \\
\hline 201 & $\mathrm{CCl}$ & 9.1 .3 & 298 & 18.6 & 23.4 & 6.4 & 145 & 2.4 & 2.8 & 2.4 & 4.0 & 4.0 & 2.3 & 0.63 & 0.57 & 2.9 & 2.0 & & 3.6 & 3.9 & 2.4 \\
\hline $208 B$ & CCVIII B & 9.1 .3 & 297 & 21.7 & 27.3 & 6.1 & 166 & 1.8 & 2.7 & 2.5 & 4.1 & 4.1 & 2.1 & & & 2.8 & 2.8 & & 5.0 & 5.9 & 2.0 \\
\hline \multicolumn{2}{|l|}{ Mean } & & 305 & 19.2 & 24.8 & 6.2 & 149.9 & 2.3 & 2.8 & 2.5 & 4.3 & 4.1 & 2.2 & 0.69 & 0.56 & 3.0 & 2.7 & 2.3 & 4.3 & 5.0 & 2.9 \\
\hline IIB & XI B & 9.1 .4 & 294 & 26.4 & 33.6 & 7.0 & 230 & 2.6 & 3.3 & 2.3 & & & 2.1 & & & 2.5 & 4.5 & & 5.3 & 5.6 & 2.1 \\
\hline $180 B$ & CLXXX B & 9.3 .4 & 283 & 26.9 & 30.8 & 6.5 & 200 & 2.3 & 3.1 & 2.3 & 4.0 & & 2.2 & 0.75 & 0.78 & 1.4 & & 2.2 & 4.2 & 6.0 & 2.7 \\
\hline 116 & CXVI & 9.1 .5 & 310 & 27.6 & 32.4 & 6.2 & 200 & 1.9 & 2.8 & 1.8 & 3.8 & & 2.6 & & & 2.4 & & & 5.0 & 5.6 & 3.1 \\
\hline \multicolumn{2}{|l|}{ Mean } & & 296 & 27.0 & 32.3 & 6.6 & 210 & 2.3 & 3.1 & 2.1 & 3.9 & & 2.3 & 0.75 & 0.78 & 2.1 & 4.5 & 2.2 & 4.8 & 5.0 & 2.6 \\
\hline \multicolumn{22}{|c|}{ 2: Houses with an additional eastern unheated room } \\
\hline $253 B$ & CCLIII B & 9.1 .4 & 295 & 20.9 & 26.4 & 6.5 & 172 & 2.1 & 3.0 & 2.0 & 4.1 & & 2.2 & & & 2.5 & 3.0 & & 5.1 & 3.5 & 2.5 \\
\hline 198 & CXCVIII & 9.1 .3 & 298 & 21.8 & 27.6 & 6.3 & 166 & 2.3 & 2.7 & 2.3 & 3.8 & 3.8 & 2.3 & & & 3.1 & 2.6 & & 4.4 & 5.7 & 2.6 \\
\hline 172 & CLXXII & 9.1 .3 & 310 & 24.2 & 29.4 & 7.0 & 200 & 2.6 & 3.2 & 2.0 & 4.3 & 4.1 & 2.2 & & & 3.1 & 2.1 & & 5.5 & 5.7 & 3.2 \\
\hline $253 \mathrm{~A}$ & CCLIII A & 9.1 .4 & 295 & 25.2 & 31.6 & 6.2 & 197 & 2.5 & 2.8 & 2.6 & 4.1 & & 2.2 & & & 3.2 & 3.2 & & 4.3 & 6.1 & 1.8 \\
\hline 249 & CCXLIX & 9.1 .4 & 286 & 23.9 & 30.5 & 6.4 & 193 & 2.3 & 3.0 & 2.1 & 3.2 & & 2.1 & & & 3.3 & & & 4.8 & 5.7 & 2.4 \\
\hline $208 \mathrm{~A}$ & CCVIII A & 9.1 .4 & 297 & 25.2 & 30.5 & 6.8 & 200 & 1.8 & 3.2 & 2.2 & 4.1 & 3.8 & 2.1 & & & 2.8 & 2.5 & & 5.0 & 5.9 & 2.0 \\
\hline 17 & XVII & 9.1 .3 & 293 & 24.1 & 29.5 & 6.6 & 186 & 2.6 & 2.8 & 2.3 & 4.2 & 4.2 & 2.4 & 0.74 & 0.74 & 2.9 & 2.6 & & 5.1 & 6.0 & 3.3 \\
\hline $106 \mathrm{~A}$ & CVIA & 9.1 .4 & 298 & 25.2 & 30.8 & 6.8 & 203 & 2.3 & 3.0 & 2.4 & 4.3 & 4.0 & 2.3 & & & 2.4 & 3.1 & & 2.7 & 5.6 & 4.3 \\
\hline 106B & CVI B & 9.1 .4 & 298 & 25.2 & 30.8 & 6.8 & 203 & 2.3 & 3.0 & 2.4 & 4.3 & 4.0 & 2.3 & & & 2.4 & 3.1 & & 4.7 & 5.7 & 2.9 \\
\hline I34A & CXXXIVA & 9.1 .3 & 298 & 25.5 & 30.5 & 6.0 & 183 & 2.4 & 2.6 & 3.0 & & & 2.3 & & & & & & 4.0 & 4.3 & 3.3 \\
\hline 157 & CLVII & 9.1 .5 & 306 & 27.5 & 32.5 & 6.6 & 210 & 2.6 & 3.0 & 2.6 & 4.7 & 4.5 & 2.2 & 0.85 & 0.60 & 2.8 & 2.2 & & 5.1 & 5.5 & 2.9 \\
\hline \multicolumn{2}{|l|}{ Mean } & & 298 & 24.4 & 30.0 & 6.5 & 192 & 2.3 & 2.9 & 2.4 & 4.1 & 4.1 & 2.2 & 0.80 & 0.67 & 2.9 & 2.7 & & 4.6 & 5.4 & 2.8 \\
\hline \multicolumn{22}{|c|}{ 3: Houses with an additional eastern heated room } \\
\hline 248 & CCXLVIII & 9.1 .3 & 303 & 20.9 & 26.6 & 6.2 & 165 & 2.4 & 2.9 & 2.4 & 4.3 & 4.4 & 2.1 & & & 2.9 & 2.7 & & 4.6 & 5.2 & 3.1 \\
\hline 3 & III & 9.1 .4 & 298 & 28.1 & 33.1 & 6.6 & 219 & 2.2 & 2.8 & 2.3 & 4.6 & 4.6 & 2.4 & & & 2.3 & 2.7 & & 5.6 & 6.1 & 2.8 \\
\hline 200 & CC & 9.1 .5 & 297 & 28.3 & 32.5 & 6.6 & 210 & 1.9 & 2.9 & 2.6 & 4.5 & 4.0 & 2.3 & & & 2.3 & 1.8 & & 4.2 & 5.3 & 3.6 \\
\hline 169 & CLXIX & 9.1 .6 & 303 & 30.3 & 35.7 & 6.8 & 243 & 2.6 & 3.5 & 2.4 & & 4.1 & 2.0 & & & & 2.6 & & 4.8 & 6.1 & 2.4 \\
\hline
\end{tabular}




\begin{tabular}{|c|c|c|c|c|c|c|c|c|c|c|c|c|c|c|c|c|c|c|c|c|c|}
\hline \multirow{2}{*}{ 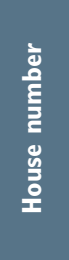 } & \multirow{2}{*}{ 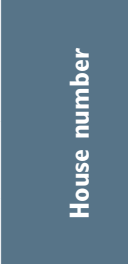 } & \multirow{2}{*}{ 艾 } & \multirow{2}{*}{ 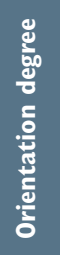 } & \multirow{2}{*}{ 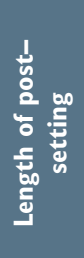 } & \multirow{2}{*}{ 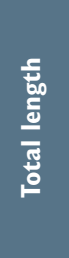 } & \multirow{2}{*}{$\begin{array}{l}\frac{5}{5} \\
\frac{\mathrm{g}}{3} \\
\frac{\mathrm{\sigma}}{2}\end{array}$} & \multirow{2}{*}{ 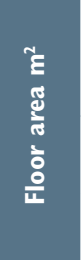 } & \multirow{2}{*}{ 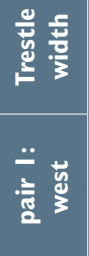 } & \multirow{2}{*}{ 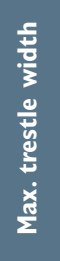 } & \multirow{2}{*}{ 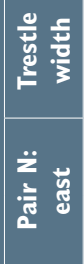 } & \multirow{2}{*}{ 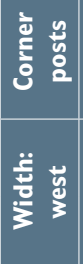 } & \multirow{2}{*}{ 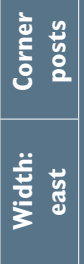 } & \multirow{2}{*}{ TQ } & \multicolumn{2}{|c|}{$\begin{array}{l}\text { Wall-post } \\
\text { distances }\end{array}$} & \multirow{2}{*}{ 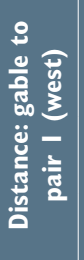 } & \multirow{2}{*}{ 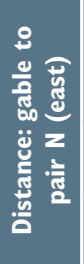 } & \multicolumn{4}{|c|}{$\begin{array}{l}\text { Distances between } \\
\text { trestles }\end{array}$} \\
\hline & & & & & & & & & & & & & & N & $S$ & & & I & $\mid-2$ & $2-3$ & $3-4$ \\
\hline $14 \mid$ & CXLI & 9.1 .7 & 309 & 29.8 & 35.0 & 6.8 & 238 & 2.5 & 3.1 & 2.5 & & & 2.8 & & & & & & 3.5 & 3.7 & 2.2 \\
\hline \multicolumn{2}{|c|}{ Mean } & & 302 & 27.5 & 32.6 & 6.6 & 215 & 2.3 & 3.0 & 2.4 & 4.5 & 4.3 & 2.3 & & & 2.5 & 2.5 & & 4.5 & 5.3 & 2.8 \\
\hline \multicolumn{22}{|c|}{ 4: Houses with an additional normal sized eastern dwelling area } \\
\hline 139 & CXXXIX & 9.3 .7 & 295 & 38.6 & 43.6 & 6.4 & 283 & 2.3 & 2.7 & 2.1 & & & 2.4 & & & & & 2.6 & 4.6 & 5.7 & 2.2 \\
\hline 155 & CLV & 9.3 .6 & 309 & 34.1 & 38.2 & 7.2 & 275 & 2.2 & 3.0 & 2.5 & 4.9 & 4.8 & 2.4 & 0.70 & 0.73 & 1.4 & 2.7 & 1.8 & 4.5 & 5.1 & 2.2 \\
\hline I44B & CXLIV B & 9.1 .6 & 378 & 32.5 & 37.9 & 7.4 & 281 & 2.2 & 2.6 & 1.8 & 3.9 & & 2.9 & & & 2.4 & & & 4.4 & 5.8 & 3.1 \\
\hline 158 & CLVIII & 9.3 .6 & 309 & 35.6 & 39.6 & 7.2 & 285 & 2.4 & 3.1 & 2.4 & 4.6 & & 2.3 & & & 2.0 & 2.0 & 2.3 & 4.2 & 5.4 & 2.9 \\
\hline 205 & $\mathrm{CCV}$ & 9.1 .6$. & 286 & 37.2 & 43.3 & 6.2 & 270 & 2.2 & 2.9 & 2.4 & 4.3 & & 2.1 & & & 3.1 & & & 5.0 & 5.9 & 2.9 \\
\hline 105 & $\mathrm{CV}$ & 9.1 .6 & 295 & 33.5 & 38.9 & 6.8 & 265 & 2.8 & 3.2 & 2.4 & & & 2.1 & & & & & & 4.6 & 6.3 & 2.9 \\
\hline IIA & $X I A$ & 9.1 .6 & 290 & 35.2 & 40.9 & 6.4 & 255 & 2.7 & 3.1 & 2.4 & 4.3 & 4.1 & 2.1 & & & 3.2 & 2.5 & & 5.6 & 5.4 & 2.8 \\
\hline \multicolumn{2}{|c|}{ Mean } & & 309 & 35.2 & 40.3 & 6.8 & 273.4 & 2.4 & 2.9 & 2.3 & 4.4 & 4.5 & 2.3 & 0.70 & 0.73 & 2.4 & 2.4 & 2.2 & 4.7 & 5.7 & 2.7 \\
\hline \multicolumn{22}{|c|}{ 5: Large and extra wide houses } \\
\hline $2 B$ & II B & 9.2 .3 & 298 & 22.7 & 28.9 & 9.0 & 240 & 2.2 & 2.7 & 2.1 & 4.6 & 4.8 & 3.3 & & & 3.1 & 3.1 & & 4.9 & 6.1 & 2.6 \\
\hline $6 \mathrm{~A}$ & VIA & 9.2 .5 & 308 & 31.6 & 37.8 & 7.9 & 299 & 2.3 & 2.4 & 2.0 & 4.5 & 4.0 & 3.3 & 3.45 & 3.4 & 3.1 & 3.1 & & 5.5 & 8.8 & 3.4 \\
\hline 14 & XIV & 9.2 .4 & 311 & 26.4 & 33.4 & 7.8 & 256 & 2.2 & 3.2 & 2.5 & 4.4 & 4.2 & 2.6 & & & 2.2 & 2.5 & 2.2 & 3.5 & 6.1 & 1.4 \\
\hline $2 \mathrm{~A}$ & II A & 9.2 .3 & 298 & 24.5 & 30.6 & 9.0 & 254 & 2.1 & 2.6 & 2.1 & 4.9 & 4.8 & 3.5 & & & 3.1 & 2.9 & & 4.9 & 6.1 & 3.7 \\
\hline $6 B$ & VI B & 9.2 .5 & 308 & 31.6 & 37.8 & 7.9 & 299 & 2.3 & 2.6 & 2.0 & 4.5 & 4.0 & 3.3 & 3.45 & 3.4 & 3.1 & 3.1 & & 5.1 & 6.7 & 2.4 \\
\hline \multicolumn{2}{|c|}{ Mean } & & 305 & 27.4 & 33.7 & 8.3 & 270 & 2.2 & 2.7 & 2.1 & 4.6 & 4.4 & 3.2 & 3.45 & 3.40 & 2.9 & 2.9 & & 4.8 & 6.8 & 2.7 \\
\hline
\end{tabular}

only when building the house, but primarily concerning tending cattle/sheep and possibly also crop production. The large house could give a much higher status than living in half-size houses. Such a house might have been the solution if two heirs should share a farmland too small to split in two halves.

When taking into consideration total length and roofed area, the material can be categorised into four main groups. Houses wider than $8 \mathrm{~m}$ and those with two equal households make up the largest group with $240-300 \mathrm{~m}^{2}$ of roofed area $(30-44 \mathrm{~m})$. The second group consists of houses with an additional small, heated room in the eastern end with $210-240 \mathrm{~m}^{2}$ (32-36 $\mathrm{m}$ in length) of roofed area. The third group has an unheated additional eastern end room, measuring $170-210 \mathrm{~m}^{2}$ (27-32 $\mathrm{m}$ in length). The fourth group lacks an additional eastern end room, measuring 100-170 $\mathrm{m}^{2}$ (18-27 $\mathrm{m}$ in length), although two such houses have $200 \mathrm{~m}^{2}$ of roofed area (Table 39, Fig. 54).

My conclusion is that the largest houses for one household are the five houses with a width of 8-9 $\mathrm{m}$, among which three measure around $250 \mathrm{~m}^{2}$ and the two others $300 \mathrm{~m}^{2}$ (Table 39, Fig. 54:5). They also distinguish themselves from all other houses by their special wall construction and are thought to belong to wealthy farmers and/or political leaders. The two phases of house 2 (type 9.2.3) have, based on the width (9 m), curved long walls and a lack of entrances for cattle in the eastern end, been interpreted as a hall (Løken 2001b).

Among the other type 9 houses, the ones with an extra heated eastern end room might represent households where some people have had a dwelling area separated from the main living room, giving them the opportunity to house more people (maybe tenants or serfs) than any other main farmhouse, representing an elite in the Forsand society compared to the remaining houses. Ramqvist (1983:157ff) has interpreted a similarly located room with a hearth at Gene (house I, II) as a kitchen area. Considering that the seven large houses with a dwelling area have sufficient space for a household in the eastern end and the fact that, at Forsand, all type 9 houses are connected to a parallel, smaller house with several hearths, which among other functions (smithy) must have served as a cooking room, it is more likely that these small, heated rooms were intended for human occupation. 


\begin{tabular}{|c|c|c|c|c|c|c|c|c|c|c|c|c|c|c|c|c|c|c|c|c|c|c|}
\hline & & & & & & & \multicolumn{4}{|c|}{ West } & \multicolumn{4}{|c|}{ East } & \multicolumn{3}{|c|}{$\begin{array}{l}\text { Length } \\
\text { interpretation }\end{array}$} & \multirow{3}{*}{ 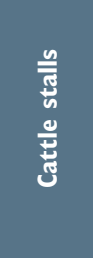 } & \multirow{3}{*}{ 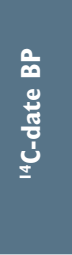 } & \multirow{3}{*}{$\frac{0}{0}$} & \multirow{3}{*}{ 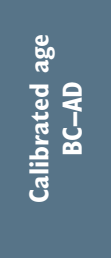 } & \multirow{3}{*}{ 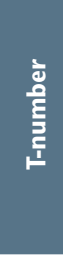 } \\
\hline & & & & & & & \multicolumn{2}{|c|}{$\begin{array}{l}\text { Door } \\
\text { width }\end{array}$} & \multicolumn{2}{|c|}{$\begin{array}{l}\text { Door } \\
\text { recess }\end{array}$} & \multicolumn{2}{|c|}{$\begin{array}{l}\text { Door } \\
\text { width }\end{array}$} & \multicolumn{2}{|c|}{$\begin{array}{l}\text { Door } \\
\text { recess }\end{array}$} & $\begin{array}{l}\text { Living } \\
\text { area }\end{array}$ & Byre & $\begin{array}{l}\text { Living } \\
\text { area }\end{array}$ & & & & & \\
\hline $4-5$ & $5-6$ & 6-7 & $7-8$ & 8-9 & $9-10$ & $10-11$ & $\mathbf{N}$ & $s$ & $\mathbf{N}$ & s & $\mathbf{N}$ & $s$ & $\mathbf{N}$ & $S$ & $\begin{array}{c}\text { West } \\
\mathbf{m}^{2}\end{array}$ & & $\begin{array}{c}\text { East } \\
\mathbf{m}^{2}\end{array}$ & & & & & \\
\hline 3.4 & 3.3 & 2.7 & 2.8 & 3.3 & 1.9 & 2.9 & & 1.3 & & & 1.4 & 1.4 & & & 12.20 & 15.40 & 7.50 & 24 & 1595 & 50 & $420-540$ & 8696 \\
\hline 3.1 & 3.3 & 3.0 & 3.0 & 2.9 & 2.0 & 2.9 & 1.3 & 1.3 & 0.5 & 0.6 & 1.3 & 1.3 & 0.5 & 0.5 & 13.20 & 13.20 & 6.20 & 20 & & & & \\
\hline 3.0 & 2.8 & 2.8 & 3.1 & 3.1 & 3.6 & 5.1 & 1.4 & 1.5 & & & 1.5 & 1.4 & & & 15.40 & 13.90 & 14.30 & 22 & 1910 & 70 & $20-220$ & 8690 \\
\hline 2.4 & 2.9 & 3.1 & 2.4 & 5.4 & 4.3 & & & 1.5 & & 0.7 & & 1.3 & & 0.6 & 12.80 & 13.00 & 12.40 & 18 & 1820 & 80 & $80-330$ & 8716 \\
\hline 2.6 & 2.9 & 3.0 & 3.9 & 3.6 & 3.2 & & 1.4 & 1.5 & 0.5 & 0.5 & I.I & 1.6 & & & 12.60 & 11.60 & 13.70 & 18 & 1770 & 70 & $130-380$ & 8699 \\
\hline 2.8 & 3.1 & 2.9 & 3.2 & 4.8 & 4.0 & & 1.4 & 1.3 & & 0.6 & 1.5 & 1.2 & & 0.8 & 13.90 & 14.90 & 10.80 & 24 & 1705 & 80 & $240-430$ & 8715 \\
\hline 3.2 & 4.0 & 3.3 & 3.2 & 4.8 & 4.9 & & I.I & 1.3 & & & 1.2 & 1.4 & & & 14.10 & 16.60 & 12.60 & 24 & 1600 & 35 & $420-540$ & 9504 \\
\hline 3.3 & 3.1 & 3.3 & 2.9 & 3.5 & 3.4 & & 1.4 & 1.5 & & & 1.2 & 1.5 & & & 13.70 & 12.60 & 12.60 & 18 & 1580 & 80 & $400-600$ & $824 I$ \\
\hline 3.1 & 2.6 & 3.2 & 2.7 & 5.0 & 5.0 & & 1.3 & 1.1 & 0.6 & 0.5 & 1.4 & 1.2 & 0.6 & & 14.10 & 14.30 & 12.50 & 27 & 1540 & 40 & $430-600$ & 5906 \\
\hline 2.9 & 3.1 & 3.1 & 3.1 & 4.3 & 4.1 & 5.1 & 1.3 & 1.4 & 0.6 & 0.6 & 1.3 & 1.4 & 0.6 & 0.7 & 13.80 & 13.80 & 12.70 & $21-22$ & & & & \\
\hline 3.1 & 2.9 & 3.1 & & & & & 1.4 & 1.7 & 1.4 & 1.2 & & & & & 14.10 & 14.80 & & 18 & 1770 & 80 & $130-390$ & 4801 \\
\hline 3.4 & 3.7 & 3.4 & 3.4 & & & & 1.3 & 1.6 & 0.8 & 1.3 & & & & & 17.40 & 20.40 & & 26 & 1640 & 60 & $260-540$ & 8551 \\
\hline 2.9 & 3.3 & 3.7 & 3.3 & & & & 1.4 & 1.2 & 1.0 & 1.2 & I.I & 1.3 & 1.0 & 0.9 & 17.70 & 9.90 & 5.80 & 16 & 1540 & 80 & $430-600$ & 5909 \\
\hline 3.2 & 3.6 & 3.1 & & & & & 1.4 & 1.7 & 1.4 & 1.2 & & & & & 14.10 & 16.50 & & 20 & 1440 & 50 & $560-660$ & 4800 \\
\hline 3.4 & 3.4 & 3.8 & 3.4 & 3.4 & & & 1.3 & 1.6 & 0.8 & 1.3 & & & & & 17.30 & 20.50 & & 26 & 1390 & 70 & $560-770$ & 5381 \\
\hline 3.2 & 3.4 & 3.4 & 3.4 & 3.4 & & & 1.4 & 1.6 & I.I & 1.2 & & & & & 16.10 & 16.40 & & $21-22$ & & & & \\
\hline
\end{tabular}

The house length and area in the two other groups form a continuous, increasing row, showing that the size was determined to the extent that the farmer included an extra eastern storage room, 1-2 extra bays for stall boxes, more or less space in the entrance room or the main living room, etc. However, in total, the main farmhouse for a household could differ by more than $100 \%$, from $100 \mathrm{~m}^{2}$ to $210 \mathrm{~m}^{2}$. There must therefore have been clear differences in wealth and social status, also visible when regarding the farmhouses.

\section{House width}

Most of the houses have no remains from the long walls. If one excludes the three very wide houses (2, 6 and 14), only eleven houses have traces that permit us to measure the house width. Eight had walls with densely set small posts, pointing to a wattle and daub wall. The other three houses had narrow ditches, and as described below, most probably with heavy boards as posts in either a bole wall or a wall with a vertical plank panelling. The width of these houses differs between 6.1 and $7.2 \mathrm{~m}$ (Table 37, folder). The measurements are evenly distributed, with $6.7 \mathrm{~m}$ as the mean width. The shortest houses (types 9.1 and 9.2) are also the narrowest, with a width of only $6.2 \mathrm{~m}$.

\section{Trestle width}

The maximum trestle width is situated at the middle of the houses (Table 37, folder, Table 39). In the different subtypes, the maximum trestle width varies between 2.7 and $3.1 \mathrm{~m}$, with a $2.9 \mathrm{~m}$ total mean value. The outmost trestles at each end are both $2.35 \mathrm{~m}$ in mean, clearly showing that the house type was built with a strictly symmetrical concept, where the two rows of posts should form a curved structure. The shortest subtypes (type 9.1-9.3) have the smallest trestle difference between the middle and the end of the houses $(0.4-0.5$ $\mathrm{m})$, while the longer ones have a difference of $0.6-0.9 \mathrm{~m}$. The explanation for this is probably that the houses were intended to have a certain curvature that was suitable when building the wall plate on top of the trestles and sufficient to strengthen the lengthwise construction.

The type 9.2.3 and 9.2.5 houses, which are 1-2 m broader than all other houses, have narrower trestles than many of the more narrow houses, indicating that a broad central aisle was not a necessary part of a house 
Table 40. The size of the different types of rooms $\left(\mathrm{m}^{2}\right)$ in the double dwelling type 9 houses, organised from west to east.

\begin{tabular}{|c|c|c|c|c|c|c|c|c|c|}
\hline House number & Storage $\mathbf{m}^{2}$ & Entrance $\mathrm{m}^{2}$ & $\begin{array}{c}\text { Hearth } \\
\text { room } \mathrm{m}^{2}\end{array}$ & Byre $\mathrm{m}^{2}$ & Entrance $\mathrm{m}^{2}$ & $\begin{array}{c}\text { Hearth } \\
\text { room } \mathrm{m}^{2}\end{array}$ & Byre $\mathrm{m}^{2}$ & ${\text { Entrance } \mathbf{m}^{2}}^{\text {Storage } \mathrm{m}^{2}}$ \\
\hline 205 & 3.1 & 5.0 & 5.9 & 6.1 & 4.0 & 6.5 & 4.8 & 4.9 & 3.0 \\
\hline IIA & 3.2 & 5.6 & 5.4 & 5.9 & 2.6 & 5.9 & 5.0 & 5.0 & 2.5 \\
\hline 48 & 4.3 & 4.2 & 5.4 & 8.8 & 2.9 & 3.2 & 4.8 & 4.0 & 2.0 \\
\hline I55 & 3.2 & 4.5 & 5.1 & 7.5 & 3.1 & 2.4 & 5.4 & 4.3 & 2.7 \\
\hline I44B & 2.4 & 4.4 & 5.8 & 5.7 & 2.9 & 3.0 & 3.9 & 3.5 & 6.2 \\
\hline I05 & 2.7 & 4.6 & 5.7 & 9.3 & 3.3 & & 6.9 & 2.9 & 2.7 \\
\hline I6I & 1.6 & 3.5 & 4.7 & 5.0 & 3.3 & 2.7 & 6.0 & 1.9 & 5.5 \\
\hline I39 & 5.1 & 4.6 & 5.7 & 10.8 & 3.1 & & 8.1 & 3.6 & 2.5 \\
\hline Mean & 2.9 & 4.6 & 5.5 & 7.4 & 3.2 & 4.0 & 5.6 & 3.8 & 3.4 \\
\hline
\end{tabular}

Fig 54. Plan of a selection of five type 9 houses, showing different types of room plans.
1: House without eastern rom

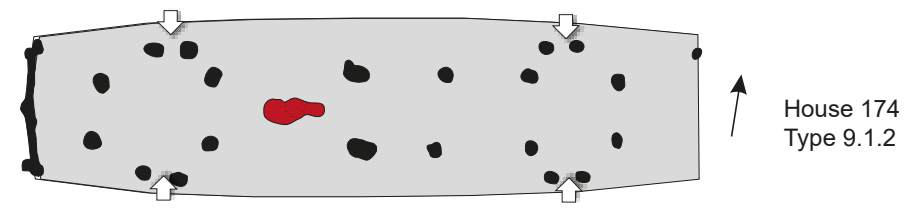

2: House with eastern unheated rom $\quad$ House 106B

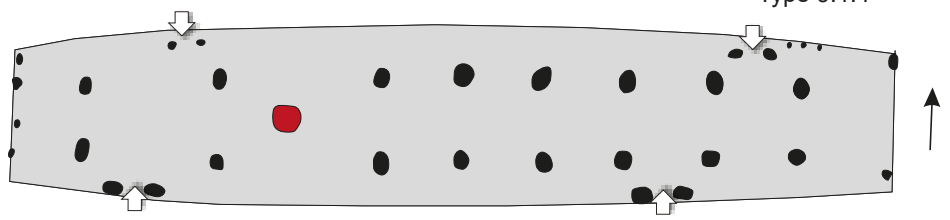

3: House with eastern heated rom

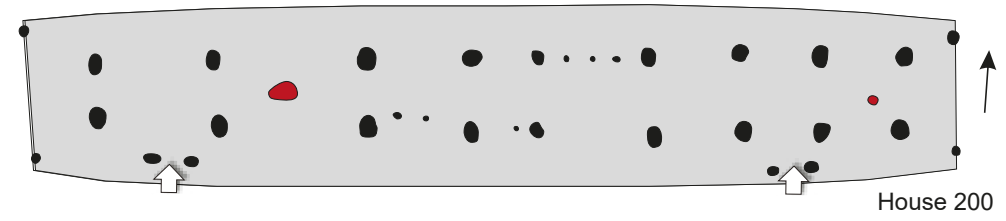

4: House with double dwelling

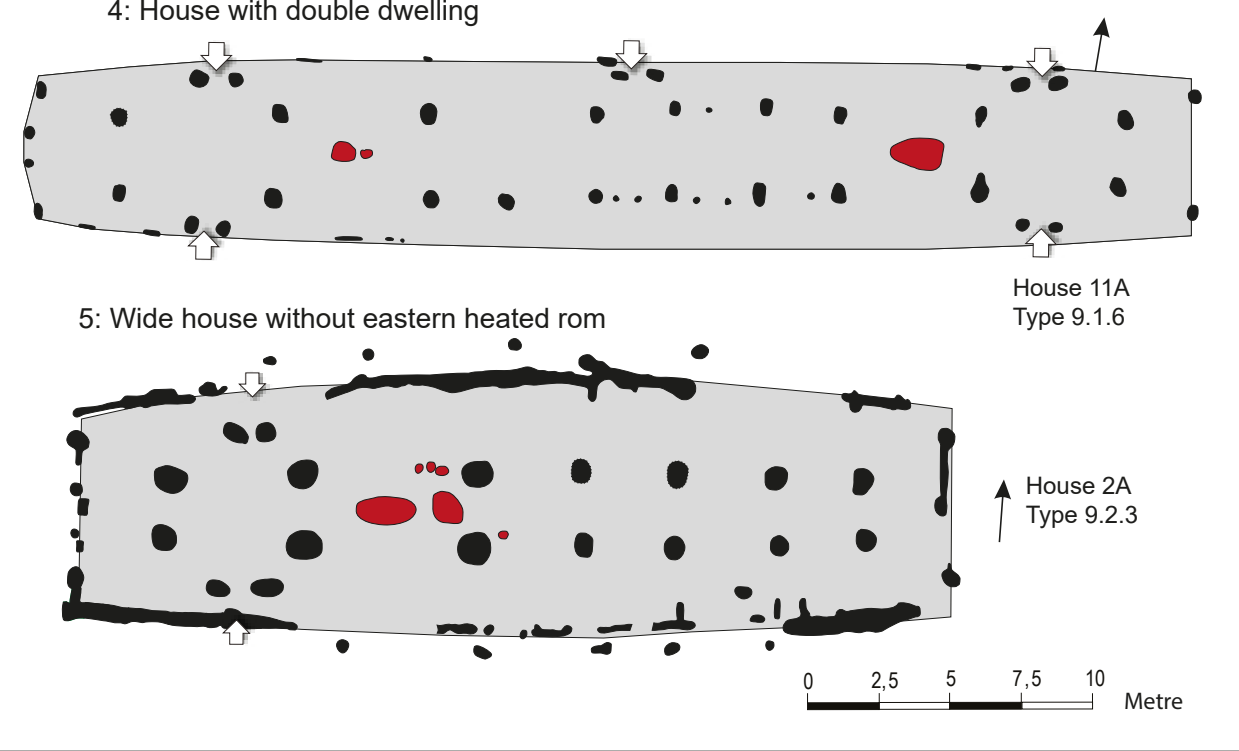


for the wealthier part of the society. On the contrary, it was rather important to have spacious side aisles, which would have been used in connection with different ceremonies taking place in those houses. The curvature of the roof-bearing structure in these houses is also less than expected $(0.5 \mathrm{~m})$, considering the length of the houses, and indicates more straight, longitudinal walls. This is the case for two of the houses $(6,14)$ while the last one (2) has the most curved long wall recorded at Forsand, with a $2 \mathrm{~m}$ difference in total width from the centre to the gables.

\section{House width and trestle coefficient}

Because of the modest trestle width of these three houses, combined with the large house width, houses 2 and 6 have the highest recorded TQ value (3.3), meaning that the aisle measures $30 \%$ of the total width (Table 37, folder, Table 39). Houses 2 and 6 , with a high TQ have the clearest traces of walls, indicating significant pressure on the long walls. The mean TQ for seven type 9.1 and 9.3 houses with documented traces of a long wall is 2.3 (between $2.1-2.4)$ or the aisle measures $44 \%$ (42-48 \%) of the total width. For all other type 9 houses, based on the estimated maximum width, the TQ is 2.27 and thus in accordance with the recorded houses. The roof was therefore normally built as a slightly underbalanced roof, with little weight on the walls. This is in accordance with a development towards relatively narrow trestles that was introduced in Swedish areas like Mälardalen (Göthberg et al. 1995:70, Herschend 1989, Ulväng 1992:26) and Scania (Artursson 2005b) from the early Roman Iron Age and was dominant in the late Roman Iron Age and the Migration Period. At Grøntoft (Rindel 1997:96f) in Jutland, there was a development from houses with a more or less balanced roof construction in Pre-Roman Iron Age I to mainly under-balanced constructions in the beginning of Pre-Roman Iron Age II. Also, the chieftain's house at Hodde (Hvass 1985) was constructed with a balanced roof. In the Roman Iron Age and Migration Period, the longhouses from Vorbasse and Hjemsted show that they had an under-balanced roof, normally between $40-48 \%$ or a TQ value between 2.1-2.4. Further south, at Flögeln, the measurements from 20 well-preserved longhouses of type 1d (Zimmermann 1992:70ff), which are very much organised as the large Vorbasse houses from the late Roman Iron Age and Migration Period, show, in contrast to the Nordic area, a mainly over-balanced roof construction as is also the case at Feddersen Wierde (Harnagel 1979).

\section{Construction of the gables}

Where gables are recorded, they consist first and foremost of two corner posts, but now and then combined with a post in the central axis and foundation trenches in between. Fig. 55 shows the different combinations of gable wall construction. Corner posts are recorded in 40 of the 44 type 9 houses, so one can conclude that such posts in the gable are a part of the house concept. There are 18 houses that have all four corner posts; in two houses, only one post has survived. Many of those houses with missing corner posts are either houses that are not totally unearthed or the house was situated in an area with many other houses, which has resulted in the destruction of smaller postholes.

According to Herschend (1989:93), corner posts are a typical northern Scandinavian phenomenon, which occurred in Sweden in the early Roman Period. According to Ulväng (1992:28), gables with corner posts are related to the introduction of the under-balanced houses and are found in Sweden in three different versions: with two corner posts; three posts, of which one is situated in the middle; and four posts, of which the two middle posts are an extension of the nearest trestle.

The corner posts are set with a $4.3 \mathrm{~m}$ total mean distance at both gables. The similar distance underlines the conclusion from the trestles adjacent to the gables that the type 9 houses should be symmetrical around the house centre. The mean values for the types 9.1.1-9.1.6 are, however, $4.2 \mathrm{~m}$ at both gables. All the houses 155-158, situated at the western fringe of the settlement, and the very wide house 2 are distinguished from the remaining material with a $4.5-4.9 \mathrm{~m}$ gable post distance.

The corner posts are located a mean distance of 2.65 $\mathrm{m}$ from the outmost trestles at each gable, measured at the crossing between the central axis and the line between the centre of the corner posts. The mean values of the different subtypes differ from 1.7 to $3.2 \mathrm{~m}$, but excluding two low values (1.7 and $2 \mathrm{~m}$ ) the others are within $2.8 \pm 0.4 \mathrm{~m}$. Only twelve of 80 measurements are outside these limits. This distance between the outmost trestle and the gable must therefore have been an integral part of the roof and gable wall construction.

Eleven houses have a gable post in the central axis, but only four of those have such a post in both gables. All houses with a central post also have corner posts, either in the same gable as the central post or, in some instances, the two types of gable construction are found in both gables.

Corner posts can be combined with a foundation ditch (six houses), and in five of these houses, also with 
a central post. Seven houses have two additional postholes located symmetrically to each side of the central axis, be it without any of the other gable features than the corner posts or in combination with a central post and also a gable ditch.

Type 9 houses had the corner posts as a necessary part of the gable construction, but apart from those, different combinations have been employed, which had consequences for how the roof and gable could be constructed.

Unfortunately, very few of type 9 houses have wellpreserved traces of the long walls. The attachment construction between the long wall and the gable corner posts is therefore uncertain. In three houses $(2,14$ and 17), the long walls seem to extend $0.5 \mathrm{~m}$ beyond the gable posts, indicating a gable wall wider than the gable post distance. But some other houses (especially 201, but also 158) indicate that the long wall bends towards the corner posts. In connection with this discussion, it is worth mentioning that such a curved wall is documented in four type 7 houses (Fig. 48), all bending towards corner posts. Another argument in favour of curved long walls towards the corner post is that the gable ditch never protrudes beyond the corner posts. As the documented gable walls - as well as the long walls - were constructed in different ways, it is also possible that different solutions were employed to connect the two walls.

The simplest type of gable wall remains is the sole central post. Such a post probably indicates that the house had a saddle roof, and the central post supported the central roof ridge. But it is not likely that only this post supported the gable construction. The remaining construction must either have been fixed to a sill beam or were not founded in postholes deep enough to survive from modern agriculture. The fact that, in some instances, only one corner post and the central post have survived, shows that it can be a matter of chance if one or both corner posts have survived. The default of a central post in one or both gables might also be the result of such accidental circumstance. Two houses have a foundation ditch between the corner posts, without any traces of a central post. In these instances, such a post was not dug down in the gravel, but it is possible that a post was attached to a sill beam placed in the ditch. As a conclusion, one cannot rule out two possible constructions: a gable wall where only the corner posts represent the strong part of the wall, indicating a hipped roof, and a wall with corner posts and a central post, more likely indicating a saddle roof.
Five houses have two postholes, symmetrically placed around the central axis in the western gable. They are set at a distance of 1-1.2 m, which is so close that they cannot have served as support for extended wall plate beams. They possibly represent an entrance in the gable and/or were part of the roof-bearing gable structure. Similar postholes are also found in connection with a gable foundation ditch, but the two functions are still possible. In one instance, the ditch and the two closely located posts are combined with a central post, ruling out the entrance interpretation. So, the posts between the corner posts must be interpreted as part of the gable wall construction. When the two symmetrical posts stand alone with the corner post, it is still possible to assume the gable wall as part of a hipped roof construction, but in connection with a central post, the house must have had a saddle roof.

\section{Long wall construction}

Only eight type 9 houses have long wall traces consisting of densely set $(0.6-0.9 \mathrm{~m})$ small, shallow postholes, while nearly all other houses lack remains from the long wall. Since the type 9 houses are broader than the type 3 houses, and consequently represent heavier roof pressure on the trestle posts and the long wall, one should expect that, if the long walls were normally built with densely set wall posts, they would be better preserved than those from the type 3 houses. The mean distances between the tiny wall posts in each type 9 houses are between 0.54 and $0.83 \mathrm{~m}$ (Table 37, folder, Table 39 and Fig. 56). This is in accordance with the figures from type 3 houses, and they must represent a continued way of building the long wall in a small part of the type 9 houses. Such walls are built in most of the subtypes, so this type of construction is not connected with, for instance, small houses for the smaller or less wealthy households.

Both type 3 and the few type 9 houses with dense wall posts have nearly balanced roofs, so the lack of wall traces is not caused by a smaller share of the roof weight on the walls. But compared to type 3 houses, the trestle posts in type 9 houses are bigger, with a rectangular shape and founded both deeper in the ground and supported by stone lining. The roof-bearing construction can therefore withstand sideways pressure better, and accordingly, there was less of a necessity to secure the long walls to the ground.

Another explanation for the missing wall-posts could be that, during the habitation period, the depth of the soil increased, so the wall posts were fixed adequately without the need to penetrate into the gravel surface. 


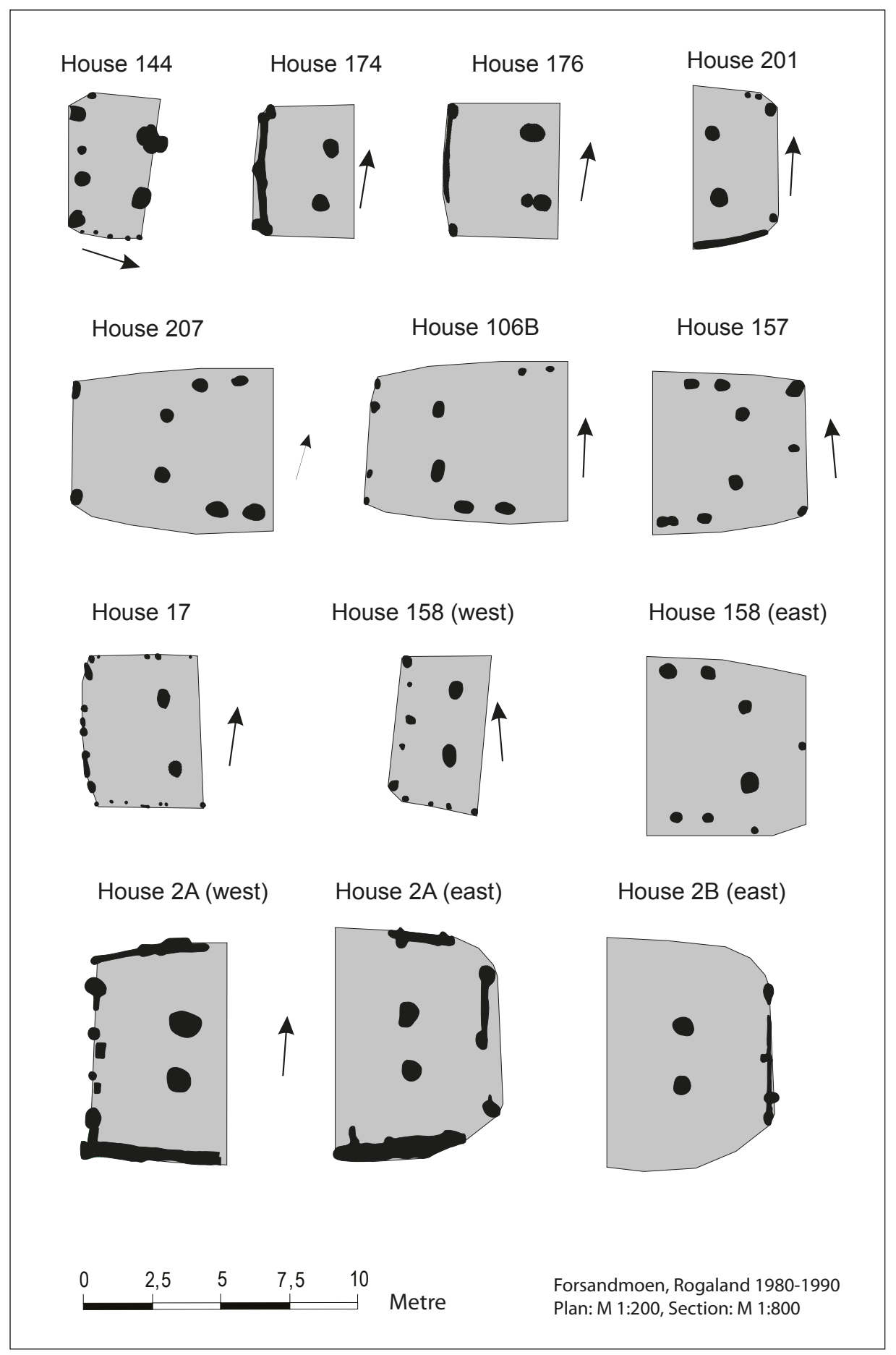

Fig. 55. Plan of different gable wall constructions in type 9 houses.

A test excavation underneath modern stone fences and other places that were undisturbed from modern agriculture showed that the soil from Roman Iron Age and Migration Period was $10 \mathrm{~cm}$ higher than during the initial settlement phases. It is therefore possible that such a wall did not make traces in the ground.

The most probable explanation for the lack of wall traces, however, is that the walls were constructed differently. During the excavations at Ullandhaug, near Stavanger (Myhre 1980), it was documented that a log was situated just inside the stone-built long walls and was held in position along the inner side by vertical slabs. Since the house had burnt down, it was also possible to document that the house had an inner wooden wall that fell onto the floor during the fire. Consequently, it is clear that the house had a wooden sill beam along the stone walls, to which the wooden wall was attached. According to wall remains from a boat house at Stend in Hordaland (Myhre 1976:41), dated to the Migration Period, the wall could have been constructed by planks joined together by cutting away half of the wood along each side of the planks. 
Fig. 56. Different long wall constructions in type 9 houses.

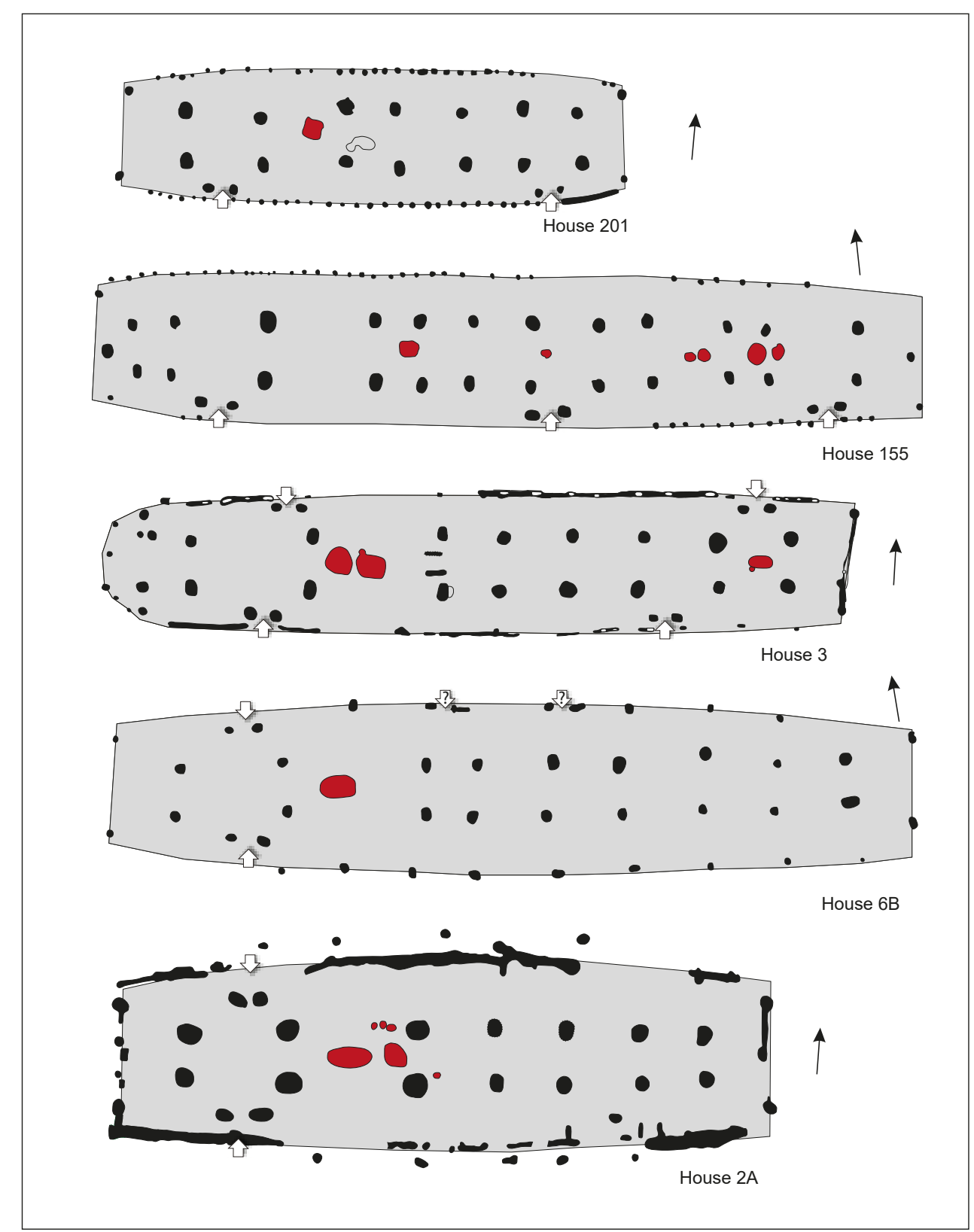

Based on this documentation, it is likely that most type 9 houses at Forsand had walls constructed with a sill beam placed on the ground (or partly dug down to prevent water, air and small animals from getting in) to which the wooden vertical plank wall was attached. The advantages of such a construction would have been that, if they were using an oak sill beam, the decay process would have been slow, the sill beam could be replaced without tearing down the wall and the wall planks were protected against the wet conditions in the soil. The life expectancy would be much longer for such a wall (and the house) than for a house with a wattle and daub wall.

Three type 9 houses use different wall constructions and demonstrate that the society had other wall constructions at its disposal than the ones preferred (Fig. 56). The long walls in house 2 are marked by a broad and slightly curved ditch, dug down 5-10 cm into the gravel. The bottom of the ditch was even, with no traces of upright posts. The ditch has therefore been interpreted as a foundation for partly dug-down sill beams like those documented at Ullandhaug. The ditch marks out a $9 \mathrm{~m}$ house width, which is $2-3 \mathrm{~m}$ wider than the majority of type 9 houses. The ditch runs $1.2-1.4 \mathrm{~m}$ outside the western entrances. This is twice as much as the norm and could indicate that the ditch instead was made by water dripping from the eaves. Since such a ditch has not been documented in connection with any other house at the plain, this interpretation seems unlikely. The roof-bearing 
postholes, entrance postholes and corner postholes in house 2 are all much larger and deeper than in all other houses $(0.76 \times 0.93 \mathrm{~m}$ as opposed to $0.52 \times 0.68 \mathrm{~m}$ at the surface), which points to a more powerful house construction due to the larger house width. The fact that the only house with similarly large postholes at the western end is house 6, with large wall postholes defining a $7.9 \mathrm{~m}$ house width (see below), also points to a very broad house width in house 2 . The $4-5$ postholes outside both long walls in house 2 , found at a 0.8-1.2 $\mathrm{m}$ distance from the centre of the ditch might signal a need for external wall support at some time in the lifetime of the house. Such a distance for inclined supports fits well, considering the distance and a probable 2-2.5 m high wall, while a 1.5-2 m distance to an assumed wall at the inside of the ditch will result in a too large an inclination to functionally disperse the roof weight.

Another house with a special long wall construction is house 6 . The wall has been constructed with large wall posts located so the wall postholes, together with the trestle postholes, make a series of transverse sections, with a mean distance of $3.4 \mathrm{~m}$, differing between 2.9 and $3.9 \mathrm{~m}$. This point to sections constructed with a tie beam to make closed triangles, giving the house transverse stability. The large wall posts and the distance between them can only be interpreted as remains from a bole wall.

House 14 also has remains from a similar northern wall course, with posts set at $3.5 \mathrm{~m}$ distance, indicating a $7.8 \mathrm{~m}$ house width. These three houses, the broadest and with the largest roofed area at Forsandmoen, are distinguished from all other houses by an exclusive wall construction, pointing to these houses as belonging to farms with special functions in the village.

Just south of house 2 is another house with a special wall construction. House 3 has narrow wall ditches, and in the ditches, there were elongated rectangu- lar postholes $(0.2 \times 0.1 \mathrm{~m}$ to $0.4 \times 0.2 \mathrm{~m})$ at irregular intervals $(1.2-1.9 \mathrm{~m}$, mean $1.6 \mathrm{~m})$ at the best-preserved part of the wall. In another part at the western end, the distance between the postholes was only $1 \mathrm{~m}$. It seems likely that the wall was constructed with broad, heavy boards as the wall frame, founded in the ditch. Between the board posts, there must either have been a bole wall or vertical planking. Due to the ditch and the lack of clay in the house, a wattle and daub wall is not likely. Two other houses have smaller parts of ditches that are interpreted as remains of similar walls.

Several panel boards from a wooden wall were found in a well in Jutland, dated to the Roman Iron Age. The planks had a slightly triangular section and a groove running down the thickest part of the plank, where the thinnest side of the neighbouring plank could be attached (Bonde 1991). The wall planks were decomposed at the lower end, indicating that the wall had been dug down in the soil, resembling the traces from house 3 .

\section{Entrances and interior doors}

As Table 38, folder, shows, the mean entrance width, measured between the centres of the postholes, is 1.4 $\mathrm{m}$ at the $\mathrm{SW}$ entrance and slightly smaller $(1.3 \mathrm{~m})$ at the three other entrances in this type of house. Looking at the subtypes 9.1.1-9.1.6 with at least three houses in the subtype, the width differs between 1.2 and $1.4 \mathrm{~m}$ in the western part, while in the eastern part, the width differs somewhat more, 1.1-1.5 m. All entrances measure between 1 and $1.5 \mathrm{~m}$. The only exceptions are the SW entrances in the two widest houses (2 and 6), which measure 1.6-1.7 $\mathrm{m}$. The NW entrances in these houses are clearly narrower, with a normal $1.3-1.4 \mathrm{~m}$ width. In these two houses, the SW entrance seems to be singled out as the most important entrance in the house, giving access from the sunny southern side to the hall in the two most prestigious houses on the plain.

Table 43. Mean values for different size measures related to hearths, cooking pits and ember pits related to an early and late phase of Roman Iron Age / Migration Period. Measurements in metres (m).

\begin{tabular}{|l|c|c|c|c|c|c|c|c|c|c|}
\hline & \multicolumn{9}{|c|}{ West } & \multicolumn{1}{c|}{ East } \\
\cline { 2 - 13 } & No & Length & Width & Area & Depth & No & Length & Width & Area & Depth \\
\hline Hearth, early phase & 8 & 0.91 & 0.68 & 0.62 & 0.12 & 10 & 0.71 & 0.53 & 0.40 & 0.06 \\
\hline Hearth, late phase & 8 & 1.02 & 0.71 & 0.72 & 0.15 & 1 & 0.70 & 0.60 & 0.42 & 0.10 \\
\hline Cooking pit, early phase & 16 & 1.00 & 0.87 & 0.87 & 0.22 & 5 & 1.10 & 0.77 & 0.85 & 0.22 \\
\hline Cooking pit, late phase & 15 & 1.38 & 0.84 & 1.16 & 0.20 & 3 & 1.43 & 0.98 & 1.40 & 0.17 \\
\hline Ember pit, early phase & 1 & 0.30 & 0.30 & 0.09 & 0.17 & 0 & & & & 0.0 \\
\hline Ember pit, late phase & 12 & 0.32 & 0.32 & 0.10 & 0.12 & 1 & 0.20 & 0.20 & 0.04 & 0.07 \\
\hline
\end{tabular}


The even sizes of the entrances in type 9 houses show that the width of the door, given $0.4 \times 0.2 \mathrm{~m}$ rectangular entrance posts, must have been $0.8-1 \mathrm{~m}$, which is still normal.

In 13 houses, it has been possible to measure 20 occurrences of a western entrance recess, among which five measurements were made in connection with the wide houses 2, 6 and 14. The entrances in those houses were deeply recessed ( $1 \mathrm{~m}$ in mean), while the entrances in the narrower houses were recessed 0.55 $\mathrm{m}$ in mean from the wall outline. The distribution was $0.5-0.7 \mathrm{~m}$ recess. The seven eastern entrances had the same distribution and a $0.6 \mathrm{~m}$ mean recess. It seems to be a tendency that the wider the house, the deeper the recess. This might be the explanation for the deep recess in the widest houses, and not that the wall was situated $0.4-0.5 \mathrm{~m}$ inside the ditch or postholes that are interpreted as the wall remains.

From this analysis, one can estimate the house width at the entrances in all type 9 houses without traces of the walls to be the distance between the opposed doors plus 1-1.2 m, and be confident that the calculated floor area is in reasonable accordance with the original size.

In seven houses, there are remains from ten interior partitions and/or doors, and they quite certainly represent dividing walls (Fig. 57). Two sets of two small postholes are found between the western entrance postholes in the western end of houses 14 and 205. This indicates that it was necessary to partition off a possible storage room in the far west end of the house from the more public western entrance room. Two houses (11B, 132) had a partition wall between the western entrance room and the main dwelling room. House 11B had a $1.1 \mathrm{~m}$ wide entrance passage marked by postholes, giving normal access from the entrance room to the adjacent room. In house 132, there are two $1 \mathrm{~m}$ long ditches set $2 \mathrm{~m}$ apart, a construction that so far is not understood, which indicate an entrance leading to the dwelling room. Also in houses 3 and 17, there seem to be two similar constructions, with a gap between the longitudinal ditches of a normal $1.1 \mathrm{~m}$ size, situated with their eastern end in line between the posts, apparently leading from the dwelling room to the east, where the byre probably was located. The ditches were first interpreted as a structure in connection with a door. However, based on a discussion of the placement of the seat of honour in the longhouse at Borg (Hershend \& Mikkelsen 2003), a hypothesis is drawn instead that this is a trace of the placement of the seat of honour. The last probable interior door in house 169 was located in the middle of the first bay to the east of the heated dwelling room, probably also partitioning the byre from the dwelling area. The interior walls/doors seem to have had two functions: to make a safe storage area and to create a private dwelling room, sheltered from the public entrance room and the economic area, the byre.

\section{The hearths and cooking pits}

In connection with investigations of ruins of dwellings or houses uncovered by mechanical topsoil stripping, dug-out pits with charcoal and possibly fire-cracked stone are usually referred to as hearths. Corresponding pits found outside of the context of a house, if they are at settlement sites with or without houses, are characterised as cooking pits. This analysis uses the word hearth without any additional clarification (e.g. for heat/light) as a general term for pits where burning of organic, botanical material - preferably wood - is encountered. Based on the hearths at Ullandhaug, Myhre (1980:190ff) proposed four different types according to the degree of charcoal and fire-cracked stone:

1 : only charcoal / soil mixed with charcoal

2: scattered fire-cracked stones and charcoal

3: layer of fire-cracked stones over a charcoal layer

4: fire-cracked stones almost without charcoal

A report from a seminar on cooking pits (Gustafson 2005b) provides solid documentation that pits with similar content are characterised as cooking pits. The term used for such pits therefore seems to be context dependent. However, the broad variation in content, but also the variation in form (such as level and profile) may indicate that there were functional differences. Inside a house, one would need light for much of the year. In addition, other forms of cooking, such as flour-based foods, for example porridge and bread, required a different type of heat than a cooking pit using hot stones.

Of the 44 type 9 houses analysed here, only one house lacks a hearth in the western end. However, five of the houses that have been rebuilt so much that they have been counted as two different houses had the same hearths in both phases. This analysis of hearths therefore encompasses 38 different houses with a hearth or hearths (Table 41, folder). These houses have a total of 83 different structures where wood was burnt and, as a result of their location relative to the position of the postholes and the house axis, are interpreted as hearths belonging to the individual house. There were 61 such structures detected in the western part of the 38 houses, while 22 were found at the eastern end of ten houses. With one exception, there hearths are found between trestles two and three from the west, meaning 


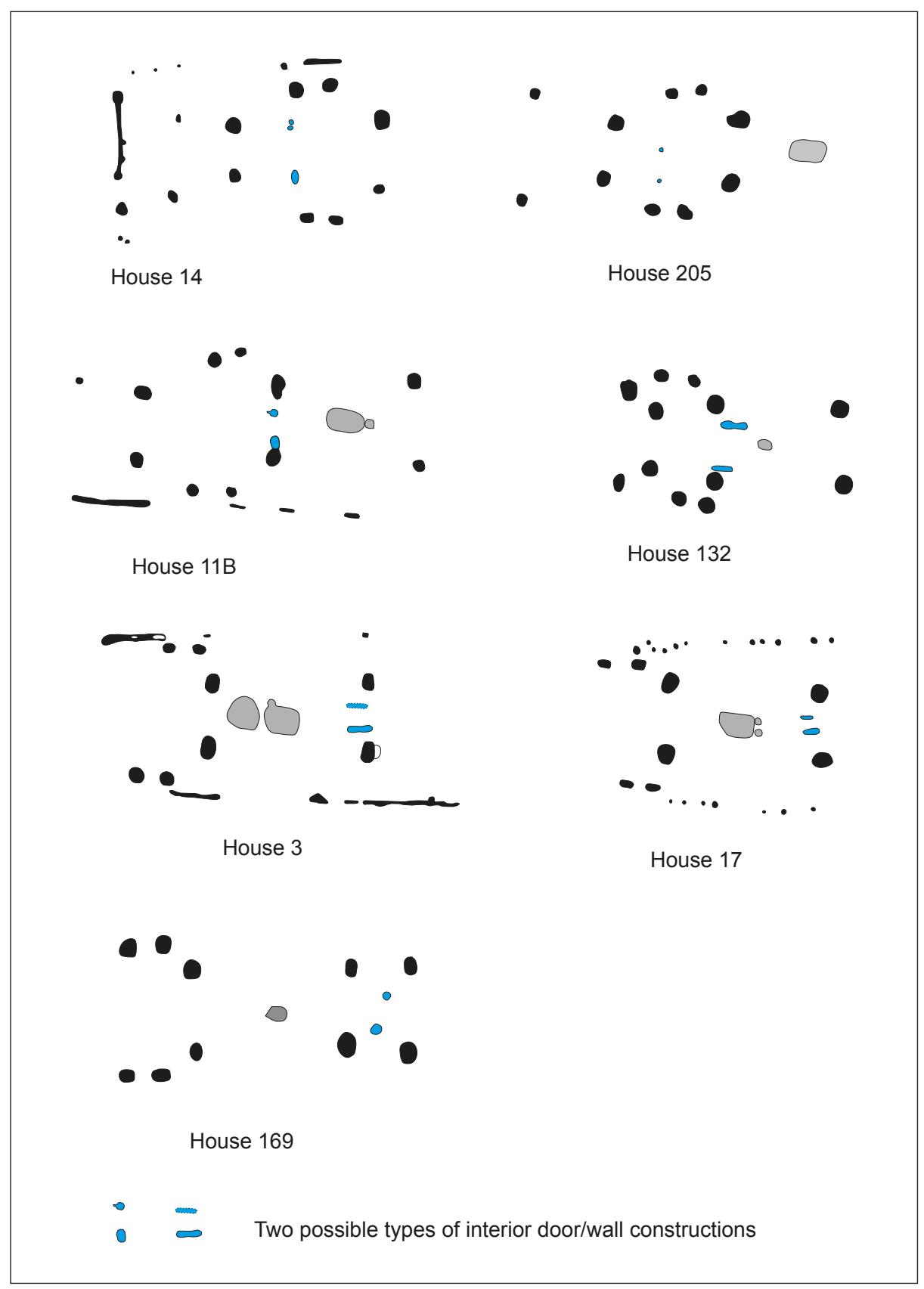

Fig. 57. Plan of a section of seven type 9 houses with remains from interior door or wall.

that at least one hearth in the western, longest room must be said to define the house type. The location of hearths in the eastern end is somewhat more varied but is mainly linked to a long room between two trestles or to a small gable room east of an eastern entrance.

There are 43 hearths that are dated or found in houses that have been dated to the $1^{\text {st }}-3^{\text {rd }}$ century AD, while 40 are from the $4^{\text {th }}-6^{\text {th }}$ century AD. A diachronic analysis of the hearths is thus possible. It turns out that a total of 16 of 22 hearths (72\%) in the eastern end belong to the oldest phase, while the time distribution is almost equivalent in the western end, with 27 out of 61 hearths (45\%) in the oldest phase. Table 41, folder, sorted by the periods $1^{\text {st }}-3^{\text {rd }}$ and $4^{\text {th }}-6^{\text {th }}$ century, shows that, in the oldest phase, most houses had double housing units, houses without extra rooms at the eastern end and houses less than $30 \mathrm{~m}$ with an extra room. In the later phase, there are wide houses without an additional hearth in the eastern part, and most houses longer than $30 \mathrm{~m}$ did not have hearths in the eastern part, in addition to some in the other groups. We thus get a picture of short houses for one household or longhouses for two households in the earliest phase, while in the later phase, a dominant feature of houses for one household of the elite was that they were wide and long. This explains the observed skew distribution of the number of hearths at the eastern end between the early and the later phase. 
The hearths have been categorised into seven horizontal shapes. Fig. 58 shows that only four of these are well represented. The figure shows that, as a whole, the shapes circular and circular/oval, oval and rounded rectangular each comprise about $30 \%$ of the hearths and with irregular shapes comprising $10 \%$, and there are no major differences between the early and the later phase. However, one can see that there are a significantly higher number of oval hearths in relation to rounded rectangular hearths in the earliest phase and that this changes to a more balanced representation in the latest phase. By contrast, there is an equal number of round and round-oval hearths in the oldest phase, while the round-oval shape is hardly found in the latest phase.

The vertical shape (Fig. 59) is divided into five shapes, of which the bowl-shape is most common. Then comes the deep bowl and the plain bowl $(<5 \mathrm{~cm})$, while troughshaped and pointed profiles are rare. Seven of the 83 have not been investigated. Most plain hearths are from the oldest phase, while the shallow bowl-shaped hearths are mostly found in the youngest phase. The other two shapes are relatively equally distributed between the phases.

There are 14 hearths that are interpreted as ember pits, of which 13 were in large rooms with hearths in the western part of the house and only one in the eastern part. Ten of these hearths are round (diameter $0.3 \mathrm{~m})$ with a basic bowl shape $(0.11 \mathrm{~m})$ and filled with charcoal, of which some of the pieces were quite large. The pits did not have a top layer of soil with a charcoal mixture, which indicates that, during use, the top part of the pit by the floor layer was filled with pure charcoal. The others are oval $(0.4 \times 0.3 \mathrm{~m})$ and deeper $(0.15$ $\mathrm{m})$. In most cases, little is preserved of the depth, but we must consider that the surface of the dwelling area must have been at least $0.15-0.2 \mathrm{~m}$ higher. Most are close to larger oval or rounded rectangular hearths and must therefore be interpreted as an integral part of the house fires. The lack of an ember pit in the eastern part, where there had been a hearth in a large main room, may indicate that these rooms were not as much used for residential spaces as those in the western end.

If we look at how the horizontal shape is combined with the vertical shape, we can observe that in both phases, round and round-oval hearths are combined with a shallow bowl shape or they are flat. Since twothirds of these only consist of charcoal, it indicates that these hearths were used in a different way and for purposes other than the oval and rounded rectangular hearths, which mainly contain thicker charcoal layers

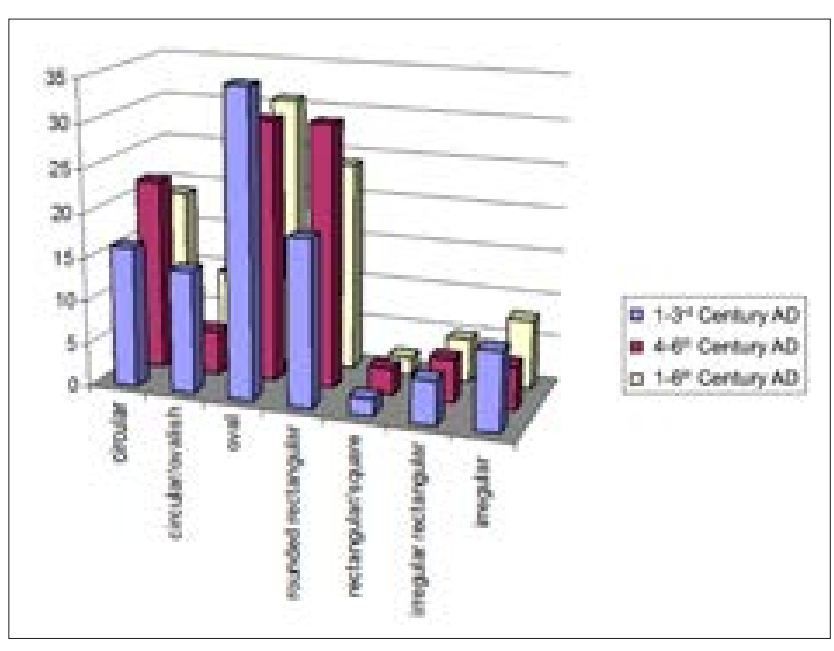

Fig. 58. The horizontal shape of hearths in type 9 houses, dispersed between an early and late phase of the Roman Iron Age and Migration Period, and the total distribution in the $\left.\right|^{\text {st }}-6^{\text {th }}$ century. Number in percentage in each time period.

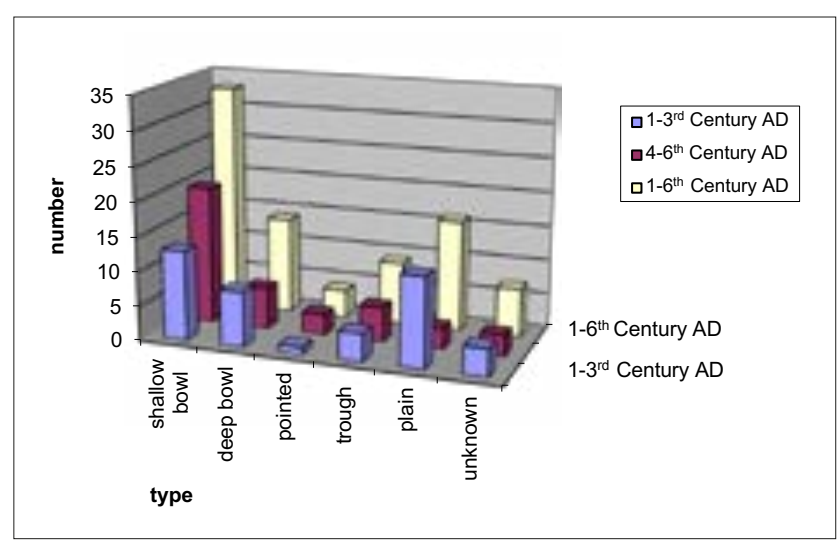

Fig. 59. The vertical shape of hearths in type 9 houses dispersed between an early and late phase of the Roman Iron Age / Migration Period and the total distribution in the $\mathrm{It}^{\text {st }}-6^{\text {th }}$ century. Number in percentage in each time period.

sometimes mixed with fire-cracked stone, layers of fire-cracked stones over a charcoal layer or are filled with stones without much coal.

If one examines the oval and rounded rectangular hearths in the oldest phase they are, with the exception of the pointed shape, distributed relatively evenly between the different profile shapes, and the flat shape is most frequently found. In the later phase, this form is almost non-existent, while half of the hearths have a shallow bowl shape and the rest have either a deep bowl shape or are trough-shaped. Thus, we see a change from an even distribution between the shapes to favouring either bowl-shaped or trough-shaped hearths. The large proportion of flat-bottom hearths in the oldest phase, which were replaced by a dominant proportion of shallow bowl-shaped hearths and a larger proportion of pointed and trough-shaped hearths, suggest that hearths in general were dug somewhat deeper 
in the youngest phase. The dominance of ember pits in the youngest phase also indicates this. An alternative interpretation may be that ember pits as part of a household's fire use are first used to a greater extent in the latest period, with the resulting effect on the statistics. This seems to be confirmed when looking at what kinds of layers are registered in a lower and an upper layer. It turns out that, in the latest phase, $70 \%$ of the hearths have a solid layer of coal, usually with no upper layer, compared with $50 \%$ in the oldest phase. In this phase, there are almost three times as many hearths that have fire-cracked stones mixed with the charcoal layer at the bottom compared to the later phase. However, taking into account the ten ember pits in the latest phase, the distribution of different layers would be approximately equal, to the extent that a change in the use of the hearths cannot be assumed. Half of the hearths in both phases have no upper layer. The remaining hearths have a layer consisting of soil and scattered charcoal, and two-thirds are also interspersed with scattered fire-cracked stones. All in all, this suggests that the most important change was that the hearths were dug somewhat deeper in the youngest phase.

Four hearths have been interpreted as cooking pits in the classic sense: consisting of a deep bowl-shaped or pointed, round or irregular pit filled with fire-cracked stone and scattered charcoal, cf. Myhre's type D (1980:193, 196). All are dated to the oldest phase. However, these were not the only cooking pits in the houses. It is reasonable to interpret pits that are bowl-shaped, trough-shaped or pointed with fire-cracked stones interspersed in the bottom or on top of the charcoal layer as cooking pits (Gustafson 2005b), corresponding to Myhre's types B and C (1980:193, 196). A total of 39 of the hearths can be interpreted as cooking pits, while 25 seem to have been used in other ways, i.e. for heat, light or other types of cooking; 14 were ember pits and five are uncertain because they have not been excavated. We can record that, on average, there is one cooking pit for each type 9 house, but only half as many hearths designed for open fire. The cooking function must therefore be regarded as a mandatory part of the interior decor, despite the fact that there are also 5-10 isolated cooking pits south of the west part of most of these houses.

Either the cooking pits in the heated part of the house also acted as pits for open fire for light and heat, or there were hearths for these functions that were not dug into ground. Here, there is also reason to point out that, in a number of contexts, built-up stone hearths have been found at Migration Period farms in Rogaland and at Sostelid in Vest-Agder (Hagen 1953, Møllerop 1962, Petersen 1933, 1936). If one looks at how the two types of hearths are distributed in the two phases, one can see that while the cooking pits are almost evenly distributed, there are far more hearths for light and heat in the earliest phase, when threequarters of the houses had an average of one hearth for heat/light while only one-third had the same in the later phase. Seen in the context of the fact that ember pits are almost only (13 out of 14) found in the later phase, which indicates a new need for protecting embers overnight, this may indicate that, during this phase, people started to use built-up hearths (alternatively on the floor) for heat and light, where the embers had to be stored in a separate pit from one day to the next - or the fire would go out.

The conclusion of this analysis must therefore be that there is a change in the techniques used for household fires from the earliest phase's use of the use of cooking pits and hearths for heat and light, dug into the ground in most houses, to the later phase, where the hearth for heat and light was placed either at floor level or on a built-up hearth, which has not left any traces in the ground.

Based on this idea of three main groups of hearths, we must investigate whether there are differences or changes in the size, depth and outline of the hearths.

Table 43 shows the most important mean values for hearths used for heat and light, for cooking areas and for ember pits. We see that, in both phases, the hearths in the western end of the houses are clearly larger in terms of length, breadth and depth than is the case at the eastern end, and their surface dimensions are $50-70 \%$ larger. There is a slight tendency that the hearths in the latest phase are a little bigger and deeper than in the earliest phase. This is seen more clearly for the cooking pits, where not only the length but also the width in the eastern end is greater in the latest phase. On the other hand, the depth over time is the same in each of the areas. In the earlier phase, the cooking pits are almost identical in size but due to their greater width, the eastern ones are markedly larger than the western ones in the youngest phase. Since twelve out of 14 ember pits belong to the western part of the houses and to the latest phase, there is no point in comparing these with the other two ember pits. We can observe they are all round, between 0.2 and $0.4 \mathrm{~m}$ in diameter (mean $0.3 \mathrm{~m}$ ), have a mean depth of $0.12 \mathrm{~m}$ and the size is about $1 / 6$ of the area of the hearths used for light and heat. 
Fig. 60. A selection of combination of hearths and ember pits in type 9 houses, as well as the location of solitary hearths.

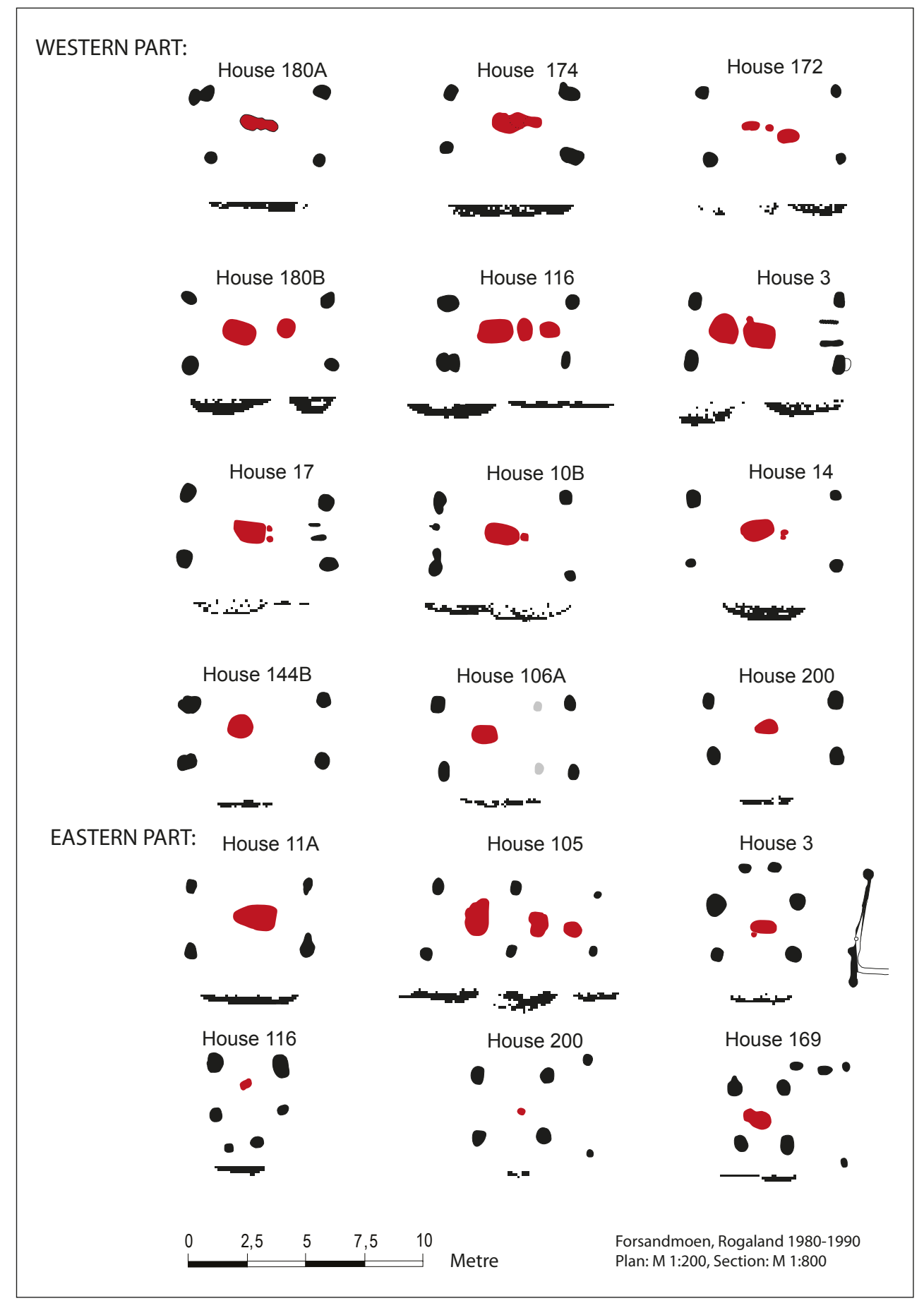

One conclusion based on this summary is that it seems that there were no particular changes in how the hearths were shaped and used during the houses' uselives and that their use seems to have been the same in both halves of the houses.

A summary of the house plan of type 9 houses shows that the hearths in many cases are situated closer together along the centre line. Only two type 9 houses lack traces of hearths in the western part. Fig. 60 contains a selection of different combinations of hearths, as well as their individual placement.
A hearth is centrally located in the room if it is on the centre axis and at the intersection of the diagonals between the two closest pairs of posts is within the perimeter of the hearth. 19 houses only have a hearth in the largest western dwelling area. These represent all horizontal shapes and size variations. Half are centrally located between the two closest pairs of posts, which may indicate that there has only been a dug-out hearth. The other half are clearly acentrally located, but on the centre axis, which therefore suggests that there could have been yet another hearth on the centre axis. In 
addition, there are five individual hearths, four of which are centrally located between two trestles, and where there is a total of eight ember pits just to the east of the hearth. This indicates that individual, central hearths at least had one or two ember pits. Together with the lack of hearths in two houses, which may mean that the traces of these were not always deposited in the subsoil, we can therefore formulate a hypothesis that there was at least one hearth combined with an ember pit and that hearths positioned acentrally indicate that an additional hearth existed along the centre axis.

Looking at the eleven houses with multiple hearths on the centre axis in the western dwelling area, we can observe that, in four houses, there are three hearths. In two houses, these are stratigraphically above each other, with the earliest in the central position. In one, the hearth has been moved eastwards twice, the first two times as a cooking pit, the last as a hearth for light and heat. In the second situation, the same is the case but to the west and as a hearth for light and heat. In both cases, the most acentral hearth may also have been used at the same time as the earliest hearth, and can thus be compared to the houses with two hearths in the room. In the other two cases, there are three hearths without stratigraphic contact with each other, so it is impossible to say which were in use at the same time. In both of these situations, there seems to have been functional differences between the hearths, with a large cooking pit and one or two hearths for light and heat, as well as an ember pit.

Seven houses have two hearths. There is a clear difference in size between them. The largest is centrally located in the room, while five of the smaller ones are located east of the main hearth and one in the opposite direction. In only one house are both hearths acentrally situated - but on the centre axis. The largest, most westerly hearths are all cooking pits, and the same is true for three of the smaller hearths, while two are flat hearths for light and heat. The last two have not been investigated. Contrary to what one would expect, there is only a difference in function between the two hearths for two of the situations with two hearths. Therefore, we cannot deny the possibility that pits with fire-cracked stones could also function as light and heat sources.

Individual hearths are found in the western end of 27 houses, of which four also have one or two ember pits just east of the hearth. Of these 27 hearths, 17 are centrally located, four major hearths only touch the diagonal lines in their periphery and seem to be acentrally located and are therefore included in the nine acentrally located hearths. Of the 27 separate hearths in the western end of the houses, almost two-thirds are classified as cooking pits, as is also the case with the hearths in the western part where there are several together. While hearths for light and heat are distributed equally with respect to central/acentral location, $75 \%$ of the cooking pits are centrally located.

In the eastern part of the houses, the ratio is equal to the number of hearths and cooking pits. The cooking pits are also mainly centrally located, while the hearths used for light and heat are predominantly acentrally located.

\subsection{Shape and size of roof-bearing and entrance postholes}

Altogether 603 roof-bearing and 245 entrance postholes are documented in connection with the type 9 houses (Table 37 and Table 38, folder). Considering the same basic type of construction of the houses and the same soil to build on, this large number of postholes constitutes a firm base for statistical analyses of the shape and size of the postholes in these houses. One must bear in mind that, since many houses were only partly excavated in the last season, $90 \%$ of the 603 recorded roof-bearing postholes have been investigated, along with $92 \%$ of the 245 known entrance postholes.

Only $17 \%$ of the roof-bearing postholes were circular (Table 38, folder), and they occur in small amounts in all subtypes. The oval postholes in all subtypes except for 9.2.3 have mean values of $0.52 \pm 0.05 \times 0.68 \pm 0.06$ $\mathrm{m}$. The length of the house does not influence the size of the postholes. The only house that has markedly bigger postholes is the wide house 2, with a mean size of $0.76 \times 0.93 \mathrm{~m}$. The circular postholes repeat this pattern with a mean size of $0.56 \pm 0.05 \mathrm{~m}$, while three similar postholes in house 2 measure $0.77 \mathrm{~m}$. Since the circular mean size is nearly in the middle between the two measures of the oval postholes, the posts in two posthole types were approximately the same size. The circular postholes seem to be randomly distributed in the houses, so such a conclusion is as expected.

But when looking at the depth of these two types of postholes, it is apparent that the oval postholes are an average of $0.08 \mathrm{~m}$ deeper than the circular ones, $0.33 \mathrm{~m}$ versus $0.25 \mathrm{~m}$.

Turning to the 190 oval entrance postholes, they are $0.1 \mathrm{~m}$ smaller than the roof-bearing postholes. The modest depth $(0.2-0.25 \mathrm{~m})$ indicates less of a need for foundation of the doorframes compared to the roof-bearing posts. An even smaller share of circular 
entrance postholes than is the case for the roof-bearing postholes underlines the need for rectangular hewn posts for the door attachment.

Postholes in the form of a core with a filler that is different from the surrounding soil, and which are often delimited by larger, sometimes vertical stones, have been found in 20 type 9 houses. In total, at least one dimension is registered from 53 roof-bearing posts and 18 entrance posts. 14 traces of roof-bearing posts document both the length and width of the cross section, while the rest only document the cross-sectional length (across the longitudinal direction of the houses). Only one entrance post has registered both cross-sectional measurements. In the analysis of the dimensions of the posts, roof-bearing posts from the six western pairs distinguish themselves from the rest since it is evident from the larger dimensions of these post-holes that, where the distance between trestle spans is larger, this may imply larger roof loads on the posts; so it makes sense that the construction should have been more powerful than in the rest of the house, which will be revealed in the following analysis.

The large cross-section of the 53 rectangular roofbearing posts varies from 20 to $52 \mathrm{~cm}$, with a mean of $36 \mathrm{~cm}$, while the short cross-section of 14 rectangular roof-bearing posts varies between 16 and $30 \mathrm{~cm}$ by an average of $24 \mathrm{~cm}$. Fig. 61 shows that two-thirds of the posts have the largest dimension between 30 and $44 \mathrm{~cm}$ and that $80 \%$ have the smallest dimension between 20 and $29 \mathrm{~cm}$. The ideal seems to have been posts that have a width that is two-thirds of the largest cross-section, and that the ideal dimension (average post) measured $36 \times 24 \mathrm{~cm}$. If we look at the imprints of the posts (14) with both transverse dimensions documented, we find the same size and proportions and only $\pm 1 \mathrm{~cm}$ deviation from $36 \mathrm{~cm}$ for $50 \%$ of the posts. It is also clear that even if half of these posts have a ratio of length and width of 2:3, there are posts that are almost square and others with a very elongated cross-section. Based on three type 9 house plans (houses 2, 3 and 6) and with different roof angles, Komber (1989:91ff) calculated the cross-sectional dimensions of the structural components in these houses. The calculated minimum cross-sectional dimensions ranged from $20 \times 12 \mathrm{~cm}$ to $26 \times 14 \mathrm{~cm}$, which is significantly less than documented by the excavation. The foundation pressure under such posts, however, becomes too high relative to the compressive strength of the subsoil even if the dimensions are increased to $40 \times 30 \mathrm{~cm}$ at trestle two from the west in house 2. Pressure-distribution agents such as wedging stones and a tightly packed layer of stone under the

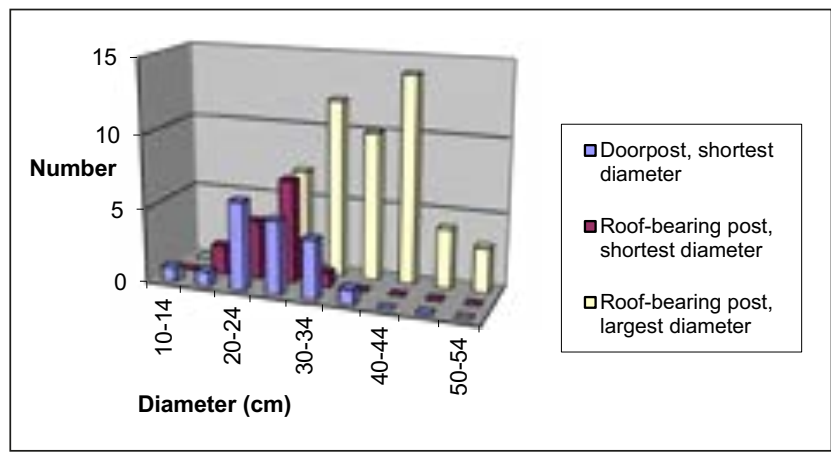

Fig. 61. Distribution of entrance and roof-bearing post dimensions from type 9 houses.

post suggest a well thought-out foundation concept (Komber 1989) to distribute pressure to the subsoil. The larger documented dimensions also testify to a desire to increased safety in the construction, while other factors, for example aesthetics, may have contributed to the coarse dimensions.

The rectangular entrance posts have a short crosssection dimension ranging from 10 to $36 \mathrm{~cm}$ and twothirds have a dimension between 20 and $29 \mathrm{~cm}$. This dimension is measured in the $\mathrm{N}-\mathrm{S}$ direction and must be compared to the short cross-section dimensions of the roof-bearing postholes. The near-perfect oval shape of the entrance postholes indicates that the entrance posts had approximately the same dimensions as the roof-bearing posts. The clearly shallower depth of the entrance postholes in relation to the holes for the roof-bearing posts, $10 \mathrm{~cm}$ in the Roman Iron Age and $15 \mathrm{~cm}$ in the Migration Period, indicates that the frame around the entrance was intended to be strong. However, since the entrance posts were not part of the structural framework, one could be less careful with the foundation. As a result of the shallower depth, the actual posthole could be made smaller and could still accommodate posts similar in size to those in the roofbearing postholes.

Only one entrance post is documented in both directions. It belongs to a $2 \mathrm{~m}$ wide door in house 2 and measures $44 \times 36 \mathrm{~cm}$. This post-depression is in line with many of the other depressions from the house's roof-bearing posts and emphasises that the entrance posts had dimensions similar to those of the roofbearing posts.

\subsection{Comparison between Roman Iron Age and Migration Period type 9 houses}

Since the type 9 houses were built over a span of more then 600 years, one should expect changes in several of the features that constitute the house-type. Table 
42 , folder, was sorted according to decreasing age and divided in two similar halves: houses from the Roman Iron Age (23) and the Migration Period (21), respectively. But the figures show that the measured features differ to a very little degree from the Roman Iron Age to the Migration Period. The Roman Iron Age houses were $1 \mathrm{~m}$ longer than the Migration Period houses and consequently had a few more square metres under the roof since the width didn't change. The trestle width in all parts of the houses differs within a few centimetres and the trestle quotient is quite similar. The distance between the corner posts is $0.2-0.25 \mathrm{~m}$ longer in the Roman Iron Age, but this cannot indicate a change in the house concept. Five out of seven houses with long walls consisting of densely set wall posts belong to the early Roman Iron Age, while one each belongs to the late Roman Iron Age and Migration Period. This illustrates that a new, better wall replaced this oldfashioned type of wall construction during the early Roman Iron Age.

The western and central part of the roof-bearing post-setting is also for all practical purposes identical, while there are some differences in the eastern part, due to a few houses with up to eleven trestles. In both periods, all subtypes are represented, indicating the same social structure and thus a demand for a differentiated house size. Concerning the size of entrances, their recess from the long walls and the size and depths of the roof-bearing and entrance postholes, including the share of oval versus circular holes, there are no differences between the two periods. Only $17 \%$ of the postholes are circular in each period. This is a much lower proportion than is documented in the Roman Iron Age type 3 houses (38\%), indicating that type 9 houses were distinguished from the older house type in the way of preparing the main construction.

The western living and entrance areas as well as the eastern byre and storage areas are equal in mean size in the two periods, while the mean size of the eastern occupation area counts one more metre in length. In both periods, there are ten houses with such a room. In the Roman Iron Age, there are five small rooms, including the gable area, measuring $6.2 \mathrm{~m}$ in length and five large corresponding rooms (including an entrance area) measuring $12.8 \mathrm{~m}$, while in the Migration Period only two houses have such a $12.6 \mathrm{~m}$ long room in the eastern end and eight $5.9 \mathrm{~m}$ long rooms.

The general conclusion to this section is that the type 9 houses were constructed based on the same principles throughout the more than 600 years that these houses were erected. A few minor changes can be detected. In the Roman Iron Age, $25 \%$ of the houses (six) had wattle and daub long walls as opposed to $5 \%$ (one house) in the Migration Period; a new wall construction replaced the at least 2000-year-old wall construction method on the Forsandmoen plain. After a transition period lasting half a millennium, hewn rectangular roof-bearing posts are nearly ubiquitous when people begin to construct the type 9 houses in the period around AD 1. The slightly longer houses in the Roman Iron Age depend solely on larger living rooms in the eastern end compared to Migration Period houses. It is remarkable that as many as five out of 21 Roman Iron Age houses are constructed with nearly two identical dwelling areas in a longhouse. An interpretation as two households with strong cooperation concerning all agricultural tasks seems very likely, while the houses with a small dwelling area in the east, like the eight houses from the Migration Period and five from the Roman Iron Age should probably be interpreted as an extra room for elderly relatives, servants, guests or the like.

\subsection{Comparative houses from Rogaland, Norway and the Nordic region}

\section{Type 9 houses in Rogaland investigated between 1930 and 1980}

Already after the second excavation season in 1981, where two type 9 longhouses were uncovered, it was clear (Løken 1983:89f) that the closest parallels could be found in the extensive house data in SW Norway, mainly excavated by Petersen $(1933,1936)$ but also data from Hagen (1953) and Myhre (1980), where also Petersen's data is presented. It appears from this data, although the documentation is often inadequate compared to modern standards. They are presented as drawings by Myhre (1980), and most longhouses at these farms have the same structural elements as the houses at Forsand. Table 44 sums up the most important data for 14 investigated houses prior to the Ullandhaug study and which belonged to type 9. In addition, Myhre describes several large houses that cannot be categorised as type 9 or that consisted of several phases which make it impossible to identify them as type 9 , as well as a number of smaller houses that did not have a byre function and therefore correspond to type 10 houses at Forsand. The table shows that, with one exception, the house length is within the same limits as the houses at Forsand, between 22 and $43 \mathrm{~m}$, while the house width is essentially about $1 \mathrm{~m}$ less.

On Myhre's (1980) older drawings, the wall outlines are often rendered irregularly, which is due to the fact 
Table 44. Compiled measured features from 16 excavated houses in Rogaland and Sostelid in Agder. Measurements in metres (m).

\begin{tabular}{|c|c|c|c|c|c|c|c|c|c|}
\hline \multirow[t]{2}{*}{$\begin{array}{l}\text { Location of } \\
\text { house foundation }\end{array}$} & \multirow[t]{2}{*}{ Total length } & \multirow[t]{2}{*}{ Max. width } & \multirow[t]{2}{*}{$\begin{array}{l}\text { Shape of } \\
\text { long wall }\end{array}$} & \multicolumn{2}{|c|}{$\begin{array}{l}\text { Entrance room } \\
\text { without hearth }\end{array}$} & \multirow[t]{2}{*}{$\begin{array}{l}\text { Dwell-ing room with } \\
\text { hearth, length }\end{array}$} & \multicolumn{3}{|c|}{ Byre } \\
\hline & & & & Length & $\begin{array}{c}\text { Doors } \\
\text { (number) }\end{array}$ & & Length & $\begin{array}{c}\text { Doors } \\
\text { (number) }\end{array}$ & $\begin{array}{l}\text { Flagstone } \\
\text { length }\end{array}$ \\
\hline Sostelid 2 & 39.0 & 6.0 & curved & 9.0 & 2 & 11.0 & 19.0 & 2 & 6.0 \\
\hline Birkeland I & 24.5 & 4.5 & straight & 7.5 & Unknown & 7.5 & 9.5 & 1 & 9.0 \\
\hline Birkeland 2 & 28.0 & 6.0 & curved & 7.0 & I & 7.0 & 14.0 & Unknown & \\
\hline Vatland 2 & 28.0 & 5.0 & straight & 6.5 & Unknown & 8.0 & 13.5 & Unknown & 5.0 \\
\hline Krågeland I & 26.0 & 5.6 & curved & 6.5 & I & 8.0 & 11.5 & I & \\
\hline Auglend I & 39.0 & 6.9 & curved & 9.0 & Unknown & 9.5 & 20.0 & Unknown & $20.0(12.5)$ \\
\hline Storrsheia I & 37.5 & 5.5 & curved & 9.0 & Unknown & 9.0 & 18.5 & Unknown & 9.0 \\
\hline Storrsheia 4 & 34.0 & 5.7 & curved & 8.0 & 2 & 9.0 & 17.0 & I & \\
\hline Storrsheia 5 & 26.0 & 5.2 & curved & 5.5 & 2 & 8.5 & 12.0 & 2 & 9.50 \\
\hline Skeie 2 & 27.0 & 6.2 & curved & 8.0 & Unknown & 8.0 & 11.0 & Unknown & \\
\hline Veddågåsen 2 & 29.0 & 5.0 & curved & 7.5 & I & 7.5 & 14.0 & 1 & 10.5 \\
\hline Murane I & 22.0 & 5.5 & straight & 5.0 & 2 & 6.0 & 11.0 & I & \\
\hline Vaula I & 23.0 & 5.0 & curved & 7.0 & 2 & 7.0 & 9.0 & 1 & 5.2 \\
\hline Vaula 3 & 23.5 & 5.0 & curved & 7.5 & I & 7.5 & 8.5 & Unknown & 5.2 \\
\hline Hodnefjell 2 & 13.0 & 4.5 & curved & 4.5 & 1 & 4.5 & 4.0 & 1 & 3.5 \\
\hline Leigvang I & 23.0 & 5.0 & curved & 5.5 & Unknown & 7.0 & 10.5 & I & 4.2 \\
\hline
\end{tabular}

that the archaeologists only dug into an assumed wall line (Fig. 87). Prior to Myhre's Ullandhaug study, there had been a bias which considered the building traditions of the Iron Age as primitive, including a belief that the walls had been irregular. When Myhre (1980) and Espedal $(1966,1967)$ examined the collapsed stone walls at Ullandhaug and Espeland, they found that foundation stones had been regularly placed in slightly curved lines, similar to Forsand. On many of Petersen's excavations, as well as at Sostelid, we can see that the width at the centre of the house is greater than at the gables and that the long walls form slightly uneven curved lines, which makes it likely that these walls were evenly curved.

Four of the 14 houses are documented in such a way that the entrance to the dwelling area is not known, while the other ten have two entrances to a single room without a hearth. It can also be noted that where the entrances are detected in the walls, they are 5-7 m from an end wall, which is the same distance from the gable to the western entrances as in the type 9 houses at Forsand. In addition, seven houses have one entrance located at the other end and two houses have two such entrances. Similarly, 1-2 hearths are located 3-4 m closer to the centre than the opposed entrances, and at the other end, a centre corridor is often marked off in the form of a stone paving, signalling that this had been a byre area. All of this is analysed above and are structural features that define type 9 houses.

Myhre (1980) interpreted the older material such that the houses were divided into two main parts: the dwelling area and the byre area. In addition, the dwelling area was divided into a dwelling area without a hearth (and just as important, in my opinion, with opposed entrances) and a dwelling area with a hearth.

There can be no doubt that some of the longhouses with outer stone walls from the old excavations and houses of type 9 from Forsand represent the same house concept, but with different solutions with regard to the wall structure. The main difference is that the houses with stone walls have these as an additional protection for the inner wooden wall, as was documented at Ullandhaug. An analysis of the two large longhouses at Ullandhaug in view of the houses at Forsand (Løken 1992d) resulted in the realisation that, in at least one of several phases, both of these houses were organised as type 9 houses. Hence, in phase 3 of Ullandhaug, house 1 was organised identically to house 169 from Forsand in terms of the position of the postholes, the location of the entrances and house length (see Løken 1992d: fig. 4).

At around the same time as ruins of dwellings with outer stone walls were being examined in SW Norway, corresponding ruins of dwellings were being examined 
at Öland (Stenberger 1933) and Gotland (Biörnstad 1955). There are also houses where the two outer rooms towards a gable have a much greater distance between the trestles than in the rest of the house, where the hearth is located between trestles 2 and 3 and where the posts in the other half are positioned more closely together, which indicates where the byre area was located (Herschend 1989). However, the houses differ from those in Norway because the entrances are located in each gable, such that each main part has its own defined entrance. The great similarities between the houses in the three areas suggest a coherent ideology and economy.

\section{House material from type 9 houses from Rogaland investigated after 1990}

During mechanical topsoil stripping after the Forsand project, several houses of the same type, with or without external stone walls, were also uncovered elsewhere in Rogaland.

Hafsøy at Eigersund was, in 1995, the first investigation after Forsand to find type 9 houses (Steen 1995). The settlement consisted of two parallel farms from the late Roman Iron Age and the Migration Period, each with a 30-32 m long type 9 house, a smaller workshop of type 10 and three four-post storage houses. The two phases of the main houses (Steen 1995:13f) each have all the features known from Forsand. The two phases of farm 1 are identical to houses 180B (type 9.3.4) and 157 (type 9.1.5), while the three phases of farm 2 are not separated.

At Gausel in Stavanger, there are two approximately $39 \mathrm{~m}$ long multi-phase longhouses built parallel to an $11 \mathrm{~m}$ wide courtyard between the houses. Both had external stone walls and one house also had foundation ditches for a wooden wall on the inside. Houses 4 and 10 had opposed entrances between trestles 1-2 from each end and to a larger dwelling area with a hearth between trestles 2-3 from each end. Two entrances are located at the centre of the house. The house is thus nearly identical to several of type 9.1.6 from Forsand $(11 \mathrm{~A}, 105)$. The other longhouse (8) consists of at least two phases $(8 \mathrm{E}, 8 \mathrm{~F})$, where $8 \mathrm{E}$ has an entrance room with opposed entrances, a dwelling area at the southern end and an additional hearth at the northern end, while $8 \mathrm{~F}$ seems to have had the dwelling area in the northern end. A stone pathway leading towards the centre of the house indicates the position of the byre. Both of these phases have great similarities with type 9.1.6 house 169 at Forsand (see also house 1 at Ullandhaug).
Among the ten houses found during the extensive excavations at Austbø, Hundvåg in Stavanger from 1999 to 2002, two (I, IV) were of type 9. One of these houses (IV) has a type 9 structure in the eastern end, with opposed entrances between trestles 1-2 and a hearth in the large room between trestles $2-3$. Then there are two large rooms and one smaller room with two hearths before two opposed entrances separate the dwelling area from the large byre area, where posts delineating stable boxes indicate space for at least 20 animals. A large area without hearths, maybe a storage area for grain and fodder, finishes the house to the west. The house seems to have had two dwelling areas at the eastern end, as is also found in house 150, the largest of the type 7 houses at Forsand, and in the oldest phase of Ullandhaug house 1 (Løken 1992d). The excavations at Austbø show that, in Rogaland, there are other concepts for large longhouses than what was common at Forsand in the late Roman Iron Age and Migration Period, together with houses that have many features similar to those at Forsand (Hemdorff 2006, Meling 2001:24f).

During a small excavation at Sande in Sola in 2014, a type 9 house more than $36 \mathrm{~m}$ long was found. In addition to a $15 \mathrm{~m}$ long dwelling area at the SW end of the house, the house also had a $12 \mathrm{~m}$ long dwelling area at the other end. In the middle, there was probably a $12 \mathrm{~m}$ long byre area (Aanderaa 2015:37f). The house shows large similarities with the houses of types 9.1.6 and 9.1.7 at Forsand, which are interpreted as houses for two households with a shared byre area.

At Sørbø in Sandnes, a farmhouse consisting of a 25 m longhouse of type 9.1.4 was investigated in 1998, and about $12 \mathrm{~m}$ away, there was a workshop about 17 $\mathrm{m}$ long that was parallel to the dwelling house. A fourpost storage building, with the same orientation as the dwelling house, must also belong to the settlement (Aakvik 1998:31). The farm, dated to the late Roman Iron Age and Migration Period, confirms that the interpretation that all of the contemporary houses at Forsandmoen can be interpreted as farms consisting of two parallel houses where four-post storage houses were also part of the farm.

In 2009, at Øksnevad in Klepp, two type 9 houses were investigated, with a length of $27 \mathrm{~m}$ (type 9.1.5) and $34 \mathrm{~m}$ (type 9.1.7), respectively. Many hearths along the centre axis testify that the houses have undergone restructuring during their lifetime. The houses are dated to the Migration Period (Hemdorff, personal communication)

In Dirdal in Gjesdal, two houses were investigated in 2006, of which the incomplete house II, consisting of 
four trestles and two opposed entrances in the house's NW end, is no doubt a type 9 house (Bjørdal 2007). House I was $22 \mathrm{~m}$ long with eight trestles and two entrances from the west side of the house and was not a type 9 house. The settlement is dated to the late Roman Iron Age and Migration Period.

At Løland in Forsand, a farm with at least seven houses was investigated in 2007 (Gil Bell 2008). House $\mathrm{V}$ was at least $30 \mathrm{~m}$ long. Due to difficult conditions, the structure was not fully preserved, but the house must have been a type 9 structure. Parallel to this, only $2 \mathrm{~m}$ away, a workshop was found. The farm is dated to the late Roman Iron Age and Migration Period.

At Myklebust in Sola, a farm was excavated in 2010 with a $42 \mathrm{~m}$ main house (I), parallel to a workshop and two four-post storage houses (Dahl 2014a). House I could be divided into two phases, where phase B was shortened to about $27 \mathrm{~m}$. Due to two phases and many repairs, the structure cannot be seen clearly, but there is no doubt that the house has a type 9 structure, with opposed entrances near a gable and, farther towards the middle, one or two dwelling areas with hearths. Near the other end, there was a hearth, and then, towards the centre, an entrance and a byre area.

In 2010, during mechanical topsoil stripping excavations in Fedjedalen in Haugesund, north of the Boknafjord, and for the first time with the exception of Avaldsnes, a type 9 house was found (Bjørdal 2011). The house has not been completely excavated since approximately 6-7 $\mathrm{m}$ with the entrance room in the western part must be missing. The dwelling area, with a large oval hearth, was $5 \mathrm{~m}$ long and four rooms may have been stalls for cattle. A paved entrance provided access to the cattle and divided a room into a storage area at the SE end of the house. Assuming a normal type $9 \mathrm{NW}$ end, the house's total length was approximately $30 \mathrm{~m}$, with nine pairs of roof-bearing posts.

Based on this analysis of houses from Rogaland, there is no doubt that type 9 houses were the most common way of structuring functions and access areas for multifunction farmhouses for people and cattle. This type of house is an expression of how much of the agrarian population in Rogaland during the Roman Iron Age and Migration Period had a common understanding of how to use building traditions to express belonging to the local society. Such consistent building traditions and internal organisation also imply benefits in the interactions between groups of citizens in that they would know how to deal with visiting others when entering the house.

\section{Type 9 houses from the rest of Norway}

At Åmol and Hol in Nannestad, only the well documented $27.5 \mathrm{~m}$ house III of the eight registered houses dated to the Migration Period contains most of the features of a type 9 house (Helliksen 1997:74f): corner posts for a $4.1 \mathrm{~m}$ wide gable approximately 2.5 $\mathrm{m}$ outside the outermost pairs of posts, a $4.3 \mathrm{~m}$ long entrance room with one entrance between pair 1-2 from the south, then a $5.7 \mathrm{~m}$ long room (where no hearth is preserved), three more rooms $(3.6-4 \mathrm{~m})$, of which the northernmost has one entrance post, while the room to the south has two posts from stall box dividers. In addition, the trestles are curved. This is a form that is almost identical to house 207 from Forsand and shows that the type 9 organisation of a longhouse was well-known in Eastern Norway. Of the more poorly preserved houses, none of these were erected according to this design, nor is it the case with the other house material from the Gardermoen project (Helliksen 1997).

At Vidarshov in Hamar, a similarly large type 9 house was investigated (Løken et al. 1996:86f, Pilø 2005:126ff). The approximately $26 \mathrm{~m}$ longhouse from the late Roman Iron Age has the same design as house III from Åmol, but with opposed entrances to the west and a preserved hearth in the large room between pairs 2-3. The house has been rebuilt twice, so it is clear that this design was preferred as an organisational principle for daily life over a long period of time.

At Åker in Hamar, in 1992-94, an approximately $1,200 \mathrm{~m}^{2}$ area was uncovered, where extensive building remains were found (Pilø 2005:93ff). Three house plans are of interest in relation to type 9 . The preserved parts of House III, consisting of heavily curved wall ditches with a maximum width of more than $8 \mathrm{~m}$ and which are terminated in a $4.3 \mathrm{~m}$ straight gable of two stout corner posts, a centre post and a pair of new roofbearing posts located $2 \mathrm{~m}$ from the gable, are almost identical to House 2 at Forsand. The house is a dated to the Migration Period (Pilø 2005:100) by a silver fitting with animal ornamentation in style I and stratigraphic analysis confirms that it is older than AD 545-655. Although most of the house has not been investigated, there is no doubt that this represents a high-status building, a hall, of type 9.2.3.

A pair of similar buildings, which are indisputably of type 9.2.3, were found at the elite settlement site at Sløinge in Halland (Lundqvist 1996). Both of these houses have been rebuilt twice and finds and dendrochronology indicate that they were in use from the Migration Period to the Late Merovingian Period 
- early Viking Period. (See the assessment of Sløinge in the section on comparative material in the Nordic region).

What also makes the comparison with Sløinge interesting is that, just north of house III at Åker, there is a complex of at least two large longhouses (houses III). The position of the postholes in the earliest $33 \mathrm{~m}$ longhouse is the same as for type 9.1.4, while the later $38.5 \mathrm{~m}$ longhouse has a structure comparable to type 9.3.4. Both houses are almost $8 \mathrm{~m}$ wide and belong to a small group of houses, including at Forsand, which differs from the usual house width of 5.5-7 m. Based on ${ }^{14} \mathrm{C}$ dated core wood from roof-bearing posts, the two houses are dated to the $8^{\text {th }}-9^{\text {th }}$ century AD (Pilø 2005:99f), which is the same as the dendrochronology of house II at Sløinge (Lundqvist 1996:16). Both settlement sites show that type 9 houses were not only built during the Migration Period but continued to be used in two well-known high-status environments into the Viking Period. This demonstrates that a framework encompassing both ordinary farm communities and an elite represented by type 9 houses - and also used during the early Roman Iron Age at Forsand - was retained through the major changes that occurred in society at the transition to the late Roman Iron Age. This applies to the central place in the Åker community, which must be the background for the large Åker find, and it applies to Sløinge, where finds of more than 50 gold-foil figures gullgubber are the clearest sign of a central place.

At Valum in Vang, excavated in 1992-94, an approximately $2,100 \mathrm{~m}^{2}$ area was uncovered, and extensive building remains were found (Pilø 2005:107ff). A sequence of three houses approximately $51 \mathrm{~m}$ long and $9 \mathrm{~m}$ wide overlap. The houses have an almost identical structure, which shows a firm view of how the shape and content of the house should be. The houses show most of the features that define type 9.3, with the difference being that an additional pair of posts was introduced between the entrance room in the west and the $6.2 \mathrm{~m}$ long dwelling area to the east, probably a hall (Pilø 2005:108). In the eastern part of the houses, the trestles are regularly spaced from $4-4.5 \mathrm{~m}$ and with $1-2$ entrances in this byre/economy area. Due to the overall width and the large space between the trestles of up to $4.5 \mathrm{~m}$, the roof-bearing pine posts have a dimension of up to $45 \mathrm{~cm}$. In total, these buildings are of a size comparable to Åker and other central settlement sites. However, the finds do not indicate that this is a central place. All the dates indicate that this sequence can be dated to within the Migration Period.
$13 \mathrm{~m}$ south of these houses lies a more than $20 \mathrm{~m}$ long but only 5-5.5 $\mathrm{m}$ wide house from the Migration Period with many of the same structural features. There have been several other smaller buildings here, and they can be interpreted as workshops for the larger buildings to the north, similar to type 10 at Forsand. The farmyard can thus have been organised as it is known from Forsand and many other places in Rogaland, with two parallel houses defining an inner courtyard area.

Different type 9 houses were found at all the three excavations that were carried out in Hedmark in 199294. The excavations represent farm areas of different size and importance and the use of type 9 houses in every case must be a strong indication that the type 9 house concept was important to the people in the area when it comes to the architectural, economic, social and symbolic environment they were looking to create.

Further north in Eastern Norway, at Brandrud and Grytting in Fron, in Gudbrandsdalen, eight combined dwellings and byres were excavated in 2010-12 (Gundersen 2016), of which Brandrud I, house 1 has all of the elements included in the definition as a house of type 9.2. It is almost identical to house 2 at Forsand, but 3-4 m shorter. Several of the other houses show many of the elements of type 9, but with certain adaptations in three houses in terms of the large heated living space in the eastern half of the house.

At Habberstad in Ullensaker, Skre (1998) has documented several smaller longhouses from the late Roman Iron Age and early Migration Period. Three houses had curved wall ditches (I-III) or corner posts (I, III, IV). House II is particularly interesting. The load-bearing structure is organised with a $3.5 \mathrm{~m}$ long entrance room (one door) at the NE end, then a $4.7 \mathrm{~m}$ long dwelling area with a central hearth and a room with no entrances at the SW end, interpreted by Skre as a byre. Considering that three of the five investigated houses at the settlement site had corner posts, this was probably also the case for house II. If so, the house shows all the key elements of a type 9 house. House IV also has opposed entrances between pairs 1-2 and a $6 \mathrm{~m}$ long room beside them. The ditches running the longitudinal direction of the house, oriented from the entrance postholes to the point where the wall should have gone, as well as corner posts with a distance between them of $4 \mathrm{~m}$, also indicate a concept closely keeping with a type 9 house. What distinguishes them from a Forsand type 9 house is the length of the houses, which were only about 16-18 m and that the two houses II and IV only had four and three pairs of posts, respectively. 
House 2 at Elgesem in Sandefjord, is a $36.5 \mathrm{~m}$ long type 9.3 almost identical to house 158 from Forsand (Samdal \& Østmo 2008:225ff), but the northern part of the house has not been clarified due to space limitations. Unlike other type 9 houses in Eastern Norway, this house has an additional pair of posts between the entrance room and the gable, as defined for type 9.3.

Of the 13 longhouses at Ringdal in Larvik (Gjerpe \& Østmo 2008), only two are type 9. House 1 is a twophase house, which was approximately $35 \mathrm{~m}$ long and $8 \mathrm{~m}$ wide in the longest phase. The northern end of the house has a type 9 structure with a room that is $3.5 \mathrm{~m}$ wide with opposed entrances and a $5 \mathrm{~m}$ dwelling area with two hearths on the centre axis, one of which is in the diagonal cross between the two closest pairs of posts. Unlike type 9 houses, there are then three rooms that are 3.5-4 $\mathrm{m}$ long, where the finds of macrofossils from grains and a possible space for an upright, warpweighted loom suggest that these rooms were not part of the economy area. At the southern end, there are three rooms about $2.5 \mathrm{~m}$ long separated from the dwelling area by a room with two entrance doors. Even though the room in the centre is larger than usual for type 9 houses, the structural similarity to the larger type 9 houses is so great that the house must represent the same ideas about the organisation of houses (Gjerpe \& Østmo 2008:55).

Also house 4, with a length of $21.5 \mathrm{~m}$ and width of $6.8 \mathrm{~m}$, has two opposed entrances in a $2.5 \mathrm{~m}$ wide room between pairs $1-2$, and a $3.5 \mathrm{~m}$ wide room between pairs $2-3$. The house also has stout corner posts and a straight gable at the northern end. However, these rooms are smaller than such rooms in similarly short type 9 houses at Forsand. The house has seven roofbearing trestles and, as a whole, the house is very similar to house 201 from Forsand (Gjerpe \& Østmo 2008:71).

House 17 also has most of the elements of a type 9 house, but it only consists of three trestle frames with roof-bearing posts. The centre room is not larger than the entrance room, which has a recessed entrance between pairs 1-2 from the SW. It has corner posts in both gables. One entrance is located adjacent to the gable at the end opposite to the entrance room. The house is similar to the type 10 workshops at Forsand. House 7 also has a corresponding organisation of posts, similar to house 8 , which, however, lacks traces of entrance posts.

In total, there are eight houses that have corner posts (houses 1, 3, 4, 6, 7, 8, 16, 17) at one or both ends, which indicates that this construction is an integral part of local building traditions. Along with the occurrence of the other elements belonging to the complex of type 9 and type 10 houses, and the fact that three houses may be characterised as type 9 houses, we must conclude that a building ideal at Ringdal over a long period during the Roman Iron Age and Migration Period was the same as that which dominates the settlement site at Forsand.

At the E6 project in Østfold, house 3 at Bustgård in Råde (Vikshåland et al. 2007:109f) is a typical type 9.1.2 house, which is identical in structure and aspect ratio to house 144A from Forsand, except that the corner posts are missing. The drainage trenches along the outside of the walls testify to slightly curved long walls (Vikshåland et al. 2007:115), that is also documented at Forsand. An interesting feature of this house is two parallel, $0.7 \mathrm{~m}$ long ditches, located just north of the central hearth. They were placed at a distance of 0.8 $\mathrm{m}$, and their northern end was in line with the third post pair from the southern end of the house. These were related to the hearth (Vikshåland et al.:117). The two houses 3 and 17 at Forsand have similar structures. The ditches were first interpreted as a structure in connection with a door. However, based on a discussion of the placement of the seat of honour in the longhouse at Borg (Hershend \& Mikkelsen 2003), a hypothesis is drawn instead that this is a trace of the placement of the seat of honour. This can also be an alternative interpretation for the house at Bustgård.

House 2 from the Roman Iron Age at Rør in Rygge (Berg 1997:37f) has a type 9.3 house plan with an additional pair of posts between the entrance room and the gable. The entrance room with one entrance and the hearth room are both 4.5-5 m long, while the economy part, which is not completely uncovered, has rooms with a bay depth of 2-4 $\mathrm{m}$. The house is comparable to 156 from Forsand (type 9.3.2), which is $27 \mathrm{~m}$ long. The long walls consist of densely set wall posts with a drainage ditch on the outside, which ends at corner posts, cf. houses 1-2 at Missingen (Bårdseth \& Sandvik 2007b:130f).

At the excavations at Aure in Sykkylven in 1991-92, a complex of several large longhouses from the late Roman Iron Age and Migration Period was uncovered (Ringstad 2001). In one of at least three phases, the house has a design that fits with type 9.3 in every respect. It is $38.5 \mathrm{~m}$ long and $7 \mathrm{~m}$ wide and is marked with very large postholes compared to Forsand. The very long entrance room $(7.5 \mathrm{~m})$ with opposed, recessed entrances lies between the $4.3 \mathrm{~m}$ long additional dwelling area which type 9.3 has closer to the gable and a 6.8 $\mathrm{m}$ long dwelling area with a central hearth. In the other 
half of the house, the posts are closer together (3-4.5 m) and an entrance provides access to that which, on the basis of traces of approximately $1 \mathrm{~m}$ wide stall boxes, must have been an economy area with a byre. The house has large wall ditches that end in the corner posts of the gables. The house is not the only representative of type 9 houses in Western Norway.

At Rutlin in Sogndal, in 1998, an approximately $50 \mathrm{~m}$ long and $6.5 \mathrm{~m}$ wide house from the late Roman Iron Age and the Migration Period was uncovered (Diinhoff \& Hjelle 2003). Between post pairs 1-2 from the west in the house was a $4.6 \mathrm{~m}$ long room without hearths. In the $5.7 \mathrm{~m}$ long room between pairs $2-3$, there was a $2 \mathrm{~m}$ long three-phase central hearth. Throughout the rest of the house, with the exception of the easternmost room, there are a total of 17 trestles with a distance between them of 1.6 and $3 \mathrm{~m}$ and ending with a 3.7 $\mathrm{m}$ long gable room at the eastern end. Although no postholes were found after entrances or corner posts, a larger gap between the post pairs 7-8 and 9-10 reveals two opposed entrances that separate the dwelling area and an economy area, dominated by an approximately $18 \mathrm{~m}$ long paved byre area with a gripping ditch along the centre axis. A greater distance between posts 2-3 from the east may indicate that there had been one or two entrances there. The postholes in the house are positioned much closer together than in type 9 houses at Forsand, but the corresponding longhouse 150 from Forsand, which belongs to type 7 with a broadly-spaced pair at the centre, has 19 pairs of posts. There, they represent the densely set pairs in the byre area, documented with stall box posts that divide the rooms into approximately $1 \mathrm{~m}$ wide stalls. Aside from the lack of corner posts and entrance posts, the house satisfies all requirements for a type 9.1 house.

At Osen in Gaular, a small, partially destroyed site was examined and documented in 2001 (Diinhoff 2003). The drawings show a three-bay house from sometime around AD 600, approximately $42.5 \mathrm{~m}$ long, oriented N-S. The house has the same layout as type 9.3.6, with eleven pairs of roof-bearing posts with two 4.5 and $5 \mathrm{~m}$ spaces between posts $2-3$ and $3-4$ from the south. These rooms must be interpreted as the entrance room and the dwelling area, as in the type 9 houses at Forsand. The southernmost pair of posts in the Osen house $1(1-2)$ corresponds to the extra pair of posts that is included in the type 9.3 houses at Forsand. Further towards the north, there are four rooms of around $3 \mathrm{~m}$ that fit with the byre area of the type 9 houses at Forsand. At the northern end, there were three approximately $4 \mathrm{~m}$ rooms for dwelling or storage functions. Seen in the context of the houses at Aure and Rutlin, it is not unreasonable to interpret this house as a poorly preserved type 9.3.6.

The last two decades have also brought to light extensive house material in Trøndelag. Frey (2010) has analysed 19 well-preserved house layouts, of which seven are from the late Roman Iron Age and Migration Period, and thus concurrent with the use of type 9 houses. None of these have a type 9 post configuration, even though they have a number of the same elements, such as Frey (2010:54) points out for the houses at Hovde, Ørlandet (Grønnesby 1999). This applies in particular to two houses (A and F) that have corner posts, a large hearth room at one end and closely placed pairs of posts at the opposite end, in addition to recessed entrances. However, these are located near the centre of the house and the hearth room closest to the western gable. The structure is thus the predominant type from the Bronze Age and Pre-Roman Iron Age (Forsand type $3)$, which also appears to be common in Trøndelag in these periods, cf. Rønne (2005).

Several of the settlement sites in Melhus (Rønne 2005) also have houses from the Roman Iron Age and the Migration Period. Most of these have entrances at the centre of the house that separate the dwelling area from the byre area, which demonstrates a continuity of tradition in the area. One of the houses, Skjerdingstad X, however, has a structure with large rooms, one with a hearth at each end and a large byre area with densely placed posts, which probably testifies to a byre function (Frey 2010:55, Rønne 2005:95). The two large longhouses at Bertnem (Farbregd 1980, Løken 1992a), which clearly differ in structure from the rest of the house material from the Roman Iron Age and Migration Period in Trøndelag, are formed based on a completely different principle, with posts placed evenly throughout the length of the house and with the hearth in the middle of the length.

\section{Evaluation of house material from the Roman Iron Age and Migration Period in South and Central Norway}

The material outside Rogaland from this period is not extensive enough to draw any clear conclusions. Many site reports have not been further analysed and published, and this overview may be incomplete. We can observe that type 9 houses have been found in a number of locations in Eastern Norway and in 2-3 locations in Western Norway, while definitive type 9 houses have not been found in Trøndelag. It also appears that type 9 houses in Eastern Norway are often smaller 
than those found in Rogaland and in Western Norway. The houses presented here demonstrate that there are many other ways to structure and construct houses, so the type 9 houses outside Rogaland are just one of many options for creating a physical and social space. We should also note that, at Forsand, a small number, altogether seven, large longhouses are concurrent with type 9 but have different house plans. Concurrent with the earliest type 9 houses, we also find the latest type 7 houses with a broadly-spaced pair at the centre of the house. In addition, seven type 3 houses were also built during the Roman Iron Age. This means that, during the Roman Iron Age and the Migration Period, onethird of the houses (20 altogether) of the total of 64 dwellings/byres that were built in this period were of types other than type 9. In other words, there was also great diversity in Forsand in terms of ways to highlight social and economic status.

\subsection{Comparative houses in the Nordic region}

In the chapter on type 3 houses, we see that these houses, together with four-post constructions, belong to a southern and middle Scandinavian building tradition, which spread to Germany and the Netherlands, the NW part of the Continent. Denmark - and especially Jutland - was therefore near at hand to search for parallel material for type 9 houses. In Jutland, we find the same trend as at Forsand in that house lengths increase from $15-20 \mathrm{~m}$ up to $30-50 \mathrm{~m}$ during the Roman Iron Age and Migration Period. However, the houses continue to have opposed entrances in the middle of the house that distinguish between the dwelling area and byre/economic area, each of which can be divided into 2-3 bays in the longest houses (Hvass 1988:70f). The walls, including the rounded gables, continue to be constructed with more or less densely set posts as the basis for wattle and daub walls or vertical plank walls, in contrast to a sill beam and plank walling construction combined with corner posts found in type 9. Most often, the distance between the roof-bearing posts is quite even, in contrast to the uneven pattern of type 9 houses. Examples of central settlement sites that demonstrate that this is a recurring pattern are Vorbasse (Hvass 1979:68-69, 1982:136), Skonager (Siemen 1985:72), Præstestien (Siemen 2000), Foulum (Jensen \& Willemoes 1982), Nørre Snede (Hansen 1987), Hjemsted (Ethelberg 1988) and Hammel (Ravn 2009). Similar houses are also known from Sjælland (Fonnesbech-Sandberg 1992). In other words, the houses in the Roman Iron Age and Migration Period are a continuation of the old Bronze Age concept with an enlarged dwelling area and, such as for type 9, with extra space in the economy area. We can safely say that, in relation to the development along familiar lines that took place in Denmark during the Roman Iron Age and Migration Period, type 9 represents a radical change in the understanding of how construction and activity patterns should be in a south-western Norwegian farming community. In relation to Denmark, type 9 represents a new, modern concept in which the location of the entrance to the longhouse at each end implies a greater distance between the human area and animal/economy area. One might say that people must have freed themselves from previous perceptions of how society should be organised and consequently from the old dependence on Jutland in terms of relying on building traditions.

I have reviewed a comprehensive material from Skåne and Blekinge from major projects and publications from the past 20 years but no type 9 houses were detected at the following published sites and projects: the Køpinge area (Tesch 1993), Fosie IV (Björhem \& Säfvestad 1993), Västkustbanan [West coast railway] (Lagerås \& Strömberg 2005), 36 partial reports and the final report for the Öresund connection (Björhem \& Magnusson Staaf 2006) and 13 partial reports for the City Tunnel project (2002-2007) all in the area around Malmö. The houses from the Roman Iron Age and Migration Period can generally be characterised as being three-bay longhouses with straight or slightly convex longitudinal walls of densely set wall posts that either end in a rounded or straight gable or in two corner posts. The position of the posts is usually regular, but in the late Roman Iron Age and Migration Period, the trestles are often grouped two by two or the like. From the end of the Pre-Roman Iron Age, the size of the houses increases to approximately $50 \mathrm{~m}$, while both medium and small houses are still found. Entrances are most often seen at the centre of the house, and entrances similar to those found in type 9 have not been detected. Neither are the houses in Skåne listed in the Hus och Gård [House and farm] project (Göthberg et al. 1995) nor at Brogård in Halland (Carlie 1992) type 9 houses. Therefore, we can conclude that, despite a very extensive dataset, type 9 houses are not known anywhere in southernmost Scandinavia in the Early Iron Age. Developments in north-west Germany also follow the same trends as in southern Scandinavia, with opposed entrances at the centre of houses, which grow in length and number of rooms relative to the 
time before the Roman Iron Age (Haarnagel 1979, Zimmermann 1992).

Further north in Sweden, type 9 houses do occur to any great extent. Houses I and II at Gene in Ångermanland (Ramqvist 1983) have major similarities with house 2 at Forsand, the excavation of which had been completed the previous year (Løken 1982). On the basis of the similarity with the house from Vidarshov, Hamar and the Gene houses, a hypothesis was formulated (Løken 1992d:41) that the house type had a connection with the Scandinavian coniferous forest belt and the agricultural forms and economies found there, and thus contrasted to the houses with opposed entrances in the middle of the house in the southern Scandinavian plains in the deciduous forest belt. This hypothesis was later accepted by Herchend $(1998,2009)$ for the conditions in Sweden and by Gjerpe (2017) for the houses in Eastern Norway. The comparison made between Forsand house 169 and Gene house II showed that the room with opposed entrances between pairs 1-2 was smaller in Gene and that the dwelling area between pairs 2-3 was significantly larger, while the structure, location of entrances, dwelling area with hearths, byre and/or storage areas and the use of corner posts were the same. Gene house I also share these features but has an extra pair of posts between the entrance room and the large dwelling area. The Gene houses have one difference in their roof-bearing construction: pairs of extra support posts are located between the roofbearing posts and the wall line throughout the entire entrance/dwelling area.

Further to the south, in Norrland, house A at Trogsta in Hälsingland (Liedgren 1992) also strongly resembles type 9 , and especially house I at Gene, because an additional pair of posts was inserted between the entrance room and living room. The house has an extra support post near the wall at the southern end of the dwelling area, while in the northern end, there are only a few stout posts with a trestle width of $3.8 \mathrm{~m}$ at the same time as the width is otherwise $1.8-2 \mathrm{~m}$. This broadlyspaced pair is also discussed in connection with type 7 at Forsand (c.f. chapter 8). The house has no entrance posts in what should be the entrance room according to the type 9 design, but right outside of this room, there was a paved slope that acted as access area to the house - which implies an entrance.

The houses at Gene and Trogsta differ from the Forsand houses because the bay length in the northern part, corresponding to the byre/storage area of the Forsand houses, is $4 \mathrm{~m}$ compared to just $3 \mathrm{~m}$ at Forsand. The bay length is also greater in the dwelling area: $9.6 \mathrm{~m}$ in Gene house II compared to a maximum of $6.5 \mathrm{~m}$ at Forsand. Liedgren has documented some other terraced houses in Hälsingsland, where the posts are visible on the surface (Liedgren 1992:22, 31) and where most of the elements of a type 9 structure can be seen. There is therefore reason to assume that the ideas that type 9 represents concerning how houses should be shaped and structured was an integral part of the Norse world of ideas.

In Mälardalen, there are also a number of documented houses that can be said to belong to type 9 . Eriksson (1995:73) points out that the houses I and VI at Görla in Uppland are so similar that a consise house plan must have been used as well as a particular measurement system when the houses were erected. He also points out that the houses from Forsand correspond to the Görla houses. House 172 from Forsand (type 9.1.2) has identical dimensions and structure as Görla house I, although the space between the trestles at Forsand is greater. Eriksson's comparison of Görla house I (Eriksson 1995:73) with Årby house 5 (Tesch 1972) and Karleby house A44 (Bennet 1985) clearly shows that these houses in Mälardalen were built according to the same principles and that the dimensions of the rooms both in the western dwelling area and in the eastern byre/storage area are quite equal. Also in the larger Görla house VII, we find most of the elements of a type 9 house, but with significantly greater distances between the pairs of posts in both halves than is usual at Forsand. The two phases of house VI at Görla can be interpreted as an additional house erected parallel to houses I and VII, as is common at Forsand, and is not interpreted as a house for a separate farm unit. Other examples of type 9 houses are two houses in Åslunda, and Darsgärde (Olausson 1998) and Södra Vallby (Karlenby 2007) in Uppland.

The southernmost occurrence of a type 9 house is from the central place Sløinge in Halland (Lundqvist 1996). As shown (Løken 2001b:fig. 21), two houses have been investigated and are both identical in size and structure to house 2 at Forsand. To ease the comparison, house II at Sløinge is shown as a mirror image in the figure. House III at Sløinge and house II at Forsand are most similar with powerful curved foundation ditches, a clearly curved position of the two rows of postholes that is exactly equal and the individual bay depths are approximately the same and both have a particularly wide entrance $(1.7-1.8 \mathrm{~m})$ towards the south in the western end as well as an entrance to the north-west, in addition to several hearths in the dwelling area between trestles 2-3. In addition, both houses 
have undergone replacement of posts, and at Forsand, the length was shortened by $1.7 \mathrm{~m}$. Sløinge house II shares a number of the mentioned features, but lacks entrances and central hearths, and the walls are constructed differently. Replacement of the posts for at least three trestles but within the same structure indicates a prolonged use-life. Due to the location, the two houses at Sløinge could not have been used simultaneously, so this high-status environment must have existed over a long period of time. House III is dendrochronologically dated to the early $8^{\text {th }}$ century, while house II is dated by the same find groups from the richer finds in house III. The finds indicate that the settlement was established in the early Migration Period and lasted well into the Viking Period. Finds of at least 40 gold-figure foils, rough garnets, glass cups and gold-foil in postholes associated with the largest space between pair 2-3 indicate that this house played a central role at a settlement site with key political and religious functions (Fabech 1991:291ff, Løken 2001b:16f).

The houses at Sløinge belong to the Merovingian Period and, the fact that the earliest date is from house II b (AD 560-660) indicates that, during their oldest phase, they were concurrent with house $2 \mathrm{~B}$ at Forsand. What is interesting is that, at a central place like Sløinge, several houses were built according to the same principles and with the same size as at Forsand. House 2 at Forsand may therefore be an expression of the same ambitions to showcase social position as was expressed at Sløinge. This is underlined by the religious deposits of gold-figure foils as well as other objects indicating status, however in a small fjord village like Forsand in south-western Norway, people did not have access to or the opportunity to deposit corresponding items in the hall room.

Arlandastad, Norrsunda, Uppland (Broberg 2004: 44-45 fig. 6) has three approximately $25 \mathrm{~m}$ long houses with type 9 post positioning with, respectively, six (9.1.1) and seven (9.1.3) trestles as well as corner posts, one with a hearth in the large dwelling area. In the farmyard, there are also three smaller houses with 3-4 trestles, probably corresponding to a type 10 workshop. The settlement is dated to the late Roman Iron Age and Migration Period.

Nyckelby, Övergran parish, Uppland has a $30 \mathrm{~m}$ long type 9.2.2 house (23) from the Migration Period, with wattle and daub walls, corner posts and a central hearth in the large room between pairs 3 and 4 (Eriksson 1998:fig. 4).

Sundkvist (1998) has presented a small selection of houses from the Roman Iron Age and Migration Period from Lundbacken in Uppland and from Uppsala and Fågelbacken in Västmannland and was able to classify them into three types. The definition of her type 1 (Sundkvist 1998:181) is almost identical to the definition of Forsand type 9, and her best example, Uppsala house 10, is almost identical to several of the Forsand type 9.1.4 houses, while Fågelbacken house 3 and Landbacken house 3 both have an additional pair of posts in the western end, meaning that they correspond to Forsand type 9.3. Uppsala house 5 also belongs to Sundkvist's type 1, and thus also type 9. Sundkvist's type 2 has a structure that corresponds to type 1 , but the difference between the dwelling area and the byre is smaller (Sundkvist 1994:76). Two of her type 2 houses, house 2 from Fågelbacken and house 1 from Uppsala, correspond to Forsand's type 9.1.1 and 9.1.2, respectively, i.e. they are shorter versions with fewer trestles than her type 1. Also, the less wellpreserved houses, Lundbacken houses 1 and 2, must be type 9 houses based on the position of the roofbearing posts. These three settlement sites therefore show that houses corresponding to type 9 at Forsand must be common in Mälardalen. However, it should be emphasised that there are houses at settlement sites in the area with other ways of structuring the position of the posts and activity areas. 


\section{Type 10: Workshop and/or dwelling house as an additional house to type 7, 8 and 9}

\subsection{The characteristics of type 10 houses}

Type 10 consists of 28 small and narrow longhouses and are associated with the combined dwelling and byre house types 7, 8 and 9. Four additional such houses were only partly excavated due to the trench system and are therefore, except for their ${ }^{14} \mathrm{C}$ dates, not included in this analysis. The type 10 houses are in most cases located parallel to and at a 4-12 $\mathrm{m}$ distance from the larger house types. They have been interpreted as a workshop house for activities such as storage, food preparation, crafting and iron forging. The following chapter is based on Table 45 (folder), Table 46 and Fig. 62.

These houses consist of 3-5 pairs of postholes that contain two straight or slightly curved rows of roofbearing posts, corner posts at the gables, $1-4$ entrances located near the gables and 1-4 hearths along the longitudinal axis. The two houses 29 and 206 have an ember pit in connection with a hearth. The roof-bearing structure measures between 5.5 and $16.5 \mathrm{~m}$ in length. In most houses, the gables were constructed with two corner posts, resulting in a total house length between 10.2 and $20.7 \mathrm{~m}$. Most type 10 houses lack traces of the longitudinal walls, but six houses with postholes in the long walls show a house width of $4.4 \mathrm{~m}$ to $5.2 \mathrm{~m}$.

In order to analyse these houses, the material has been divided according to the number of trestles in the roof-bearing construction into types 10.1-3. Types 10.1-2 have been divided into three and two subtypes, respectively, according to house length. Type 10.1 consists of the majority of houses (18), while the two other subtypes (10.2 and 10.3) consist of seven and two houses, respectively.

\section{Dating}

$31{ }^{14} \mathrm{C}$ samples (Table 45 , folder) date type 10 houses to the period from the middle of the early Roman Iron Age to the first part of the Merovingian Period. Nearly half of the dates, altogether 13 - from ten of the houses - are from the $1^{\text {st }}$ to the $3^{\text {rd }}$ century, and one is stratigraphically older than AD 80-320. Another twelve houses, each with one sample, are dated to the $4^{\text {th }}$ to the $6^{\text {th }}$ century. In addition, three partly exca-

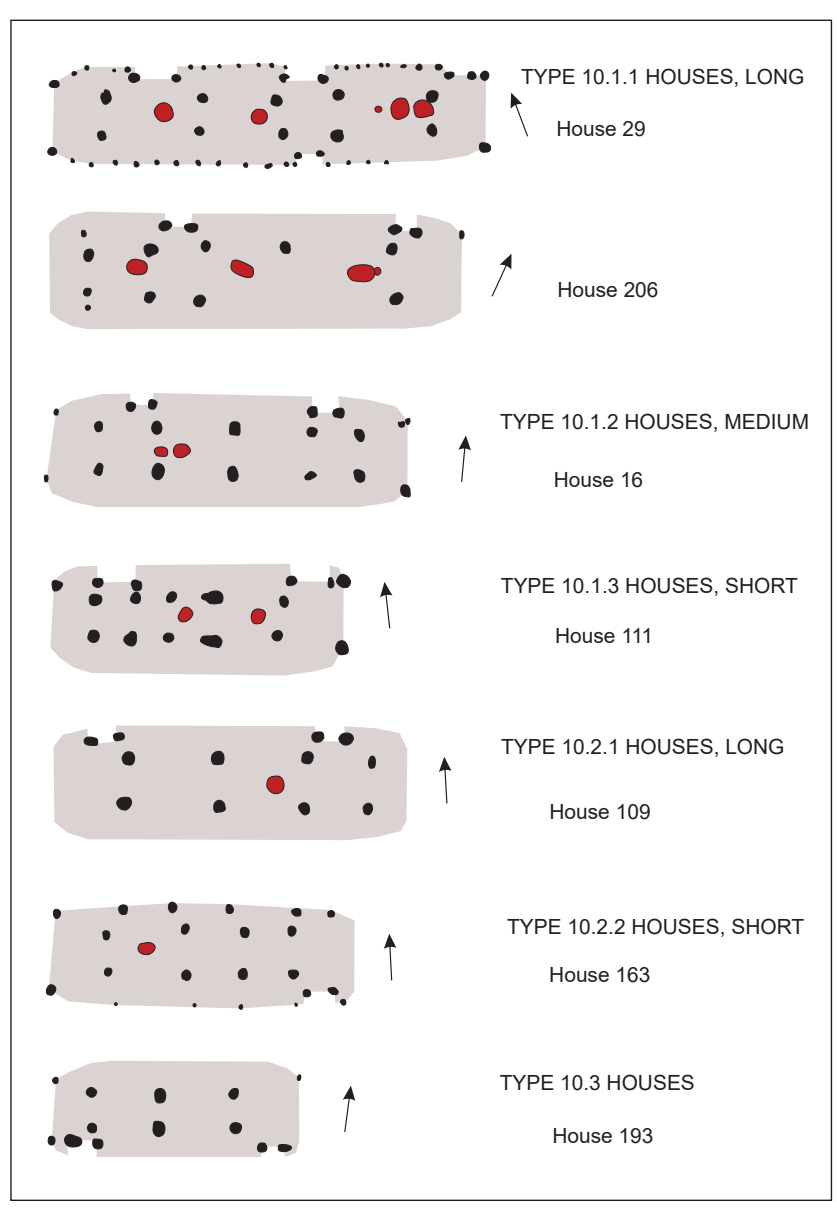

Fig. 62. House plans of the different subtypes of type 10 houses. vated houses are dated to the $4^{\text {th }}$ to $6^{\text {th }}$ century. Two houses are dated to the $7^{\text {th }}$ century and the remaining four houses are not dated. This time distribution is similar to that of the house types 7-9 with which they are associated.

\section{Orientation and length of the post-setting}

Table 46 shows that the average orientation for the different subtypes varies between $288^{\circ}$ and $306^{\circ}$ and the total average value is nearly E-W. Fig. 63 shows how the orientation of all the houses is distributed with the majority between $290^{\circ}$ and $310^{\circ}$. The pattern is the same as for the type 9 houses, which is hardly astonishing since one house of each house type is located parallel to each other, constituting a farmyard. 
Table 46. Average measurements of compiled features from type 10.1-10.4 houses. Measurements in metres (m). Estimated measurements in italics.

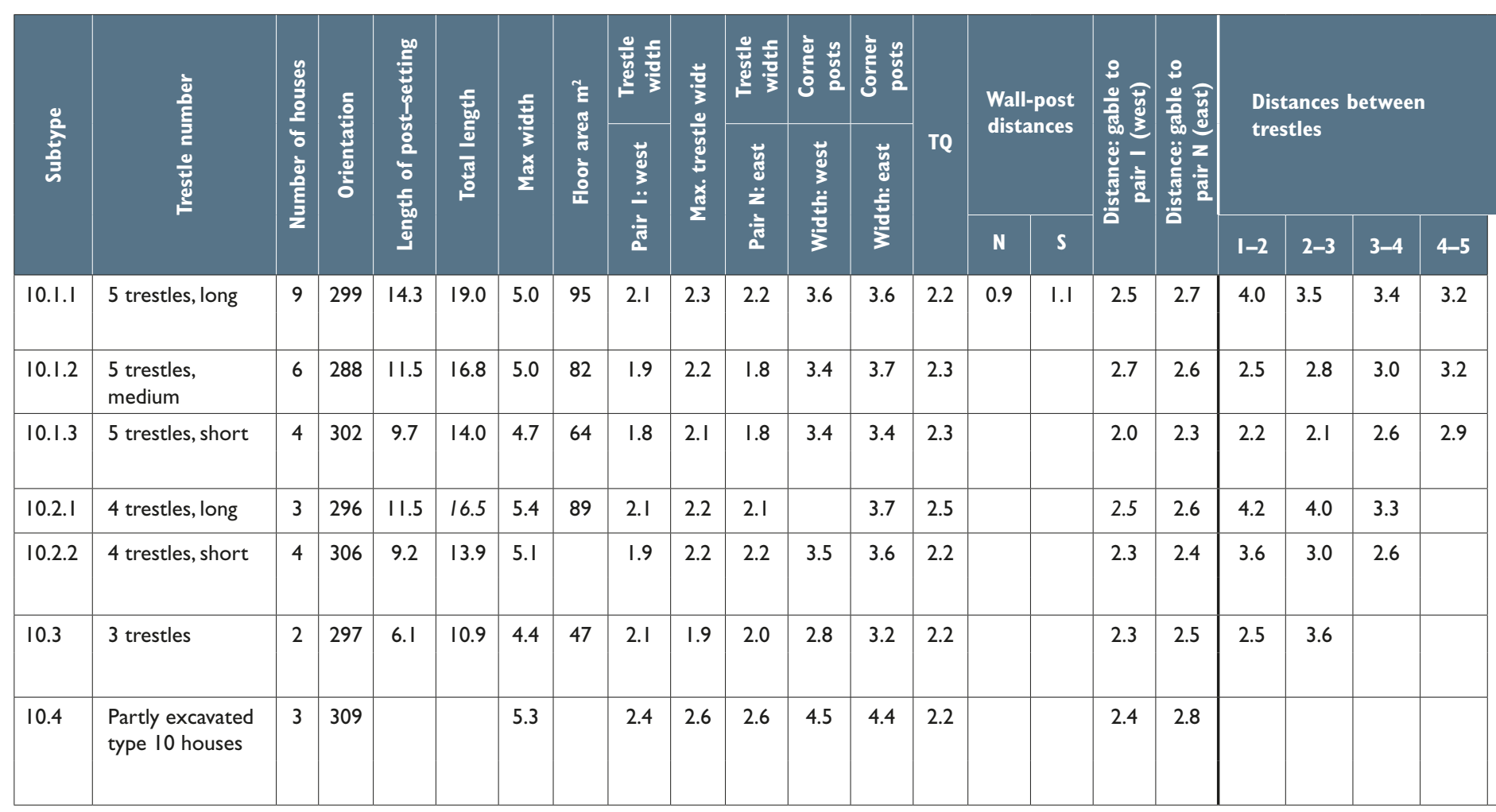

The length of the post-setting is only partly dependent on the number of trestles in the house. The length of subtype 10.2.1, with four trestles, is similar to that of subtype 10.1.2, with five trestles (Table 46). Likewise, the subtype 10.2.2 has the same length as type 10.1.3. The reason for this is that the average length between trestles of the subtypes is different. Subtype 10.2.1 has an average trestle distance of $3.9 \mathrm{~m}$ (total post-setting: $11.5 \mathrm{~m}$ ), while the subtype 10.1.2 has an average trestle distance of $2.9 \mathrm{~m}$ (total post-setting: $11.5 \mathrm{~m}$ ). Subtype 10.2.2, which also has four trestles, has an average trestle distance of $3.1 \mathrm{~m}$ (total postsetting: $9.2 \mathrm{~m}$ ), while subtype 10.1.3, which also has five trestles, has an average trestle distance of $2.5 \mathrm{~m}$ (total post-setting: $9.7 \mathrm{~m}$ ). Due to the different distances between the trestles, the four subtypes cluster in two average lengths of post-settings: 11.5 and $9.5 \mathrm{~m}$, both with a mixture of four- and five-trestle distances. Type 10.1.1 has a longer average trestle distance $(3.5 \mathrm{~m})$ than the other type 10.1 subtypes, and represents the longest group of type 10 houses, while type 10.3 houses are clearly the shortest type. Type 10.1.1 houses are mainly found associated with type 9 houses of medium length (30-35 m), while many of the larger type 9 houses (35-45 m) with a separate dwelling room in each end of the house have a smaller house attached to the farmhouse.

\section{House width, trestle width and trestle coefficient}

Only six houses have remains from the longitudinal walls, showing a house width between $4.4 \mathrm{~m}$ to 5.2 $\mathrm{m}$ (average $4.8 \mathrm{~m}$ ). The average distance from the entrances to the central axis of all the houses is $2 \mathrm{~m}$ near the gables and $2.2 \mathrm{~m}$ in the middle of the house. The entrances in the houses with documented longitudinal wall outlines are on average $0.4 \mathrm{~m}$ recessed from the wall. This indicates that the houses without documented walls had an average width of $4.8-5 \mathrm{~m}$. The type 10 houses are therefore almost $2 \mathrm{~m}$ narrower than the combined dwelling/byre houses (type 9) with which they are mainly associated (6.1-7.2 $\mathrm{m}$, average $6.7 \mathrm{~m}$ ). The narrow house width probably indicates that type 10 houses were intended for other activities than those taking place in type 9 houses.

The average values for the three subtypes of type 10.1 show that the longer the house, the wider the trestles. The average TQ for six type 10 houses with documented traces of the long wall is 2.4 (between $2.3-2.5)$. The roof was therefore normally built as a slightly under-balanced roof, with little weight on the walls - a type of construction also found in type 9 .

\section{Construction of the gables}

Traces of the gables have been found in 20 of the type 10 houses. 18 of these have remains of $1-4$ corner 


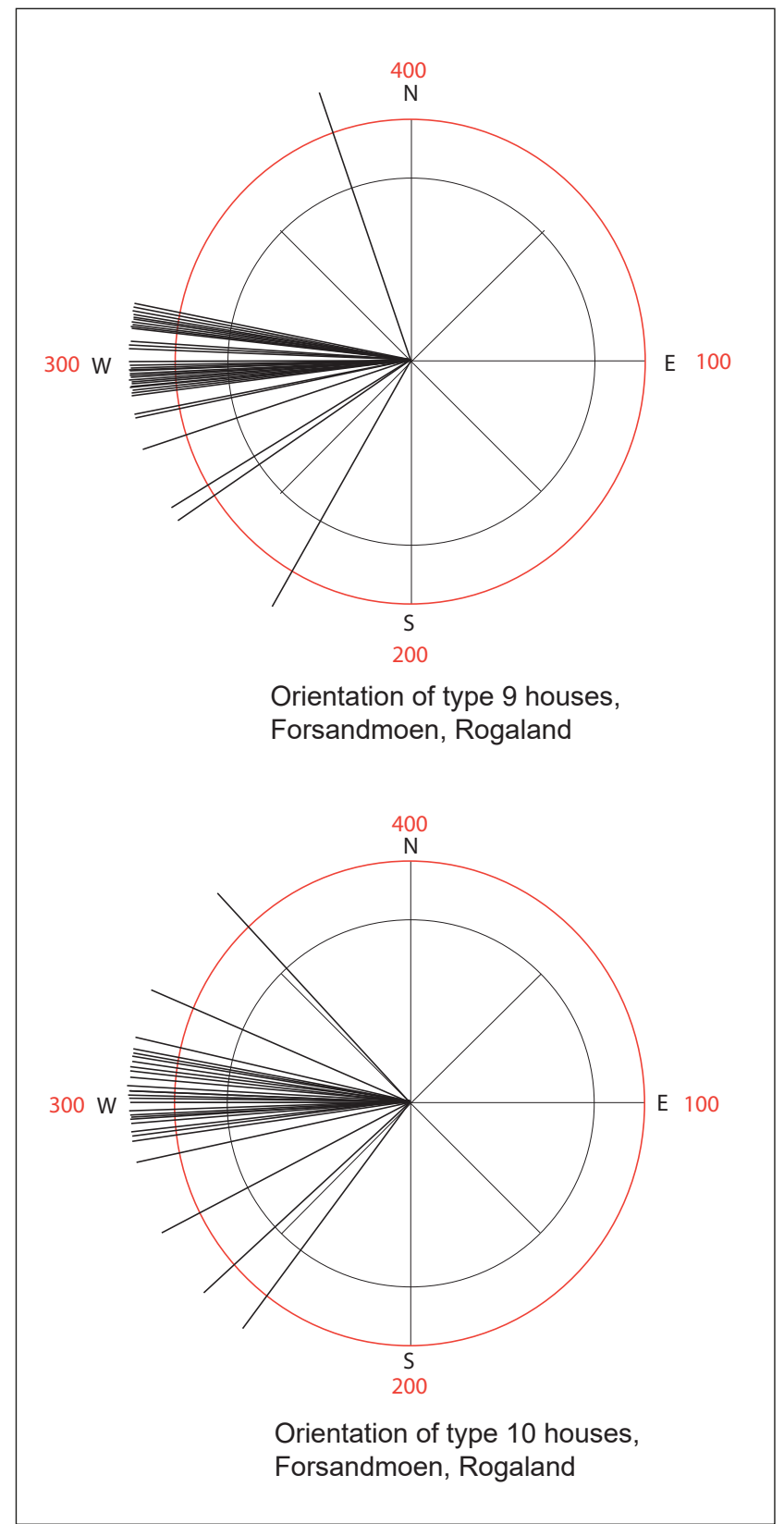

Fig. 63. Comparison of house orientation between type 9 and 10 houses.

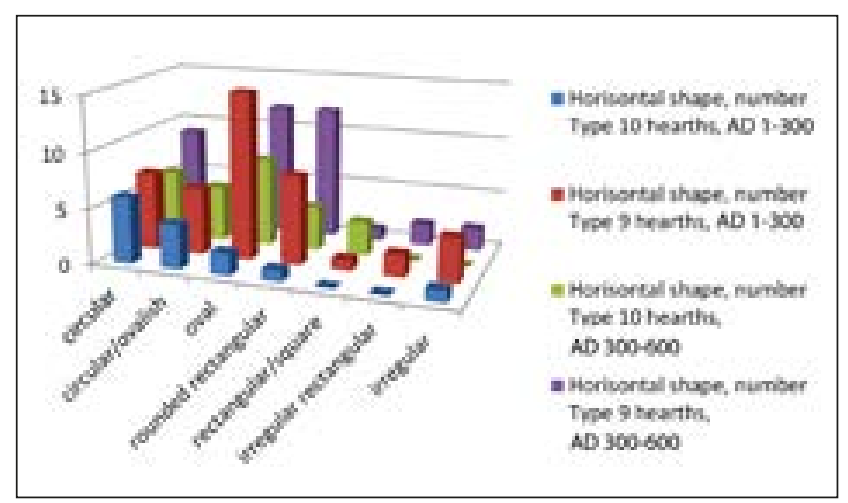

Fig. 64. Comparison of the horizontal shape of hearths between type 9 and 10 houses during two periods in the Roman Iron Age / Migration Period.
This is possible because the entrance in some instances is directed towards the farmland. But in the two houses 29 and 32A, two such entrances in each house open onto a $4 \mathrm{~m}$ wide farmyard between two houses, where a cart could not have been operated. The wide doorway was more likely made to provide improved lighting for domestic work, like weaving or forging. One $1.1 \mathrm{~m}$ interior door has been recorded in a house, representing an interior wall constructed between two trestles and just to the west of an entrance door.

\section{Hearths and cooking pits}

A total of 43 hearths have been found in 27 type 10 houses, among which 28 have been ${ }^{14} \mathrm{C}$ dated. With the exception of three hearths, association to another dated hearth located in the same house is also assumed to date the other twelve hearths. Nearly half of the hearths were situated in the central part of the houses. This is a quite different pattern compared to the type 9 houses, which never had hearths in the central area. The remaining hearths were found in the eastern and western gable rooms, but in contrast to type 9 houses, most of them were located in the eastern end. The wide distribution of the hearths in type 10 houses is an indication that these houses were intended for domestic activities such as toolmaking, food and garment preparation, and in a few cases also served as a smithy and probably as sleeping quarters.

The horizontal and vertical shape of the 43 hearths has been analysed and compared with the 83 hearths belonging to the type 9 houses. Seven horizontal and six vertical shapes have been recorded. Fig. 64 and Fig. 65 show the distribution of the different shapes from house types 9 and 10 and the time span between $1^{\text {st }}-3^{\text {rd }}$ and $4^{\text {th }}-6^{\text {th }}$ century.

Fig. 64 shows that three of the horizontal shapes were seldom used (rectangular/square, irregular rectangular and irregular), and when found, they belonged to type 9. The figure also shows that, in the first half of the period when the house types were used, the preferred horizontal hearth shape differs between the two house types. Circular and/or circular-oval hearths were mostly used in type 10 houses, while oval and rounded rectangular were preferred in type 9 houses. In the second period, the oval and rounded rectangular shapes still occurred twice as often as the circular ones in type 9 houses, while in the type 10 houses, the oval and rounded rectangular shapes became as frequently occurring as the circular ones.

Six vertical shapes have been recorded and Fig. 65 shows that only three of them were in frequent use in 
type 10 houses, while five of the types were often used in type 9. The shallow bowl was the most frequently used shape of the hearths in both house types and periods, while the deep bowl and the trough were less frequently used. Plain hearths occur in the early phase of house type 9 as opposed to none in the type 10 houses, which thus indicates that different activities took place in the two different house types.

\section{Shape and size of roof-bearing and entrance postholes}

Altogether, 224 postholes for roof-bearing posts and 90 entrance postholes have been documented in type 10 houses (Table 45 , folder). Both types have a 2:3 ratio of oval postholes compared to 1:3 of circular postholes; thus the ratio of circular postholes in this house type is twice as high as is documented in the type 9 combined dwelling/byre house (17\%).

The 154 oval postholes for roof-bearing posts measure on average $0.49 \times 0.63 \mathrm{~m}$ and $0.32 \mathrm{~m}$ in depth, which is $0.03,0.05$ and $0.01 \mathrm{~m}$ less than the average measurements from the same type of postholes found in type 9 houses. The 70 circular postholes, on average 0.5 and $0.32 \mathrm{~m}$ in depth, are $0.05 \mathrm{~m}$ smaller than those in type 9 houses, while the depths are equal.

Turning to the 90 entrance postholes, the 60 oval postholes measure on average $0.4 \times 0.55 \mathrm{~m}$ and $0.25 \mathrm{~m}$ in depth, which is also a few centimetres smaller than the similar postholes belonging to the type 9 houses. The 30 circular postholes have an average diameter of $0.42 \mathrm{~m}$ and depth of $0.23 \mathrm{~m}$.

These figures show that, in spite of the small width of the type 10 houses compared to type 9 houses (on average 4.8 and $6.7 \mathrm{~m}$ ), the similar size of the different types of postholes indicates that equally large timbers were used when building the two different house types. This is surprising since the shorter posts and beams and less weight from the roof in the smaller houses should be expected to entail a reduction in the size of the roof-bearing and entrance posts (Komber 1989). As the pollen analysis shows (Høeg 1999, PrøschDanielsen 1996, Prøsch-Danielsen \& Simonsen 1988), the forests in the Forsand area were greatly reduced in the Roman Iron Age and the Migration Period, so large timbers were not easily at hand. Maybe there was a fixed tradition for using specific dimensions when building the large houses that were expected to last for a long time?

14 occurrences of preserved traces of the roof-bearing posts (9) and entrance posts (5) are documented. Seven of the roof-bearing posts are between $25-30 \mathrm{~cm}$

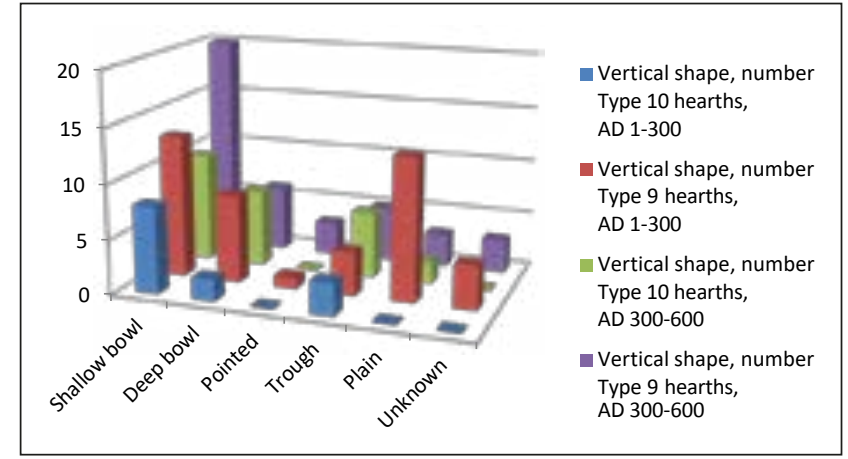

Fig. 65. Comparison of the vertical shape of hearths between type 9 and 10 houses during two periods in the Roman Iron Age / Migration Period.

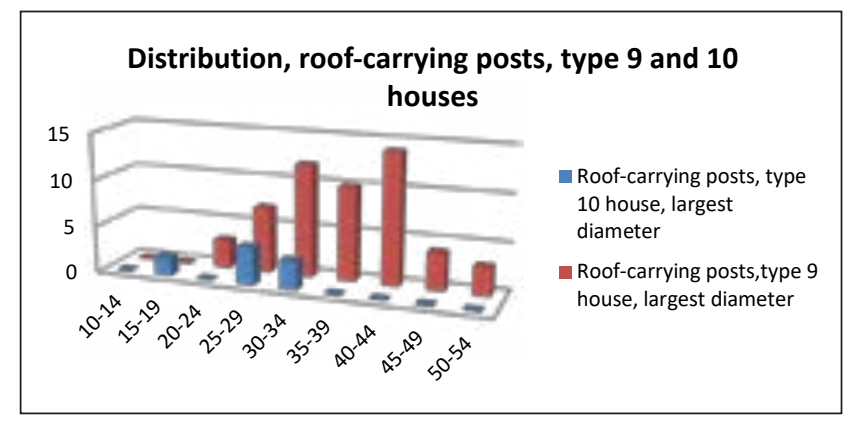

Fig. 66. Comparison between type 9 and 10 houses of the largest measures from roof-bearing posts $(\mathrm{cm})$.

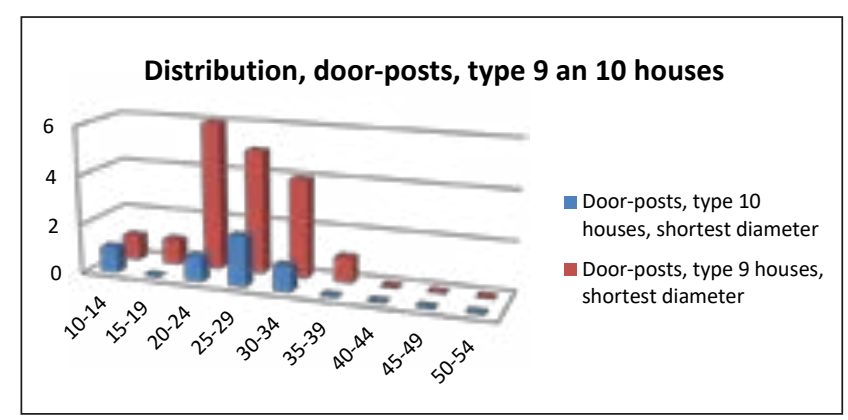

Fig. 67. Comparison between type 9 and 10 houses of the smallest measurements from door-posts $(\mathrm{cm})$.

and two are $15-16 \mathrm{~cm}$. Compared to the documented type 9 posts (Fig. 66), the type 10 posts cover only the lower part of the type 9 post distribution and below. This may indicate that the type 10 posts were smaller than the type 9 posts, even if the postholes were of a similar size.

The five traces of type 10 entrance posts fit well with the distribution of the type 9 entrance posts (Fig. 67). Due to the very restricted material of the actual post sizes in type 10 houses and due to the fact that the posthole sizes within the two house types in general showed that the type 10 postholes were somewhat smaller than those in type 9 houses, the conclusion must be that people followed the same idea when building those two house types. 


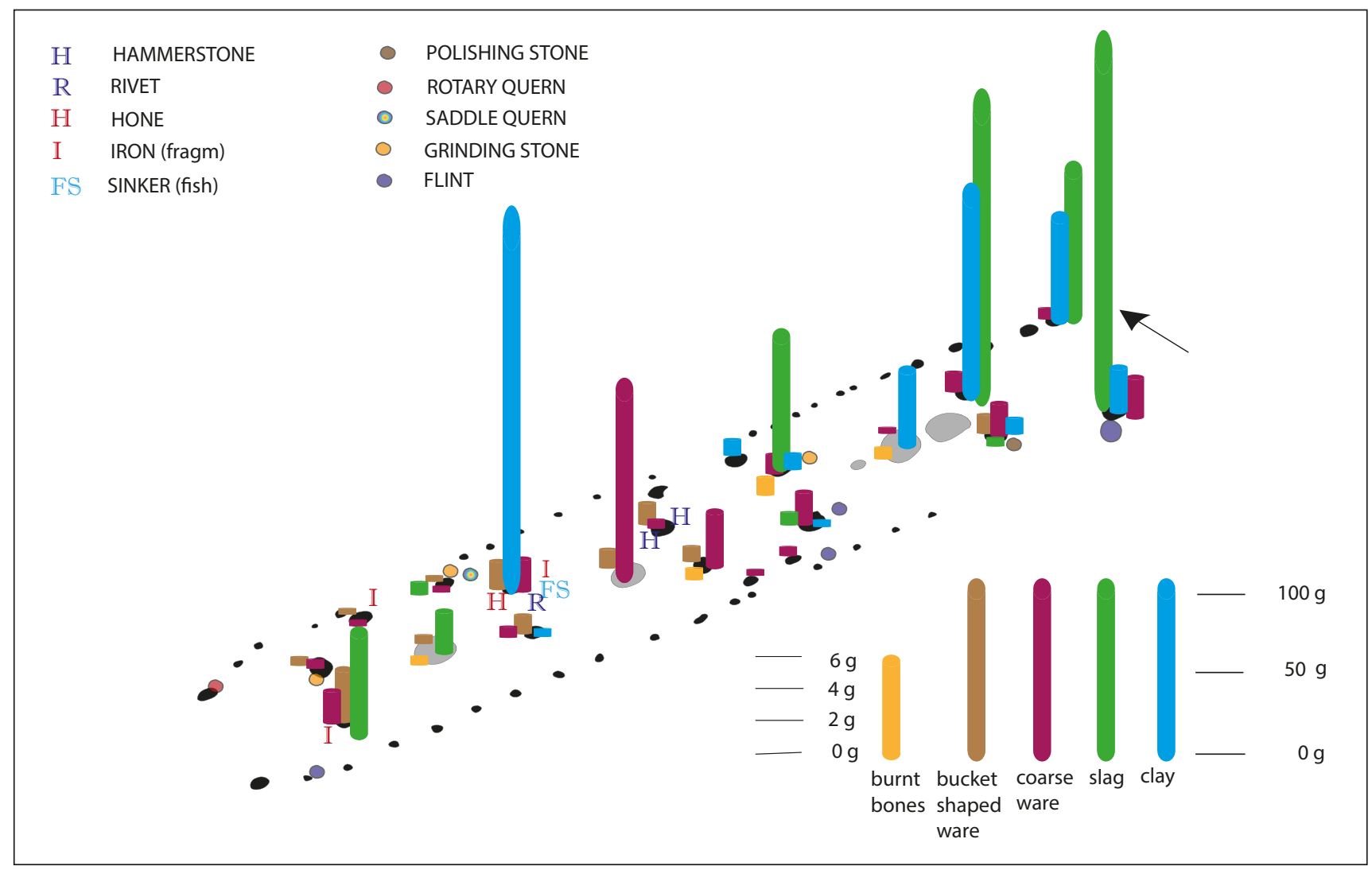

Fig. 68. Distribution of five find units from type 10 houses.

\subsection{Structure of the houses and distribution of the finds}

As shown in Fig. 62, all subtypes normally have two entrances, either in the northern or in the southern long wall. In most instances, the entrances are situated in the outermost rooms adjacent to the gable rooms, but in several houses, one of the two entrances was instead situated in the gable room. This pattern is similar to type 9 houses. However, in type 9 houses, the norm is opposed entrances in either end of the longitudinal walls. The two houses 29 and 151 have such a pair of opposed entrances in one of the central rooms, giving multiple accesses to all parts of the house. Most of the hearths are situated in rooms without entrances, but in six houses, the entrance gives direct access to a hearth. The remains of a smithy were found in two of these. When two or more hearths were found in a house, they were preferably located in different rooms along the axis and also centrally in the room. This pattern shows that the entire house could be heated so that different activities could be undertaken simultaneously in different parts of the house. Due to the number and location of hearths, it does not appear likely that these houses were used as byre. What kind of activities that took place in these houses might be uncovered by analysing the distribution of the finds in the houses.

Like the analysis of the finds in the type 9 houses, the distribution of finds in the type 10 houses has been graphically illustrated with columns reflecting the amount of five different types of material (buckedshaped pottery, coarse ware, clay, burnt bones, slag) that occur in the houses (cf. type 3 and 9 houses) (Fig. 68). In addition, the figure also shows the distribution of items that occur infrequently.

Sherds of bucket-shaped pottery are found in rather small quantities in the western half of the houses, as was also the case in the type 9 houses without hearths in the eastern end, but the amounts are much smaller compared to in type 9 houses. What is also interesting is that decorated fine ware has not been found in type 10 houses, indicating that these houses were not used for important meals. On the other hand, coarse ware has been found in all parts of the type 10 houses, indicating that meals had been cooked with this type of pottery throughout the house. Alternatively, the coarse ware had been used as storage jars. The fairly even amount of pottery in the different postholes throughout the houses does not point to any preferred area for such activity. Except for one large find of coarse ware in a central hearth, and as opposed to the situation 
in type 9 houses, pottery has not been found in the hearths of type 10 houses, indicating a different use of the hearths in the two house types.

Contrary to the very few slag finds (5 finds of altogether $43 \mathrm{~g}$ ) in type 9 houses, the type 10 houses have 15 finds of slag $(765 \mathrm{~g})$ from postholes and one hearth in all parts of the house. Metalworking was therefore likely a normal activity in type 10 houses, while such work hardly took place in the type 9 houses.

Pieces of burnt clay have also been frequently found in type 10 houses, mostly in the eastern half of the houses. Despite the fact that the number of type 10 houses is half that of the type 9 houses and that the floor area of the type 9 houses is at least twice as large as that of type 10 , more than $80 \%$ more clay was found in the type 10 houses compared to what was found in the type 9 houses.

The amount of burnt bones in type 10 houses $(2.4 \mathrm{~g})$ is very modest compared with in type 9 houses (45.1 g). Maybe preparing meat seldom took place in this type of house. The frequently occurring cooking pits in the farmyard to the south of the SW entrances in type 9 houses indicate that meat was prepared outdoors and consumed in the main hall room of type 9 houses.

Other finds are quite scarce in the type 10 houses (Fig. 68) compared to type 9 houses (cf. Fig. 86). However, most of the types of finds found in type 9 houses are also present in type 10 houses. Probably most daily work that needed to be undertaken on a farm was undertaken in both type 10 and type 9 houses. The distributions of the different types of finds, such as iron objects, sinkers, hones, hammer stones and querns, are found only in the western part of the house - just as in type 9 houses. Flint and grinding/polishing stones are mainly located in the eastern part, indicating that there were different areas for different types of activities.

\subsection{Comparison between Forsand and the Nordic region}

As shown above, the workshops from Forsand were all built according to certain ideas of how such a building should be constructed and organised. A few type
10 houses have been found elsewhere in Rogaland, for instance at Høgevollen, Egersund (Steen 1995:15) and Austbø, Stavanger (Hemdorff 2006:6-7), which show that this type of workshop had a wider distribution than Forsand. In both situations, the 4.5-5 m wide type 10 houses were located parallel to and at a distance of 4-5 $\mathrm{m}$ from a large dwelling/byre house from the late Roman Iron Age and Migration Period.

Smaller houses are normally found in connection with the larger combined dwelling/byre house in all parts of the Nordic region in the Roman Iron Age and the Migration Period. As shown in chapter 10, no type 9 houses were found in the Danish area or the southernmost part of Sweden (Scania). The additional smaller houses in these areas do not show a structure resembling the type 10 houses at Forsand. From the northern and central part of Sweden, where the type 9 houses are well known (Eriksson 1995, Göthberg 2000:56ff, Liedgren 1992, Olausson 1998, Ramqvist 1983), it is also difficult to find workshops with a close resemblance to type 10, but a small house is often situated parallel to or at right angle to a large combined dwelling/byre house. The best example seems to be the settlement at Genesmon, Ångermanland, where three narrow workshop houses (IV, VIII, IX: 13-23 x $5 \mathrm{~m}$ ) were parallel to and at a distance of 6-13 $\mathrm{m}$ from the two large (39-42 x 7.7-8.5 m) dwelling/byre houses I-II. The finds of fragments of moulds and crucibles from the workshop houses show that they were used for casting brooches. The workshops at Genesmon are not comparable with those at Forsand at a more detailed level, but their size and location in relation to the dwelling/byre houses represents the same concept for a farm as is predominant at Forsand.

At present, the type 10 workshop houses from Forsand have not been found outside of Rogaland and may represent a regional building type. In many ways, the house type is a diminished type 9 house, where many of the activities that took place in the western end of the type 9 houses were also performed there. Forging and metal work is the only additional activity that has been demonstrated in type 10 houses. 


\section{Type 17: Small rectangular workshop}

This house type consists of two pairs of circular postholes for roof-bearing posts making an E-W oriented rectangle larger than $6.1 \times 3.4 \mathrm{~m}$; symmetrically situated between the western pair of roof-bearing postholes is a pair of entrance postholes.

This type consists of the three houses 18, 112 and 184 (Fig. 69). They are larger than the type 18 four-post granaries, measuring $6.1 \times 3.4 \mathrm{~m}$ to $6 \times 5.5 \mathrm{~m}$, while the largest type 18 four-post house measures $4.5 \times 3.9 \mathrm{~m}$. Compared to the four-post buildings with an average area of $7.2 \mathrm{~m}^{2}$, the average floor area of type $17\left(24.4 \mathrm{~m}^{2}\right)$ shows that it is a different type of building. The houses have a few other features, but not all features are found in all the houses. Two houses have additional postholes in the E-W oriented sides, aligned with the corner postholes; one of them also has one posthole in the middle of the eastern side, while the last one has two interior postholes. Lastly, one house also has an entrance in the eastern side. The four main postholes in the construction are approximately equal in size and depth $(0.3-0.35$ $\mathrm{m}$ in diameter and $0.17-0.25 \mathrm{~m}$ in depth).

The entrance postholes in each house are markedly larger than the four corner postholes in the house. They measure between 0.35 and $0.6 \mathrm{~m}$ in diameter and are from $0.1 \mathrm{~m}$ to $0.37 \mathrm{~m}$ in depth. In addition to serving as doorframes, they were therefore most probably also part of the roof-bearing construction.

All three houses are so large that they cannot have been constructed without additional roof support in addition to the four corner posts. This has been solved in different ways. Probably by two narrow trestles of large posts in house 18, which also served as doorframes, or by a post in the eastern end of house 184 to support a roof ridge where the doorframes in the other end supported a short post beneath the roof ridge. In house 112, two internal posts probably supported the roof.

The two longitudinal walls of the most rectangular house, 184, were divided into three $2 \mathrm{~m}$ sections by two small postholes, indicating that the walls had been constructed as bole walls.

This type of house is only recorded once outside Forsandmoen: at the Pryssgården site in Östergötland, Sweden (Borna-Ahlkvist 1998:49). The house was smaller $(4 \times 4.5 \mathrm{~m})$ but had the same construction as in house 184, except for having only one wall post in the long walls. The house is dated to the Viking Period, and Borna-Ahlkvist (1998:50) compares the house with the large four-post houses from Fosie and the Köpinge area (Björhem \& Säfvestad 1993:293, Tesch 1993:192). To my mind, none of those houses represent the same type as the ones at Forsand or house 209 from Pryssgarden. The Pryssgården house is also interpreted as having bole wall. No interpretation concerning function has been made.

The three houses are located in each of the three main late Roman Iron Age and Migration Period settlement areas (Areas A, B and E). Two of the houses have been ${ }^{14} \mathrm{C}$ dated to late Roman Iron Age or early Migration Period and confirm that the houses belong to farms from that period. The undated house 112 is located right to the south of a four-phased farm with the longhouses 105, 106A, 106B, 107, dated to the late Roman Iron Age and Migration Period, and $20 \mathrm{~m}$ west of another such four-phased farm. Considering the uniform construction of the three houses, it is likely that the undated house also belongs to the same period as the two dated ones.

All three houses seem to be an additional special purpose building associated with the normal farm from the period, consisting of a large longhouse with an area for human occupation as well as a byre and storage areas

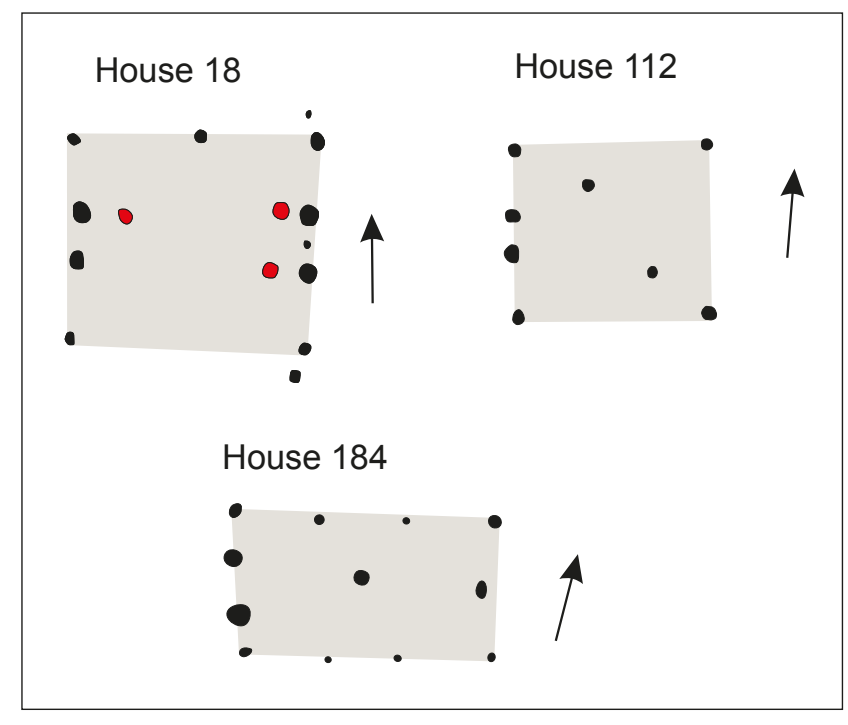

Fig 69. House plans of three small, square workshops of type 17. 
for food and fodder and a smaller workshop house. Despite the similar construction, the houses of type 17 seem to have served different functions: house 18 as a workshop for either an iron smithy or bronze casting; judging from the amount of slag and burnt clay, whereas house 112 was probably used for threshing crop from barley and wheat, judging from finds of spikelets from chaff and approximately 330 charred grains from barley and wheat. The last one, house 184, did not contain anything to indicate what activities that had taken place. 


\section{The life expectancy of houses}

\subsection{The life expectancy of post-built houses}

For how long did the individual wooden longhouses at Forsandmoen exist? This is a crucial question for the understanding of the settlement, especially the number of contemporary farms. Danish, German and Dutch archaeologists have suggested that three-aisled houses with earth-founded posts have a short life expectancy. The excavations at Feddersen Wierde (Haarnagel 1979) were an important contribution to this assessment; there, it was possible to establish eight settlement phases within the occupation period of the Wurt, giving a mean 30-40 year lifespan of a house before a new house was built. Gerritsen (2003:39) refers to the fact that the life expectancy depended not only on the durability and diameter of the wooden posts and type of soil, but also the lifecycles of the inhabitants. Ijzereef and van Regteren Altena (1991:74f) estimate that an alder post in a West Friesland house would have a lifespan of 16-24 years. Consequently, a house would not last for more than 25 years. They suggest that oak posts $(0.15 \mathrm{~m}$ in diameter) would increase the possible lifespan to 60 years. A much-repaired house in the Assendelver Polders is believed to have been inhabited for 35 years (Therkorn 1987:219). Given the sandy soils in the eastern Netherlands, which are believed to yield poorer preservation conditions than the clay and turf soil in the polders, Gerritsen (2003:39) assumes that, even when using oak posts, houses in such soil would only have lasted for 20 years or slightly more.

Zimmermann (1998:50-63, 180) discusses the life expectancy question in detail and concludes that earthfast post constructions may survive between 10 and 100 years, normally between 10 and 50 years, depending on a series of conditions. He regards the different climate as an important factor to the longer life expectancy proposed in Scandinavia compared to Germany and Netherlands. Zimmermann also refers to the 43-year-long research project Field Stake Test (Purslow 1976, Purslow \& Williams 1978), where core and splinter stakes $(5 \times 5 \mathrm{~cm}$ in cross section $\times 60 \mathrm{~cm}$ in length) from 16 different species and all from different parts of Europe were set down in different types of soil in England. The lifespan of the post was defined by when the stake broke with a certain force by a hammer, meaning that the stake at this time was totally rotten. Not surprisingly, oak had the best preservation against decaying, up to 43 years in clayish soil and more than 60 years in sandy soil (Zimmermann 1998:55). Yew could last for 15 and 26 years, respectively, while pine and larch lasted 15 and 18 years. Zimmermann finds that a $10 \times 10 \mathrm{~cm}$ post would last twice as long as these figures presented above. Consequently, the oak posts at Forsand, which are $20 \mathrm{~cm}$ in diameter, would be expected to last for an average of approximately 200 years and the pine posts for $60-70$ years.

An interesting view has been put forward by Reynolds $(1994,1995)$ concerning the consequences for the house construction when the earthfast posts are heavily decayed. He claimed that the dug-down posts are necessary when erecting a building, but thereafter a building with bracing members would be still standing even if the earthfast part of the posts had vanished and the posthole was filled with stones and soil. Berglund and Sjölin (2005:35) also point to the possibility of replacing the decayed parts of the post with stones to support the post at ground level, and thus increasing the life expectancy of the posts without detectable traces in the posthole. House 1 at Ullandhaug (Myhre 1980), where 14 roof-bearing posts were set on flagstones and only two were dug down, is an example of the limited need for earthfast posts from a constructional point of view (Komber 1989:42). The focus on the life expectancy of posts is therefore probably less important than other cultural and maintenance factors when it comes to the lifespan of individual houses. Ängeby (1999:11f) has pointed to a strong symbolic and ideological meaning attached to the farmhouse and the central hearth. The life expectancy will therefore also depend on ideological and social factors as well as technical and economic choices. However, since the question of the life expectancy of earthfast posts is regarded as crucial for understanding the lifespan of the houses, I will discuss this issue in more detail below. 
Simonsen (1996:96) has tentatively proposed that the lifespan of Bronze Age houses at Thy in Denmark was 30 years, based on the understanding that even firm oak posts would only survive for such a short time in Danish soil. Based on a series of ${ }^{14} \mathrm{C}$ dates, Ethelberg (2000:203-209) analysed an Early Bronze Age settlement at Br. Gram in southern Jutland and concluded that large Bronze Age halls could last for as long as 100 years, while normal sized houses, $20-30 \mathrm{~m}$ in length, would have a life expectancy of 50-60 years. He also found such a lifespan likely at the Højgård settlement, based on the assumption that the Early Bronze Age houses there represent only one farm at a time. Thus, each of the 13 longhouses were standing for an average of 60 years during the 800 years of occupation. But as Artursson (2005b) pointed out, the interpretation of the individually situated farm represents a traditional view and the settlement more likely consisted of two or more contemporaneous farms. His proposal (2005b:133) of a clustered settlement with four farms in three phases is, however, not more plausible. This is because with three phases, the lifetime of a house would have been 200 years or more, given the occupation period from $1800 / 1700-1100 / 1000 \mathrm{BC}$. The clustering of the houses indicates that there was more than one house at a time, so Højgård might have consisted of one farm in some periods and 2-3 farms in others.

Björhem and Säfvestad (1993) have analysed the possible lifespan of the Bronze Age houses at Fosie IV in Scania, Sweden more thoroughly. Based on documented renewal of roof-bearing posts, the amount of clay taken from contemporary pits nearby the houses, knowledge from modern times of how often small and more comprehensive repairs of the daubed walls had to be undertaken, as well as the chronology at the different sites, they concluded that a house with no or little signs of post renewal may have lasted between 80 and 140 years - in mean 100 years (Björhem \& Säfvestad 1993:143). One house, where nearly all posts had been renewed, is thought to have existed for 200 years.

Björhem and Säfvestad did not evaluate how long the roof-bearing posts could last in the sandy moraine clay, which is the basis for Simonsen's analysis. The two analyses can therefore not be directly compared, but in my opinion, the evaluation made by Björhem and Säfvestad is more reliable because it is based on empirical calculations and not a "supposition concerning the lifespan of the houses" (Simonsen 1996:96, author's translation).

If the roof-bearing posts were made of oak and sufficient protection techniques were practiced, Gröhn
(2004:330) thought that a house in Scania could last for as much as 100 years. Also Arén (1992:122) stated that oak in Uppland, Sweden would last for as much as 90 years without decaying severely. A lifespan between 75 and 100 years has also been proposed by Götberg (2000) concerning the Mälar region. Artursson (2005b) discusses a few Late Neolithic and Bronze Age settlements in South Sweden and Jutland. He reinterpreted the Limensgård site, Bornholm (2005b:105) and suggested that it consisted of three phases with 3-4 farmhouses within a 350-year period (2050-1700 BC); this would imply a 120-year mean lifespan for a house. At the Br. Gram site (2005b:137f), he concluded that the lifespans for the different houses were between 50 and 100 years, well in accordance with Ethelberg's view.

Concerning the Iron Age, Ethelberg (2003:250-253) suggests, in his analysis of the Hjemsted Banke, that a main longhouse could expect to be replaced within no more than $30-35$ years. At Hodde (Hvass 1985), the settlement is divided into three phases covering 150 years. Seven of the byre houses were used throughout the whole settlement period. With varying amounts of the roof-bearing posts replaced, those houses existed for more than 100 years. However, most houses had shorter lifespans within a part of the settlement period, so a more average lifetime was probably $50-80$ years and posts were not replaced in those cases. Herschend (2009:231) finds that the life length of the houses from the early Roman Age settlement at Vendehøj in Jutland was at least 60 years. Ängeby (1999:22f) finds that the ${ }^{14} \mathrm{C}$ dates from the houses at Orred show that the youngest house $2 \mathrm{~b}$ had a lifespan of 200-250 years, and Ramqvist (1983) interprets the houses at Gene as having a 200-year lifespan.

\subsection{The life expectancy of type 3 and type 9 houses at Forsand}

This overview shows that the lifetime of houses similar to type 3 and type 9 at Forsandmoen is regarded to be longest in Scania (80-140 years), 50-80 years in Jutland, 30 years in NW-Germany and only 20-30 years in the Netherlands. Since these estimates vary so much, they are unfortunately of little help when assessing the lifespan of the buildings at Forsandmoen. In the following, I will investigate the different general and local factors that would have affected the lifespan of a house. The question of lifespan is an important one, since the shorter it is the more houses need to be built within a given time period. Establishing a use-life for the houses can make a huge difference between 
interpretations of the settlement as either an individually situated farm repeatedly rebuilt and relocated, or a small, nucleated hamlet.

\section{Life expectancy of houses from the perspective of ideology}

One understanding of the lifespan of a house is that it may be compared to a newly established couple (Gerritsen 1999:140ff). In that line of thought, a new house is built for a newly married couple, new houses are built for their children, and when the old couple either die or move into their children's house, the old house would be left to rot. Such a house would show no signs of renewal of the construction and would hardly exist for more than 20-30 years. Even though this line of thought is interesting, my view of this question is a more practical one. Considering the investment of time and resources required to erect a medium sized type 3 house in the Bronze Age or in early Pre-Roman Iron Age society at Forsandmoen, and considering the knowledge of the tool types people had at their disposal (for instance small socketed bronze axes) and the type of agriculture on which their subsistence depended, it appears reasonable that the inhabitants would have put considerable effort into the maintenance of the houses so they could last as long as possible. Symbolic rituals in connection with the building of new houses and the demolition of old ones could be included into this. However, I think it is less helpful to use analogies from warmer areas (Madagascar, as Gerritsen has used), where houses of lighter construction represent substantially less building costs than in the Nordic region. It is also worth mentioning that, in Norwegian medieval laws, a tenant farmer had the right to tear down and take away the materials from the houses to a new farm, showing a very different attitude to a house as a lasting home for generations.

\section{Physical conditions that determine the life expectancy of houses}

The condition of the roof-bearing posts is the crucial factor for how long a house could last before it had to be abandoned. The decaying processes mainly took place in the part of the post buried in the ground, particularly where the conditions frequently changed from moist to dry, which is the case for the level immediately beneath the floor. If a house is well looked after and the roof does not leak, the superstructure, preserved by smoke from the hearths, would last as long as the buried part of the posts would permit in the environment. Wattle and daub walls had to be repaired and rebuilt frequently through the lifespan of the house (Björhem \& Säfvestad 1993:141) and would not be a deciding factor for its overall life expectancy. The factors that influence the decaying process of the roof-bearing posts in the soil the houses at Forsandmoen should therefore be investigated in more detail.

The Forsandmoen plain, deposited in front of the terminal moraine Vassrygjen, consists of $35 \mathrm{~m}$ deep sloping layers of coarse gravel. This type of gravel has low vertical capillary ability, so inside a house, the gravel will be almost dry only a few centimetres above the ground water table, which is far down in the gravel, well below the house. Due to the surrounding mountains the local climate is characterised by much rain and snow in autumn and winter, up to $1,700 \mathrm{~mm}$ annually in recent years. Large amounts of rainwater falling down on the thatched roofs would have ended up in the ground along the walls, where it would either have been redirected by ditches along the wall courses or absorbed into the ground, where it would have sunk down to the water table. The lack of wells at Forsandmoen shows that water could not be collected in this way, opposed to the situation known from many other areas, where wells demonstrate that the groundwater table is much higher in clayish and/or sandy soils. Due to the mentioned low capillary ability, rain water would also hardly find its way horizontally $1.5-2 \mathrm{~m}$ from the outside of the house into the ground beneath the house and cause moist conditions around the posts. This differs from what can be seen at settlements situated on clayish or sandy-clayish soils, where the capillary ability is much higher. This means that, $50 \mathrm{~cm}$ above the ground water table, a sandy-clayish soil contains $20 \%$ water as opposed to less than $5 \%$ in coarse gravel.

Soil scientist Prof. Emeritus Langohr, University of Ghent, has kindly elaborated on this problem (personal communication: e-mail of 22 June 2007). In moist conditions, hardwood with tannins (antiseptic substances), as are present in an oak post, will last for $50-80$ years and, in dry conditions (above the ground water table), for more than a century. This is 5-10 times longer than birch wood. The posts will also last longer in acidic soils - as is the case at Forsandmoen - than in alkaline environments. If the capillary ability of clayish soil inside a house is maintained, such soil will be much worse for the post's preservation than sandy soils. However, if the clayish soil or a clay floor dries out and cracks, the capillary ability will be broken, and dry conditions will occur around the posts. A deep-water table, coarse gravel and a cracked clay floor would provide excellent 
Fig. 70. Two wooden nails with different tree ring span; the nail to the left represents extremely slow annual growth compared to the one to the right (photo: Å. Pedersen, AM, UiS).

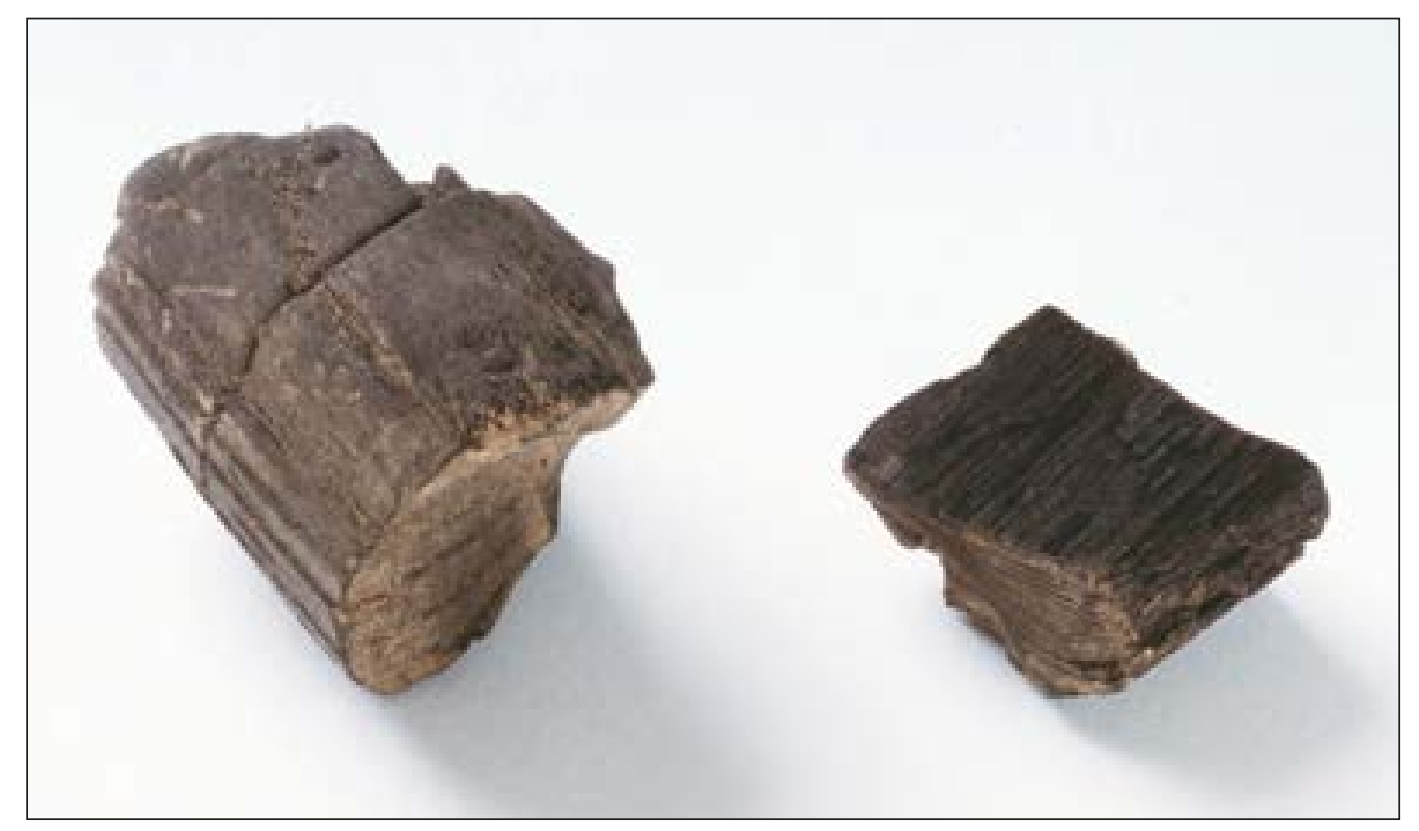

preservation conditions for posts, while a high water table, clayish soil and a clay floor that has not cracked would provide poor preservation conditions.

The most important factor in determining the lifespan of the roof-bearing posts is, therefore, the depth of the groundwater table combined with the type of soil. Forsandmoen has the best combination of these factors, while in southern Scandinavia, conditions seem less favourable for a similarly long lifespan of the posts.

There are also other features that may influence the preservation of the posts: the type of wood and its treatment. During the course of the Bronze Age, the Forsand plain became farmland without forest, and thus the posts had to be made from trees grown in the less fertile, rocky hillsides. The oak and pine charcoal from the postholes show that the wood often had quite narrow tree-rings, which is to be expected for slow-growing trees. This would have given better resistance to decaying processes than among trees that had grown faster on more fertile land. The fragments from wooden nails (Fig. 70) are good examples of slow-growing pine trees with great resistance to the rotting process. The pine trees also have an advantage compared to the preferred oak wood in southern Scandinavia because if one cuts the tip of the tree and lets it grow for a number of additional years, the cells will be filled with resin (Godal 1994:54). The technique is well known from still-standing Early Medieval buildings. Pine tar extraction kilns are dated back to the $11^{\text {th }}$ century AD, but the use of pine tar in boats is known from the Roman Iron Age onwards (Rolfsen 2002:261), which demonstrates that the preserving effect of pine tar was recognised at least from the Roman Iron Age.
In one of the first years of the project, the farmer told us that the fence around our first excavation area, with radially split oak and pine fence posts $(10 \mathrm{~cm}$ wide) still in good condition in the buried part, had been made by his father approximately 60 years earlier, when the field was cleared of stones. It is therefore reasonable to assume that the $20 \pm 5 \mathrm{~cm}$ posts in the type 3 houses could have lasted for a markedly longer period of time.

Yet another factor is worthwhile mentioning: quite frequently, the stones in the postholes seem to have been placed around the post as if to wedge the post in the hole. In many cases, the posts had been set on a slab or stones so that they were lifted free from the bottom of the posthole and away from possible moisture in the ground. The shallow depth of the postholes compared to the total post length cannot have given much lateral stability to the construction. It is therefore possible that the stone lining was not so much a measure to wedge the posts but to insulate them from the surrounding soil. Since the postholes around the post and stones were not filled with earth, sand or gravel, the post would not have suffered as much from the decaying processes as posts where soil was tightly packed around the post. Thus, the bottom part of the post would last as long as the upper parts, which could be centuries if the roof and the walls were maintained properly.

Another factor that may have influenced the lifespan of a house was the temperature and especially the length of winter, when lower temperatures reduce the activity of small organisms, bacteria and the like. Low temperatures with snow will probably result in a slower decaying process than a warmer climate with changing temperatures around zero. This would especially affect 
a wattle and daub wall construction. The walls at the inland valley settlement at Forsand could last longer than settlements along the western coast of Jutland or in Scania. In any case, such walls had to be maintained (small re-daubing, larger repairs or even new walls) during the time that the main frame construction could last. Björhem and Säfvestad (1993:141) supposed that house 81 at Fosie IV, which has double postholes throughout the roof-bearing structure had lasted for as long as 120 years. They reckoned that a thatched roof, which at most lasts for 50-60 years, had to be renewed once or twice during this period.

\section{Type 3 houses}

Based on the above discussion, the post-built houses at Forsand normally had a life expectancy of 80-100 years. This conclusion is drawn based on the combined type of ground material, construction material and climate. It is quite likely that many houses would have lasted longer than this period, rather than shorter. This is in accordance with the assessments presented above based on comparative data mainly from central and northern Sweden. Since most of the type 3 houses have only one phase and one ${ }^{14} \mathrm{C}$ date, it is thus not possible to use ${ }^{14} \mathrm{C}$ dates to get a better assessment of the life expectancy of type 3 houses.

\section{Type 9 houses}

Three or four type 9 houses were erected in approximately the same spot at five different locations at Forsandmoen in such a way that they must have been erected in a continuous sequence of houses. In the following, I will examine the dating evidence for these locations and six other situations with many ${ }^{14} \mathrm{C}$ dates in order to assess the time span of the sequence and thus the average lifespan for these Roman Iron Age and Migration Period houses. A presumption of this analysis is that the three or four houses at one location were built without a fallow phase between each new house.

It is, of course, not possible to attain a precise lifespan for each individual house in a sequence of 3-4 houses due to the uncertainties of the calibrated dates from each of the houses. However, it is possible to assess the time differences between the different dates and calculate the average time span from the earliest to the latest date. Still, since each calibrated date has a time span within a 1 sigma probability, it is necessary to choose a certain method for this calculation. I have therefore chosen the middle date from each calibrated date to assess the time gap between the phases, and the date is regarded as representing the last use of the hearth in that house phase. I have also chosen the earliest date as the starting date for the erection of the second phase and the latest date as the time of abandonment of the latest phase in my attempt to calculate the average lifetime for the 2-3 latest phases in the house sequence. Hopefully, this investigation, covering five such late Roman Iron Age and Migration Period sequences, each consisting of four houses, or phases, and in addition six houses with two to six dates each, can shed some light concerning whether the lifespan was only 30 years, as assumed by most Danish archaeologists, as much as 100 years or beyond, as suggested by some Swedish archaeologists, or something in between.

\subsection{Eleven radiocarbon dated house sequences}

In the following, I examine eleven house sequences, i.e. houses that overlay each other and represent a continuous habitation on more or less exactly the same location.

\section{House sequence 1}

Houses 105, 106 and 107 were situated just west of a circular burial mound in the NE corner of Area A (Fig. 52). House 106, oriented due E-W, was renewed and the structure changed in the dwelling area, still using a lot of the old postholes for the roof-bearing posts; therefore house 106 and its second phase are regarded as two different houses and thus phases. Most of house 107 is situated in the same area as house 106, but at a slightly different angle (WNW-ESE), while the western end of house 105 covers the same area as house 106, but due to the WSW-ENE orientation, the eastern end of house 105 is situated north of the eastern end of houses 106 and 107. The sequence then represents the four phases presented in Fig. 71, which also includes the radiocarbon dates from the houses. The dates cover a period from the turn of the early to the late Roman Iron Age to the later part of the Migration Period. If we regard the middle value of the earliest date from house 107 (AD 225), representing the last use of the hearth, as the time of the erection of phase two and the middle value of the latest date as the abandonment of phase four (AD 490), the average lifespan of phases 2-4 would be 90 years.

\section{House sequence 2}

Immediately east of house sequence 1 , sequence 2 consist of houses 116, 135, 132 and 141 and was located 


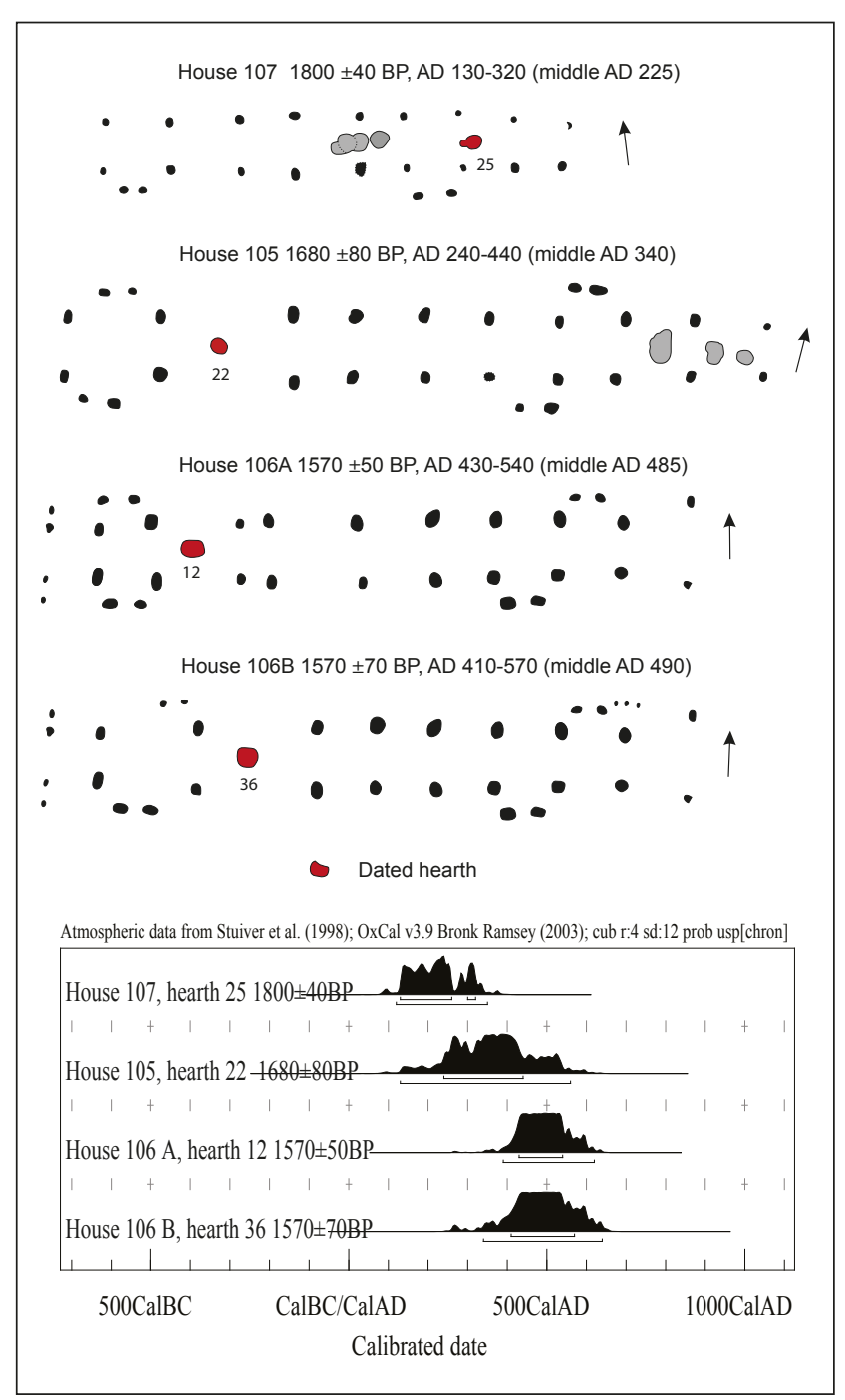

Fig. 7I. House sequence I: Four type 9 houses: 106, 105, 106A and 106B.

south of and partly below the burial mound. The houses all had the same alignment but differed somewhat in their N-S location, but all four covered the central part of the house area. As can be seen in Fig. 72, the dates from the four phases cover approximately the same time sequence as houses 105-107. The middle value of the earliest date from house 116 indicates that phase two was constructed around AD 230 and the middle value of the latest date indicates that the abandonment of phase four took place around $\mathrm{AD} 480$, giving an 85-year average lifespan for phases 2-4.

\section{House sequence 3}

In the middle of Area E, also just south of a burial mound, there was a house sequence consisting of the three houses 198, 200 and 201. They had the same E-W alignment and were located along the same central axis. The younger houses partly used postholes originally dug for the older house and partly new postholes

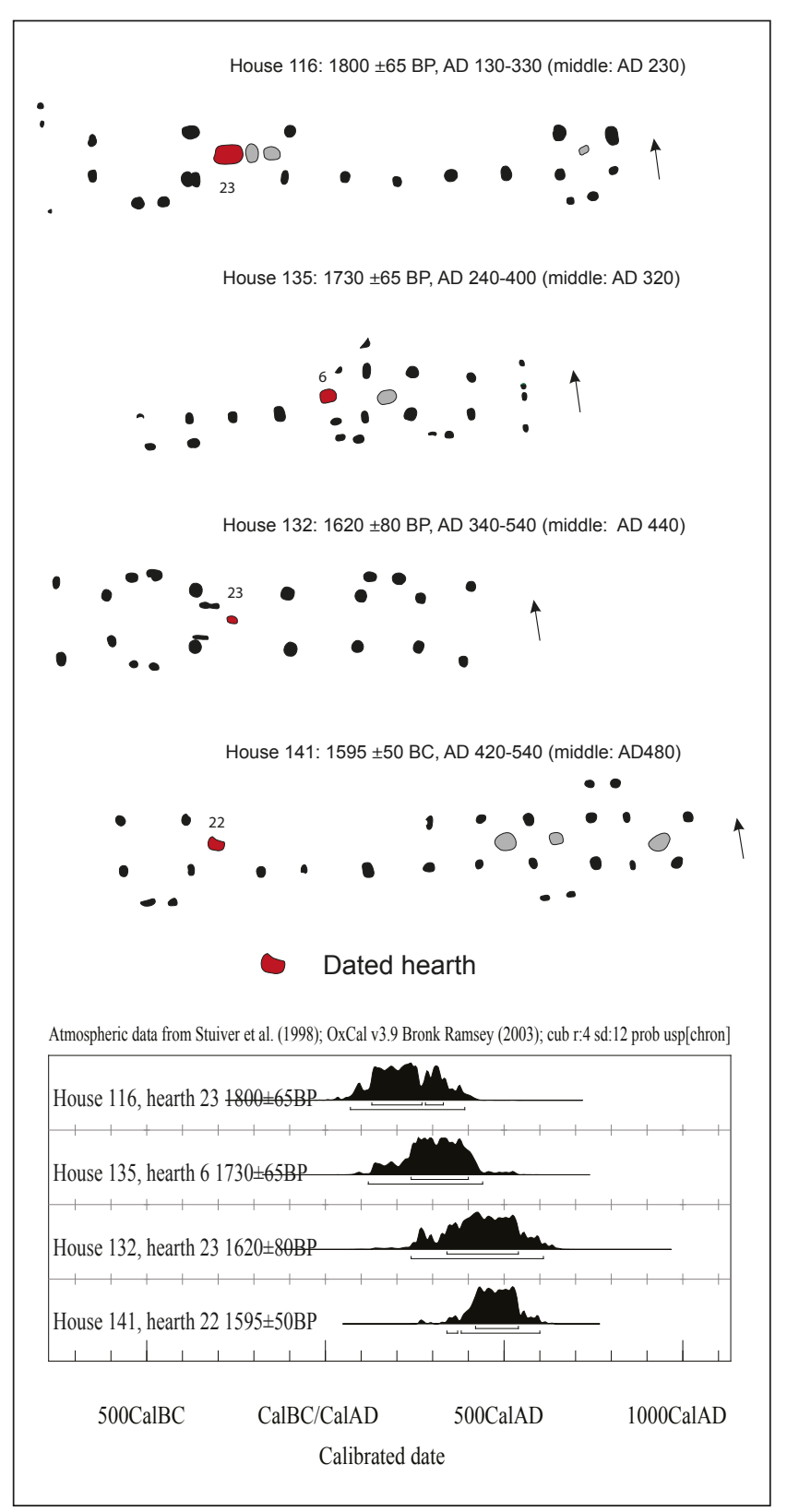

Fig. 72. House sequence 2: Four type 9 houses: 116, 135, 132 and $\mathrm{I} 4 \mathrm{I}$.

that interfered with older postholes. House 198 from the second phase had the most easterly location and the phase three house, 200, the most westerly. Fig. 73 shows that the middle value from the earliest house 201 indicates that phase two was constructed around AD 200 and the middle value of the latest date sets the abandonment date of phase three at AD 345, resulting in an average lifespan of 75 years for phases 2-3.

\section{House sequence 4}

Four consecutive E-W oriented houses, 155, 156, 157 and 158, were situated at the westernmost part of Area E. 156, 157 and 158 were the three youngest, and were placed within a common area just south of house 155, 


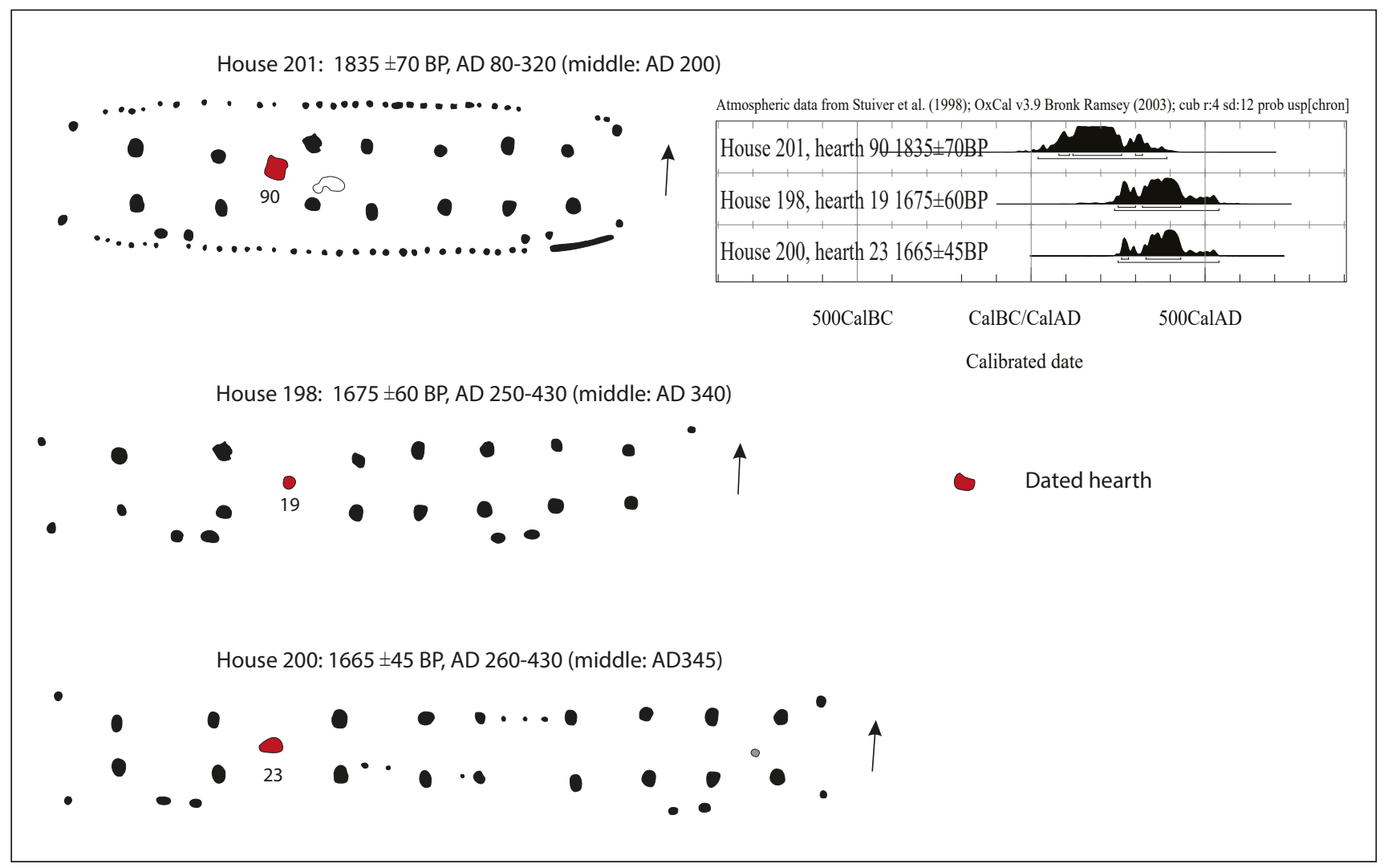

Fig. 73. House sequence 3: Three type 9 houses: 20I, 198 and 200.

that was the earliest, but the northern walls of houses 156, 157 and 158 were so close to this house that none of the later ones could have been constructed before house 155 had been torn down. None of houses 156, 157 and 158 shared postholes with house 155, so the three houses represent totally new houses even though they were all constructed within the area covered by the largest house, 158. Stratigraphic observations between the three houses showed that house 156 is older than house 157. Considering the ${ }^{14} \mathrm{C}$ dates, the house sequence was most likely in this order: 156, 158 and 157. Fig. 74 shows that the earliest middle value from house 155 indicates that phase two (house 156) was erected around AD 200 and the middle value of the latest date sets the abandonment of phase four (house 157) at AD 390, resulting in an average lifetime of 60 years for phases 2-4. However, since sherds of bucket-shaped pottery were found in postholes from the roof-bearing posts belonging to both houses 157 and 158, the occupation period for this sequence must by far have exceeded AD 400. The bucket-shaped pottery found in the westernmost part of house 158, outside the area belonging to the younger house 157, is a clear indication that phase three in this sequence lasted until at least AD 400, and therefore the three latter phases existed from AD 200 to AD 450/500, resulting in an average lifetime of at least 90 years for each house in the sequence.

\section{House sequence 5}

The last house sequence consists of the four type 9 houses 10A, 11A, 11B and 17, also situated just south of a burial mound within a $50 \times 30 \mathrm{~m}$ area and placed $50 \mathrm{~m}$ SE from sequence 4. In the centre of that area, two E-W oriented houses were built on the same spot; the smaller house $11 \mathrm{~B}$ was built inside the larger house $11 \mathrm{~A}$. Houses $10 \mathrm{~A}$ and 17 were situated very close to respectively the north and south side of house 11 . There is no stratigraphic information on the sequence of the houses. House 10A has the earliest date, while the three other houses have four dates, all covering the period AD 420-600, therefore the dates do not provide any information of the sequence of their construction. It is reasonable to suggest that houses $11 \mathrm{~A}$ and $11 \mathrm{~B}$ were built as a sequence since they share some postholes in the eastern part. The second phase in this sequence was probably house 17 , since several hearths that probably represent an open air cooking area connected to house $11 \mathrm{~A}$ and $11 \mathrm{~B}$ were located south of these houses. The hearths are stratigraphically earlier than the postholes belonging to house 17. Sherds of bucket-shaped pottery have been found in postholes from houses 11A 


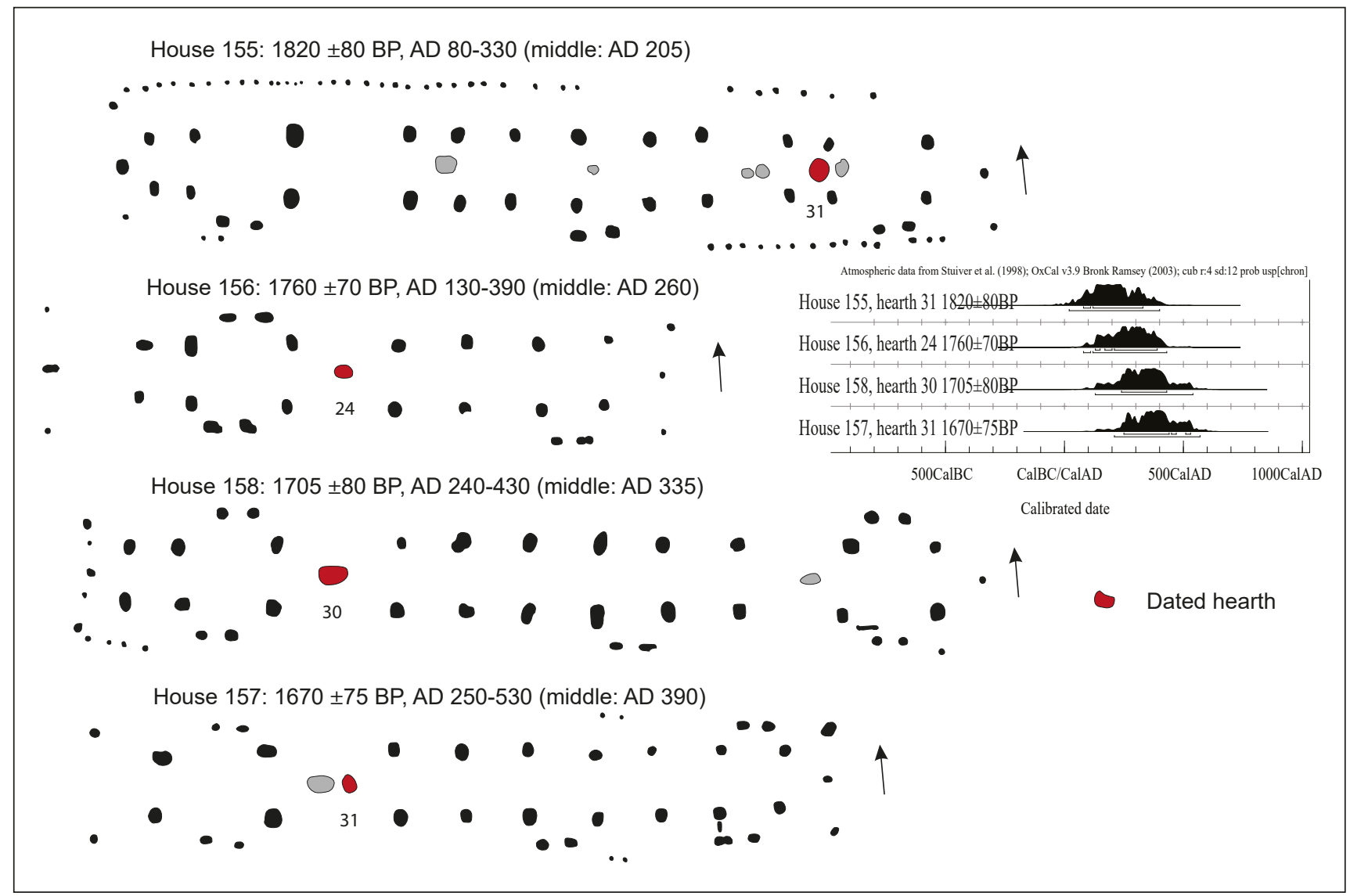

Fig. 74. House sequence 4: Four type 9 houses: 155, 156, I58 and I57.

Fig. 75. House sequence 5: Four type 9 houses: 10A, I7, IIB and IIA.

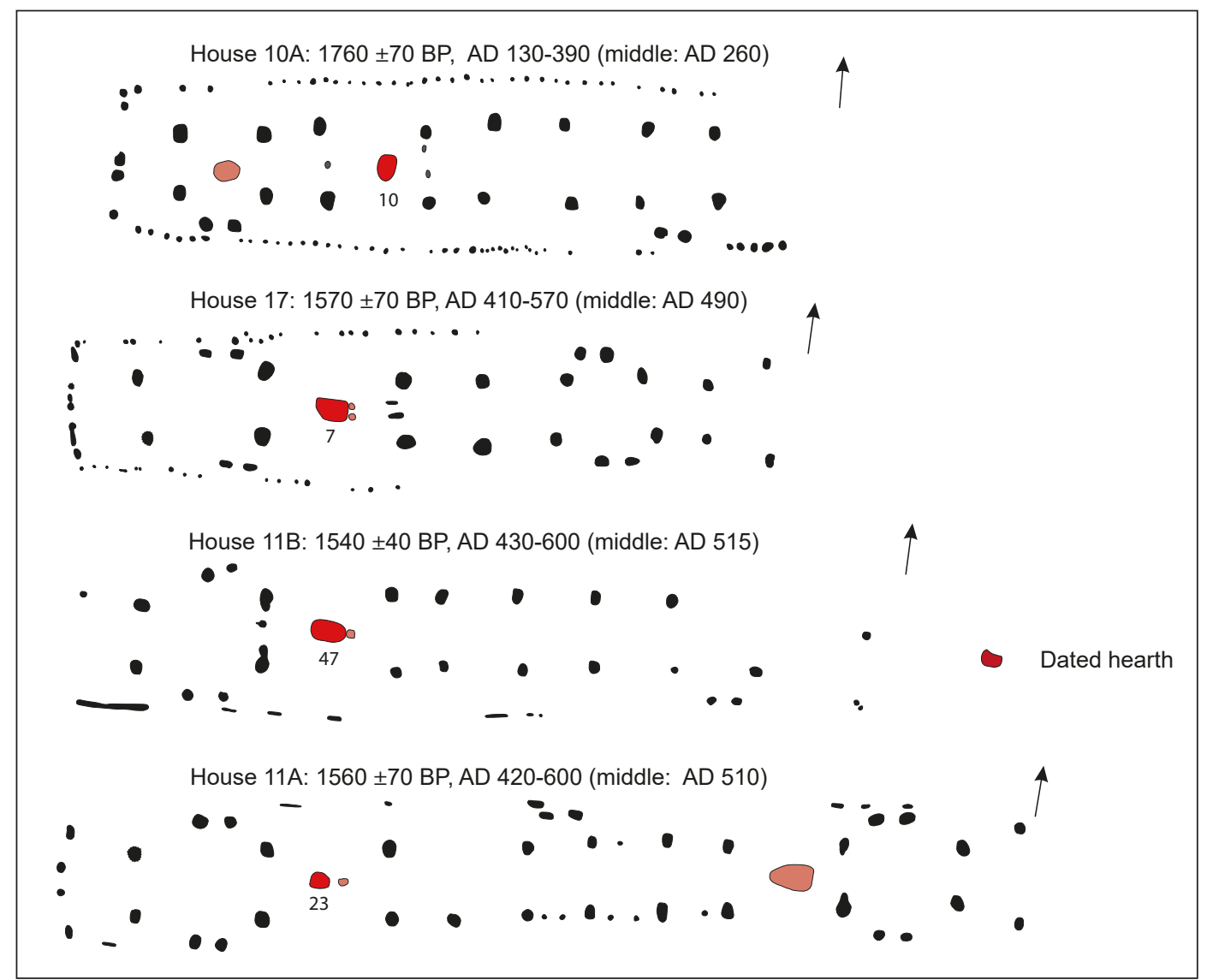




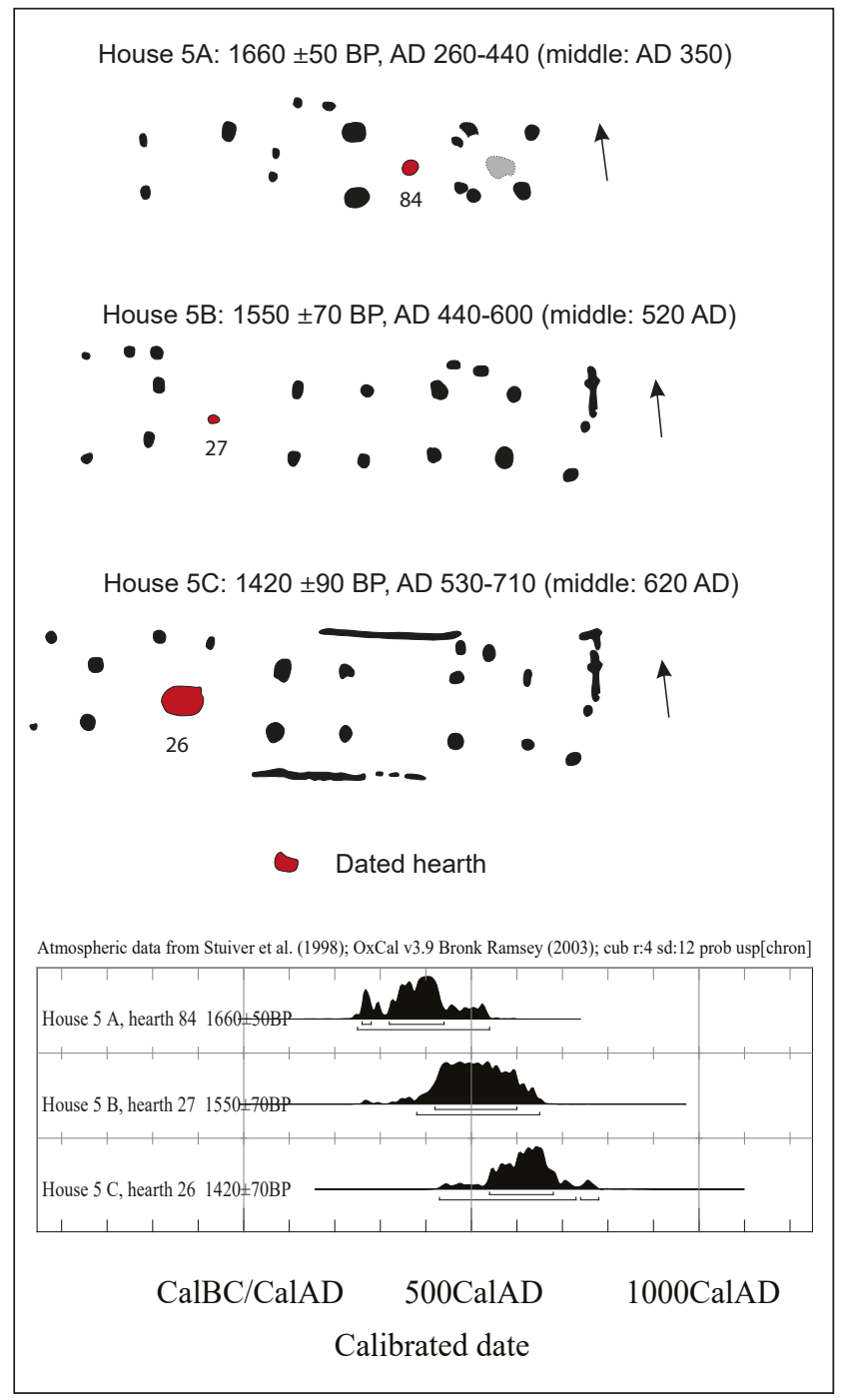

Fig. 76. House sequence 6: Three type 10 houses: 5A, 5B and 5 C. and 11B, while house 17 has no such finds, indicating an earlier date compared to houses $11 \mathrm{~A}$ and 11B. Fig. 75 shows that the earliest middle value from house $10 \mathrm{~A}$ indicates that phase two, house 17, was erected around $\mathrm{AD} 260$ and the middle value of the latest date places the abandonment of phase four, house 11B, at AD 510, resulting in an average lifetime 85 years for phases $2-4$.

\section{House sequence 6}

The type 10 house 5 may also shed some light on the issue of lifespan. It was situated in the SW corner of Area $\mathrm{E}$ and rebuilt two times, each phase with its own hearth. Fig. 76 shows that the oldest middle value from house $5 \mathrm{~A}$ indicates that phase two was erected around $\mathrm{AD} 350$, and the abandonment of phase three around AD 620 results in an average lifetime of 135 years for phases $2-3$. Such an average life expectancy seems long compared with the other calculations.

\section{House sequence 7}

House 5 has been interpreted as a workshop building connected to the large type 9 house 6 , situated $10 \mathrm{~m}$ to the south of it. This house (Fig. 77) is two-phased and the dates (AD 260-540) indicate a second phase of occupation from AD 400 to AD 660. This long occupation period may be explained by the exceptional construction of house 6 , which made it possible to continue using it for more than 100 years longer than any other farmhouse. The similarly long life expectancy of nearly the same period for the two connected houses 5 and 6 increases the probability of a long life expectancy for this farm.

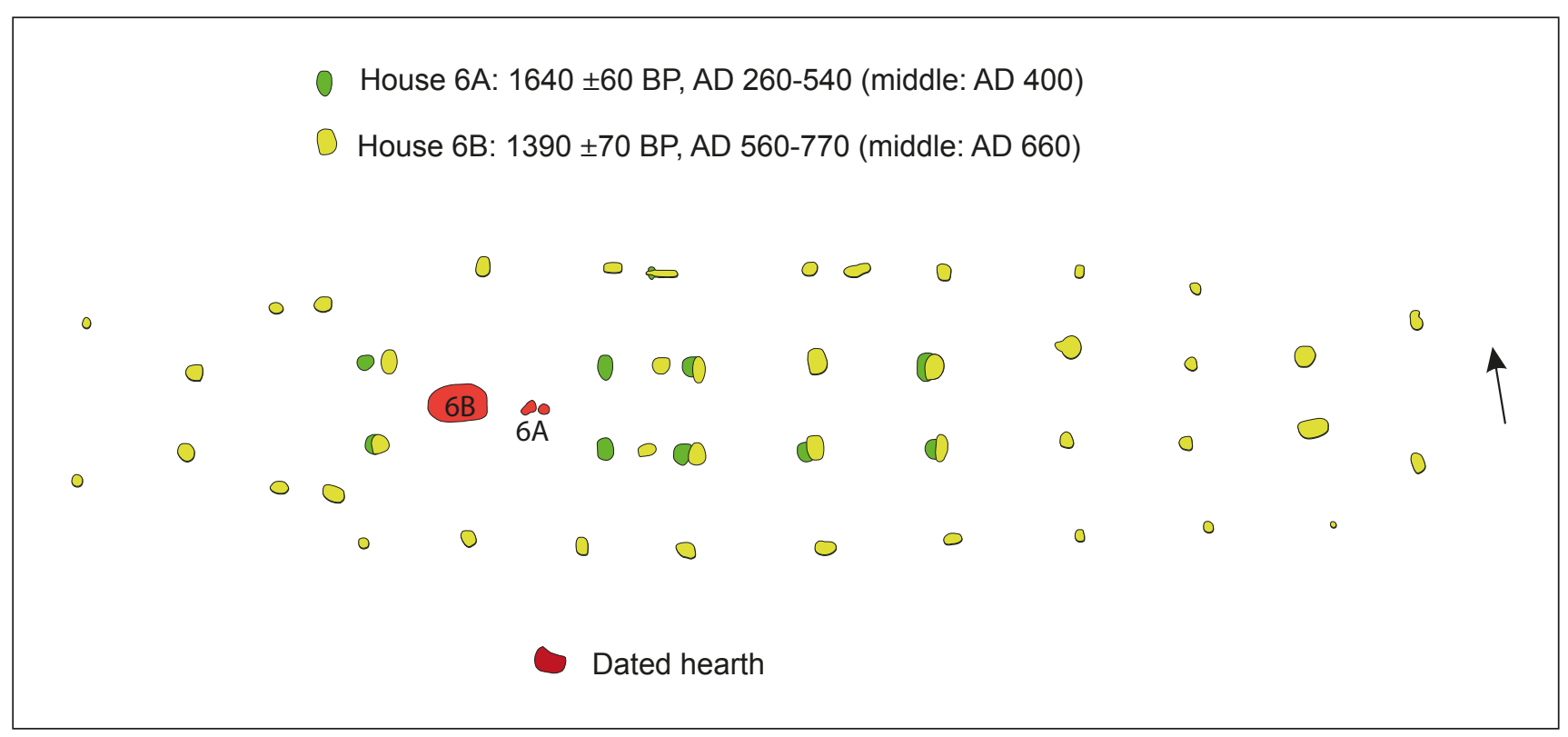

Fig. 77. House sequence 7: Two type 9 phases: $6 \mathrm{~A}$ and 6B. 


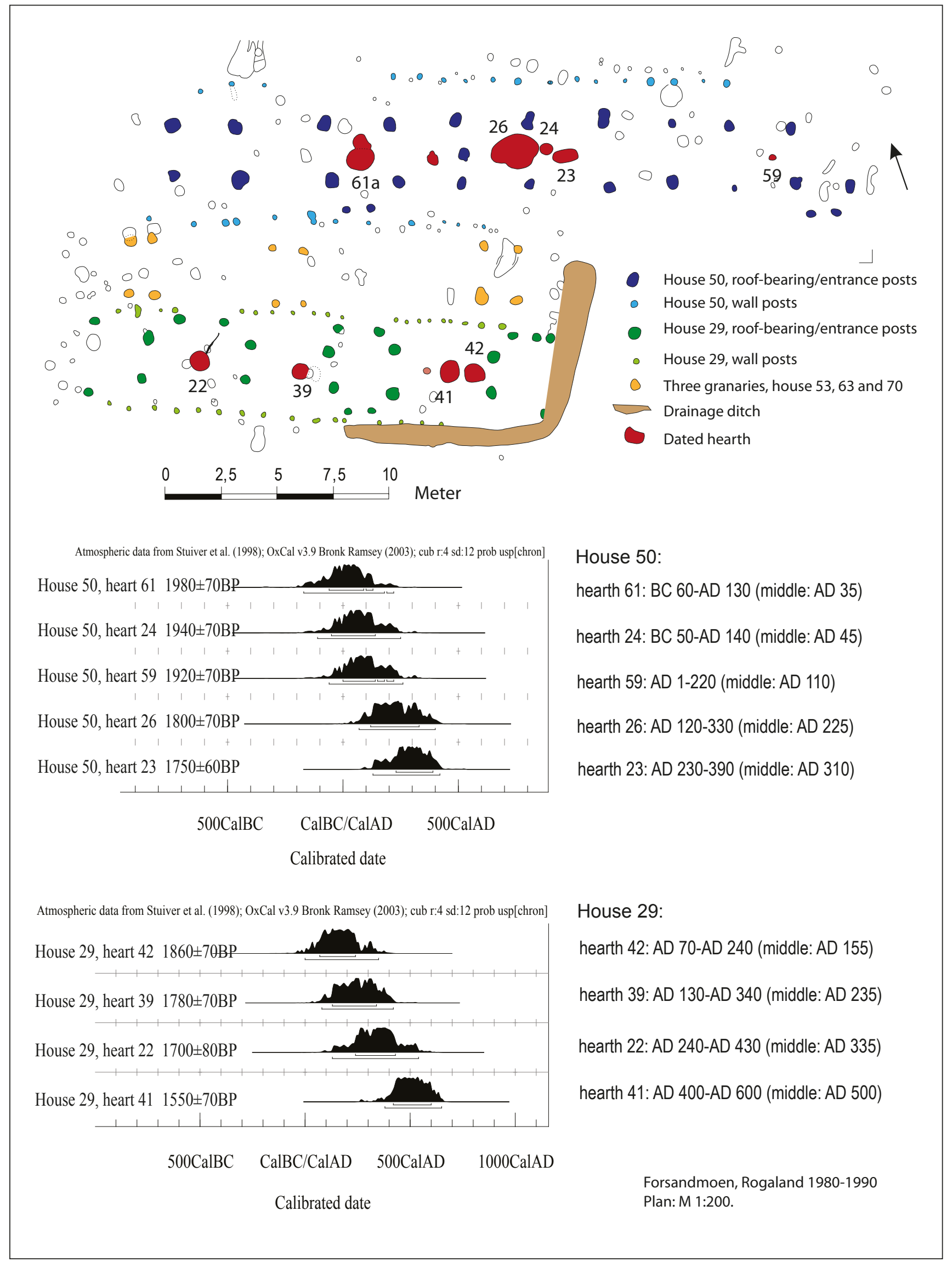

Fig. 78. Plan of the best documented farmyard at Forsandmoen: dwelling/byre house 50 (type 8), workshop 29 (type 10) and the three four-post granaries 53, 63 and 70 . 


\section{House sequences 8 and 9}

The nine dates from the two houses 50 and 29, situated in the NE corner of Area A, indicate a very interesting situation (Fig. 78). These houses are situated parallel to each other, separated by three four-post storage houses, and make up a well-organised farmyard measuring $35 \mathrm{x}$ $18 \mathrm{~m}$, where all houses are likely to be contemporaneous.

The dwelling and byre house 50 was rebuilt on the same spot, while workshop 29 displays no traces of repair. It is therefore possible that workshop 29 and the storage buildings were supplementary to house 50 . The two houses lack any finds of bucket-shaped pottery, which may indicate an occupation period before approximately AD 350 .

\section{House sequence 8}

The dwelling house 50 has been dated by five ${ }^{14} \mathrm{C}$ dates. All samples were taken along the central axis and three centrally between the two adjoining bays and, therefore, are by all accounts contemporaneous with the house. In the middle of the house, the large hearth (26) consisted of at least three different hearths intersecting each other and underlining a long period of use. Fig. 78 shows that the earliest middle value from hearth $61 \mathrm{~A}$ indicates that the hearth was used around AD 35 and the latest dated hearth 23 was used around AD 310, resulting at a 275-year lifetime of the house, or approximately 135 years for each phase.

\section{House sequence 9}

Workshop house 29 had four hearths along the central axis (Fig. 78). Three of these, 22, 39 and 41, were located centrally in three large bays and are therefore considered to be part of the house. The last hearth, 42 , was situated in between one of the mentioned hearths and the nearest trestle and also most likely belonged to the house. Fig. 78 shows that the oldest middle value from hearth 42 indicates use around AD 155 and the hearth with the latest date was used around AD 510, indicating that the house had a 355-year lifespan.

However, when comparing the dates from houses 50 and 29, it becomes clear that the three latest dates from house 50 cover the same time span as the three earliest ones from house 29. The youngest hearth 41 in house 29 is markedly later than the older one and is incompatible with the lack of finds of bucket-shaped pottery. If this date is excluded the three other dates cover the time span from AD 155 to AD 335, giving a 200-year lifespan of the one-phased house.

The conclusion may be that house 50 was established early in the $1^{\text {st }}$ century AD, that the other houses were erected approximately one hundred years later and that the farm was abandoned in the first half of the $4^{\text {th }}$ century.

\section{House sequence 10}

House 3 was a large, well-built type 9 house (Fig. 79) located between house 2 to the north and house 5 to the south near the SW corner of Area E. Six ${ }^{14} \mathrm{C}$ dates can shed light on the question of the occupation period of the house. Hearth 10, stratigraphically earlier than a posthole from a roof-bearing post, is dated to $\mathrm{AD}$ $180-430$, thus giving the hearth a middle date of $\mathrm{AD}$ 305 . The two centrally located hearths 26 and 97, dated respectively to AD 240-410 and AD 250-430 fit nicely with the date of the earlier hearth and confirm that the house was constructed in the first half of the $4^{\text {th }}$ century. The dates from ember pit 98 adjacent to a central hearth and another centrally located hearth, 27, with the dates AD 410-570 and AD 440-660 demonstrate that the house could well have been standing until the beginning of the $6^{\text {th }}$ century. This implies an occupation period of nearly 200 years for a house without traces of repair or rebuilding.

\section{House sequence 11}

House 2 was the most prominent house from the Migration Period at Forsandmoen (Fig. 80), situated 5 $\mathrm{m}$ north of house 3 . The $30 \mathrm{~m}$ long and $9 \mathrm{~m}$ wide house with curved longitudinal walls was rebuilt using older postholes in the western end and new postholes in the eastern end in connection with shortening the length by $1.7 \mathrm{~m}$ in the eastern end. The dates show that the house was constructed around the second part of the $3^{\text {rd }}$ century and burnt down in the second part of the $6^{\text {th }}$ century, resulting in a 250-year total lifetime of the house, or 125 years in each phase.

\section{Closing remarks}

The six house sequences (1-6) with $3-5{ }^{14} \mathrm{C}$ dates show that the lifespan of one house phase might vary from 90 to 135 years (respectively 90, 100, 100-110, 90, 85 and 135 years, on average 101 years), while the two-phased houses 50, 2 and 6 (sequences 7, 8, 11) have indications of a longer lifespan (respectively 130, 135 and 120 years). The two one-phased houses 29 and 3 (sequences 9 and 10) may have had an even longer existence of approximately 200 years, though this is uncertain.

These datings indicate a much longer lifespan than considered by most archaeologists in Denmark, Germany and the Netherlands, where 25 to 50 years has been regarded as most probable. To attain such a 


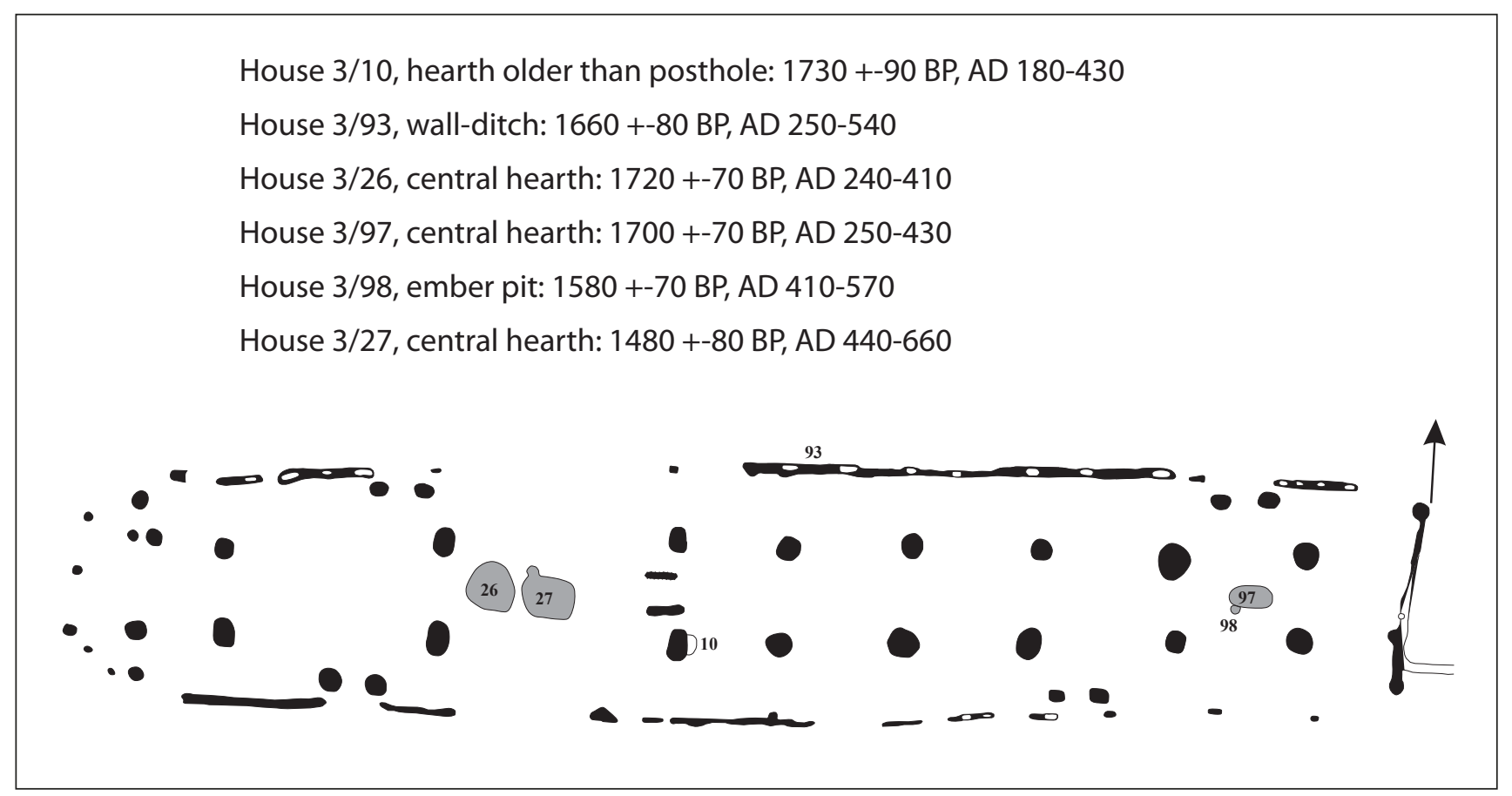

Fig. 79. ${ }^{14} \mathrm{C}$ sequences from house 3. The time distributions from the six radiocarbon dates from the houses are shown.

short life span in the sequences presented above, one would have to choose the latest part of the 1 sigma probabilities in the earliest date in the sequence and the earliest time from the 1 sigma probabilities in the latest date in the sequence. Interpreted this way, house sequence 1 results in a 37-year life expectancy, while in house sequence 2 , the life expectancy would only be 30 years. To my mind, this would be a much less viable way of treating the ${ }^{14} \mathrm{C}$ dates than what has been done above. Concerning house sequences 1-6, each comprising 3-4 house phases, I find an average life expectancy of 90-100 years to be reasonable, based on the radiocarbon dates, the building timbers and the natural conditions on the plain. The long lifespan estimates from the one- or two-phased houses are probably less reliable.
Fig. $80 .{ }^{14} \mathrm{C}$ sequences from house 2. The time distributions from the three radiocarbon dates from the house are shown.
House 2/35, central hearth: $1770 \pm 80 \mathrm{BP}, \mathrm{AD} 130-390$ (middle AD 260)

House 2/34, central hearth: $1440 \pm 50 \mathrm{BP}, \mathrm{AD} 560-660$ (middel AD 610)

House 2/25, ember pit: $1600 \pm 50$ BP, AD 410-540 (middle AD 475)

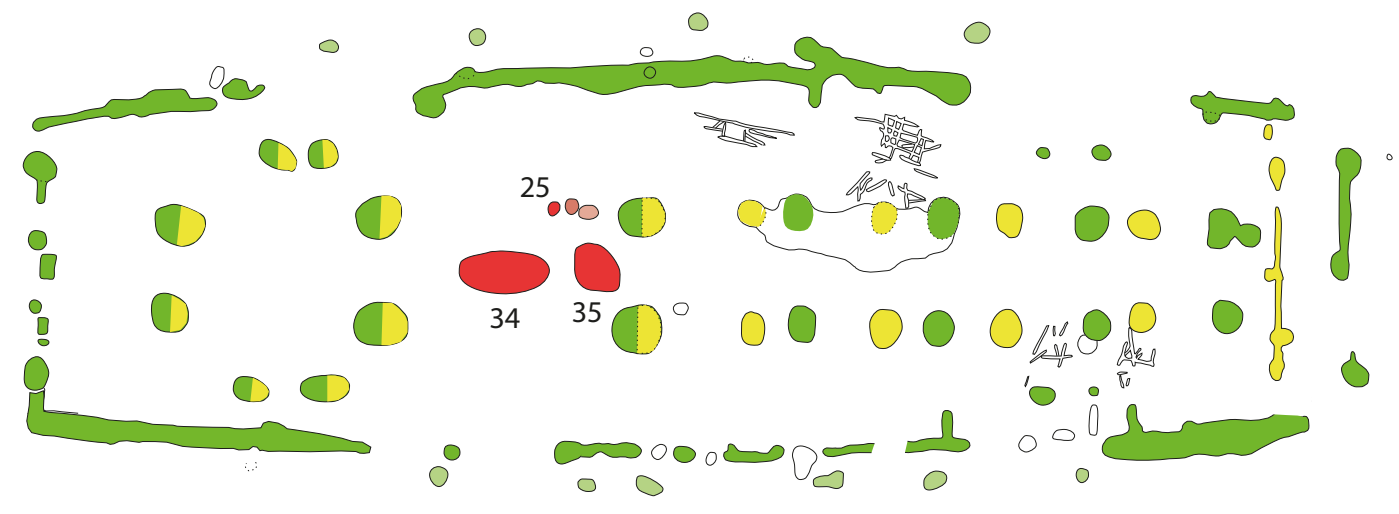

Dated hearth 


\section{Interpretation of activity areas in combined dwelling and byre houses}

\subsection{Location of the dwelling section in type 3 houses}

The houses of type 3 are characterised by two approximately equally sized parts, separated by a small entrance hall with two opposed entrances. What activities have taken place in the two parts of the house? This chapter examines the different constructive features and findings in order to determine what has been the house's living space and if the other part may have functioned as a byre.

\section{The location of the longest bay}

The size of the trestle span may indicate where people lived and where cattle were stalled (Carlie 1999:120). However, the size of the trestle spans is by itself not sufficient to determine the function of different parts of longhouses. The situation at Forsandmoen is ideal for an investigation of this issue: 38 type 3 houses were of the same main construction type and were built on a homogenous outwash plain, relying on the same natural conditions, such as soil and climate. In addition, the same team excavated them all, using comparable documentation principles. The data may therefore constitute a basis for a more thorough investigation of the matter.

Based on the premise that larger trestle spans indicate living sections, the size of the trestle bay indicates that the living section was located in the eastern part of type 3 houses in as many as 27 out of 38 houses (Table 5, folder); only five houses seemed to have the opposite pattern. In addition, four houses had equally large bays in each part. Two houses were excluded from the analysis because a part of them had not been excavated. This appears to indicate a preferred living section in the eastern end and an economic section (byre) in the western part, based solely on the trestle bays. All the three mentioned groups are distributed in all periods from the Bronze Age to the late Roman Iron Age, indicating that there was no chronological development in the location of the largest bay. A thorough investigation of features other than the length of trestle bays may hopefully shed light on the question of how the two parts have been organised.

\section{Location of clay in the houses}

In south Scandinavian archaeology, houses with opposed entrances in the middle of the house often have remains of a clay floor (and a hearth) in the western part, while the eastern part normally lacks such features.

Burnt clay is often documented in both the roofbearing and wall posts at Forsand. The coarse gravel at Forsandmoen has very low clay content, and the nearest deposit is situated $0.6 \mathrm{~km}$ away down by the seashore. This means that the clay was deliberately brought into the houses and used for instance as a clay floor, in wattle and daub walls or for other purposes. Only a limited amount of clay has been found in wall postholes, so wattle and daub walls are rarely documented this way. However, since the postholes are small and the upper two-thirds of the original holes is likely to have been removed by ploughing, only a few fragments of burnt clay containing impressions of twigs and smooth wall surface have been found in type 3 houses. One fragment with two twig impressions and eight fragments with one twig impression were found in postholes belonging to houses 62 and 190, of which house 62 had nearly totally preserved rows of narrowly spaced wall posts (Fig. 20). One similar fragment with one twig impression was also found in the two 129 and 147A houses of other types. All these twig impressions measure $2 \mathrm{~cm} \pm 0.1-0.2 \mathrm{~cm}$. In all these houses as well as the three other houses 122, 221 and 223 there were finds of one or two fragments of burnt clay with a smoothed surface, which can only stem from a wall or a floor. The best finds of clay fragments from a wattle and daub wall are found in the large type 7 house 150 from the early Roman Period. A fragment with two twig impressions separated by $1.4 \mathrm{~cm}$ of clay, two coherent fragments with an impression of bark, five impressions from twigs with diameters from 2-3 
Fig. 8I. Distribution of five finds units from 38 type 3 houses: pottery, clay, slag/furnace remains, burnt bones and charred cereal grains.

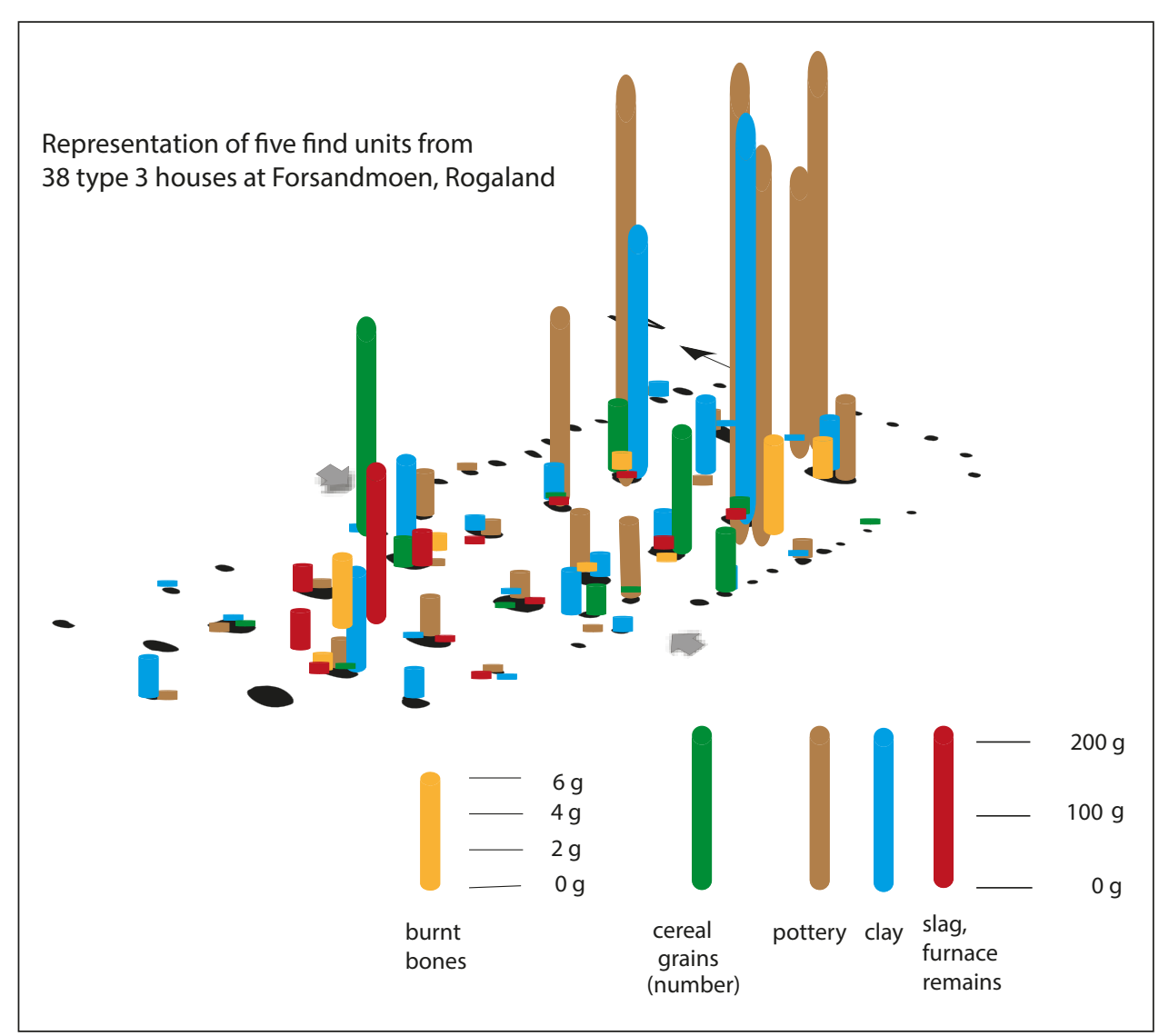

Table 47. The distribution in time of type 3 houses with or without collected clay.

\begin{tabular}{|l|c|c|c|c|c|c|}
\hline & Early Bronze Age & Late Bronze Age & Early Pre-Roman Iron Age & Late Pre-Roman Iron Age & Roman Iron Age & $\begin{array}{c}\text { Not } \\
\text { dated }\end{array}$ \\
\hline Houses with most clay & 0 & 2 & 5 & 2 & 3 & 0 \\
\hline Houses with little clay & 2 & 3 & 4 & 5 & 2 & 2 \\
\hline Houses with clay & 2 & 5 & 9 & 1 & 3 & 2 \\
\hline Houses without clay & 0 & 2 & 1 & 4 & 4 \\
\hline
\end{tabular}

$\mathrm{cm}$ and nine fragments with a smoothed surface are particularly obvious. These fragments show that type 3 houses, as well as other types of houses with walls consisting of densely placed wall posts, had wattle and daub walls.

When analysing the distribution of clay in the houses, it is clear that the houses have been divided into two parts. The dividing line is drawn between the posts in the entrances, resulting in six roof-bearing and two entrance postholes in each part of a six-trestle house for the most common type of these houses.

Clay has evidently been an integrated part of the construction of this type of floor, since as many as 26 out of 38 houses had clay content in the roof-bearing postholes (Table 5 , folder). However, only a small number of the postholes (119 out of 423, $28 \%$ ) have a content of clay that has been collected (102 postholes) or reported in drawings or comments (17 postholes) from
26 different houses. A total of 84 postholes with clay are located in the eastern part and only 33 in the western part, showing that clay was more frequent in the eastern part. Such a pattern is unlikely if the clay solely originated from wattle and daub walls, if the walls had the same construction all around the house. The most reasonable interpretation is therefore that most of the clay originates from the floor in the human occupation zone (see below). The amount of collected clay is more than twice as large in the eastern part (1190 g) as in the western part $(510 \mathrm{~g})$. Fig. 81 shows how the total amount of clay is distributed in type 3 houses. This is, of course, not as large a quantity as one should expect from clay floors, but we must bear in mind that the sampled clay was deposited at least $20 \mathrm{~cm}$ down in the posthole. The clear difference between the two parts is likely to reflect a difference in the construction and use of the house. 
Most of the houses have small amounts of clay in one to four postholes, but ten houses have larger amounts $(>50 \mathrm{~g})$, which makes it possible to interpret the clay as remains from a clay floor. Eight of the houses (21, 25, 55A, 62, 188 (with a documented clay floor), 190, $216 / 217$ and 219) have most clay in the eastern part, and six of them also have the largest trestle span in that part. The last two, 21 and 62, have nearly equal sized spans on each side of the entrances. Four of the houses have clay in all postholes in the eastern part and none in the opposite part, while one of them, 190, also has clay in most of the western postholes, indicating a clay floor throughout the house.

The last two of the houses, 61 and 37, have clay mainly in the western part. House 61, where the longest trestle span is in the east, seems to have had a clay floor in the west. Unfortunately, the small amounts of pottery found in the postholes of this house cannot contribute to the interpretation of where the living section was located. The central part of house 37 has not been unearthed, so the structure of the house is uncertain, but the house has a long trestle span $(3.4 \mathrm{~m})$ in the east. Clay was also found in all four excavated postholes in the eastern part of the house and much more pottery than in the western part. Probably, the whole house had a clay floor but with the living section located in the east.

This indicates that remains from a clay floor in the roof-bearing postholes are mainly found in the eastern part of the houses, where the longest trestle span is also located. This suggests that the eastern part was the dwelling area. However, a few houses may have had a clay floor in both parts.

The eastern part of house 188 was buried underneath a small grave mound and warrants special mention. The excavation of that mound initiated the whole Forsandmoen project because a $10 \mathrm{~cm}$ thick clay floor as well as postholes was discovered underneath the mound. The layer of clay covered the whole eastern part of the house, as far west as the mound had sealed off the floor. This find proves that type 3 houses had a clay floor even though the inhabitants had to transport large amounts of clay more than half a kilometre.

Ten years after the mound was excavated, the area west of the mound was uncovered and house 188 was fully excavated. It is important to note that only one of the remaining eight postholes in the eastern part contained a small quantity of clay. It is therefore possible that even houses with small amounts of clay in the eastern postholes originally may have had a clay floor.

26 of the type 3 houses, six of these undated, have clay content in the roof-bearing postholes. Table 47 shows how houses with and without collected clay samples are distributed throughout the settlement period. The distribution shows that the use of clay floors in houses has been the normal way to equip the living section through the Bronze Age and Pre-Roman Iron Age periods, since only three out of 22 houses lack remains of clay floor in those periods, while in the Roman Iron Age, as many as four out of seven dated houses lack remains of clay. The lack of clay floors in the Roman Iron Age probably reflects that clay floors are not documented in the main house types (type 7-10) used in the Roman Iron Age and Migration Period.

\section{Location of pottery in the houses}

Assuming that half of the house contained a living section and the other half a byre, one should expect differences in the finds from the structures in the two parts. However, one or two small, single sherds of pottery in a posthole might not belong to the period of house occupation - especially if found outside the core where the post was located. Such finds in one part of the house or the other cannot be used to identify the living section.

The number of postholes with pottery in the two parts of the houses is more equally distributed than was the case for the clay finds. There are 28 postholes in the western part and 50 postholes in the eastern part. In Table 5, folder, the bay where the most pottery was located in each house is marked in orange, and only in two houses was most pottery found in the western part. However, looking at the weight of the pottery in total, the eastern part has yielded $3433 \mathrm{~g}$ as opposed to $202 \mathrm{~g}$ in the western part. Fig. 81 illustrates the difference in total distribution between the two parts of the type 3 houses. This difference is a strong indication in favour of interpreting the eastern part as the preferred living quarters.

House 31 has more pottery ( $45 \mathrm{~g}$ versus $15 \mathrm{~g}$ ) in the western part, but unfortunately no clay in the postholes. The trestles in this house have equally large spans on either side of the entrances. House 190 also has more pottery in the western part, but smaller amounts (24 $\mathrm{g}$ versus $6 \mathrm{~g}$ ), and nearly equal amounts of clay as well as nearly equally large trestle spans. The available evidence makes it difficult to determine the living section in these houses.

House 21 has equally long trestle spans in each part of the house. However, since both pottery and clay are nearly exclusively found in the eastern part, the living section is very likely to have been there.

Pottery was only recovered from the western part of houses 219 and 229. However, since the amount is 
Fig. 82. Distribution of artefacts in type 3 houses not incorporated in Fig. 8I. Rogaland (pottery, slagg, clay, cereal grains, furnace remains and burnt bones are excluded)

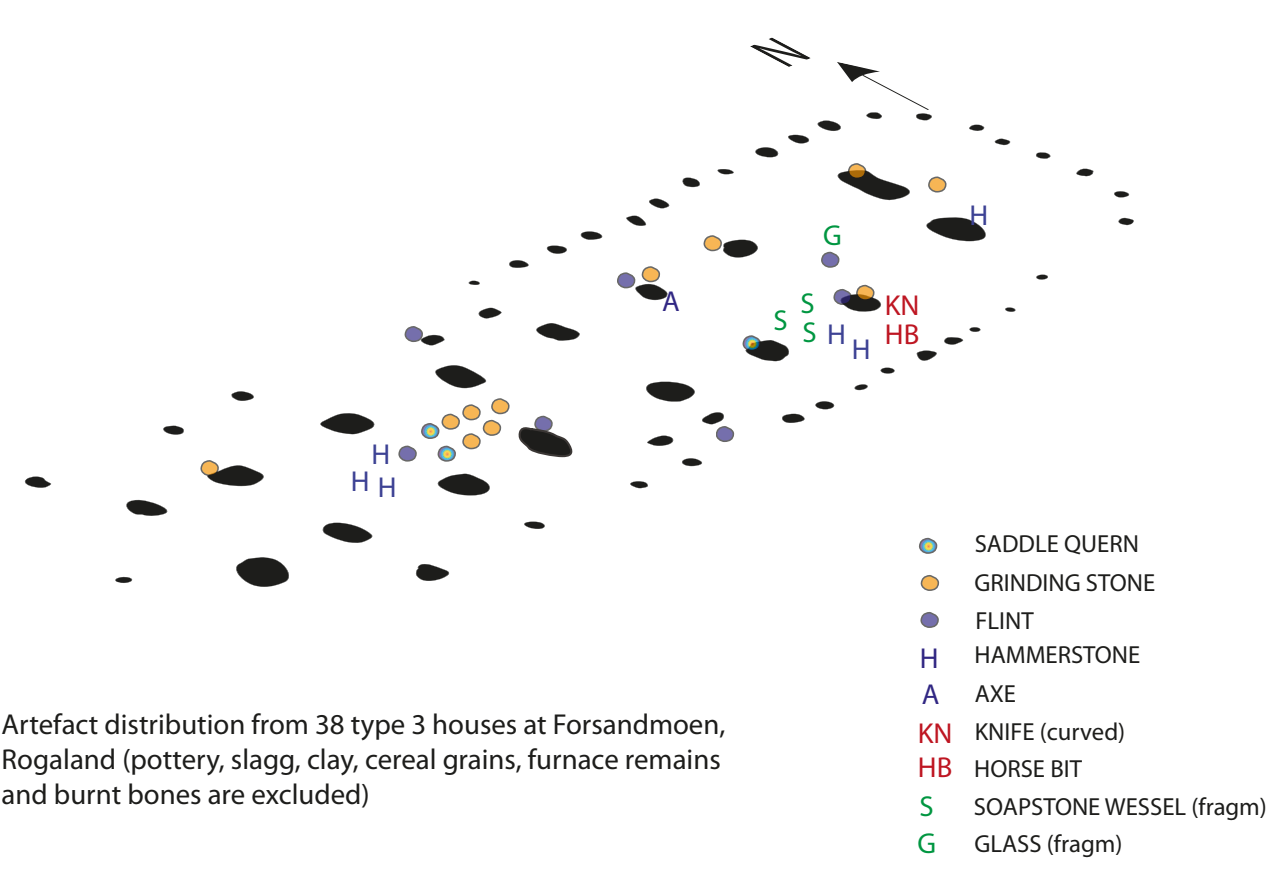

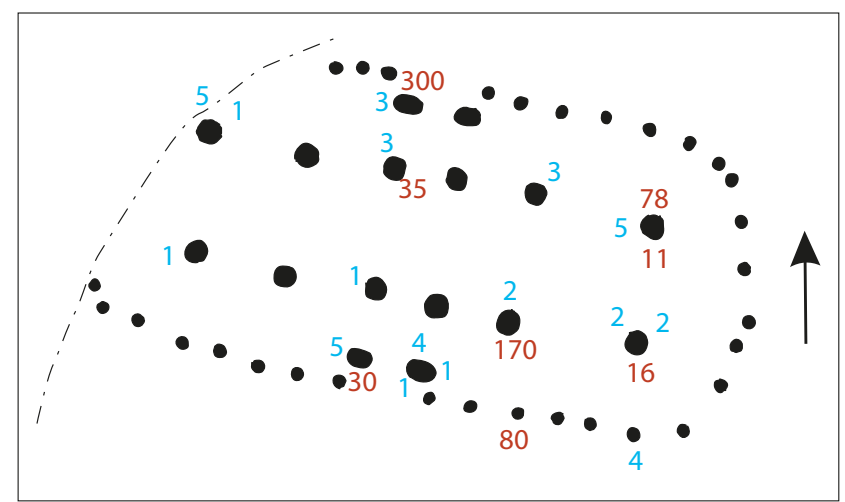

Fig. 83. Distribution of large and small charred grain finds in type 3 houses, where the large brown finds were related to an activity in a house while the small blue finds were deposited by chance.

scarce (6-9 g), and the largest trestle span is in the eastern part, it is reasonable to follow the interpretation concluded from the other houses. One of the houses also contained much more clay in the eastern part.

\section{Location of other finds}

Figure 82 shows how the artefacts in type 3 houses are distributed. Five grinding stones and one saddle quern, all found in the eastern part, also indicate that the living section was there. One shard from a glass vessel and three sherds from soapstone vessels were also found in the eastern part, as were a curved iron knife, a bridle, a stone axe, three hammer stones and a couple of flint flakes. These finds support the interpretation that daily life activities were in the eastern part and finds connected to metal working (slag, furnace remains) in
Table 48. Distribution of charred cereal grains in type 3 houses.

\begin{tabular}{|l|c|c|c|}
\hline Period & $\begin{array}{l}\text { Number } \\
\text { of houses }\end{array}$ & $\begin{array}{l}\text { Number } \\
\text { of grains }\end{array}$ & $\begin{array}{l}\text { Ratio grains/ } \\
\text { house number }\end{array}$ \\
\hline Bronze Age & 3 & 101 & 34 \\
\hline Early Pre-Roman Iron Age & 4 & 192 & 48 \\
\hline Late Pre-Roman Iron Age & 5 & 347 & 70 \\
\hline Roman Iron Age & 5 & 123 & 25 \\
\hline Not dated & 3 & 36 & 12 \\
\hline Total & 20 & 799 & 40 \\
\hline
\end{tabular}

some houses were situated in the western part. In total, there are 20 miscellaneous finds from postholes in the eastern part of type 3 houses, and only three finds (two flint flakes and a grinding stone) from the postholes in the opposite part of the house, confirming the pattern seen from the clay and pottery finds.

From seven longitudinal wear depressions in the house axis in the western part - possibly the result of cattle moving into the byre or human activity - there were two parts of saddle querns, three hammer stones, five grinding stones, a flint flake, burnt bones, fragments of slag and forge/furnace remains. In two other houses, slag was also found in postholes and "activity" depressions in the western part, of which one house also had slag in the eastern part. Fig. 81 illustrates the distribution of slag finds. Their presence indicate that ironworking took place in the western part in some houses. The amount of querns, grinding stones and hammer stones in the wear depression also indicates 
that ordinary household activities at least occasionally happened in the western part, even though the longitudinal and centrally located wear depression from activity marks this part out as a byre. The abundant finds in activity depressions in the western end must not be overemphasised, since similar depressions in the other half are lacking. Fig. 81 also shows that burnt bones were found in the entrance zone, the western wear depression and to the east, like most other finds. The grinding stones and saddle querns in the western depressions could indicate that the cereal crops were ground there. However, the lack of charred grain finds (Fig. 83) does not support such an activity in that area.

\section{Location of charred grains}

A total of 799 charred grains from cereals have been collected from 20 of the 38 type 3 houses. The methods used to retrieve and analyse the charred plant material are shortly described in chapter 3.5 . Only the results of the analysis of grains from cereals in type 3 houses will be discussed here. Remarkably, in nearly all 20 houses, the grains have - with three exceptions - been found in only one posthole in each house. In type 9 houses, small amounts of cereals are often found in more than one posthole as well as in three of the type 1 and 2 houses. The amount of grains from the different houses varies from 1-300. Two houses have yielded more than 100 grains, while in 13 houses, there were only between 1-6 grains. As underlined in the discussion of the small pottery finds in many of the postholes, such a small amount of grains in a posthole may not be related to activities in the house. Most probably they were deposited, by chance, before the house was constructed.

As Fig. 83 shows, the eight samples with more than ten grains are located in the eastern part and in the entrance room. This indicates that cereals were used in the eastern living section. An approximately equal amount of grains located in the entrance rooms (381) and the eastern dwelling parts (370) suggests that activities such as grinding and cleansing as well as food preparation resulted in equally frequent depositions of grain in those two parts of the house. Consequently, such activities were not frequent in the western part, where only seven grains $(1 \%)$ were found. Fig. 81 shows the total distribution of cereal finds. There is a clear concentration in the entrance room and the nearest area to the east. The two samples with 200-300 grains in a posthole can possibly be interpreted as offerings in connection with the construction or destruction of the house. A majority of twelve small finds in the eastern and central part as opposed to three small finds in the western part support the conclusion that the eastern part was the area where cereal food was processed and consumed. The distribution of small finds also favours the view that single or multiple grains were deposited during the period of use. The occurrence of 30-35 grains in two postholes of the entrance room can also be the result of threshing the harvest here.

Two finds with 15 and 20 grains that are located in the western part are excluded in Fig. 81-83 . Contrary to all finds included in the figure, they belong to houses where the living section, including a hearth, was in the western end. They therefore express the same pattern: grains were deposited in the living section, wherever this was located.

Grains have been found in nearly equal amounts (265, 362 ) in the same number of houses (eight) of subtypes 3.1 and 3.3, indicating that the two types represent the same type of habitation pattern. Subtype 3.2 is less well represented since only one such house has a minor grain find (16 grains).

Looking at the distribution through time (Table 48), most grains are found in the late Pre-Roman Iron Age, while the houses from the Roman Iron Age contain considerably fewer grains in their postholes. The ratio of number of grains per house increases from the Bronze Age to the late Pre-Roman Iron Age. Then it drops to the lowest level in the Roman Iron Age. This is in accordance with the tendency found at Gausel (Børsheim \& Soltvedt 2002).

Threshing of grain along Norway's west coast has been a challenge due to the heavy rainfall in the autumn, which makes it difficult to have a dry enough surface to thresh on, as one would have in more southern, warmer and drier areas. Instead, people have historically made an impermeable floor in a part of the barn where there were also openings in two ends. There, the grain could be threshed, and the airflow helped to separate the chaff from the grain during subsequent cleaning. The amount of grain finds in the entrance room of the type 3 houses suggests that this process may also have been carried out following this method when the climate changed towards the end of the Bronze Age and in the Pre-Roman Iron Age.

There is a source from antiquity that probably confirms such a practice in the early Pre-Roman Iron Age in Norway. The Greek seafarer and explorer Pytheas from Marseilles circumnavigated Britain in about 325 $\mathrm{BC}$, and he wrote a book about his expedition, where he describes that, from the north-western point of Britannia (outer Hebrides) he sailed six days north to a land called Thule (near the frozen sea (pepéguia 
thalatta, "solidified sea"), which had no nights at midsummer when the sun is passing through the sign of the Crab (at the summer solstice); it was also the case that, in these parts, the nights were very short, two or three hours long in some places, such that the sun rose again a short time after it had set (wikipedia contributors, Pytheas).

He probably landed a lot further north than Rogaland, most likely in Møre og Romsdal or even further north as the artic circle (Lofoten?) as Nansen (1911) has proposed, while Cunliffe (2002) argue in favour of Iceland. In the preserved parts of his book, reproduced by Strabo from Polybius, the following description is provided of the people there: the people live on millet (Panicum miliaceum) and other herbs, and on fruits and roots; and where there are grain and honey, the people get their beverage, also, from them. As for the grain, he says that - since they have no pure sunshine - they pound it out in large storage houses, after first gathering in the ears thither; for the threshing floors become useless because of this lack of sunshine and because of the rains (wikipedia contributors, Pytheas).

In Western Norway and in Trøndelag, there are houses of a similar type to the type 3 houses in Forsand (see chapter 5.3-5.4), so these descriptions can also be representative of the society in Rogaland and Forsand. It is therefore probable that the grain finds in the entrance rooms in the type 3 houses are just as likely to be remains from threshing as sacrificial acts. What we also learn is that at least part of the grain harvest, most likely from barley (Hordeum), was used to brew beer.

\section{Interior doors}

Interior doors are recorded in only the two houses 21 and 49. In house 49 , the $0.8 \mathrm{~m}$ wide door was situated between the eastern postholes in the entrance room, making the eastern part sheltered from the entrance area.

In house 21, the interior door postholes, set $1.4 \mathrm{~m}$ apart, divided the westernmost part with the longest trestle span from the rest of the house, $1.8 \mathrm{~m}$ west of the entrance room. The house has nearly equally long trestle spans on each side of the entrance room. Clay and other finds were mainly in the eastern part, including a bridle in one of the easternmost postholes for roof-bearing posts. This interior door therefore does not appear to be associated with the living section. The interior entrance marks a large entrance room, 3.2 $\mathrm{m}$ wide, which is comparable to the similar sized, but much later house 13 located $80 \mathrm{~m}$ further south.

\section{Stall boxes}

In house 21, the easternmost $3.2 \mathrm{~m}$ long part is divided into three 1-1.1 $\mathrm{m}$ wide stall boxes by two small postholes. Such a feature has been documented in a few Roman Iron Age and Migration Period houses at Forsand. Similar postholes were also found in the PreRoman Iron Age houses K IX and P Vb at Grøntoft. In these instances, the remains leave no doubt as to their function as part of the stall box construction (Rindel 1997:51). These two postholes, interpreted as stall boxes in house 21 are confusing, since remains of a clay floor, human activities - including the offering of a horse bit in a posthole - and the possible stall boxes were situated in the eastern end. Considering that such possible stall box postholes are not documented in other type 3 houses, the interpretation of stall boxes is therefore rejected here in favour of an interpretation suggesting that the feature is a kind of supporting construction, for instance, around a possible hearth in the easternmost room in the house.

\section{Hearths}

Nine houses have hearths situated in such a position that they probably belonged to the house (Table 5, folder). Four of those features belong to houses dating from the Roman Iron Age. These circular hearths are undoubtedly connected to the houses, two in the living section in the east in houses 82 and 123, and two in the western part of houses 12 and 13 . House 25 has an oval hearth situated centrally in the easternmost trestle span. The hearth consisted of a partly burnt clay patch with a charcoal layer on top, like the hearths found in types 5, 6 and 11, dating to the Late Bronze Age and Pre-Roman Iron Age. Since clay and pottery were found in the same part of the house, the hearth is seen as belonging to the house. The remains of a clay floor in house 246/247 had traces of a fire on top indicating the location of a hearth in the eastern part of the house.

The hearths in the following three houses connected to type 3 houses are less certain. The circular hearth in house $55 \mathrm{~A}$ is symmetrically located between four postholes for roof-bearing posts. However, as eight other similar hearths are situated in the area, the location of this hearth in relation to the postholes may be a coincidence. The two other houses 31 and 39 contained large (1.5 $\mathrm{m}$ in diameter), shallow hearths situated in the middle between two trestles and around the central axis in the eastern part. However, the bowl-shape of these hearths, packed with fire-cracked stones and charcoal, is not elsewhere associated with houses from the Bronze Age and Pre-Roman Iron Age. Therefore, it 
is with some caution that these hearths are included in the interpretation of these houses.

\section{Depressions}

Seven shallow depressions are situated in the western end and one in the eastern end (Fig. 19-20). They differ in size from $1.2 \times 1.9 \mathrm{~m}$ to $1.4 \times 4.8 \mathrm{~m}$, and their depths are between 10 and $25 \mathrm{~cm}$. They consist of soil, some fire-cracked stones, charcoal and sherds of pottery, the finds mentioned above and pieces of burnt mica schist. Clay is missing in six of these westerly-situated depressions, which indicates that this part of these houses did not have a clay floor. The large $25 \mathrm{~cm}$ deep depression in the western part of house 190 (Fig. 20) contained 0.9 $\mathrm{kg}$ of clay scattered in small pieces. The clay was not a preserved floor layer and the deep depression makes it unlikely that the clay represents the remains of a floor. In contrast, the depression in the eastern part of house $241 / 242$ had a continuous $2-10 \mathrm{~cm}$ thick clay layer in the depression. It is very likely that this represents a small part of a clay floor, while the seven depressions in the western end of the houses are likely depressions from the activity of cattle on their way in and out of the byre in the western part of the house.

The elongated shape of four of these depressions, stretching as much as $5 \mathrm{~m}$ from the entrance room and situated in the central axis, supports such an interpretation (Fig. 19-20). The remaining three depressions are oval or irregular, but also situated around the central axis, and may have had the same function. In Tengesdal, a similarly large depression - measuring 5 $\mathrm{x} 1.2-1.5 \mathrm{~m}$ and stretching from the entrance through two bays, as in Forsand house 190 - has been found in a recently excavated early Pre-Roman Iron Age house (Reiersen 2015:37). At Gausel (Børsheim \& Soltvedt 2002:48), three type 3 houses dated to the early PreRoman or early Roman Iron Age have been found with large flagstone paved depressions of approximately $4.7-5.5 \times 1.2-1.5 \mathrm{~m}$, situated in the area opposite the dwelling area. The trestles that surrounded these paved depressions defined 2 or $3 \mathrm{~m}$ wide bays, suitable for stalling four or six cattle in each bay or ten to twelve cattle in each byre. These houses represent the best proof for the interpretation of the depressions at Forsand as the result of stalling cattle in the houses. Among 64 well preserved type I-IV houses from Grøntoft, there were six similar, elongated or square depressions (Rindel 1997:50f). They are all situated in the eastern part, right up to the gable of the house, together with stall boxes. The similarity of this feature between the two sites (Forsand and Grøntoft) leaves little doubt that the wear depression at Forsand was caused by cattle. It is also interesting to note that, while 60 of the houses at Grøntoft have traces of stall boxes and only six have wear depressions, there are seven depressions at Forsand from only 38 houses. The doubled ratio (18\% versus $9 \%$ ) at Forsand compared to Grøntoft indicates that cattle stalling normally must have taken place in the western end of the type 3 houses at Forsand.

\section{Conclusion}

This analysis of the various features documented in type 3 houses at Forsand indicates that the living section in nearly all houses was in the eastern end. In Fig. 91 all the distribution patterns from pottery, clay, burnt bones, slag and charred grains in stone-built houses from other sites show a clear western distribution of finds. In Forsand, remains of two clay floors and many houses with clay in the eastern postholes show that clay floors were frequent in this type. A large majority of pottery finds and other types of finds in the eastern part, together with the location of the longest trestle span, the occurrence of a few hearths and an interior door giving access to the eastern part all suggest that the living section was in the eastern end.

The different information commented on in the following paragraphs is visualised in Table 5, folder, in the section where distances between the trestles are given. In this table, the line for each house is marked with different colours according to which house had the longest span (green), most pottery (yellow), most clay (blue), most hearths (red) and most wear depressions (grey). When there are equally long trestle spans on each side of the entrance room, both trestle spans are coloured. When more features are recorded on a side of the house other than the side where the house had trestle spans marked with the length measurement, an additional cell has been marked further out.

The table shows that 20 houses have the longest trestle span in the eastern part of the house, together with finds of either pottery (four houses: $45,56,74,123$ ), clay (three houses: $39,219,229)$ or both pottery and clay (13 houses: 19, 25, 55, 62, 82, 89, 91-93, 97-99, 188, 212, $213,215,241 / 242$ ) found in the postholes in that end. There is no pottery in the western part of these houses, and only three have finds of clay in the western part. The remains of a clay floor in houses 188 and 241/242, together with five hearths situated in the eastern part, strengthen the interpretation of the eastern part as the dwelling area. The seven depressions located in the western part of these houses indicate that the 
western part had another function than the eastern part. Judging from some of the elongated depressions and their location in relation to the western trestle in the entrance room and to the west, a reasonable interpretation is that the depressions are the result of cattle traffic in and out of the byre. Together, these seven features support the interpretation that the eastern part served as the living section in type 3 houses.

Still, this sample of 20 houses only represents half of the type 3 houses. There are ten houses with no finds at all. Seven of these (41, 50, 80, 130, 143, 170 and 219) have the longest trestle-span in the eastern part, and one of them has a wear depression in the western part. Despite the lack of finds - but bearing in mind the conclusion from the 20 houses mentioned above - the seven houses are interpreted as most probably having the living section in the east. The remaining three (12, 49 and 232) have the longest span in the west - and one of the three houses contained a hearth where the long western span was present - and are therefore interpreted as houses with the living section in the west.

Three houses (190, 81 and 31) have equally long trestle spans in each part of the house. Therefore, the roof-bearing structures cannot help to interpret the location of the living section. Two of the houses (190 and 81) have wear depressions in the west, combined with an abundance of clay in the east and pottery in either the eastern or western part of the house. In the third one (31), pottery was found in the west but there was a probable hearth in the eastern part. These three houses must have had the living section in the east despite the lack of roof-bearing structures supporting this interpretation.

The two houses 13 and 21 have a slightly longer span in the western part, but in house 21, there was clay and pottery in the eastern end. It is therefore interpreted as having the living section in the east, while the other house, 13, has a central hearth in the westernmost part, where a long trestle span is present, making it quite likely that the living section was located in that area. House 208, which was partly unearthed, has a 3 $\mathrm{m}$ wide span to the west of the entrance room. As a possible type 3.2 house, this long span is interpreted as a western dwelling area. Finally, the two houses 37 and 110 are only partly excavated and a conclusion as to where the living section was located is impossible to reach.

Altogether, this analysis shows that the living section in type 3 houses is, with some degree of probability, interpreted to be located in the eastern part in 30 out of 38 houses; in six houses, it was more probably located in the western part and for two partly excavated houses, the location of the dwelling area is undetermined.

\subsection{Location of the dwelling section in type 9 houses}

In the type 9 houses, the location of the hearths makes it clear that the western part was the residential area of the house. Some houses also had a heated room at the eastern end. The area in between, with regular short bays, sometimes with remains from stalls, is interpreted as the byre area. The distribution of the different types of finds indicates where different activities took place, both in the dwelling area as well as in the byre area. Below, I have also compared the distribution pattern to the distribution patterns in stone walled houses of the same type, investigated in the early 1900s.

\section{Distribution of finds in type $\mathbf{9}$ houses}

Regrettably, the artefacts occurring in postholes and hearths at Forsandmoen are not abundant. It is therefore difficult to interpret where different occupation zones were located, based on the finds in an individual house. However, since type 9 houses are of similar construction and they all belong to one settlement site within a continuous habitation period, it is reasonable to treat all finds from this house type as belonging to two house types: short houses with 5-7 trestles and houses with eight or more trestles, including all houses with a hearth in the eastern end.

Fig. 84 shows how three types of ceramic ware, clay and burnt bones are distributed in 18 short houses. Looking first at the pottery distribution, we can see that $92 \%$ of a total of $635 \mathrm{~g}$ of pottery was located in the western part, while there was only $52 \mathrm{~g}$ in the eastern part. The pottery consists of $260 \mathrm{~g}$ of bucket-shaped pottery, $140 \mathrm{~g}$ fine ware and $237 \mathrm{~g}$ coarse ware, mainly found in the central hearth(s) and the six postholes for roof-bearing posts in the western end. A large proportion of the pottery (308 g, $49 \%$ ) derives from house 2, leaving only $329 \mathrm{~g}$ to be divided between 17 houses (only $19 \mathrm{~g}$ /house). This pattern marks out house 2 as special, which is also indicated by its shape and width. The distribution of charred bones confirms that the western part was the area for food preparation and consumption, as does the scorched mica schist, which for the most part was found in the central hearth. Since this type of stone is scorched and mainly found in hearths it should be associated with food preparation. The amount of clay shows a different pattern, with most of it located eastwards from the transition 


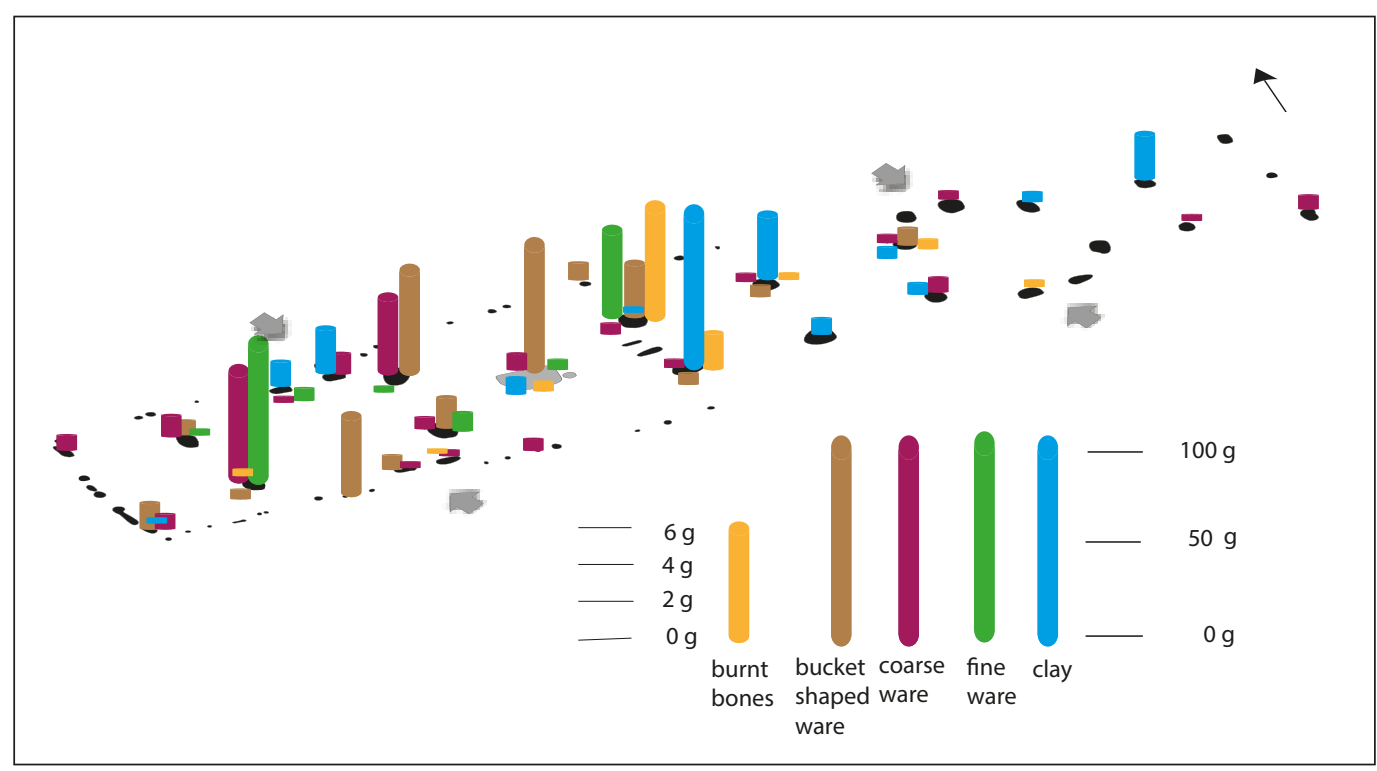

Fig. 84. Distribution of five finds units from 18 short type 9 houses: pottery, clay, slag/ furnace remains, burnt bones and charred cereal grains.

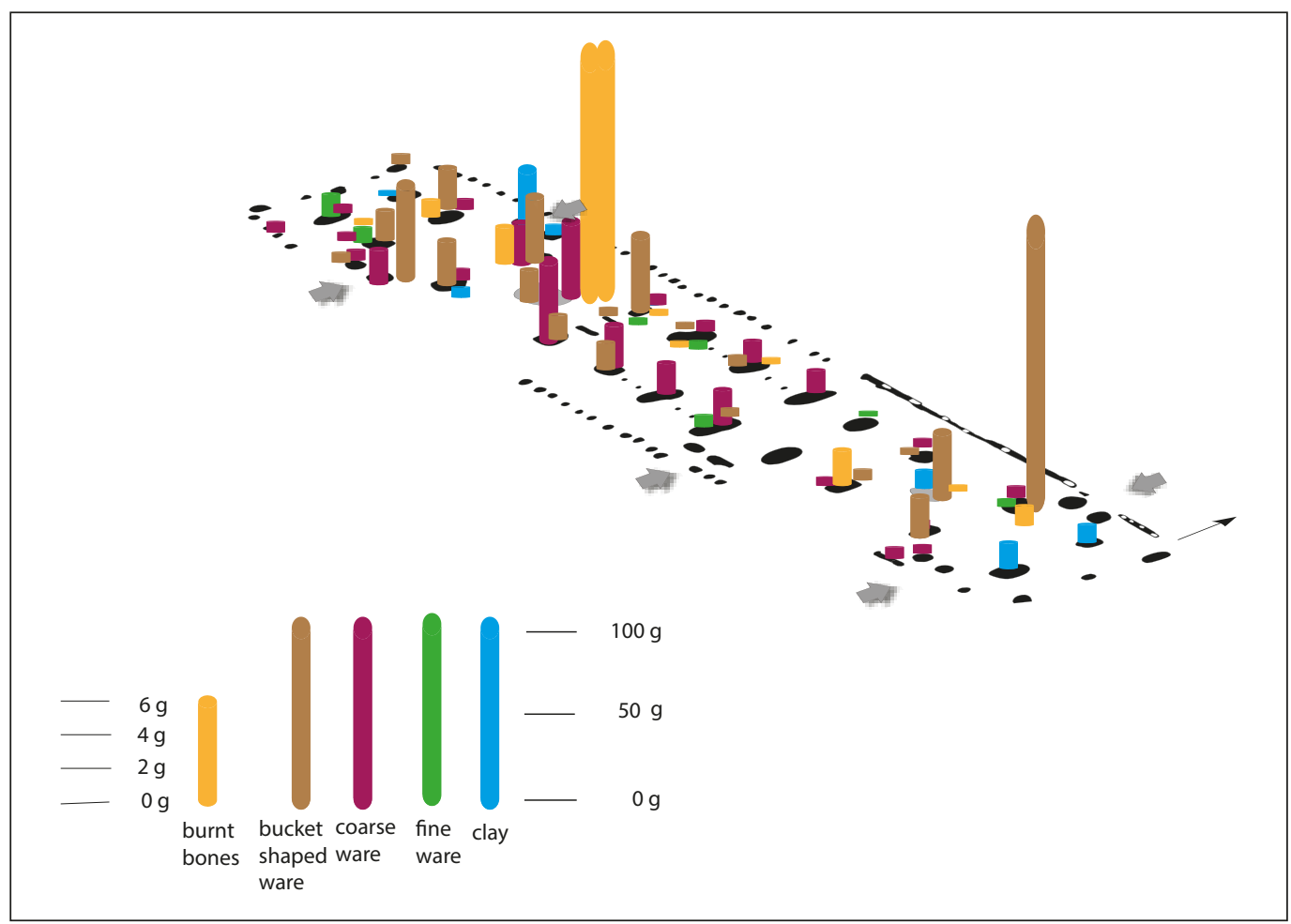

Fig. 85. Distribution of five finds units from 20 long type 9 houses: pottery, clay, slag/ furnace remains, burnt bones and charred cereal grains.

trestle between the western and eastern part. The scarce amount of clay in the western part indicates that clay floors were not used in this type of house.

The overall picture from these artefact types is that most finds have been recovered from the western part and a large part from the western entrance room, which probably also served as an unheated room for daily activities. In the eastern part, there are hardly any finds that indicate human occupation on a daily basis.

Fig. 85 shows the similar distribution in longhouses with a heated room in the eastern end - together with some longhouses without such a hearth in the eastern end - in total 20 houses. As was the case with the shorter houses, most pottery is found in the western living section and a relatively small amount in the central, byre section. These houses have twice as much bucket-shaped pottery as the shorter houses, but considering the many houses with two dwelling areas, this is not surprising. The distribution of bucket-shaped pottery is the most remarkable. Approximately equal amounts (250 g and $242 \mathrm{~g}$ ) were located in the heated areas, while the central area (byre) counts for only 26 g (5\%). Activities involving bucket-shaped pots were 
Fig. 86. The distribution of all other find groups in type 9 houses, except for those shown in Fig. 84 and 85 .

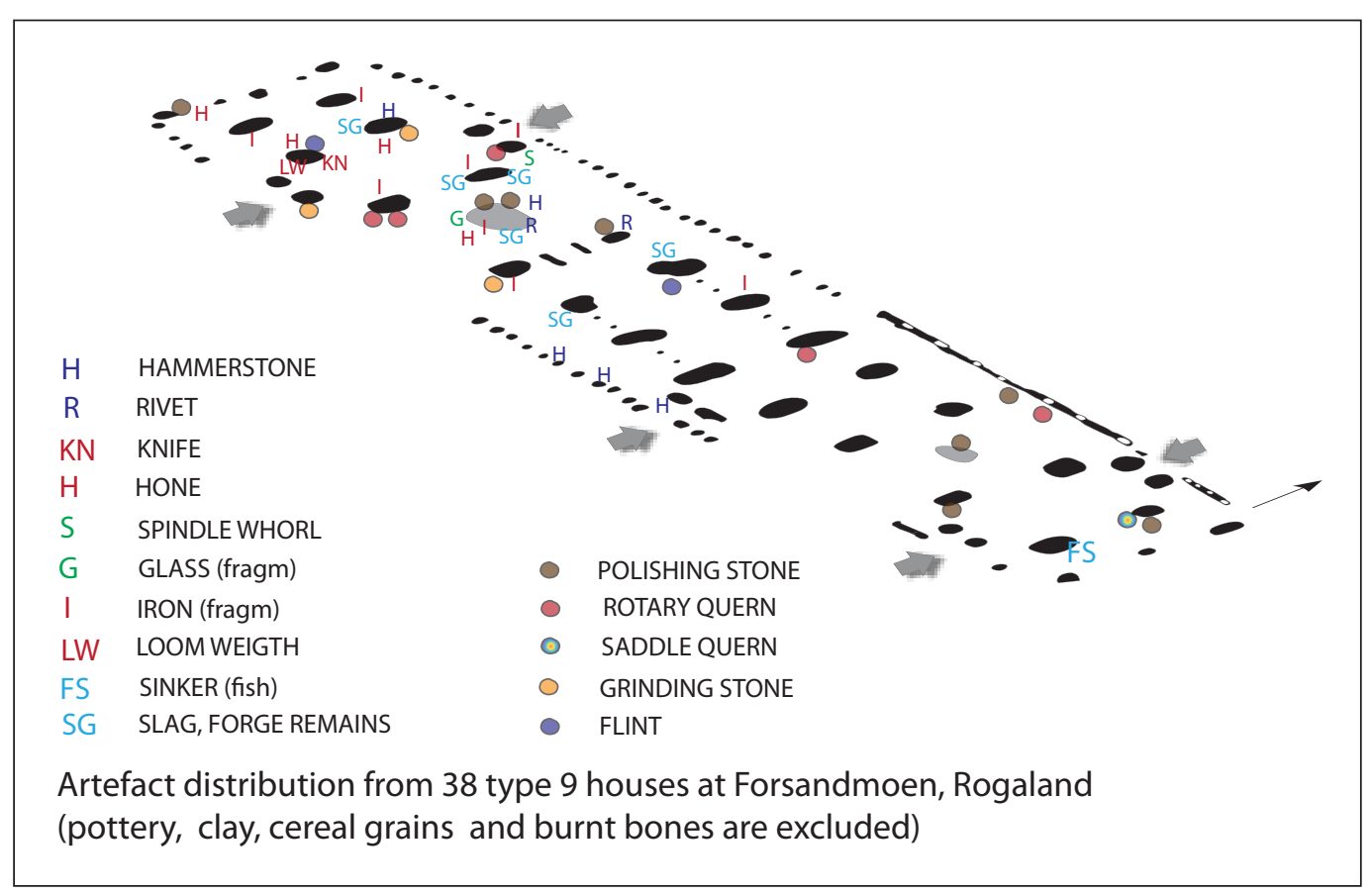

restricted to the two heated areas as opposed to the coarse ware that has been found in most of the postholes in the byre area and - surprisingly - nearly nothing in the eastern dwelling area. However, the amount of coarse ware in the byre area is markedly lower (33 $\%)$ than in the western living section (60\%), indicating that activities involving coarse ware took place to a certain degree in the central (byre) area. This pattern might be the result of more internal traffic/activity in the byre due to the many houses with double heated areas. The distribution of clay, found only in the heated areas, is the opposite of the shorter houses, which only had clay in the byre area. The small amounts do not invite any interpretation of this difference and likewise cannot support a clay floor interpretation.

The overall picture of these houses is that all types and the greatest number of finds were located in the central, heated room and to a lesser extent to the western entrance room and the eastern heated area (apart from the bucket-shaped pottery in the eastern heated room). These finds may support an interpretation of the central heated room as a hall room in these large houses, just as the large amount of bucked-shaped pottery in house 2 has been interpreted as belonging to a large hall.

The distribution of all other find groups not included in Fig. 84 or Fig. 85 is visualised in Fig. 86. The distribution supports the view that the western area was the main dwelling area and that hardly any of the artefact types have been found in the byre area. There are also surprisingly few such artefacts in the eastern dwelling area, based on the amount of pottery in the same area. Considering that only $25 \%$ of type 9 houses have this eastern dwelling area, the low number of finds is maybe not so remarkable.

The total distribution of artefacts (Fig. 84-86) and the location of hearths and the remains from stall boxes are a strong indication that $75 \%$ of the houses were divided into a western dwelling area and an eastern byre and storage space. The remaining twelve houses were divided into the same two areas and an additional dwelling area in the eastern end. The somewhat restricted amount of finds in this eastern area might be an indication of this area having less importance in daily activities. The large amount of bucket-shaped pottery in the eastern heated room compared to other finds and the small amount of coarse ware may indicate a special purpose area. On the other hand, eight of these houses have a similar sized dwelling area in the eastern end as in the western end. It is possible that these houses contained two households with a common byre in the central section.

If we look in more detail at the artefacts shown in Fig. 86, there is a single shard from a glass beaker, an iron knife, a spindle whorl, a loom weight, a sinker and two iron rivets - all found in the two dwelling areas. There are also a few types of artefacts connected with grinding or polishing that occur more frequently. Five fragments from rotary querns and one saddle quern - all used as wedging stones in postholes - indicate the importance of crop production in the Roman Iron Age and Migration Period. In addition, three grinding 


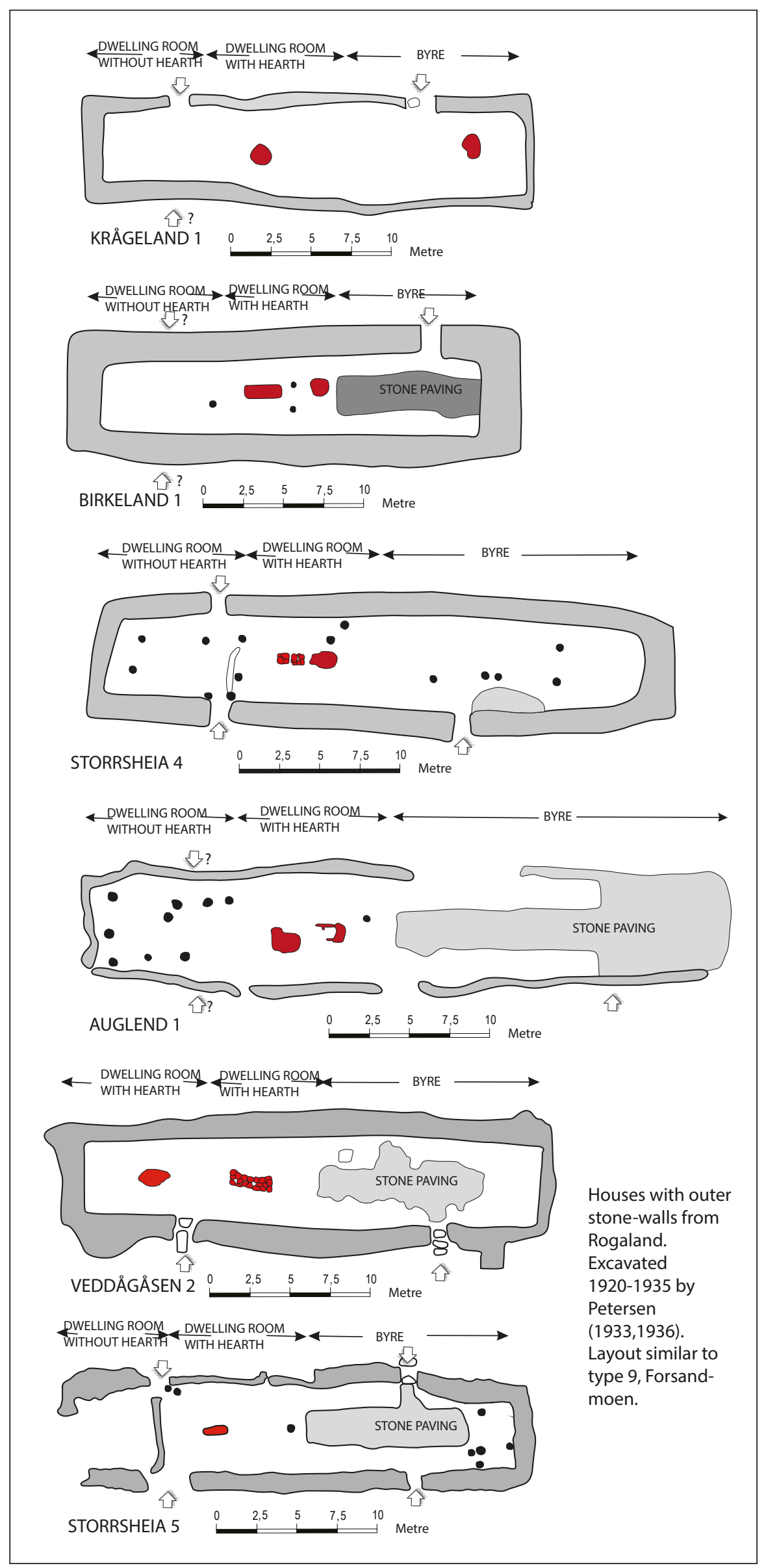

Fig. 87. Six Roman Iron Age / Migration Period houses with outer stone-built walls, excavated in the 1920s and 1930s (after Myhre 1980). 


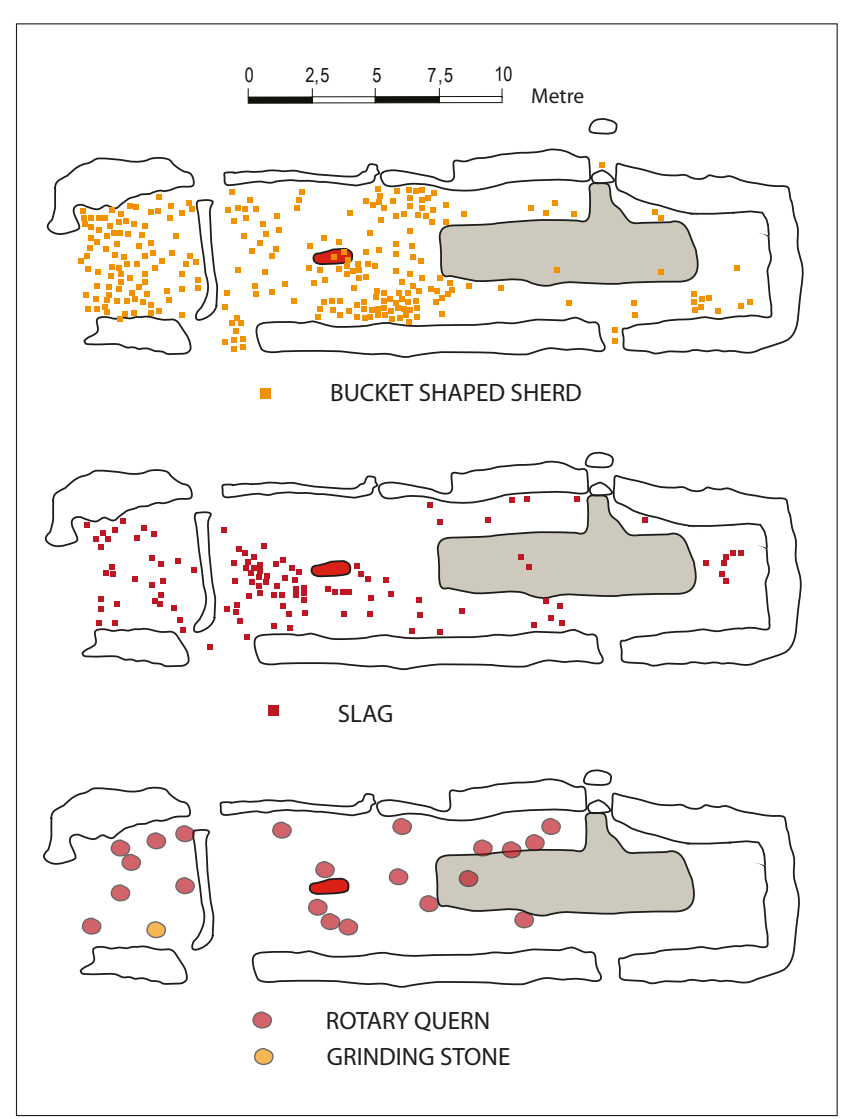

Fig. 88. The distribution of pottery, slag and querns found in stone-built houses relocated to one typical house plan.

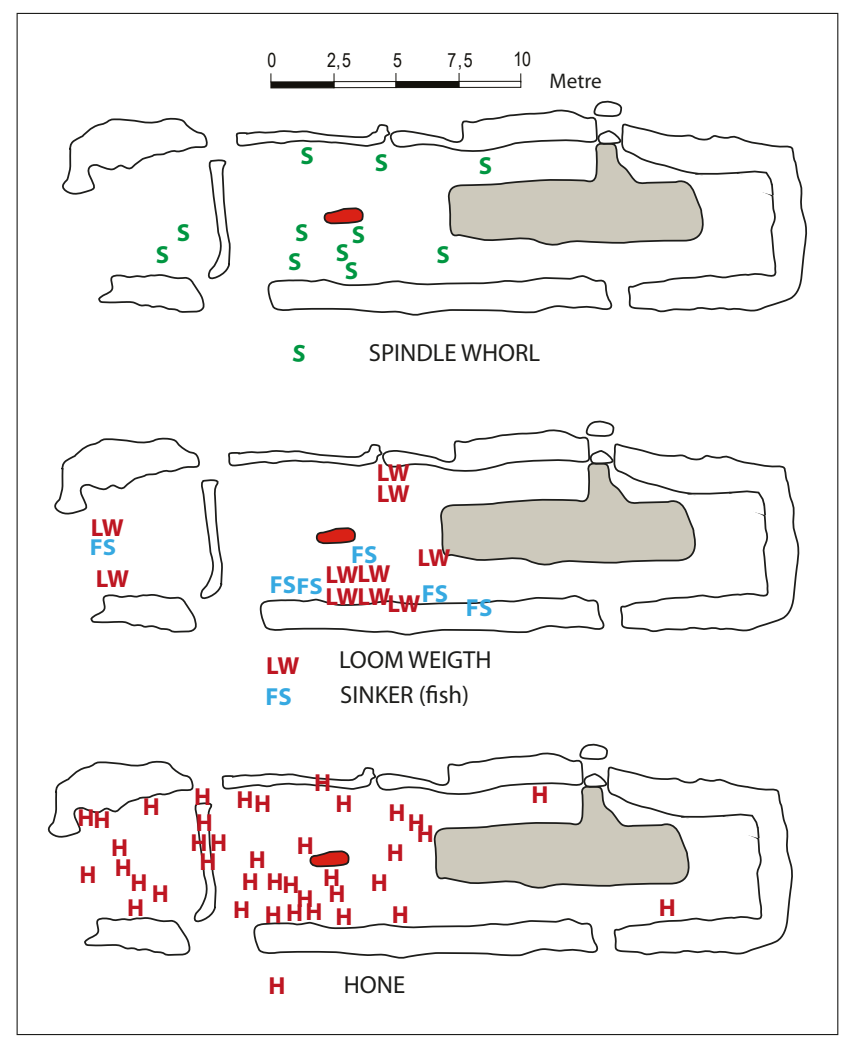

Fig. 89. The distribution of spindle whorls, loom weights and hones found in stone-built houses relocated to one typical house plan. stones, eight polishing stones and five hammer stones are connected to meal preparation and tool maintenance; most of them were found in the dwelling areas. Three hones were found in the western gable room, while a fourth was recovered from a central hearth. Seven of eight iron fragments are scattered throughout the western dwelling area, as are slag and forge remains. The central hearth distinguishes itself from the postholes with eight different find categories in addition to all types of pottery and charred bones, indicating that the area around the hearth was the main area for daily life.

This division in activity areas coincides closely with Myhre's (1980) room divisions based on 43 longhouses excavated in Rogaland in the years 1927-1968, where he interpreted different sections of the houses as heated or unheated habitation rooms, byres, storage rooms and special purpose rooms, such as a smithy. 14 of those houses have a size and structure closely comparable with the type 9 houses at Forsand.

The house plans from six of these houses have been redrawn to show their structure clearly (Fig. 87). All of them have what Myhre interpreted as a living room with hearth(s) approximately in the middle of the house and a gable room as a living room without heating in one end. In four instances, there are entrances located in this room, as is normal in type 9 houses. It should be mentioned that entrances were often not discovered during these early excavations due to the lack of examination of the outer stone walls. Two houses have traces of a partition wall between the two living rooms. Ten of the houses have stone paving in the central aisle, in the part not used as the human dwelling area (four examples in Fig. 87). Together with one

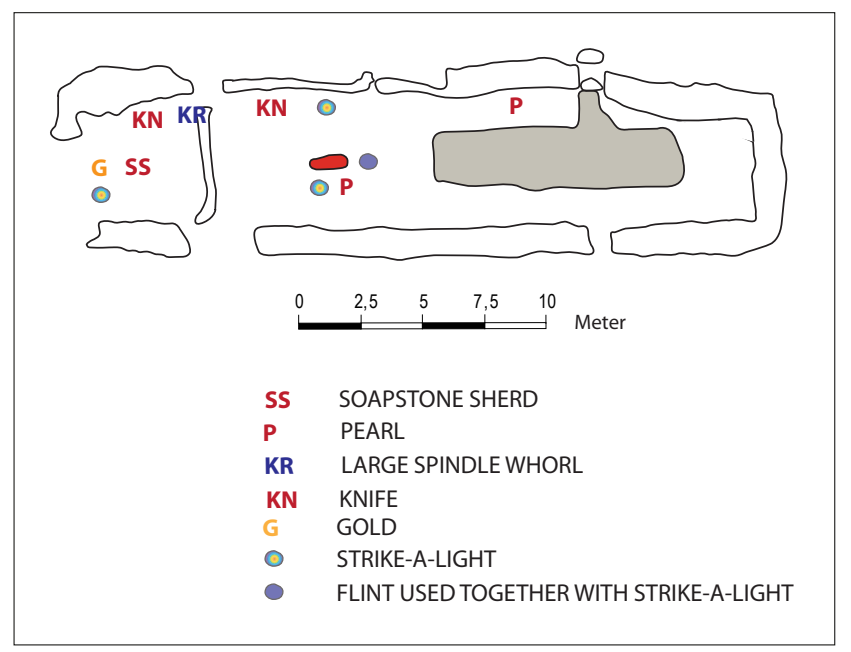

Fig. 90. The distribution of items not presented in Fig. 89 and 90 found in stone-built houses relocated to one typical house plan. 
or two entrances near the gable, this part must have functioned as a byre. A couple of these houses had a stone-fenced cattle lane, leading the cattle to the byre entrance. Three of these stone pavings do not cover the central aisle right to the gable, indicating a storage area or space for tending smaller animals, probably sheep and/or goats.

As demonstrated earlier (Løken 1983, 1992d), these houses have a similar construction and internal structure, and thus a similar organisation of daily life as in type 9 houses at Forsand. It is therefore also interesting to compare the find pattern from the Forsand houses with the previously excavated houses. However, the finds from each previously excavated house are not very abundant. In order to get a broader picture of the find distribution I have, as precisely as possible, placed all finds in each find category marked by Myhre (1980:268-318) from the individual 14 house plans into the most representative location of these plans. The distribution pattern is shown in Fig. 88-91.

In Fig. 88, the bucket shaped pottery shows two concentrations along the long walls near the byre area and the nearby gable wall, and nearly none in the byre area. The distribution may indicate activity areas near the central hearth and probably a storage area near the gable. The amount of slag in the two living rooms indicates metal work in the living rooms, but clearly less than what was found in rooms interpreted as smithies. Rotary querns are distributed quite evenly throughout the house, including the adjoining part of the byre. Few are found in a primary location, and many of the destroyed querns may have had a secondary function, such as supporting a post.

Fig. 89 shows that spindle whorls and loom weights are markedly concentrated in the inner part of the main living room, where the hearth gave heat and light. The location of the sinkers is less understandable unless they have served as loom weights. It is unlikely that textiles were manufactured in the unheated entrance room. Hones are mainly found in the heated room, but also to a certain extent in the gable room, indicating that work on and repair of iron tools was an indoor activity. A number of rarely occurring artefacts (Fig. 90) show the same distribution as the more frequent artefact types: around the hearth in the main room and near the gable in the entrance room.

Fig. 91 illustrates a concentration of finds along the one long wall in the heated room, with a major concentration in front of the hearth. At the opposite long wall, smaller concentrations are located to each side of the hearth. Considering discussions of the location of the high seat (Herschend 1997:50f, Herschend

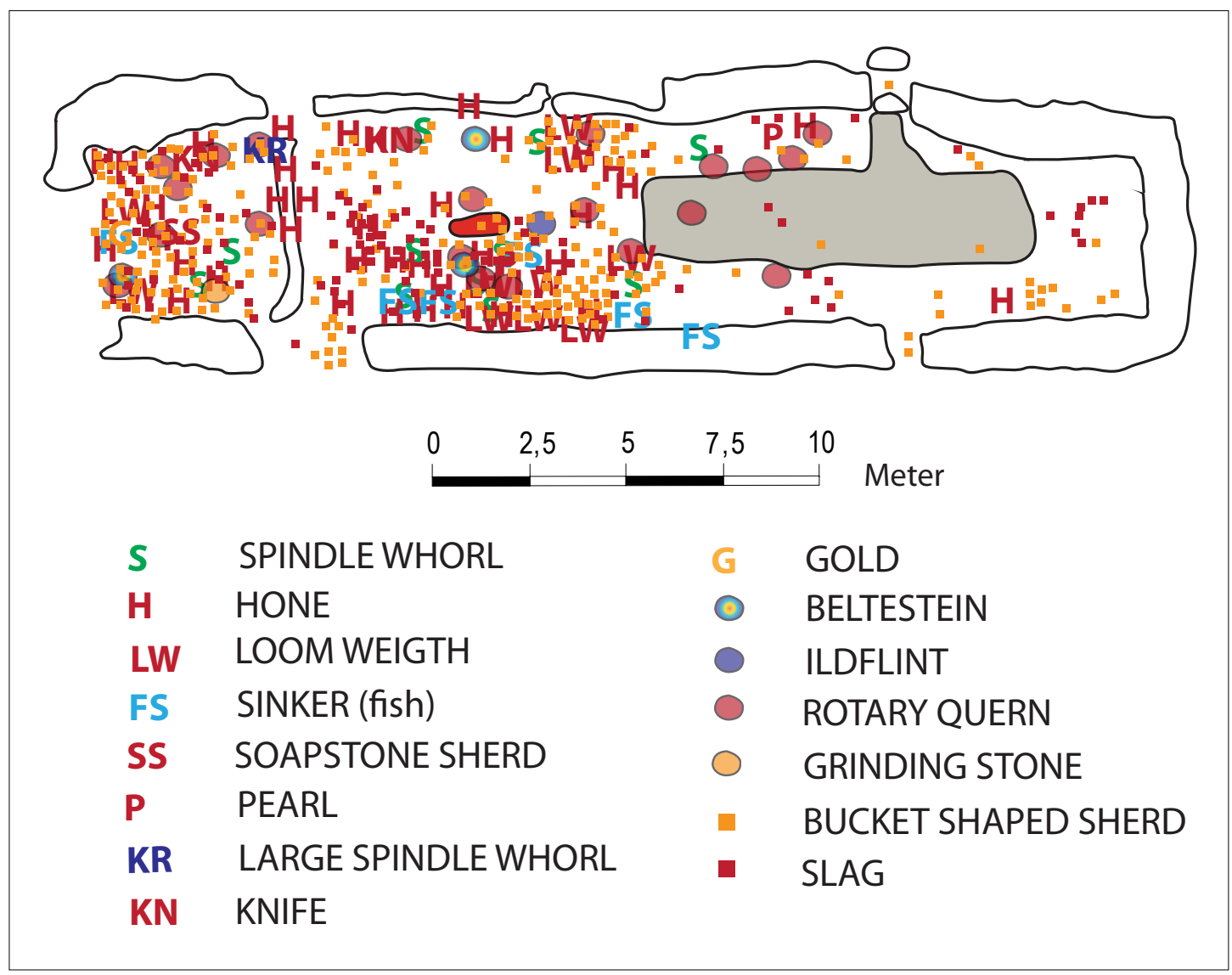

Fig. 91. The combined find distribution from Fig. 88-90 found in stone-built houses relocated to one typical house plan. 
\& Mikkelsen 2003, Söderberg 2005:200f), where one alternative location that is considered likely to have occurred in the Roman Iron Age and the Migration Period is alongside the outer wall and in front of the hearth, this pattern can be viewed as an indication of such a location of the high seat for the master and mistress of the house at the Migration Period farms.

A concentration of finds was also located along the gable wall, which is an indication that equipment and food were stored in the unheated room. Few finds have been made in between the opposite doors. In spite of the light from the entrances, this trafficked area has not been attractive for storage. In the byre there are - except for the rotary querns - hardly any finds indicative of other activities than tending the domestic animals.

The results from this analysis of the find distributions found in the farmhouses excavated prior to the excavations at Forsand have brought to light knowledge of the whereabouts of several activity areas that could not be seen in the find pattern from the postholes at Forsand, especially the location of the high seat and the area for weaving at the opposite long wall. The distribution pattern of the finds from Forsand also confirms that the unheated western gable room was used as much as the heated room for several activities and that very few activities - save for crop-grinding - took place in the byre area. 


\section{The byre in house types 3 and 9}

This chapter deals with the byre area in the type 3 and 9 combined dwelling and byre houses. What factors indicate where the byre was located and how much capacity it had? Did the size change depending on the time the houses were built or the size of the residential area? Were there traces of activities other than stalling cattle in the byre?

\subsection{The byre in type 3 houses}

The analysis of features such as the location of the longest trestle distance, wear depressions along the central axis, interior doors, hearths and the distribution of pottery, clay, other finds and charred grains (chapter 5) show that 31 of the total 38 type 3 houses probably had the dwelling area in the eastern part; only five houses are believed to have had the western part as the dwelling area. The location of the dwelling area could not be determined in the two remaining houses. It is therefore possible to analyse 36 houses in relation to the function of the different parts of the houses, since the size of the dwelling and byre areas in type 3 houses are the main components for how many inhabitants and cattle a house could take. In the following paragraphs, I therefore discuss the likely number of human inhabitants as well as the number of stalled cattle in type 3 houses.

Table 49 shows the mean relevant measurements for the different subtypes of type 3 houses, and Table 50 lists the similar measurements for all houses dated within four periods as well as the undated houses. The total length and width have been commented on in chapter 5 , but to summarise, types 3.1.2 and 3.3 have the same length and width and consequently the same floor area $\left(127-130 \mathrm{~m}^{2}\right)$. Also, their mean size increases by $2 \mathrm{~m}$ in length from one sub-period to the next through the Bronze Age, Pre-Roman Iron Age and Roman Iron Age, starting at $14 \mathrm{~m}$ and reaching $20 \mathrm{~m}$ in the Roman Iron Age. This is a nearly 50 \% increase in the floor area (from $87 \mathrm{~m}^{2}$ to $128 \mathrm{~m}^{2}$ ).

Table 51 shows how the mean size of the dwelling and the byre area - as well as the probable number of stalled cattle - differs within five subtypes and four different chronological periods. The Bronze Age houses as well as the undated houses are nearly the same size and differ quite clearly from the other three periods. Houses from the early Pre-Roman Iron Age are also approximately the same size as the undated ones, while this is not the case for the late Pre-Roman Iron Age and Roman Iron Age houses. So, the undated houses probably belong to the Bronze Age and early Pre-Roman Iron Age. This means that there are 26 houses from the period 1500-200 BC. They are distributed as follows: two houses in Bronze Age Periods II-IV (1500-900 $\mathrm{BC}), 24$ houses in Bronze Age Periods V-VI and the early Pre-Roman Iron Age (900-200 BC) and twelve houses in the period from $200 \mathrm{BC}$ to $\mathrm{AD} 400$. In the period 900-200 $\mathrm{BC}$, there were approximately three to four houses each century and only two houses per century thereafter. Based just on these figures, the settlement size seems to be restricted in Bronze Age Periods II-IV. However, in this period, the settlement also comprised six type 1 houses as dwelling houses. In the period 900-200 BC, it seems that type 3 is the only type of byre house that was used - indicating that this is the main period for this type of house - while later on; type 3 houses were mainly replaced by type 7-9 byre houses.

The type 3 byre house is divided into three main parts, with separate parts for animals and humans and an entrance room in the middle. Only type 3.1.2 has an entrance room that differs significantly from the other subtypes, with a $2.7 \mathrm{~m}$ mean width as opposed to a 1.3-1.8 $\mathrm{m}$ width in the other subtypes. The smallest house type (3.2) and the largest house type (3.1.2) have the largest area allocated to the entrance room (14\%). In comparison, 8-9 \% of the total portion of space is dedicated to the entrance room in the two subtypes with the greatest number of houses (10-11). The most striking difference lies between the two subgroups with the longest houses (3.1.2 and 3.3, both 19.6-19.9 m) where type 3.1.2 has an entrance room nearly twice as large as the type 3.3 houses. The long 6 -trestle houses distinguish themselves not only from ordinary 6-trestle houses but also from the equally long type 3.3 houses in having a large entrance room. The only other house with such a large entrance room 
Table 49. Size of dwelling/byre in house type 3 subtypes. Measurements in metres $(\mathrm{m})$.

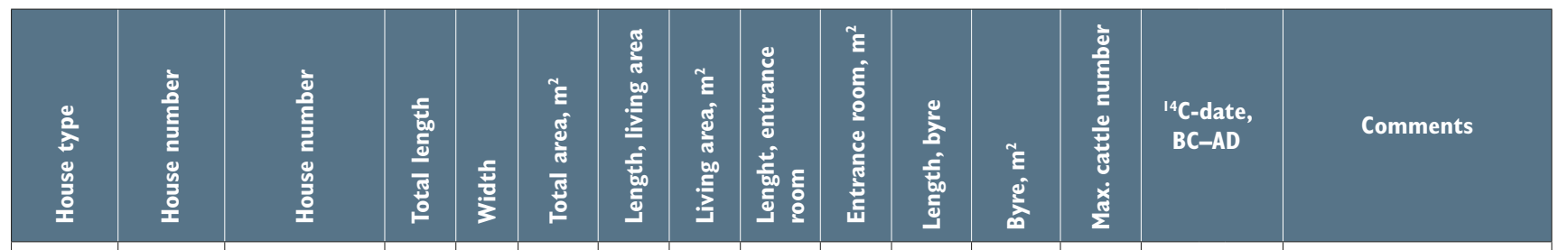

\begin{tabular}{|c|c|c|c|c|c|c|c|c|c|c|c|c|c|c|}
\hline 3.I.1. & 25 & $X X V$ & 14.4 & 5.0 & 72.0 & 6.7 & 33.5 & 1.4 & 7.0 & 6.3 & 31.5 & 8 & $-800--370$ & \\
\hline 3.I.I. & 31 & XXXI & 15.1 & 6.2 & 93.6 & 6.9 & 42.8 & 1.6 & 9.9 & 6.5 & 40.3 & 10 & & \\
\hline 3.I.I. & 39 & XXXIX & 14.8 & 6.0 & 88.8 & 7.4 & 44.4 & 1.4 & 8.4 & 6.0 & 36.0 & 8 & & \\
\hline 3.I.I. & 61 & LXI & 16.0 & 6.1 & 97.6 & 6.9 & 42.1 & 1.3 & 7.9 & 6.8 & 41.5 & 10 & $-160--60$ & \\
\hline 3.I.I. & 75 & LXXIV & 14.4 & 6.0 & 86.4 & 6.7 & 40.2 & 1.6 & 9.6 & 6.0 & 36.0 & 8 & $-900--540$ & \\
\hline 3.I.I. & 83 & LXXXII & 15.8 & 5.6 & 88.5 & 9.8 & 54.9 & 1.4 & 7.8 & 5.1 & 28.6 & 6 & $10-330$ & \\
\hline 3.1.1. & 89 & LXXXIX & 15.4 & 6.8 & 104.7 & 8.4 & 57.1 & 1.2 & 8.2 & 5.6 & 38.1 & 8 & $-330--50$ & \\
\hline 3.1.1. & 188 & CLXXXVIII & 14.6 & 6.0 & 87.6 & 7.1 & 42.6 & 1.2 & 7.2 & 6.3 & 37.8 & 8 & $-790--400$ & \\
\hline 3.1.1. & 212 & CCXII & 15.7 & 6.8 & 106.8 & 7.8 & 53.0 & 1.3 & 8.8 & 6.5 & 44.2 & 8 & $-1260--910$ & \\
\hline 3.1.1. & 215 & CCXV & 12.6 & 5.8 & 73.1 & 6.2 & 36.0 & 1.2 & 7.0 & 5.2 & 30.2 & 6 & $-900--770$ & \\
\hline 3.1.1. & 247 & CCXLVII & 13.0 & 6.0 & 78.0 & 5.1 & 30.6 & 1.2 & 7.2 & 5.7 & 34.2 & 6 & $-525--395$ & \\
\hline Mean & & II houses & 14.7 & 6.0 & 88.8 & 7.2 & 43.4 & 1.3 & 8.1 & 6.0 & 36.2 & $7-8$ & & \\
\hline 3.1 .2 & 13 & XIII & 19.6 & 6.3 & 123.5 & 7.9 & 49.8 & 3.5 & 22.1 & 8.3 & 52.3 & 12 & $230-340$ & Human habitation in west \\
\hline 3.1 .2 & 21 & $X X I$ & 18.4 & 6.7 & 123.3 & 8.0 & 53.6 & 3.1 & 20.8 & 7.3 & 48.9 & 12 & $-360--100$ & \\
\hline 3.1.2. & 81 & LXXXI & 18.0 & 6.5 & 117.0 & 8.3 & 54.0 & 1.5 & 9.8 & 8.2 & 53.3 & 12 & $-170-15$ & \\
\hline 3.1.2. & 123 & CXXIII & 22.4 & 6.9 & 154.6 & 11.2 & 73.9 & 2.6 & 17.2 & 8.6 & 56.8 & 12 & $75-315$ & \\
\hline Mean & & 4 houses & 19.6 & 6.6 & 129.6 & 8.9 & 57.8 & 2.7 & 17.5 & 8.1 & 52.8 & 12 & & \\
\hline 3.I.Prob & 49 & XLIX & 15.6 & 6.4 & 99.8 & 6.8 & 43.5 & 2.8 & 17.9 & 6.1 & 39.0 & 8 & & Human habitation in west \\
\hline 3.1. Prob & $41 / 43$ & $X C I / X C I I I$ & 15.8 & 6.5 & 102.7 & 7.8 & 50.7 & 1.7 & 11.1 & 6.3 & 41.0 & 8 & & \\
\hline 3.I. Prob & 219 & CCXIX & 15.2 & 6.0 & 91.2 & 7.7 & 46.2 & 1.3 & 7.8 & 6.2 & 37.2 & 8 & $-760--250$ & \\
\hline 3.I.Prob & 229 & CCXXIX & 14.5 & 5.8 & 84.1 & 6.9 & 40.0 & 1.3 & 7.5 & 6.3 & 36.5 & 8 & $-390--195$ & \\
\hline Mean & & 4 houses & 15.3 & 6.2 & 94.5 & 7.3 & 45.1 & 1.8 & 11.1 & 6.2 & 38.4 & 8 & & \\
\hline 3.2 . & 41 & XLI & 13.8 & 5.6 & 77.8 & 5.5 & 30.8 & 1.5 & 8.4 & 6.9 & 38.6 & 10 & & \\
\hline 3.2. & 50 & $L X$ & 10.3 & 5.7 & 58.7 & 5.3 & 30.2 & 1.6 & 9.1 & 3.5 & 20.0 & 4 & $-800--200$ & \\
\hline 3.2. & 130 & CXXX & 19.1 & 6.5 & 124.2 & 6.3 & 41.0 & 3.8 & 24.7 & 9.0 & 58.5 & 12 & $230-395$ & \\
\hline 3.2. & 143 & CXLIII & 12.1 & 6.0 & 72.6 & 4.7 & 28.2 & 1.6 & 9.6 & 5.8 & 34.8 & 8 & & \\
\hline 3.2 . & 213 & CCXIII & 11.1 & 6.0 & 66.6 & 5.9 & 35.5 & 1.2 & 7.2 & 4.0 & 24.0 & 4 & $-395--210$ & \\
\hline 3.2. & 218 & CCXVIII & 12.7 & 5.8 & 73.7 & 5.1 & 29.6 & 1.3 & 7.5 & 6.3 & 36.5 & 6 & $-760--395$ & Human habitation in west \\
\hline 3.2 . & $24 I / 42$ & CCXLI/LII & 11.5 & 5.6 & 64.4 & 5.4 & 30.2 & 2.4 & 13.4 & 3.6 & 20.2 & $4 ?$ & $-400--170$ & \\
\hline Mean & & 7 houses & 12.9 & 5.9 & 76.8 & 5.5 & 32.2 & 1.9 & 11.4 & 5.6 & 33.2 & $6-7$ & & \\
\hline 3.3. & 45 & XLV & 15.2 & 6.6 & 100.3 & 6.5 & 42.9 & 1.2 & 7.9 & 7.5 & 49.5 & 12 & $-1520--1260$ & \\
\hline 3.3 . & 80 & LXXX & 18.3 & 6.2 & 113.5 & 8.2 & 50.8 & 1.4 & 8.7 & 8.7 & 53.9 & 12 & $-10-320$ & \\
\hline 3.3. & 97/98/99 & $X C V I I / V I I I / I X$ & 19.8 & 6.4 & 126.7 & 7.8 & 49.9 & 1.6 & 10.2 & 10.4 & 66.6 & 16 & $-760--400$ & \\
\hline 3.3. & 19 & $\mathrm{XIX}$ & 21.0 & 6.8 & 142.8 & 9.7 & 66.0 & 2.1 & 14.3 & 9.2 & 62.6 & 16 & $-360--10$ & \\
\hline 3.3. & $55 \mathrm{~A}$ & LVA & 16.2 & 6.3 & 102.1 & 10.3 & 64.9 & 1.4 & 8.8 & 4.5 & 28.4 & 4 & $-510--260$ & \\
\hline 3.3. & 190 & CXC & 21.5 & 6.4 & 137.6 & 8.6 & 55.0 & 1.4 & 9.0 & 11.5 & 73.6 & 18 & $-400--200$ & \\
\hline 3.3. & 12 & XII & 21.5 & 6.5 & 139.8 & 9.9 & 64.4 & 1.8 & 11.7 & 9.8 & 64.7 & 16 & $220-415$ & Human habitation in west \\
\hline 3.3. & 231 & CCXXXII & 20.5 & 6.2 & 127.1 & 9.1 & 56.4 & 1.5 & 9.3 & 9.8 & 60.8 & 16 & $-400--190$ & Human habitation in west \\
\hline 3.3. & 170 & CLXX & 21.2 & 5.9 & 125.1 & 10.4 & 61.4 & 1.4 & 8.3 & 9.4 & 55.5 & 16 & $-510--40$ & \\
\hline 3.3. & 62 & LXII & 24.1 & 6.4 & 154.2 & 12.0 & 76.8 & 1.7 & 10.9 & 10.4 & 66.6 & 18 & $-50-140$ & \\
\hline Mean & & 10 houses & 19.9 & 6.4 & 126.9 & 9.3 & 58.9 & 1.6 & 9.9 & 9.1 & 58.2 & $14-15$ & & \\
\hline
\end{tabular}


Table 50. Size of dwelling/byre in type 3 houses in different periods. Measurements in metres (m).

\begin{tabular}{|c|c|c|c|c|c|c|c|c|c|c|c|c|c|c|}
\hline 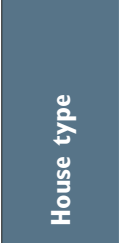 & 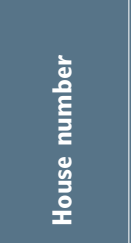 & 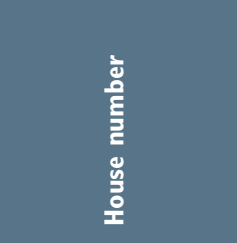 & 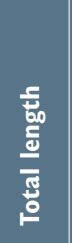 & 咅 & 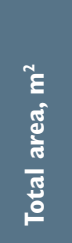 & 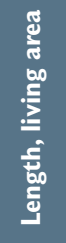 & 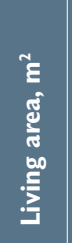 & 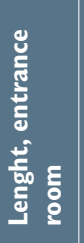 & 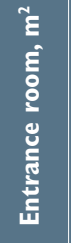 & 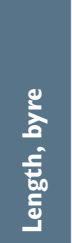 & 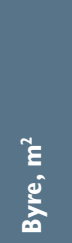 & 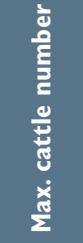 & $\begin{array}{l}{ }^{14} \text { C-date } \\
\text { BC-AD }\end{array}$ & Comments \\
\hline \multicolumn{15}{|c|}{ Not dated } \\
\hline 3.1. Prob & $91 / 93$ & XCI/XCIII & 15.8 & 6.5 & 102.7 & 7.8 & 50.7 & 1.7 & II.I & 6.3 & 41.0 & 8 & & \\
\hline 3.I. Prob & 49 & XLIX & 15.6 & 6.4 & 99.8 & 6.8 & 43.5 & 2.8 & 17.9 & 6.1 & 39.0 & 8 & & $\begin{array}{l}\text { Human habitaton } \\
\text { in west }\end{array}$ \\
\hline 3.I.I. & 31 & $X X X I$ & I5.I & 6.2 & 93.6 & 6.9 & 42.8 & 1.6 & 9.9 & 6.5 & 40.3 & 10 & & \\
\hline 3.I.I. & 39 & XXXIX & 14.8 & 6.0 & 88.8 & 7.4 & 44.4 & 1.4 & 8.4 & 6.0 & 36.0 & 8 & & \\
\hline 3.2 . & 41 & $\mathrm{XLI}$ & 13.8 & 5.6 & 77.8 & 5.5 & 30.8 & 1.5 & 8.4 & 6.9 & 38.6 & 10 & & \\
\hline 3.2 . & 143 & CXLIII & 12.1 & 6.0 & 72.6 & 4.7 & 28.2 & 1.6 & 9.6 & 5.8 & 34.8 & 8 & & \\
\hline Mean & 6 houses & & 14.5 & 6.1 & 89.2 & 6.5 & 40.1 & 1.8 & 10.9 & 6.3 & 38.3 & $8-9$ & & \\
\hline \multicolumn{15}{|c|}{ Bronze Age } \\
\hline 3.3. & 45 & XLV & 15.2 & 6.6 & 100.3 & 6.5 & 42.9 & 1.2 & 7.9 & 7.5 & 49.5 & 12 & $-1520--1260$ & \\
\hline 3.I.I. & 212 & CXII & 15.7 & 6.8 & 106.8 & 7.8 & 53.0 & 1.3 & 8.8 & 6.5 & 44.2 & 8 & $-1260--910$ & \\
\hline 3.I.I. & 74 & LXXIV & 14.4 & 6.0 & 86.4 & 6.7 & 40.2 & 1.6 & 9.6 & 6.0 & 36.0 & 8 & $-900--540$ & \\
\hline 3.I.I. & 215 & CCXV & 12.6 & 5.8 & 73.1 & 6.2 & 36.0 & 1.2 & 7.0 & 5.2 & 30.2 & 6 & $-900--770$ & \\
\hline 3.I.I. & 25 & $x X V$ & 14.4 & 5.0 & 72.0 & 6.7 & 33.5 & 1.4 & 7.0 & 6.3 & 31.5 & 8 & $-800--370$ & \\
\hline 3.2. & 60 & $L X$ & 10.3 & 5.7 & 58.7 & 5.3 & 30.2 & 1.6 & 9.1 & 3.5 & 20.0 & 4 & $-800--200$ & \\
\hline 3.I.I. & 188 & CLXXXVIII & 14.6 & 6.0 & 87.6 & 7.1 & 42.6 & 1.2 & 7.2 & 6.3 & 37.8 & 8 & $-790--400$ & \\
\hline 3.3. & $97 / 98 / 99$ & XCVIIIXCVIII/XCIX & 19.8 & 6.4 & 126.7 & 7.8 & 49.9 & 1.6 & 10.2 & 10.4 & 66.6 & 16 & $-760--400$ & \\
\hline 3.I. Prob & 219 & CCXIX & 15.2 & 6.0 & 91.2 & 7.7 & 46.2 & 1.3 & 7.8 & 6.2 & 37.2 & 8 & $-760--250$ & \\
\hline 3.2 . & 218 & CCXVIII & 12.7 & 5.8 & 73.7 & 5.1 & 29.6 & 1.3 & 7.5 & 6.3 & 36.5 & 6 & $-760--395$ & $\begin{array}{l}\text { Human habitaton } \\
\text { in west }\end{array}$ \\
\hline Mean & 10 houses & & 14.5 & 6.0 & 87.7 & 6.7 & 40.4 & 1.4 & 8.2 & 6.4 & 40.0 & $7-8$ & & \\
\hline \multicolumn{15}{|c|}{ Early Pre-Roman IA } \\
\hline 3.1.1. & 247 & CCXLVII & 13.0 & 6.0 & 78.0 & 5.1 & 30.6 & 1.2 & 7.2 & 5.7 & 34.2 & 6 & $-525--395$ & \\
\hline 3.3 . & $55 \mathrm{~A}$ & LVA & 16.2 & 6.3 & 102.1 & 10.3 & 64.9 & 1.4 & 8.8 & 4.5 & 28.4 & 4 & $-510--260$ & \\
\hline 3.3. & 190 & $\mathrm{CXC}$ & 21.5 & 6.4 & 137.6 & 8.6 & 55.0 & 1.4 & 9.0 & 11.5 & 73.6 & 18 & $-400--200$ & \\
\hline 3.3. & 170 & CLXX & 21.2 & 5.9 & 125.1 & 10.4 & 61.4 & 1.4 & 8.3 & 9.4 & 55.5 & 16 & $-510--40$ & \\
\hline 3.3 . & 232 & CCXXXII & 20.5 & 6.2 & 127.1 & 9.1 & 56.4 & 1.5 & 9.3 & 9.8 & 60.8 & 16 & $-400--190$ & $\begin{array}{l}\text { Human habitaton } \\
\text { in west }\end{array}$ \\
\hline 3.2. & $24 I / 242$ & CCXLI/CCXLII & 11.5 & 5.6 & 64.4 & 5.4 & 30.2 & 2.4 & 13.4 & 3.6 & 20.2 & $4 ?$ & $-400--170$ & $\begin{array}{l}\text { Cattle number } \\
\text { not used }\end{array}$ \\
\hline 3.2. & 213 & CCXIII & II.I & 6.0 & 66.6 & 5.9 & 35.5 & 1.2 & 7.2 & 4.0 & 24.0 & 4 & $-395--210$ & \\
\hline 3.I.Prob & 229 & CCXXIX & 14.5 & 5.8 & 84.1 & 6.9 & 40.0 & 1.3 & 7.5 & 6.3 & 36.5 & 8 & $-390--195$ & \\
\hline Mean & 8 houses & & 16.2 & 6.0 & 98.1 & 7.7 & 46.8 & 1.5 & 8.8 & 6.9 & 41.7 & $10-11$ & & \\
\hline \multicolumn{15}{|c|}{ Late Pre-Roman IA } \\
\hline 3.3. & 19 & $\mathrm{XIX}$ & 21.0 & 6.8 & 142.8 & 9.7 & 66.0 & 2.1 & 14.3 & 9.2 & 62.6 & 16 & $-360--10$ & \\
\hline 3.1 .2 & 21 & $X X I$ & 18.4 & 6.7 & 123.3 & 8.0 & 53.6 & 3.1 & 20.8 & 7.3 & 48.9 & 12 & $-360--100$ & $\begin{array}{l}\text { Human habitaton } \\
\text { in west }\end{array}$ \\
\hline 3.I.I. & 89 & LXXXIX & 15.4 & 6.8 & 104.7 & 8.4 & 57.1 & 1.2 & 8.2 & 5.6 & 38.1 & 8 & $-330--50$ & \\
\hline 3.1.2. & 81 & LXXXI & 18.0 & 6.5 & 117.0 & 8.3 & 54.0 & 1.5 & 9.8 & 8.2 & 53.3 & 12 & $-170-15$ & \\
\hline 3.I.I. & 61 & LXI & 16.0 & 6.1 & 97.6 & 6.9 & 42.1 & 1.3 & 7.9 & 6.8 & 41.5 & 10 & $-160--60$ & \\
\hline Mean & 5 houses & & 17.8 & 6.6 & 117.1 & 8.3 & 54.6 & 1.8 & 12.2 & 7.4 & 48.9 & $11-12$ & & \\
\hline \multicolumn{15}{|c|}{ Roman IA } \\
\hline 3.3. & 62 & LXII & 24.1 & 6.4 & 154.2 & 12.0 & 76.8 & 1.7 & 10.9 & 10.4 & 66.6 & 18 & $-50-140$ & \\
\hline
\end{tabular}




\begin{tabular}{|c|c|c|c|c|c|c|c|c|c|c|c|c|c|c|}
\hline 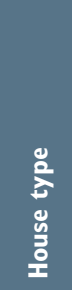 & 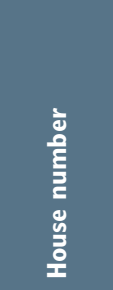 & 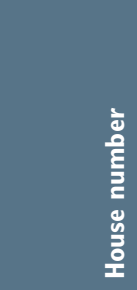 & 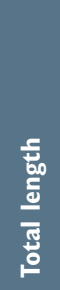 & $\frac{\text { 횽 }}{\frac{3}{3}}$ & 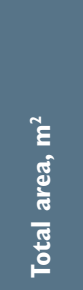 & 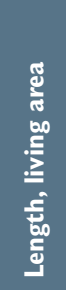 & 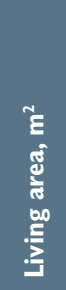 & 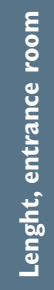 & 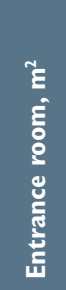 & 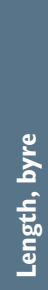 & $\begin{array}{l}\tilde{\Xi} \\
\tilde{y} \\
\tilde{0}\end{array}$ & 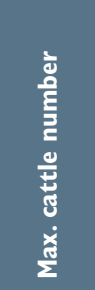 & $\begin{array}{l}{ }^{14} \text { C-date } \\
\text { BC-AD }\end{array}$ & Comments \\
\hline 3.3. & 80 & LXXX & 18.3 & 6.2 & 113.5 & 8.2 & 50.8 & 1.4 & 8.7 & 8.7 & 53.9 & 12 & $-10-320$ & \\
\hline 3.1.1. & 82 & LXXXII & 15.8 & 5.6 & 88.5 & 9.8 & 54.9 & 1.4 & 7.8 & 5.1 & 28.6 & 6 & $10-330$ & \\
\hline 3.1.2. & 123 & CXXIII & 22.4 & 6.9 & 154.6 & 11.2 & 73.9 & 2.6 & 17.2 & 8.6 & 56.8 & 12 & $75-315$ & \\
\hline 3.3. & 12 & XII & 21.5 & 6.5 & 139.8 & 9.9 & 64.4 & 1.8 & 11.7 & 9.8 & 64.7 & 16 & $220-415$ & $\begin{array}{l}\text { Human habitaton } \\
\text { in west }\end{array}$ \\
\hline 3.1 .2 . & 13 & XIII & 19.6 & 6.3 & 123.5 & 7.9 & 49.8 & 3.5 & 22.1 & 8.3 & 52.3 & 12 & $230-340$ & $\begin{array}{l}\text { Human habitaton } \\
\text { in west }\end{array}$ \\
\hline 3.2 . & 130 & $C X X X$ & 19.1 & 6.5 & 124.2 & 6.3 & 41.0 & 3.8 & 24.7 & 9.0 & 58.5 & 12 & $230-395$ & \\
\hline Mean & 7 houses & & 20.1 & 6.3 & 128.3 & 9.3 & 58.8 & 2.3 & 14.7 & 8.6 & 54.5 & $12-13$ & & \\
\hline
\end{tabular}

is the equally long house 130 (type 3.2 with 5 trestles, $19.1 \mathrm{~m}$ ). It is tempting to interpret these houses with a large entrance room as having some special functions connected to leadership in secular and religious activities that necessitated space. In one instance, a centrally located hearth was also found in the entrance room (house 13). Similarly, a $27 \mathrm{~m}$ long type 3.1.2 house with a large central hearth in a $3.6 \mathrm{~m}$ wide entrance room at Hovde, Sør-Trøndelag has been interpreted as a main dwelling house for a local chieftain (Grønnesby 1999).
The width, and consequently the area, of the entrance room increased through time, in particular from the early to late Pre-Roman Iron Age. However, the portion that the entrance room represents in relation to the total area did not change significantly $(9.4 \%$ versus $10.8 \%$ ). Since the width of the actual entrances is stable through all periods, the increase in the width of the entrance room must be related to a need for more space in the late Pre-Roman Iron Age and Roman Iron Age than earlier. From the Bronze Age to the Roman

Table 5I. Average size of dwelling/byre features in type 3 houses, sorted by subtypes and by periods. Measurements in metres ( $\mathrm{m}$ ).

\begin{tabular}{|c|c|c|c|c|c|c|c|c|c|c|c|c|c|c|}
\hline $\begin{array}{l}\text { House } \\
\text { type }\end{array}$ & $\begin{array}{l}\text { Number } \\
\text { of houses }\end{array}$ & 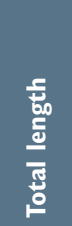 & 豆 & 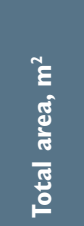 & 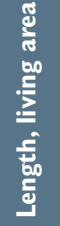 & 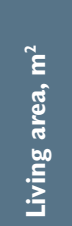 & 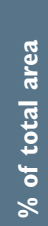 & 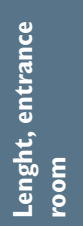 & 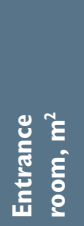 & 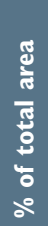 & 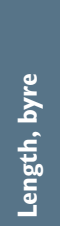 & 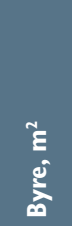 & 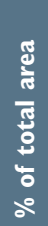 & $\begin{array}{l}\text { Max. cattle } \\
\text { number }\end{array}$ \\
\hline 3.1 .1 & 11 & 14.7 & 6.0 & 88.8 & 7.2 & 43.4 & 49 & 1.3 & 8.1 & 9 & 6.0 & 36.2 & 41 & $7-8$ \\
\hline 3.1 .2 & 4 & 19.6 & 6.6 & 129.6 & 8.9 & 57.8 & 45 & 2.7 & 17.5 & 14 & 8.1 & 52.8 & 41 & 12 \\
\hline prob.3.I & 4 & 15.3 & 6.2 & 94.5 & 7.3 & 45.1 & 47 & 1.8 & 11.1 & 12 & 6.2 & 38.4 & 41 & 8 \\
\hline 3.2 & 7 & 12.9 & 5.9 & 76.9 & 5.5 & 32.2 & 45 & 1.9 & 11.4 & 14 & 5.6 & 33.2 & 42 & 6 \\
\hline 3.3 & 10 & 19.9 & 6.4 & 126.9 & 9.3 & 58.9 & 46 & 1.6 & 9.9 & 8 & 9.1 & 58.2 & 46 & $14-15$ \\
\hline
\end{tabular}

\begin{tabular}{|c|c|c|c|c|c|c|c|c|c|c|c|c|c|c|}
\hline Period & $\begin{array}{l}\text { Number } \\
\text { of houses }\end{array}$ & 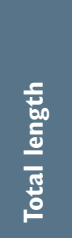 & $\frac{5}{\frac{5}{0}}$ & 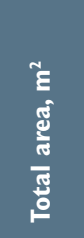 & 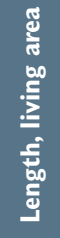 & 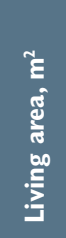 & 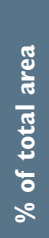 & 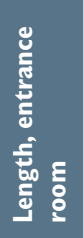 & 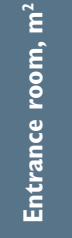 & 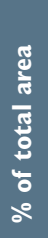 & 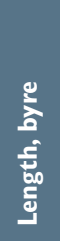 & 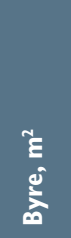 & 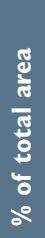 & $\begin{array}{l}\text { Max. cattle } \\
\text { number }\end{array}$ \\
\hline Undated & 6 & 14.5 & 6.1 & 89.2 & 6.5 & 40.1 & 45 & 1.8 & 10.9 & 12 & 6.3 & 38.3 & 43 & $8-9$ \\
\hline Bronze Age & 10 & 14.4 & 6.0 & 87.1 & 6.7 & 40.4 & 46 & 1.4 & 8.2 & 9 & 6.4 & 40.0 & 46 & $8-9$ \\
\hline Early Pre-Roman IA & 8 & 16.2 & 6.0 & 98.1 & 7.7 & 47.6 & 48 & 1.5 & 8.8 & 9 & 6.8 & 41.7 & 42 & $|0-1|$ \\
\hline Late Pre-Roman IA & 5 & 17.8 & 6.6 & 117.1 & 8.3 & 54.6 & 47 & 1.8 & 12.2 & 10 & 7.4 & 48.9 & 42 & $11-12$ \\
\hline Roman IA & 7 & 20.1 & 6.3 & 128.3 & 9.3 & 58.8 & 46 & 2.3 & 14.7 & 11 & 8.6 & 54.5 & 43 & $12-13$ \\
\hline
\end{tabular}


Iron Age, the entrance area increased by $80 \%$, while the total area was only $50 \%$ larger. This also indicates a need for more space in the most public part of the house.

Approximately $90 \%$ of the house area is intended as a dwelling area for people and cattle. Generally, the dwelling area for people is slightly larger (4\%) than the part for cattle. The dwelling area increased (46\%) over time, about as much as the total area also increased (48 $\%)$, while the byre part only increased $36 \%$; the size of the byre area in relation to the total area decreased from $46 \%$ in the Bronze Age to $42-43 \%$ in the late Pre-Roman Iron Age and Roman Iron Age.

My conclusion is that the ratio between the dwelling area and the byre in the type 3 houses did not change significantly through more than 1000 years, from the middle of the Bronze Age to the Roman Iron Age. This may indicate that the type of household and economy such as agriculture, fishing, hunting and gathering changed little. On the other hand, when iron tools became available in the middle of the period, they must gradually have had a great impact on daily life, as evidenced by finds of an iron knife and a bridle from the early Pre-Roman Iron Age.

What really changes through time is the available space for both people and cattle. How should a $50 \%$ increase in the dwelling space be interpreted? The most noticeable increase takes place between the early and late Pre-Roman Iron Age, when iron technology affected many parts of daily life. The increase may reflect a need for more space for each inhabitant rather than an increase of individuals in the household. Based on different sources, Myhre (1983:156) has estimated that an individual had $12.5 \mathrm{~m}^{2}$ at their disposal in the dwelling area in the late Roman Iron Age and Migration Period. Based on this number, the Roman Iron Age type 3 houses would in mean have enough room for five adults, but the figure varies from three to six in the actual houses (Table 52). In the Bronze Age, on the other hand, the figures vary between two and four, with three as the mean value. These figures are based on the assumption that the household consisted of a nucleated family, with some possible extension in the later part of the period in question.

Such calculations are rather uncertain, but fortunately there is another entry to this discussion. The byre part increased in average size by $36 \%$ from the Bronze Age $\left(38.3 \mathrm{~m}^{2}\right)$ to the Roman Iron Age $\left(54.5 \mathrm{~m}^{2}\right)$, which is a smaller increase in floor area than in the dwelling part (Table 51). This could mean that the relative significance of cattle breeding decreased through time. Archaeologists seem to agree that at least from the Late Bronze Age cattle were stalled in two rows in byres. Finds from Hodde (Hvass 1985) and Grøntoft (Becker 1971, Rindel 1997) show that cattle normally had 0.8-1.1 $\mathrm{m}$ at their disposal. At Forsandmoen, no stall boxes were found in type 3 houses - although house 21 might be an example - but in the type 9 houses from the Roman Iron Age and Migration Period, one finds the same sizes. With these sizes as a point of reference, each byre has been analysed in order to calculate the maximum amount of cattle that could be stalled within the trestle spans, not including the gable room.

Two houses excavated in Jutland, similar to Forsand type 3, were burnt and thereby remains from the house construction and remains from human and animal inhabitants have been preserved (Haack Olsen 2007, Nielsen 2002). In the house from Sdr. Ydby, a row of small posts adjacent to the last roof-bearing trestle divided off the space next to the gable. In this room, there were no animal remains, and Haack Olsen suggests that this was a room for keeping tools or storing fodder. Only the area between the trestle spans was available for stall boxes. However, as the house from Nørre Tranders in Ålborg shows (Nielsen 2002:7), a sheepfold occupied space for two cow/ox/horse boxes, so the possible number must be regarded as the maximum stalled cattle in that part. On the other hand, the traces of stall boxes from Grøntoft show that also the gable room had stall boxes (Rindel 1997). The amount of cattle in the byres at Forsand has been calculated from possible stall boxes within the trestle spans giving space for other animals in the gable area.

The probable number of cattle for each house is given in Table 53 in accordance with the subtypes. Four houses only had space for four cattle, while two houses could house 18 cattle. It is not surprising that the two largest house types (3.1.2 and 3.3) had room for markedly more cattle than the other three sub-types. These two types had equal-sized dwelling areas with space for six adults and 12-14 cattle. Looking at the two types in more detail, type 3.3 consists of one house, 55A, that was shorter than other type 3.3 houses and had space for only four cattle. If this house is excluded, the remaining type 3.3 houses could have had room for 12-18 cattle (in mean 16). Type 3.3 houses therefore differ greatly from 3.1.2. They only had space for twelve cattle, although the two types have equal-sized dwelling areas and total area. This underlines the possible special purpose of houses with wide entrance rooms. The smallest type (3.2.) could house three adults and 
Table 52. Number of inhabitants and cattle in type 3 houses, sorted by periods. Measurements in metres $(\mathrm{m})$. Estimated measurements in italics.

\begin{tabular}{|c|c|c|c|c|c|c|c|c|c|c|c|c|c|c|}
\hline 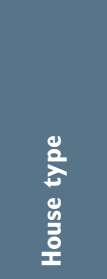 & 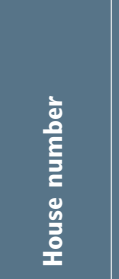 & 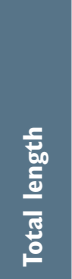 & 章 & 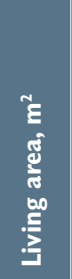 & 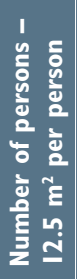 & 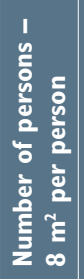 & 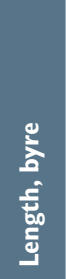 & $\begin{array}{l}\tilde{E} \\
\tilde{c} \\
\tilde{c}\end{array}$ & 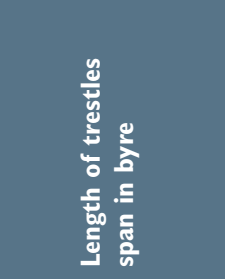 & 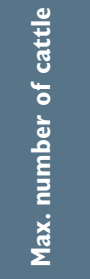 & 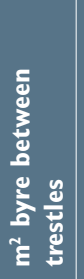 & 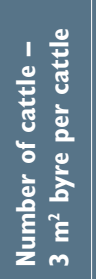 & $\begin{array}{l}{ }^{14} \mathrm{C} \text {-date } \\
\text { BC-AD }\end{array}$ & Comments \\
\hline 3.I. Prob & $91 / 93$ & 15.8 & 6.5 & 50.7 & $4-5$ & $6-7$ & 6.3 & 41.0 & $1.9-2.3$ & 8 & 27.3 & $9-10$ & & \\
\hline 3.I. Prob & 49 & 15.6 & 6.4 & 43.5 & $3-4$ & $5-6$ & 6.1 & 39.0 & $2.0-2.0$ & 8 & 25.6 & $8-9$ & & Human habitaton in west \\
\hline 3.I.I. & 31 & 15.1 & 6.2 & 42.8 & $3-4$ & $5-6$ & 6.5 & 40.3 & $1.8-2.7$ & 10 & 27.9 & $9-10$ & & \\
\hline 3.I.I. & 39 & 14.8 & 6.0 & 44.4 & $3-4$ & 5.-6 & 6.0 & 36.0 & $1.5-2.2$ & 8 & 22.2 & $7-8$ & & \\
\hline 3.2 . & 41 & 13.8 & 5.6 & 30.8 & $2-4$ & $3-4$ & 6.9 & 38.6 & $2.0-2.8$ & 10 & 31.2 & $10-11$ & & \\
\hline 3.2 . & 143 & 12.1 & 6.0 & 28.2 & $2-3$ & $3-4$ & 5.8 & 34.8 & $1.9-1.8$ & 8 & 22.2 & $7-8$ & & \\
\hline Mean & & 14.5 & 6.1 & 40.1 & $3-4$ & 5 & 6.3 & 38.3 & & $8-9$ & 26.1 & $8-9$ & & \\
\hline 3.3. & 45 & 15.2 & 6.6 & 42.9 & $3-4$ & $5-6$ & 7.5 & 49.5 & $1.9-1.6-1.9$ & 12 & 35.6 & $11-12$ & $-1520--1260$ & \\
\hline 3.1.1. & 212 & 15.7 & 6.8 & 53.0 & $4-5$ & $6-7$ & 6.5 & 44.2 & $2.1-2.3$ & 8 & 29.9 & 10 & $-1260--910$ & \\
\hline 3.I.I. & 215 & 12.6 & 5.8 & 36.0 & $2-3$ & $4-5$ & 5.2 & 30.2 & $1.5-1.8$ & 6 & 19.1 & $6-7$ & $-900--770$ & \\
\hline 3.I.I. & 74 & 14.4 & 6.0 & 40.2 & $3-4$ & 5 & 6.0 & 36.0 & $2.1-1.8$ & 8 & 23.4 & $7-8$ & $-900--540$ & \\
\hline 3.1.1. & 25 & 14.4 & 5.0 & 33.5 & $2-3$ & $4-5$ & 6.3 & 31.5 & $2.2-2.0$ & 8 & 21.0 & $7-8$ & $-800--370$ & \\
\hline 3.I.I. & 188 & 14.6 & 6.0 & 42.6 & $3-4$ & $5-6$ & 6.3 & 37.8 & $2.1-2.1$ & 8 & 25.2 & $8-9$ & $-790--400$ & \\
\hline 3.3 . & 97/98/99 & 19.8 & 6.4 & 49.9 & 4 & $6-7$ & 10.4 & 66.6 & $2.2-3.4-2.7$ & 16 & 53.1 & $17-18$ & $-760--400$ & \\
\hline 3.2 . & 60 & 10.3 & 5.7 & 30.2 & $2-3$ & $3-4$ & 3.5 & 20.0 & 1.6 & 4 & 9.1 & 3 & $-800--200$ & \\
\hline 3.2 . & 218 & 11.7 & 5.8 & 29.6 & $2-3$ & $3-4$ & 6.3 & 36.5 & $1.2-2.1$ & 6 & 19.1 & $6-7$ & $-760--395$ & Human habitaton in west \\
\hline 3.I. Prob & 219 & 15.2 & 6.0 & 46.2 & $3-4$ & $5-6$ & 6.2 & 37.2 & $2.2-1.9$ & 8 & 24.6 & $8-9$ & $-760--250$ & \\
\hline Mean & & 14.4 & 6.0 & 40.4 & $3-4$ & $5-6$ & 6.4 & 39.0 & & $8-9$ & 26.0 & $8-9$ & & \\
\hline 3.I.I. & 247 & 13.0 & 6.0 & 30.6 & $2-3$ & $3-4$ & 5.7 & 34.2 & $1.9-1.7$ & 6 & 21.6 & $7-8$ & $-525--395$ & \\
\hline 3.3. & $55 \mathrm{~A}$ & 16.2 & 6.3 & 64.9 & $5-6$ & $8-9$ & 4.5 & 28.4 & $1.2-1.2$ & 4 & 15.3 & 5 & $-510--260$ & \\
\hline 3.3 . & 170 & 21.2 & 5.9 & 61.4 & $4-5$ & $7-8$ & 9.4 & 55.5 & $1.9-1.7-1.7-2-0$ & 16 & 43.1 & $14-15$ & $-510--40$ & \\
\hline 3.3 . & 190 & 21.5 & 6.4 & 55.0 & $4-5$ & $6-7$ & 11.5 & 73.6 & $2.2-3.0-2.2-2.1$ & 18 & 60.8 & $20-21$ & $-400--200$ & \\
\hline Mean & 110 & 15.7 & 6.8 & 54.4 & $4-5$ & $6-7$ & 6.1 & 41.5 & $2.0-2.0$ & 8 & 27.2 & $9-10$ & $-400--200$ & Only half unearthed \\
\hline 3.3 . & 232 & 20.5 & 6.2 & 56.4 & $4-5$ & $7-8$ & 9.8 & 60.8 & I.7-2.0-2.0-2.0 & 16 & 47.7 & $15-16$ & $-400--190$ & Human habitaton in west \\
\hline 3.2 . & $241 / 242$ & 11.5 & 5.6 & 30.2 & $2-3$ & $3-4$ & 3.6 & 20.2 & 1.5 & 4 & 8.4 & $2-3$ & $-400--170$ & \\
\hline 3.2 . & 213 & 11.1 & 6.0 & 35.5 & $2-3$ & $4-5$ & 4.0 & 24.0 & 1.9 & 4 & $1 \mathrm{I} .4$ & $3-4$ & $-395--210$ & \\
\hline 3.I. Prob & 37 & 18.0 & 6.8 & & & 0 & $?$ & $?$ & $?$ & $?$ & 0.0 & $?$ & $-395--200$ & Undetermined \\
\hline 3.I. Prob & 229 & 14.5 & 5.8 & 40.0 & $3-4$ & 5 & 6.3 & 36.5 & $2.1-2.1$ & 8 & 24.4 & $8-9$ & $-390--195$ & \\
\hline Mean & & 16.3 & 6.2 & 47.6 & $3-4$ & $5-6$ & 6.8 & 41.6 & & $9-10$ & 26.0 & $9-10$ & & \\
\hline 3.1 .2 & 21 & 18.4 & 6.7 & 53.6 & $4-5$ & $6-7$ & 7.3 & 48.9 & $2.6-3.2$ & 12 & 38.9 & 13 & $-360--100$ & Human habitaton in west \\
\hline 3.3. & 19 & 21.0 & 6.8 & 66.0 & $5-6$ & $8-9$ & 9.2 & 62.6 & $1.9-2.6-2.7$ & 16 & 49.0 & $16-17$ & $-360--10$ & \\
\hline 3.I.I. & 89 & 15.4 & 6.8 & 57.1 & $4-5$ & $7-8$ & 5.6 & 38.1 & $1.6-1.9$ & 8 & 23.8 & $7-8$ & $-330--50$ & \\
\hline 3.1 .2 & 81 & 18.0 & 6.5 & 54.0 & $4-5$ & $6-7$ & 8.2 & 53.3 & $2.7-3.3$ & 12 & 39.0 & $13-14$ & $-170-15$ & \\
\hline 3.1.1. & 61 & 16.0 & 6.1 & 42.1 & $3-4$ & $5-6$ & 6.8 & 41.5 & $1.9-2.6$ & 10 & 27.5 & $9-10$ & $-160--60$ & \\
\hline Mean & & 17.8 & 6.6 & 54.6 & $4-5$ & $6-7$ & 7.4 & 48.9 & & $11-12$ & 35.6 & $11-12$ & & \\
\hline 3.3. & 62 & 24.1 & 6.4 & 76.8 & $6-7$ & $9-10$ & 10.4 & 66.6 & 1.6-1.9-1.7-1.5-1.7 & 18 & 54.6 & $18-19$ & $-50-140$ & \\
\hline 3.3. & 80 & 18.3 & 6.2 & 50.8 & $4-5$ & $6-5$ & 8.7 & 53.9 & $1.9-2.1-2.5$ & 12 & 40.3 & $13-14$ & $-10-320$ & \\
\hline 3.1.1. & 82 & 15.8 & 5.6 & 54.9 & $4-5$ & $6-7$ & 5.1 & 28.6 & 3.0 & 6 & 16.8 & $5-6$ & $10-330$ & \\
\hline 3.1.2. & 223 & 22.4 & 6.9 & 73.9 & $5-6$ & $9-10$ & 8.6 & 56.8 & $3.1-3.4$ & 12 & 44.9 & 15 & $75-315$ & \\
\hline 3.3. & 12 & 21.5 & 6.5 & 64.4 & $5-6$ & $8-9$ & 9.8 & 64.7 & $1.9-1.9-2.1-1.8$ & 16 & 50.1 & $16-17$ & $220-415$ & Human habitaton in west \\
\hline 3.1 .2 & 13 & 19.6 & 6.3 & 49.8 & 4 & $6-7$ & 8.3 & 52.3 & $3.1-2.5$ & 12 & 35.3 & $11-12$ & $230-340$ & Human habitaton in west \\
\hline 3.2. & 130 & 19.1 & 6.5 & 41.0 & $3-4$ & $5-6$ & 9.0 & 58.5 & $3.5-3.4$ & 12 & 44.9 & 15 & $230-395$ & \\
\hline Mean & & 20.1 & 6.3 & 58.8 & $4-5$ & $7-8$ & 8.6 & 54.5 & & $12-13$ & 41.0 & $13-14$ & & \\
\hline
\end{tabular}


six cattle, obviously a house for the basic nuclear family (household).

Type 3.1.1, with six trestles, is the most frequent type at Forsandmoen. These houses have space for four adults and eight stalled cattle. Table 53 also shows that the different values of probable type 3.1 fit well with those of 3.1.1. It seems reasonable to classify the probable 3.1 as 3.1 .1 , so nearly $50 \%$ of type 3 houses consist of this type.

Table 53 shows the calculated number of cattle in each byre according to the width of the trestle spans in the byre, given a stall box width of preferably around $1 \mathrm{~m}$, but varying from 0.85 to $1.15 \mathrm{~m}$. Table 52 shows that, in the Bronze Age and early Pre-Roman Iron Age, the type 3 houses could stall 8-9 cattle, while in the later periods the number increased to 11-13 cattle. However, looking at Table 52, one can see that, in each of the four main periods, there are houses that have room for 16-18 cattle as well as small byres with only 4-8 stall boxes. So, the type 3 houses in the settlement consisted of a mix of different houses sizes, indicating households with varying degrees of access to farmland and/or pastures for their herd.

Another way to calculate the maximum number of cattle in a single house is to use as a starting point the space a cow needs when stalled in two rows in the byre. According to Haarnagel (1979:251), a $200 \mathrm{~kg}$ cow at the Feddersen Wierde needed $2.5-3 \mathrm{~m}^{2}$. Several tests at the Feddersen Wierde showed that this type of calculation fit well with the counted stall boxes. Table 52 and Table 53 present similar calculations based on the area between the trestles that constitute the byre part. At Forsand, both types of calculations are in accordance with each other.

Compared with the Feddersen Wierde, the type 3 houses at Forsand have a much more varied house width, from $5 \mathrm{~m}$ to $6.9 \mathrm{~m}$. When Table 52 was sorted according to increasing width, and Table 54 and the house data was divided into four classes, we could see that houses wider than $6.2 \mathrm{~m}$ in mean could stall one more cow per house than the estimated number of stall boxes. For houses with lesser width, the two calculations were equal. The extra width in the central aisle must have caused this difference, and the further discussion, the estimated number of stall boxes based on the length of the trestle span is used as a basis. Table 52 , sorted according to periods, shows that only in the Roman Iron Age, byres could contain more than one cow per house, according to calculations based on the area (13.7) and compared to the probable number of stall boxes (12.6). So, except for the Roman Iron Age, time is not a factor in the small differences between the two calculation methods.

Calculations of the household size, based on 12.5 $\mathrm{m}^{2}$ of floor area per adult, are included in Table 52 and 53. The calculated number of resident adults is so small that the results are hardly conclusive. Only the two largest subtypes may have had five adults in the household, the smallest hardly more than three. Type 3.1.1 could house four adults. Benedictow (1993:162) has claimed that such a household size was the normal size in the medieval period, when the farms were split up to such a high degree that the households had to be small. He is also critical (Benedictow 1993:108) of a household size of 10-13 adults in the Migration Period as put forward by Myhre (1983). My own calculations (Løken 1987a:84) showed large differences, with five people at the smallest farms to as many as 25 at the largest. In my opinion, even if the factor of $12.5 \mathrm{~m}^{2}$ per adult is adequate in the Roman Iron Age and Migration Period, it is too much in the Bronze Age and Pre-Roman Iron Age. The burnt house from Nørre Tranders (Nielsen 2002) was $18 \mathrm{~m}$ long and 5 $\mathrm{m}$ wide, which is equivalent to a mean sized type 3.1 house at Forsand. Judging from a published photo of the house under excavation, an entrance area divided the house into two approximately $8 \mathrm{~m}$ long parts. The living room for humans was then approximately $40 \mathrm{~m}^{2}$. A minimum of five adults, including three individuals aged 12-18 and two adults, lived in the house when the fire broke out. On the basis of this example, we may assume that an area requirement of $8 \mathrm{~m}^{2}$ per person is a better figure for calculating the household size in regard to type 3 houses. In Tables 52, 53 and 54, the household size is also calculated based on an $8 \mathrm{~m}^{2}$ area requirement.

In the $18^{\text {th }}$ century, the normal cattle herd in Western Norway counted 1.5-2 cows for each household individual (Myhre 1983:155ff). If we look at the ratio for different house types and use the factor of $12.5 \mathrm{~m}^{2}$ per person, filling up the household to the nearest whole person and calculating the number of cattle for the three smallest house types (3.1.1, probable 3.1 and 3.2) we can estimate that they housed 2.1-2.4 cattle/person, while the two largest types (3.1.2 and 3.3 , respectively) would have housed 2.6 and 3.3 cattle/person. Compared with the traditional Western Norwegian mixed crop and dairy husbandry economy, and considering the more advanced technology of the $17^{\text {th }}$ and $18^{\text {th }}$ century, these figures appear too high if the cattle were winter-stalled, based on the household's ability to collect a sufficient amount of fodder. Using 


\begin{tabular}{|c|c|c|c|c|c|c|c|c|c|c|c|c|c|c|c|c|c|c|c|c|c|c|c|c|c|c|c|c|}
\hline$y$ & & & & & & & & & & & & & & & 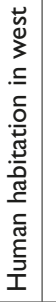 & & & & & 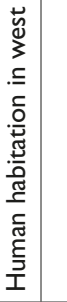 & & & & & & & & \\
\hline 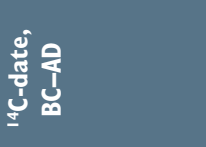 & $\begin{array}{l}\frac{0}{a} \\
i \\
i \\
o \\
\underline{d}\end{array}$ & $\begin{array}{l}2 \\
i \\
1 \\
o \\
0 \\
i\end{array}$ & $\begin{array}{l}0 \\
\text { o } \\
1 \\
1 \\
8 \\
0 \\
1\end{array}$ & $\begin{array}{l}0 \\
0 \\
0 \\
1 \\
o \\
o \\
1 \\
1\end{array}$ & $\begin{array}{c}8 \\
⿱ 亠 \\
1 \\
1 \\
\circ \\
o \\
1\end{array}$ & & 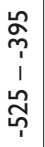 & $\begin{array}{l}0 \\
0 \\
1 \\
0 \\
0 \\
m\end{array}$ & $\begin{array}{l}0 \\
0 \\
1 \\
1 \\
\\
1\end{array}$ & $\begin{array}{l}0 \\
m \\
1 \\
0\end{array}$ & & & & & 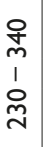 & $\begin{array}{l}8 \\
\frac{0}{1} \\
1 \\
0 \\
0 \\
m\end{array}$ & $\begin{array}{l}\frac{1}{1} \\
\frac{1}{2} \\
\frac{1}{1}\end{array}$ & $\begin{array}{l}\frac{n}{m} \\
1 \\
n \\
n\end{array}$ & & & & 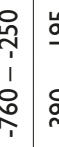 & $\begin{array}{l}n \\
\frac{n}{1} \\
1 \\
0 \\
\text { a } \\
1 \\
1\end{array}$ & & & 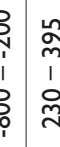 & & \\
\hline 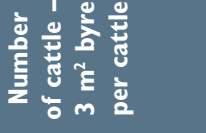 & 으 & $\hat{\jmath}$ & $\stackrel{\infty}{i}$ & $a_{1}^{\infty}$ & $\begin{array}{l}a \\
\infty \\
\infty\end{array}$ & $\infty$ & $\begin{array}{c}\infty \\
1 \\
\end{array}$ & $\left|\begin{array}{l}\infty \\
1 \\
\wedge\end{array}\right|$ & $\frac{0}{\alpha}$ & $\begin{array}{l}0 \\
1 \\
n\end{array} \mid$ & $\frac{0}{1}$ & 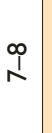 & $\begin{array}{l}\infty \\
1 \\
\wedge\end{array}$ & $\stackrel{\infty}{1}$ & $\stackrel{\underline{I}}{\underline{I}}$ & $\underline{m}$ & $\underline{m}$ & $\underline{\underline{n}}$ & $\begin{array}{l}\frac{a}{1} \\
\stackrel{m}{m}\end{array}$ & \begin{tabular}{c|c}
$\hat{\omega}$ & \multicolumn{1}{c}{} \\
\end{tabular} & $\frac{0}{\alpha}$ & $\begin{array}{ccc}a & 0 \\
\infty & 0\end{array}$ & $\begin{array}{lll}0 \\
\infty \\
\infty & 0 \\
0\end{array}$ & $\begin{array}{cc}a & = \\
\infty & c\end{array}$ & $\bar{c} \bar{c}$ & $n$ & $\frac{\infty}{1}$ & $\begin{array}{l}\infty \\
1 \\
n\end{array}$ \\
\hline 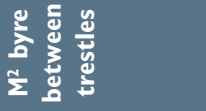 & $\begin{array}{r}\dot{\sim} \\
\dot{\sim}\end{array}$ & $\bar{\sigma}$ & $\stackrel{\nabla}{\ddot{\sim}}$ & $\frac{\stackrel{\rho}{N}}{\text { N }}$ & カָ̉ & $\hat{\sim}$ & $\stackrel{0}{\bar{N}}$ & 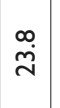 & $\stackrel{n}{\sim}$ & $\mid \begin{array}{l}\infty \\
\underline{\dot{\omega}} \\
\end{array}$ & $\stackrel{a}{\grave{i}}$ & $\tilde{\mathcal{N}}$ & $\underset{\sim}{\stackrel{m}{\sim}}$ & $\stackrel{\sim}{\tilde{n}}$ & $\stackrel{m}{m}$ & $\begin{array}{c}\stackrel{\rho}{\infty} \\
\stackrel{m}{m}\end{array}$ & $\stackrel{\circ}{\dot{m}}$ & $\begin{array}{l}a \\
\dot{f}\end{array}$ & $\stackrel{n}{\dot{m}}$ & 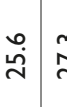 & $\stackrel{m}{\sim}$ & $\stackrel{\circ}{\sim} \underset{ }{\sim}$ & $\stackrel{\Delta}{\sim} \underset{\sim}{\sim}$ & \begin{tabular}{c}
$\infty$ \\
\multirow{n}{\infty}{}
\end{tabular} & 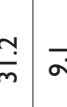 & $\therefore \quad \begin{array}{l}q \\
\dot{f}\end{array}$ & & \\
\hline 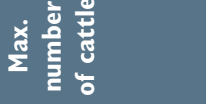 & $\infty$ & 0 & $\infty$ & $\infty$ & $\infty$ & $\begin{array}{l}\infty \\
1 \\
n\end{array}$ & 0 & $\infty$ & 으 & 0 & 으 & $\infty$ & $\infty$ & $\begin{array}{l}\infty \\
1 \\
1\end{array}$ & $\simeq$ & $\simeq$ & $\simeq$ & $\simeq$ & $\simeq$ & $\infty$ & $\infty$ & $\infty \quad 0$ & $\infty \quad 0$ & $\infty \subseteq$ & ㅇ & 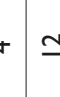 & & $\infty$ \\
\hline 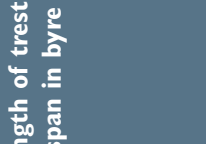 & $\underset{\substack{i \\
i \\
i}}{i}$ & 京 & $\frac{\infty}{\frac{1}{i}}$ & 唄 & $\begin{array}{c}\bar{i} \\
\bar{i} \\
\dot{i}\end{array}$ & & $\begin{array}{c}\hat{\alpha} \\
\bar{\alpha} \\
\underline{-}\end{array}$ & $\begin{array}{l}\sigma \\
\dot{\sigma} \\
\underline{b} \\
-\end{array}$ & $\begin{array}{l}0 \\
\stackrel{1}{\alpha} \\
\underline{\alpha}\end{array}$ & $\stackrel{0}{m}$ & $\begin{array}{l}\hat{i} \\
\infty \\
\underline{-}\end{array}$ & 范 & & & $\begin{array}{l}\stackrel{L}{i} \\
\frac{I}{m}\end{array}$ & 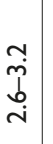 & $\begin{array}{c}m \\
p \\
1 \\
i\end{array}$ & $\begin{array}{c}\dot{m} \\
\frac{\hat{T}}{m}\end{array}$ & & 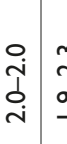 & ִָ & 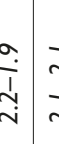 & $\frac{\bar{i}}{i}$ & & & $\stackrel{\substack{+m \\
⿱ n \\
m \\
m}}{=}$ & & 立 \\
\hline 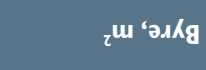 & $\mathfrak{f}$ & o̊ & iे & $\frac{n}{m}$ & $\stackrel{\infty}{m}$ & 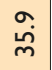 & $\stackrel{\sim}{m}$ & $\bar{\infty}$ & $\stackrel{\stackrel{n}{\sigma}}{\frac{n}{\sigma}}$ & $\stackrel{\infty}{\infty}$ & $\begin{array}{c}m \\
\dot{q}\end{array}$ & $\begin{array}{l}\stackrel{\circ}{\dot{m}} \\
\dot{m}\end{array}$ & 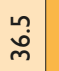 & $\begin{array}{l}\text { ָ̌ } \\
\text { m. }\end{array}$ & 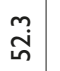 & 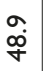 & $\stackrel{m}{m}$ & 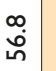 & $\begin{array}{l}\infty \\
\text { ن் }\end{array}$ & $\stackrel{\circ}{\stackrel{m}{m}}$ & $\frac{0}{\sigma}$ & 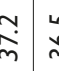 & $\begin{array}{ll}n \\
m \\
m\end{array}$ & مि & 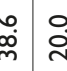 & 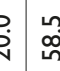 & & $\begin{array}{l}\infty \\
\stackrel{m}{m} \\
\end{array}$ \\
\hline 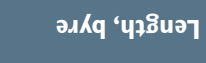 & นุ & กี & ㅇ. & m̧ & m̧ & $\overline{0}$ & $\hat{\omega}$ & $\stackrel{\circ}{\circ}$ & $\stackrel{\infty}{\infty}$ & $\overline{\dot{n}}$ & 周 & $\stackrel{0}{\circ}$ & $\stackrel{0}{\circ}$ & : & $\underset{\infty}{m}$ & $\stackrel{m}{\sim}$ & $\underset{\infty}{\infty}$ & $\stackrel{\infty}{\infty}$ & $\bar{\infty}$ & $\bar{\omega}$ & m & 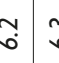 & $\begin{array}{c}m \\
0 \\
0\end{array}$ & $\begin{array}{c}m \\
6\end{array}$ & 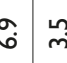 & $\begin{array}{l}0 \\
i\end{array}$ & & in \\
\hline 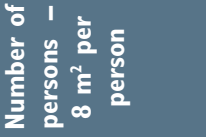 & $\hat{\imath}$ & q & n & L & $\begin{array}{l}0 \\
n \\
n\end{array}$ & $\begin{array}{l}0 \\
n \\
n\end{array}$ & I & $\stackrel{\infty}{1}$ & $\begin{array}{l}0 \\
n\end{array}$ & $\hat{\imath}$ & $\begin{array}{l}\varphi \\
n\end{array}$ & $\begin{array}{l}0 \\
⿱ ⺊ \\
n\end{array}$ & 号 & in & $\hat{b}$ & $\hat{b}$ & $\hat{b}$ & $\frac{0}{1}$ & 趸 & 号 & $\hat{b}$ & 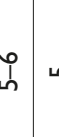 & n & $\begin{array}{lll} & 5 \\
n & 2 & \end{array}$ & $\begin{array}{l}y \\
m\end{array}$ & t) & & I \\
\hline 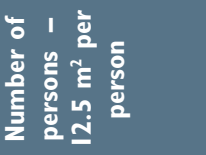 & $q$ & $\stackrel{m}{\sim}$ & m & $\stackrel{m}{i}$ & m & m & $\stackrel{m}{\sim}$ & $q$ & m & $q$ & m & m & m & m & $\sigma$ & 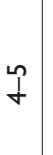 & $\stackrel{n}{f}$ & 号 & $\stackrel{n}{f}$ & m & t & I & $\begin{array}{l}4 \\
m\end{array}$ & di & 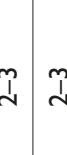 & 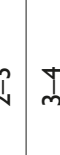 & & $\stackrel{n}{\sim}$ \\
\hline 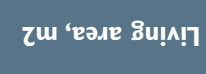 & $\stackrel{\circ}{\stackrel{\leftrightarrow}{n}}$ & $\begin{array}{l}\stackrel{\circ}{0} \\
\text { in }\end{array}$ & r̃ & 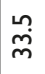 & $\begin{array}{l}0 \\
\stackrel{\sim}{\mathfrak{J}}\end{array}$ & $\overline{\dot{\sigma}}$ & 品 & $\bar{i}$ & $\overline{\mathfrak{g}}$ & $\begin{array}{l}\text { aे } \\
\dot{\dot{H}}\end{array}$ & $\begin{array}{l}\infty \\
\dot{\sim} \\
\dot{y}\end{array}$ & $\underset{j}{\dot{J}}$ & $\begin{array}{l}m \\
\dot{q}\end{array}$ & $\stackrel{\dot{m}}{\ddot{\gamma}}$ & $\begin{array}{l}\infty \\
\dot{q} \\
\dot{q}\end{array}$ & 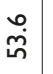 & $\begin{array}{l}\stackrel{0}{*} \\
\dot{H}\end{array}$ & 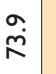 & $\stackrel{\infty}{i}$ & 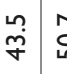 & în & 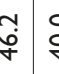 & $\begin{array}{l}0 \\
\dot{\sigma}\end{array}$ & 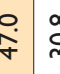 & 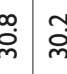 & 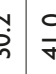 & & $\begin{array}{c}\underset{\sim}{\infty} \\
\underset{\sim}{n}\end{array}$ \\
\hline 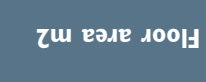 & $\begin{array}{l}\infty \\
\stackrel{\infty}{0} \\
\stackrel{\delta}{0}\end{array}$ & $\bar{\kappa}$ & 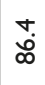 & $\stackrel{n}{\stackrel{n}{r}}$ & 吕 & 定 & $\stackrel{\circ}{\circ}$ & 守 & $\stackrel{\circ}{\stackrel{\alpha}{\alpha}}$ & $\begin{array}{c}\infty \\
\dot{\infty} \\
\dot{0}\end{array}$ & $\stackrel{\text { న̊ }}{\alpha}$ & $\stackrel{\substack{\infty \\
\infty}}{ }$ & $\bar{a}$ & $\underset{\infty}{\substack{\infty \\
\infty}}$ & $\begin{array}{l}\stackrel{0}{0} \\
\stackrel{\leftrightarrow}{\text { In }}\end{array}$ & 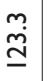 & $\stackrel{\stackrel{ }{\Xi}}{\stackrel{2}{=}}$ & 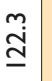 & $\underset{\mathbb{Z}}{\mathbb{Z}}$ & 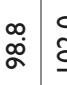 & తి & $\underset{\infty}{\stackrel{\infty}{\infty}}$ & 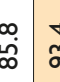 & অ. & 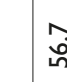 & $\stackrel{0}{\circ}$ & & $\stackrel{\circ}{i}$ \\
\hline чтр!М & $\stackrel{\infty}{\infty}$ & $\stackrel{\infty}{i}$ & o. & in & 0 & คें & : & $\begin{array}{c}\infty \\
0 \\
0\end{array}$ & $\bar{\omega}$ & $\stackrel{\circ}{\circ}$ & กี & O: & $\overline{6}$ & : & m̧ & $\hat{\circ}$ & นُ & $g a$ & $\stackrel{\circ}{6}$ & $\stackrel{t}{\dot{\sigma}}$ & ڤn & $\begin{array}{c}0 \\
0 \\
0\end{array}$ & 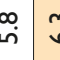 & $\begin{array}{c}m \\
0 \\
0\end{array}$ & نْ & $\begin{array}{c}n \\
i\end{array}$ & & : \\
\hline 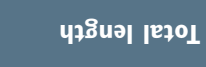 & $\underline{\hat{n}}$ & 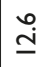 & $\underset{\dot{I}}{\stackrel{+}{+}}$ & $\stackrel{+}{\dot{I}}$ & $\begin{array}{l}\dot{0} \\
\dot{ \pm}\end{array}$ & $\underset{\dot{m}}{\stackrel{m}{q}}$ & $\stackrel{\circ}{\stackrel{\rho}{\dot{m}}}$ & 葛 & $\stackrel{0}{\underline{\dot{\rho}}}$ & $\begin{array}{l}\stackrel{\infty}{\leftrightarrow} \\
\underline{\underline{\rho}}\end{array}$ & $\underline{\underline{\underline{\rho}}}$ & $\begin{array}{l}\infty \\
\dot{I} \\
\stackrel{ \pm}{*}\end{array}$ & $\underline{\stackrel{\circ}{\rho}}$ & $\stackrel{\dot{ \pm}}{\dot{ \pm}}$ & $\stackrel{\circ}{\stackrel{\varrho}{0}}$ & $\begin{array}{l}\stackrel{+}{\Phi} \\
\underline{\infty}\end{array}$ & $\begin{array}{l}\stackrel{\circ}{\underline{\Phi}} \\
\underline{2}\end{array}$ & $\stackrel{\Xi}{\sharp}$ & $\stackrel{\circ}{\circ}$ & 单 & 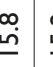 & 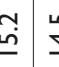 & $\stackrel{4}{ \pm}$ & 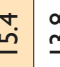 & $\begin{array}{c}\infty \\
\dot{m} \\
\end{array}$ & $\stackrel{0}{2}$ & & $\overline{\mathrm{I}}$ \\
\hline səqunu әsnoH & $\stackrel{\sim}{\sim}$ & $\frac{\stackrel{n}{N}}{N}$ & 文 & $\ddot{n}$ & $\stackrel{\infty}{\infty}$ & 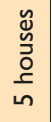 & $\hat{\sim}$ & ळ & $\bar{\sigma}$ & $\infty$ & $\bar{m}$ & 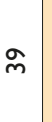 & 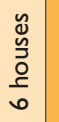 & 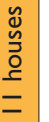 & $\underline{m}$ & $\bar{N}$ & $\bar{\infty}$ & I & 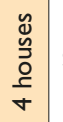 & g & $\frac{m}{\sigma}$ & $\grave{\bar{\nu}}$ & సิ & 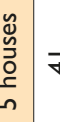 & $\bar{\sigma} 8$ & : & & $\stackrel{q}{q}$ \\
\hline əd/१-əsnoH & $\div$ & $\dot{\overline{\dot{m}}}$ & $\dot{\bar{m}}$ & $\dot{\overline{\dot{m}}}$ & $\frac{\dot{\overline{\dot{m}}}}{\dot{m}}$ & 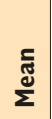 & $\dot{\overline{\dot{m}}}$ & $\frac{\dot{\bar{m}}}{\dot{m}}$ & $\dot{\overline{\dot{m}}}$ & $\dot{\overline{\dot{m}}}$ & $\dot{\overline{\dot{m}}}$ & $\dot{\bar{m}}$ & $\begin{array}{l}\underset{\mathbf{\tau}}{\Sigma} \\
\frac{\mathbf{\omega}}{\Sigma}\end{array}$ & 苞 & 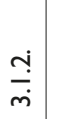 & $\frac{\stackrel{M}{1}}{\dot{m}}$ & $\frac{\stackrel{i}{a}}{\bar{m}}$ & $\frac{\stackrel{\sim}{M}}{\dot{m}}$ & $\begin{array}{l}\frac{\tilde{\Xi}}{\Sigma} \\
\frac{\pi}{\Sigma}\end{array}$ & 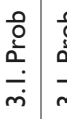 & 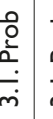 & 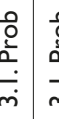 & 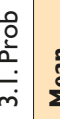 & 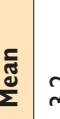 & 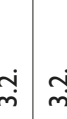 & نे & & ָું \\
\hline
\end{tabular}




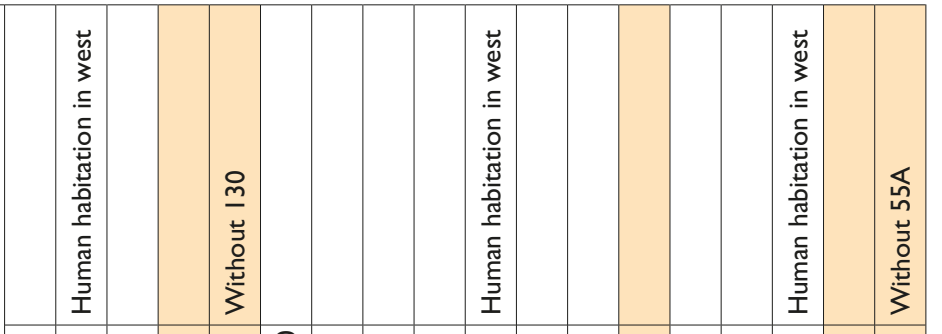

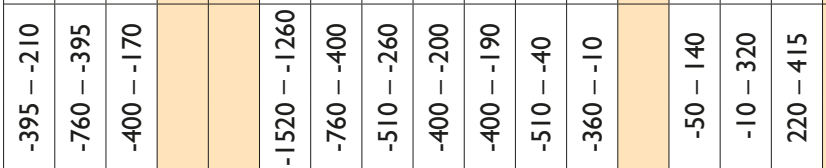

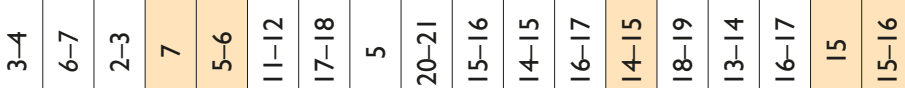

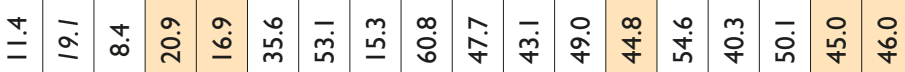

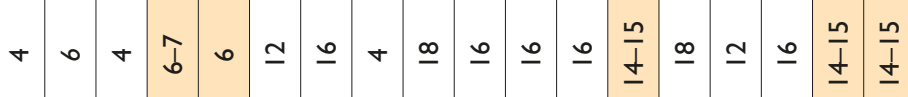

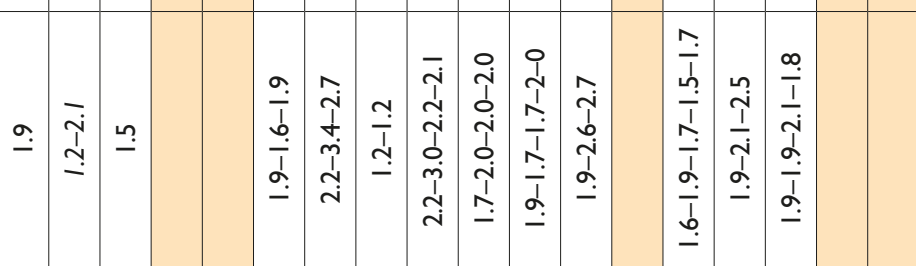
守 我

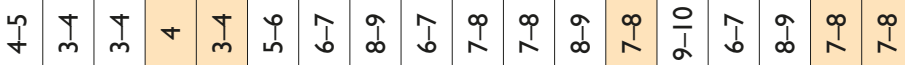

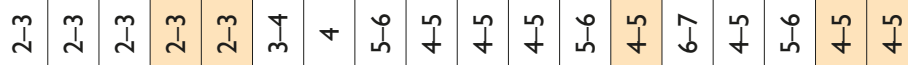

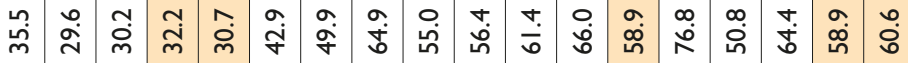

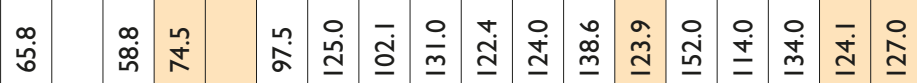

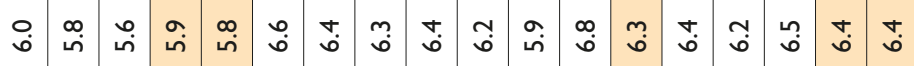

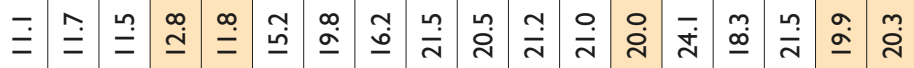

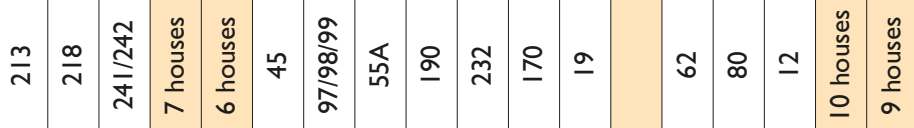

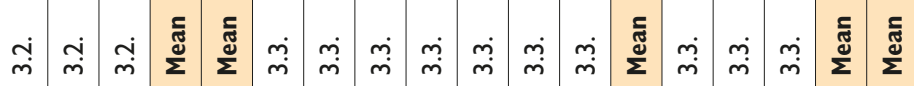

the $8 \mathrm{~m}^{2}$ area requirement per person, the ratio of cattle per person is $1.4-1.5$ for the smallest houses and 1.7 and 2.1 cattle/person for type 3.1.2 and 3.3, respectively. Considering the means to collect fodder in the Bronze Age and Early Iron Age, the cattle/ person ratio based on the $8 \mathrm{~m}^{2}$ area requirements seems more reasonable than the $12.5 \mathrm{~m}^{2}$ requirement. Still, the ratio of 2.1 cattle/person is so high that one may search for possible explanations like large farms bringing in labour from outside the household to collect fodder or that these farms had better pastures than the smaller ones. The small dwelling house types 5, 6 and 11, dated to the same period as most of the type 3 houses (Bronze Age Periods V-VI and Pre-Roman Iron Age), might have functioned as homes for people without access to land and/or cattle.

The household size calculated on the basis of 12.5 $\mathrm{m}^{2} /$ person (mean 3.8 people/36 houses) fits well with Benedictow's view, but according to Lindanger (1987:147), the mean household size in Rogaland at the beginning of the $17^{\text {th }}$ century was six people increasing to 8.4 people in 1801 . Based on the figure of $8 \mathrm{~m}^{2} /$ person the mean type 3 household size housed 5.9 people, and in mean stalled ten cattle (1.7 cattle/adult). This household size seems more reasonable than the size based on $12.5 \mathrm{~m}^{2} /$ adult, since a mean 2.6 cattle/adult ratio is out of the question in a mixed SW Norwegian crop and dairy husbandry economy. With comparative evidence from the burnt house from Nørre Tranders, we have reached a reasonably firm basis for calculating the household size and number of stalled cattle at the settlement at Forsandmoen during the period when the type 3 house was the preferred farmhouse.

\subsection{The byre in type 9 houses}

Houses 11A, 200 and 144 have well documented traces of stall boxes (Fig. 92). Between three trestle spans in each house, there are small postholes in line between the rows of the roof-bearing postholes. They divide the space between the roof-bearing supports in 3-4 distances, each measuring 0.8-1 $\mathrm{m}$ in width. Another one, 180B, has only one such post. This distance is well documented from many Danish byres with traces of stall boxes (Hvass 1980, Rindel 1997). The traces from the houses at Forsand are situated in the central part of the house. In house 200 , they are located in the three nearest trestle bays to the dwelling room and could contain 20 cattle. In 

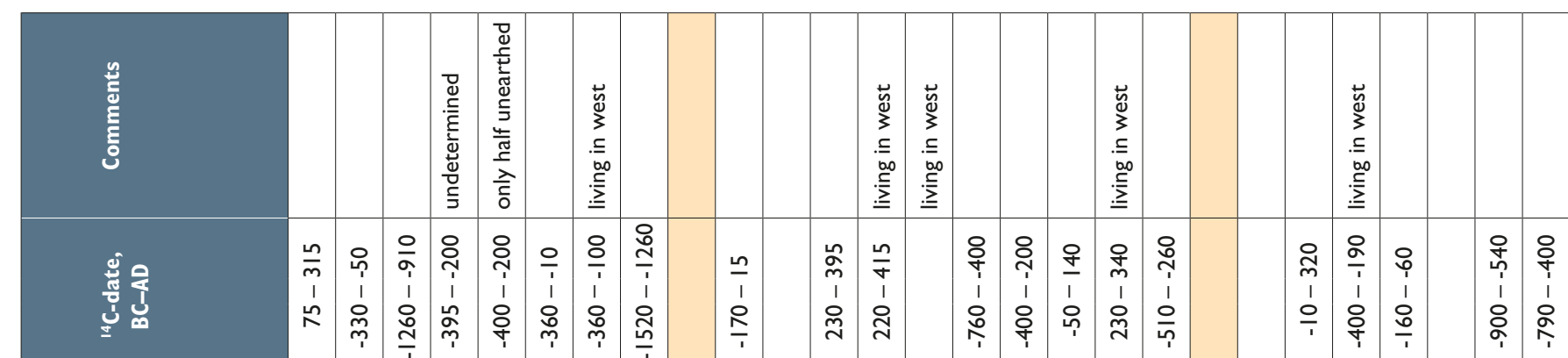

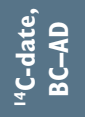

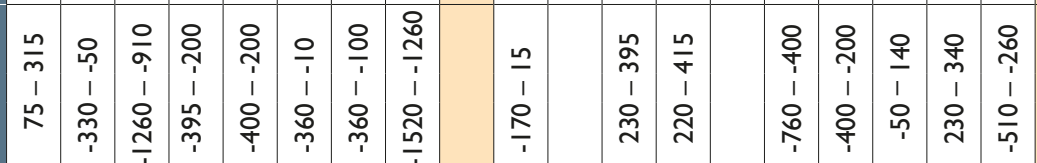

雨

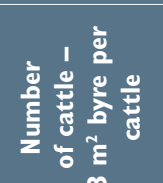

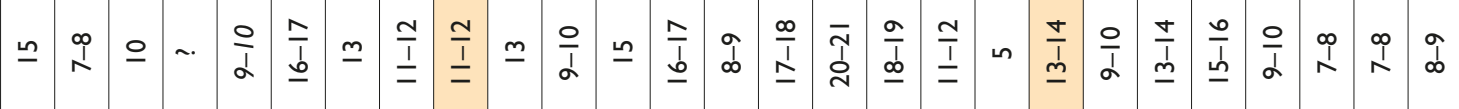

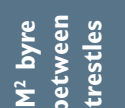

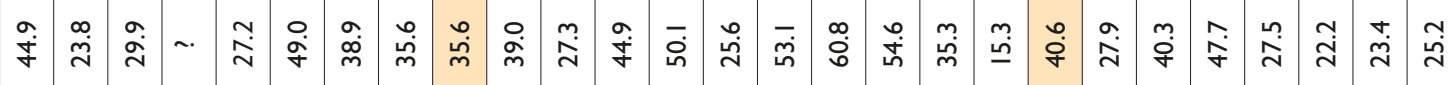

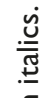

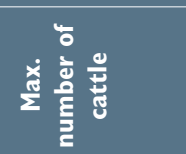

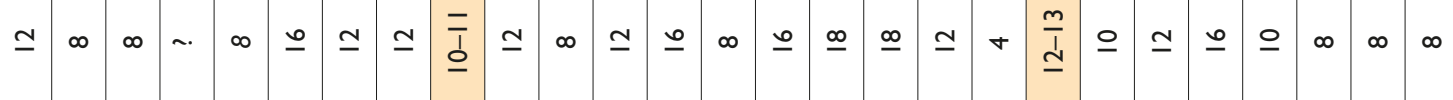

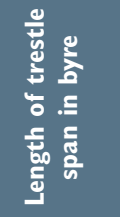

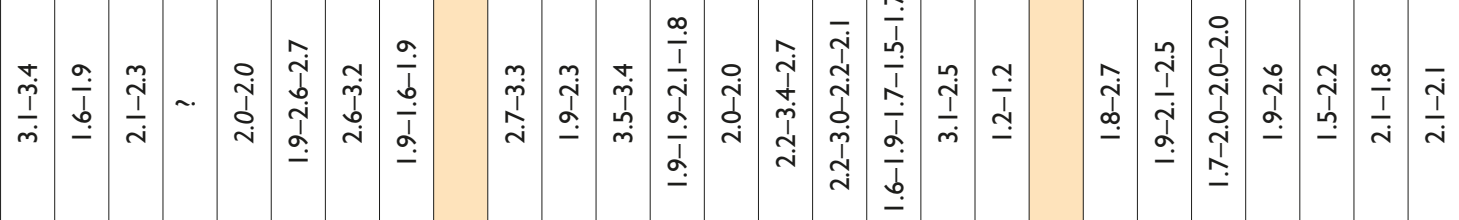
$\frac{5}{3}$

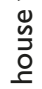

$\stackrel{0}{=}$

岕

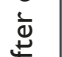

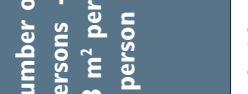

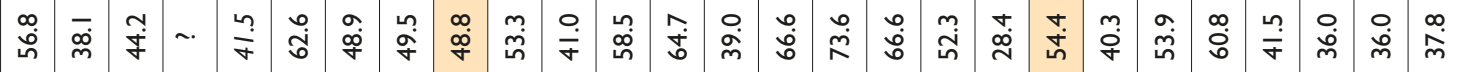

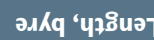

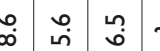

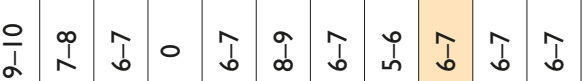

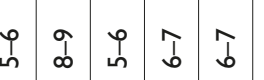

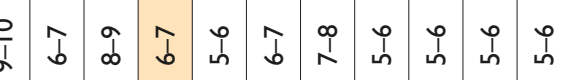

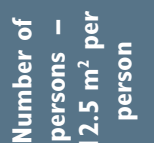

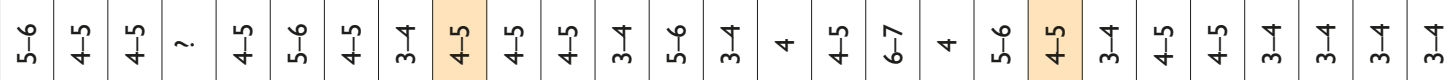

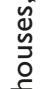

m

公

$\subseteq$

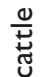

믇

蒫

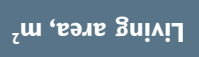

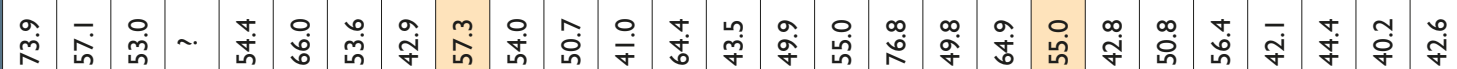

ч7Р:M

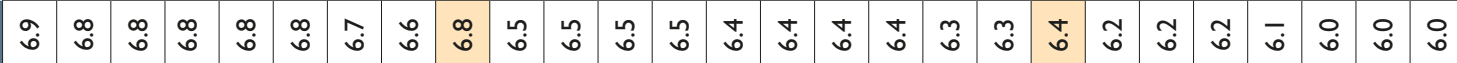

4วริบับ เеาำ

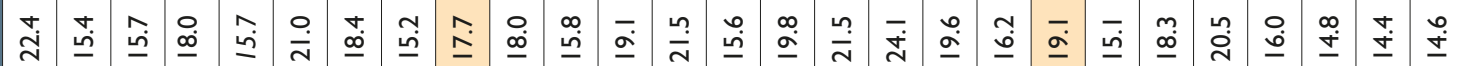

产

¿

ләqunu әsnoH

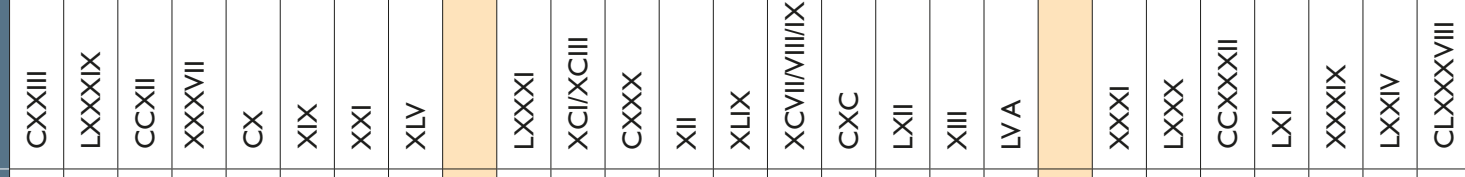

ஸें

$\frac{0}{\frac{\pi}{0}}$

adk כsnoh

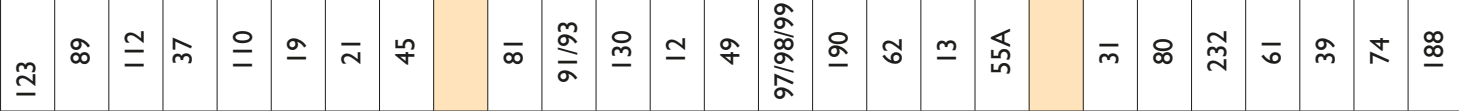

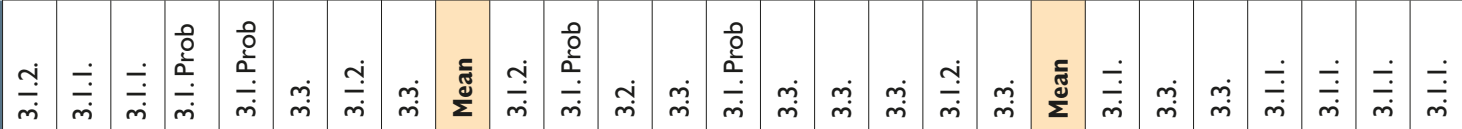




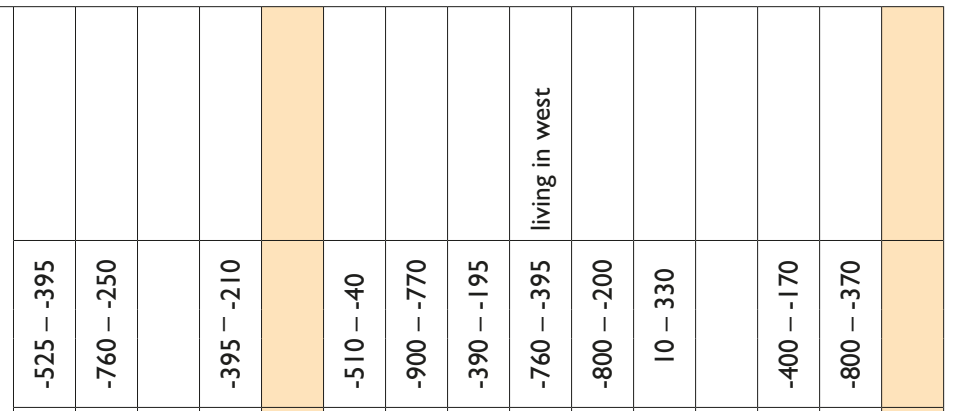

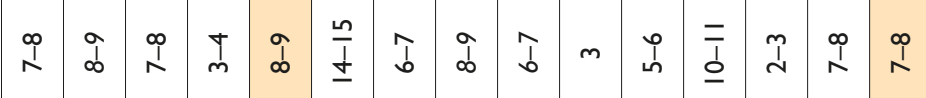

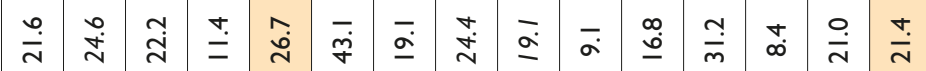

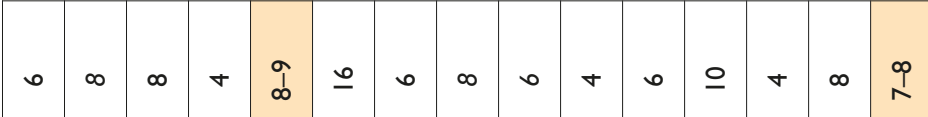

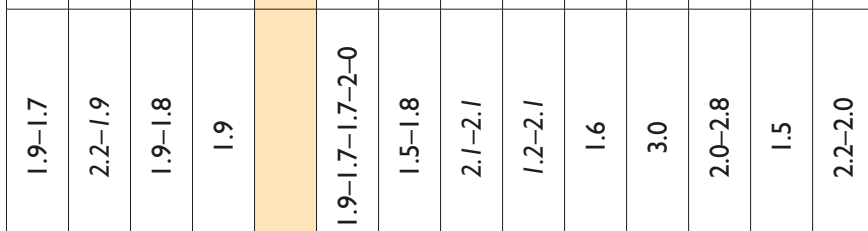

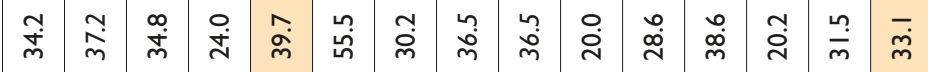

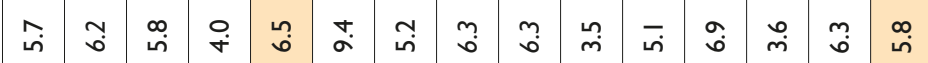

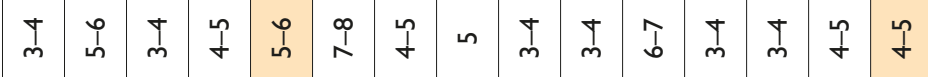

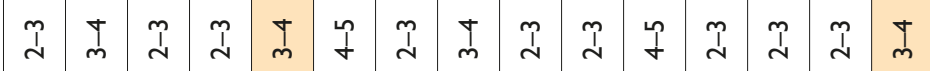
悹

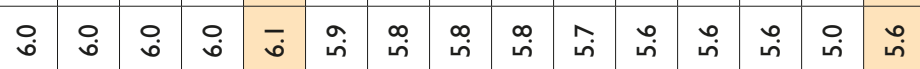

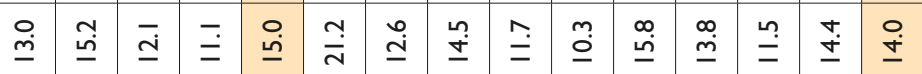

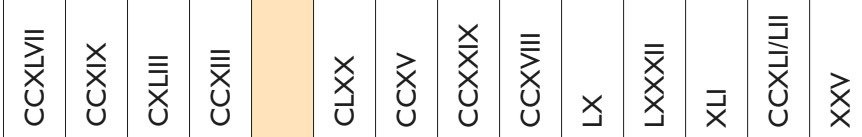

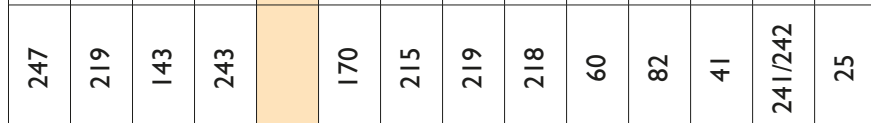

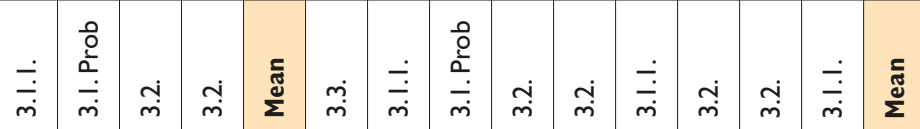

addition, there is one more bay to the east, with space for an additional six cattle, before reaching the eastern entrance room. Since it is not likely that this bay - through which the cattle had to pass at least twice a day - served as a storage room, it is possible that the house could stall 26 cattle. Due to the lack of traces of stall boxes, a possibility is that this space was intended for calves, sheep or pigs. The other house, 11A, has five bays, three with stall boxes in the middle of the house, separating two identical dwelling and entrance areas. An entrance gives access to the central bay, and the eastern two bays and the southern part of the central bay have postholes for stall boxes sized as mentioned above. Given the layout of the house as a farmhouse for two equal households, it is most likely that the two western bays were also a byre area for cattle, with a total of twelve cattle in each part and additional three

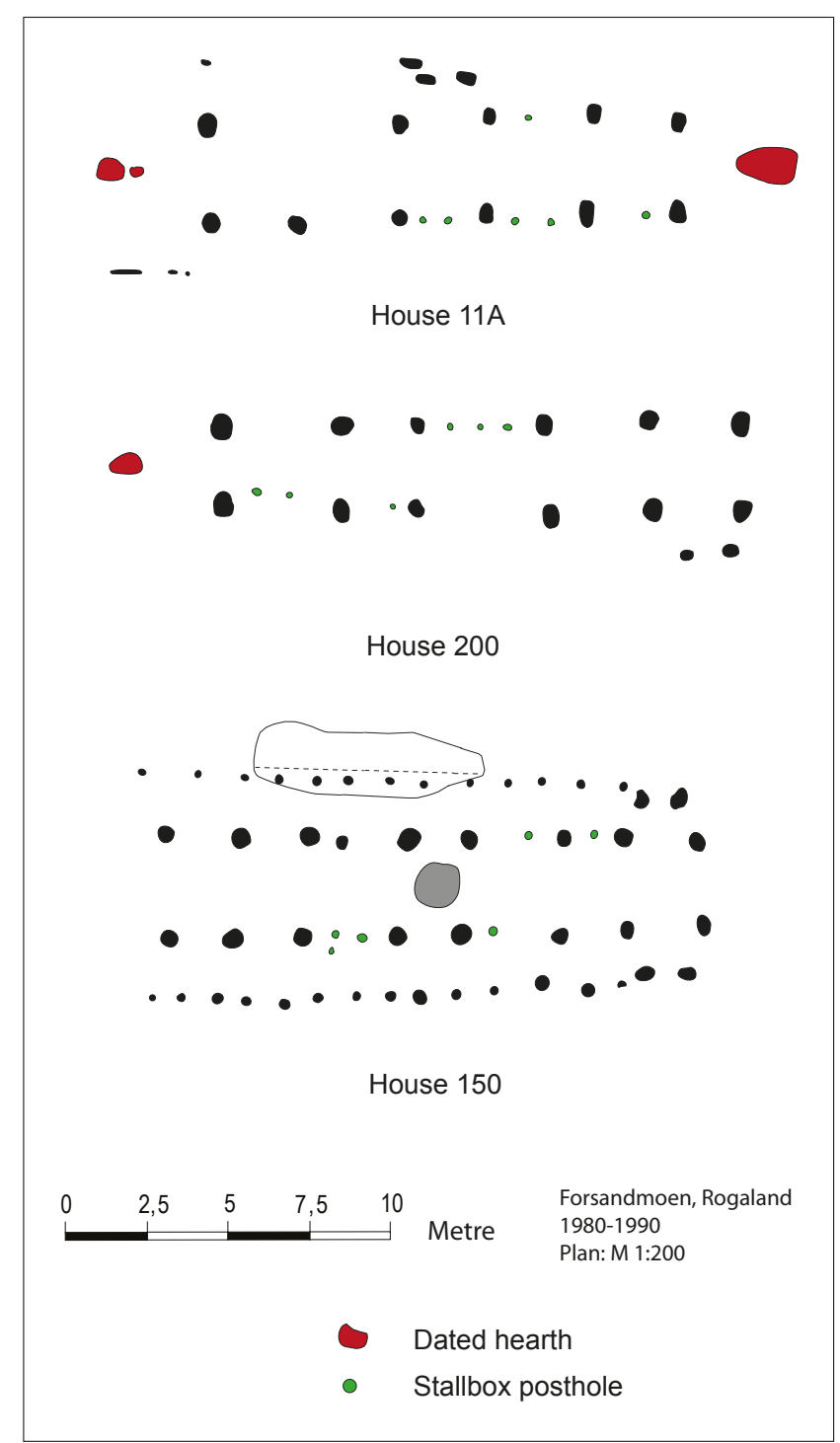

Fig. 92. The house plan of three byres with stall boxes in the houses IIA, I50 and 200. Only the central part of each house is shown. 
in the central bay. The third house, the $\mathrm{N}-\mathrm{S}$ oriented house 144, has two small postholes in the western roof-bearing row of postholes, dividing the space into three distances measuring $0.8-1.2 \mathrm{~m}$ in width. One small posthole in the eastern row is also situated $1 \mathrm{~m}$ from the nearest roof-bearing posthole, indicating stall boxes there as well. These structures probably show that a byre had also been located in this house.

Only four examples of byres with stall boxes from 44 type 9 houses are not much to prove that this area in the houses was the byre area. However, as Table 37 and Table 38 show, the spans in the eastern or middle part of the houses predominately measure either \pm 2 or $\pm 3 \mathrm{~m}$, making those areas well suited for dividing them into equal parts for cattle boxes. There is also good documentation from earlier excavations of long farmhouses with outer stone-built walls (Myhre 1980, Petersen $1933,1936)$ that the cattle path from the pastures led to the part opposite the dwelling area, showing that stalling cattle was normal. In house 3 at Ullandhaug (Myhre 1980), the area without finds and with a low phosphate content measured $16 \mathrm{~m}$, long enough for 32 cattle. In addition, there is flagstone pavement along this part of the central aisle in ten such houses, indicating a byre area as well as stall boxes to either side. They show that the herd in these houses differs from nine to 39, depending on the house size, with 24 as the mean value (Løken 1987a). It must also be mentioned that one other Forsand house has stall box remains. The $50 \mathrm{~m}$ long type 7 house 150 from the early Roman Iron Age had four bays adjacent to the NE entrances with traces of stall box posts that could house 20 cattle (Fig. 92). In addition, two $2 \mathrm{~m}$ long bays situated as an extension of the four byre bays could stall eight additional cattle, so the stalling capacity in this house was possibly 28 cattle.

The byre in type 9 houses, measured in length and in the estimated number of possible cattle, varies from $8 \mathrm{~m}$ to $20.5 \mathrm{~m}$ and from six to 26 cattle. Fig. 93 shows the distribution of the different byre sizes, distributed with half of the houses to the Roman Iron Age and the Migration Period, respectively. From the Roman Iron Age, two-thirds of the dataset is concentrated in three byre sizes with twelve, 18 and 24 stall boxes, while in the Migration Period; the dataset is more evenly distributed. Byres with a capacity of less than twelve cattle are seldom found, just like the byres found on the farms with stone-built houses in Rogaland (Løken 1987a:84).

However, as shown in chapter 10, there are eight houses among the 44 type 9 houses that have a similar normal-sized dwelling area at each end of the house

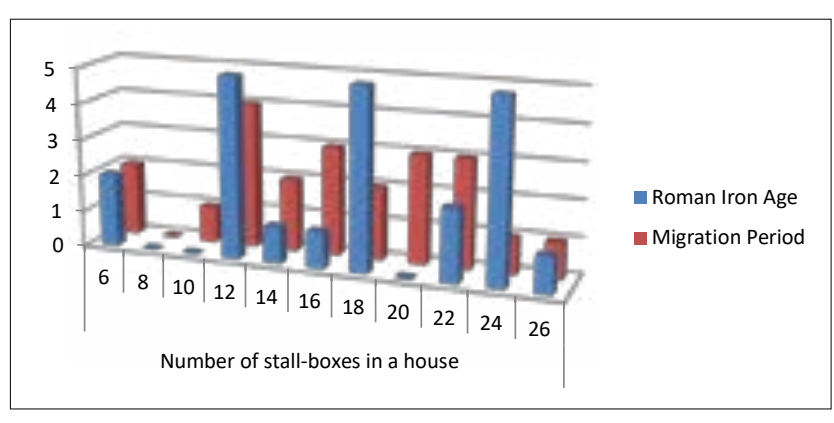

Fig. 93. Distribution of the different byre sizes from 44 type 9 houses.

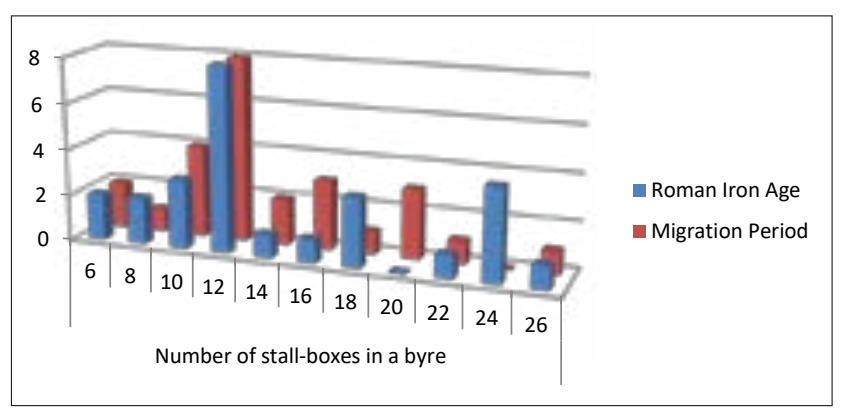

Fig. 94. Distribution of the different byre sizes from type 9 houses if the eight double dwelling houses are interpreted as having 16 individual byres. In total 52 byres.

(type 9.1.6-7 and, 9.3.6-7) (Table 40). They are therefore interpreted as houses containing two households that share a byre in the middle of the house. The byres in those houses can contain 18 (three houses), 22 (three houses) or 24 (two houses) cattle. Each of the 16 households in these eight houses could therefore on average stall only eight, ten or twelve cattle, which is comparable to the size of only twelve byres found in the 36 other type 9 houses. The consequence of this interpretation of the eight houses with two households is that the majority of households (29 out of 52) living in type 9 houses only had space for 6-12 cattle (Fig. 94). However, if the eight houses were regarded as single households the amount of small stables (13 with 6-12 cattle) would have been a minority compared to the 31 stables with a size of 14 to 26 cattle.

Fig. 94 shows that 30 houses with small byres $(6-12$ cattle) are gathered in the lower end of the distribution area, with a peak of twelve cattle, while the remaining 22 byres are more evenly distributed within seven different sizes (14-26 cattle). The number of small as well as larger byres is evenly distributed between the Roman Iron Age and the Migration Period, so there is no change in the proportions from one period to the next. It is therefore reasonable to assume that husbandry practices did not change much during these two periods. The society can be characterised by a large proportion (58\%) of small (6-12 cattle) holdings, 
a fewer larger (14-20 cattle) holdings (27\%) and some large (22-26 cattle) ones (15\%).

The subgroups 9.1.1-9.1.7 are defined by an additional bay at the eastern end of the house, thus increasing exponentially from four bays in 9.1.1 to ten bays in 9.1.7. However, the still-expanding area in the eastern end does not imply a similar increase in the byre area since some of the new area in the type 9.1.3-9.1.7 houses was used for a partly heated room located east of the byre entrance(s). As Table 38 shows, type 9.1.2 - with two byre-bays - can stall twice as many cattle (twelve) as type 9.1.1 (six), while type 9.1.3 has room for 13 cattle and has the same byre size as type 9.1.2 because the additional bay, located to the east of the byre entrance(s), was used as either a heated room or for storage purposes. The capacity in the byres in the still larger houses 9.1.4 and 9.1.5 increases by six cattle (9.1.4) and twelve (9.1.5), compared to type 9.1.3, to 19 and 25 cattle, respectively. Type 9.1 .5 with a capacity for 25 cattle represents the largest type 9 house for one household; the eight type 9.1.6-7 and 9.3.6-7 have smaller stalling capacity ( 21 cattle) because these houses had two similarly sized dwelling areas.

In conclusion, the byre stalling capacity differs from six to 26 cattle. Four times more cattle to tend must imply a need for four times more working capacity in the largest houses than in the smallest. One would therefore expect that the dwelling area in the largest houses should be similarly larger than in the smallest. However, looking at the sizes of the western dwelling area in the different subtypes of type 9 (Table 38), the length of that part increases from $11.5 \mathrm{~m}$ in type 9.1.1 to $13.5 \mathrm{~m}$ in types 9.1 .3 and 9.1.4, while type 9.1 .5 only measures $12.6 \mathrm{~m}$. The western dwelling area $(13.8 \mathrm{~m})$ in the longest houses (9.1.6-7 and 9.3.6-7) is approximately the same size as in types 9.1.3-4, while the eastern dwelling area $(11.5 \mathrm{~m})$ is the same size as found in the smallest houses (type 9.1.1). The difference in length between the two dwelling areas might indicate that the two households did not have an equal economic and/or social position.

The important observation is that the size of the western dwelling area of a household does not increase proportionally with the increase of the size of the byre. Nevertheless, in type 9.1.3-9.1.5, one bay in the eastern end was used to create a room - in some cases with a hearth - that could be used as an extra dwelling space for the additional people needed when the number of cattle in the byre exceeded what was common for type 9.1.1-2.

I think this analysis confirms that a large part of the type 9 houses served as a byre area for stalled cattle and that the herds belonging to the different farmhouses varied from six to 26 stalled cattle. These figures are maximum suggestions since some space in that part could have been used for sheep/goats and/or pigs. The byre sizes in type 9 houses at Forsandmoen in the Roman Iron Age and the Migration Period correspond well to the sizes found when excavating visible house structures in the first part of the $20^{\text {th }}$ century. The sizes probably mirror both natural conditions regarding soil and vegetation, as well as social decisions. One important observation is that there are many more smallholdings at the not so very fertile outwash plain at Forsandmoen compared to the excavated visible farms found in more hilly landscapes. 


\section{Settlement synthesis}

\subsection{Introduction to the development of the settlement}

In this chapter, I investigate how houses and construction changed through time. The number of farms, households, people and cattle that existed at different times are all important factors to consider. Were the farms moved around when new houses were to be erected or were several houses built consecutively in the same place? Did a farm consist of one longhouse or several buildings? How did the relationship between agriculture and cattle husbandry change over time? Is there any connection between the size of the farms or the households and people's approach to agriculture, that is, which grain types were cultivated and in what quantities? What can these factors tell us about social conditions at the settlement?

Before I discuss the first period of the settlement, it is important to point out the important question of how to calculate household sizes at different times. The previous chapters show that, in the Bronze Age, house types 1, 2 and 3 were built as combined dwelling and byre houses, while in the Roman Iron Age and the Migration Period, house types 7, 8 and 9 were used. The chapters describing the houses and house types demonstrate a significant difference in size between quite small houses (lengths between 10-25 m) in the Bronze Age and Pre-Roman Iron Age and longer houses (between 25-50 m) in the Roman Iron Age and Migration Period. If inhabitants were allotted an equal amount of space in both periods, it would mean that the size of the household increased sharply. Alternatively, at some point, there was a change in the requirement of space per person, which would entail that the size of the household increased to a lesser extent than the size of the houses would indicate.

Based on, among other things, the remains of a burnt-down house in Denmark, I argued in chapter 15 that individual occupants could each have had $8 \mathrm{~m}^{2}$ at their disposal in the type 3 houses. Tables 52 and 53 shows that the dwelling area of these houses could have housed between 4 and 9 adults. We can also see that the average number of inhabitants (six people) in the two type 3 houses from the Early Bronze Age is higher than in the houses from the Late Bronze Age and early PreRoman Iron Age (4-5 people). The size of the houses in the Late Bronze Age and early Pre-Roman Iron Age probably represents the level of a nuclear family. Later, the average increases steadily to 7-8 people in the Roman Iron Age, as some of the houses would have had room for ten people. The steady increase in size over a period of more than 1000 years probably indicates a steady development of the society and agricultural technology. Nevertheless, in the Roman Iron Age, some people continued to hold onto the traditions of living with opposite entrances that separate the dwelling area in the east and the byre area in the west. These late type 3 houses may represent an extended family.

I have not touched on the question of the household size for house types 7-9 in this book, but have previously analysed the size of a household and the population size for the settlement at Forsandmoen during the Migration Period (Løken 1990, 2001a). The basis for this analysis was Myhre's (1983) calculations of the population size at individual farms and for Rogaland in general at that time. Myhre based his work on the number of preserved farms of the Ullandhaug type (house outlines with preserved stone walls, Myhre 1980) from the Migration Period, drawing on the research of two American researchers (Casselberry 1974, 1975, Narrol 1962), who attempted to calculate the population as proportional to the area of the dwelling. However, Myhre used the proportion of constructed area as his basis instead. He concluded that, for the farms from the Roman Iron Age and Migration Period, an area of $12.5 \mathrm{~m}^{2}$ per person was an area that gave a probable result in relation to the number of spaces for cattle and agricultural area for the farms. I wrote (Løken 1987a) an article on the same questions, but also focused on coastal settlements with a different economic basis compared to the settlements investigated by Myhre. I came to the same conclusion as Myhre with regard to Ullandhaug-type settlements. Regarding coastal settlements, I found that, in these rather small houses, each person had to manage with $6 \mathrm{~m}^{2}$ in order to accommodate a nuclear family of 4-5 adults. This result was also 
a partial basis for my assessment of $8 \mathrm{~m}^{2}$ per person for the type 3 houses.

In the following, therefore, the basis for estimating the size of a farm will be $8 \mathrm{~m}^{2}$ for the three oldest house types and $12.5 \mathrm{~m}^{2}$ for the three younger house types. With the substantial change in the size of the households and the settlement taking place during the transition to the early Roman Iron Age, it is important to consider what else may have changed. An important factor that has also been investigated in connection with the Forsand project is what was cultivated in the different periods and whether changes in the composition of the grains had an impact. Another clearly important factor was the effect of the Roman conquests in France, Germany and England at the transition between the Pre-Roman Iron Age and the Roman Iron Age in terms of trade opportunities, a more stratified social organisation and migration.

\section{The establishment of the settlement}

Reindeer hunters in the high mountains east of Forsandmoen were the first known humans in the area, about 8000 BC (Bang-Andersen 2003). Remains from Stone Age hunter-gatherers have been found in the areas surrounding Forsandmoen. Before the excavations started in 1980, however, only a pressureflaked arrowhead from the Late Neolithic was known from the plain itself. From the bog Åsheim, situated in the hills $1.5 \mathrm{~km}$ to the west of Area A (Fig. 6), the first traces of pollen from the grazing indicator ribwort plantain (Plantago lanceolata) are found, dated to 3950 $\pm 50 \mathrm{BP}, 2500-2300 \mathrm{BC}$, the Middle Neolithic. The first pollen from barley (Hordeum) occurs in the same bog 1300-1000 BC (2950 £50 BP) (Høeg 1999:171f).

\subsection{The Bronze Age}

\section{Bronze Age Period II (1500-1300 BC)}

Two settlement sites were established at Forsandmoen around 1400 BC (Fig. 95). One was situated at the northern edge of the central part, Area A, with the slope of the Bergefjell mountain north of it. This area has the best sun exposure on the plain. In addition, it is protected from the cold easterly winter winds by the rock outcrop Odda. The central area, measuring 200 $\mathrm{m}$ east-west $\mathrm{x}$ 50-80 m north-south, was in continuous use for more than 2000 years, until the plain was abandoned around AD 700.

Based on 15 radiocarbon dates of seeds, the two houses, 32B and 90 were constructed in the decades prior to $1400 \mathrm{BC}$ (the combined date for each house is $3160 \pm 20 \mathrm{BP}, 1430-1410 \mathrm{BC}$ from five charred grains from different postholes). The houses were placed $90 \mathrm{~m}$ apart and constructed in quite different ways. House $32 \mathrm{~B}$ is a large type 1 house, measuring $21.5 \times 8 \mathrm{~m}$, with six pairs of interior roof-bearing posts. The house has three entrances, one for each separate room in the building. In addition, there is an interior door to the eastern part of the building. House 32B, which most likely represents a typical house for its time, had separate rooms and entrances for people and animals (Løken 1998b). A total of 72 pieces of flint from two postholes for entrance posts are testimony to a continued lithic technology during the lifetime of the house. House 90 is smaller, 16 x $7 \mathrm{~m}$, with four pairs of interior roof-bearing posts and a simpler layout, without traces of interior dividing walls. This may indicate that the building was not intended for use by both humans and animals. No flint was found in the features of this building. Both houses shared an interesting feature. Large amounts of charred seeds were found in the easterly posthole in the southern row of roof-bearing posts. The seeds were from naked and hulled barley (Hordeum vulgare var. nudum and $H$. vulgare var. vulgare) and different types of wheat (Triticum sp.) (Fig. 7, Table 1). Naked barley constitutes nearly $90 \%$ of the deposit in the posthole in house 32B, while hulled barley makes up $97 \%$ of the cereals in the house 90 posthole. The large amount of nearly single-species seeds makes it likely that they derive from intentional deposits, probably of a sacrificial nature (Bakkevig 1991, 1992, Prøsch-Danielsen \& Soltvedt 2011). House 32B also contained smaller amounts of cereals in other postholes, probably deriving from various activities in the house.

The cultivation of different cereals was an important part of the economy of the people who settled at Forsandmoen during Period II of the Bronze Age. The presence of deposits of nearly single-species barley of two different types makes it probable that these types were grown in separate fields. Finds of coprolites from sheep in house $32 \mathrm{~B}$, in addition to a finger bone from a hoofed animal, show the presence of animal husbandry.

The earliest example of a type 3 house, house 45 (15 x $6.6 \mathrm{~m}$ ), was built $25 \mathrm{~m}$ NNE of house $32 \mathrm{~B}$, thus introducing a typical house type, which was in use up to the late Roman Iron Age. The house has been dated to 1520-1260 BC and may represent the continuation of the settlement in Area A towards the end of Period II.

A second settlement was established in the southeastern area, Area B, a little less than one km SE of 
Area A. Since the mountains to the east and the south loom over this area, it has less sun exposure than Area A. However, the distance to the Forsand river is very short, providing a stable year-round water source.

The earliest cultural remains here come from a charcoal layer underneath a clearance cairn. The charcoal layer is dated to 1520-1410 BC (Prøsch-Danielsen 1996:12). Analysis of pollen in the clearance cairn shows that agriculture continued unabated here until the heath was established AD 620-680. However, only one house belonging to this early period has been uncovered here so far, $300 \mathrm{~m} \mathrm{SW}$ of the clearance cairn. In addition, only one pair of posts belonging to house 239 has been found and excavated. One of these postholes is dated to $1680-1210 \mathrm{BC}$.

The pioneer settlement at Forsandmoen can be described as two small settlements. In Area A, the settlement contains one larger and one smaller unit. The settlement in Area B is less well known but had a least one unit. Clearing of stones took place, probably both in fields and in pasture areas. Area A saw the construction of a large well-built house, comparable to contemporaneous houses in Jutland. It had interior compartments, probably with different functions, but the preservation does not allow for more detail. The three large houses in Area A show that the settlement, consisting of a farm with one house and 1-2 fourpost storage houses, existed throughout most of Bronze Age Period II. House 32B can be interpreted as a house with three rooms, but the structure does not allow us to say anything certain as to whether cattle were stalled there. The oldest discovery in Rogaland of a type 3 house with a section for stalling cattle, from Kvåle in Jæren (Soltvedt et al. 2007:59f), is dated to the early part of Bronze Age Period I. This shows that indoor winter feeding of cattle probably occurred from the beginning of the Bronze Age. The type 2 houses, such as house 32B at Forsand, as well as house II at Austbø (Juhl 2001) from Bronze Age Period II, may well have had a byre in the middle part of the house. Interpreted as a house for human dwelling only house, it may have room for more than one nuclear family (20-25 persons) (Løken 1998:119), but with ten cattle placed in the $6 \mathrm{~m}$ long central room, 10-15 inhabitants is a more likely figure. On the other hand, the somewhat younger house 45, the oldest type 3 house on the plain, indicates that cattle (10-12) were stalled in the western part of the house, while the dwelling area in the east did not provide space for more than 5-6 people. See also Table 55 for an overview of developments in the average size of the dwelling area, number of inhabitants, number of stalled cattle and the relationship between the number of people and cattle for the four types of houses 3, 7, 8 and 9 through the periods in which each type of house was erected.

The economy of the farms was based on the cultivation of two kinds of barley (naked and hulled) (Hordeum vulgare var. nudum and $H$. vulgare var. vulgare) and smaller amounts of wheat (Triticum sp.). The two major discoveries in the post holes (possibly offerings) of houses 32B and 90, of either almost only naked or hulled barley, respectively, may indicate that these cereal grains were cultivated in separate fields. Finds from cattle, as well as bone and coprolites from sheep and goat, show that these animals were probably an important part of people's diet. The differences between the buildings in Area A can provide a basis for assuming that there was social differentiation in the settlement (Løken 1998b:119).

The two earliest dates from houses at Forsandmoen are $3210 \pm 65 \mathrm{BP}, 1680-1450 \mathrm{BC}$ [barley (Hordeum), house 32 in Area A] and $3215 \pm 110 \mathrm{BP}, 1680-1320 \mathrm{BC}$ [oak (Quercus), house 329 in Area B]. A combined date of five charred grains from a post hole with a large grain deposit (3160 $\pm 20 \mathrm{BP}, 1430-1410 \mathrm{BC}$ ) from house $32 \mathrm{~B}$ means that the house was most likely erected in the first part of Period II, and the use of oak in house 239 in Area B, taking into account the possibility of old wood, suggests that this house also belongs to period II. It is also worth noting in this context that two cooking pits (Table 2), stratigraphically older than houses 2 and 3 in Area E (Figs. 99, 100), are dated to Period II and III, respectively. Between houses 2 and 3, there was an approximately $110 \mathrm{~m}^{2}$ undated house with a $3 \mathrm{~m}$ wide, slightly curved post-setting, like in type 1 houses. This house may have been associated with these cooking pits.

On this basis, it is possible to envisage that, in the pioneer phase, the new inhabitants tried to establish their settlement sites in at least three different places on the plain. The material is not sufficient to indicate anything about the order or whether the oldest houses in Areas A and B are concurrent. The houses in Areas $B$ and $E$ are both a short distance to a safe water source, while the house in Area A had much better sun exposure and wind protection. My conclusion is that, in the pioneer phase, people tested various locations with different advantages and disadvantages, but that, during Period II, or the beginning of Period III, they ended up choosing Area A for a more long-term settlement. The settlement did not consist of more than one household at any given time with a population of between 5-15 individuals and $10-15$ cattle. 


\section{Forsandmoen, Forsand municipality Map of settlement area}

$\subset$ House feature with preserved wall remains

$\square$ House feature without wall remains

$\square$ Bronze Age II $\longrightarrow$ Bronze Age III

$\square$ Bronze Age IV $\square$ Bronze Age V

Gravemound / cairn

$\bigcirc \quad$ Excavated gravemound / cairn

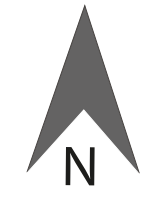

TGB/TL 2009/2014

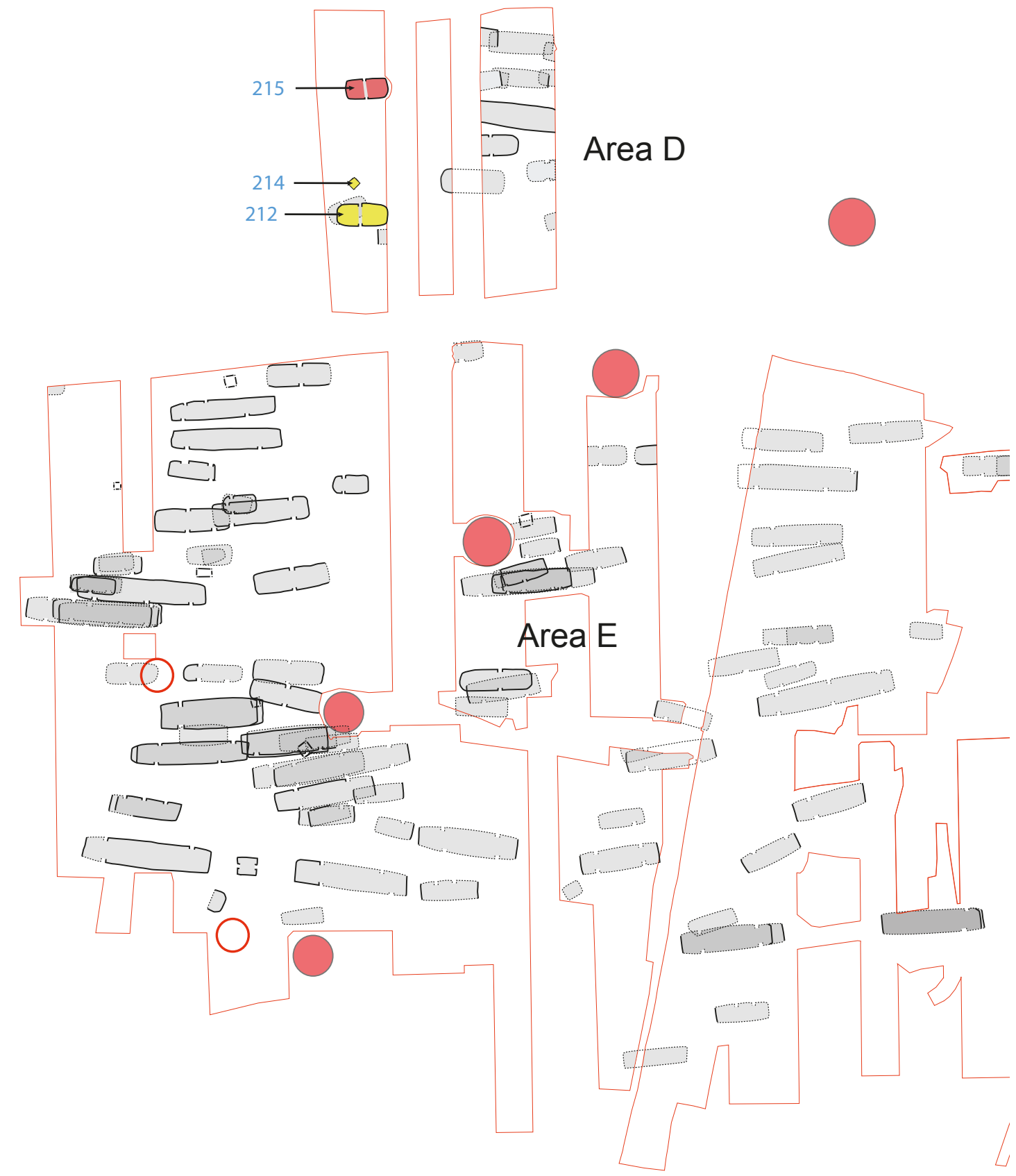

Area D
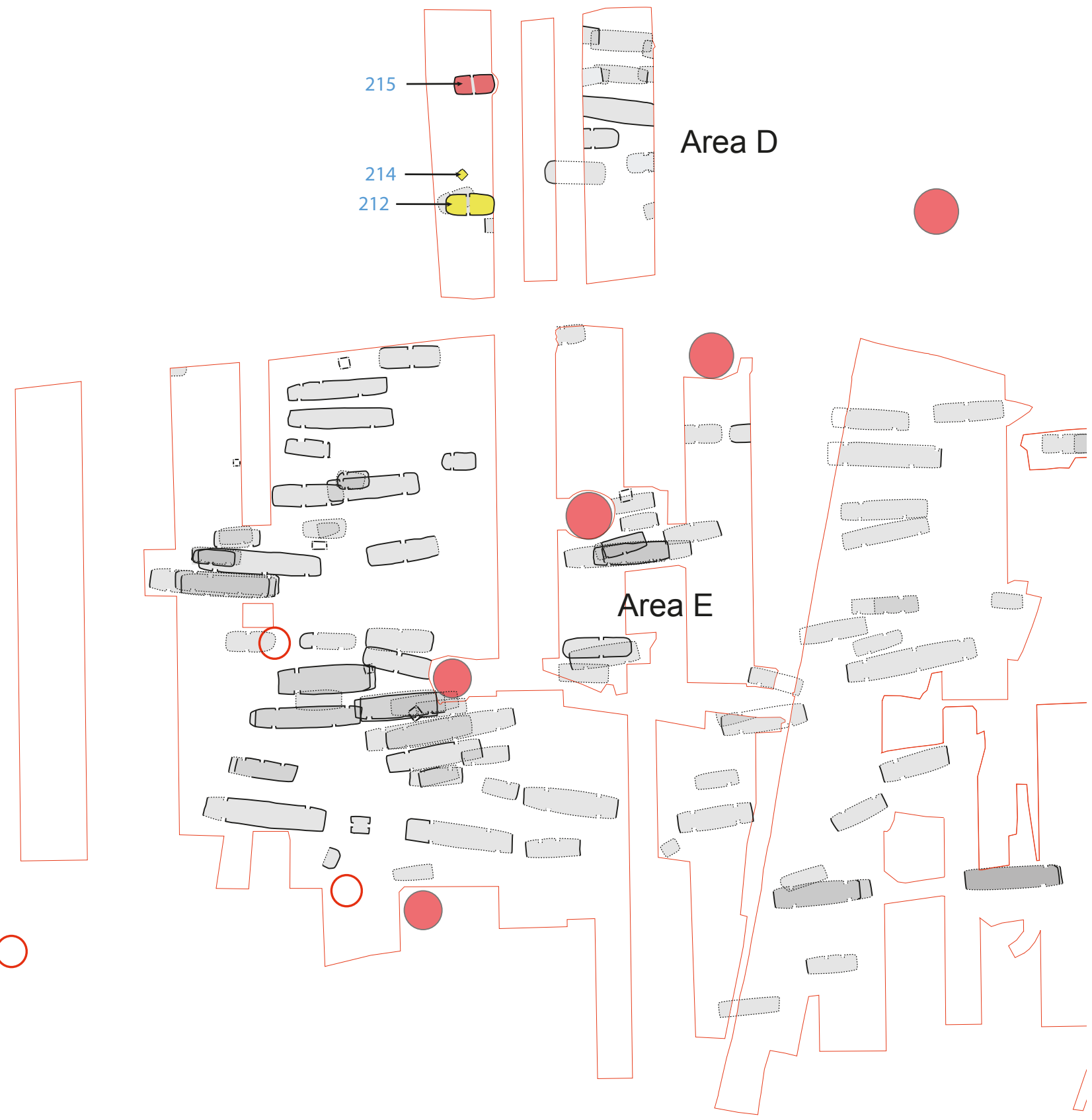

$\bigcirc$

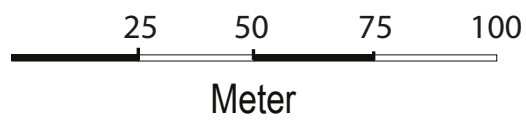




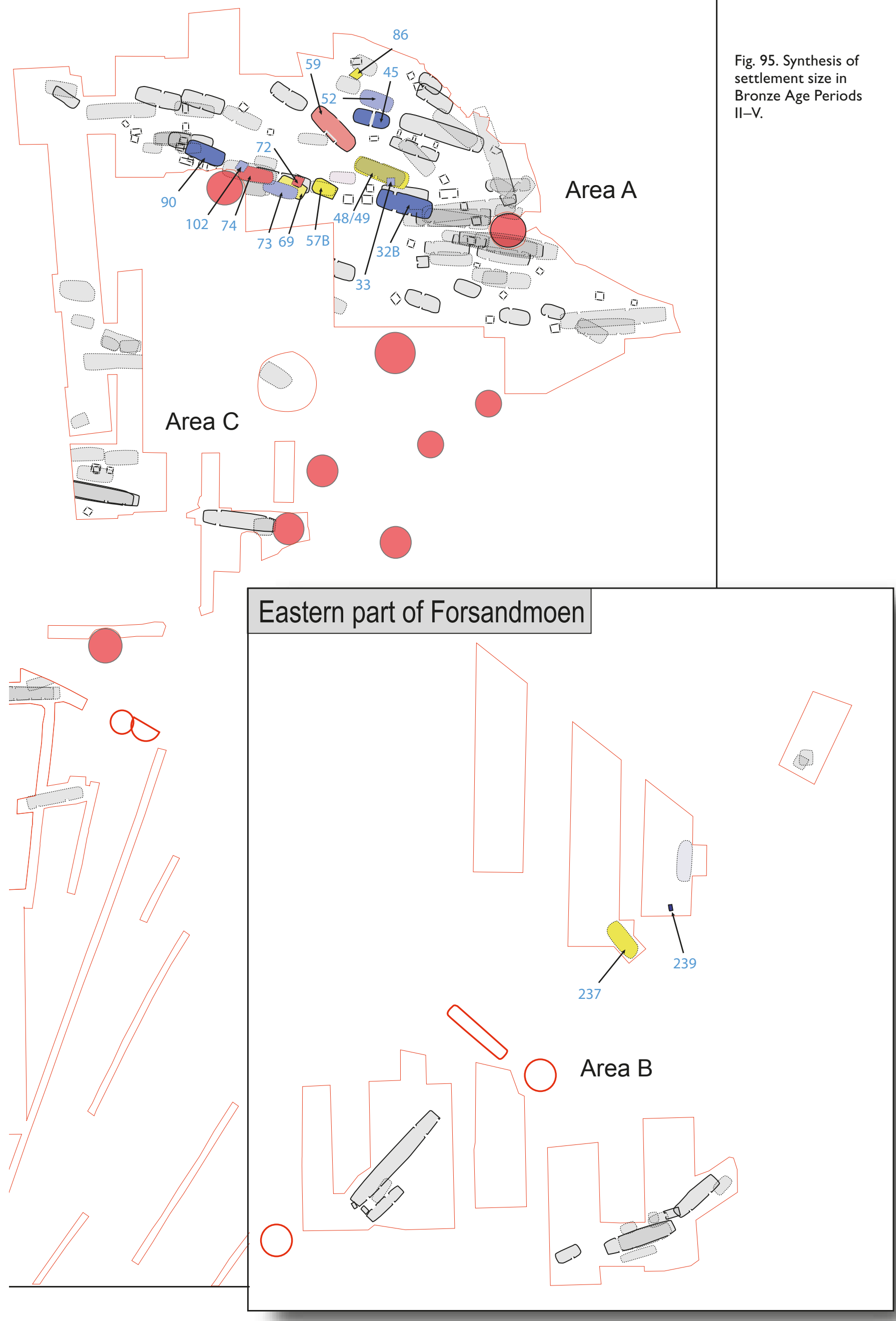


Table 55. Average size $\left(\mathrm{m}^{2}\right)$, number of inhabitants, number of stalled cattle and the ratio cattle to humans for house types $3,7,8$ and 9 over the course of their use.

\begin{tabular}{|c|c|c|c|c|c|c|}
\hline House type & Number of houses & $\begin{array}{l}\text { Average dwelling } \\
\text { area } \mathbf{m}^{2}\end{array}$ & $\begin{array}{l}\text { Average number } \\
\text { of inhabitants }\end{array}$ & $\begin{array}{l}\text { Average number } \\
\text { of cattle }\end{array}$ & $\begin{array}{l}\text { Ratio cattle/ } \\
\text { inhabitants }\end{array}$ & Period \\
\hline type 3 & I house & 42 & 5 & 12 & 2.5 & BRA II \\
\hline type 3 & 3 houses & 46 & 6 & 8 & 1.4 & BRA IV \\
\hline type 3 & 2 houses & 38 & 5 & 8 & 1.4 & BRAV \\
\hline type 3 & 7 houses & 38 & 5 & 8 & 1.6 & BRAVI \\
\hline type 3 & 12 houses & 47 & 6 & 9 & 1.6 & Early P-RIA \\
\hline type 3 & 5 houses & 51 & 6 & 12 & 1.9 & Late P-RIA \\
\hline type 3 & 4 houses & 65 & 5 & 11 & 2.2 & Early RIA \\
\hline type 3 & 3 houses & 50 & 6 & 12 & 2.0 & Late RIA \\
\hline \multicolumn{2}{|l|}{ Mean 37 houses } & 47 & 6 & 10 & 1.7 & \\
\hline type 7 & 2 houses & 83 & 9 & 14 & 1.5 & Late P-RIA \\
\hline type7 & I house: 150 & 231 & 19 & 24 & 1.3 & Early RIA \\
\hline type 7 & 4 houses & 111 & 9 & 16 & 1.8 & RIA \\
\hline \multicolumn{2}{|l|}{ Mean 7 houses } & 104 & 11 & 17 & 1.5 & \\
\hline type 8 & 5 houses & 118 & 9 & 17 & 1.9 & Early RIA \\
\hline type 8 & 3 houses & 92 & 7 & 13 & 1.9 & Late RIA \\
\hline \multicolumn{2}{|l|}{ Mean 8 houses } & 109 & 8 & 16 & 1.9 & \\
\hline type 9 & Mean 7 houses, 9 households & 85 & 7 & 12 & 1.7 & Early RIA \\
\hline type 9 & Mean 10 houses, 12 households & 103 & 8 & 13 & 1.6 & Late RIA \\
\hline type 9 & Mean 30 houses, 33 households & 107 & 9 & 16 & 1.8 & Mig. P \\
\hline \multicolumn{2}{|c|}{ Mean 54 households } & 102 & $8-9$ & 15 & 1.7 & \\
\hline
\end{tabular}

\section{Bronze Age Period III (1300-1100 BC)}

Four houses that likely belong to Period III of the Bronze Age are all situated in Area A (Fig. 95). House 52 , which was only partly preserved, lays parallel to and just north of house 45 . It is dated to 1310-1020 BC and may have been the successor to house 45 . Another smaller longhouse, 73, is dated to 1260-900 BC, and may thus belong to Period III or Period IV. Both of these houses were smaller than the dwelling houses from Period II. In addition, there are two buildings (house 33 and 102) consisting of two pairs of post each, with a hearth close to or in the centre of the posts. They have been dated to 1220-930 BC and 1420-1120 BC, respectively. Four-post constructions of this type are normally interpreted as buildings for storage and are quite common throughout the entire period of settlement. Several other such constructions have a central hearth and it may be that they were used for activities other than storage, maybe even as dwellings. The only structure dated to Period III outside Area A is a hearth dated to $1400-1120 \mathrm{BC}$, which was stratigraphically older than house 2, like the nearby hearth from Period
II in Area E. These hearths display some kind of continuous activity.

After the pioneer settlement on the plain in Period II in Area A and B, it appears that the settlement continued in a limited fashion only in Area A, and with smaller houses. It may be that there was only one small household at a time.

The houses dated to Bronze Age Period III are so limited that there is a possibility that the settlement was smaller than in the previous period. No combined dwelling and byre house is dated to the period but two houses are large enough to have been used as such, although cattle stalls have not been demonstrated with any certainty. Like in Period II, the population cannot have been larger than $5-15$ individuals. It is also possible that the settlement was moved to areas between Areas A and D due to the need for new fields. These areas, which have not been investigated, have phosphate values that are just as high as Areas A and D. Fig. 95 shows that, in the next period, a settlement was established in Areas B and D. Perhaps, during large parts of the Bronze Age, the settlement had a mobile 
adaptation to use areas with good agricultural returns when new houses had to be built.

One important find of charred cereal casts light on the agriculture during Period III. Inside house 59, dated to Period V by five radiocarbon dates of charred seeds, a pit which contained approximately 5,500 charred seeds was found. The pit did not appear to have a structural link to house 59, and was dated to $1280-1120$ $\mathrm{BC}$, based on a combination date of five charred seeds, dated individually - placing the pit firmly in Period III. An analysis of 332 seeds determined to species (Bakkevig 1991, 1992, Prøsch-Danielsen \& Soltvedt 2011) shows that wheat (Triticum) is present in $25 \%$ of the cereals, compared to $10 \%$ or less in the two older samples, while barley (Hordeum) constitutes $75 \%$. Like in house 32B in Period II, naked barley (Hordeum vulgare var. nudum) (86 \%) dominates over hulled barley Hordeum vulgare var. vulgare) (14\%). The total distribution of species is shown in Fig. 7 and Table 2. This collection of grains may also represent an offering of the autumn's harvest. The high percentage of wheat cereals, compared to the finds from Bronze Age Period II, may reflect a shift to a greater emphasis on wheat crops, which is also found in the Late Bronze Age and the Pre-Roman Iron Age.

\section{Bronze Age Period IV (1100-900 BC)}

The settlement continues in Area A during this period (Fig. 95). A large longhouse was built (house 48; $22 \times 7$ $\mathrm{m}, 1010-830 \mathrm{BC}$ ) with a substantial distance between the two rows of posts (type 1). The house had six pairs of roof-bearing posts and two entrances placed between the two central pairs of posts. It was heavily rebuilt to the smaller type 3 house 49 ( $16 \times 6.4 \mathrm{~m})$. These two houses probably represent a sequence of houses within a continuous settlement from Period IV to the transition to Period V.

During Period IV, a four-post building of a trapezoid shape (house 86, type 13, 1050-900 BC), was erected very close to the hillside. It has a central hearth, just like the rectangular four-post constructions of the previous period. A similar construction was found at Prestegården, in the municipality of Strand, not far from Forsandmoen (Løken 2009). This settlement did not contain any longhouses, only two other small buildings and a cairn of fire-cracked rocks, indicating that the trapezoid construction was a dwelling. This may also have been the case at Forsandmoen.

There is a U-shaped wall-trench (type 12) surrounding four pairs of roof-bearing posts (house 57B; 1280 $820 \mathrm{BC}) 10 \mathrm{~m} \mathrm{SW}$ of house 48 . The fact that there is no wall-trench at one end of the house could mean that the house may not have been a closed construction. If the construction is contemporary with house 48 , as is possible based on the radiocarbon dates, it may be a small outbuilding belonging to a larger longhouse.

The small longhouse 73 from Period III seems to have been replaced by an even smaller longhouse 69 . The latter house is not dated, but can be placed in the Bronze Age due to its layout. Based on other constructions in the same area, dated to Period V and VI, house 69 most probably dates to Period IV.

The earliest building in Area D (the small area to the west) was constructed about $360 \mathrm{~m}$ WSW of house 48 . House $212(15.7 \times 6.8 \mathrm{~m})$ was a well-built version of a type 3 house, with six pairs of posts and oppositely placed entrances between the two central pairs of posts. Only about $2 \mathrm{~m}$ north of the northern long wall of this building, a four-post storage house, 214, was found. This is the earliest example of a typical settlement unit during the Bronze Age and the Pre-Roman Iron Age. House 212 was dated to 1290-900 BC, indicating that the two buildings may have been erected already in Period III.

The partly preserved type 3 house 237 (13 x $6 \mathrm{~m})$ dated to $1010-820$ BC was uncovered in Area B, about 20 metres SW of a house from Period II. Considering the results of the pollen analysis of the clearance cairn, this house raises the question of whether settlement in this area was continuous throughout Periods II-IV.

The houses from Period IV testify to a rather limited settlement in Area A, consisting of only a multi-phase longhouse and three smaller buildings of unknown function. The settlement in Area B (be it re-established or continuous) and the establishment of a new farm unit in Area $\mathrm{C}$ point to a consolidated and maybe even expansive agricultural society on Forsandmoen.

In Bronze Age Period IV, a type 1 house, 48, of the same size as in Period II appears again. Also here, it is not possible to determine whether the house had an area for stalling cattle. If the dwelling area was in the eastern part, as in the type 3 houses, it may have provided space for twelve people, while the area east of the slightly offset opposed entrances may have provided space for ten cattle (Table 55). With a reverse location of the dwelling and byre areas, the house would accommodate six people and a total of 16 cattle. The ratio of 2.7 cattle per person means that this interpretation is least likely. House 49, the reconstructed house at the same place, however, provided space for the same number of people (5-8) and cattle (eight) as house 45 in Period II. House 212 can also be compared to house 


\section{Forsandmoen, Forsand municipality Map of settlement area}

$\subset$ House feature with preserved wall remains

$\square$ House feature without wall remains

Bronze Age VI Bronze Age 800-400 BC

- Bronze Age/Early Pre-Roman Iron Age 800-200 BC

- Gravemound / cairn

$\bigcirc \quad$ Excavated gravemound / cairn
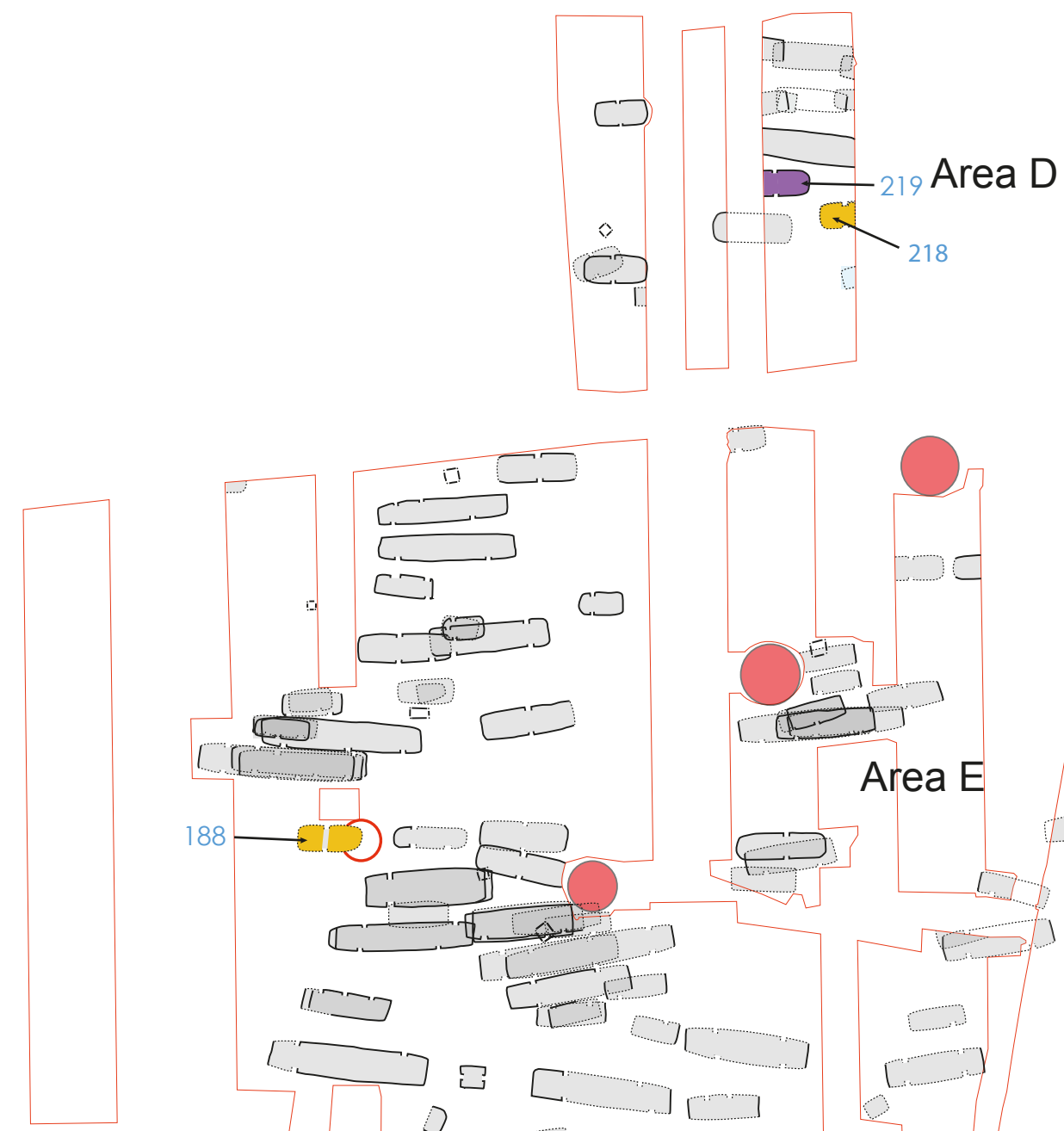

Area $\mathrm{E}$

88

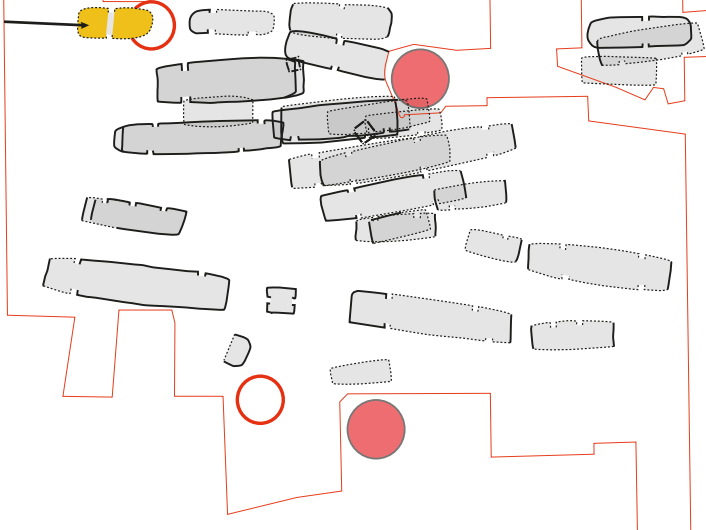

$\bigcirc$

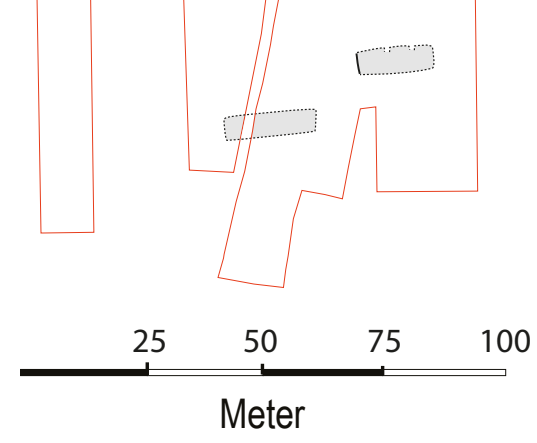




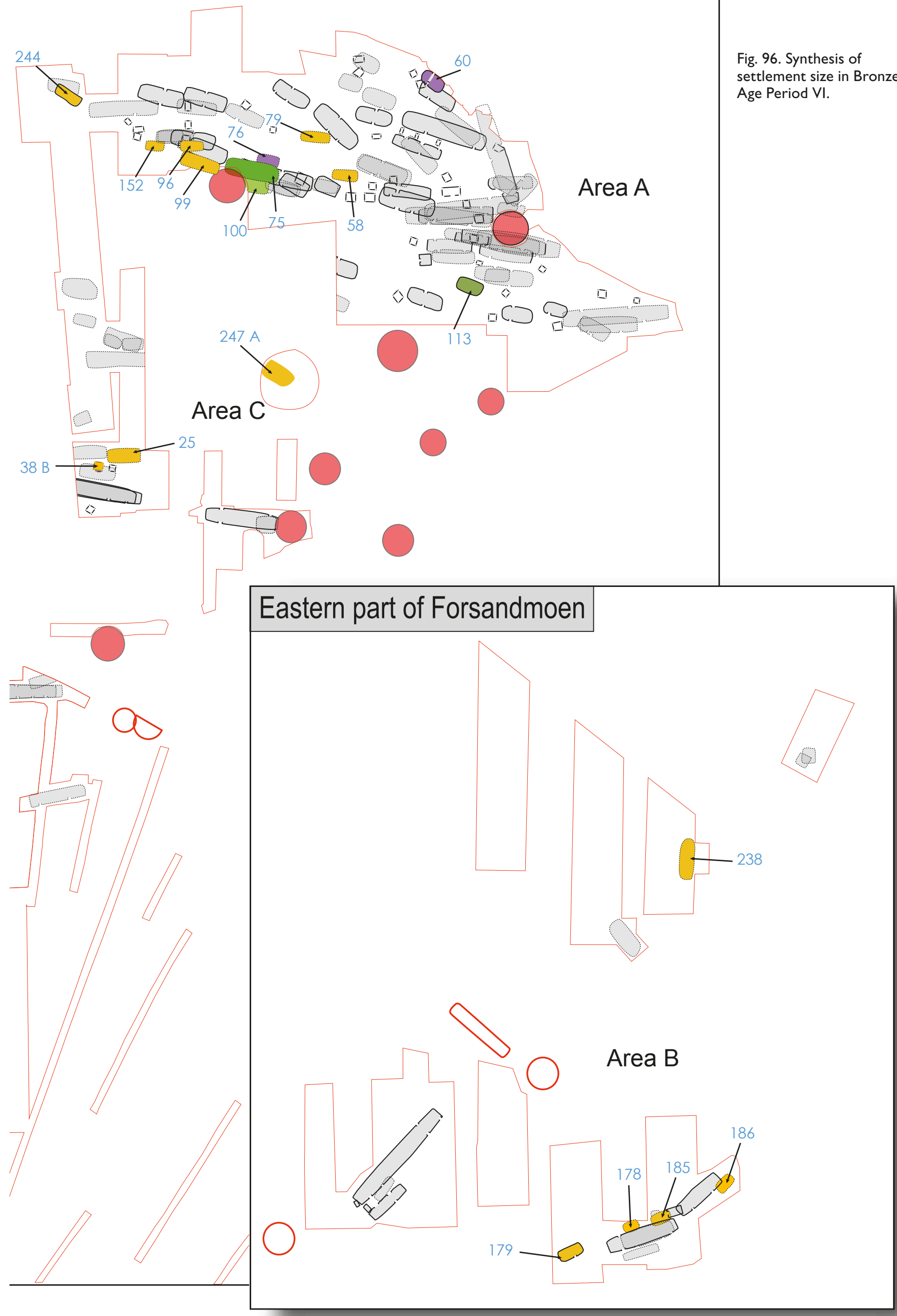


49; a wear depression along the centre axis in the western part of the house is probably the first indication of providing winter fodder for eight cows. House 237 was also the same size as house 212 . In addition, the settlement also had two houses, 57 and 69 , for $6-9$ people, but without space for cattle.

In all, one can imagine that at least two farms have existed at any given time, as well as a household without the possibility of stalling cattle. The settlement has still not consisted of more than 15-20 individuals and 20-25 cattle. The buildings can be characterised as scattered individual farms over large parts of the plain. Some other types of buildings, for storage or activities using fire, belong to farms in Areas A and D.

\section{Bronze Age Periods V-VI (900-500 BC)}

A total of 16 houses have a radiocarbon date within Bronze Age Periods V-VI (Fig. 95, 96). Of these, four probably belong to each of the two periods, based on their radiocarbon date. Eight houses with a date interval of 780/760-410/370 BC likely belong to Period VI. In addition, four houses have a date interval of 800/760-260/200 BC. Whether these belong to Period VI or the early Pre-Roman Iron Age cannot be ascertained based on the available data. If these four houses are divided equally between Period VI and the early Pre-Roman Iron Age, then the situation is that Period V appears to have the same number of dated buildings as in Period III and IV (four houses), while Period VI has a much larger number of buildings - a total of 15-16. In addition, several of the 63 four-post constructions likely belong to Periods V-VI. There is also one instance of artefact-dating of a nonradiocarbon dated house: based on the recovery of a soapstone casting mould of type $\mathrm{C} 1 \mathrm{~B} / \mathrm{C} 3$ (Fig. 16) in a posthole, one house has been dated to Periods V-VI (Baudou 1960).

\section{Bronze Age Period V (900-700 BC)}

House 59, a large longhouse of type $1(22 \times 8 \mathrm{~m})$, was erected centrally in Area A (Fig. 95), with a trestle width of more than $4 \mathrm{~m}$. The combined date to 813-792 BC from four charred grains from different postholes in the house show that the house belonged to the middle part of Period V. Due to the large size of the building, it was probably home to a household larger than a nuclear family, just like houses $32 \mathrm{~B}$ and 48. The house had a large distance between the trestles in the western part. East of the central, oppositely placed entrances, the trestles are separated by only about $2 \mathrm{~m}$. A separate entrance leads to this room. Of all the Bronze Age houses at Forsandmoen, house 59 is the richest in artefact recoveries. Most of the pottery, lithic material and burnt clay were found in the western part, burnt bones were recovered from the entire floor area, while burnt hazelnut and mica schist was recovered from the eastern part. The differential setting of the trestles and the artefact distribution both point to different functions of the western and eastern part of the building. It seems likely that the western part was used as a dwelling, while the eastern part was a byre, just as is known from contemporary Danish Bronze Age houses.

A smaller household may be represented by a small type 3 house (house 74; $14 \times 6$ m, 900-540 BC), built $35 \mathrm{~m} \mathrm{SW}$ of house 59. Just east of this house, there was a four-post construction ( $72 ; 3.9 \times 4.5 \mathrm{~m})$ erected above two interconnected pits dated to $980-800 \mathrm{BC}$ and 900-590 BC. The two houses may represent a small farmstead.

House 215, dated to Period V, was found in Area D $(12.6 \times 5.8 \mathrm{~m}, 920-520 \mathrm{BC})$. The house is situated $30 \mathrm{~m}$ north of, and probably succeeds, house 212 from Period IV. The house is a completely preserved but smaller version of house 212. Both houses had a depression in the western part, a feature which in later houses is connected to the presence of a byre. House 215 has greater distance between the trestles in the eastern than in the western part, which also indicates a byre in the western part.

Based on these dates, there can be little doubt that Area D was established as a settlement area in continuous use from Periods IV-VI into the Pre-Roman Iron Age. With a distance to Area A of 300-350 m it appears likely that the Area D settlement was a separate entity, which probably developed out of the Area A settlement.

The size of the settlement in Area A appears to be more or less like the previous periods: a large and a small longhouse, which both served as a combined dwelling and stable. The large longhouse has been moved successively towards the NW (from house 32B in Period II, 48/49 in Period IV to 59 in Period V). It could be that Area A had a two-unit settlement from Period II to V, but the settlement in Period III is not well known. Five hundred years after the initial settlement, there is an expansion into Area D. The settlement in Area B is known only in Periods II and IV, but this area has been investigated less thoroughly.

The structure of house 59 may indicate that the house was divided into three rooms, such as house 32B. Between the two entrances in the southern wall, the 
posts are so close together that this can mark a byre with room for 8-10 cattle, while the rooms at each end are the size of the corresponding rooms in house 32B (10-15 people). Both of the two type 3 houses during this period are the same size as the previous houses of this type, with room for a household of 5-6 people and eight cattle (Table 55). The pattern of the settlement in Periods IV and V is therefore one large and one smaller farm relatively close together in Area A and one or two scattered farms in Areas B and D. During Bronze Age Periods IV and V the settlement at Forsandmoen probably consisted of 1-2 households (farms) of varying sizes and not more than a total of $15-20$ people and 20-25 cattle.

\section{Bronze Age Period VI (700-500 BC)}

Period VI sees a marked increase in the number of houses, encompassing a total of 17 houses in most of the phosphate-enriched areas (Figs. 95, 96). Three of these are dated to Period VI by radiocarbon or artefacts finds. Due to the changes in the content of atmospheric ${ }^{14} \mathrm{C}$ content the calibrated dates in the period $900-200$ $\mathrm{BC}$ have very long uncertainties (known as the DeVries perturbation). Ten houses are dated to 800-400 BC and are thought to belong to Period VI, while four are dated to $800-200 \mathrm{BC}$ and may also belong to the early Pre-Roman Iron Age.

The last large longhouse of type 1 in Area A (75; 23 x $8 \mathrm{~m}$ ) is situated $40 \mathrm{~m} \mathrm{SW}$ of house 59. It has a large trestle width. Just as house 59, it has a longer distance between the individual trestles in one part than in the other, but in this case, it is the eastern part that has the longer distance between the trestles. An entrance in the southern wall leads to a narrow room, which divides the two parts. The house is situated in the same area as house 74 from the preceding period. The two houses may represent a two-phased settlement unit. House 75 is dated to Period V-VI by a remarkable find of both parts of a soapstone casting mould for a socketed axe (Fig. 16).

Three additional houses are situated here as well, but cannot all be contemporaneous with house 75 , as they are either placed too close to it or have overlapping construction features. West of house 75 , there is a type 3 house $(99 ; 15.6 \times 6.4 \mathrm{~m})$ dated to $760-400$ BC. South of house 75 , there is a house with four trestles $(100 ; 5.6$ $\mathrm{x} 4 \mathrm{~m}$ ) dated to $770-510 \mathrm{BC}$. This is probably a storage house. To the north of house 75 , house 76 is a type 16 storage house with three trestles, dated to $800-200$ $\mathrm{BC}$, and thus it might as well belong to the Pre-Roman Iron Age.
The type 11 house 58 (760-370 BC) was situated $20 \mathrm{~m}$ east of house 75 . Only house 58 has remains from short longitudinal walls. It is uncertain whether these constructions were dwellings or sheds for outdoor activities. They are therefore not included in the estimated number of inhabitants in the period. The analysis of this house type (chapter 6.4) showed that all the undated houses were situated either in connection with type 3 houses or with type 5 and 6 houses that were dated to Bronze Age Period VI or the early PreRoman Iron Age. The remaining five houses of type 11 (house 79, 96, 152, 244 in Area A and 178 in Area B) are outlined in Fig. 96 as dated to 800-200 BC. Probably two or three of them more likely belonged to the early Pre-Roman Iron Age.

House 113, a small type 5 house $(10 \times 5.5 \mathrm{~m}, 810-510$ $\mathrm{BC}$ ) is situated about $90 \mathrm{~m} \mathrm{ESE}$ of house 75 . This is the most south-easterly house within Area A in this phase. It has four narrow trestles, and a large oval hearth between the easternmost posts. The building is very similar to the later type 5 houses 127 and 128 from the early Pre-Roman Iron Age, which are situated 10 and $25 \mathrm{~m}$ towards east, respectively. The three houses may represent a sequence. The layout and the small size indicate that these buildings probably were dwellings only.

Five type 3 houses are dated to 800-400 BC $(25,99$, 188, 218 and 247) and two similar ones, 60 and 219, are dated to 800-200 BC. They are situated in Areas A, C, $\mathrm{D}$ and $\mathrm{E}$ (south-west). House type 3 is a typical building for a household that made its living both from animal husbandry and the cultivation of plants. The distance between the units varies from 50 to $200 \mathrm{~m}$, and if contemporaneous, this may indicate that the houses were separate units with fields surrounding the buildings. The houses were among the smallest of type 3, only 10-15 m long, and probably intended for a small number of adults (maybe five) and a limited number of cattle (possibly 8-10). Four type 3 houses were constructed in Area D during Periods IV-VI, and an additional two in the early Pre-Roman Iron Age. This indicates that Area D had continuous settlement throughout the Late Bronze Age and the early Pre-Roman Iron Age.

In Area $\mathrm{D}$, the settlement continued with the type 3 houses 218 and 219, which are dated to 760-390 BC and $800-200 \mathrm{BC}$, respectively. They probably represent a continued agricultural settlement from the two preceding periods of the Late Bronze Age.

House 25 in Area C is dated to 780-380 BC. It is situated close to two other similar type 3 houses, 39 and 41 (see Fig. 97). The fact that these three similar houses 


\section{Forsandmoen, Forsand municipality Map of settlement area}

$C$ House feature with preserved wall remains

House feature without wall remains

$\square$ Early Pre-Roman Iron Age

$\square$ Late Pre-Roman Iron Age

Gravemound / cairn

$\bigcirc \quad$ Excavated gravemound / cairn
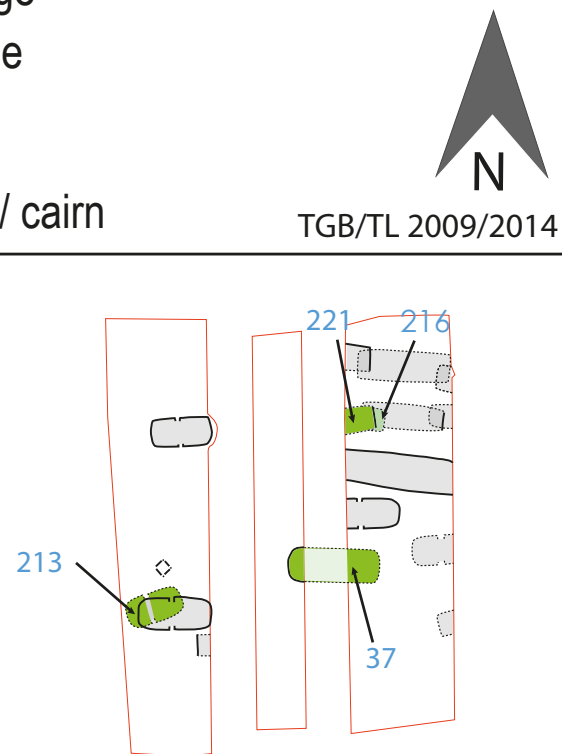

Area D
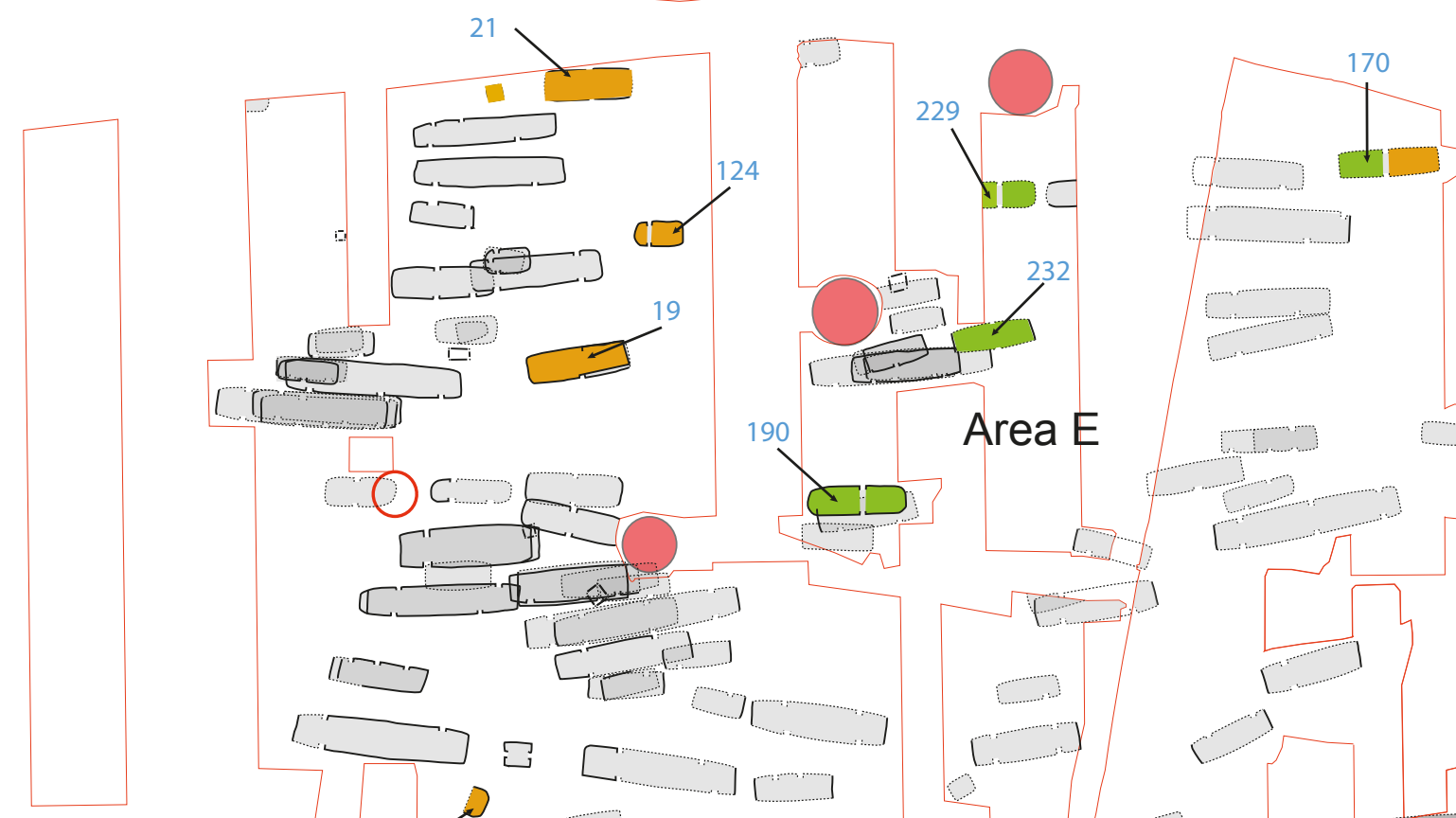

○
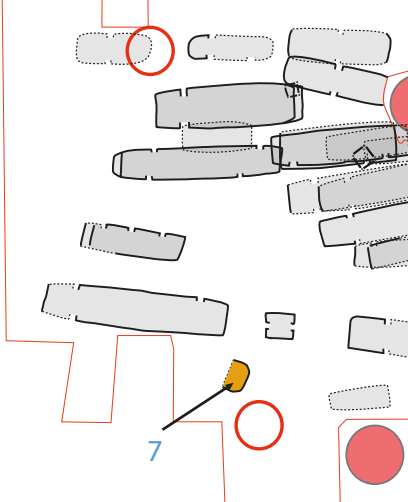

Area $\mathrm{E}$ 

were situated close to each other indicate a settlement unit with a fixed farmstead through Bronze Age Period VI and the early Pre-Roman Iron Age. Since the two other houses are not dated, it is not possible to be more specific than this. Houses 39 and 41 have therefore been outlined on Fig. 97. Three four-post storage buildings (38A, 38B and 40) are located directly south of houses 25 and 41 and overlay house 39 . One or two of the storage buildings may thus belong to house 25 .

In contrast to the concentration of buildings in Areas C and D, the type 3 house 188 (760-400 BC) in Area E is an isolated occurrence. It may represent a short-lived settlement in the south-western part of the plain.

House 238 (type 3) in Area B is dated to Period VI. It is oriented $\mathrm{N}-\mathrm{S}$ and consists of five wide trestles only. The layout of the house suggests that it may have had both a dwelling and a byre.

At the southern part of Area B, there are four small houses placed in a row, 178, 179, 185 and 186. Two of these are dated to Period VI. House $179(11 \times 5 \mathrm{~m})$ is dated to 760-405 BC. Just like house 113 in Area A, it is of type 6 with five trestles. The three easternmost houses have a short distance between each other. Just as in house 113, there was a large oval hearth at the eastern end of house 179, in addition to a smaller one in the largest, middle room. This house was probably intended for human use only. The preserved fragments of house 185 , dated to $750-410 \mathrm{BC}$, indicate that the house had two rows of roof-bearing posts. The two smaller houses in this row (house 178 and 186) are also most likely from the late part of the Bronze Age since there was no other settlement in this area until the beginning of the early Roman Iron Age. The row structure of the two dated longhouses and the two small houses may indicate that they were constructed concurrently, and that their layout was planned like this. Then again, the houses are situated along a slight hillside in the terrain, so it could be that a desire to build in this location caused the houses to be built in a row, as we see in building remains from the Roman Iron Age in the same place. The lack of buildings from the Pre-Roman Iron Age shows that the area was either abandoned or the buildings were located outside the excavated areas. Traces of buildings in Area B only appear again after approximately 500 years, in the early Roman Iron Age, in the form of a $50 \mathrm{~m}$ longhouse.

In Bronze Age Period VI, there was one large combined dwelling and byre house of type 1 in addition to seven type 3 houses, one of which (99) has a size comparable to house 75 (Table 55). In addition, there was a type 5 house, 3-4 small type 11 houses and a storage house of type 16. Probably, some of the many four-post storage houses in Area A were also used during this period. Based on the size of the houses (see Table 52), the settlement in Period VI may have consisted of two large longhouses, each with space for 8-12 adults and $12-16$ cattle. In addition, there were seven smaller type 3 houses, each with space for 4-6 adults and 6-8 cattle and three type 6 houses with space for $5-6$ people and maybe a couple of cattle. The period also includes 3-4 type 11 houses, which probably only functioned as a house for a small nuclear family. This probably means that the settlement at no time comprised more than four households with winter-fed cattle and two families with no cattle, about 30-35 adults and 40-45 cattle. The buildings were spread to all areas and seem to change location when new houses were to be built. However, two houses in Area D, separated by only a few metres, seem to have followed each other.

\section{Summary of developments in the Bronze Age}

Based on the assessments above, four type 1-2 dwelling and byre houses, five type 3 dwelling and byre houses and four other dwelling houses appear to have been erected in Bronze Age Periods II-V. In addition, the settlement also comprises at least three four-post buildings with a hearth inside and some four-post granaries. In Bronze Age Period VI, there are nine dwelling and byre houses (two type 1-2 and seven type 3), eight dwelling houses (six type 11 and two type 6) and two 6-8-post granaries and probably some four-post granaries. The number of houses (19) is doubled compared to the number of houses (nine) dated to the earlier four Bronze Age Periods. These numbers show that the settlement in Bronze Age Period V experienced a considerable growth in size to 3-4 simultaneous farms from only one or sometimes two farms in the earlier Bronze Age Periods.

When summarising the development of settlements through the Bronze Age, it is obvious that settlements through Bronze Age Periods II-V were of a modest size. In Area A, there was only one farm unit with a dwelling and byre house most of the time, as well as some smaller buildings for storage and possibly shorter stays. In three of the periods, there was a large longhouse, with room for both people and potentially for stalled cattle. This type of building was also found in the last period of the Bronze Age. In Period IV and continuing into the following periods, the settlement expanded when a new farm unit was established in Area D.

In the case of Bronze Age Period VI, the number of dated houses indicates that the settlement is clearly 
larger than in the early periods of the Bronze Age. In Area A, three larger houses for combined housing and byre/storage functions were located close together in the western part of the area. They may represent a settlement unit throughout the period. In addition, there are three other, smaller houses spread over the area, which may also have had a residential function and may represent individual households. In Area D, the two houses with combined housing and byre/storage functions, together with corresponding houses in this area in Bronze Age Periods IV and V, testify to a continuous settlement in this area, which continues in the Pre-Roman Iron Age.

Alternatively, the type 3 house 188 in Area E can be interpreted to signify an unstable settlement, where a household is established and then later moves to another place on the plain, since there are no newer houses nearby until the end of the Pre-Roman Iron Age. The other two lone houses of the same type (houses 25 and 247A) in Area C may also be understood as part of a settlement relocation pattern, but unlike house 188, only a minor area around these houses has been investigated, therefore we cannot exclude that there may have been earlier or later buildings nearby. However, two similar but undated houses adjacent to house 25 indicate continuous habitation in the Pre-Roman Iron Age.

With regard to Area B, the areas beyond the excavation sites that have not been investigated are so large that the sporadically occurring houses dated to the Bronze Age cannot be used for anything other than to observe that there have been short-lived buildings in the area between long uninhabited intervals.

It should be noted that during Periods III-VI the buildings in Area A consisted of at most two simultaneous farm units with medium to large longhouses, while the houses in the other areas during Periods IV-VI are generally smaller type 3 houses. We must consider, partly on the basis of analyses of macrofossils, if this is related to changing economic conditions. What we can note, however, is that the main houses with the exception of the houses in Area B from Period $\mathrm{VI}$ - are all of the type with opposed entrances in the middle, most likely as an entrance room for the dwelling area for people on one side and for the byre on the other. In conjunction with one of the houses in Areas $\mathrm{C}$ and $\mathrm{D}$, there were some smaller buildings, so that the settlement unit is similar to that found in Area A, but smaller.

Therefore, based on the houses, there is no reason to assume that the new farm units are based on a different subsistence strategy than those in Area A. However, as new establishments, they may have had access to smaller areas or other resources, or they may represent smaller social units, which may have led to less need for such a large built-up area.

Smaller units were also established in Area A at the end of Bronze Age Period VI. It is possible that the three new small type 11 houses in Area A, and the new launch of small houses in Area B, most of these without the traditional construction layout with opposed entrances in the middle, signal changes in the economic and social pattern represented by the larger, older houses. For example, the large farm units of the Bronze Age are split into more and smaller family farm units which could have had their own property rights over the cattle (Kristiansen 1988), a trend that becomes more apparent in the earliest part of the Iron Age. In this context, we can observe that a similar development also happens at Forsandmoen.

There is reason to emphasise that there is settlement stability in the central area from Bronze Age Period II and up to AD 500, but that the buildings within the $100 \times 200$ m wide Area A changed location a number of times.

The figures mapping the settlement phases (Figs. 95-101) illustrate that, at some point, there is a leap in the size of the settlement. The population increased in the middle of the Late Bronze Age and the number of short, narrow houses which combined a dwelling part and byre part increased as well, while at the same time the type of grain grown changed from almost exclusively barley (Hordeum) and $5 \%$ wheat (Triticum) in the Early Bronze Age to a smaller proportion of barley (67 $\%$ ) and $32 \%$ wheat in the Late Bronze Age (Fig. 7 and Table 1). Were changes in both cattle use and farming behind this settlement growth? The increase in the early Pre-Roman Iron Age may be related to the introduction of iron technology to the inventory of tools. Iron extraction has been detected on the plain from around $400 \mathrm{BC}$.

\subsection{The Pre-Roman Iron Age}

\section{Early Pre-Roman Iron Age (500-200 BC)}

In relation to the westernmost concentration of buildings in Area A in Bronze Age Period VI, four houses were established at the beginning of the Pre-Roman Iron Age in the south-east corner (Fig. 97), where there was a type 6 house, 113, in the previous phase. The two easternmost of these, houses 127 and 128 were of the closely comparable type 5 , which, based on the 
structure, could function as dwellings for humans only. The two western type 3 houses in this row, 31 and 110, were intended for both people and animals. Only the two houses 110 and 127 are ${ }^{14} \mathrm{C}$ dated to the period (400-200 BC and 390-200 BC), while house 128 is dated to the same period because of the almost identical form to 127. House 31 is, like house 110, a type 3 house, and dated to this period based on the row structure between the four houses. In the area east of house 128, the fragmentary, undated type 3 house 143 has been investigated, and can only have belonged to this phase, since a large type 7 house, 140 (100 BC-AD 80), overlaps with house 143.

At a distance of $100 \mathrm{~m}$ west of house 110, and northernmost in Area C, another smaller type 6 house, $241 / 242$, also dated to the period [760-260 BC (central hearth) and 410-160 BC (posthole)]. This may have been a single house, but we cannot ignore the fact that, in the $80 \mathrm{~m}$ not investigated between this house and house 110 in the above-mentioned row of houses, there may have also been 1-2 houses.

Thus, early in the Pre-Roman Iron Age, the settlement was moved towards the south and to a windier area than closer to the mountainside in the north. Since this area has been little used before or after, the three easternmost of these houses, 31, 127 and 128, probably each had a four-post storage house (131, 137 and 142) located close to each of them. These are not dated other than by their spatial placement relative to the longhouses.

The row structure may indicate that the move occurred due to certain needs for relocation. It might very well be that the houses at a settlement are moved in order to use nutrient-rich soil at the settlement site as farmland. The row structure is reminiscent of how the houses were organised at settlement sites in Denmark. For example, the houses at Hodde are located at the northern and southern edges of the village (Hvass 1980), as in village A at Grøntoft (Becker 1971) and at Fosie IV (Björhem \& Säfvestad 1993:296-300). The five houses in the southern part of Area A represent two different types of houses: two houses for an agricultural population, which has houses that can accommodate cattle stalls in the house's western part, as well as three houses where the inhabitants probably did not have this opportunity.

In addition to these buildings, house 55A (800-200 $\mathrm{BC})$ was built along the mountainside to the north partially overlapping with house 60 from the previous period. As shown in Fig. 97, another house, 54 (360-1 $\mathrm{BC})$, partially overlapped with house $55 \mathrm{~A}$ in a later part of the Pre-Roman Iron Age. Thus, it appears that a household, which, based on the house size, increased in size from period to period, maintained continuity at the settlement from as early as late in Bronze Age Period VI and throughout a large part of the PreRoman Iron Age.

About $130 \mathrm{~m}$ south-west of the row of houses in Area A (110, 31, 127 and 128) and in the south-west corner of Area C, there was, in Bronze Age Period VI, a small type 3 house, 25, together with two other similar houses, 39 and 41, which are undated. In Fig. 97, it is suggested that these belong to the Pre-Roman Iron Age, thereby representing a three-phase settlement continuity for a household. Two of the three four-post storage buildings (38A, 38B and 40), which are located south of houses 25 and 41 and overlap with house 39, are proposed to belong to house 41.

House 27A (490-170 BC) of type 11, was situated $30 \mathrm{~m}$ north of houses 39 and 41 . During this period, there were probably also a couple of type 11 houses in the north-western part of Area A, cf. phase map for Bronze Age Period VI (Fig. 96). These can contribute to the understanding of a more complex housing pattern during this period.

In Area D, the settlement continues with two houses in the early part of the Pre-Roman Iron Age. House 213 (400-200 BC) partially overlaps with house 212 from Bronze Age Period IV and is a small type 3 house with space for stalled cattle between two trestles only. Both the deviating orientation of the house and the time difference between the two houses show that this is a newly established household. The second house 37 (390-200 BC), which is only partially excavated due to the trench system, was probably also a type 3 house, but with far more room for cattle. As in Area A, we find two contemporaneous houses that reflect different living conditions.

In the same area, there has also been an investigation of structure 216 that consists of one pair of posts with a smelting pit with slag and sintered clay on the centre axis between them. The construction probably protected the smelting pit, which is dated to $800-200$ BC. Overlapping this building, the second building 221 contained a central hearth, dated to $740-410 \mathrm{BC}$. The postholes of this building also contained slag. The combination of these dates indicates an early start to iron forging at Forsandmoen.

In Area E, 100-150 m south of these houses, there are three type 3 houses on an SSW-NNE oriented axis. The southernmost of these, 190 (400-200 BC), is a large well-built type 3 house in Area E, located $100 \mathrm{~m}$ 
east of the first established house, 188, from the previous period. The other two, 229 (380-200 BC) and 232 (410-110 BC), were about the same size. The two southernmost houses 190 and 232 represent the start of a three-to-four-phased farm site, but with a break in the last part of the Pre-Roman Iron Age, while the northernmost of the three houses, 229, has no dated successor. However, only $2 \mathrm{~m}$ to the east is a corresponding type 3 house that may have been erected sequentially. In Area E, these three houses now indicate that several households were established in an open $\mathrm{N}-\mathrm{S}$ row structure, with the houses placed with their long sides opposite each other, also known from several sites in Sweden and Denmark. All of these represent the largest type of household during the Bronze Age and the early Pre-Roman Iron Age, with the exception of the four large type 1 houses from the Bronze Age.

\section{Summary of the developments in the Early Pre-Roman Iron Age (500-200 BC)}

The houses that belonged to the settlement in the early part of the Pre-Roman Iron Age clearly show that the settlement increased in scope from the end of the Bronze Age. Based on the large number of houses (14 altogether) we can assume that there was a continuously active settlement in the four areas with at least one household - and in Area A with at least two households. In total, it appears that there may have been five coexisting households during this period, while previously there may have been $2-3$ households. Ten of the houses were large and well-built with a dwelling area in the eastern end and a byre and/or storage area in the west. The analyses of these type 3 houses (chapter 5) demonstrate a capacity to accommodate $4-18$ cattle.

Additionally, there are no buildings dated to the PreRoman Iron Age in the two areas of Area B where there were buildings in Late Bronze Age Period VI. However, in the southernmost field about $200 \mathrm{~m}$ north of the row of small buildings, there was a type 13 building, 235 (410-200 BC), with a hearth in the middle, and overlapping with this, a four-post building. This can hardly be considered a continuation of the settlement in this area, but perhaps more likely a shelter for herders or used in connection with harvesting.

Based on the assessments above, twelve type 3 dwelling and byre houses and four other dwelling houses appear to have been erected in the early Pre-Roman Iron Age. In addition, the settlement also comprises a trestle construction with a pit with remains from a smithy and some four-post granaries. The row of four type 3 houses and one type 5 house shows that the south-eastern part of Area A was the preferred area in this period, but many houses were also constructed in Areas $\mathrm{C}, \mathrm{D}$ and $\mathrm{E}$.

From the overall pattern in Fig. 97 it seems reasonable that at least five farms were simultaneously established in the period: one farm in each of the Areas C, D and $\mathrm{E}$ and two in Area A. The large distances between the 6-7 type 3 houses in the Areas D and E seem to indicate that the location of the farm would have been moved when a new house was to be built, while the inhabitants in Area $\mathrm{C}$ seem to remain within the chosen area in three house-generations.

Fig. 97 shows that twelve combined dwelling and byre houses of type 3 (Table 55), two dwelling houses of type 5 , a smithy (house 216) and probably $2-3$ houses of type 11 are dated to the early Pre-Roman Iron Age. Based on the assessments in chapter 15 and table 52, I propose that each adult inhabitant needs an area of $8 \mathrm{~m}^{2}$ in the dwelling part and each cow needs a width of $1 \mathrm{~m}$ in the byre. This means that the type 3 houses in Areas A, C and D on average provided space for 6 adults and 7 cattle, while the large type 3 houses in Area E may each have accommodated 7-8 people and 16-18 cattle. Based on how the dated houses are located in the area and considering that large areas with phosphate-rich soil have not been investigated between Areas A, C and $D$, the settlement in the early Pre-Roman Iron Age may have consisted of at least five farm areas, two of which were in Area A, and one each in Areas C, D and E. The settlement at Forsandmoen in the early Pre-Roman Iron Age may therefore have consisted of 40-45 people based in six households, of which 10-12 people would have been living in type 5 and type 11 houses, without space for cattle. The five farms may have had space for 50-55 cattle. Based on the location of the farms in Areas C, D and E, it would seem that the farm was moved when a new house was to be built.

\section{Late Pre-Roman Iron Age (200-1 BC)}

In Area A, the concentration of buildings was moved from the row of houses in the south-east part of the area to a series of three large type 3 houses, 61, 81 and 89 , towards the foot of the mountain to the north-west (Fig. 97). All the roof-bearing posts in house 61 (160 BC-AD 60), the easternmost of these three houses, were replaced at least once and a few of them more than once; so the house must have had a long use-life through the period. The two westernmost houses 81 and 89 (170 BC-AD 30, 340-1 BC) are just barely overlapping and consequently must have been erected sequentially during the period. In the north-east corner of the 
area, house 54 (360-1 BC) overlaps with the previous house 55A, while house 140 (100 BC-AD 80), which overlaps with house 143 from the early Pre-Roman Iron Age, was erected in the south-eastern end of area A. These two houses are the two oldest houses of type 7 dated with certainty, characterised by a trestle in the middle of the house and near the central hearth that is positioned farther out to the longitudinal walls than the other trestles, probably to create a larger room for different types of activities (see chapter 8). The partly excavated house 129 also belongs to this period.

In Area E, the buildings were moved approximately $60-70 \mathrm{~m}$ to the west to a new N-S oriented row of three houses. Two of these, house 21 and 19 (360-50 $\mathrm{BC}, 360-50 \mathrm{BC}$ ) are large type 3 houses with lengths of 18 and $21 \mathrm{~m}$ and $6.6 \mathrm{~m}$ wide, while the two small houses, 124 (350-1 BC) and 122 (not dated) are of type 5, corresponding to houses 127 and 128 in the row settlement in Area A in the previous period, and do not have space for stalled cattle. House 122 is almost identical to house 124 and is therefore approximately the same age. These two houses may have been associated with each of the two combined dwelling and byre houses 19 and 21. They may represent a farm that has moved within the area throughout the late Pre-Roman Iron Age. In house 21, between two trestles in the eastern part of the house, there were smaller posts that divide the room into six $1 \mathrm{~m}$ wide stalls. These houses confirm the view from the previous period that the settlement comprises both households with much cattle as well as households without. Due to dating uncertainty the large type 3 house $170(550-1 \mathrm{BC})$, found in the north-eastern part of Area E, can only be dated to the Pre-Roman Iron Age. U-shaped constructions were constructed in the south-western corner of Area $\mathrm{E}$ as well as in Area C (houses 7 and 44).

In Area $C$, house 41, the last in the cluster of three type 3 houses, probably belongs to this period. A possible U-shaped construction, house 44 (210 BC-AD 200 ), is stratigraphically earlier than house 34 from the beginning of the early Roman Iron Age. A find of slag from smithing activities indicates that it belongs to the last century of the Pre-Roman Iron Age. A U-shaped ditch construction (7; BC 360-AD 50) in the southernmost part of Area E contains a waste pit dated to the period.

\section{Summary of the developments in the late Pre-Roman Iron Age}

In total, there are eight dated houses that can be considered as dwellings with room for stalled cattle. In addition to the dwelling houses 124 and 122, the type 6 dwelling house 129 (360-60 BC) and two U-shaped structures, 7 and 44, were found in Area A. The extent of the settlement seems to have been somewhat smaller than in the previous period, bearing in mind that four dates (about 350-50 BC) belong to the middle of the Pre-Roman Iron Age have been included as belonging to the last part of the Pre-Roman Iron Age. In all, it is possible that the settlement comprised 3-4 households at all times. Based on the larger buildings in the late Pre-Roman Iron Age compared to the previous period, the population probably did not decrease as much as the reduced number of households indicates.

However, considering that the six houses from the Pre-Roman Iron Age in Area E cover 200-250 years, it is unlikely that this row structure was visible in the settlement. Most likely, they represent a household that moved in such a way that it later appears as a pattern. Also in Area A, there could have been a corresponding relocation of two-three farm units that caused such a pattern. The lack of buildings in Area D is perhaps the main reason for the decrease in the number of households from the early to late Pre-Roman Iron Age.

The number of houses, including five type 3 houses and two type 7 houses (Table 55), is smaller than in the previous phase, and no houses have been dated to Area D. The settlement therefore probably consisted of two farms in Area A, one in Area C and one in Area E. One of the farms in Area A (type 7) is larger than the other three farms and may have accommodated ten adults and 14-15 cattle, while the other farms could on average have consisted of five people and 8-9 cattle. The three type 6 houses could each have housed 6-7 people and the three type 11 houses each may have had three people. In total, the settlement in the late Pre-Roman Iron Age may have comprised a population of 30-35 people and 40-45 cattle divided between 5 households. This settlement seems to be reduced in scope in the latter part of Pre-Roman Iron Age, which is in line with the total distribution of ${ }^{14} \mathrm{C}$ datings (cf. Fig. 10).

The analysis of the Pre-Roman Iron Age macrofossils, collected from nine different houses, mainly dated to the middle and last part of the period, shows that the composition of the various grain varieties changed somewhat from the Bronze Age, because a smaller proportion of charred oat (Avena) (12\%) began to appear, whilst wheat (Triticum) is reduced to half compared to in the Late Bronze Age (17 \%) and barley (Hordeum) accounts for $67 \%$ just like in the Late Bronze Age (Fig. 7 and Table 1). The relationship between the two types of barely (Hordeum vulgare var. nudum and $H$. vulgare 
var. vulgare) changed compared to the Late Bronze Age, with hulled barley accounting for almost $37 \%$ in contrast to only $21 \%$ in the Late Bronze Age.

\subsection{Roman Iron Age AD 1-350}

\section{Early Roman Iron Age AD 1-175}

A total of 22 dated houses from the early Roman Iron Age indicates that the settlement increased sharply in the transition from $\mathrm{BC}$ to $\mathrm{AD}$ (Fig. 98). In comparison, in the Pre-Roman Iron Age the number of dated houses was reduced from 14 in the early part of the period to eleven in the later part.

In the western part of Area A, the two type 3 houses 81 and 89 from the late Pre-Roman Iron Age were moved $15-30 \mathrm{~m}$ to the south to houses 62 (50 BC-AD 220) and 80 (40 BC-AD 330), while house 82 (AD 1-340) was built in the northern location to replace house 61 . The $40 \mathrm{~m}$ longhouse 50 was built on the site of houses 54 and 55 from the Pre-Roman Iron Age. It was inhabited throughout the early and most of the late Roman Iron Age (cf. chapter 13) based on several improvements in the construction and the dates of the many hearths. In this innermost corner of Area A, we can therefore observe that there was a household with land continuity from Bronze Age Period VI to the late Roman Iron Age. In the south-eastern part of Area A, the small type 7 house was replaced by a new type of house (type 9), several of which were built during the transition to the early Roman Iron Age. House 139 is a large house (43.5 x $6.4 \mathrm{~m}$ ) with a large dwelling area with hearths at each end and a large byre and/or storage area in the middle. It is understood as a house for two households with a shared byre (see chapter 10). Only 30-40 m NW of house 139, another, smaller type 9 house, 116 (32.7 x 6.2 m, AD 130-330) was built for one household at the end of the early Roman Iron Age or the transition to the late Roman Iron Age. At the same place, a further three type 9 houses were built during the late Roman Iron Age and the Migration Period. Parallel to and just south of house 116 was the small type 10 workshop 118 (AD 1-220). Houses 155 and 161 in Area E and houses 150 and 151 in Area B, are examples of other farm units that also consist of a large longhouse and a workshop. The combined type 9 house and workshop became an almost universal concept for the design of a farm unit during the rest of the settlement period. The six combined dwellings and byres probably represent three farm units through the early Roman Iron Age.

In Area E, the three late Pre-Roman Iron Age farm units were moved approximately $20-30$ m westwards at the end of the Pre-Roman Iron Age, where houses 119, 123 and 155 were built in a N-S oriented row. However, these houses are quite different. House 119 is a type 7 house, represented by the smaller houses 54 and 140 in Area A at the end of the previous phase, while house 123 is a type 3 house and house 155 a type 9 house. This means that, in this area, there was a parallel construction of the three houses representing the most important concepts for a combined dwelling and byre in the Early Iron Age at Forsandmoen. This period should be regarded as a time of transformation from the older construction layout with the entrance area that distinguishes between the dwelling area and the byre to a period when a greater separation between the human and animal spheres in the houses was brought on.

The two houses 118 and 120 (just south of house 119, see Figs. 98 and 99), which are situated parallel to each other, are so similar that they have been considered as succeeding each other. In addition, house 119 has such a significant structural and spatial resemblance to the much larger house 150 in Area B that they are probably somewhat contemporaneous. House 119, however, is dated to 400-170 BC based on an unidentified type of charcoal in a clay mixture in a posthole, while house 120 is dated to AD 130-240. An assessment of all the dates for type 7 houses indicates that this type first occurs in the last part of the Pre-Roman Iron Age. The house has therefore been placed in the early Roman Iron Age, as a precursor to the parallel and equally large near-identical house 120, dated to the transition from the early to the late Roman Iron Age.

House 123 was just $25 \mathrm{~m}$ south of house 119 and was a variant of type 3. It has opposed entrances in the middle of each long side, but also an entrance at the SE end of the house. An elongated ditch in the western end was probably caused by wear from animals. Each of the two rooms at the eastern end has a central, round hearth, which is unusual in previous type 3 houses. In one of these, a shard of a thick-walled, light bluish glass was found, which can be dated to the early Roman Iron Age based on the colour, which is consistent with the ${ }^{14} \mathrm{C}$ date from the house (AD 20-320).

The large house 155 (AD 80-330), like the contemporaneous house 139 in Area A, has an approximately equally large dwelling area at each end, separated by a shared byre area. Two such houses were also built in the late Roman Iron Age and another three houses in the Migration Period. These houses may indicate that, from the early Roman Iron Age, there may have been constraints on establishing new farm units. Maybe the cultivated land was divided so that 


\section{Forsandmoen, Forsand municipality Map of settlement area}

CHouse feature with preserved wall remains

House feature without wall remains

Early Roman Iron Age

Gravemound / cairn

Excavated gravemound / cairn
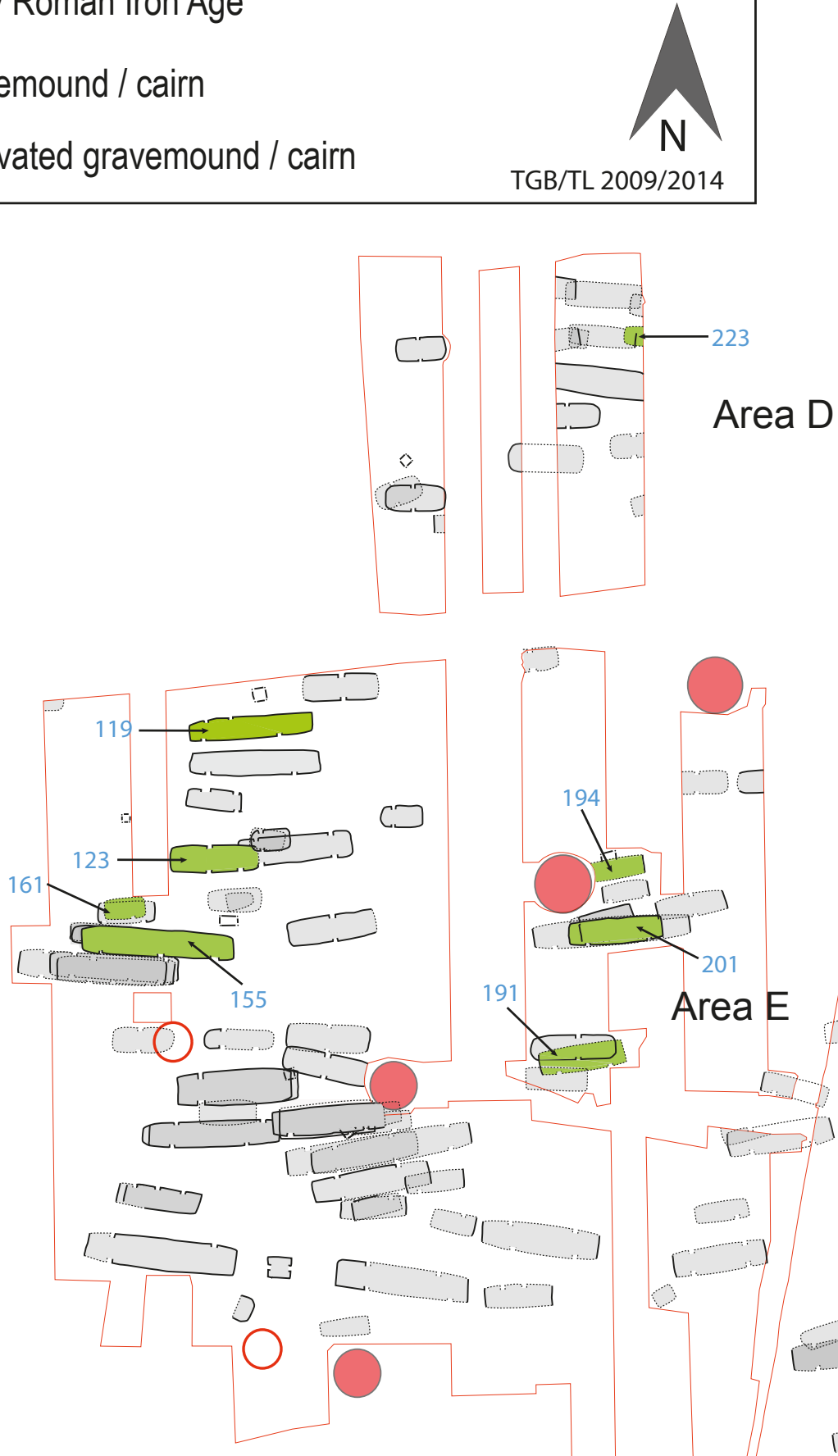

Area $\mathrm{E}$

$\bigcirc$

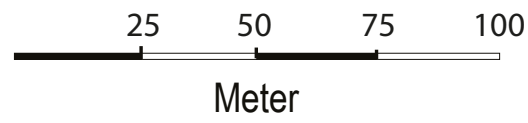




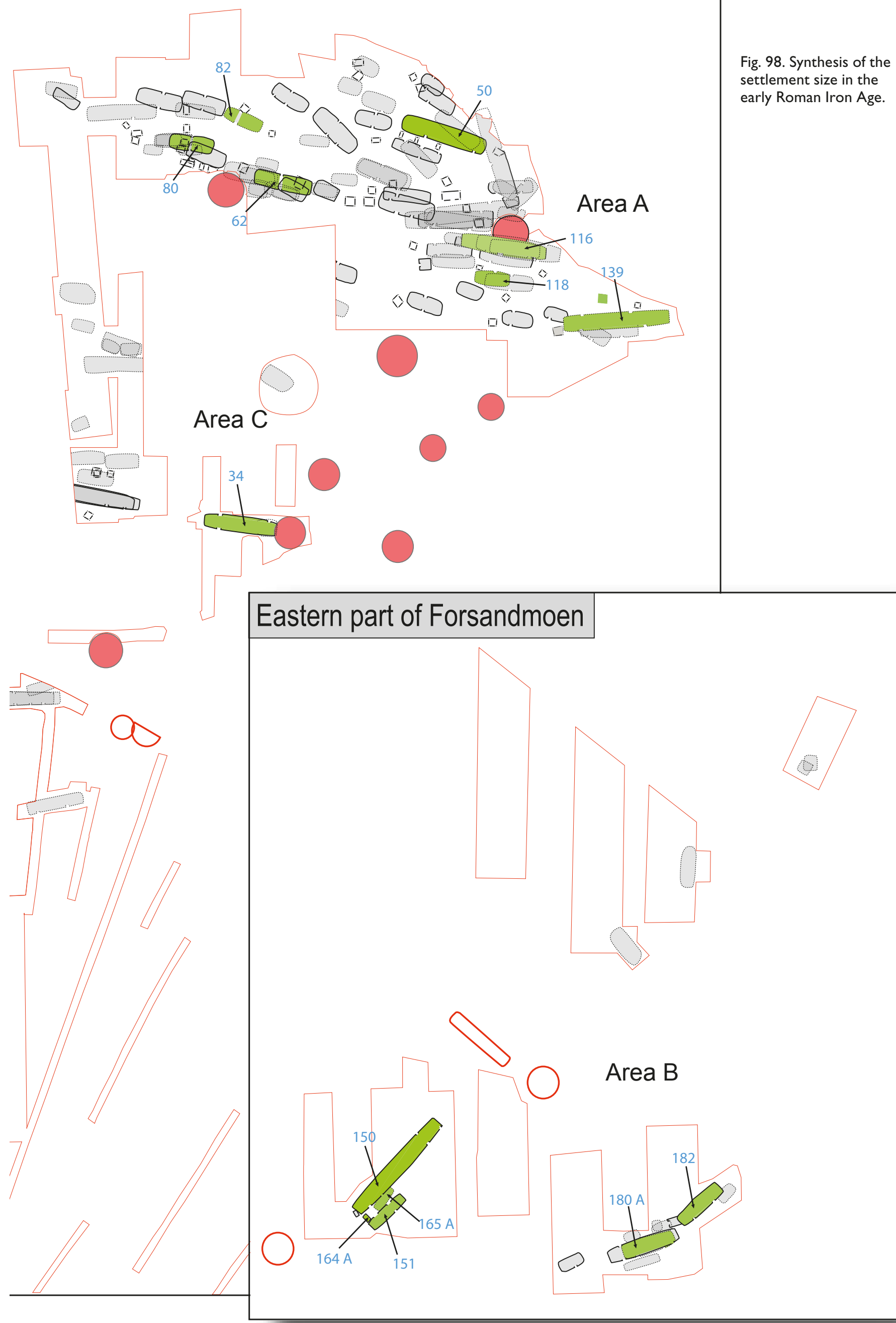


two heirs could continue to belong to the farm unit. However, a consequence of this interpretation is that each of the two co-localised households would have only been able to make use of a certain number of stalls in the byre (10-12), which is similar to a $20-25$ $\mathrm{m}$ long type 9 house and, based on the possible number of stalls, must have had the poorest resource base at Forsandmoen. The dating of house 155 indicates that the uselife of the house stretched into the late Roman Iron Age. Just north of house 155 is a small, undated workshop, 161, that can only belong to house 155 , since the three other workshops that are located north of house 155 have dates that match the dates of the main houses 156, 157 and 158, which are situated just south of house 155 .

A little farther east in Area E, houses 191 and 201 are located on the same place as houses 190 and 232 were situated in the early Pre-Roman Iron Age. House 191 (20 BC-AD 220) is also of the early type 3 , while house 201 is a small version of the new type 9 house. The dating of house 201 (AD 80-320) indicates that the house was built at the end of the early Roman Iron Age and was still inhabited in the first part of the late Roman Iron Age. House 194, with a similar date (AD 130-250) and located partly under a burial mound $10 \mathrm{~m}$ north of house 201, was probably a workshop for house 201 . Two more type 9 houses were also erected at the same place as house 201 during the late Roman Iron Age and the early Migration Period.

In Area $C$, another type 7 house, 34, was built approximately 50 m ESE of houses 39 and 41 from the PreRoman Iron Age. There was probably a smithy in that area during the last part of the Pre-Roman Iron Age and house 34 ( $30 \times 6.6 \mathrm{~m}, \mathrm{AD} 20-220)$ followed this activity in the early part of the late Roman Iron Age.

The total of six combined dwelling and byre houses in Areas $C$ and E probably entail a population of 14 farm units throughout the early Roman Iron Age.

In Area D, parts of a small house is dated to the period. This does not provide sufficient basis for claiming that the settlement continued in this area. However, the existence of the large combined house 220 in the limited excavated area makes it reasonable to assume that the settlement continued at this site in the late Roman Iron Age.

At the transition to the early Roman Iron Age, new buildings were again established in Area B. First, a fragmentary, preserved house, 165A, was built, consisting of at least five trestles and a double hearth. It has been dated to the early Roman Iron Age (AD 1-220). A type 7 house, 150, with a SW-NE orientation (which is an exceptional occurrence at Forsandmoen), partially overlaps with house 165A. Parallel to this, with the southern end in line with the southern end of house 150 , and at a distance of $5 \mathrm{~m}$, is a smaller workshop, 151. At the southern end of the space between the two houses, there is a storage house, $164 \mathrm{~A}$, with three trestles, so that the farmyard is closed to the south. There can be little doubt that this reflects a planned design of the yard. House 150 is a well-built, regularly organised house with two dwelling areas with separate entrance rooms at the south-western end, a large byre and/or storage area in the middle with space for 16-20 cattle in documented stall boxes and another large dwelling area with a hearth in the northern end (Løken 2001b). There was a smithy in the southern end of workshop 151 . The site seems to reflect a household with access to more resources than the other households in the early Roman Iron Age. Based on six ${ }^{14} \mathrm{C}$ samples, houses 150 and 151 have been dated from 25 BC-AD 75 to AD 215-335. Considering the dating of house $165 \mathrm{~A}$ to the early part of the early Roman Iron Age, it is likely that houses 150/151 were in use for most of the early Roman Iron Age and into the first part of the late Roman Iron Age.

In addition to this farm, a smaller type 9 house was established in the later part of the early Roman Iron Age (AD 60-230) approximately $130 \mathrm{~m}$ east of house 150 . House 182 is one of the smallest type 9 houses $(21.5 \times 6.3 \mathrm{~m})$ with room for only six cattle. Just west of this house, the large type 9 house 180B $(30.8 \times 6.5 \mathrm{~m}$, AD 80-320) was built around the transition from the early to the late Roman Iron Age, with room for maximum 22 cattle. In the same place, and partially using the same postholes, we also find house 180A (21.4 $\mathrm{x}$ $6.4 \mathrm{~m}$ ) of the same size and stall capacity as house 182 and which is dated to the latter part of the late Roman Iron Age and into the Migration Period (AD 240-410), based on a date from the central hearth of the house. Parallel to, and just $2 \mathrm{~m}$ south of house 180, a workshop was also dated to the late Roman Iron Age and early Migration Period (AD 240-440).

No stratigraphic observations allow us to determine whether houses $180 \mathrm{~A}$ or $180 \mathrm{~B}$ is a reconstruction of the previous house. The similarity between houses 182 and $180 \mathrm{~A}$ would indicate that they were established consecutively and that the large house $180 \mathrm{~B}$ is the result of an expansion of $180 \mathrm{~A}$ to the west with a new dwelling area. The dating seems to contradict this, but since all the postholes of house 180B have a dark, charcoal-rich filler, while those that only belong to house 180A lack such a charcoal mixture, this may indicate that house $180 \mathrm{~A}$ is the oldest of the two. 
Such an expansion of this farm may be due to the fact that the large farm unit 150/151 burnt down at around this time. Thus, it seems a large farmhouse was established in the south-eastern area in the early part of the early Roman Iron Age and fell into disuse in the first part of the late Roman Iron Age. In the last part of the early Roman Iron Age, a smaller farm unit with house 182 was established $130 \mathrm{~m}$ farther east. This house was then replaced by the corresponding large house 180A which, in the middle of the late Roman Iron Age, was converted and enlarged into house 180B.

\section{Summary of developments in the early Roman Iron Age}

Based on the assessments above, there appears to have been three farm units in Area A, three in Area $E$, two in Area $B$, one in Area $C$ and perhaps one in Area D - a total of at least nine farm units throughout the period. It can therefore seem that the settlement increased sharply, not least because it covered a much larger area, which provided greater opportunities for accommodating animals and humans. In addition, the number of households now appears to have been about the same in Area E as in Area A, which suggests that Area E later became the centre of the settlement.

The period is distinguished by a wide variety of houses with combined dwelling and byre functions. Four type 3 houses were built. These are the smallest of the combined houses in this period, but the largest of this type. The other type of combined house used during this period was type 7 . These were introduced with two relatively small houses at the end of the PreRoman Iron Age and, during this period, three such houses with lengths from $30-50 \mathrm{~m}$ were built. This type ends with two long houses in the next period. However, the period is characterised by the emergence of an entirely new type of house: type 9. With two 35-43 m longhouses and five fairly short houses (21-25 $\mathrm{m}$ ) the type appears to be fully developed from the beginning of the period. This type of house was to become almost universal as a combined dwelling and byre house for the rest of the settlement period. While in the Pre-Roman Iron Age, four-post storage houses can be found close to many of the type 3 houses, type 10 workshops appeared in the early Roman Iron Age as a new type of building in conjunction with three of the type 9 houses and house 150 (type 7). This combination of the dwelling and byre house with a workshop was to become the norm in the next periods.

The amount of charred grains from five houses from the early Roman Iron Age is only $25 \%$ of what was found from the late Pre-Roman Iron Age. However, it shows that there was a major change in which grains were grown and the relative difference between them in the material that has been preserved in the postholes of the houses. The modest amounts from the early Roman Iron Age was found in 2-15 different postholes in each individual house. This indicates that it has many origins so that, contrary to more unified deposits, it reflects what was actually grown over time. Wheat (Triticum) was now hardly grown and, of the two types of barley (Hordeum sp.) that were grown, we see that the share of hulled barley (Hordeum vulgare var. vulgare) has increased to $70 \%$, while in the previous period the distribution was $63 \%$ naked barley (Hordeum vulgare var. nudum) and only $37 \%$ hulled barley. However, the amount of charred grains from the two Roman periods is so small that the ratio between the two types of barley might be random. However, the most important change is that, of the entire variety of material, oat (Avena) now comprised almost $2 / 3$ of the grains and barley just $1 / 3$ (Fig. 7, Table 1). This suggests a radical change in agricultural activities, possibly also in terms of livestock, based on the now much larger combined dwelling and byre houses, which testify to more space for cattle stalls. In this context, we can also see that the new houses of types 7 and 9 represent another way to organise access and traffic in the houses, by replacing the shared entrance area for humans and animals in the middle of the long sides with entrances at each end for people and animals, respectively. In addition, some finds suggest that there had been an inner door between the dwelling area and the byre area. Some of the medium-sized type 9 houses also have a small dwelling area at the eastern end, which may indicate that some of the members of the households, perhaps with those of lower status, lived closer to the animals' entrance to the house. This, along with the special design and secluded location of the large farm 150/151 in relation to the buildings in the central area of the plain, may suggest that the society was developing towards greater social and economic inequalities, as grave finds in Rogaland also indicate (Slomann 1972).

With the transition to the early Roman Iron Age, the two type 7 houses from the late Pre-Roman Iron Age bear witness to a shift in the floor plan and consequently the construction of the houses, and the organisation of daily life in the large combined longhouses. In the early Roman Iron Age, eleven out of 15 dated houses are built as either: the new type 9 (seven), type 7 (three) or type 8 (one), while only four are built as type 3 (Table 55). Two of the type 9 houses, 139 and 155, had equally large 
dwelling areas at each end, such that the settlement had 17 households in total. Based on Table 52, we can calculate that the total area and the living space in the type 3 houses increased from $110 \mathrm{~m}^{2} / 50 \mathrm{~m}^{2}$ in the late PreRoman Iron Age to $127 \mathrm{~m}^{2} / 65 \mathrm{~m}^{2}$ in the early Roman Iron Age. At the same time, the total area / living space of the type 9 houses is $187 \mathrm{~m}^{2} / 85 \mathrm{~m}^{2}$, an increase of 50 $\%$ and $25 \%$ in total area and living space, respectively, compared to the contemporary type 3 houses. Also the type 7 houses 34 and 119, which are approximately the same size $\left(193 \mathrm{~m}^{2} / 105 \mathrm{~m}^{2}\right)$ as the contemporary type 9 houses, show that there was a need for a corresponding increase in the total area / living space (31 \% and $25 \%$ ) in relation to the type 7 houses in the late Pre-Roman Iron Age. In addition, house 150 is twice as large as houses 34 and 119 (total area / living space, $353 \mathrm{~m}^{2} / 240$ $\mathrm{m}^{2}$ ). This, in addition to the fact that the house has two dwelling areas at each end as well as a hall in the middle of the house, suggests an increased social differentiation at Forsandmoen from the beginning of the early Roman Iron Age.

This demonstrates a clear increase in the size of the house area and the introduction of a completely different concept underlying the physical framework and subsequently for economic and social conditions. The size of the byre indicates that the amount of winterfed cattle increased significantly in the new types of houses, but this also means that the number of people increased when the houses grew bigger. Or did people in a new environment, at a time of new, possibly Roman, influences, need more space for each person? In the following, I will consider the size of the population of the farms in the early Roman Iron Age based on an assumption of an area of $8 \mathrm{~m}^{2}$ per person in the dwelling area, and then I will perform the same evaluation based on $12.5 \mathrm{~m}^{2}$ per person.

The four type 3 houses, 62, 80, 82 and 123, could accommodate an average of eight adults and also had twelve stalls for cattle, based on the same calculating method as used in the previous period. However, this would mean that, on these farms, the ratio of people per cattle would be as low as 1.3 , while the other contemporary houses had an average of 1.8. I therefore choose to keep the same area standard for these type 3 houses as for the previous type 3 houses. This means that these farms had a smaller household of five people. But this also means that, for two of these farms, the byre area would accommodate too many cattle in relation to the number of people.

The three type 7 houses represent both the largest farm in the Roman Iron Age, house 150, and two smaller, equally large farms, houses 34 and 119. The dwelling area in house 150 could accommodate almost 30 people, but since the house has a hall located in the middle, this number is probably too high, other than on special occasions. Subtracting the size of the hall, which is equivalent to ten people, the rest of the dwelling area will still accommodate 20 people, which is twice as many as any other household in the early Roman Iron Age. The house could, based on the number of stall boxes, have had room for 20-28 cattle in the byre area. The two other type 7 houses could accommodate 12-14 people and 18 cattle.

Most houses are of type 9 and six of them (116, 139, 180A, 182, 191 and 201) are quite similar in size to the type 3 houses during this period and could therefore accommodate ten people and twelve cattle, while the last type 9 houses (155 and 139) are significantly larger and have equally large dwelling areas at each end of the building. In total, the dwelling areas in each house had space for 22 people and the byre areas in the middle could accommodate 20 cattle. This means that these houses were inhabited by two households, each of which, both in terms of people and cattle, was of an equal size to both the type 3 houses and the other type 9 houses during this period.

Altogether, 15 different large, combined dwelling and byre houses from the early Roman Iron Age have been investigated at Forsandmoen, resulting in a total of 17 households. It may be that not all of these were in use at the same time. Provided that the uselife of the houses was as argued in chapter 13 , about $50 \%$ of the houses may have been in use at the same time. The lack of more than one radiocarbon date for most of the houses makes it difficult to assess how many of them were in use in the early and late part of the period. Considering that there may have been four simultaneous farms and five households in the late Pre-Roman Iron Age, we can imagine that the number of farms increased during the period. As the next chapter shows, the increase continued in the late Roman Iron Age.

In some places, we can assume that buildings followed one another. In Area B, house 182 is replaced by house $180 \mathrm{~A}$, which in turn is converted to house $180 \mathrm{~B}$ at some point in the late Roman Iron Age. The farm consisting of houses 150, 151 and the storage house $164 \mathrm{~A}$, as shown by eight ${ }^{14} \mathrm{C}$ dates (cf. Table 2), was in use from the early $1^{\text {st }}$ century AD to well into the late Roman Iron Age. Together, the houses may have been inhabited by 30 people and 30-40 cattle. In Area E, the settlement of a three-phase farm with house 191 ends, while $30 \mathrm{~m}$ further north, house 201 continues in a 
four-phase building with a further two phases into the early Migration Period. Further west, houses 119 and 123 probably follow the two type 3 houses 19 and 21 from the late Pre-Roman Iron Age, and were probably in use at the same time since they continue into the late Roman Iron Age with houses 120 and 20. Concurrently with these, house 155 must also have been taken into use, since this plot is still used in three later phases until into the Migration Period. In Area E, therefore, there must have been four farms in use at the same time. The number of inhabitants on these farms can be estimated at $50-55$ people and they have space for 70 cattle.

In Area $\mathrm{C}$, a dating of house 34 indicates a uselife in the first part of the early Roman Iron Age, and it is consequently concurrent with the above-mentioned areas. The house could accommodate twelve people and 18 cattle.

The dates from houses 139 and 116 in Area A may indicate that house 139, which follows house 140 from around AD 1, fell out of use when house 116 was built on a previously unused area in the latter part of the early Roman Iron Age. Based on five datings, House 50, which is a little further north, may have been built at the beginning of the early Roman Iron Age and remained in use until well into the late Roman Iron Age. In the north-west of this area, houses 62,80 and 82 replaced each other in turn. The oldest is house 62 , from the first part of the early Roman Iron Age, while the other two have both been dated to the early Roman Iron Age and well into the late Roman Iron Age. The three houses 50, 62 and 116 had space for 40 people and 58 cattle.

If we summarise this, the settlement in the early Roman Iron Age may have consisted of ten farms, but with twelve households, which together had 125 people and 160 cattle. In this case, this implies that the society underwent extensive development at the time of the transition to the Roman Iron Age. The number of inhabited houses doubled, and the living space for each household increased from 60 to $100 \mathrm{~m}^{2}$. The number of people therefore tripled from the late Pre-Roman Iron Age, based on the same space requirement per person.

However, in chapter $16.1 \mathrm{I}$ argue that the required space per person in the dwelling area of the new types of houses (7, 8 and 9) in the Roman Iron Age and Migration Period, due to various changes in society, appears to have been $12.5 \mathrm{~m}^{2}$, somewhat larger than before. If so, the population at Forsandmoen may have been 100-105 people, while the number of winterfed animals remained stable at 160 . The ratio of 1:1.5 between people and animals was common in early modern times in Rogaland (Myhre 1983:155f), a ratio that also provides enough labour capacity for agriculture considering the time required for collection of winter fodder in outfield areas. Based on this calculation, the settlement would have tripled in size in from the late Pre-Roman Iron Age. This may not be so likely because too many houses must then be considered as having been used throughout the period.

An alternative and perhaps more likely way to look at the development of the settlement in the period may be that half of the recorded 17 households each belonged to roughly each half of the 150-175-year-long early Roman Iron Age. Two of the farms, houses 50 and 150, were however, in use throughout the entire Roman Iron Age, meaning that the settlement in the early Roman Iron Age included nine households at any given time, with a total of 70 people and 110 stalled animals, which seems likely on the basis of the changes that otherwise occurred over time.

An alternative calculation divides 60 people into eight households, meaning seven people per household. But this average figure conceals that the number of people in house types 3 and 9 was the same as in type 3 houses from the late Pre-Roman Iron Age, on average six people, while the average for types 7 and 8 houses was twelve people. This must therefore mean that the households in type 3 and 9 houses continued to be the size of a nuclear family, but with a higher requirement for space per household (13) of $77 \mathrm{~m}^{2}$. For types 7 and 8, the dwelling area for each of the four households is $146 \mathrm{~m}^{2}$. So, we get a division in the size of the farms, where one-third of the farms have a dwelling area that is almost twice as large as the others. The types 3 and 9 houses have an average of eleven cattle, which is the same as the type 3 houses in the late PreRoman Iron Age, while type 7 and 8 houses can now accommodate 20 cattle, up from 14 for similar houses in the late Pre-Roman Iron Age. Overall, it is clear that the transition to type 9 houses in the early Roman Iron Age does not imply any change in household size or amount of livestock for ordinary farms. However, to a greater extent than in the late Pre-Roman Iron Age, house types 7 and 8 represent a small proportion of farms where the household is so large that it may have been a form of extended family or with a number of inhabitants in a dependency relationship with the house's nuclear family. This probably also means that there was a new social differentiation within the society at Forsandmoen, even if this is not visible through the construction of burial mounds before the late Roman Iron Age. 
The establishment of the new house types 7, 8 and 9 also entails an important change in the daily life of the household. Entrances for the animals in one end and for people in the other, in contrast to the shared entrance at the centre of the house in the type 3 houses, indicates a new understanding of people in relation to animals and that many of the daily routines must have changed.

During this time, it is still the case that a household chose to move when a new house was to be built. At the same time, however, there are several places where new houses were built on or near the old ones. The trend is thus from a settlement that changes location to a more permanent plot for the individual farm. We will see how this becomes normal in the late Roman Iron Age.

At the transition to the Roman Iron Age, there was a major change in what was cultivated on the plain. From a situation in the Pre-Roman Iron Age, where the crops consist of $70 \%$ barley (Hordeum), around $20 \%$ wheat (Triticum) and just over $10 \%$ of a new type of grain for Forsandmoen - oat (Avena), we see that the main crop in the early Roman Iron Age is oat (62 \%), while the amount of barley is only $30 \%$ and wheat cultivation is almost absent. This distribution continues for the rest of the Roman Iron Age and Migration Period.

\section{Late Roman Iron Age AD 175-350}

In the late Roman Iron Age, the number of dated houses increased to 34 compared to 22 dated houses in the early Roman Iron Age. The most obvious change from the previous period is that the buildings in Area A were concentrated in the north-eastern corner of the area and a new hub of farms was established in the SW-corner of area E (Fig. 99).

On the farm unit comprising houses 29 and 50, it appears that house 50, which was established in the early Roman Iron Age (AD 120-330, 230-390), fell into disuse in the middle of the period. The four dates from centrally placed hearths in the adjacent workshop 29 (AD 70-340, 130-340, 240-430, 420-600) indicate that the house predominantly belonged to this period, but one of the dates may indicate continued use into the Migration Period. This unit is perhaps the most special of all farms at Forsandmoen. In the approximately $3 \mathrm{~m}$ wide courtyard between the two buildings, there are three four-post storage houses, each located just west of the three doors facing house 50 . This demonstrates that the farm was built to facilitate good communication lines between the buildings and that sufficient storage space was easily accessible and protected.
To the south and partly below a later burial mound a new, smaller type 9 house, 135 (AD 230-430, 240-400) was built where house 116 had been located in the previous period. Workshop 130 (AD 240-400) also succeeds house 118 from the previous period on the southern side of houses 116 and 135. Two additional type 9 houses, 131 and 141, were built in the area around house 135 during the Migration Period. A fourphase farm seems to have been continuously located at this site through the end of the early Roman Iron Age until the end of the Migration Period.

Just west of the above-mentioned burial mound, there was also a farm unit with house 107 (AD 130-230, 130380) and workshop 111 (AD 130-390) in the first part of the late Roman Iron Age. House 107 has a special house plan, with two rooms in the eastern end, each with a dated hearth, separated by an entrance room, while the byre area was located in the western end. In the narrow 2-3 m space between this house and workshop 111, there was a worn track from people and animals along the house towards the door at the western end. Later in the late Roman Iron Age, house 105 was built (AD $240-400,400-600)$ partially overlapping the western end of house 107. This is one of the largest type 9 houses with a dwelling area at each end and a shared byre area in the middle. Workshop 145 (AD 210-410) is located just north of the eastern part of the house. The twophase house 106A and 106B was built in the Migration Period, and in the same area as house 107 , indicating a farm unit continuously throughout the late Roman Iron Age and Migration Period.

Another large type 9 house in Area A has been dated to the late Roman Iron Age. House 144 (AD 130-380) has an almost $\mathrm{N}-\mathrm{S}$ orientation, which is unique for Forsandmoen, and was well-hidden behind the rocky outcrop to the south, Odda. Like house 105, this house also had a dwelling area at each end around a byre area. The roof-bearing trestles in the dwelling area at the southern end, which have been partially replaced twice, indicate a long uselife. The same is true for several repaired and replaced entrances to the byre area. The southern end of house 144 overlaps with the eastern end of house 105 and, based on dating, house 144 must be the earliest and coexisting with house 107. Furthermore, the western longitudinal wall of house 144 is right against the gable of house 50. As described above, house 50 must have been abandoned in the middle of the late Roman Iron Age. House 144 is probably a direct successor to this house and does not have an adjacent workshop along its western side. 
This may explain why house 29 continued to be used after house 50 fell into disuse. From when house 60 was established in Bronze Age Period IV, house 144 is, via houses $55 \mathrm{~A}, 54$ and 50 - all situated nearby the foot of the mountain in the north-eastern corner of Area A - apparently the last link in a farm's gradual relocation within a $70 \times 30 \mathrm{~m}$ area.

In the southernmost part of Area $C$, about 30 m west of the area where house 34 was situated in the early Roman Iron Age, and approximately $170 \mathrm{~m}$ south-west of houses 105 and 107, the new type 7 house, 24 (AD 260-540), was built in the last part of the late Roman Iron Age. The house's western part could not be investigated, but from the curvature of the wall, the house must have been about $40 \mathrm{~m}$ long. This house differs from the other type 7 houses because the two dwelling areas were located in the eastern end and probably a byre area in the uncovered western part. The four-post house 42 found west of an entrance into the southern longitudinal wall of the house may have been part of the farm. Despite the dating, the lack of sherds from bucket-shaped vessels may indicate that the house was not used during the Migration Period. This house, together with the houses from the Pre-Roman Iron Age and the type 7 house 34 from early Roman Iron Age, makes it clear that the area must be regarded as a long-used farm area.

In the westernmost part of Area E house 120 (AD 130-AD 240) is followed by house $119.5 \mathrm{~m}$ south of the western end of house 120 and parallel to this, house 118 (AD 1-220) was built at some point in the early Roman Iron Age. The manner in which the two houses are situated in relation to each other corresponds to the relationship between houses 150 and 151. This, as well as the dates, makes it most likely that house 118 belongs together with house 120 as a farm unit, rather than to house $119.20 \mathrm{~m}$ to the south of house 120 , a variant of a type 9 house (20; AD 210-400) followed house 123 from the previous period.

Around $20 \mathrm{~m}$ farther south, the farm from the previous period, consisting of the type 9 house 155 and workshop 161, is followed by the smaller type 9 house 156 (AD 130-390), also this with workshop 159A (AD 120-390) on the northern side where the western part of house 155 previously stood. During the construction of this farm unit, both houses moved $10 \mathrm{~m}$ to the south, within the same location. The two workshops have their doors on the southern longitudinal wall, facing the north-western entrance of the respective main houses. This illustrates the two houses as a functional unit in each phase. The large farmhouse was then successfully replaced by two new buildings, 157 and 158 during the Migration Period, and there were also two more workshops, houses $159 \mathrm{~B}$ and 160 , to the north of them.

Within a small area of $60 \times 30 \mathrm{~m}$, during a period from the late part of the early Roman Iron Age and until the early Migration Period, there were buildings continuously through four phases of houses. A certain number of posts were changed in all phases, emphasising the long duration of the houses on this farm.

To the south-east of this farm is a cluster of eight longhouses, six of which are large houses with dwelling and byre areas, while two are smaller workshops. Houses 12 and 13 are the latest versions of type 3 . Both are dated to the late Roman Iron Age with almost identical dates (AD 210-430, 220-390), but since they partially overlap, they must be successive. Due to the fact that house 12 also overlaps with house 2, which dates back to the late Roman Iron Age and Migration Period, the uselife of houses 12 and 13 must be mostly placed in the late Roman Iron Age, but before house 2 was built sometime in the $4^{\text {th }}$ century AD.

Only $10 \mathrm{~m}$ south of houses 12 and 13 is the combined dwelling and byre house $10 \mathrm{~A}$ with a slightly different type 9 structure. This has also been dated to the late Roman Iron Age (AD 90-250, 130-390) and must have been used simultaneously with one of these houses. Workshop 16A, approximately $15 \mathrm{~m}$ south of house $10 \mathrm{~A}$, has also been dated to the late Roman Iron Age (AD 240-420). The house has two entrances to the north and thus faces house 10A. Since the three intermediate large main houses $11 \mathrm{~A}, 11 \mathrm{~B}$ and 17 were dated to the Migration Period, house 16A must have been associated with house 10A. Together they form the first phase of a farm unit on this site, consisting of five phases ending in the Merovingian Period.

The western end of house 10A overlaps with the eastern part of the large house 3. Four dates from central hearths or ember pits in house 10A, two from the late Roman Iron Age and two from the Migration Period / early Merovingian Period, as well as one date to the late Roman Iron Age from a hearth stratigraphically earlier than a roof-bearing posthole from house 3 , house $10 \mathrm{~A}$ must have fallen into disuse in the early AD 300s, and then replaced with house 17.

Houses 1, 2 and 3 are located on the westernmost side of the house cluster. House 1 is a workshop with two entrances in the southern longitudinal wall and must therefore be seen in relation to the dwelling and byre house 2 , which has an entrance at the north-western 


\section{Forsandmoen, Forsand municipality Map of settlement area}

House feature with preserved wall remains House feature without wall remains Late Roman Iron Age First part of Late Roman Iron Age Gravemound / cairn Excavated gravemound / cairn

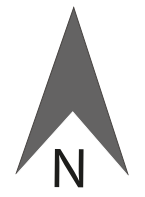

TGB/TL 2009/2014
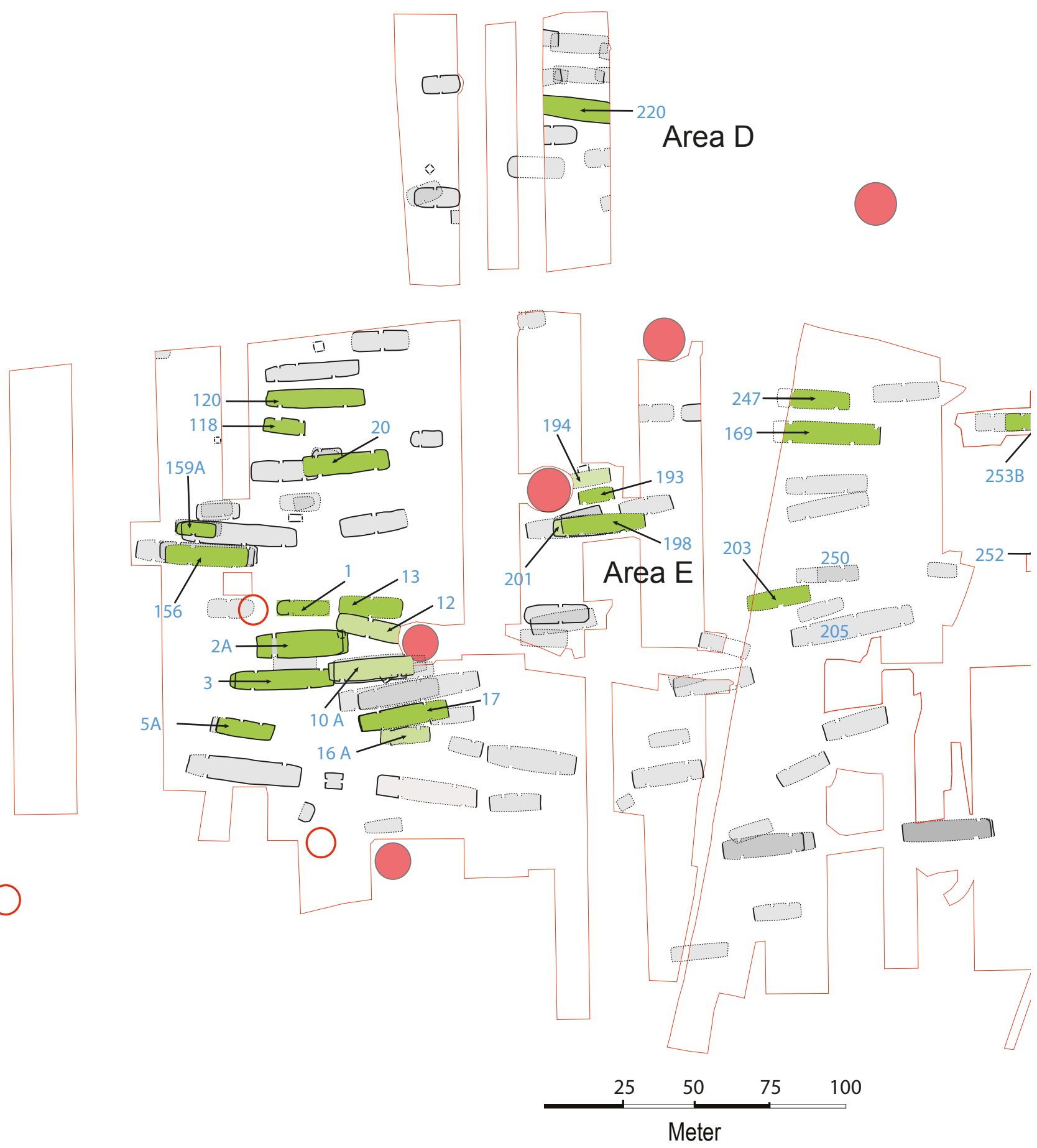


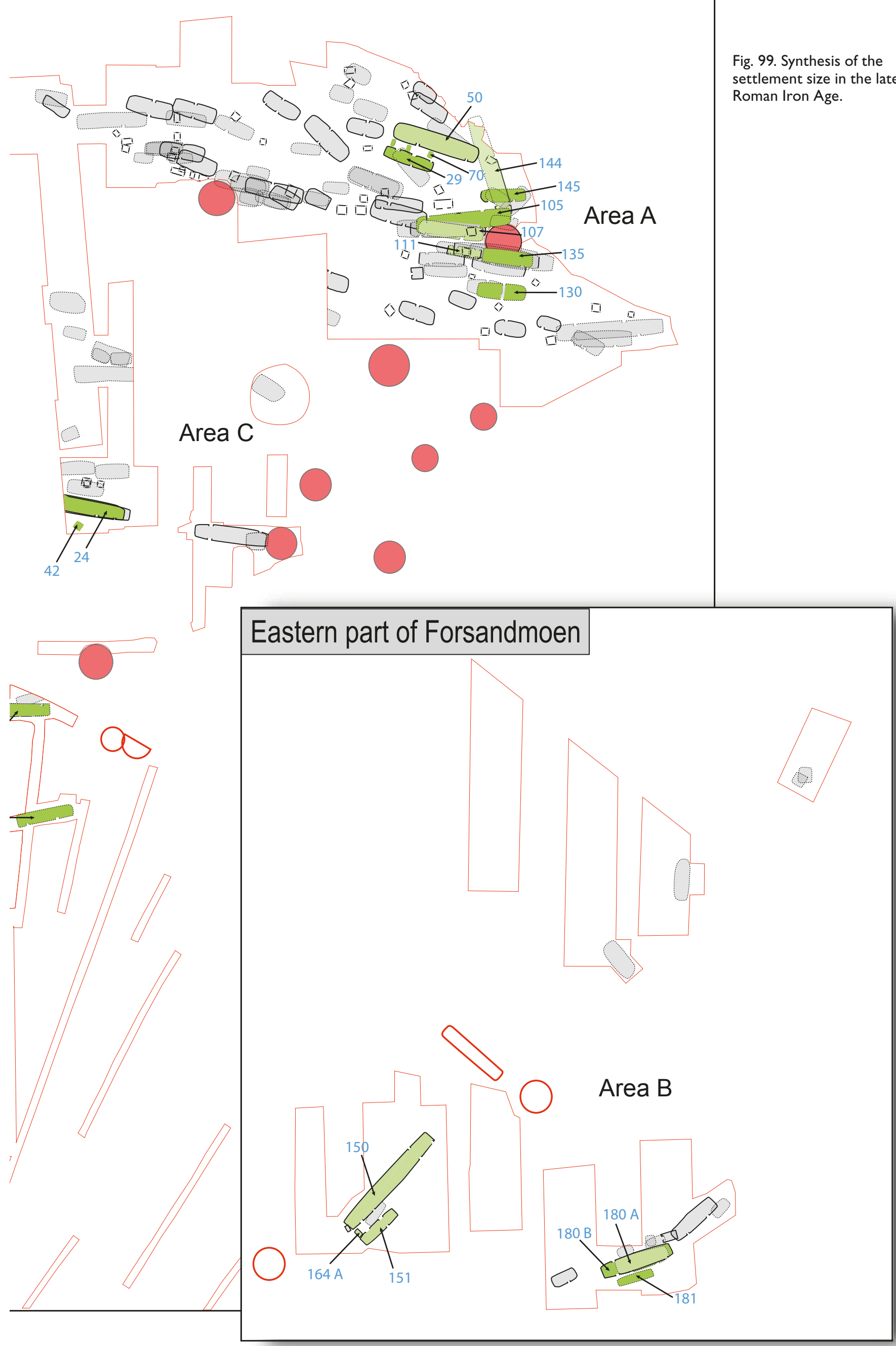


end of the house. The dating of the house's central hearth (AD 260-540) covers the last part of the late Roman Iron Age and the Migration Period.

House 2A, with its curved longitudinal walls, massive width $-9 \mathrm{~m}$ at the centre - and complicatedly constructed gable walls, is the most special house from the late Roman Iron Age and the Migration Period at Forsandmoen (type 9.2.3). The house was remodelled and shortened by $1.7 \mathrm{~m}$ at the eastern end (house 2B). The two central hearths in the house have been dated to the late Roman Iron Age and early Merovingian Period, respectively AD 130-390 and 560-660), while an ember pit has been dated to the Migration Period (AD $410-540)$. Seen in the context of the dates of the associated house 1 AD 260-540), it is reasonable to assume that house 2 and thereby a farm unit was established at the end of the Roman Iron Age, around AD 300.

House 3 is a typical type 9 house, with a dwelling area in the west, a byre and/ or storage area in the middle and a small dwelling area with a hearth in the eastern end. The ten dates and some replaced posts indicate a long life. Just as for house 2, the datings testify to an establishment at the end of the late Roman Iron Age (central hearths: AD 240-410 and 250-430) and that it was in use well into the Merovingian Period (ember pit: AD 410-570, central hearth: AD 440-660). The date from a hearth (AD 180-430), which is intersected by a posthole from a roof-bearing post, gives an older limit for when the house was built. The dating of the cooking pit directly north and south of the house (AD 430-610 and 390-560) emphasises that the Migration Period was the house's main period.

Located $10 \mathrm{~m}$ south of the western end of house 3 , we find house phases $5 \mathrm{~A}-\mathrm{C}$. In all its phases, the entrances are located in the north long wall. This suggests that houses 3 and 5 formed a farm unit, although house 6 is located closer - just $7 \mathrm{~m}$ south of house 5 . The three phases of house 5 have been respectively dated to the late Roman Iron Age, the Migration Period and the Merovingian Period (260-440, 420-600 and 530-760). The conclusion must be that the farm, consisting of houses 3 and 5, was in use for more than 250 years, despite the fact that house 3 was not substantially rebuilt.

At a distance of 50-80 m ENE of the farm with houses 1 and 2, there were two houses (191 and 201) from the early Roman Iron Age. Based on the dates, house 201 was also probably used in the early days of the late Roman Iron Age, but was then replaced by the larger house 198 (AD 250-430). This and the subsequent house 200 in the Migration Period used some of the same postholes as house 201. Based on the dates, house 200 was contemporaneous with 198 (AD 260430), but finds of sherds from a bucket-shaped vessel in the westernmost part, which was not overlapped by the other two older houses, shows that house 200 must have been used during the Migration Period. The postholes indicate that a large number of roofbearing posts were replaced. All three houses had the same orientation and represent a continuous renewal of an ever-growing farmhouse for people and cattle. Workshop 194 was likely replaced in the late Roman Iron Age by the somewhat smaller, undated house 193, so that the farm unit throughout this time consisted of two parallel houses.

Another $50 \mathrm{~m}$ towards the ENE, we can observe that a farm with type 9 house 169 (AD 90-250) was established in the transition between the early and late Roman Iron Age, based on the dates. Workshop 247 (AD 250-420), dated to the late Roman Iron Age, is located parallel to and only $6 \mathrm{~m}$ north of house 169 . A cooking pit in a group of cooking pits, located just south of the south-west entrance to house 169, was also dated to the late Roman Iron Age (AD 250-375). In this house a bottom sherd from a pointed-bottom green cup (type Straume 1987: tafel 7) was found, which dates back to AD 350-450. In the same pit, five sherds from a decorated bucket-shaped vessel were found, thereby confirming the date of the glass sherd to the transition from the late Roman Iron Age to the Migration Period. This farm must therefore have been used through most of the late Roman Iron Age and well into the first part of the Migration Period.

A partially destroyed workshop 203 (AD 250-430), located $50 \mathrm{~m}$ south of house 169 , has also been dated to the late Roman Iron Age. It is located north-west of the large type 9 house 205, but since this workshop is not located parallel to the main house 205 , such as is normal for a workshop, its relationship to house 205 is uncertain. House 205 has been dated with certainty to the Migration Period. The same goes for house 250, a workshop 10-12 m north and parallel to house 205, where four central hearths have been dated to the Migration Period and one to the late Roman Iron Age. This could mean that house 203 has no connection with the farms 205 and 250, but two dates from cooking pits to the late Roman Iron Age - one of which was located in a concentration south of the SW entrance to house 205 and another south-west of workshop 250 - indicate that this site has its origins in the last part of the late Roman Iron Age, and that house 203 may therefore belong to the main house 205 in an early phase. 
A two-phase type 9 house, 253A-B, was found in the easternmost part of Area E, approximately 35 m east of house 169. The two phases represent a rebuilding of the oldest, smallest house 253B (AD 220-405) in the same place, but where the later phase 253A (AD 395 545) was shifted to the west. Unfortunately, the 2007 investigations did not have the resources to investigate the area either to the north, where a road lay, or to the south. It is therefore unclear whether this farm had a parallel workshop nearby.

However, due to findings in trial trenches farther east and south, workshop 252 dated to the late Roman Iron Age (AD 250-420) was found $40 \mathrm{~m}$ south of house 253. This distance is much greater than otherwise documented for the houses in a farm unit at Forsandmoen. The entrances to this house are both on the southern side, so they do not open towards house 253. This could indicate that there was a type 9 house on the southern side. However, the investigation trenches to the north and south of this house did not reveal other building remains, so there is therefore a possibility that the two contemporaneous houses did form a unit. Based on the dates, the site was used during the last part of the late Roman Iron Age and the first part of the Migration Period.

In Area D, the more than $30 \mathrm{~m}$ long house 220 (AD 240-430) has been dated to the late Roman Iron Age / early Migration Period. Only the middle $20 \mathrm{~m}$ of the house has been excavated and shows that, compared to type 9, it had an unusual house plan with two rooms, each with its own centrally located round hearths in the eastern part. The entrances to the house must have been in areas that have not been uncovered farther to the east. To the west of the rooms with hearths, there was an additional room, after which an internal door gave access to a presumed byre area in the eastern part. No other house that could have been the workshop for this farm has been uncovered in the limited excavated areas of Area D.

In Area B, house $180 \mathrm{~A}$ was probably used during the first part of the late Roman Iron Age, after which the house was rebuilt and extended to the south-west to house 180B (see section on early Roman Iron Age). Parallel to and just south of house 180, the narrow building 181 (AD 240-440) was built in the late Roman Iron Age. This was probably a workshop different to all others on the plain. The dates and finds of bucketshaped vessels suggest that both houses were used in the early Migration Period.

The large farm with houses 150 and 151 continued to be in use during the first part of the late Roman Iron Age.

\section{Summary of developments in the late Roman Iron Age}

Based on the assessments above, there appear to have been three densely situated farm units in Area A, ten in Area E, two in Area B, one in Area C and one in Area $\mathrm{D}$; this makes a total of at least 16 farm units during the period. It can therefore seem that the settlement has again increased. Two of the houses have similar space for a household in each end, indicating that the number of households in the settlement increased even more than the number of farm units. Until the early Roman Iron Age, the majority of the houses were built in Area A. This period represents a change in this pattern since ten farm units are located in Area $E$ and only three in Area A. Seven of the E-W oriented farms in Area $\mathrm{E}$ were densely located in the western part of Area E, which would indicate a nucleated hamlet with some sort of shared fields around the farm houses. The other three farm units in Area A were more dispersed, in an E-W oriented row, and together with four other farm units in Areas B, C and D, they give the impression of separated farms, each surrounded by its fields. Therefore, there were possibly two ways to organise farming and daily life in this period. The seven nucleated farms were probably more dependant on cooperation in their agricultural enterprises than the more dispersed farms.

The buildings in Area A are, in the last part of the late Roman Iron Age, concentrated in a small area towards the mountain in the north. The two E-W oriented farms are located close together, each consisting of a main house for people and cattle as well as an adjacentworkshop. The easternmost of these was established in the early Roman Iron Age, while the westernmost was established during this period. Both were then rehabilitated with new houses until the end of the Migration Period. There is a third farm with a long history just north of these two. This farm fell into disuse in the early part of the period. It therefore seems that the settlement in this area was reduced from three to two farms during the late Roman Iron Age. At the same time, Area $\mathrm{C}$ continued to have one household during part of the period.

The development in Area E was completely different. While there were no more than five households at any given time in the early Roman Iron Age, this seems to increase to ten households in the late Roman Iron Age. In the area farthest to the south-west, the main houses 10A and 12 appear to have been established in previously unused land areas. During the late Roman Iron Age, house 12 was replaced by house 13, while 
house $10 \mathrm{~A}$ was replaced by house 17 , at the same time as houses 2 and 3 were erected west of and barely overlapping with the area where house $10 \mathrm{~A}$ stood previously. Together with the two workshops 1 and 5, they formed, just as in Area A, a correspondingly dense settlement consisting of two large type 9 main houses and a smaller type 3 house. At a distance of 25-70 m north-west of this cluster, the three main houses 156, 20 and 120, as well as their associated workshops 159A and 118, continued on the same places as those of houses 155, 123 and 119 in the early Roman Iron Age. $80 \mathrm{~m}$ north-east of the dense settlement with houses 2, 3 and 13, the settlement continues with house 201 from the early Roman Iron Age into the late Roman Iron Age and is converted into house 198. In addition, in the eastern part of Area E, two separate settlement sites were established with houses 169 and 253B, both with an adjacent workshop. The three farmhouses 13, 20 and 120 were probably vacated during this period while the other seven farmhouses, whether they were rebuilt or replaced by a new house, continue on the same place into the Migration period.

These ten farms are spread within an area of $300 \mathrm{~m}$ $\mathrm{E}-\mathrm{W}$ and $150 \mathrm{~m} \mathrm{~N}-\mathrm{S}$. While the seven farms in the westernmost part of Area $\mathrm{E}$ are located close together, the three easternmost are about $50 \mathrm{~m}$ to the nearest farm. The farms in Areas C and D, houses 24 and 220, were also quite a distance away from other farms. All are situated in such a way that there are no other farms in one or more directions from this populated area, giving people access to nearby fields directly from the farmhouses.

It therefore appears that, in the late Roman Iron Age, a more spread-out settlement structure developed, with at least a few fields close to each individual farm. However, in two places, there were 2-3 and seven farms so close together that the inhabitants must have cooperated. Depending on which traces of settlement may have existed in the relatively large areas that have not been investigated between Area A and Area E, it appears that, in the central part of Forsandmoen in the late Roman Iron Age, a total of 14 farm units were established within an area of approximately 600 $\mathrm{m}$ SW-SE x 250-300 m NW-SE. In addition, there was a farm in Area B. Ten of these farms must have been inhabited at the same time during the last part of the period, since the settlement continues into the Migration Period at these locations. Only settlement areas where houses 12/13, 20, 24, 120 and 220 were previously found are not in use during the Migration Period. These may have been moved, since ten new farms were later established in the south-eastern part of Area E during the Migration Period.

There are 21 combined dwelling and byre houses that have been dated to the late Roman Iron Age, which means we can assume that, within this 175-200-year period, the settlement consisted of 10-11 farms on average. Since two of the units consisted of the largest type 9 house with equally large dwelling areas at each end and a shared byre in the middle, there were 12-13 households simultaneously at Forsandmoen. Twelve of the combined dwelling and byre houses also had a smaller ancillary house located parallel to the main house at a distance of 4-10 m. These 22 households, based on a space requirement per person of $12.5 \mathrm{~m}^{2}$ in the dwelling area and a $1 \mathrm{~m}$ width for each cattle in the byre area, may have provided space for almost 200 people and around 300 cattle. In the late Roman Iron Age, we can therefore envisage a society that consisted of around twelve households throughout the period, with just under 100 people and 160 stalled cattle. Compared to the early Roman Iron Age, the number of households did not increase much, while the number of people and especially the number of stall boxes indicates that cattle husbandry gained a greater importance in the late Roman Iron Age. The ratio between the number of cattle and the number of people rose from 1.3 in the early Roman Iron Age to 1.6 in the late Roman Iron Age. This ratio varies from house to house, with two exceptions (2.6 and 3.1), between 1 and 2 which is in line with common agricultural practice in western Norway in the 1500s and 1600s. The dwelling area provides on average space for nine people, compared to seven in the early Roman Iron Age. With the exception of house 150, which had room for 20 people with its large hall in the middle of the house, the number of inhabitants varies between eight and twelve, meaning that most farms had a household that was larger than a nuclear family.

In the late Roman Iron Age, the use of type 3 houses disappears from the settlement at Forsandmoen. This type was in use for a total of 1800 years, from about $1400 \mathrm{BC}$ to AD 400. The long uselife of this house type demonstrates that the concept of opposed entrances in the middle of the long side of the house, which distinguished between the dwelling area and the byre area, was important for an agricultural community on a plain on the arm of a fjord, where the possibility of daily interaction with neighbours was modest and where the use of metal was limited for the most part, and so the community was bound by tradition. Table 55 shows a summary of important parameters for the 
type 3 houses in the different periods. In total, there are 43 houses that are included in the table, which shows the average for the houses during each period. We see that there is great stability in terms of both the size of the dwelling area and the number of cattle through the Bronze Age and early Pre-Roman Iron Age, if we ignore the one house in period I. The change comes in the late Pre-Roman Iron Age and Roman Iron Age, where the dwelling area increases to $54 \mathrm{~m}^{2}$, compared with $38 \mathrm{~m}^{2}$ in the previous three periods. This increases the number of cattle to twelve in the late Pre-Roman Iron Age, compared to eight previously. The increase coincides in time with the adoption of iron, which gave people better opportunities than before to obtain winter fodder in the late Pre-Roman Iron Age. The houses of the last three periods accommodate seven people and twelve cattle each, and this is comparable to the type 9 houses from the early Roman Iron Age, where the byre had the same number of stalls. The difference is that the requirement for space for people becomes greater when changing the organisation of daily life by separating the area for people from the area for animals. This must be linked to greater mobility and more impulses from the outside world, probably because of the expansion of the Roman Empire to the north, as can be seen by all the Roman imports.

The new type 9 houses are most frequently used in the Roman Iron Age and Migration Period. In fact, people built more houses (47, but with room for 54 households) of this type in the last 600 years of the settlement period than of type 3 , with 43 houses, in the first 1,400 years. Table 55 shows that through the early and late Roman Iron Age and Migration Period, both the dwelling area and the number of stalls for cattle increase while the ratio between cattle and humans remains stable at around 1.7 cattle per person. This means that, in the Migration Period, $50 \%$ more people had twice as much space in the dwelling area of the type 9 houses as the space people had available in the Roman Iron Age type 3 houses. The increase in the dwelling area therefore probably means that the average population in this type of house rose from seven to nine residents. This means that while type 3 and type 9 houses in the early Roman Iron Age had roughly the same space for people and stalled cattle, type 9 houses in the late Roman Iron Age and especially in the Migration Period are markedly larger than the Roman Iron Age type 3 houses.

Turning now to the last new types of houses (types 7 and 8), which with two exceptions only exist in the Roman Iron Age and Migration Period, Table 55 shows that these types of houses, on average, in terms of the size of the dwelling area and thereby also the number of people, as well as space for stalled cattle, represent the same type of economy as type 9 houses. Only the large house 150, with room for double the number of people as well as cattle, stands out from other houses in the early Roman Iron Age. It is of course important as an example of social differentiation. The large late Roman Iron Age and Migration Period farms (houses 1-3) testify that this continued during these periods. The modest finds from funerary contexts at Forsandmoen, however, suggests that this was not a society that was able to accumulate as much wealth as elsewhere in Rogaland.

The three new types of houses show that, from around AD 1, the inhabitants of Forsandmoen were in a situation where they were willing to experiment with how to shape their environment with regard to both the physical environment and the houses, as well as social and economic aspects such as cattle husbandry and organising space. It is probably not so likely that the two types of houses at Forsand arose on their own in the small community there. However, we can observe that they did not come as impulses from Jutland, from where we usually envisage that the people of southwest Norway drew their impulses, because houses of this type did not exist in Jutland before the late Merovingian Period and Viking Period. As shown in chapters 10 and 11, there are well documented examples of both types of houses from the beginning of the Roman Iron Age in several places in Eastern Norway, as well as in Mälardalen and Götaland in Sweden, but not in Jutland. One should probably just note that these new types of houses originate from one or more places within the Norwegian-Swedish coniferous forest belt and not the southern Scandinavian deciduous forest belt.

The limited charred grain material from four different houses from the late Roman Iron Age confirms that the changes in which cereals were cultivated - which occurred from the Pre-Roman Iron Age to the early Roman Iron Age (Fig. 7, Table 1) - represent a permanent agricultural transformation. Approximately two-thirds of the grains are from oat (Avena); of the barley grains (Hordeum sp.), about $75 \%$ are hulled barley (Hordeum vulgare var. vulgare). The same distribution between barley and oat continued into the Migration Period, but then only hulled barley was grown by that time.

This change in agriculture is probably due to several factors. During the Pre-Roman Iron Age, the climate became somewhat cooler, and there was an increase in 
precipitation. In response to this climate change, we see that oat (Avena) was cultivated to a certain extent (12 $\%)$ for the first time. At the same time, the proportion of wheat (Triticum) that was cultivated was reduced by half from the Late Bronze Age and hulled barely (Hordeum vulgare var. vulgare) increased compared to naked barely (Hordeum vulgare var. nudum). As shown above, this trend continues to an even greater extent in the Roman Iron Age and Migration Period. Oat and hulled barley were preferred because these species tolerate this climate better than wheat and naked barley. Another advantage is that oat can be used to make oat bread, which can be stored for long periods of time and thus provides food security. We also know that hulled barley was suitable for making beer, which was an important ingredient in Iron Age society.

\subsection{The Migration Period (AD 350-560/570)}

\section{The Migration Period}

A total of 51 different buildings were used during the Migration Period, which implies a clear expansion of the settlement from 36 houses in the late Roman Iron Age. Ten of these houses (1, 2, 3, 5, 17, 169, 180, 181, 247 and 253) were built at the end of the late Roman Iron Age, but also have dates and/or finds that demonstrate use during the Migration Period. In addition, three of these, houses 2, 3 and 5, have dates from central hearths that may indicate continued use in the Early Merovingian Period.

Fig. 100 shows that the settlement continues in most places where a farm was established in the late Roman Iron Age. The settlements comprising houses 13, 20 and 120 from the late Roman Iron Age in Area E, as well as houses 220 and 24 in Areas D and C, respectively, disappear approximately at the turn to the Migration Period. But at the same time, the settlement was expanded with eleven new farm units in Area E, namely the dwelling and byre houses $6,14,172,174$, 176, 208, 35, 207, 205 and 248, and also house 26 in Area $\mathrm{C}$, so that, including Area A and Area B, there are buildings on 20 different farms during the Migration Period, versus 15 in the late Roman Iron Age. Ten of them have either a multi-phase building or two separate buildings on the same or almost the same place and were likely used throughout the period.

In Area A, house 105 is followed by the converted two-phase house 106A and B (AD 430-540 and 410570). A workshop, 32A (AD 260-540) has been found north-west of the main house. Although this house is situated differently compared to other workshops, it must have been part of the farm together with the main houses 105-107, since there are no other main houses to which it may have belonged. There are similar situations with houses 206 and 207, which are situated in relation to each other in approximately the same manner, and the same probably also goes for house 203 relative to house 205 (see late Roman Iron Age). About $6 \mathrm{~m}$ south of house 106 there was a parallel workshop, 108 (AD 390-540). Its two entrances in the northern longitudinal wall show that house 108 was facing house 106. Directly to the west of house 108 was a smelting pit with slag, in the corner of a four-post building, house 30 . The smelting pit has been dated to the late Roman Iron Age / Migration Period (AD 240-540) and most likely belonged to the farm with houses 105-107, established in the late Roman Iron Age. House 112 (type 17) is also situated just south of workshop 108. This is one of three such houses found on the plain. The dates of the two other houses (AD $260-540$ and 340-540), as well as the area in which house 112 is located, suggest that this house was part of the farm unit with houses 105-107 as the core of the site.

In the Migration Period, there were two other main houses located just east of this farm, 132 (AD 340-540) and 141 (AD 420-540). No workshop can be linked to these two houses. This area was also home to house 116 from the early Roman Iron Age and house 135 from the late Roman Iron Age. The two four-phase farms were so close together that it is difficult to determine how they were related to each other. It is unlikely that houses 106 and 141 were contemporaneous. However, regardless of how we interpret the order of houses in this delimited area, there would have been two inhabited farm units throughout most of this period, as was also the case in the late Roman Iron Age.

As shown in Fig. 100, houses 116, 135 and 141 are partially covered by a burial mound. They must therefore be earlier than the end of the Migration Period, and may have been built by the few residents who lived on the plain during the Merovingian Period (see below, chapter 16.7).

If we look at Area $E$, the most significant change from the late Roman Iron Age is that, in the south-eastern corner of the settlement from the late Roman Iron Age, there are six new farms, five of which are a main house and an associated workshop, while the last building consists only of the main house. The two main houses 35A-B (AD 410-560 and 440-615) and 208A-B (AD $400-560$ and 435-610) were rebuilt through a decrease/ 
increase of the length at one end of the house, house 176 (AD 250-530) was repaired with two new sets of posts in the western dwelling area, while workshop 250A-B ( 5 dates between AD 250-425 and 430-620), associated with the main house 205 ( 2 dates to AD 420-540), has been moved westwards at the same place. The main house 205 was $43 \mathrm{~m}$ long and of the type that has an equally large dwelling area at each end, thus representing two households. Four of these six new farms probably had such a long uselife that they were likely in use for a large part of the period. The last two of the new farms, houses 171/174 (AD 340-540 and 430-640) and 206/207 (AD 380-540 and 540-605) are both dated to the Migration Period. The dates of five of these six farms indicate that they were in use in the $6^{\text {th }}$ century $\mathrm{AD}$, while house 176 probably belongs to the end of late Roman Iron Age and Migration Period.

In addition, another three new main houses, 6, 14 and 172 , were established in the south-western corner of Area E. They are located next to each other, almost towards the edge down towards Fossanåna and where there is access to the shortest route to the plain from the sea. The type 17 house 18 (AD 260-540) was situated between houses 6 and 14. Both of the large main houses are unusually wide $(8 \mathrm{~m})$ and house 6 has a unique construction for Forsandmoen, with the longitudinal walls constructed of stout posts that stand approximately $3 \mathrm{~m}$ apart, right outside the roof-bearing posts, such that the roof and wall posts, together with the struts in each trestle would form a stable frame. The house was rebuilt when the posts were replaced. Based on the dates (AD 260-540 and AD 560-770), house 6 likely had a uselife from the early Migration Period and well into the Merovingian Period. The shape of the house, its construction, lack of entrance and dwelling area at the eastern end and the $8 \mathrm{~m}$ long $\left(64 \mathrm{~m}^{2}\right)$ dwelling area in the west indicates that the residents of the house held a special position in the community on the plain.

Aside from the width of the house, house 14 (AD 430-600) is a more common large type 9 house, with a large entrance area to the west and an additional entrance to the rooms east of the byre area, which together with ancillary house 23 (AD 440-520) on the northern side, has been interpreted as a farm unit. Just east of this farm unit is yet another farm in the E-W row, consisting of the type 9 house 172, which, contrary to many of the farms at Forsandmoen, is situated north of the smaller house 173 (AD 430-610), which is an extension of house 14, while the main house 172 (AD 250-430) similarly is an extension of workshop 23 for house 14. We can therefore understand houses 14 and 173 as belonging to one farm and 23 and 172 to another. However, the pattern with two parallel houses with a courtyard in between them is otherwise so common in the late Roman Iron Age and Migration Period that two interconnected houses in a row are unlikely.

These two houses do not have traces of any repairs, and even though both houses contained finds of sherds from bucket-shaped vessels, the date of the main house suggests that this farm was vacated early in the Migration Period.

The westernmost farm from the late Roman Iron Age in Area E, house 156 and 159A, is followed by two type 9 houses and two workshops in the Migration Period. Houses 158 (AD 240-430) and 157 (AD 250-530) are located within and slightly west of house 156 . Both are newly built houses without the use of older postholes. House 158 is a large house with an equally large dwelling area at each end. The dating of the house may indicate that it was built towards the end of the late Roman Iron Age. Finds of sherds from a bucket-shaped vessel in the westernmost part, which was not part of house 157, indicate that the house was also used in the early Migration Period. The four houses on this site, 155, 156, 157 and 158 , were probably used in the period AD 150/200 to $450 / 500$, that is, about 75 years for each phase.

Just to the SSW of this farm, houses 1, 2 and 3 and 5 were established around the middle of the late Roman Iron Age and, as described in the section on the late Roman Iron Age, houses 2, 3 and 5 have dates and several finds of sherds from bucket-shaped vessels, which indicate a uselife through the Migration Period and into the beginning of the Merovingian Period. During the Migration Period, house 2A was converted into the somewhat shorter variant $2 \mathrm{~B}$, which eventually burnt down.

Just east of houses 2 and 3, house 10A from the late Roman Iron Age is followed by the three-phase farm with type 9 main houses (11A-B and 17). House 11A is a large house of the same type and has a dwelling area at each end, while the stratigraphical later house 11B located inside house 11A and with a similar orientation did not have a heated room at the eastern end. Parallel to and just south of houses 11A-B is house 17, which is similar in size to house $11 \mathrm{~B}$. House 17 may not have been contemporaneous with houses $11 \mathrm{~A}-\mathrm{B}$ and the dates from the central hearths in the three houses, 11A (AD 430-600 and 420-540), 11B (AD 420-600) and 17 (AD 410-570) all coincide with the Migration Period. The dating of house 10A (AD 130-390) may indicate that the first of the three houses were built at the end of the late Roman Iron Age and that they stood 


\section{Forsandmoen, Forsand municipality \\ Map of settlement area}

CDouse feature with preserved wall remains

House feature without wall remains

$\square$ Migration Period

First part of Migration Period

Gravemound / cairn

$\bigcirc \quad$ Excavated gravemound / cairn

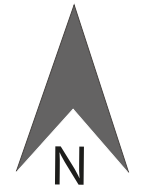

TGB/TL 2009/2014

$+\quad$ Bucket-shaped pottery

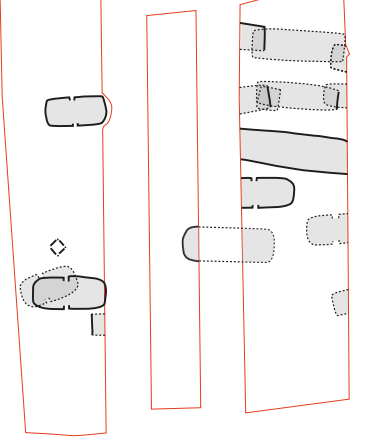

Area D
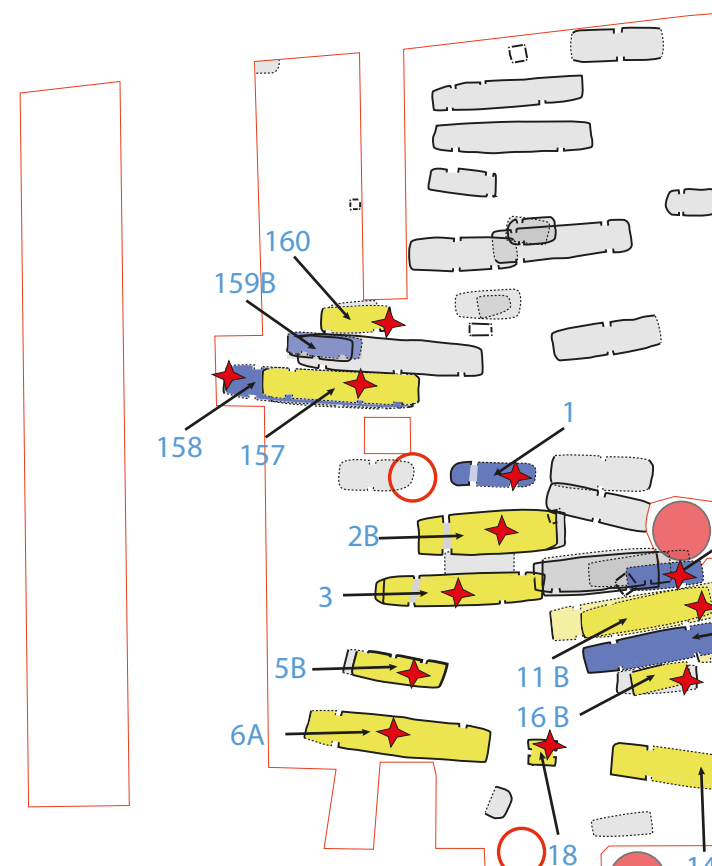

$\bigcirc$
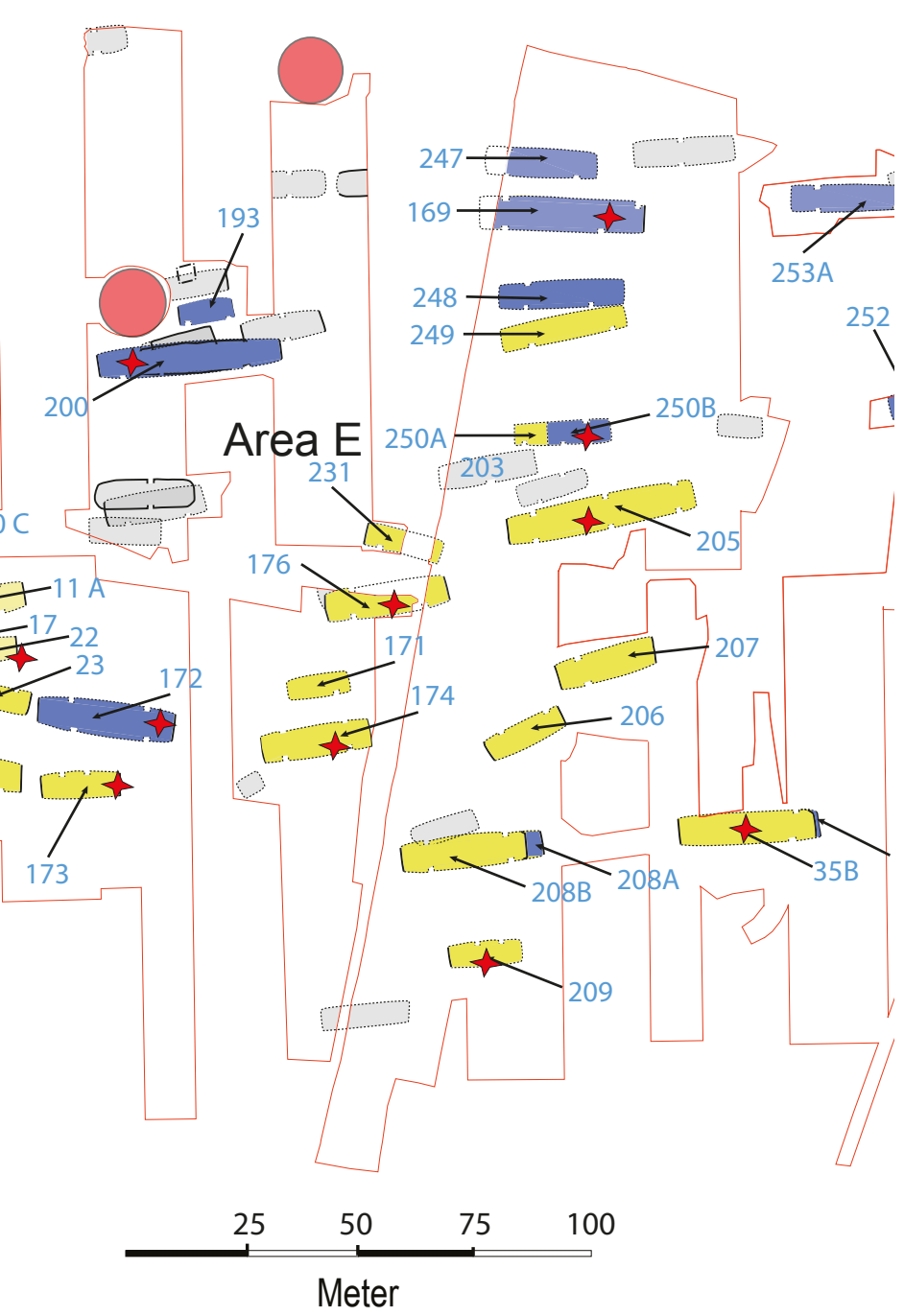
for a period of 200-250 years (AD 300/350-500/550). The first house that could have been built after house $10 \mathrm{~A}$ must have been house 17 since houses 11A-B are so close to house 10A that they cannot have existed at the same time.

All three houses from the Migration Period may have had a workshop attached to the farm. The workshop 10C (AD 260-540) for house 17, which was constructed just north of workshop 16A for house 10A, was built on the ruins of 10A. In other words, they used the courtyard area of the site when they built new houses. Probably, house 17 was built before house 10A was torn down and replaced with a new workshop. Obviously, cf. Fig. 100 , there is no rule as to whether a workshop should be located north or south of the main house. The workshops 16B and 22 (AD 430-600) were then placed fairly close, on the southern side of houses 11A-B.

At the transition to the Migration Period, $50-60 \mathrm{~m}$ north-east of this farm, house 198 was destroyed in favour of the $32 \mathrm{~m}$ long type 9 house 200, which was built on the same place but $5 \mathrm{~m}$ to the west. The two houses have identical dates (AD 250-430 and 260430), but finds of sherds from a bucket-shaped vessels in the westernmost part of house 200 - which, based on comparisons of the dates for houses 198 and 200, was not used by house 198 - show that house 200 probably fell into disuse in the early part of the Migration Period. This farm was thus abandoned earlier than most of the others.

House 200 has the best preserved traces of stalls in the centre of the house. In the three middle bays, directly to the east of the dwelling area and between the roof-bearing postholes, were small postholes dividing the rooms into $0.9-1.2 \mathrm{~m}$ wide stalls, i.e. there were no more than 20 cattle in the byre area. A couple of other houses from the period for which there is also similar, but less extensive documentation of posts for stalls, indicate that a considerable number of cattle were stalled in the winter.

At a distance of $60 \mathrm{~m}$ ENE of house 200, the farm comprising of houses 169 and 247 was established in the late Roman Iron Age. Finds of a glass shard and sherds from bucket-shaped vessels show that the farm was also used in the early part of the Migration Period (see the section on the late Roman Iron Age). Two almost identical type 9 houses, 248 and 249, were built approximately $15 \mathrm{~m}$ south of and parallel to house 169 . At the eastern end, the houses are so close to each other that they may not have been in use at the same time. The dates of houses 248 (AD 350-540 and 400-550) and 249 (AD 410-440 and 410-550) demonstrate that both were used in the Migration Period. No workshop was found that could have been linked to these houses. Since the dates of these houses are later than those of houses 169 and 247, houses 248/249 may represent a move of the farm 169/247 at some point later in the Migration Period and with a subsequent new construction later in the period. Alternatively, houses 248-249 may represent a new established farm at the same time as the last phase of use of house 169 and which continued into the Migration Period after house 169 was abandoned.

In Area $C$, house 26 was built about 50 m north of the late Roman Iron Age house 24. Based on the date (AD 410-690) it belongs to the Migration Period and the earliest part of the Merovingian Period. The small house 243 a few metres to the north-west, which was dated to the Merovingian Period (AD 680-880), reinforces the assessment that house 26 has had a uselife in the Merovingian Period.

In Area B, based on the dates of houses 180 and 181 (AD 240-410/440), and not least through the discovery of sherds of bucket-shaped pottery, we know that the houses were still in use in the early part of the Migration Period. The small type 17 workshop, dated to AD 340-540, situated close to the northern end of the main houses $180 / 181$, confirms a settlement period well into the Migration Period in Area B. However, even if Area B was not inhabited, the vegetation-historical analysis of a clearance cairn located approximately 500 $\mathrm{m} \mathrm{NE}$ of the abandoned settlement indicates that farming activities continued until AD 620-680, which is the same as the latest dating of the prehistoric farming activities in the clearance cairn. Subsequently, the prehistoric fields were sealed by a compact layer of heather peat (Prøsch-Danielsen 1996:13).

\section{Summary of the developments in the Migration Period}

At nine sites within the settled areas on the plain, there were buildings that continued from the late Roman Iron Age associated with the following main houses: in Area A, houses 106A-B and 132/141; in Area E, houses 157/158, 2B/3, 17/11A-B, 200, 169, 253; and in Area $B$, house 180 . The five former sites were inhabited throughout the entire Migration Period, while the latter four were probably abandoned in the first part of this period.

In addition, ten new areas were taken in use during the Migration Period. Of these, the following five settlement clusters have either a new house $(248 / 249)$ or a house that had two phases, where building structures 
were either extended or shortened (house 35A-B and 208A-B), longitudinally shifted (house 205/250A-B) or repaired with one or more posts replaced in the old postholes (house 176). They may therefore have been used throughout the period. The remaining five areas have settlements dated to the Migration Period (the main house mentioned first): houses 6/5, 14/23, 174/171, 207/206 and 26A. Four of these areas have houses that were not repaired and probably thus represent a settlement for a part of the period. The main house 6 was probably used throughout the Migration Period, judging by the dates and that the position of the posts was changed when they were replaced.

The 20 farm units in the overall settlement on the plain therefore seem to consist of eleven areas in the Migration Period (106A-B, 132/141, 157/158, 2b/3, 6/5, 17/11A-B, 248/249, 35A-B, 208A-B, 205/250A-B and 176), which were inhabited throughout the period, while nine had a shorter uselife. Five areas, 172, 169, 200, 253 and 180, were probably only used in the first part of the Migration Period. The last four houses, 14, 174, 207 and 26A had an unknown uselife during the period. These may represent farm units that were established in a new location when the four farm units 172, 169, 200 and 253 in Area E were abandoned in the middle of the Migration Period, while the abandoned farm unit 180 from Area B disappeared from history. Such a scenario implies a stable settlement situation with 15 farms throughout the Migration Period. This means that the settlement in the Migration Period was larger than in the late Roman Iron Age by three farm units and thus may have consisted of 15 farms. Two households in the large houses 11A and 205 imply that the number of households was at least 17.

In view of the knowledge that almost no farm units are dated to the Merovingian Period (see below), meaning that the settlement entered a rapid decline at this time, another scenario may be that the four generally dated, single phase farm units from the Migration Period were instead divided in two during their respective halves of the period. This would mean that the beginning of the Migration Period represents a maximum settlement of 17-18 farm units which, at the end of the period, was significantly reduced to $13-14$ units.

With all the newly established houses in the southernmost and eastern part of Area E, a coherent, densely populated area of $300 \mathrm{~m} \mathrm{E}-\mathrm{W}$ and $170 \mathrm{~m} \mathrm{~N}-\mathrm{S}$ was established during the Migration Period. The individual farms are all oriented E-W and appear to form 3-4 row structures (Løken 2006). The northernmost farms from the late Roman Iron Age, houses 20, 120, 169 and
253, were abandoned either at the end of the late Roman Iron Age or in the first part of the Migration Period, such that in the last part of the Migration Period, the settlement in Area E consisted of twelve farms, each with a main house and a workshop with a total of 14 households, since the two longhouses11A and 205 had a household at each end. Within this area, there was no space for anything other than the farms with a yard area around each unit, which entails that all agricultural areas must have been located around this settlement. The dense structure indicates an economically and socially organised community.

A total of 30 houses or house phases have been registered as belonging to the Migration Period, of which three houses also have a dwelling area in the east end, such that the data in total consists of 33 households from 20 different farms. 16 of these are located in Area E, where 16 of a total of 18 ancillary houses are also located on 13 of the 15 farm units in Area E. The 30 houses with room for 33 households have an average dwelling area of $107 \mathrm{~m}^{2}$ (Table 55). With the assumption of an area requirement of $12.5 \mathrm{~m}^{2}$ per person, each household may have consisted of nine people and, on average, the houses had space for 16 stalled cattle. The ratio of 1.9 cattle per person is slightly higher than in previous periods, but represents the same type of agricultural technology as in the Roman Iron Age. The introduction of more effective harvesting tools such as the scythe and the billhook in the time after AD 1 may be the reason why the number of cattle could be increased. Looking more closely at the houses from the Migration Period, where all the main houses are of type 9 , we see that the size of the houses varies by just about $100 \%$ from the smallest to the largest, both with regard to dwelling and byre areas. The houses fall into five groups, each with 6-7 houses. The groups range from six people and eleven cattle to eleven people and 21 cattle. In addition, two houses can accommodate 14 people but only 17 cattle. We can therefore conclude that the settlement in the Migration Period included households with large differences in access to agricultural and pasture resources.

The ancillary houses were a necessary part of life on a farm during the Migration Period as well as in the late Roman Iron Age, but a few already existed in the early Roman Iron Age. Since these houses often have many hearths or cooking pits located along the centre axis, and several have remains of a forge, they are interpreted as houses for practical functions and not for dwelling. The area for these is $80 \mathrm{~m}^{2}$ on average. If this space was included as living space, it would 
Table 56. Overview of the main features in relation to size $\left(\mathrm{m}^{2}\right)$ of dwelling area, house area, ancillary house area, total farmhouse area, farm plot area, number of inhabitants, number of cattle and ratio of cattle to humans for the 14 farms from the Migration Period village in Area E. The material has been divided into three groups according to increasing total farmhouse area; all other features show a similar mean increase from one group to the next.

\begin{tabular}{|c|c|c|c|c|c|c|c|c|}
\hline House number & $\begin{array}{l}\text { Dwelling } \\
\text { area } \mathrm{m}^{2}\end{array}$ & $\begin{array}{l}\text { House } \\
\text { area } \mathrm{m}^{2}\end{array}$ & $\begin{array}{l}\text { Ancillary } \\
\text { house } \mathrm{m}^{2}\end{array}$ & $\begin{array}{c}\text { Total farm } \\
\text { house area } \mathrm{m}^{2}\end{array}$ & $\begin{array}{l}\text { Farm } \\
\text { plot } \mathrm{m}^{2}\end{array}$ & $\begin{array}{l}\text { Number of } \\
\text { inhabitants }\end{array}$ & $\begin{array}{l}\text { Max number of } \\
\text { cattle }\end{array}$ & $\begin{array}{l}\text { Ratio cattle/ } \\
\text { inhabitants }\end{array}$ \\
\hline $11 A+16$ & 80 & 154 & 42 & 168 & 1200 & 6 & 13 & 2.2 \\
\hline $205+250$ & 78 & 129 & 49 & 178 & 1850 & 6 & 12 & 2.0 \\
\hline $11 A+16$ & 90 & 136 & 42 & 178 & 1200 & 7 & 14 & 2.0 \\
\hline $205+250$ & 87 & 138 & 49 & 187 & 1850 & 7 & 12 & 1.7 \\
\hline 249 & 86 & 195 & 0 & 195 & 2700 & 7 & 16 & 2.3 \\
\hline $35 \mathrm{~A}$ & 113 & 196 & 0 & 196 & 2300 & 9 & 12 & 1.3 \\
\hline$|74+| 7 \mid$ & 82 & 144 & 61 & 205 & 1770 & 6 & 12 & 2.0 \\
\hline Mean 7 households & 88 & 156 & 50 & 186 & 1838 & 7 & 13 & 1.9 \\
\hline$|76+23|$ & 83 & 166 & 70 & 236 & 2250 & 7 & 14 & 2.0 \\
\hline $207+206$ & 80 & 158 & 92 & 238 & 2400 & 6 & 12 & 2.0 \\
\hline $208 A+209$ & 127 & 207 & 75 & 281 & 2450 & 10 & 14 & 1.4 \\
\hline $157+160$ & 140 & 215 & 71 & 286 & 2700 & 11 & 24 & 2.2 \\
\hline $14+23$ & 183 & 261 & 61 & 322 & 1450 & 15 & 16 & 1.1 \\
\hline Mean 5 households & 122 & 201 & 74 & 272 & 2250 & 10 & 16 & 1.7 \\
\hline $6+5 B$ & 138 & 299 & 100 & 399 & 2150 & 11 & 26 & 2.4 \\
\hline $2 A+3+1$ & 260 & 473 & 87 & 560 & 3800 & 20 & 20 & 2.0 \\
\hline Mean 2 households & 200 & 386 & 94 & 480 & 2975 & 16 & 23 & 2.2 \\
\hline Mean 14 households & 105 & 182 & 55 & 236 & 2240 & $8-9$ & 15 & 1.9 \\
\hline
\end{tabular}

mean that the population of the farms in the Roman Iron Age and Migration Period would increase by six people on average to a total of 15 people per farm. This would in turn mean that the number of people per cattle would only be slightly above 1 , a ratio that is not known in western Norwegian agriculture in the Middle Ages or in recent times. The 33 households on the 20 established farms cannot be contemporaneous. Some must have been built in the late Roman Iron Age, while others were built during the Migration Period. Based on either several consecutive houses on an area or a clear reconstruction in which the size of the house or replaced posts changed the house, 15 main houses with a dwelling and byre as well as the assumed hall, house 2, may have been used simultaneously in the main part of the Migration Period. Houses 11A and 205 consisted of two households, so that the settlement on the plain in the Migration Period consisted of a total of 17 households. Only four of the 15 main houses do not have a house placed parallel to them, so that a farm can be defined as two parallel houses of type 9 and type 10 . Two of the farms, $106 \mathrm{~B}$ and $6 \mathrm{~A}$, also have a smithy close by.

One of the 15 farms probably consisted of three houses: an ordinary type 9 house, house 3, with a type
10 house, house 1 , located $20 \mathrm{~m}$ to the north, and between these the most remarkable house on the plain in the Migration Period - house 2. This house, with heavily curved long walls, large width of $9 \mathrm{~m}$, a large hall room with both a long hearth and a cooking pit, and with no traces of a byre, is interpreted as the hall of a large farm consisting of the three mentioned houses.

This means that two farms were built simultaneously in Area A, one farm in Area $\mathrm{C}$ and twelve farms with 14 households in Area E. Area B and D no longer have traces of settlement and almost all buildings are concentrated in Area E.

I will now examine the settlement in Area $\mathrm{E}$ in more detail (Table 56). First and foremost, it is noticable that these twelve houses have the same variation and average amount of living space - the calculated number of inhabitants and the capacity for storing cattle - as for all the 30 main houses during the Migration Period. In the late Roman Iron Age, the settlement in Area E had a fairly open and spacious layout, with five farms in the northernmost part, as well as a cluster of five farms in the south-western corner. The five farms in the north were abandoned either in the late Roman Iron Age or early in the Migration Period. Instead, ten new farms were established in the southern part of the area. In the 
south-western corner, approximately $80 \mathrm{~m} \mathrm{~N}-\mathrm{S}$ x 100 $\mathrm{m}$ E-W, three new farms, $6 \mathrm{~A}, 14$ and 172 , were built close to two of the three $(2 \mathrm{~B} / 3$ and 17$)$ from the late Roman Iron Age. East of this dense building cluster, seven new, more scattered farms were established in an area that measured $150 \mathrm{~m} \mathrm{~N}-\mathrm{S} \times 80 \mathrm{~m} \mathrm{E}-\mathrm{W}(174,176$, 205, 207, 208 and 35). Six of these are situated as three short rows of pairs of farms, each consisting of two houses. The latest established farm (248/249) is located north of these rows, very close to the farm with house 169 from the late Roman Iron Age. In the middle of the Migration Period, the village consisted of Area E, with twelve farms and 14 households (Table 56), while there were three farms, 106B, 141 and 26B, in Areas A and C.

Based on the position of all the 30 main houses, I have previously suggested that this settlement can be understood as a village where the farms were organised in three or four east-west oriented rows (Løken 2006). This idea was formulated before the excavation in 2007 (Dahl 2008). During the 2007 investigations, three new farms were found in the easternmost part of Area E, 248/249, 205/250 and 252/253, as well as an ancillary house (247) for house 169, which extended the row structure in an easterly direction. In my article (2006), I constructed a network of lines, representing centre lines between the various farms as well as external boundaries $10 \mathrm{~m}$ outside the farmhouses, which together formed the basis for calculating the area of the different farms (see Fig. 100).

However, since the smallest, most often newly established farms in the east were farther apart than the dense core in the west with larger established farms, this gave a result that was almost the opposite of what one would expect. There was no visible connection between medium-sized buildings and a large plot of land. I have argued (Løken 2006:212f) that the settlement at Forsandmoen had farms on four levels. Here, no assessment was made of how many farms could have been contemporaneous. There was one farm for a leading family with $590 \mathrm{~m}^{2}$ of built-up area, two farms with a built-up area of $400 \mathrm{~m}^{2}$, six farms with $300 \mathrm{~m}^{2}$ and nine farms with $200 \mathrm{~m}^{2}$. The community at Forsandmoen was therefore considered a socially stratified society where the inhabitants must have differing access to different economic, social and religious positions.

As a result of the surveys and discoveries of new farms in 2007 (Dahl 2008), there was a need to extend the boundaries (see Fig. 4 for the 2007 areas). The farm areas were calculated and incorporated into Table 56. It shows that the twelve farms with 14 households can be more realistically divided into three levels based on total farm unit size. The number of small farms with a size of up to $200 \mathrm{~m}^{2}$ is now larger than in the previous calculations (Løken 2006:312f), and thus the proportion of small farms is larger than the proportion of farms with an size between $200 \mathrm{~m}^{2}$ and $300 \mathrm{~m}^{2}$, and there is only one example of the two largest levels (560 $\mathrm{m}^{2}$ and $400 \mathrm{~m}^{2}$ ) in Area E.

Table 56 also shows that the average size of the farmsteads at the three levels, defined by the centre lines, increases with the total size of the farms. In agricultural communities, such as villages, the size of the houses will be the foremost factor for highlighting differences in wealth. Given the differences in the size of the houses and byres, and the different constructions of some large buildings, Holst (2010:172) believes that settlements such as the one at Forsand contain plenty of indications of social inequality. This is especially seen with the special construction of houses 2 and 6 (cf. chapter 10). Holst also discusses the differences in the farm plots at Nørre Snede where the size varies between $500 \mathrm{~m}^{2}$ and $2,750 \mathrm{~m}^{2}$, but the average area $\left(1,200 \mathrm{~m}^{2}\right)$ for eight fenced farms from the Migration Period is far less than the area calculated by means of the centre lines at Forsand $\left(2,240 \mathrm{~m}^{2}\right)$. Seven slightly older farms at Nørre Snede had an average area of 1,940 $\mathrm{m}^{2}$, which must be said to be similar to that found at Forsand. Ethelberg (2003:236f) has given a couple of examples of fenced in elite farms in Southern Jutland. They had farmed fields of $2,400 \mathrm{~m}^{2}$ and $2,460 \mathrm{~m}^{2}$, surrounding farm buildings of $256 \mathrm{~m}^{2}$ and $320 \mathrm{~m}^{2}$, respectively. On this basis, it should be justified to say that the settlement at Forsand had a density and structure that corresponds to villages in Jutland.

In this analysis, the settlement in the village, Area E, may have had a population of 120 people and a maximum of 220 cattle in the byres in the middle of the Migration Period, around AD 450. The ratio between people and animals ends up at 1.9, which is within the usual range of variation in western Norway in recent times. This ratio is slightly higher than in the late Roman Iron Age (1.6), which confirms that there was a change towards an increase in cattle husbandry, starting in the late Pre-Roman Iron Age. The average number of people per household is 8.3 , with a variation from six to 20 . This is 0.5 person less than for all households during the Migration Period and also on average one person less per household than in in the late Roman Iron Age.

In addition, during the Migration Period, there were also settlements on three other farms, 106B, 141 and $26 \mathrm{~B}$, in Areas $\mathrm{A}$ and $\mathrm{C}$, on the areas where the houses 
132A and B and house 106A (early phase of 106B) with the ancillary house 32A stood in the late Roman Iron Age and, according to ${ }^{14} \mathrm{C}$ dating, were also in use during the Migration Period. These houses and house 26B, dated to the Migration Period and continuing into the Merovingian Period, must represent a concurrent settlement such as the one in Area E. Houses 106B and 141 represent farms of the size of the middle level in Area E while house 26B represents level 1. It is not possible to say anything about the fields of these farms, but together they represent about 25 people and 45 cattle. Thus, we can conclude that a total of about 150 people and $260-270$ cattle must have lived in the two areas.

Many will probably ask if it is conceivable that there may have been such a populous settlement with so many cattle for 150-200 years at the end of the early Iron Age. I have discussed the required need for agricultural land for people at that time and in that society. I think it is difficult to cast any doubt on the calculated number of stalls for domestic animals, but obviously the stalls were reserved not only for dairy cows, but also for young animals, oxen and/or horses for ploughing and riding. There is also no doubt that 33 large combined dwelling and byre houses have been inhabited for a time in the Migration Period. This interpretation also rests on the fact that the construction of new houses has occurred repeatedly at the different areas. Therefore, based on series of ${ }^{14} \mathrm{C}$ dating from these areas, the argument can be made for the lifetime of a house of about $80-100$ years. Such a lifetime might be considered as too long, but there are also arguments for longer lifetimes (cf. chapters 5, 10 and 13). If, instead, one envisages a lifetime of 60 years for the houses, as Herschend (2009) does for the Roman Iron Age, it could result in about 10-11 of the 33 inhabited main houses from the Migration Period being in use concurrently at any given time through the Migration Period. I therefore consider that a population of 100 people with about 180 cattle stalls at their disposal must be a minimum estimate for the settlement at Forsandmoen during the Migration Period.

Analysed charred grains from four houses have been dated to the Migration Period, as well as from both the early and late Roman Iron Age (Fig. 7). In one of the houses from the Migration Period, over 1,300 grains were retrieved, and of these, 850 could be determined to species: hulled barley (Hordeum vulgare var. vulgare) constituted $37 \%$ and oat (Avena) $63 \%$. The far fewer finds from the three other houses also confirm this distribution of the two grain types. As in the Roman
Iron Age, no naked barley (Hordeum vulgare var. nudum) was found. In total, for the last 600 years of the Early Iron Age, the charred grains reflect a traditional agriculture based on one-third barley and two-thirds oat in the diet. Aside from one exception, the ancillary house 34 of type 10 , the grains have been recovered from nine combined dwelling and byre houses of type $9(10,14,29,50,105,120,150,173$ and 174) and two type 3 houses (12 and 13). This distribution of cereal finds indicates that much of the food-processing was performed in the living room in main farm house and to a lesser degree in the ancillary houses.

\subsection{The Merovingian Period}

\section{The houses of the Merovingian Period} (560/570-800)

Only two buildings have dates that cover the transition between the Migration Period and the Merovingian Period, while eight buildings have dates between AD 530-650 and 680-880 and therefore probably reflect that the settlement continued in a very contracted form during this period (Fig. 101).

In Area E, the main house 3 has a date (AD 440$660)$ that does necessarily entail a settlement into the Merovingian Period, while the large, well-built house 2 has a date from the central hearth (AD 560-660) that supports an interpretation of continued settlement into the Merovingian Period. Particularly considering that house $10 \mathrm{~B}$, which is located $5 \mathrm{~m}$ to the south-east of the eastern part of the house, also has a date from a central hearth (AD 660-860) and undoubtedly belonged to the Merovingian Period. South of houses 2 and 3, house $6 \mathrm{~B}$ and house $5 \mathrm{C}$ have dates from central hearths (AD 530-760 and AD 560-770) which cover most of the Merovingian Period. It seems very likely that these two farm units $(2 \mathrm{~B} / 10 \mathrm{~B}$ and $6 \mathrm{~B} / 5 \mathrm{C})$, consisting of the two largest, widest houses with the most complex construction, and the corresponding workshop, were still in use well into the Merovingian Period.

A new farm unit was probably also established in the westernmost part of Area A during the Merovingian Period. The main house 134 is a poorly preserved type 9 house dated to AD 650-860. Directly to the northwest of this is a small house, 145, possibly a workshop, that has been dated to the early Merovingian Period (AD 530-650).

About $100 \mathrm{~m}$ south of this farm unit, in Area C, we find the last farm unit from the Merovingian Period. The dating of house 26 (AD 410-690) indicates a settlement here at the end of the Migration Period and 
into the Merovingian Period, especially considering the date from the nearby house 243 (AD 680-880).

Neither of the two main houses in the farm units in these areas have a house plan completely in line with the norm for Migration Period houses. The same applies to the ancillary houses. This may indicate that they were built in a period when the knowledge of the construction, the requirements to follow a long-standing understanding and acceptance of how a house should be built had been lost in the time when society on the plain disappeared for a short period of time.

Another house was dated to the Merovingian Period. In house 109, located just south of the main house 106 in the eastern part of Area A, a central hearth has been dated to AD 600-770. The house is a workshop of the typical type from the Migration Period. No other dates in this area extend into the Merovingian Period, so it is hard to consider this house as belonging to a farm unit that was in use during the Merovingian Period. The house was likely a workshop for the main houses 106A and $B$ and replaced the partially overlapping workshop 108 in the last part of the Migration Period.

In summary, in connection with the abandonment of the settlement at Forsandmoen, the two most significant units of houses $-2 \mathrm{~B} / 3$ and $6 / 5$ - continued for longer than all other farm units before they were abandoned and one of them, house $2 \mathrm{~B}$, burnt down at some point during the first half of the Merovingian Period, while the other, house $6 / 5 \mathrm{C}$, lasted into the Merovingian Period, if the dates are taken at face value. These units were located at the farthest point to the south-west in the settlement area and had the easiest access to the sea, approximately $1 \mathrm{~km}$ to the WSW.

At a distance of $350-450 \mathrm{~m}$ to the north-east of these units, the two farm units 134 and 26/243 were established in the transition to the Merovingian Period as the last phase that was in use in the settlement at Forsandmoen. Until the early 1900s, when several small farms were established, the heather and grass plain was used as pastures and hayfields for the two farms Berge and Forsand at the headland by the outlet of the Lysefjord. The mountains around the plain, which had become almost completely deforested since the end of the Roman Iron Age, have remained unforested until modern times.

It is difficult to assess how many of the three farms were still inhabited after the catastrophic period in the years AD 536-45 when 14-15 households gradually disappeared. The farms with the main houses $2 \mathrm{~B}$ and 6 may each have held 10-12 inhabitants and 15-20 stalls, but the hard times may have resulted in either more or less inhabitants. House $26 \mathrm{~B}$ provided space for six people and ten stalls, so at the end of the $6^{\text {th }}$ century, the population could hardly have been more than 25 people and 40-45 cattle. In the $7^{\text {th }}$ century, after the farm with house 134A was established, the two households consisted of a total of 15-20 people and 20-25 cattle. At the beginning of the $8^{\text {th }}$ century, probably the last settlement was abandoned and Forsandmoen became heathlands, used as pasture.

\subsection{Summary of the development of the settlement from $1400 \mathrm{BC}$ to AD 700}

The settlement was established in two places on the plain around 1400 BC. In Area A, the buildings consisted of a large house, probably combined dwelling and byre (type 1) and some smaller buildings, including type 3, through Bronze Age Periods II-V. The settlement consisted of no more than 1-2 households that lived by cultivating naked and hulled barley in fields cleared of rock, in addition to cattle. In Area B there are traces of two houses from a probably non-continuous settlement in two of these periods (II, IV).

During Bronze Age Period IV, the settlement expanded as Area D was established as a new settlement area 300 $\mathrm{m}$ WSW of Area A, so that the settlement on the plain most probably consisted of 2-3 contemporaneous units during Bronze Age Periods IV and V.

In period $\mathrm{VI}$, the extent of the settlement was about the same in Areas A and D, comprising houses of type 1 and 3. A couple of small types of houses, only suitable as dwellings, occur in Areas A and B. In addition, type 3 combined dwelling/byre houses were built in several places in Areas B, C and E, increasing the number of simultaneous units to at least 3-4.

In the Pre-Roman Iron Age, the newly established settlement from period VI disappeared from Area $B$, while the settlements in the other areas increased somewhat, meaning that there was a settlement of at least 4-5 units during the period. A new type of house, type 7, appeared for the first time at the end of the late Pre-Roman Iron Age. In Area A, the location of the unit was moved during the period from the south, where it appears that a row structure was established, to situating the centre of the settlement in the northern part of the area at the end of the period. Also in Area E, the settlement shifted in a western direction during the period. In Area D, the buildings of the Late Bronze Age went out of use during the earlier part of the period. Traces of buildings from Areas C, D and $\mathrm{E}$ indicate that the distances between farm units were 


\section{Forsandmoen, Forsand municipality Map of settlement area}

$C$ House feature with preserved wall remains House feature without wall remains

$\square$ Merovingian Period

$\square$ First part of Merovingian Period

Gravemound / cairn

$\bigcirc \quad$ Excavated gravemound / cairn
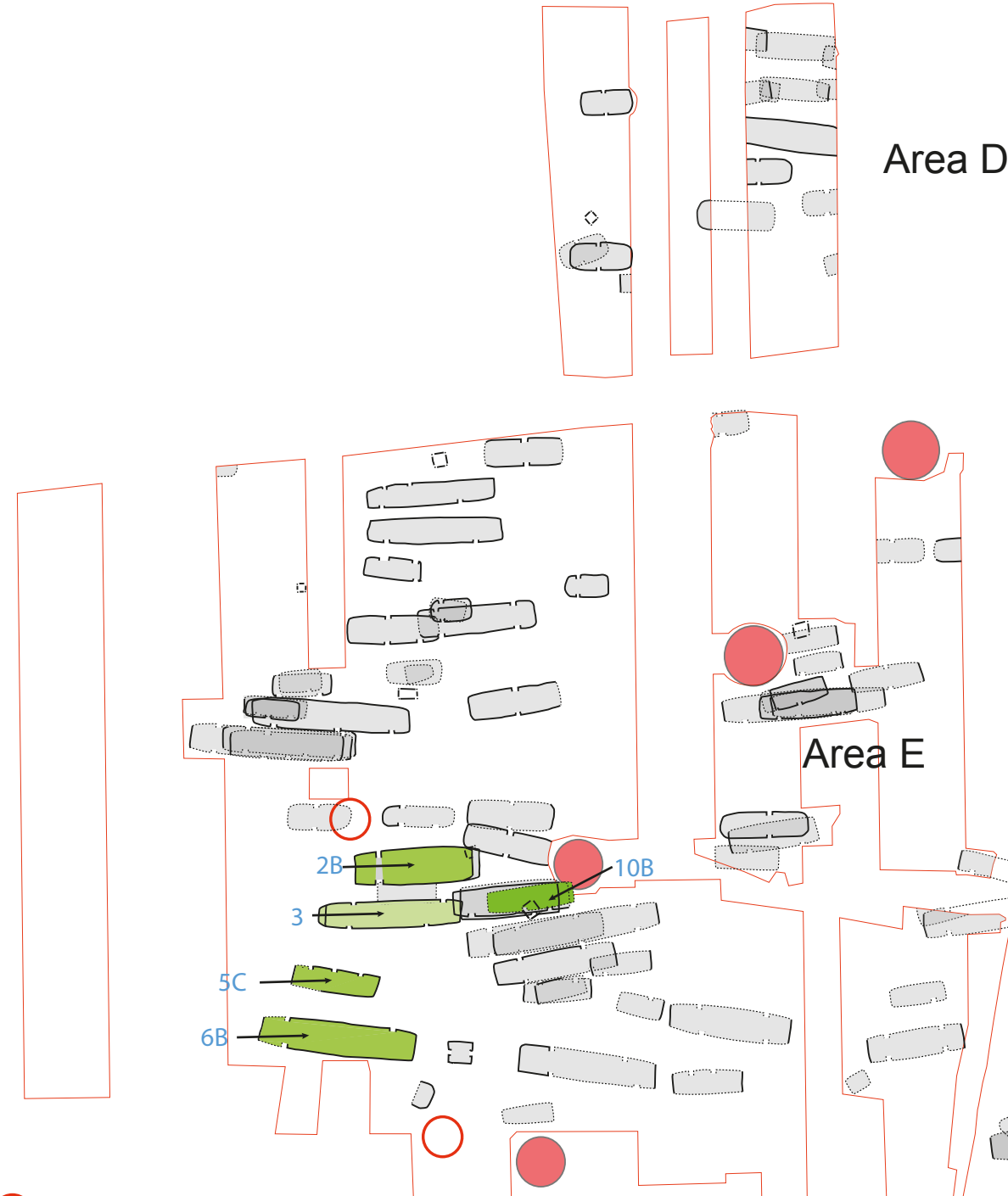

Area E

○

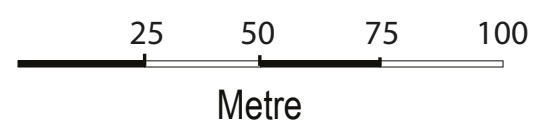




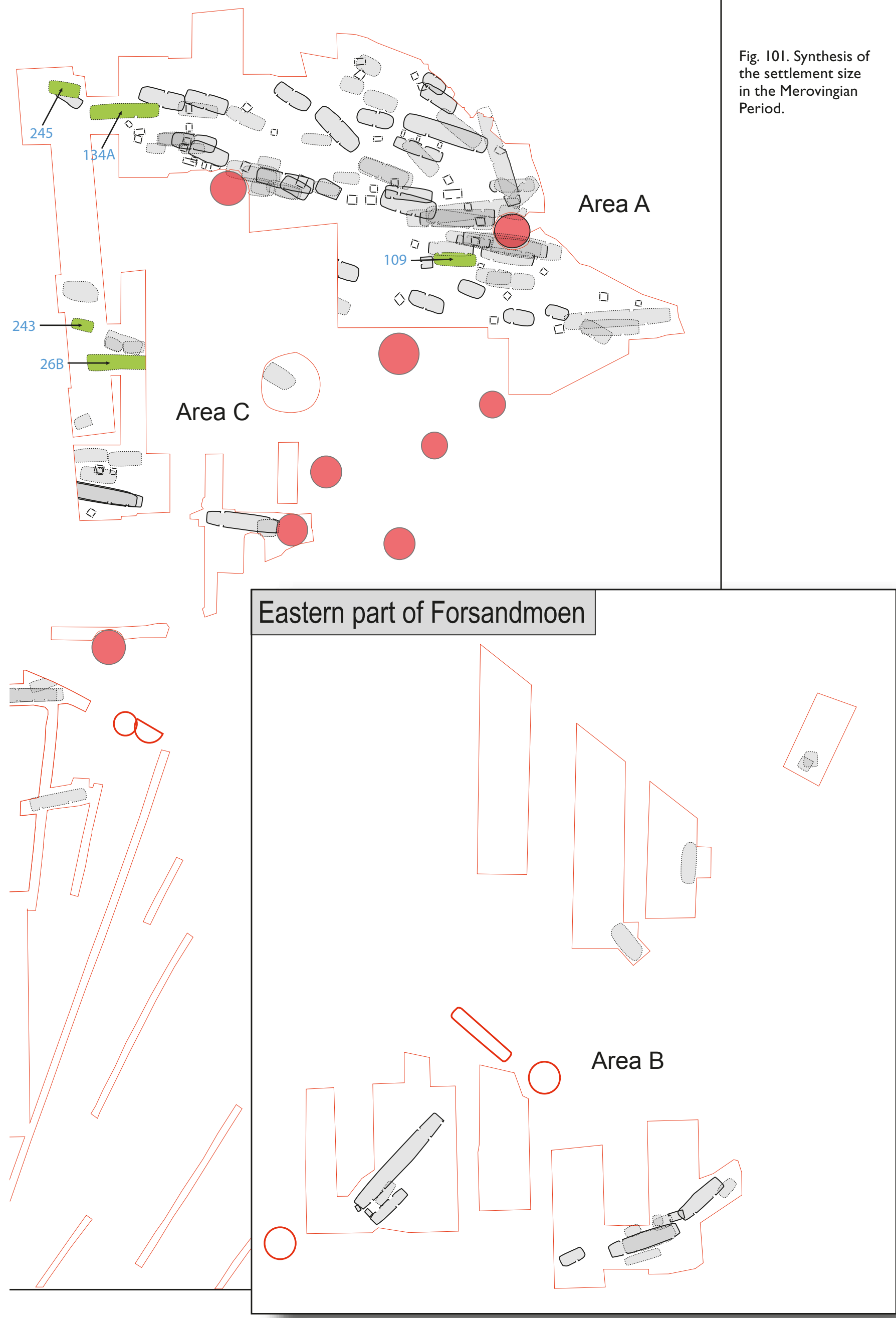


larger than what appears to be the case in Area A. From an agricultural point of view, wheat (Triticum) became the dominant type of crop in the Late Bronze Age and the Pre-Roman Iron Age.

During the early Roman Iron Age, the size of the settlement in Area E matched that of Area A for the first time. In several instances, farm units were established and remained at the same place until the settlement was abandoned. Together with three dwelling units in Area B and Area C, around 8-10 units coexisted in the early Roman Iron Age. In all periods following Bronze Age Period III, the type 3 house with a dwelling and byre function was the most important house in the settlement. From the early Roman Iron Age and for the rest of the duration of the settlement, large, combined type 9 dwelling and byre houses became most prevalent, while types 3 and 7 were found in a few cases during the Roman Iron Age. The early Roman Iron Age was thus a transformative period in terms of the building traditions, when animals got their own entrance to their area of the houses, which might indicate a greater distance between animals and people. In terms of farming practices, oat (Avena) became the most important grain, while hulled barley (Hordeum vulgare var. vulgare) accounted for one-third of the grain. These proportions continued for the rest of the settlement period.

In the late Roman Iron Age, a number of new units were established in Area E, with settlements at ten sites compared to only two in Area A. In the western part of Area E, seven farm units were so close together that they give the impression of a village-like structure, while other units are more solitary. Along with the settlements in Areas B, C and D, this means that the number of contemporaneous units must have increased to 12-13.

The pattern from the late Roman Iron Age continued through the Migration Period, but the settlement unit in Area E expanded into the southern and eastern part, increasing the number of farms to 16 , in addition to four units in Areas A, B and C. Some of these were abandoned in the early part of the Migration Period and some established in the later part of the period, so that we can expect a stable population of 15-16 units. They were organised as a large cluster in Area E, where the individual farms were placed in 3-4 row-like structures, such that all the farms had access to farmyard of at least $2000 \mathrm{~m}^{2}$ (Løken 2006), as well as into a smaller settlement area with two farms in Area A. The buildings from the Roman Iron Age in Area B were relocated early in the Migration Period.
Table 57. Suggested number of farms, houses, inhabitants and cattle present during each of the eleven settlement phases at Forsandmoen. The number of houses for each period includes, in addition to the period-specific byre-dwellings, ancillary houses (type 10), houses intended specifically for human occupation (types $5,6, \mathrm{II}$ ), and various storage buildings (types II-18). As the central area of the settlement was not investigated, the numbers presented here should be seen as the minimum. Furthermore, 20 dwelling houses and 74 storage buildings have not been dated and cannot be assigned to a specific period.

\begin{tabular}{|l|c|c|c|c|}
\hline Period & $\begin{array}{c}\text { Number } \\
\text { of farms }\end{array}$ & $\begin{array}{c}\text { Number of } \\
\text { houses }\end{array}$ & $\begin{array}{c}\text { Number of } \\
\text { inhabitants }\end{array}$ & $\begin{array}{c}\text { Number } \\
\text { of cattle }\end{array}$ \\
\hline Bronze Age II & I & 1 & $5-15$ & $10-15$ \\
\hline Bronze Age III & I & 2 & $5-15$ & $10-15$ \\
\hline Bronze Age IV & 2 & 4 & $15-20$ & $20-25$ \\
\hline Bronze AgeV & 2 & 4 & $15-20$ & $20-25$ \\
\hline Bronze Age VI & 4 & 6 & $30-35$ & $40-45$ \\
\hline $\begin{array}{l}\text { Early Pre-Roman } \\
\text { Iron Age }\end{array}$ & 6 & 7 & $40-45$ & $50-55$ \\
\hline $\begin{array}{l}\text { Late Pre-Roman } \\
\text { Iron Age }\end{array}$ & 5 & 7 & $30-35$ & $40-45$ \\
\hline $\begin{array}{l}\text { Early Roman } \\
\text { Iron Age }\end{array}$ & 9 & 16 & 70 & 110 \\
\hline $\begin{array}{l}\text { Late Roman Iron } \\
\text { Age }\end{array}$ & 12 & 31 & 100 & 160 \\
\hline Migration Period & 17 & 30 & 150 & 260 \\
\hline $\begin{array}{l}\text { Merovingian } \\
\text { Period }\end{array}$ & 2 & 4 & $15-20$ & $20-25$ \\
\hline
\end{tabular}

Only three of the farms from the Migration Period were still in use in the Merovingian Period. Based on two ${ }^{14} \mathrm{C}$ dates, a new farm unit was established in Area A during that period, probably in the $8^{\text {th }}$ century AD. That unit must have been the last to be abandoned.

After a slow development of the settlement on the plain through the Bronze Age and the Pre-Roman Iron Age, where there was an increase in the number of settlement units from 1-2 to 5-6, the settlement increased rapidly to 12-13 units in the late Roman Iron Age to 17 units by the middle of the Migration Period. Table 57 summarises the evolution of the number of households, inhabitants and cattle through the eleven phases of the settlement, from Bronze Age Period II (about $1400 \mathrm{BC}$ ) and to the conclusion in the middle of the Merovingian Period (c. AD 700). It is noteworthy that, during the first 800 years, the size of the settlement remained largely unchanged, and only consisted of 1-2 households with $10-25$ people and $15-25$ cattle. From the beginning of Bronze Age Period VI and through the Pre-Roman Iron Age, approximately 700 years, the settlement expanded considerably to comprise 4-6 households with 30-45 people and 35-55 cattle. Through the last approximately 700 years of the 
settlement, it underwent a tremendous growth, with triple the number of households from six households in the early Pre-Roman Iron Age to 17 in the Migration Period. The population size quadrupled to 150 people and the number of cattle increased fivefold to 260 , then, in the Merovingian Period, dropped to a similar level as in the Early Bronze Age.

Eventually, the last two units were abandoned in the $7^{\text {th }}-8^{\text {th }}$ century AD. In Chapter 17 , I will discuss the process of abandonment and its possible causes. 


\section{The abandonment of the Forsandmoen settlements and the Fimbulwinter in AD 536-37}

\section{A narrative from Forsandmoen AD 536-545}

In March-April AD 536, the inhabitants of Forsandmoen saw dark clouds, hovering high in the sky, ascending over the moor. The sun was more diffuse through the clouds, with a gloom as if in late autumn. There was none of the normal springtime heat during the day. The situation persisted and the spring chill remained, vegetation was low and the hillsides were constantly covered with snow, so pastures were bad. Spring work gradually started although the soil had dried up badly. During the summer, the grain grew slowly, was less abundant and more stunted than before. On the meadows and uncultivated outfields, the winter feed grew poorly. Everybody recognised the sign of a bad harvest and the probability of hunger during the coming winter. The chieftain at the main farm summoned all the inhabitants for a sacrifice to ask the gods for a good harvest. But there would not be enough food either for people or for animals. Many cattle were slaughtered so the people could salvage the rest of their livestock. Hunger stood at the door throughout the winter. The clouds continued, the winter was 3-4 degrees colder than normal. Even the best supplied households could barely manage and were in no position to help the people at the poorest farms. Large numbers of both people and cattle died during the winter and spring of AD 536-37. The dense clouds high in the sky continued through the spring and began to dissolve only in late autumn. Yields of grain and fodder were still poorer than the previous year and, during the next winter, most of the inhabitants of Forsandmoen died of starvation. The few people who had gathered on the two or three largest farms broke through to a new, more normal spring in AD 538 and the settlement was able to continue for at most 100 years before the plain was completely deserted. Later, the plain was only used as grazing land for the settlement at the Forsand proper on the Lysefjord.

This could be the tale of why the thriving settlement at Forsandmoen, which had its beginnings around $1400 \mathrm{BC}$, was almost laid waste in the $6^{\text {th }}$ century AD. Life on the not-too-fertile moraine plain had not always been easy when cold or wet summers struck - or when winter was particularly harsh - but the settlement had increased in size for 2000 years, from just one or two farms in the Early Bronze Age to slightly fewer than 20 farms in the late Roman Period in the $4^{\text {th }}$ century AD. In the $5^{\text {th }}$ century $\mathrm{AD}$, it appears that the number of farms was reduced by two or three farms before a disaster struck during the $6^{\text {th }}$ century AD, reducing the settlement to 1-2 farms at the beginning of the $7^{\text {th }}$ century AD. What could cause such devastating effects on a seemingly robust and prospering settlement? When did it happen during the $6^{\text {th }}$ century? And how fast did it happen? These are three important questions to be explored.

\subsection{The difficulty of uncovering the real period of use}

A large number of ${ }^{14} \mathrm{C}$ dates have been obtained from the village at Forsandmoen (see chapter 3.7) (Løken 1998b, 2001b, 2003, 2005). As many as 210 dates, essentially one from each house, or house phase, as well as the three series of dates of charred grains from three Bronze Age houses, provide a good basis for an interpretation of the period of settlement and changes in its extent throughout the years. We recognised early on (Høeg 1999, Løken 1987c, Prøsch-Danielsen \& Simonsen 1988) that the settlement on the outwash plain began in the middle of Bronze Age Period II. Radiocarbon dates from three houses in two areas date the establishment of the settlement to shortly before $1400 \mathrm{BC}$. The charred soil, representing the start of grain cultivation in the area, directly below the bottom stone layer in a clearance cairn, has been dated to 3210 \pm 65 BP, 1520-1410 BC (Prøsch-Danielsen 1996). The first occurrence of grazing has been dated to c. 1900-1700 BC, while the first traces of arable farming in the pollen diagram from a bog in the hillsides has been dated to 1150 BC (Høeg 1999:172f). Three independent datasets confirming landscape use and settlement in the area provide a good validation as to when the plain was settled. 
I have, during the 1980s (Løken 1987b:166, 1988a:178), expressly stated that the settlement came to an end about AD 600. Later, however, several new dates and adjustments of the calibration curve have shifted their timescale to a later date. Thus, it appears that two houses must have been in use at least until the middle of the $7^{\text {th }}$ century AD. Three additional houses, dated to the $7^{\text {th }}-8^{\text {th }}$ century $\mathrm{AD}$, probably represent a short-lived attempt to re-establish a settlement.

The large number of dates has also made it possible to establish phases of the settlement, which - through several expansion stages (see Fig. 10) - results in a maximum phase in the late Roman Iron Age and Migration Period, consisting of one large village and one smaller hamlet, comprising a total of nearly 20 farm units, when taking the last supplementary excavation at the settlement area in 2007 into account (Dahl 2008, Løken 1991).

During the $6{ }^{\text {th }}$ century AD, a steep drop in ${ }^{14} \mathrm{C}$ dates supports that Forsandmoen was transformed from a thriving and expansive settlement, with at least 200 inhabitants and 3-400 stalled cattle, to only $1-2$ farms in the $7^{\text {th }}-8^{\text {th }}$ century AD. This must be regarded as a settlement-related and demographic disaster, especially because the plain in the $7^{\text {th }}$ century AD was transformed from being farming and pastoral area with scattered woods along streams, rivers and outer edges of the plain to a pure heath plain (Prøsch-Danielsen 1996).

It is not only at Forsandmoen that settlements were abandoned around AD 550-600. A wide variety of farms with houses with stone-built exterior walls, such as Ullandhaug (Myhre 1980) and the Høyland area in Sandnes (Myhre 1972) testify to widespread abandonment. Some of them also have finds from the Late Iron Age, in the form of new settlements built on top of collapsed houses. It can be argued that this abandonment at c. AD 550-600 is only apparent because people stopped using artefacts upon which the dating of most farms was founded, namely decorated ceramics - and especially the bucket-shaped pottery. Since few of these types of farms have been investigated after the ${ }^{14} \mathrm{C}$ method was adopted, this may not be entirely dismissed. However, looking at Ullandhaug, the radiocarbon dates show that the settlement lasted from close to AD 1 and up to the $6^{\text {th }}$ century AD. Later, in the Merovingian Period, several wall ramparts from the house remains were used for burials and for building grave mounds over the house ruins, confirming that the farm was abandoned at this time (Myhre 1980:30f, 83f).

In the last decade, a point of view has been presented to the effect that, although many farmsteads were laid waste, this was not due to a demographic decline. Rather, this came out of a reorganisation of the farm structure with a concentration of buildings around central large farms - probably at locations where historic farms were later situated. In recent years, the excavations in Rogaland also suggest that a certain relocation of the settlements took place.

At Gausel, we see that the buildings from the early Pre-Roman Iron Age until the Merovingian Period were steadily positioned closer to the highest point. Based on the rich boat graves for men and a particularly rich woman's grave, all from the Viking Period and situated near the highest point, it is reasonable to assume that the settlement was moved to the top of the hill in the Viking Period, where the historic farm has remained until the present (Børsheim \& Soltvedt 2002:237).

From the Roman Iron Age and Migration Period, at an E-W oriented edge of an E-W oriented depression at Austbø on Hundvåg in Stavanger, there are four Roman Iron Age and Migration Period farmsteads situated in a row with an internal distance of 100-300 m (Hemdorff 2006, Meling 2001, 2017:159, Tzigaridas 2001). Based on the limited resource area, they most likely represent four changes of location of a farm through the Roman Iron Age and Migration Period rather than four simultaneous farms. From this farm area, there are no Late Iron Age radiocarbon dates. However, 200-300 m north of the depression, a larger farm area was established at Skeie in the Merovingian Period - and continued into the Viking Period (Meling 2017:161, Skaare 1998, Tzigaridas 1997). It is likely that the old farm in the eastern part of the island Hundvåg was moved to the new location as the last relocation phase, at around the turn to the Merovingian Period (Meling 2017:167).

At Tastarusta in Stavanger a Pre-Roman Iron Age farm was established somewhat below the hilltop, and the same area was later settled in the Merovingian Period and Viking Period, while the settlements from the Roman Iron Age and Migration Period were located elsewhere on the hill (Armstrong 2007, 2008). However, these examples should be interpreted as a local change of the houses within a settlement or a farm and not as a concentration of farms in fewer settlements.

Survey trenches at the Forsand headland at the outlet of the Lysefjord have shown that there were farm buildings in at least three locations in the late Roman Iron Age and Migration Period, representing the same areas that belonged to the farms Forsand, Gjøyse and Berge from historical times. The excavation at Berge in 2013 showed that the settlement there had consisted of a more than 67 $\mathrm{m}$ long combined dwelling and byre house situated parallel to a $30 \mathrm{~m}$ long workshop building, obviously belonging 
to the local chieftain in the Forsand area (Dahl 2014b). As land resources on the headland were far less than those at Forsandmoen, it is absolutely out of the question that the inhabitants living on the plain could be moved to the headland and live there together with the original population. At Forsand, there can be no other solution than a massive reduction in the settlement and population in the middle of the $6^{\text {th }}$ century.

What may have caused a protracted trend towards an ever larger settlement through nearly 2000 years to end with an abrupt termination of most of the farms at the end of the Migration Period? I pointed out early on (Løken 1988a, 1988b) that the comprehensive settlement that was established during the Roman Period implied a substantial exploitation of the environment, resulting in the complete eradication of the forest on the plain during the late Roman Iron Age. In addition, the extensive settlement on the plain from Roman times, with fixed farmyards and field areas, may imply that arable land was over-exploited - probably due to a lack of fertiliser and too few years with crop turnover. Furthermore, could the presence of the fungus ergot (Claviceps purpurea) in grains indicate overly humid conditions? Ergot infected grain entails a great risk of serious illness in the population (Bakkevik 1998:60). The likely number of cattle, horse, sheep and goats probably represented a heightened grazing pressure on the plain and the surrounding areas, with potentially ensuing resource deficiencies. Throughout the Roman Iron Age and Migration Period, arable farming was based on a distribution of one-third of barley (Hordeum) and two-thirds of oat (Avena). Over the course of this period, there was an increased frequency of grains with poor maturation, which has been interpreted as a sign of agricultural difficulties (Bakkevik 1998:59). Excavations have shown that, during the late Roman Iron Age and Migration Period, a massive waterimpermeable podzol-profile developed - which is probably what caused the establishment of the heather moorlands on the plain. Destruction of the agricultural basis due to over-exploitation was seen as the main reason to why the settlement was laid waste by the end of the Migration Period.

On the basis of reports of repeated years of low temperatures, floods and crop failure (Lamb 1981 in Høeg 1999) in Europe around the mid-500s, however, climate change has also been highlighted as a possible factor. Likewise, the Plague of Justinian, both in AD 542-43 and in AD 558, has been proposed as a possible explanation for the decline in the number of farms by the end of the $6^{\text {th }}$ century AD. Finally, trade relations with the Roman Empire going broke at the end of the $5^{\text {th }}$ century, would also have had an impact. Roman imports (glass, bronze pots, gold, etc.) facilitated the establishment of a redistributive system during the Roman Iron Age. This was based on collecting items (for example sealskin, hides and horns) from the effective use of outfields; these are items that lost their value when commodity exchange ceased. The redistributive system therefore collapsed when trade lapsed. Much of the basis for the large settlement at Forsandmoen therefore dissipated, with a reduction in the scale of the settlement as a result. It is difficult to accept that one of these factors - or a combination of several of them - should be able to destroy, in a matter of decades, a society that had adapted to the local conditions for centuries.

We know that, throughout history, crop failure has been reported in Norway due to weather conditions that resulted in mass deaths in single or several consecutive years (Dyrvik 1996:51f, 105f). In particular, this happened in the so-called Little Ice Age between AD 1400 and AD 1800. However, the communities in Norway rebounded when conditions improved. Another example is the effects of the volcanic eruption in Tambora in 1813-14, which in combination with Britain's blockade of grain imports from Denmark in the late Napoleonic wars - caused a famine in Norway. However, this was only noticeable as a recession in the demographic developments in Norway. Whatever it was that made the settlement at Forsandmoen collapse in the middle of the $6^{\text {th }}$ century AD, the result was that the plain was utterly abandoned, despite the fact that the population tried to maintain a couple of farms for 150 years. What power caused this? Which types of phenomena could have had such an ability to shape the lives of people of Forsandmoen?

\subsection{Did a volcanic eruption cause the Fimbulwinter?}

In the paper Fimbulvintern, Ragnarök och klimatkrisen 536-537 e. Kr. [The Fimbulwinter, Ragnarok and the climate crisis AD 536-537], Gräslund (2007) presents a theory that the notion of the Fimbulwinter had nothing to do with one or more cold winters, since the Norsemen were well accustomed to winter weather, but that it was related to a "huge volcanic eruption or cosmic eruption, which clouded the sun around the whole globe during the years AD 536-537 and triggered a serious climate crisis in the northern hemisphere throughout the entire period 536-545" (Gräslund 2007:114).

There are several reasons behind the hypothesis of a climate crisis that occurred from AD 536. Arjave (2007) and Iversen (2017) mentions that a number of ancient sources 
describe a situation where the sun did not shine brightly for two years but was coloured blue; there was no shadow at noon, it did not get hot during the day, the moon was deprived of its natural shine, the crops did not mature, the winter was colder and drier than normal and seasons did not change as usual (ref. letter of Cassiodorus to Rome in the autumn of AD 536). Similarly, in AD 536-537, Prokopios described a situation in Syracuse and Carthage that corresponds with a description by the church historian John Lydo of Ephesus about a darkness that lasted 18 months. Also in Constantinople, Zachariah wrote that the sun darkened by day and likewise the moon at night for a period from 24 March 536 to 24 June the following year, i.e. 15 months. This is referred to as a northern phenomenon and no one has been able to trace similar accounts in Egypt. Likewise, there are several Chinese sources about a similar shade of celestial bodies and cold, frost and snow in July, as well as famine in the years AD 536-538 (Houston 2000).

The reports of unsuccessful grain crops are important, which is a reasonable agricultural outcome if clouds covered the whole of Europe from the end of March and until midsummer the next year. It would mean poor yields for two years, with necessarily disastrous consequences for the Nordic societies where food stocks rarely went as far as the subsequent summer.

A volcanic eruption in AD 536 has been confirmed through analyses of drill cores in Antarctica, where a distinct layer of sulphate from AD $540 \pm 17$ years is interpreted as precipitation after such eruptions (Traufetter et al. 2004). Similarly, layers dated to AD 533-34 \pm 2 years, have also been found in the Greenland ice (Larsen et al. 2008). These precipitates are the most powerful in the first millennium AD. Large amounts of sulphur dioxide must have circulated in the stratosphere as a layer above the clouds, as described in the Kalevala. The amount of sulphate in the Greenland ice sheet is $40 \%$ higher than after the eruption of Mount Tambora in 1815, which led to a cold winter and a disastrously cold summer the following year - particularly for north-east North-America and Northern Europe - with famine as a result (Larsen et al. 2008). The effect of the eruption in AD 535-536 may therefore have been far more extensive considering how much less prepared people were for crop failure in prehistory.

The effect of the eruption can also be seen in the growth of annual rings in the forests of the northern hemisphere. Between AD 536 and AD 545, the annual rings are very narrow, which points to very poor conditions for the trees in the summer. This series of narrow tree rings, beginning in AD 536 and continuing for five years, shows that the eruption caused a 10-year cold snap. From dendrochronological analysis, it is estimated that the average summer temperatures of that decade fell by 3-4 degrees Celsius.

Toohey et al. (2016:409f) have investigated how much the dust would reduce the "growing degree days" (GDD), defined as the sum of daily mean temperatures above a given threshold $\left(5{ }^{\circ} \mathrm{C}\right)$ throughout the growing season. The simulated percentage of GDD anomalies in AD 536 in Europe is approximately $10 \%$ in most of Central and Southern Europe, and increase strongly with latitude, reaching values of $20-30 \%$ in Northern Europe, such as in southern Norway and around the Baltic Sea. A picture of the absolute changes in agricultural productivity resulting from volcanic cooling can be constructed with the help of an index of temperature dependent cultivation suitability (CSIT). Using this metric, the simulated temperature anomalies for AD 536 imply that the greatest absolute agricultural impact was in Europe, at the northernmost margin of nominal cultivation in Scandinavia. In many Scandinavian locations, these decreases amount to a complete diminishment of CSIT, implying severe crop failure. Decreases in simulated CSIT after the eruption in AD 540 are roughly similar to those of AD 536; due to the temporal proximity of the two strong volcanic events and the persistence of each event through two summers, such crop failure is likely to have occurred for multiple years from AD 536-545.

\subsection{The effects of volcanic eruptions on society}

Gräslund (2007) shows in his treatment of the Norse sources that the two years of "dust veil", with clouds in the stratosphere, and the consequences for the climate and agriculture have been enshrined as the story of the Fimbulwinter. Through close reading of the different sources, he believes that the Fimbulwinter is not meant to describe a normal Nordic winter, since the people were accustomed to dealing with normal winters, but a period when the sun had no effect and it was as night in the daytime. The Völuspá states that "the sun's skin turns black during the following summers, but when the Fimbulwinter ends, the sun is clear again”. The Völuspá does not use the word winter but talks about darkened summers. There are similar stories in the Kalevala, but there the darkening occurs in the summer, which has led to the Kalevala not being interpreted as a parallel to the Norse sources. Gräslund (2007:114) states that "it thus seems to have been a notion in Norway and Finland that the sun was gone or darkened several summers in a row, 
with very cold summers as the result and that this caused a temporary demographic disaster".

Traditionally, the end of the Migration Period has been regarded as a time with major changes in the archaeological material. In a Norwegian context, the abandonment of many Migration Period farms in Rogaland in particular has been understood as a society in some kind of crisis (Myhre 1972, 1978, 1980). The cessation of production of the distinctive western Norwegian bucket-shaped ceramics by the middle of the $6^{\text {th }}$ century AD (Kristoffersen \& Magnus 2010:46) is another important factor indicating a change in society. In Sweden, there are also sudden changes in the settlement patterns. Arrhenius (1983:68) finds that a transition phase occurs about AD 550 and Jørgensen (1997) demonstrated that a change in women's clothing occurred around AD 540. The wealth of gold and prestige goods from burial mounds ceases in $6^{\text {th }}$ century AD, probably because of the offerings of precious prestige objects like gold bracteates and gold rings increased dramatically by the mid AD 500s. Axboe $(1999,2001)$ believes that the constantly clouded sky and damaged crops would have been regarded as a fundamental threat to society and may have spurred religious acts and led to requests for different sacrifices and offerings - including the offering of the most precious gold artefacts that have been found. He therefore sees the events of AD 536 to be a satisfactory explanation for the many finds of offerings dated to the first half of the $6^{\text {th }}$ century AD. The largest burial mound in Norway - Raknehaugen in Romerike, $90 \mathrm{~m}$ in diameter and $19 \mathrm{~m}$ high, consisting of three thick layers of logs separated by thick layers of soil - was erected in the period AD 533-551 (Skre 1997:31). This burial construction may also be considered as a communal sacrifice to the gods. Likewise, the purpose of the very small fragments of human remains in the bottom of the mound may also have been sacrifice.

There are many papers dealing with the dust veil of AD 536-537 and its severe effects on society. Jones (2000) has investigated developments in Britain using all possible data and source material. In Britain, the Britons started a retaliation against the newly arrived Anglo-Saxons in AD 460 and won a decisive battle at Bandon Hill in AD 500. The Romano-British society thrived and, to a certain extent, life in towns and trade with Gaul continued. Fortified hillforts were centres of imports, including amphora containing wine, oil or other commodities - as well as fine dining ware. The time before and after Bandon Hill is referred to as "years of good, stable government" by Gildas, but the period after AD 540 is described as "a time when spiritual corruption and political chaos set in". A massive emigration of Britons to Armorica took place, transforming
Armorica into Brittany and the elite wares of exotic goods were replaced by utilitarian kitchen wares. Soon after this emigration, the Britons are not traceable in the archaeological record, while an Anglo-Saxon expansion in Britain began around AD 550, supported by invaders from the Nordic countries, judging by graves such as Sutton Hoo and the overall distribution of items such as saucer and cruciform brooches. Probably, many Britons also suffered from genocide or were assimilated. Jones therefore thinks that the AD 536 dust veil was one of two incidents that caused the breakdown of the Romano-British society in the middle of the $6^{\text {th }}$ century. The other factor is thought to be the Plague of Justinian, which is reported to have appeared in Ireland and Wales soon after AD 540. The Britons were more vulnerable to the plague than the Anglo-Saxons because of their trade connections to Gaul and Brittany, while the Anglo-Saxons had no trade to that area. Jones's conclusion is that "the event (536) and its aftermath provide plausible explanations for the disappearance of British culture in Anglo-Saxon areas" (Jones 2000:33). I think that the severe effects he has disclosed in Anglo-Saxon and Briton society are, in many ways, similar to Nordic societies and important to understanding why significant changes also took place in the Nordic region. And probably, the renewed Anglo-Saxon invasion after AD 550 was brought about by the famine after the dust veil incident in the Anglo-Saxon homelands.

Young (2000) argues that AD 535 is the dividing line between classical and modern times. Theodoric the Great, the ruler of Italy (AD 493-526) claimed to be the legal and official agent of the eastern Emperor in Constantinople; he showed great respect for the Roman senate and enforced Roman laws and governed with the help of highly qualified Roman officials, maintaining the roads, the water system and other public infrastructure, while also asserting leadership through the traditional diplomatic techniques of marriage, alliance and giftexchange. He also built himself a splendid mausoleum in Ravenna in the style and manner of the highest Roman aristocracy, regarding himself as a part of an ongoing Roman Empire, whose amenities and institutions he did his best to preserve - which he did successfully during the first quarter of the $6^{\text {th }}$ century AD (Young 2000:38). After AD 536, the Gothic wars devastated Italy as a result of Constantine's attempt to conquer Italy, where Belisarius's army besieged and occupied Rome in 536. Not much of the administrative and technical infrastructure survived these wars, which continued until the Ostrogoths were eliminated around AD 550 - but the bishops stepped into the power void, taking responsibility for exercising 
effective local power. Later, in AD 568, the barbaric, pagan Lombards, who conquered the northern area and the mountainous spine of Italy while the Byzantines held the coast and some towns, caused extensive damage to whatever urban infrastructure and rural landscape that had been spared in the Gothic wars. Thus, a state of political and cultural division was created, animated by frequent warfare that became the Italian way of life. The dust veil of AD 536 and the outbreak of the Plague of Justinian were certainly important factors in the process of redesigning Italy in the middle of the $6^{\text {th }}$ century AD, but warfare and political forces must have been more important.

Also Gaul witnessed the beginning of sweeping political changes in the year AD 536, but less apparently catastrophic than in Italy. The Frankish success of AD 480-536, forging Frankish war bands into an effective kingdom, was the origin of the long-term shift in political, economic and cultural power from the surviving late Antique cultural institutions to the new, more rural, local and feudal institutions in the late $6^{\text {th }}$ century AD. Did the cataclysmic environmental events in the aftermath of $\mathrm{AD}$ 536 play a role in that shift? (Young 2000:39). In the 50 years after AD 536, Gregory of Tours report droughts, thunderstorms, rains provoking flooding, excessively cold weather, famine - particularly in conjunction with war and several outbursts of plague (probably the Plague of Justinian) (Young 2000:40f).

Not all of these natural disasters occurring after AD 536 and throughout the $6^{\text {th }}$ century can be directly related to the AD 536 event. As Tanner (2000:93f) shows, a cooler climate period began around AD $550 \pm 50$ and lasted to approximately AD 800-850. The climate in this period seems to have been colder than the climate in the Little Ice Age and this probably explains the climatic hardships that occurred in the aftermath of AD 536. However, the observed changes to the sky in AD 536 have not been described in relation to the Little Ice Age. So the AD 536 event, whether the cause was a volcanic eruption or the impact of a meteorite, probably occurred by chance at the beginning of this 300 -year cold period.

The AD 536 event also seems to have impacted the course of the Mayan civilisation. As Robichaux (2000:48f) shows, the two neighbouring Mayan regional states Tikal and Caracol responded differently to the AD 536 event. Both ceased to erect stelae after AD 536, but while the Tikal people - with one exception in AD 553 for a new ruler appointed in AD 536 - did not set up stelae again until AD 692, many monuments were erected by the Caracol people throughout the entire period. It seems that the people in lowland Tikal were more vulnerable to the climate changes that followed the AD 536 event than was the case in Caracol, which was situated at a higher elevation. Chase and Chase (2000) propose that Caracol defeated Tikal in a war after AD 536 and that Caracol became the leading power in the area for a century and a half.

Extreme weather conditions also characterise the decade following AD 536 in Chinese historical accounts (Houston 2000). The stars were not visible in the spring and autumn equinoxes in AD 536 due to the clouds and, in the Quing state, frost and snow in July and August killed the seedling crops, causing a major famine that autumn. The problems continued in the years AD 537 and AD 538 and, in a kingdom north of the Yellow River, 70-80 \% of the people perished. The Chinese records bear information on responses undertaken to adapt to the cold and drought following AD 536, when crop yields were diminished and less grain tax could be collected. The Northern Wei was split in two states, probably as an adaption to more limited resources.

\subsection{Can the volume of ${ }^{14} \mathrm{C}$ dates reveal if the decline of Forsandmoen is related to the AD 536 eruption?}

Is it possible to explore how fast and in what period the settlement suffered the abandonment? From the excavations at Forsandmoen, 168 houses, or houses phases (Table 3) have been radiocarbon dated using 210 charcoal samples (Fig. 10).

If we look closely at the dates from the late Roman Iron Age, the Migration Period and the Merovingian Period - altogether 108 houses and house phases dated by 128 radiocarbon dates - and we use 25 -year intervals instead of 50-year intervals as in Fig. 10, and if the dates are only included if at least 15 years of the 1 deviation probability is within each quarter-century, we get a more nuanced picture (Fig. 102). The level of dates is constant from the early AD 100s and for 400 years, but with a peak for a century from AD 225-325. Here, we see that, in the period from $\mathrm{AD} 550$ to 575 , the number of dates is reduced by half, which must mean that it is during the decades around AD 550 and not towards AD 600 that the settlement changed in size. Many of the dates in the period AD 550-600 are found at the latest parts of the dating uncertainty. The decline is therefore actually more powerful than the graph suggests.

Another way to shed light on the issue is to record how midpoints of the dating uncertainty are distributed to 50and 25-year periods, respectively. The graph with 50-year intervals (Fig. 103) shows that, between AD 400 and AD 550 , each 50 -year period counts for between ten and 16 
dates, while afterwards it is between zero and four dates. The number of dates is reduced to one-third from the first to the second half of the $6^{\text {th }}$ century AD. Breaking the number of midpoint dates down to 25-year intervals, the graph (Fig. 104) shows a marked change from the two 25-year periods AD 475-525 - with eleven and 13 dates to only 1-2 dates for most periods from AD 525-550 and the next 250 years. It is tempting to interpret this as an expression that something has happened in society before the middle of the $6^{\text {th }}$ century AD.

These graphs leave no doubt that the large settlement at Forsandmoen was practically laid waste in the first half of the $6^{\text {th }}$ century AD, and most likely between AD 525 and 550. On the basis of the evidence and argument presented by Gräslund (2007) and the other evidence presented above, I believe that the climate crisis after the volcanic eruption in AD 536-537 must have been by far the most important cause for this ruin. The situation at Forsandmoen can be seen as evidence that this climate crisis had such a devastating effect on Norse society that it reasonably would be subject to the development of the myth known as the Fimbulwinter tale.

However, if the settlement was laid waste through the hard Fimbulwinter period of AD 536-545 we must ask why the settlement was not re-established when the weather returned to normal? One or to two farms continued on the plain for at least another 150 years and three dates until the late 700s may indicate that a single farm existed almost until the transition to the Viking Period. Using these graphs, we can draw conclusions about this lengthy final phase. This is not the place to delve into the causes, but a possible explanation must be outlined.

We can conclude that the climate crisis in AD 535/36545 was followed by a colder and wetter climate beyond the $6^{\text {th }}$ century AD, according to many contemporary sources in Europe (Lamb 1981, Tanner 2000). This probably also had an effect on Rogaland and at Forsandmoen, causing a more waterlogged soil when the settlement was abandoned. Meanwhile, we can see that the moor began spreading out from about AD 550 (Prøsch-Danielsen 1996), which would have initiated an increasing podzolisation process and, within a few generations, would have transformed the plain into a barren heathland with a water-impermeable hardpan that made crop production impossible until modern drainage techniques could be employed. After a time, the remaining and possibly increasing population after the difficult years in the last second half of the $6^{\text {th }}$ century AD would not have been able to move back to the moor. The large settlement through 400 years of the late Roman Iron Age and Migration Period had exploited the resource base to the

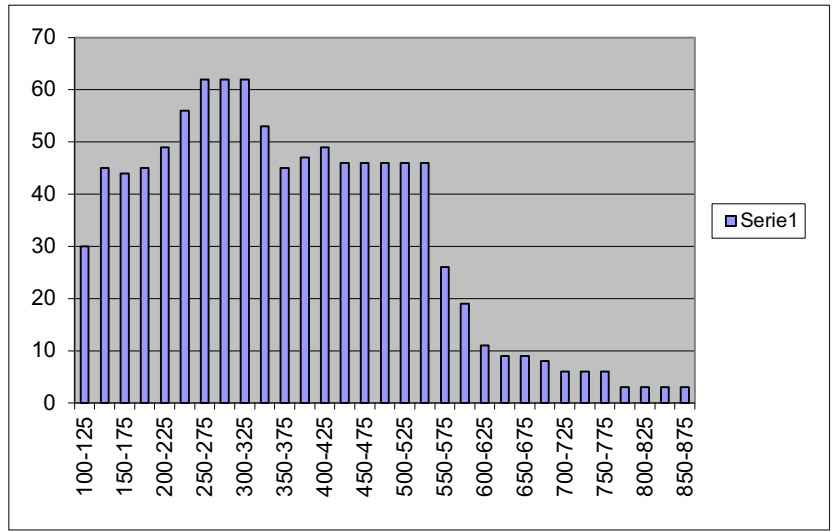

Fig. 102. Graphical representation of 128 radiocarbon dates, using I standard deviation, recorded in 25-year intervals, in the Roman Iron Age, the Migration Period and the Merovingian Period.

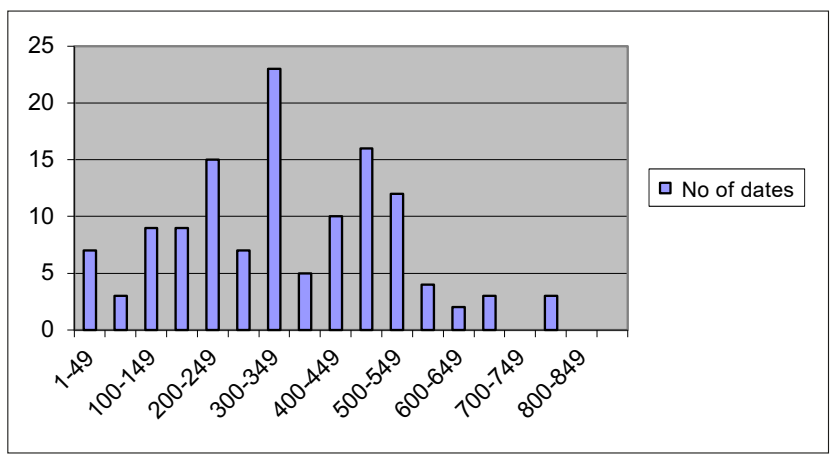

Fig. 103. Graphical representation showing the number of midpoints of the dating uncertainty distributed to 50-year periods, in the Roman Iron Age, the Migration Period and the Merovingian Period.

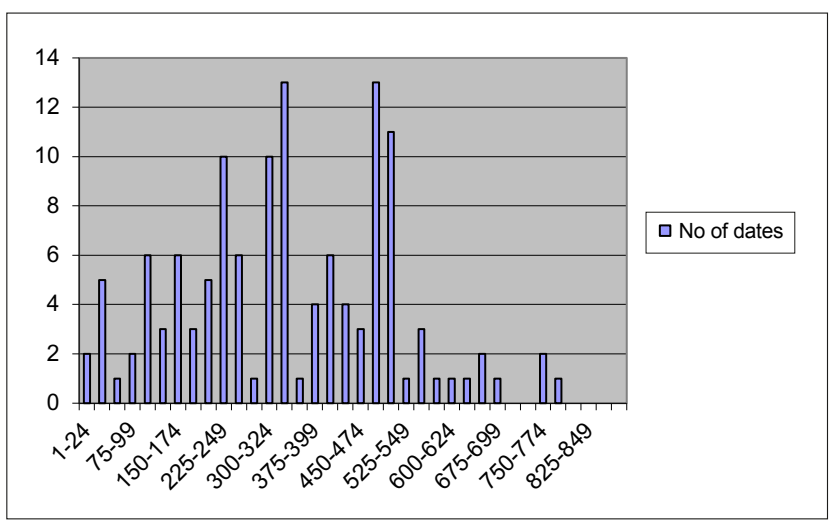

Fig. 104. Graphical representation showing the number of midpoints of the dating uncertainty distributed to 25-year periods, in the Roman Iron Age, the Migration Period and the Merovingian Period.

limit, so the area was no longer attractive as a settlement area. The effects of the environmental changes known as the Fimbulwinter and the subsequent Late Antique Little Ice Age (Little 2007) therefore had an enduring and devastating effect on the 2200-year-old settlement at Forsandmoen. 


\section{References}

Andersen, B. G. 1992. Jens Esmark - a pioneer in glacial geology. Boreas Pioneer series 21.Taylor \& Francis, Oslo, 97-102.

Arén, E. 1992. Rekonstruktion av ett långhus - har vi nogot att lära av det? Västmanlands fornminnesförening Årsskrift. Västmanlands läns museum, Västerås, 117-132.

Arjave, A. 2007. The mystery Cloud of the Year 536 CE in the Mediterranean Sources. Dumbarton Oaks Papers 59. Harvard University Press, Cambridge, Mass, 73-94.

Armstrong, N. 2007. Forstadsvikinger på Tasta. Frá haug ok heiðni 1. Rogalands arkeologiske forening, Stavanger, 3-9.

Armstrong, N. 2008. Hus frå eldste og yngste jernalder på Tasta. Frá haug ok heiðni 1. Rogalands arkeologiske forening, Stavanger, 17-23.

Arrhenius, B. 1983. The chronology of the Vendel graves. In Lamm, J. P. \& Nordström, H.-Å. (eds.). Vendel Period Studies. Statens Historiska Museum, Stockholm, 39-70.

Artursson, M. 2005a. Byggnadstraditionen. In Lagerås, P. \& Strömberg, B. (eds.). Bronsåldersbygd: 2300-500 f. Kr. Skånska spår - arkeologi längs Västkustbanan. Riksantikvarieämbetet, UV Syd, 20-83.

Artursson, M. 2005b. Gårds- och bebyggelsestruktur. In Lagerås, P. \& Strömberg, B. (eds.). Bronsåldersbygd : 2300$500 f$. Kr. Skånska spår - arkeologi längs Västkustbanan. Riksantikvarieämbetet, UV Syd, 84-159.

Axboe, M. 1999. The year 536 and the Scandinavian gold hoards. Medieval Archaeology vol. 43. Society for Medieval Archaeology, London, 186-188.

Axboe, M. 2001. Amulets Pendants and Darkened Sun. In Magnus, B. (ed). Roman Gold and the Development of the Early Germanic Kingdoms : aspects of technical, socio-political, socio-economic, artistic and intellectual development, A.D.1-550 : Symposium in Stockholm 14-16 november 1997. Konferenser 51, Kungl. Vitterhets Historie och Antikvitets Akademien, Stockholm, 119-136.

Bakkevig, S. 1980. Phosphate Analysis in Archaeology Problems and Recent Progress. Norwegian Archaeological Review vol. 13, no. 2. Scandinavian University Press, Oslo, 73-100.

Bakkevig, S. 1981a. Kjemisk arkeologi - om fosfatanalyse. Frá haug ok heiðni 4. Rogalands arkeologiske forening, Stavanger, 308-315.

Bakkevig, S. 1981b. Results obtained in the Field by use of Phosphate Spot Test in Norway, and the cost and Utility compared to other methods. Revue d'Archeometrie 5. Le Groupe, Rennes, 81-88.

Bakkevig, S. 1982a. Part 2. Macrofossil Analysis - Salt Water Flotation Material from Rugland in Jæren. In Lillehammer, A. (ed.). Explore Interdisciplinary Boundaries, AmSskrifter 9. Arkeologisk museum i Stavanger, 41-56.

Bakkevig, S. 1982b. Three-dimensional field mapping of phosphate content in archaeological sites. PACT Journal 7. Conseil de l'Europe, Assemblée parlementaire 1977, Strasbourg, 279-284.
Bakkevig, S. 1983. Fosfatanalyse som forundersøkelsesmetode - noen norske erfaringer. Rapport RÄ̈ 1 . Riksantikvarieämbetet och Statens Historiska Museer, Stockholm, 38-43.

Bakkevig, S. 1991. Charred seeds from Forsandmoen, a prehistoric village in SW-Norway. Methods of retrieval and results from the Bronze Age. In Hajnalová, E. (ed.). Palaeoethnobotany and Archaeology. International WorkGroup for Palaeoethnobotany 8th Symposium, Nitra-Nové Vozokany 1989. Acta Interdisciplinaria Archaeologica VII. Archaeological Institute of the Slovak Academy of Sciences, Nitra, 29-36.

Bakkevig, S. 1992. Prehistoric Cereal Raising at Forsandmoen, South-Western Norway. Changes between the Bronze Age and the Iron Age. Laborativ Arkeologi 6. Arkeologiska forskningslaboratoriet, Stockholms universitet, 49-55.

Bakkevig, S. 1995. Neue makrofossile Beiträge zur Kenntnis des vorhistorischen Getreideanbaus in Südwestnorwegen. In Kroll, H. \& Pasternak, R. (eds.). Res archaeobotanicae : proceedings of the nineth Symposium Kiel 1992. International Workgroup of paleoethnobotany (IWGP), Kiel, 5-15.

Bakkevig, S. 1998. Problemer i bronsealderens korndyrking på Forsandmoen, Rogaland, SV-Norge. In Løken, T. (ed.). Bronsealder i Norden - Regioner og interaksjon, AmS-Varia 33. Arkeologisk museum i Stavanger, 55-62.

Bakkevig, S. \& Løken, T. 1985. Rapport om fosfatkartering av Forsandmoen, gnr. 37 og 41, Forsand kommune. Rapport i topografisk arkiv, Arkeologisk museum i Stavanger.

Bang-Andersen, S. 2003. Encircling the living space of Early Postgacial reindeer hunters in the interior of southern Norway. In Larson, L. (ed.). Mesolithic on the Move. Papers presented at the Sixth International Conference on the Mesolithic in Europe, Stockholm 2000. Oxbow Books, Oxford, 194-204.

Baudou, E. 1960. Die regionale und chronologische Einteilung der jüngeren Bronzezeit im Nordischen Kreis. Studies in North European Archaeology 1. Almqvist \& Wiksell International, Stockholm.

Bech, J. H. 2003. The Thy Archaeological Project. In Thrane, Henrik (ed.). Diachronic Settlement Studies in the Metal Ages. Jysk Arkæologisk selskabs skrifter 45. Jutland Archaological Society, Højbjerg, 45-60.

Becker, C. J. 1965. Ein früheisenzeitliches Dorf bei Grøntoft, Westjütland. Vorbericht über die Ausgrabungen 1961-63. Acta Archaeologica XXXVI. Munksgaard, København, 209-222.

Becker, C. J. 1968. Das zweite Früheisenzeitliche Dorf bei Grøntoft, Westjütland. 2. Vorbericht. Acta Archaeologica XXXIX. Munksgaard, København, 235-255.

Becker, C. J. 1971. Früheisenzeitliche Dörfer bei Grøntoft, West-jütland. 3. Vorbericht: Die Ausgrabungen 1967-68. Acta Archaeologica XLII. Munksgaard, København, 79-110. 
Becker, C. J. 1972. Hal og hus i yngre bronzealder. Nationalmuseets Arbejdsmark. København, 5-16.

Becker, C. J. 1980. Bebyggelsesformer i Danmarks yngre bronzealder set i forhold til ældste jernalders landsbysamfund. Bronzealderbebyggelsen i Norden. Skrifter fra Historisk institut, Odense Universitet 28, 127-141.

Benedictow, O. J. 1993. The Medieval Demographic System of the Nordic Countries. Middelalderforlaget, Oslo.

Bennet, A. 1985. Karleby och Gärtuna. Bebyggelse och gravar från bronseålder och järnålder $i$ Östertälje socken i Södermanland. Rapport UV 1984:29, Riksantikvarieämbetet.

Berg, E. 1997. Gård og grav på Rør i Rygge, Østfold. Dobbeltsporprosjektet. Arkeologiske undersøkelser 19941996. Varia 47, Universitetets Oldsaksamling, Oslo.

Berge, J. 2007. Undersøking av hustomter frå slutten av yngre steinalder og eldre bronsealder Kleppe, gnr.1, bnr. 22, Kleppestemmen, Klepp k. Oppdragsrapport. Arkeologisk museum i Stavanger.

Berggren, Å. \& Celin, U. 2004. Öresundsförbindelsen. Burlöc 20 C. Rapport över arkeologisk slutundersökning. Rapport 36, Malmö Kulturmiljö.

Berglund, A. \& Sjölin, M. 2005. Arbetet på fältet - om metod och dokumentasjon. Arkeologiska möten utmed väg 26, Borgunda - Skövde. Skrifter från Västergötlands museum 33. Skara, 22-36.

Berntsen, O. S. \& Pilskog, F. 1998. Rapport om den arkeologiske undersøkinga på Sandved, Skeiane, 40/246 og Brueland, 41/22, Sandnes k., Rogaland fylke. Innberetning i topografisk arkiv, Arkeologisk museum i Stavanger.

Bertelsen, J. B., Christensen, M., Mikkelsen, M., Mikkelsen, P., Nielsen, J. \& Simonsen, J. 1996. Bronzealderens bopladser $i$ Midt- og Nordvestjylland. Skive museum.

Biörnstad, A. 1955. Previous investigation of Iron Age building remains on Gotland. In Stenberger, M, (ed). Vallhagar. A migration period settlement on Gotland, Sweden. Munksgaard, København, 873-977.

Bjørdal, E. 2007. Rapport frå undersøking av område med treskipa langhus frå folkevandringstid, eldstadar og kokegroper i Dirdal. Dirdal, gnr 78/bnr 2, Gjesdal kommune. Oppdragrapport B 15. Arkeologisk museum i Stavanger.

Bjørdal, E. 2011. Hus og grav frå jernalderen - om ei arkeologisk utgraving i Fedjedalen i Haugesund kommune. Frá haug ok heiðni 2. Rogalands arkeologiske forening, Stavanger, 18-22.

Björhem, N. \& Säfvestad, U. 1993. Fosie IV. Bebyggelsen under brons- och järnålder. Malmöfynd 6. Malmö museer.

Björhem, N. \& Magnusson Staaf, B. 2006. Öresundsförbindelsen \& arkeologin. Långhuslandskapet. En studie av bebyggelse och samhälle från stenålder till järnålder. Malmöfynd 8, Malmö kulturmiljö.

Bjørlo, A. H. 2011. Et førromersk gårdsanlegg og vikingtidsgraver på Skadberg, Sola kommune. Frá haug ok heiðni 3. Rogalands arkeologiske forening, Stavanger, 8-15.

Boas, N. A. 1991. Bronze Age Houses at Hemmed Church, East Jutland. Journal of Danish Archaeology 8/1989. Odense, 88-107.

Bonde, N. 1991. Dendrokonologiske dateringsundersøgelser i Nationalmuseet 1991. Arkcologiske udgravninger i Danmark 1991. Det Arkæologiske Nævn, København, 255-271.

Borna-Ahlkvist, H. 1998. Gruppering av olika hustyper i Pryssgården. In Borna-Ahlkvist, H., Lindgren-Hertz, L. \& Stålbom, U. (eds). Pryssgården. Från stenålder til medel- tid. Arkeologisk slutundersökning RAÄ 166 och 167 Östra Eneby socken Norrköpings kommun Östergötland. Rapport 13, Riksantikvarieämbetet UV Linköping, 28-52.

Boysen, A. \& Andersen, S. W. 1983. Trappendal. Barrow and House from the Early Bronze Age. Journal of Danish Archaeology 2. Odense, 118-126.

Briner, J. P., Svensen, J. I., Mangerud, J., Lohne, Ø. S. \& Young, N. E. 2014. A ${ }^{10}$ Be chronology of south-western Scandinavian Ice Sheet history during the Lateglacial period. Journal of quaternary science 29 (4). Quarternary reseach assosiation, Wiley, 370-380.

Broberg, A. 2004. Mellansvensk bebyggelsearkeologi. En forskningsöversikt med blicken riktad mot 90-tallets uppdragsarkeologi. In Kyhlberg, O. (ed.). Arkeologi $i$ Attundaland. Skrifter 4. Riksantikvatieämbetet, Arkeologiska Undersökningar, Stockholm, 32-51.

Brøgger, A. W. 1925. Det norske folk $i$ oldtiden. Instituttet for sammenlignende kulturforskning. Aschehoug, Oslo.

Brøgger, A. W. 1927. Norsk arkeologmøte, Oslo, 9.-10. desember 1927. Universitetets Oldsaksamling Årbok, Første Årgang. Oslo, 90-108.

Børsheim, R. \& Soltvedt, E-C. 2002. Gausel - utgravningene 1997-2000. AmS-Varia 39, Arkeologisk museum i Stavanger.

Bårdseth, G. A. 2008. Kulturhistorisk syntese. In Bårdseth, G. A. (ed.). Evaluering - resultat. E6-prosjektet Østfold. Band 5. Varia 69. Kulturhistorisk museum, Oslo, 79-104.

Bårdseth, G. A. \& Sandvik, P. U. 2007a. Borge vestre. Gardsbusetjing frå yngre bronsealder og førromersk jernalder. In Bårdseth, G. A. (ed.). Hus og gard langs E6 $i$ Råde kommune. E6-prosjektet Østfold. Band 1. Varia 65. Kulturhistorisk museum, Oslo, 57-122.

Bårdseth, G. A. \& Sandvik, P. U. 2007b. Missingen. Ein Storgard frå romartid (lokalitet 4 og 5). In Bårdseth, G. A. (ed.). Hus og gard langs E6 i Råde kommune. E6-prosjektet Østfold. Band 1. Varia 65. Kulturhistorisk museum, Oslo, 123-191.

Bårdsgård, I. J. 1980a. Innberetning om utgravning om gravrøys 78-177 F4 X4, Forsand gnr. 41, Forsand k. Rapport i topografisk arkiv, Arkeologisk museum i Stavanger.

Bårdsgård, I. J. 1980b. Innberetning om utgravning om gravrøys 78-177 F4 X5, Forsand gnr. 41, Forsand k. Rapport i topografisk arkiv, Arkeologisk museum i Stavanger.

Bårdsgård, I. J. 1982. Boligsituasjonen i Rogaland i bronsealder og førromersk jernalder. Nicolay 38. Arkeologistudentene ved IAKH, Universitetet i Oslo, 23-32.

Carlie, L. 1992. Brogård - ett brons- och järnålderskompleks $i$ södra Halland. Dess kronologi och struktur. Skrifter № 6 . Hallands länsmuseer, Lund.

Carlie, L. 1999. Bebyggelsens mangfald. En studie av södra Hallands järnåldersgårdar baserad på arkeologiska och historiska källor. Acta archaeologica Lundensia. Series in $8^{\circ}$. No. 29 (diss). Lunds universitet. Almqvist \& Wiksell international, Stockholm.

Casselberry, S. E. 1974. Further refinement of formulae for determining population from floor area. World Archaeology 6. Taylor \& Francis Group, England, 117-126.

Casselberry, S. E. 1975. More on a Demographer`s view of Prehistoric Demography. Current anthropology 16. University of Chicago Press, 640.

Chase, A. F. \& Chase, D. Z. 2000. Sixth and seventh century variability in the Southern Maya Lowlands: centralization and integration at Caracol, Belieze. In Gunn, J. D. (ed.). The Years without summer. Tracing A.D. 536 and its aftermath. 
BAR International Series 872. Archaeopress, Oxford, $55-66$.

Cunliffe, B. 2002. The Extraordinary Voyage of Pytheas the Greek: The Man Who Discovered Britain (Revised ed.). Walker, New York.

Dahl, B. I. 2007. Rv - 44 Omkjøringsvei Kleppe. Delrapport Kleppevarden. Oppdragsrapport B, 13, Arkeologisk museum i Stavanger.

Dahl, B. I. 2008. Arkeologisk utgravning på Forsandmoen 2007. Forsand gnr. 41, bnr. 4. Oppdragsrapport B, 15, Arkeologisk museum i Stavanger.

Dahl, B. I. 2014a. Arkeologisk utgraving av hus og graver. Myklebust gnr. 3, Sola kommune, Rogaland. Oppdragsrapport B, 20, Arkeologisk museum, Universitetet i Stavanger.

Dahl, B. I. 2014b. Sju nye langhus i Bergevik på Forsandsneset. Frá haug ok heiðni 2. Rogalands arkeologiske forening, Stavanger, 18-22.

Diinhoff, S. 1996. Hornnes-prosjektet. De arkeologiske bopladsudgravninger på Hornnes, gnbr. 20/7, Førde k, Sogn og Fjordane. Rapport, Historisk museum, Universitetet i Bergen.

Diinhoff, S. 2003. Arkæologiske frigivningsundersøgelser $i 2001$ og 2002 ved Osen gard, gnr. 94, bnr. 1. Gaular kommune, Sogn og Fjordane. Rapport, Bergen Museum.

Diinhoff, S. 2005a. Den vestnorske agrarbosetningen. Fra sen stenalder til folkevandringstid. Arkeologiske resultater fra et tiår med fladeafdækninger på Vestlandet. In Høgestøl, M., Selsing, L., Løken, T., Nærøy, A. J. \& Prøsch-Danielsen, L. (eds.). Konstruksjonsspor og byggeskikk. Maskinell flateavdekking - metodikk, tolkning og forvaltning. AmS-Varia 43, Arkeologisk museum i Stavanger, 77-87.

Diinhoff. S. 2005b. En kritisk evaluering av fladeafdekning som udgravingsmetode. In Høgestøl, M., Selsing, L., Løken, T., Nærøy, A. J. \& Prøsch-Danielsen, L. (eds.). Konstruksjonsspor og byggeskikk. Maskinell flateavdekking - metodikk, tolkning og forvaltning. AmS-Varia 43, Arkeologisk museum i Stavanger, 67-73.

Diinhoff, S. 2006. En bronsealders bosætning ved Fremre Øygarden i Lærdal. In Barndon, R., Innselset, S. M., Kristoffersen, K. K. \& Lødøen, T. K. (ed.). Samfunn, symboler og identitet - Festskrift til Gro Mandt på 70-års dagen. UBAS Universitetet i Bergen Arkeologiske skrifter, Nordisk 3. Universitetet i Bergen, 67-85.

Diinhoff, S. \& Hjelle, K. 2003. Udgravningsrapport. Rutlin, gbnr. 22/4, Sogndal kommune, Sogn og Fjordane. Rapport, Bergen Museum.

Dyrvik, S. \& Feldbæk, O. 1996. Mellom brødre 1780-1830. Aschehougs norgeshistorie bind 7. Aschehoug, Oslo.

Eriksen, M. H. 2015. Portals to the past. An archaeology of doorways, dwellings, and ritual practice in Late Iron Age Scandinavia. (diss). Department of archaeology, conservation and history, University of Oslo.

Eriksson, T. 1995. Hus och gravar i Görla. Rapport 29, Riksantikvarieämbetet, UV-Stockholm.

Eriksson, T. 1998. Egen härd guld värd - härdar från äldre järnålder i sydvästra Uppland. In Anderson, K. (ed.). Suionum Ninc civitates. Nya undersökningar kring norra Mälardalens äldre järnålder. Occasional Papers in Archaeology (OPIA) 19. Institutionen för arkeologi och antik historia, Uppsala universitet, 211-237.

van Es, W. A. 1967. Wijster. A native village beyond the imperial frontier 150-425 A.D. Palaeohistoria XI. Goeningen Institute of Archaeology, Rotterdam.
Esmark, J. 1823. Bidrag til vor Jordklodes Historie. Magazin for Naturvidenskab.

Espedal, O. 1966. Espeland. Frá haug ok heiðni 3. Rogalands arkeologiske forening, Stavanger, 237-241.

Espedal, O. 1967. Ei yngre romertids hustuft på Espeland i Høyland. Frá haug ok heiðni 4. Rogalands arkeologiske forening, Stavanger, 85-88.

Ethelberg, P. 1988. Die Eisenzeitliche Besiedlung von Hjemsted Banke, Skjærbæk Sogn, Sønderjyllands Amt. Offa 45. Karl Wacholt, Neumünster, 119-153.

Ethelberg, P. 1993. Two more House Groups with Threeaisled Long-houses from the Early Bronze Age at Højgård, South Jutland. Journal of Danish Archaeology 10. Odense, 136-156.

Ethelberg, P. 2000. Bronsealderen. In Madsen, L.S. \& Madsen, O. (ed.). Det Sønderjyske Landbrugs Historie. Sten- og bronsealder. Skrifter 81. Haderslev museum og Historisk Samfund for Sønderjylland, Haderslev, 135-280.

Ethelberg, P. 2003. Gården og landsbyen i jernalder og vikingetid (500 f.Kr. -1000 e.Kr.). In Madsen, L.S. \& Madsen, O. (eds.). Det Sønderjyske Landbrugs Historie. Jernalder, vikingetid \& middelalder. Skrifter 82. Haderslev museum og Historisk Samfund for Sønderjylland, Haderslev, 123-371.

Fabech, C. 1991. Samfundsorganisation, religiøse ceremonier og regional variation. In Fabech, C. \& Ringtvedt, J. (eds.) Samfundsorganisation og regional variation. Norden $i$ romersk jernalder og folkevandringstid. Jysk arkæologisk Selskabs Skrifter XXVII. Højbjerg, 283-303.

Fagerlund. D. 2007. Stora hus från äldre järnålder. In Götberg. H. (ed.). Hus och bebyggelse i Uppland. Delar av förhistoriska sammanhang. Arkeologi E4 Uppland 3. Upplandsmuseet, Riksantikvarieämbetet, Societas Archaeologica Upsaliensis. Uppsala, 173-194.

Farbregd, O. 1980. Perspektiv på Namdalens jernalder. Undersøkingar på Veiem, Sem, Værem og Bertnem. Viking XLIII. Norsk arkeologisk selskap, Oslo, 20-80.

Floor, J. 1980. Rapport fra ØK-registrering, Forsand kommune. Rapport i topografisk arkiv, Arkeologisk museum i Stavanger.

Fokkens, H. 1999. Cattle and martiality: changing relations between man and landscape in the late Neolithic and the Bronze Age. In Fabech C. \& Ringtvedt, J. (eds.). Settlement and Landscape. Proceedings of a conference in Århus, Denmark, May 4-7 1998. Jutland Archaeological Society, Århus, 35-44

Fonnesbech-Sandberg, E. 1992. Problemer i østsjællandsk bopladsarkæologi. In Hansen, U. L. \& Nielsen, S. (eds.) Sjellands jernalder. Beretning fra et symposium 24. IV. 1990 i København. Arkæologiske Skrifter 6. Arkæologisk Institutt, Københavns Universitet, 21-36.

Frey, E. H. 2010. Byggeskikk $i$ Trøndelag gjennom eldre jernalder - belyst ved materiale fra moderne flategravninger. Masteroppgave i arkeologi, Institutt for arkeologi og religionsvitenskap, NTNU.

Gellein, K. 2000. Undersøkelse av frigitt gravrøys 78-177 H4 R14, Forsand, 41/3, 23, Forsand k., Rogaland. Innberetning i topografisk arkiv, Arkeologisk museum i Stavanger.

Gellein, K. \& Skjelstad, G. 2001. En gravrøys fra folkevandringstid på Forsand. Frá haug ok heiðni 1. Rogalands arkeologiske forening, Stavanger, 32-36.

Gerritsen, F. 1999. The cultural biography of Iron Age houses and the long term transformation of settlement pattern in the southern Netherlands. In Fabech C. \& Ringtvedt, J. (eds.). Settlement and Landscape. Proceedings of a 
conference in Århus, Denmark, May 4-7 1998. Jutland Archaeological Society, Århus, 139-148.

Gerritsen, F. 2003. Local Identities. Landscape and community in the late prehistoric Meuse-Demer-Schelde region. Amsterdam Archaeological Studies 9. Amsterdam University Press.

Gil Bell, T. 2008. Arkeologisk utgravning, Løland, Forsand kommune. Innberetning i topografisk arkiv, Arkeologisk museum i Stavanger.

Gjerpe, L. E. 2008a. Kapittel 3 Hus. In Gjerpe, L. E. (ed.). Kulturhistoriske, metodiske og administrative erfaringar. E18-prosjektet Vestfold bind 4. Varia 74. Fornminneseksjonen, Kulturhistorisk museum, Oslo, 21-44.

Gjerpe, L. E. 2008b. Kapittel 6 Radiokarbondateringer - kulturhistoriske og kildekritiske erfaringer. In Gjerpe, L. E. (ed.). Kulturhistoriske, metodiske og administrative erfaringar. E18-prosjektet Vestfold bind 4. Varia 74. Fornminneseksjonen, Kulturhistorisk museum, Oslo, 85-95.

Gjerpe, L. E. 2017. Effektive hus. Bosetning, jord og rettigheter på Østlandet i jernalderen. (diss). Institutt for arkeologi, konservering og historie, Universitetet i Oslo.

Gjerpe, L. E. \& Østmo, M. 2008. Kapittel 3 Ringdal 13 - Hus fra romertid-merovingertid og graver fra førromersk jernalder. In Gjerpe, L. E. (ed.). Hus, boplass- og dyrkingsspor. E18prosjektet Vestfold bind 3. Varia 73. Fornminneseksjonen, Kulturhistorisk museum, Oslo, 39-142.

Godal, J. B. 1994. Tre til tekking og kledning. Frå den eldre materialforståinga. Landbruksforlaget., Oslo.

Gräslund, B. 2007. Fimbulvintern, Ragnarök och klimatkrisen 536-537 e. Kr. Saga och Sed. Kungl. Gustav Adolfs Akademiens årsbok. Uppsala, 93-123.

Gröhn, A. 2004. Positioning the Bronze Age in social theory and research context. Acta archaeologica Lundensia, Series in $8^{\circ}$ no 47 (diss). Lunds universitet. Almqvist \& Wiksell, Stockholm.

Grønnesby, G. 1999. Eldre jernalders hus og hall på Hovde i Trøndelag. Viking LXII. Norsk arkeologisk selskap, Oslo, 69-80.

Grønnesby, G. 2006. Fra stolpehull til hushold. Utgravninger av hustomter på Kvenild, Trondheim, 1998. In Høgestøl, M., Selsing, L., Løken, T., Nærøy, A. J. \& Prøsch-Danielsen, L. (eds.). Konstruksjonsspor og byggeskikk. Maskinell flateavdekking - metodikk, tolkning og forvaltning. AmS-Varia 43. Arkeologisk museum i Stavanger, 97-107.

Gundersen, I. M. 2016. Brytningstid i Gudbrandsdalens jernalder. Natur- og kulturhistoriske forutsetninger for maktsenterutviklingen. In Gundersen, I. M. (ed.). Gård og utmark $i$ Gudbrandsdalen - Arkeologiske undersøkelser $i$ Fron 2011-2012. Portal forlag, Kulturhistorisk museum, Kristiansand, 318-331.

Gustafson, L. 2000. I Ryghs fotspor på Veien, Ringerike. Langhus, graver og stedsnavn. In Sandnes, B., Sandnes, J., Stemshaug, O. \& Stenvik, L. F. (eds.). Oluf Rygh. Rapport fra symposium på Stiklestad 13.-15. mai 1999. Nornarapporter 70 B. Norna-förlaget, Uppsala, 95-119.

Gustafson, L. 2001. The longhouses at Veien: a 'central place' in eastern Norway dating from the Roman Iron Age. In Brandt, J. R. \& Karlsson, L. (eds.). From huts to houses. Transformation of ancient societies. Proceedings of an International Seminar organized by the Norwegian and Swedish Institutes in Rome, 21-24. September 1997. Acta Instituti Romani Regni Sueciae, Series in $4^{0}$, LVI. Stockholm, 195-200.
Gustafson, L. 2005a. Hvor gammelt er huset? Om datering av langhusene på Veien, Ringerike. In Høgestøl, M., Selsing, L., Løken, T., Nærøy, A. J. \& Prøsch-Danielsen, L. (eds.). Konstruksjonsspor og byggeskikk. Maskinell flateavdekking - metodikk, tolkning og forvaltning. AmS-Varia 43. Arkeologisk museum i Stavanger, 45-56.

Gustafson, L. 2005b. Kokegroper på en jernaldergård Moer i Ås, Akershus. In Gustafson, L., Heibreen, T. \& Martens, J. (eds.). De gåtefulle kokegroper. Varia 58. Kulturminneseksjonen, Kulturhistorisk museum, Oslo, $116-124$.

Gustafson, L. 2016. Møter på Veien - kultplass gjennom 1500 år. Et maktsenter på Ringerike i eldre jernalder. Fornminneseksjonen, Kulturhistorisk museum. Portal forlag. Kristiansand.

Guttormsen, T. S. 1998. Arkeologiske undersøkelser på Moer nordre, gårdsnr. 54, bruksnr. 350, Ås kommune, Akershus fylke. Innberetning, Universitetets Oldsaksamling.

Göthberg, H. 2000. Bebyggelse i Förändring. Uppland från slutet av yngre bronsålder til tidig medeltid. Occasional Papers in Archaeology (OPIA) 25 (diss). Institutionen för arkeologi och antik historia, Uppsala universitet.

Göthberg, H., Kyhlberg, O. \& Vinberg, A. 1995. Hus och Gård. Hus och Gård i det förurbana samhället. Rapport från ett sektorforskningsprosjekt vid Riksantikvarieämbetet. Katalogdel. Skrifter 13, Riksantikvarieämbetet, Arkeologiska Undersökningar, Stockholm.

Hadevik, C. \& Gidlöf, K. 2003. Öresundsförbindelsen. Fosie 11A-D samt Broläge Larsbovägen. Rapport över arkeologisk slutundersökning. Rapport 22, Malmö Kulturmiljö.

Hagen, A. 1953. Studier i jernalderens gårdssamfunn. Universitetets Oldsaksamling Skrifter IV. Oslo

Hansen, T. E. 1987. Die Eisenzeitliche Siedlung bei Nørre Snede, Mitteljütland. Acta Archaeologica 58. Munksgaard, København, 171-200.

Helliksen, W. 1997. Gård og utmark på Romerike 1100 f.Kr. -1400 e.Kr. Gardermoprosjektet. Varia 45. Universitetets Oldsaksamling, Oslo.

Hemdorff, O. H. 1992. Innberetning om undersøkelse av langrøys, flyfotoreg.nr. 78-177 F4 R15, Forsand 41/3,23, Forsand $k$. Rapport i topografisk arkiv, Arkeologisk museum i Stavanger.

Hemdorff, O. H. 2006. Gårder og grav fra romersk jernalder, Austbø gnr. 7, bnr. 2, Hundvåg, Stavanger kommune. Oppdragsrapport B, 2. Arkeologisk museum i Stavanger.

Hemdorff, O. H. \& Kjeldsen, G. 1992. De brant de døde. Frá haug ok heiðni 4. Rogalands arkeologiske forening, Stavanger, 17-20.

Hemdorff, O. H. \& Løken, T. 1996. Notat om konstruksjon av 2 kart over det fjernete fornminnefeltet 78-177 F4 R10, Forsand, 41/6, Forsand k. (Datert 08.02.96). Topografisk arkiv, Arkeologisk museum i Stavanger.

Herschend, F. 1987. Uppbyggligheter - kring husrekonstruksjonens problem. Forntida Teknik nr.15. Instituttet för förhistorisk teknologi, Östersund, 22-33.

Herschend, F. 1989. Changing houses. Early medieval house types in Sweden 500 to 1100 A.D. Tor 22, Tidskrift för nordisk fornkunskap. Societas Archaeologica Upsaliensis, Uppsala, 79-104.

Herschend, F. 1997. Livet i Hallen. Tre fallstudier i den yngre järnålderns aristokrati. Occasional Papers in Archaeology (OPIA) 14. Institutionen för arkeologi och antik historia, Uppsala universitet.

Herschend, F. 1998. The idea of the good in late Iron Age society. 
Occasional Paper in Archaeology (OPIA) 15. Institutionen för arkeologi och antik historia, Uppsala universitet.

Herchend, F. 2009. The Early Iron Age in South Scandinavia. Social Order in Settlement and Landscape. Occasional Paper in Archaeology (OPIA) 46. Institutionen för arkeologi och antik historia, Uppsala universitet.

Herschend, F. \& Mikkelsen, D. K. 2003. The main building at Borg (I:1). In Munch, G. S., Johansen, O.S. \& Roesdahl, E. (eds.). Borg in Lofoten. A chieftain's farm in North Norway. Arkeologisk skriftserie I. Lofotr. Lofotr - Vikingmuséet på Borg Tapir, Bøstad, 41-76.

Hertz, J., Schou Jørgensen, M., Madsen, H. J. \& Ørsnes, M. 1980-1992. Arkcologisk felthåndbog. Rigsantikvarens Arkæologiske Sekretariat - Museumstjenesten. 1. udg. 1980-7. udg. april 1992 (25. udsendelse). København Viborg.

Hjelle, K. 1984. Rapport fra pollenanalytiske undersøkelser på Forsandmoen, Rogaland. Rapport i topografisk arkiv, Arkeologisk museum i Stavanger.

Hodder, I. 1982. Symbols in action. Ethnoarchaeological studies of material culture. New studies in archaeology. Cambridge University Press.

Hofseth, E. H. 1985. Det går i spinn. In Ness, J. R. (ed.). Artikkelsamling 1. AmS-Skrifter 11. Arkeologisk museum i Stavanger, 33-62.

Holst, M. K. 2010. Inconsistancy and stability - Large and small farmsteads in the Village of Nørre Snede (Central Jutland) in the first millennium AD. Settlement and Coastal Research in the Southern North Sea Region = Siedlungs- und Küstenforschung im südlichen Nordseegebiet vol. 33. VML, Rahden/Westf, 155-179

Houston, M. S. 2000. Chinese Climate History and State Stability in A.D. 536. In Gunn, J. D. (ed.). The Years without summer. Tracing A.D. 536 and its aftermath. BAR International Series 872. Archaeopress, Oxford, 71-77.

Hvass, S. 1979. Die Völkervanderungszeitliche Siedlung Vorbasse, Mitteljütland. Acta Archaeologica 49, 1978. Munksgaard, København, 61-111.

Hvass, S. 1980. Vorbasse. The Viking-Age Settlement at Vorbasse, Central Jutland. Acta Archaeologica 50, 1979. Munksgaard, København, 137-208.

Hvass, S. 1982. Ländliche Siedlungen der Kaiser- und Volkerwanderungszeit in Dänemark. Offa 39. Karl Wacholtz, Neumünster.

Hvass, S. 1983. Vorbasse. The Development of a Settlement through the First Millenium AD. Journal of Danish Archaeology 2. Odense, 127-136.

Hvass, S. 1985. Hodde. Et vestjysk landsbysamfund fra celdre jernalder. Arkæologiske Studier vol VII. Akademisk forlag, København.

Hvass, S. 1988. Jernalderens bebyggelse. In Mortensen, P. \& Rasmussen, B. M. (eds.). Jernalderens stammesamfund. Fra Stamme til Stat i Danmark 1. Jysk Arkæologisk Selskabs Skrifter XXII. Århus, 53-92.

Høeg, H. I. 1999. Pollenanalytiske undersøkelser i Rogaland og Ersdal i Vest-Agder. In Selsing, L. \& Lillehammer, G. (eds.). Museumslandskap. Artikkelsamling til Kerstin Griffin på 60-årsdagen. AmS-Rapport 12 B. Arkeologisk museum i Stavanger, $145-226$

Haack Olsen, A.-L. 2007. Gård i flammer. Skalk: nyt om gammelt 5. Højbjerg, 3-9.

Haarnagel, W. 1979. Die Grabung Feddersen Wierde Bd, II: Methode, Hausbau, Siedlungs- und Wirtshaftsformen sowie Sozialstuktur. Franz Steiner, Wiesbaden.
Haavaldsen, P. 1984. På spor etter bronsealderens buplasser. Frá haug ok heiðni 3. Rogalands arkeologiske forening, Stavanger, 96-97.

Haavaldsen, P. 1985. Utgravning av en U-formet tuft på Rosk, Bø, Hå kommune. Rapport i topografisk arkiv, Arkeologisk museum i Stavanger.

Ijzereef, G. E. \& van Regteren Altena, J. F. 1991. Nederzettingen uit die Midden- en Late Bronstijd uit Andijk en Bovenkarspel. In Fokkens, H. \& Roymans, N. (eds.). Nederzettingen uit die Bronstijd en Vroege Ijzertijd in di Lage Landen,. Nederlandse Archeologische Rapporten 13. Rijksdienst voor het Oudheidkundig Bodemonderzoek, Amersfoort, 61-82.

Iversen, F. 2017. Estate division: Social Cohesion in the Aftermath of AD 536-7. In Iversen, F. \& Petterson, H. (eds.). The agrarian life of the North 2000 BC - AD 1000. Studies in Rural Settlement and Farming in Norway. Portal, Kristiansand, 41-75.

Jensen, A.-E. \& Willemoes, A. 1982. Foulum - en boplads fra ældre germansk jernalder. MIV: museerne $i$ Viborg Amt 11. Viborg, 20-47.

Jones, E. 2000. Climate, Archaeology, History and the Arthurian tradition: a multiple-source study of two darkage puzzles. In Gunn, J. D. (ed.). The Years without summer. Tracing A.D. 536 and its aftermath. BAR International Series 872. Archaeopress, Oxford, 25-34.

Juhl, K. 2001. Austbø på Hundvåg gennem 10000 år. Arkeologiske undersøgelser i Stavanger kommune 1987-1990, Rogaland, Syd-vest Norge. AmS-Varia 38. Arkeologisk museum i Stavanger.

Jørgensen, A. N. 1997. The Male Graves. In Jørgensen, L. \& Jørgensen, A. N. (eds.). Nørre Sandegård Vest. A Cemetery from the 6th-8th Centuries on Bornholm. Det kongelige nordiske oldskriftselskab, København, 60-117.

Kaland, P. E. 1979. Landskapsutvikling og bosetningshistorie i Nordhordlands lyngheiområde. In Fladby, R. \& Sandnes, J. (eds.). På leiting etter den eldste garden. Skrifter 6 Norsk lokalhistorisk institutt. Universitetsforlaget, Oslo, 41-70.

Kaliff, A. 1996. Ringeby. En grav- och kultplats från yngre bronsåldern. Arkeologisk undersökning, RÄ̈ 6, Kvillinge sn, Norrköpings kommun, Östergötland. Rapport. Riksanikvarieämbetet, UV Linköping 51. Linköping.

Kaliff, A. 1997. Gravbyggnader och altare. Arkeologiska spår av bronsålderns eskatologiska föreställningar. Fornvännen 92. Vitterhetsakademien, Stockholm, 1-18.

Karlenby, L. 2007. Bostadens inre liv under nordisk äldre järnålder. Götberg. H. (ed.). Hus och bebyggelse i Uppland. Delar av förhistoriska sammanhang. Arkeologi E4 Uppland 3. Upplandsmuseet, Riksantikvarieämbetet, Societas Archaeologica Upsaliensis. Uppsala, 123-152.

Kaul, F. 1985. Priorsløkke - en befæstet jernalderlandsby fra ældre romersk jernalder. Nationalmuseets Arbejdsmark. København, 172-183.

Kjeldsen, G. 1992. Innberetning om undersøkelse og frigivning av gravrøyser på Forsand, 41/4, Forsand k., Rogaland. Rapport i topografisk arkiv, Arkeologisk museum i Stavanger.

Komber, J. 1989. Jernalderens gårdshus. AmS-Varia 18. Arkeologisk museum i Stavanger.

Komber, J. 1998. Det nordiske bronsealderhusets form og konstruksjon. In Løken, T. (ed.). Bronsealder i Norden - Regioner og interaksjon. AmS-Varia 33. Arkeologisk museum i Stavanger, 45-54.

Kortlang, F. 1999. The Iron Age urnfield and settlement of 
Someren - "Waterdael". In Theuws, F. \& Roymans, N. (eds.). Land and ancestors. Cultural dynamics in the Urnfield period and the Middel Ages in the Southern Netherlands. Amsterdam Archaeological Studies 4. Amsterdam University Press, 133-197.

Kraft, J. 1830. Topographisk-statistisk beskrivelse over kongeriget Norge. Fjerde Deel. Christiania (Oslo).

Kristiansen, K. 1988. Oldtid 4000 f.Kr.-1000 e.Kr. In Bjørn, C. (ed.). Det danske landbrugs historie I. Landbohistorisk Selskab, Odense, 13-107.

Kristiansen, K. 1999. Symbolic structures and social institutions. The twin rulers in the Bronze Age Europe. In Gustafson, A. \& Karlsson, H. (eds.). Glyfer och arkeologiska rum - en vänbok til Jarl Nordbladh. Gøteborgs universitet, $537-552$

Kristoffersen, S. \& Magnus, B. 2010. Spannformete kar. Utvikling og variasjon. AmS-Varia 50. Arkeologisk museum i Stavanger.

Lagerås, L. \& Strömberg, B. 2005. Bronsåldersbygd 2300-500 f. Kr. Skånska spår - arkeologi längs Västkustbanan. Riksantikvarieämbetet, avd. för arkeologiska undersökningar, UV Syd. Lund.

Lamb, H. H. 1981. Climate from 1000 B.C. to 1000 A.D. In Jones, M. \& Dimbleby, G. (eds.). The Environment of Man: the Iron Age to the Anglo-Saxon Period. BAR British Series 87. Oxford, 53-65.

Larsen, G., Vinther, B. M., Briffa. K. R., Melvin, T. M., Clausen, H. B., Jones, P. D., Siggaard-Andersen, M. L., Hammer, C. U., Eronen, M., Grudd, H., Gunnarson, B. E., Hantemirov, R. M., Naurzbaev, M. M. \& Nicolussi, K. 2008. New Ice Core Evidence for a Volcanic Cause of the AD 536 dust-veil. Geophysical Research Letters Vol. 35 (4). American Geophysical Union, Washington. DOI 10.1029/2007GL032450.

Liedgren, L. 1992. Hus och gård i Hälsingland. En studie av agrar bebyggelse och bebyggelseutveckling $i$ norra Hälsingland Kr.f.-600 e.Kr. Studia Archaeologica Universitas Umensis 2 (diss). Arkeologiska institutionen, Umeå Universitet.

Lindanger, B. 1987. Attrydding 1520-1660. In Hovland, E. \& Næss, H. E. (eds.). Fra Vistehola til Ekofisk. Rogaland gjennom tidene I. Universitetsforlaget, Stavanger, 153-164.

Little, L. K. 2007. Life and afterlife of the first plague pandemic. In Little. L. K. (ed.). Plague and the end of the antiquity. The pandemic of 541-740. Cambridge University Press, 3-32

Lundeberg, B. R. 1972. Planterester fra Ullandhaug, et gårdsanlegg på Jeren fra folkevandringstiden. Cand. Real i botanikk, Universitetet i Bergen.

Lundqvist, L. 1996. Slöinge - en stormansgård från järnåldern. In Lundqvist, L., Lindeblad, K., Nielsen, A.-L. \& Ersgård. L. (eds.). Slöinge och Borg. Stormansgårdar $i$ öst och väst. Skrifter 18, Arkeologiska undersökningar. Riksantikvarieämbetet, Stockholm, 9-52.

Løken, T. 1978. Nye funn fra et gammelt gravfelt. Kan gård og gravplass gå tilbake til eldre bronsealder? Viking XLI. Norsk arkeologisk selskap, Oslo, 133-165.

Løken, T. 1982. Folkevandringstidsboplass på Forsandmoen - detaljer i byggeskikken klarlagt. Frá haug ok heiðni 3. Rogalands arkeologiske forening, Stavanger, 75-84.

Løken, T. 1983. En ny type gårdsanlegg på Forsand i Rogaland. In Ólafsson, G. (ed.). Hus, gård och bebyggelse. Föredrag från det XVI nordiska arkeologmötet, Island 1982. pjóðminjasafn Íslands, Reykjavik, 81-93

Løken, T. 1984a. Et folkevandringstids landsbyanlegg på
Forsandmoen, Forsand i Rogaland. In Liedgren, L. \& Widgren, M. (eds.). Gård och kulturlandskap under järnåldern. Svensk-norskt seminarium i Hudiksvall 18-20 augusti 1983. Kulturgeografiskt seminarium $2 / 84$. Stockholm, 59-77.

Løken, T. 1984b. Landsbyen på Forsand - eldre og større. Frá haug ok heiðni 3. Rogalands arkeologiske forening, Stavanger, 88-91.

Løken, T. 1985. Forprosjektet på Forsand avsluttet. Frá haug ok heiðni 3. Rogalands arkeologiske forening, Stavanger, 250-257.

Løken, T. 1987a. Driftsformer i folkevandringstidsgården i Rogaland. Viking L. Norsk arkeologisk selskap, Oslo, 79-97.

Løken, T. 1987b. The Settlement at Forsandmoen - an Iron Age Village in Rogaland, SW-Norway. Studien zür Sachsenforschung 6. Niedersächsisches Landesmuseum Hannover, Urgeschichts-Abteilung, Hildesheim, 155-168.

Løken, T. 1987c. Forsand: Nå også med den første kjente bronsealderlandsby i Norge. Frá haug ok heiðni 3. Rogalands arkeologiske forening, Stavanger, 236-243.

Løken, T. 1988a. Forsandmoen - har bebyggelsen også vært organisert som landsby i eldre romertid? Frá haug ok heiðni 4. Rogalands arkeologiske forening, Stavanger, 146-157.

Løken, T. 1988b. Bygg fra fortiden. Forsand i Rogaland bebyggelsessentrum gjennom 2000 år. AmS-Småtrykk 21 . Arkeologisk museum i Stavanger.

Løken, T. 1988c. Forsandmoen - et samfunn i blomstring og krise gjennom folkevandringstid. In Näsman, U. \& Lund, J. (eds.) Folkevandringstiden i Norden. En krisetid mellem celdre og yngre jernalder. Aarhus Universitetsforlag, 169-188.

Løken, T. 1990. Sommerens utgravning på Forsandmoen: Folkevandringstidslandsbyen igjen i sentrum for oppmerksomheten i den tiende og siste sesong. Frá haug ok heiðni 4. Rogalands arkeologiske forening, Stavanger, 108-117.

Løken, T. 1991. Forsand i Rogaland - lokalt sentrum i de sørlige Ryfylkeheiene. In Wik, B. (ed.). Rapport fra 18. nordiske arkeolog-kongress, Trondheim 1989. Gunneria 64. NTNU-Vitenskapsmuseet, Trondheim, 207-221.

Løken, T. 1992a. En folkevandringstidsgård - langhus og grophus på Bertnem i Overhalla. Spor. Fortidsnytt fra Midt-Norge 2. Fakultet for arkeologi og kulturhistorie, Vitenskapsmuseet, Trondheim, 26-28.

Løken, T. 1992b. Forsand og jernalderens landsbyanlegg i Rogaland - ressursbakgrunn og struktur. In Myrvoll, S. et al. (eds.). Gård - Tettsted - Kaupang - By. Seminar i Bergen 11.-13. desember 1991. Nytt fra Utgravningskontoret i Bergen (NUB) 3, Riksantikvaren, 53-69.

Løken, T. 1992c. Utgravningsrapport for Forsandprosjektet 1980-1990. Angår boplassområdene 78-178 F4 R18 og R19, Forsand, gnr. 41 og Berge, gnr. 37, Forsand k. Rapport i topografisk arkiv, Arkeologisk museum i Stavanger.

Løken, T. 1992d. Ullandhaug sett i lys av Forsandundersøkelsene. In Skår, A. K. (ed.). Gammel gård gjenoppstår. Fra gamle tufter til levende museum. AmS Småtrykk 26. Arkeologisk museum i Stavanger, 31-46.

Løken, T. 1995. Romertid i Norge - boliger og bosetningsstruktur. In Sørheim, H. (ed.). NAM 1993: Foredrag ved det Norske Arkeologmøtet $i$ Ålesund 1993. Sunnmøre museum, Ålesund, 24-41.

Løken, T. 1998a. Det forhistoriske huset i Rogaland - belyst ved flateavdekkende utgravninger. In Kyhlberg, O. (ed.). Hus och tomt under förhistorisk tid. Bebyggelsehistorisk Tidskrift 33, 1997. Swedish Science Press, Uppsala, 169-184. 
Løken, T. 1998b. Hustyper og sosialstuktur gjennom bronsealder på Forsandmoen, Rogaland, Sørvest-Norge. In Løken, T. (ed.). Bronsealder $i$ Norden - Regioner og interaksjon. AmS-Varia 33. Arkeologisk museum i Stavanger, 107-122.

Løken, T. 1999. The longhouses of Western Norway from the Late Neolithic to the 10th Century AD: representatives of a common Scandinavian building tradition or a local development? In Skjelderup, H, \& Storsletten, O. (eds.). Grindbygde hus $i$ Vest-Norge. NIKU-seminar om grindbygde hus, Bryggens Museum 23-25.03.98. NIKU Temahefte 30. Norsk institutt for kultuminneforskning, Oslo, 52-64.

Løken, T. 2001a. Forsands forhistorie. Frá haug ok heiðni 3. Rogalands arkeologiske forening, Stavanger, 6-19.

Løken, T. 2001b. Oppkomsten av den germanske hallen - Hall og sal i eldre jernalder i Rogaland. Viking LXIV, Norsk arkeologisk selskap, Oslo, 49-86.

Løken, T. 2003. Forsandmoen - Stedet for den største forskningsgravningen på AmS. Frá haug ok heiðni 3. Rogalands arkeologiske forening, Stavanger, 11-15.

Løken, T. 2006. Høvding, bonde, leilending og ufri i Rogalands eldre jernalder. In Glørstad, H, Skar, B \& Skre, D.(eds.). Historien i forhistorien. Festskrift til Einar Østmo på 60-års dagen. Skrifter 4. Kulturhistorisk Museum, Universitetet i Oslo, 309-322.

Løken, T. 2009. Arkeologisk utgravning av bronsealderboplass. Prestegården (Løbrekk), gnr. 31, bnr. 1, Strand kommune. Oppdragrapport 7. Arkeologisk museum, Universitetet i Stavanger.

Løken, T. \& Hemdorff, O. H. 1996. Undersøkelse i forbindelse med overtredelse av lov om kulturminner ved fjerning av grav-og rydningsrøyser på Forsand, gnr. 41, bnr. 6, Forsand kommune. Rapport i topografisk arkiv, Arkeologisk museum i Stavanger.

Løken, T., Pilø, L. \& Hemdorff, O. H. 1996. Maskinell flateavdekking og utgravning av forhistoriske jordbruksboplasser - en metodisk innføring. AmS-Varia 26. Arkeologisk museum i Stavanger.

Marstrander, S. 1977. Bronze Age Gold Finds in Norway. Universitetets Oldsaksamling Årbok 1975/76. Oslo, 41-56.

Martens, J. 2007. Kjølberg søndre - en gård med kontinuitet tilbake til eldre jernalder? In Ystgaard, I. \& Heibreen, T. (eds.). Arkeologiske undersøkelser 2001-2002. Varia 62. Fornminneseksjonen, Kulturhistorisk Museum, Oslo, 89-110.

Mauritzen, M. 1970. Fosforanalyser av jordprøver ved Stavanger Museum. Stavanger Museum Årbok 1969, 49-56.

Meling, T. 2001. Ein storgard frå romartid på Hundvåg i Stavanger. Frá haug ok heiðni 4. Rogalands arkeologiske forening, Stavanger, 23-27.

Meling, T. 2017. Farm - manor - estate : agricultural landscape and settlement at Hundvåg, Southwest Norway. In Iversen, F. \& Petterson, H. (eds.). The agrarian life of the North 2000 $B C-A D$ 1000. Studies in Rural Settlement and Farming in Norway. Portal, Kristiansand, 151-172.

Mikkelsen, M. 2012. "Dobbeltgårde" i yngre bronzealder. In Boddum, S., Mikkelsen, M. \& Terkildsen, N. (eds). Bebyggelsen i yngre bronzealders lokale kulturlandskab. Yngre bronzealders kulturlandskab 2. Viborg museum \& Holsterbro museum, Holsterbro, 41-66.

Mikkelsen, P. H. \& Nørbach, L. C. 2003. Drengsted. Bebyggelse, jernproduksjon og agerbrug $i$ yngre romersk jernalder og celdre germansk jernalder. Jysk Arkæologisk Selskabs skrifter XLIII. Moesgaard Museum, Århus.
Moore, H. 1986. Text, Space and Gender: an anthropological study of the Marakwet of Kenya. Cambridge University Press.

Myhre, B. 1972. Funn, fornminner og ødegårder. Jernalderens bosetning $i$ Høyland fiellbygd. Stavanger museums skrifter 7. Stabenfeldt, Stavanger.

Myhre, B. 1973. I en åker på Gjerland i Førde. ARKEO: arkeologiske meddelelser fra Historisk museum, Universitetet $i$ Bergen 1. 15-18.

Myhre, B. 1976. Nausttuft fra eldre jernalder på Stend i Fana. Nausttuftene som kilde til kunnskap om bygningskonstruksjon, bosetning og samfunnsforhold. Viking XL. Norsk arkeologisk selskap, Oslo, 29-78.

Myhre, B. 1978. Agrarian Development, Settlement History and Social Organization in Southwest Norway in the Iron Age. In Kristiansen, K. \& Paludan-Müller, C. (eds.). New Directions in Scandinavian Archaeology. Studies in Scandinavian prehistory and early history 1 . National Museum of Denmark, Lyngby, 224-271.

Myhre, B. 1980. Gårdsanlegget på Ullandhaug I. AmS-skrifter 4. Arkeologisk museum i Stavanger.

Myhre, B. 1983. Beregning av folketall på Jæren i yngre romertid og folkevandringstid. In Ólafson, G. (ed.). Hus, gård och bebyggelse. Föredrag från det XVI nordiska arkeologmötet Island 1982. Pjóðminjasafn Íslands, Reykjavik, 147-164.

Müller-Wille, M. 1977. Bäuerliche Siedlungen der Bronze und Eisenzeit in den Nordseegebieten. In Jankuhn, H., Schützeichel, R. \& Schwind, F. (eds.). Das Dorf der Eisenzeit und des frühen Mittelalters. Siedlungsform-wirtschaftliche Funktion-soziale Struktur. Abhandlungen der Akademie der Wissenschaften in Göttingen, Phil-Hist klasse 101. Göttingen, 152-218.

Møllerop, O. 1962. Gårdsanleggene på Vaula, Mosterøy. Frá haug ok heiðni 2. Rogalands arkeologiske forening, Stavanger, $145-150$.

Møllerop, O. 1964. Utgravningene ved Risavika sommeren 1964. Frá haug ok heiðni 3. Rogalands arkeologiske forening, Stavanger, 41-51.

Måge, B. 1993. Innberetning for de arkeologiske undersøkelsene på Nerabø, gnr. 22, Lysebotn, Forsand kommune, mai 1992. Innberetning i topografisk arkiv, Arkeologisk museum i Stavanger.

Nansen, F. 1911. In Northern Mists. Arctic Exploration in Early Times. Volume I. Translated by Arthur G. Chater. New York. Heinemann, London.

Narrol, R. 1962. Floor area and settlement population. American Antiquity 27. Cambridge University Press, New York, 587-589.

Nicolaysen, N. 1860-1866. Norske Fornlevninger. En oplysende Fortegnelse over Norges Fortidslevninger, celdre end Reformationen og henførte til hver sit Sted. Foreningen til Norske Fortidsmindesmærkers Bevaring, Kristiania.

Nielsen, J. N. 1983. Iron Age Settlement and Cemetery at Sejlflod in Himmerland, North Jutland. Journal of Danish Archaeology 1/1982. Odense, 105-117.

Nielsen, J. N. 2002. Flammernes bytte. Skalk: nyt om gammelt 6. Højbjerg, 3-10.

Nitter, M. 2009. Klimarom. Klimaets avhengighet av skala og landskap. In Nitter, M. \& Pedersen, E. S. (ed.). Tverrfaglige perspektiver. AmS-Varia 49. Arkeologisk museum i Stavanger, 119-130.

Nord, J. \& Sarnäs, A. 2005. Öresundsförbindelsen. Lockarp 7D-E. Rapport över arkeologisk slutundersökning. Rapport 18. Malmö Kulturmiljö.

Norr, S. 1996. A Place for Proletarians? A Contextual Hypothesis on Social Space in Roman and Migration Period 
Long-Houses. Current Swedish Archaeology 4. Swedish Archaeological Society, Stockholm, 157-164.

Olausson, M. 1998. Hus och tomt i Uppland och Södermanland under yngre bronsålder och äldre järnålder. In Kyhlberg, O. (ed.). Hus och tomt under förhistorisk tid. Bebyggelsehistorisk Tidskrift 33, 1997. Swedish Science Press, Uppsala, 95-115.

Olsson, M., Ingwald, J. \& Paulsson-Holmberg, T. 2005. Öresundsförbindelsen. Naffentorp 5A. Rapport över arkeologisk slutundersökning. Rapport 12. Malmö Kulturmiljö.

Oma, K. A. 2016. Sheep, dog and man. Multi-species becomings leading to new ways of living in Early Bronze Age longhouses on Jæren, Norway. In Dommasnes, L. H., Gutsmiedl-Schümann, D. \& A. T. Hommedal (eds.) The farm as a social arena. Waxmann, Münster \& New York, 23-51.

Petersen, J. 1926. Rapport om befaring på Forsandmoen, Forsand kommune. Innberetning i topografisk arkiv, Arkeologisk museum i Stavanger.

Petersen, J. 1933. Gamle gårdsanlegg i Rogaland 1. Instituttet for sammenlignende kulturforskning, Serie B, Skrifter XXIII. Aschehoug, Oslo.

Petersen, J. 1936. Gamle gårdsanlegg i Rogaland 2. Instituttet for sammenlignende kulturforskning, Serie B, Skrifter XXXI. Aschehoug, Oslo.

Petersen, J. 1938. Leksaren. Viking II. Norsk arkeologisk selskap, Oslo, 151-158.

Petersen, J. 1944. De gamle øydegårdene i Rogaland. Stavanger museum Årshefte 1942-1943. Dreyer, Stavanger, 38-55.

Petersen, J. 1945. Rapportom befaring på Forsandmoen, Forsand kommune. Innberetning i topografisk arkiv, Arkeologisk museum i Stavanger.

Petersen, J. 1952. Forhistoriske gårdsanlegg i Rogaland. Undersøkelser gjennom 25 år. Stavanger museum Årbok 1951, Dreyer, Stavanger, 12-31.

Pilø, L. 1989. Den førromerske jernalder $i$ Vestnorge. Et kulturhistorisk tolkningsforsøk. Masteroppgave i arkeologi, Universitetet i Bergen.

Pilø, L. 2005. Bosted - urgård - enkeltgård. En analyse av premissene i den norske bosetningshistoriske forskningstradisjon på bakgrunn av bebyggelsesarkeologisk feltarbeid på Hedemarken. Oslo Arkeologisk Serie (OAS) 3 (diss). Institutt for arkeologi, kunsthistorie og konservering, Universitetet i Oslo.

Provan, D. 1968. Fosforanalyser og arkeologiske undersøkelser. Frá haug ok heiðni 3. Rogalands arkeologiske forening, Stavanger, 180-187.

Provan, D. 1971. Soil Phosphate Analysis as a Tool in Archaeology. Norwegian Archaeological Review 4 (1). Routledge Taylor \& Francis Group, London, 37-50.

Prøsch-Danielsen, L. 1986. Innsamling av pollenprøver fra flaten på Forsand. Innberetning i topografisk arkiv, Arkeologisk museum i Stavanger.

Prøsch-Danielsen, L. 1988. Principal Components Analysis of Pollen Types from Prehistoric Agricultural Settlements at Forsandmoen, South-West Norway. Correlation between Cereals, Herbs, Weeds and Grasses. In Solheim Pedersen, E. (ed.). Artikkelsamling II. AmS-Skrifter 12. Arkeologisk museum i Stavanger, 66-71.

Prøsch-Danielsen, L. 1996. Vegetasjonshistorisk undersøkelse av felt med rydningsrøyser på Forsand gnr. 41 bnr.6, Forsand $i$ Rogaland. Oppdragsmelding 010, NIKU Norsk institutt for kulturminneforskning, Oslo.
Prøsch-Danielsen, L. 2001. Forsandmoen - landskap og bosetning i endring. Frá haug ok heiðni 3. Rogalands arkeologiske forening, Stavanger, 25-33.

Prøsch-Danielsen, L. \& Bakkevig, S. 1990. Spor etter forhistoriske krøtterstier mellom Forsandlandsbyen og utmarka. Frá haug ok heiðni 1. Rogalands arkeologiske forening, Stavanger, 22-26.

Prøsch-Danielsen, L. \& Simonsen, A. 1988. Principal Components Analysis of Pollen, Charcoal and Soil Phosphate Data as a Tool in Prehistoric Land-use Investigation at Forsandmoen, South-West Norway. Norwegian Archaeological Review 21 (2). Routledge Taylor \& Francis Group, London, 85-102.

Prøsch-Danielsen, L. \& Soltvedt, E.-C. 2011. From saddle to rotary hand querns in south-western Norway and the corresponding crop plant assemblages. Acta Archaeologica vol. 82 (1). Levin \& Munksgaard, København, 129-162.

Purslow, D. F. 1976. Results of field tests on natural durability of timber (1932-1975). Building Research Establishment current paper 76. Aylesbury, Bucks.

Purslow, D. F. \& Williams, N. A. 1978. Field trials on preserved timber out of ground contact. Building Research Establishment current paper 78. Aylesbury, Bucks.

Ramqvist, P. H. 1983. Gene. On the origin, function and development of sedentary Iron Age settlement in Northern Sweden. Archaeology and Environment 1 (diss). Department of Archaeology, University of Umeå.

Ravn, M. 2009. Hammel - en jernalderplads i Østjylland. In Nitter, M. \& Solheim Pedersen, E. (eds.). Tverrfaglige perspektiver 1. AmS-Varia 49. Arkeologisk museum i Stavanger, 53-66.

Reiersen, K. 2015. Arkeologiske undersøkelser av hus og øvrige bosetningsspor fra eldre bronsealder og førromersk jernalder, ID 177381. Nordre Tengesdal gnr. 81, bnr. 4, Bjerkreim kommune, Rogaland. Oppdragsrapport B 2015. Arkeologisk museum i Stavanger.

Reynolds, P. J. 1994. Experimental archaeology - a perspective for the future. C.J.F. Reuvens-Lezing 5. Leiden. Worc Arch Soc 1972.pdf (butser.org.uk) (sist tilgjengelig 11.12.2020).

Reynolds, P. J. 1995. The live and death of a posthole. Occational papers, Butser ancient farm 1. Waterlooville, Hants, Microsoft Word - posthole.doc (butser.org.uk) (sist tilgjengelig 11.12.2020).

Rindal, B. 2011. Plant remains from Ullandhaug, an iron age farm site from the migration period in southwest Norway. In Nitter, M. (ed.). Tverrfaglige perspektiver 2. AmS-Varia 53. Arkeologisk museum, Universitetet i Stavanger, 53-63.

Rindel, P. O. 1997. Grøntoft - og etableringen af det strukturerede landsbysamfund $i$ Vestjylland $i$ 1.årtusinde f.Kr. Bd 1. Hovedtekst. (diss). Institutt for arkeologi og Etnologi, Københavns universitet.

Ringstad, B. 2001. Aura-Pål sitt rike. Auregarden i førhistorisk tid og tidleg mellomalder. Sykkylven Sogenemd, Molde.

Robichaux, H. 2000. The Maya Hiatus and the A.D.536 Atmospheric Event. In Gunn, J. D. (ed.). The Years without summer. Tracing A.D. 536 and its aftermath. BAR International Series 872. Archaeopress, Oxford, 45-53.

Rolfsen, P. 1976. Hustufter, grophus og groper fra eldre jernalder ved Oddernes kirke, Vest-Agder. Universitetets Oldsaksamling Årbok 1972-74. Oslo, 65-82.

Rolfsen, P. 1980. Et pottemakerverksted fra romertiden. In Johansen, Ø., Mikkelsen, E., Marstrander, L. \& Rolfsen, P. (eds.). Festskrift til Sverre Marstrander på 70-års dagen. 
Universitetets Oldsaksamling Skrifter, Ny rekke 3. Oslo, $15-20$.

Rolfsen, P. 2002. Tjæremiler i Norge - med utgangspunkt i en tjæregrop på Hovden. In Hofseth, E. H. (ed.). UKM - En mangfoldigforskningsinstitusjon. Skrifter 1. Universitetets Kulturhistoriske Museer, Oslo, 255-265.

Rostovány, V. A. \& Hydén, S. 2002. Öresundsförbindelsen. Svagertorp 8 B-C. Rapport över arkeologisk slutundersökning. Rapport14, Malmö Kulturmiljö.

Rudin, G.-B. \& Brink, K. 2002. Öresundsförbindelsen. Lockarp 7A. Rapport över arkeologisk slutundersökning. Rapport 16, Malmö Kulturmiljö.

Rønne, O. \& Løken, T. 1998. Utgravning av boplassområde på Forsandmoen, Berge, Forsand. Rapport i topografisk arkiv, Arkeologisk museum i Stavanger.

Rønne, P. 2005. Arkæologiske undersøgelser forud for bygningen af ny E6 gennom Melhus, Sør-Trøndelag. In Høgestøl, M., Selsing, L., Løken, T., Nærøy, A. J. \& Prøsch-Danielsen, L. (eds.). Konstruksjonsspor og byggeskikk. Maskinell flateavdekking - metodikk, tolkning og forvaltning. AmS-Varia 43. Arkeologisk museum i Stavanger, 89-96.

Samdal, M. \& Østmo, M. 2008. Hus frå romertid-folkevandringstid og boplasspor og fotgrøfter frå jernalder. In Gjerpe, L. E. (ed.). Hus, boplass-og dyrkingsspor, E18-prosjektet Vestfold bind 3. Varia 73. Fornminneseksjonen, Kulturhistorisk museum, Oslo, 225-242.

Sandvik, P. U. 1999. Analysar av plantemakrofossilar $i$ jordprøver frå Sandved, Skeiane gnr. 40, bnr. 246 og Brueland gnr. 41, bnr. 22, Sandnes kommune, Rogaland. Oppdragsrapport 1999-8, Arkeologisk museum i Stavanger.

Selsing, L. 1982. Rapport om sondering $i 2$ myrer for valg av vegetasjonshistorisk lokalitet på Forsand. Innberetning i topografisk arkiv, Arkeologisk museum i Stavanger.

Selsing, L. 1983. Innberetning til top.ark om innsamling av pollenprøver på boplassarealet på Forsandmoen, gnr. 41, Forsand. Innberetning i topografisk arkiv, Arkeologisk museum i Stavanger.

Selsing, L. 2016. Intentional fire management in the Holocene with emphasis on hunter-gatherers in the Mesolithic in South Norway. AmS-Skrifter 25. Arkeologisk museum i Stavanger.

Shetelig, H. 1909. En ældre jernalders gaard på Jæderen. Bergens Museum Årbok 1909, 1-18.

Siemen, P. 1985. Skonager - en jernalderby fra 5.-7. århundrede efter Kristus. Mark og Montre: fra Sydvestjyske museer 1985. Ribe, 69-77.

Siemen, P. 2000. Prcestestien. Settlement from 4th-9th Century. Arkæologiske Rapporter 3, 1. Esbjerg Museum.

Simonsen, A. 1968. Pollenanalyse av et jordprofil fra jernaldergården ved Ullandhaug. Frá haug ok heiðni 4. Rogalands arkeologiske forening, Stavanger, 192-195.

Simonsen, A. 1969. Palynologiske undersøkelser ved nausttuftene på "Øyren”, Hå (Subrecent vegetation development at "Øyren" south of Stavanger. A pollen diagram from a former lagune once used as a harbour) (in Norwegian with English summary). Stavanger Museum Arbok 79. 39-48.

Simonsen, A. 1971. Breiavatn og Stavangers eldste historie (The history of Lake Breiavatn and the city of Stavanger). Stavanger Museum Årbok 81, 39-49.

Simonsen, A. 1977. Jens Esmark og istidsteorien. Naturen 4. Universitetet i Bergen, 167-174.

Simonsen, J. 1996. Bebyggelsen på Glattrupnæsset i ældre bronzealder. In Bertelsen, J. B., Christensen, M.,
Mikkelsen, M., Mikkelsen, P., Nielsen, J. \& Simonsen, J. 1996 (eds.). Bronzealderens bopladser i Midt-og Nordvestjylland. De arkæologiske museer i Viborg Amt, Skive, 90-103.

Skjølsvold, A. 1970a. En bronsealders boplass med hustuft fra Ogna i Rogaland. Viking XXXIV. Norsk arkeologisk selskap, Oslo, 25-46.

Skjølsvold, A. 1970b. To keltertids hustufter fra Ogna i Rogaland. Viking XXXIV. Norsk arkeologisk selskap, Oslo, 47-72.

Skre, D. 1997. Raknehaugen. En empirisk loftsrydding. Viking LX. Norsk arkeologisk selskap, Oslo, 7-42.

Skre, D. 1998. Herredømmet: Bosetning og besittelse på Romerike 200-1350 e.Kr. Acta Humaniora 32 (diss). Det historisk-filosofiske fakultet, Universitetet i Oslo.

Skaare, K. 1998. Vikingene på Skeie - kongens naboer? Frá haug ok heiðni 4. Rogalands arkeologiske forening, Stavanger, 17-20.

Slomann, W. 1972. Bosetning og bosetningsproblemer i sydvest-Norge i eldre jernalder. Stavanger Museum Årbok 81, 1971, 5-38.

Soltvedt, E.-C., Løken, T., Prøsch-Danielsen, L., Børsheim, R. \& Oma, K. 2007. Bøndene på Kvålehodlene: boplass-, jordbruks-og landskapsutvikling gjennom 6000 år på Jaren, SV Norge. AmS-Varia 47. Arkeologisk museum i Stavanger.

Steen, B. 1995. Høgevollen. En boplads fra ældre jernalder ved Egersund. Frá haug ok heiðni 4. Rogalands arkeologiske forening, Stavanger, 7-16.

Steinecke, M. Ekenberg, A., Hansson K. \& Ifverson, P. 2005. Öresundsförbindelsen. Sunnanå 9A-F. Rapport över arkeologisk slutundersökning. Rapport 34. Malmö kulturmiljö.

Stenberger, M. 1933. Öland under eldre järnåldern : en bebyggelsehistorisk undersökning. Monografier 19. Kungliga vitterhets-, historie och antikvitets akademien, Stockholm.

Straume, E. 1987. Gläser mit Facettenschliff aus skandinavischen Gräbern des 4. und 5. Jahrhunderts n. Chr. Skrifter LXXIII. Instituttet for sammenlignende kulturforskning. Universitetsforlaget, Oslo.

Sundkvist. A. 1994. Hus och rum från järnåldern. Tor 26. Tidskrift för nordisk fornkunskap. Societas Archaeologica Upsaliensis, Uppsala, 67-82.

Sundkvist, A. 1998. Rumsindelning i järnåldershus - mer änn att finna mellanväggar? In Anderson, K. (ed.). Suionum Ninc civitates. Nya undersökningar kring norra Mälardalens äldre järnålder. Occasional Paper in Archaeology (OPIA) 19. Institutionen för arkeologi och antik historia, Uppsala universitet, 167-187.

Söderberg, B. 2005. Aristokratisk rum och gränsöverskridande. Järrestad och sydöstra Skåne mellan region och rike 6001000. Skrifter 62, Riksantikvarieämbetet, Arkeologiska Undersökningar, Stockholm.

Sørheim, H., Bertheussen, M., Hafsaas, H., Bakkevig, S. \& Bogarp, C. 2004. Hus, åker, groper, graver og gripedyr. Litt om de foreløpige resultatene på Søra Bråde 2. Frá haug ok heiðni 4. Rogalands arkeologiske forening, Stavanger, 3-19.

Sørheim. H. 2007. Arkeologisk undersøkelse av gravrøys 78-177 F4 R15 i 2001. Oppdragsrapport B 6, Arkeologisk museum i Stavanger.

Tanner W. F. 2000. Beach ridge history, sea level change and the A.D. 536 event. In Gunn, J. D. (ed.). The Years 
without summer. Tracing A.D. 536 and its aftermath. BAR International Series 872. Archaeopress, Oxford, 89-97.

Tesch, S. 1972. Kring en järnåldersgård I Turingesocken, Södermanland. 3 betygsuppsats i nordisk fornkunskap, vt 1972 (stencil). Uppsala universitet.

Tesch, S. 1993. Houses, Farmsteads, and Long-term Change. A Regional Study of Prehistoric Settlements in the Köpinge area, in Scania, Southern Sweden. (diss). Institutionen för arkeologi och antik historia, Uppsala universitet,

Therkorn, L. L. 1987. The structures, mechanics and some aspects inhabitant behaviour. In Brandt, R. W., Groenmanvan Waateringe, W. \& van der Leeuw, S. E. (eds.). Assendelver Polder papers 1. Cingula 10. Universiteit van Amsterdam, 177-224.

Toohey, M., Krüger, K., Sigl, M., Stordal, F. \& Svensen, H. 2016. Climatic and societal impacts of a volcanic double event at the dawn of the Middle Ages. Climatic Change 136 (3). Springer Netherlands, Dordrecht, 401-412. DOI:10.1007/ s10584-016-1648-7.

Tornbjerg, S. Å. 1985. Bellingegård, a Late Iron Age Settlement Site at Køge, East Zealand. Journal of Danish Archaeology 4. Odense, 146-156.

Traufetter, F., Oerter, H., Fischer, H., Weller, R. \& Miller, H. 2004. Spatio-temporal variability in volcanic sulphate deposition over the past $2 \mathrm{kyr}$ in snow pits and firn cores from Amundsenisen, Antarctica. Journal of Glaciology Vol. 50 (168). Cambridge University Press, 37-146.

Tzigaridas, Z. 1997. Undersøkelsene på Skeie, Hundvåg - en storgård fra yngre jernalder? Frá haug ok heiðni 4. Rogalands arkeologiske forening, Stavanger, 16-20.

Tzigaridas, Z. 2001. Rapport om de arkeologiske undersøkelsene på Krosshaug-Loen, Austbø, gnr. 7, bnr.26, 1049, Stavanger kommune. Innberetning i topografisk arkiv, Arkeologisk museum i Stavanger.

Ulväng, G. 1992. Mälardalens hustyper. En studie av hustyper i Mälardalen under sten-, brons- och järnålder. C-uppsats, Institutionen för arkeologi, Uppsala Universitet.

Vikshåland, L. H., Sageidet, B. M. \& Sandvik, P. U. 2007. Bustgård. Neolittisk kulturlag, helleristninger fra bronsealder og hus fra eldre jernalder (lokalitet 33 og 34). In Bårdseth, G. A. (ed.). Hus og gard langs E6 i Fredrikstad og Sarpsborg kommunar, E6-prosjektet Østfold. Band 3. Varia 67. Kulturhistorisk museum, Oslo, 101-142.

Vikshåland, L. H. \& Sandvik, P. U. 2007a. Årum nedre og Årum øvre. Hus, boplasspor og skålgroper fra bronsealder (lokalitet 18, 21 og 56). In Bårdseth, G. A. (ed.). Hus og gard langs E6 i Fredrikstad og Sarpsborg kommunar, E6-prosjektet Østfold. Band 3. Varia 67. Kulturhistorisk museum, Oslo, 5-20.

Vikshåland, L. H. \& Sandvik, P. U. 2007b. Molteberg nordre. $\varnothing$ ks av bronse fra eldre bronsealder. Rydningsrøyser og aktivitetsspor fra jernalder (lokalitet 24 og 25). In Bårdseth, G. A. (ed.). Hus og gard langs E6 $i$ Fredrikstad og Sarpsborg kommunar, E6-prosjektet Østfold. Band 3. Varia 67. Kulturhistorisk museum, Oslo, 45-52.

Vikshåland, L. H. \& Sandvik, P. U. 2007c. Bustgård. Et treskipet hus fra romertid (lokalitet 36). In Bårdseth, G. A. (ed.). Hus og gard langs E6 i Fredrikstad og Sarpsborg kommunar, E6-prosjektet Østfold. Band 3. Varia 67. Kulturhistorisk museum, Oslo, 143-156.

Waterbolk, H. T. 1964.The Bronze Age Settlement of Elp. Helinium IV. Revue consacrée à l'archéologie des PaysBas, de la Belgique et du Grand-duché de Luxembourg. Wetteren, 97-131.

Wessel, O. 1982. Topometermåling i Herning, juli 1981. Landinspektøren, København.

Wikborg, J. \& Onsten-Molander, A. 2007. Aspekter på tid. Hus i Tiundaland under äldre järnålder. In Götberg, H. (ed.). Hus och bebyggelse i Uppland. Delar av förhistoriska sammanhang. Arkeologi E4 Uppland 3. Upplandsmuseet, Riksantikvarieämbetet, Societas Archaeologica Upsaliensis. Uppsala, 107-122.

Wikipedia contributors. (2020, December 18). Pytheas. In Wikipedia, The Free Encyclopedia. Retrieved 11:19, January 5, 2021, from https://en.wikipedia.org/w/index.php ?title=Pytheas\&oldid $=995040474$

Wishman, E. 1990. Draving showing the mapped solar course at Forsandmoen. Tegning i topografisk arkiv, Arkeologisk museum i Stavanger.

Young, B. K. 2000. Climate and crisis in sixth-century Italy and Gaul. In Gunn, J. D. (ed.). The Years without summer. Tracing A.D. 536 and its aftermath. BAR International Series 872. Archaeopress, Oxford, 35-44.

Zimmermann, W. H. 1978. Economy of the Roman Iron Age Settlement at Flögeln, Kr. Cuxhaven, Lower Saxony. Husbandry, Cattle Farming and Manufacturing. BAR International Series (Supplementary) 48. Oxford, 147-165.

Zimmermann, W. H. 1992. Die Siedlungen des 1. bis 6. Jahrhunderts nach Christus von Flögeln-Eekhöltjen, Niedersachsen. Die Bauformen und ihre Funktionen. Probleme der Küstenforschung im südlichen Nordseegebiet 19. Hildesheim.

Zimmermann, W. H. 1998. Pfosten, Ständer und Schwelle und der Übergang vom Pfosten- und Ständerbau - Eine Studie zu Innovation und Beharrung im Hausbau. Probleme der Küstenforschung im südlichen Nordseegebiet 25, Oldenburg.

Ängeby, G. 1999. Långhusets livstid - en disskussion kring järnålderhusets brukningstid och sociala funktioner utifrån ett manghundraårigt halländsk exempel. In Artelius, T., Englund, E. \& Ersgård, L. (eds.). Kring västsvenska hus - boendets organisasjon och symbolik $i$ förhistorisk tid och historisk tid. Institutionen för arkeologi, Göteborgs universiet. 9-26.

Aakvik, J. 1998. Undersøkelsen på Sørbøtunet, Sandnes - bosetning tidligere enn antatt. Frá haug ok heiðni 4. Rogalands arkeologiske forening, Stavanger, 30-32.

Aakvik, J. 2001. Rapport om arkeologisk undersøkelse av yngre jernalders båtgrav og tre mindre forhistoriske bygninger på Husabø, gnr. 6, bnr. 4, Hundvåg, Stavanger $k$. Oppdragsrapport (B) 2002/2. Arkeologisk museum i Stavanger.

Aanderaa, F. 2015. Arkeologiske undersøkelser av treskipet hus og øvrige anleggsspor fra elder jernalder. Oppdragsrapport B 6. Arkeologisk museum, Universitetet i Stavanger. 